\title{
Elementos para una didáctica del lenguaje y las matemáticas en estudiantes sordos de niveles iniciales
}

Dora Inés Calderón Olga Lucía León Corredor 

Calderón, Dora Inés

Elementos para una didáctica del lenguaje y las matemáticas en estudiantes sordos de niveles iniciales / Dora Inés Calderón, Olga Lucía León Corredor. -- Bogotá : Editorial Universidad Distrital Francisco José de Caldas, 2016.

306 páginas ; $24 \mathrm{~cm}$.

ISBN 978-958-8972-33-6

1. Educación de sordos 2. Español - Enseñanza - Lengua de señas 3. Matemáticas - Enseñanza - Lengua de señas I. León Corredor, Olga Lucía II. Tít. $371.912 \mathrm{~cd} 21 \mathrm{ed}$.

A1536846

CEP-Banco de la República-Biblioteca Luis Ángel Arango 


\section{Elementos para una didáctica del lenguaje y las matemáticas en estudiantes sordos de niveles iniciales}

Dora Inés Calderón

Olga Lucía León Corredor

(Resultados de Investigación Proyecto “Desarrollo de competencia comunicativa en matemáticas en estudiantes sordos de niveles iniciales" COLCIENCIAS-Universidad Distrital Francisco José de Caldas) 


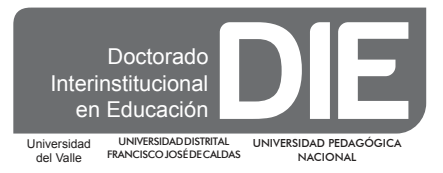

UNIVERSIDAD DISTRITAL FRANCISCO JOSÉ DE CALDAS

\section{Carlos Javier Mosquera Suárez}

Rector (E)

Universidad Distrital Francisco José de Caldas

\section{Giovanni Rodrigo Bermúdez Bohórquez}

Vicerrector Académico

Universidad Distrital Francisco José de Caldas

ISBN Impreso: 978-958-8972-33-6

ISBN Digital: 978-958-8972-34-3

(C) U. Distrital Francisco José de Caldas

\section{Preparación Editorial}

Doctorado Interinstitucional en Educación

Sede U. Distrital Francisco José de Caldas

http://die.udistrital.edu.co

\section{Elban Gerardo Roa Díaz}

Asistente editorial

eventosdie@udistrital.edu.co

Representante grupos de investigación: Interculturalidad, Ciencia y TecnologíaINTERCITEC, y del Grupo Didáctica de la Química-DIDAQUIM, del Énfasis de Educación en Ciencias.

Juan Carlos Amador Baquiro Representante de los grupos de investigación: Moralia, Estudios del Discurso,

Filosofía y Enseñanza de la Filosofía, Grupo de investigación Interdisciplinaria en Pedagogía de Lenguaje y las MatemáticasGIIPLyM y Jóvenes, Culturas y Poderes, del Énfasis de Lenguaje y Educación.

Martin Eduardo Acosta Gempeler Representante de los grupos de investigación: Grupo de Investigación Interdisciplinaria en Pedagogía de Lenguaje y las Matemáticas GIIPLyM, Matemáticas Escolares Universidad Distrital-mescud y Edumat, del Énfasis de Educación Matemática

Bárbara García Sánchez Representante del grupo de investigación Formación de Educadores, del énfasis de Historia de la Educación, Pedagogía y Educación Comparada

\section{Fondo de publicaciones}

Carrera 24 No. 34 - 37

PBX: (57+1) 3239300, ext.6201

publicaciones@udistrital.edu.co

Diseño, Diagramación e impresión

Fundación Común Presencia

Cra 11 No. 61 - 35 (401)

Tel: 249 5782. Bogotá.

Prohibida la reproducción total o parcial de la presente obra por cualquier medio sin permiso escrito de la Universidad Distrital Francisco José de Caldas

Bogotá, Colombia, 2016
U. Distrital Francisco José de Caldas 


\section{Contenido}

\section{Introducción}

Parte I: FUNDAMENTACIÓN DIDÁCTICA PARA LOS APRENDIZAJES MATEMÁTICOS Y COMUNICATIVOS DE POBLACIONES SORDAS

EN NIVELES INICIALES

1. El ambiente didáctico como un sistema didáctico. Dora Inés Calderón y

Olga Lucía León

1.1. Principios de un ambiente de aprendizaje

1.2. Elementos para el diseño de ambientes de aprendizaje

2. El desarrollo del lenguaje y de la discursividad en la formación inicial en matemáticas en estudiantes sordos. Dora Inés Calderón

2.1 Modos discursivos y sujeto escolar

2.1.1. La descripción como un modo discursivo

2.1.2 La narración como un modo discursivo

2.1.3 Otros modos discursivos en el aula

2.2 El desarrollo de la lengua de señas como lengua primera en los procesos de formación discursiva de la persona sorda

2.3. El bilingüismo como factor de desarrollo lingüístico-discursivo en el aula de niños sordos

2.3.1. El desarrollo lingüístico-discursivo de la lengua de señas (LS) como factor de escolarización de las personas sordas

2.3.2. El bilingüismo en el aula de sordos: un factor necesario

\section{El ambiente de las experiencias: micro-mundo de la aproximación}

Olga Lucía León

3.1. La cantidad y el micromundo de la aproximación

3.2. La forma y el micro-mundo de la aproximación

3.3 El sentido numérico: micromundo de la precisión en cantidades discretas

3.3.1 El proceso de subitización y la numerosidad

3.3.2. El proceso de conteo 
3.4.1 Trayectoria hipotética de aprendizaje de la forma

3.4.2 Trayectoria Hipotética de aprendizaje de Subitización 117

3.4.3. Trayectoria Hipotética de aprendizaje de Conteo

Parte II: PROPUESTAS PARA EL DESARROLLO DIDÁCTICO: LOS DISPOSITIVOS DIDÁCTICOS

1. Dispositivos didácticos para el desarrollo de competencia comunicativa en matemáticas. Dora Inés Calderón y Olga Lucía León

1.1. El proyecto de aula como estrategia pedagógica y como dispositivo didáctico

1.2. El taller como dispositivo didáctico

146

1.3. El juego como dispositivo didáctico

Parte III: PROYECTO DE AULA "CRIANDO LOMBRICES Y SEMBRANDO PLANTAS" UNA PROPUESTA PARA EL DESARROLLO DE COMPETENCIA COMUNICATIVA EN MATEMÁTICAS EN ESTUDIANTES SORDOS DE NIVELES INICIALES

1. Proyecto de aula "criando lombrices y sembrando plantas".

Dora Inés Calderón y Olga Lucía León

1.1 Introducción

1.2 Objetivos 164

1.3 Descripción del proyecto 165

1.4 Descripción de las fases

2. Sistema de talleres del proyecto de aula

2.1 Organización de los talleres en el micromundo de la aproximación de la cantidad Fase 1

2.2 Organización de los talleres en el micromundo de la aproximación de la cantidad Fase 2

2.3 Organización de los talleres en el micromundo de la precisión de la cantidad Fase 3 


\section{Introducción}

Este libro presenta los resultados de la investigación "El desarrollo de competencia comunicativa en matemáticas en estudiantes sordos", código 1130-405-20203, cofinanciado por Colciencias y la Universidad Distrital Francisco José de Caldas en la vigencia 2007-2010. El proyecto fue realizado por el Grupo de Investigación Interdisciplinaria en Pedagogía del Lenguaje y las Matemáticas- GIIPLyM. En términos generales, se pretendió diseñar una propuesta didáctica para la formación matemática inicial de niños sordos, a partir del desarrollo matemático de la lengua de señas colombiana y su relación con sistemas semióticos como el castellano, el figural geométrico y el de numeración decimal.

Para investigar el desarrollo de competencia comunicativa en matemáticas en estudiantes de primeros grados, se optó por la metodología de investigación denominada ingeniería didáctica (Artigue y otros, 1995; Calderón y León, 2012). Desde esta metodología se realizó un diseño para alcanzar el macro objetivo mencionado arriba, a partir del desarrollo de cuatro fases de la ingeniería: la fase de análisis preliminar, en la que se estudió el estado del fenómeno por investigar, es decir el estado de la educación matemática y del lenguaje en aulas de niños sordos de primeros grados y la preparación de los elementos para el diseño didáctico. Para ello se realizaron tres etnografías en colegios exclusivos de niños sordos. La segunda fase de análisis a priori estuvo dedicada a la concepción y el de las situaciones didácticas, que dio como gran resultado EL DISEÑO DIDÁCTICO construido para el desarrollo de competencia comunicativa en matemáticas. Se consideró el diseño didáctico como un macro dispositivo que articuló aspectos de tipo matemático, cognitivo y lingüísticocomunicativo en la perspectiva de la enseñanza y del aprendizaje. Las tercera y cuarta fases de experimentación y de análisis a posteriori constituyeron la validación del diseño y la identificación de aspectos didácticos emergentes. ${ }^{1}$

Esta publicación presenta fundamentalmente el resultado de la fase II, es decir el Diseño Didáctico construido, que constituye un sistema didáctico. El diseño puso en juego: i) variables macrodidácticas como cultura sorda, bilingüismo y políticas educativas para la inclusión y la integración de personas diversas en el aula y ii) variables microdidácticas como procesos de aprendizaje matemático (ver las trayectorias en los micromundos de la aproximación y de la precisión en el campo aritmético) y de lenguaje en su dimensión semiótica y discursiva y funcional con respecto al conteo y aspectos relacionados con el uso de materiales y estrategias de trabajo en el aula. De igual manera, en una perspectiva de la educación bilingüe, se estableció una relación de comparación gramatical y pragmática entre la lengua de señas colombiana (LSC) y el español

1. Todo el resultado descrito en las fases puede consultarse en el informe final del proyecto entregado a Colciencias en octubre de 2010. 
escrito, concluyendo, de manera parcial, la presencia de principios discursivos comunes como la unidad acto de habla con sus componentes intencionalidad discursiva y contenido proposicional y, por ello, la necesidad de configurar un estudio de la LSC en una perspectiva discursiva, como un estudio diferente, aunque complementario, de un estudio puramente gramatical de esta lengua.

Como gran resultado de investigación se configuró la categoría AMBIENTE DE APRENDIZAJE. En esta perspectiva se construyó el diseño didáctico como un ambiente didáctico para el profesor y como un ambiente de aprendizaje para el estudiante. Todo el sistema didáctico se presenta en tres grandes partes constitutivas: la Parte I propone la Fundamentación didáctica para los aprendizajes matemáticos y lingüístico-comunicativos en poblaciones sordas de niveles iniciales; así, esta parte, compuesta por tres capítulos, se articulan los elementos de fundamentación didáctica y epistemológica en matemáticas y en lenguaje y comunicación, necesarios para considerar una didáctica de las matemáticas y de la comunicación para primeros grados de escolaridad en aulas con estudiantes sordos. La Parte II, compuesta por tres capítulos, presenta la propuesta para el desarrollo didáctico que se construyó en el proyecto y que tomó como macro dispositivo el proyecto de aula. Finalmente, la Parte III, conformada por tres capítulos presenta un ejemplo de organización didáctica para el desarrollo de competencia comunicativa en matemáticas en estudiantes sordos de niveles iniciales, mediante el sistema de talleres diseñado para el Proyecto de aula "Criando lombrices y sembrando plantas".

Así pues, la publicación de este sistema didáctico como producto de la investigación mencionada, pretende aportar a la acción didáctica en lenguaje y en matemáticas, a la reflexión en estos campos didácticos y a la investigación didáctica en lenguaje y en matemáticas, en particular con poblaciones sordas. 


\section{Parte I: FUNDAMENTACIÓN DIDÁCTICA PARA LOS APRENDIZAJES MATEMÁTICOS Y COMUNICATIVOS DE POBLACIONES SORDAS EN NIVELES INICIALES}





\section{El ambiente didáctico como un sistema didáctico}

\section{Dora Inés Calderón- Olga Lucía León}

La generación de un diseño didáctico exige, sin lugar a dudas, la puesta en escena del conocimiento profesional del profesor (Shulman, 1986); es decir la articulación de los distintos elementos involucrados en la acción didáctica: los estudiantes, los profesores y los contenidos, con miras a diseñar, gestionar y evaluar ambientes de aprendizaje propicios para los aprendizajes puestos en juego en el aula. El punto de partida en este capítulo es la necesidad de configurar las relaciones epistemológicas que articulan un diseño didáctico. Por esta razón se parte de la concepción del ambiente de aprendizaje y en él los elementos fundamentales del ambiente en términos de conocimientos por aprender y modos lingüístico-comunicativos que favorecen los aprendizajes y la comunicación en el ambiente.

De acuerdo con lo anterior, la pregunta por el aprendizaje convoca dos tipos de reflexión: una de corte psicológico o cognitivo y otra de corte didáctico. En la primera, generalmente se consideran los procesos implicados en el aprendizaje de un saber particular, en nuestro caso de las matemáticas escolares de primeros grados de escolaridad. Las respuestas a este tipo de preguntas son, generalmente respondidas desde estudios de tipo psicológico. La segunda reflexión convoca las relaciones que se manifiestan en los procesos de enseñanza y de aprendizaje situadas en los contextos escolares. Esta segunda reflexión es la que orienta este trabajo, con miras a situar la, tan común hoy, categoría "ambiente de aprendizaje" en el entorno de las relaciones didácticas.

La opción por la categoría "ambiente", para referir el sistema didáctico tiene, para este diseño didáctico, dos asideros teóricos: uno de tipo pedagógico, en el sentido general de una teoría de la educación y uno de tipo didáctico, más particular, referido a las relaciones del aula.

En el asidero de tipo pedagógico, consideramos como punto de partida una teoría del aprendizaje de corte social constructivista (Vigotsky, 1973; Bruner, 1997/1999; Ausubel, 1978; Echeverry, 1996), en la que identificamos dos elementos importantes: i) el lenguaje como factor de desarrollo psicosocial, como potencial semiótico, noético e interactivo que faculta al humano para su participación y su desarrollo en el seno de la vida social y cultural para la co-construcción de conocimiento acerca del mundo y de las relaciones físico-sociales en ese mundo. Se considera, entonces, que los saberes construidos individualmente como "presaberes" o saberes anteriores y la interacción social 
(Vigotsky, 1973; Ausubel, 1978) son dos factores definitivos para los procesos de aprendizaje. El segundo elemento: ii) la mediación semiótica como un factor que opera en todo proceso de aprendizaje y en toda relación social. Es decir, se reconoce que los instrumentos (entre los que se cuentan los lenguajes) que intervienen en las relaciones con el mundo físico y social adquieren carácter simbólico y generan tipos de relaciones, formas de conocer y clases de conocimientos.

Recogiendo los dos elementos anteriores, en la teoría socio-cultural de Vigotsky (1973) y Leontiev (1969), entre otros, la psiquis no es una entidad pasiva, es activa. El humano adquiere los conocimientos, no como reflejo de patrones preestablecidos, sino a través de procesos dinámicos, generados por la actividad y la participación social que va desarrollando en los distintos entornos sociales. En esa medida, la estructura de las actividades, el resolver problemas y las mediaciones semióticas serán aspectos que intervienen en la configuración de los aprendizajes en la escuela. Por esa misma razón, una opción pedagógica habrá de considerar estos elementos como un punto de partida de su fundamentación.

En el segundo fundamento, es decir el didáctico, el ambiente se reconoce como un sistema didáctico configurado por el profesor y configurante de las relaciones entre los actores que intervienen en ese ambiente. Es decir, ese ambiente es un entramado de elementos y de relaciones que configuran el ámbito didáctico: actores de la comunidad educativa (profesores, estudiantes, padres, etc.); saberes escolarizados (propuestos en los currículos, en los sistemas escolares con intencionalidades escolarizantes); espacios (escenarios físicos y sociales dispuestos para el acto educativo); instrumentos y herramientas para llevar a cabo el proceso pedagógico y didáctico (materiales de todo tipo, mobiliarios, recursos físicos, informáticos, etc.); relaciones configuradas entre los distintos elementos.

Desde los anteriores planteamientos, optamos por asumir una serie de presupuestos elaborados por distintos autores acerca de lo que es un ambiente de aprendizaje. Se presenta una delimitación antropológica y una sistémica, con el fin de presentar una opción estructural y funcional de la categoría "Ambiente de aprendizaje" como un lugar para el aprendizaje escolar y como un producto didáctico, es decir, como ambiente didáctico.

Desde el punto de vista antropológico. En una perspectiva histórica, vale la pena considerar la emergencia de la palabra "ambiente". Según D. Raichvarg (1994, citado por Duarte, 2003) la expresión data de 1921 y es introducida en el contexto de los geógrafos para referirse a "medio" como el escenario de relaciones del ser humano con el entorno. En este sentido, se observa la necesidad de trascender la simple idea de espacio físico hacia una concepción que pone en relación dinámica y activa al ser humano y al entorno; de igual manera, se involucra una dimensión pedagógica en tanto que se considera 
que, en la relación con el entorno se aprende y se está en condiciones de reflexionar sobre la propia acción y sobre las de otros.

Según Duarte (2003), desde otros saberes, el ambiente es concebido como el conjunto de factores internos biológicos y químicos y externos físicos y psicosociales que favorecen o dificultan la interacción social. Implica aspectos del espacio físico como entorno natural y las diversas relaciones humanas que ocurren en ese entorno y que, además, aportan sentido a la existencia del humano. Desde esta perspectiva, se trata de un espacio de construcción significativa de la cultura.

Así pues, en el desarrollo de la noción de ambiente de aprendizaje, referida concretamente al contexto de la educación, observamos que distintos autores instauran propuestas de definición. A continuación presentamos algunas que representan la síntesis de estas ideas.

El ambiente de aprendizaje es el escenario donde existen y se desarrollan condiciones favorables de aprendizaje, contempla las condiciones materiales necesarias para la implementación del currículo, las relaciones interpersonales básicas entre maestros y alumnos, "[...] las dinámicas que constituyen los procesos educativos y que involucran acciones, experiencias y vivencias de cada uno de los participantes; actitudes, condiciones materiales y socio-afectivas, múltiples relaciones con el entorno y la infraestructura necesaria para la concreción de los propósitos culturales que se hacen explícitos en toda propuesta educativa (Duarte, 2003, p. 6, citado por Cano, 2005).

El ambiente es una fuente de riqueza, una estrategia educativa y un instrumento que respalda el proceso de aprendizaje ${ }^{2}$, pues permite interacciones constantes que favorecen el desarrollo de conocimientos, habilidades sociales, destrezas motrices, etc., el ambiente es un concepto vivo, cambiante y dinámico, lo cual supone que el ambiente debe "[...] cambiar a medida que cambian los niños, sus intereses, sus necesidades, su edad y también a medida que cambiamos nosotros, los adultos, y el entorno en el que todos estamos inmersos" (De Pablo, 1999: 9, citado por Duarte, 2003).

De acuerdo con las anteriores definiciones, un ambiente de aprendizaje exige dos condiciones: ser un espacio físico (o virtual) acondicionado de cierta manera y que, por ello, ofrece ciertas posibilidades de estar en él; tiene la condición de ser un lugar. Es decir, tiene condiciones de existencia locativa y de diferenciación de otros espacios. Complementaria y necesariamente, es un escenario social; es decir, ofrece y permite realizar distintas relaciones sociales, en una perspectiva bio-ecológica (Calderón, León, Peña y otros, 2010). En este segundo requisito, consideramos el criterio ecológico y ergonómico: espacios para el bienestar, para la comodidad física, afectiva, intelectual y so-

2 Las negritas son nuestras 
cial; para el desarrollo de los intereses de las personas que habitan el espacio, que construyen el ambiente y se construyen en él.

En concordancia con lo anterior, la expresión "ambientes de aprendizaje" también alude a la de "ambientes educativos". En este sentido, se observa que su puesta en marcha incidirá fuertemente en una teoría sistémica del currículo por cuanto éste ha de ser concebido desde la perspectiva ambiental de la educación: desde la ecología, desde la psicología, desde la comunicación y el lenguaje, desde la etología y la proxémica, desde las disciplinas que intervienen en la escuela, entre otros. Más, cuando actualmente proliferan ideas y prácticas relacionadas con ambientes educativos en la sociedad contemporánea, que no necesariamente son ambientes escolares, pero que requieren diferenciarse y articularse. En correspondencia con ello, se reconoce que los cambios propuestos y los realizados en la educación en los últimos años, exigen instaurar distintas formas y estrategias para el desarrollo de la formación escolar en los diferentes niveles y grados. Todo este movimiento demanda de la pedagogía una reconsideración de su sentido, social que rebasa los escenarios escolares. Se requiere ampliar la mirada hacia la articulación de la formación en la institución escolar y su papel en la comprensión y el abordaje de los problemas sociales: los conflictos socioeducativos, el desarrollo humano de los sujetos y de las comunidades, la exclusión, entre otros, en escenarios que no son necesariamente escolares.

Desde el punto de vista didáctico, el ambiente de aprendizaje es una construcción intencional, didácticamente hablando. A nuestro juicio, es el resultado de la planificación compleja de un escenario para facilitar y para promover el aprendizaje de los estudiantes. Exige por ello, diseñar el ambiente -en el sentido de construir un diseño didáctico- poniendo en juego articulaciones curriculares y didácticas (Calderón y León, 2001); es decir, ha de partir del análisis de las intencionalidades que orientarán el proceso de aprendizaje en un tiempo específico. A partir de allí, surge, de acuerdo con la mayoría de los autores expertos en ambientes de aprendizaje (Duarte, 2003; Flórez, 2005; Miranda, 2009; Loughlin y Suina, 1997; Moreno y Molina, 1993; Domínguez Velilla et al, 2003; Goodyear, 1997; García Cano, sf; De Pablo, 1999; entre otros), la organización, del ambiente de aprendizaje.

Tal organización implica disponer espacial y socialmente el aula, de acuerdo con pautas de relaciones bio-sociales propias de este espacio social (Calderón, 2010): las personas, los roles, los saberes, los objetos (materiales, instrumentos), en concordancia con las actividades que se proponen para ser realizadas, según los intereses didácticos. El ambiente de aprendizaje constituye, entonces, un entorno delimitado en el cual ocurren ciertas relaciones de trabajo escolar. Este tipo de relaciones de trabajo, las escolares, son las que distinguen claramente este ambiente de otros ambientes sociales. En este sentido, el "ambiente de aprendizaje" ha de permitir que ingresen, se instauren y 
se desarrollen formas de trabajo, de relaciones socioculturales y discursivas relacionadas con el estudio, la reflexión, la solución de problemas, alrededor de temas escolares.

De igual manera, el diseño de un ambiente de aprendizaje, con estas características, requiere analizar las condiciones de los actores que participarán en el ambiente, en calidad de estudiantes y de profesores. Condiciones de edad, de género, de desarrollo intelectual y social, de condiciones físicas, fisiológicas y sensoriales, con el fin de adecuar todos los aspectos intervinientes para facilitar el trabajo escolar en ese ambiente. Por esta razón, han de considerarse tanto los recursos físicos como las estrategias de trabajo, de acuerdo con los canales de percepción, los niveles de aprendizaje y las prácticas culturales propias de los actores del ambiente; es decir, con las necesidades de las personas involucradas en este escenario educativo. Todos estos aspectos influyen de forma significativa en el desarrollo del aprendizaje y en la construcción de la experiencia sociocultural en tal ambiente.

Así, desde los puntos de vista anteriores, presentaremos principios y requerimientos para la configuración de un ambiente de aprendizaje.

\subsection{Principios de un ambiente de aprendizaje}

Se propone un conjunto de principios que aluden a las condiciones y relaciones entre los actores que participan en el ambiente, los saberes y el escenario; principios que permiten considerar la articulación del ambiente de aprendizaje como un sistema didáctico.

- "Se aprende haciendo" y esta es la base del aprendizaje significativo (Ausubel, 1978). Según el planteamiento vigotskyano, se aprende de la relación con los objetos, de las acciones; el proceso de aprendizaje ocurre de la acción verbalizada externa (materializada) a la mental interna (asimilada). La posibilidad de tematizar, de resolver problemas exige la acción del sujeto en el entorno físico-social en que circulan tales temas y problemas. Desde este punto de vista, la creatividad puede ser comprendida como liberación de heurísticas (Flórez, 2005), de formas de descubrir, de comprender por parte de los estudiantes.

En este contexto, el ambiente de aprendizaje ha de proporcionar condiciones para que todas las personas del grupo tengan acceso al conocimiento, a las tareas y las actividades propuestas para ese ambiente; el contacto con los materiales y las actividades diversas que permitan abarcar un amplio abanico de aprendizajes cognitivos, afectivos y sociales (Flórez, 2005: 11).

- El sujeto que aprende es ante todo sujeto social. El ambiente comunitario, 
de participación, define la posibilidad de que un sujeto se sitúe y se desarrolle socioculturalmente, de acuerdo con su naturaleza humana: somos con los otros y por los otros. En esta perspectiva un ambiente de aprendizaje, como todo ambiente social, habrá de constituirse en un espacio de vida compartido, solidario y democrático. Se espera que los estudiantes se involucren en un proyecto comunitario y lo desarrollen mediante una acción conjunta y de reflexión crítica. El ambiente ha de propiciar que progresivamente se dé la construcción de un grupo humano cohesionado con los objetivos, metas e ilusiones comunes (Cano y Lledó, 1995). El ambiente construido como entorno escolar ha de facilitar a todas las personas acercarse unos a otros y establecer interacciones satisfactorias comunes a sus metas en este ambiente.

A la vez, y en consonancia con el anterior principio, reconocer cómo aprenden los estudiantes tendrá repercusiones en lo que se refiere a la construcción del ambiente del aula, pensado como ambiente dinámico, con la posibilidad de recrearse, cambiarse y suprimirse, dependiendo de los proyectos que se estén desarrollando. "El entorno ha de ser construido activamente por todos los miembros del grupo al que acoge, viéndose en él reflejadas sus peculiaridades, su propia identidad" (Flórez, 2005: 12). En esta última idea, un ambiente de aprendizaje ha de propiciar también la construcción de la identidad como sujeto escolar y social, comprensivo y co-constructor de las prácticas socio-culturales y discursivas propias de los entornos escolares.

Adicionalmente, y como un factor importante de este principio, se hace necesario reconocer que la sociabilidad es un elemento primordial de los procesos de enculturación y que por ello exige condiciones afectivas, comunicativas e intelectuales que permitan a los sujetos ser y estar con los otros de manera satisfactoria y evolutiva. En esta perspectiva, destacamos un componente, pocas veces tenido en cuenta por la escuela, que contribuye grandemente al desarrollo saludable de la convivencia social: la afectividad como actitud básica de las relaciones sociales. Según Brito (1996) y Cardoso (2000), citados por Duarte (2003) existe una estrecha relación entre afectividad y desempeño cognitivo en el aula. Los estudios de estos autores llegan a la conclusión de que los estudiantes obtenían mejores resultados en el aprendizaje de las matemáticas, cuando la asimilación de los conceptos estaba acompañada de metáforas cargadas de humor. El humor, según De Bono (1974/2006), no sigue los patrones de razonamiento lógico (vertical), sino la dinámica del pensamiento lateral: en los juegos de palabras (chistes), el doble significado de una palabra se usa como mecanismo para cambiar de esquema y obligarnos a ir por la vía lateral. El humor siempre implica sorpresa para que sea efectivo. De acuerdo con este autor, necesitamos modificar los esquemas y salir de la estructura lógica y rígida del pensamiento vertical. Por eso, el humor es, sin duda, una de las características de las personas creativas. Comprender este factor permitirá considerar momentos y formas de relación con las tareas y las actividades y con las mismas personas que, si bien parecen romper con 
"el orden establecido", se convierten en potentes factores emocionales que garantizan relaciones vitales con el proceso de aprendizaje.

- El aula es ubicua (Flórez, 2005). Esta idea implica reconocer que los procesos didácticos no sólo tienen lugar en el espacio físico (o virtual) denominado aula, sino que otros ambientes sociales pueden ser concebidos con funciones didácticas: otros escenarios de la escuela (la biblioteca, el auditorio, el salón de audiovisuales, etc.); escenarios extraescolares como la calle, la cafetería, el teatro, el museo, el barrio, y la vida misma. En la base de esta idea está que la motivación por aprender, por conocer se convierte en un factor psicopedagógico y que, en este sentido, distintos ambientes sociales que forman parte de la vida cotidiana pueden adquirir funciones didácticas que apoyen los procesos cognitivos. Un ambiente escolar diverso, trasciende la idea del centrismo del aula como espacio físico y único escenario del aprendizaje. Distintos escenarios sociales, articulados a una noción de aula abierta, dependiendo de las tareas emprendidas y de los objetivos perseguidos, permitirán, con más facilidad, Ilevar a cabo la premisa de "aprendizaje para la vida", de "aprendizaje significativo" (Ausubel, 1973). Es un hecho que tal articulación es más efectiva bajo la noción de ambiente de aprendizaje.

Así, el entorno escolar, en su dimensión ambiental, ha de concebir distintos sub-escenarios para que todos los participantes sean acogidos, para que puedan expresar sus expectativas, sus intereses, sus ideas sus estados de ánimo y, en esa dinámica de convivencia, puedan desarrollar relaciones interpersonales, metodologías y empleo de materiales, orientados a la consecución de los objetivos de la actividad, de manera comunitaria. En este sentido se hace necesario crear ambientes en el aula, cualitativamente diferentes: algunos más orientados hacia la lúdica, otros hacia la exploración científica, hacia la creación, hacia la aplicación, hacia el trabajo colectivo y cooperativo; otros espacios más individuales, etc. En general, se propone que los ambientes de aprendizaje consideren las distintas dimensiones de desarrollo del sujeto (afectiva, intelectual, social, física) y puedan potenciar tales dimensiones, de acuerdo con los propósitos didácticos y curriculares.

- Los saberes son sistémicos. Los contenidos escolares tienen la característica de provenir de los distintos campos de conocimiento científico, tecnológico, artístico y sociocultural en general. Los currículos se convierten en la explicitación, entre otros, de la selección y de la organización de tales campos de conocimiento (Gimeno Sacristán, 1996). El saber escolar es complejo como todo saber y configura sistemas. Implica conjuntos de conceptos, de procesos, de procedimientos, de usos, de aplicaciones y variedad de lenguajes relacionados con los aspectos anteriores. Adicionalmente, y teniendo en cuenta el primer principio aludido, el aprendizaje tiene como condición el saber previo y la acción que convoca el nuevo saber. 
Así, los nuevos conocimientos, los que propone la escuela, tendrán que ser dispuestos de cierto modo para ser aprendidos. No basta con la disponibilidad de marcos conceptuales idóneos; se requiere la disposición de tales marcos de modos inductivos, deductivos abductivos (León, 2005), que faciliten a los estudiantes diferenciaciones y comprensiones progresivas en el curso del aprendizaje. Se requiere también que existan modos de articulación de nuevos conceptos interconectados de manera múltiple a las redes de conceptos preexistentes en los integrantes del ambiente. Adicionalmente, se hace necesario posibilitar la identificación de indicadores y niveles de aceptabilidad de los aprendizajes alcanzados, por parte de los estudiantes y del mismo profesor; es decir, modos de monitoreo de los propios aprendizajes, sea en la aplicación de los conocimientos o sea en la reflexión sobre ellos. Habrá de considerarse, desde un punto de vista didáctico, que el desarrollo de competencias en los saberes por aprender tendrá que estructurarse en relación con los contenidos; que obedezcan a una planeación conceptual que guíe las actividades en procesos cíclicos que varíen de un nivel de abstracción a otro.

En esta perspectiva, el profesor no será la única y la última fuente de conocimiento; se hace necesario disponer de múltiples fuentes (libros, videos, situaciones, experiencias, entre otros), facilitando a los estudiantes el uso de distintos y variados recursos, lenguajes y herramientas, para la exploración de un campo de saber. En esta medida, se podrán considerar el desarrollo de procesos, destrezas, actitudes y aptitudes sobre nuevos conocimientos. El docente, más que un proveedor de conocimientos será un "gestor" un dinamizador y un evaluador de procesos de aprendizaje.

Desde los cuatro principios propuestos para la configuración de ambientes de aprendizaje, es un hecho que la pedagogía adquiere una dimensión tecnológica, en el sentido griego de la thécné. Es decir, ha de convertirse en una explicación del quién del aprendizaje como un sujeto constructor, activo, proclive a la acción semiotizadora, simbólica y a la incorporación y a la transformación de las formas de producción sociocultural del conocimiento. Del mismo modo, ha de proporcionar elementos para la comprensión y la puesta en escena de las exigencias que una propuesta educativa que sostiene esa idea de sujeto del aprendizaje tendría que desarrollar.

\subsection{Elementos para el diseño de ambientes de aprendizaje}

En este apartado generalizaremos el aporte de distintos autores con respecto a los elementos indispensables que han de ser tenidos en cuenta para la configuración de un ambiente de aprendizaje. En particular, tomamos el aporte de María Lina Iglesias Forneiro, maestra de educación infantil de la Universidad de Santiago de Compostela (sf/ 2006), en su artículo "Ambiente de aprendizaje en Educación Infantil: dimensiones y variables a considerar". En términos 
generales, encontramos que los autores hacen alusión a los elementos que configuran el ambiente en un momento dado; es decir, se explicitan los aspectos que intervienen in situ. Nosotros hemos aclarado antes que el ambiente de aprendizaje como ambiente didáctico habrá de estructurar también la etapa de planeación y la de evaluación, es decir, compromete el diseño en su totalidad, en sus tres momentos: a priori, en ejecución y a posteriori. A continuación explicitaremos la configuración del ambiente para la ejecución de las relaciones didácticas.

De acuerdo con los distintos autores consultados, hemos observado que se consideran, en general, dos tipos de elementos: i) Los objetos materiales y didácticos entre los que se cuentan: la "organización espacial, la dotación y la disposición de los materiales para el aprendizaje y la organización para propósitos especiales" (Loughlin, E. y Suina, H., 1997: p. 25). ii) Las condiciones para la interacción en el ambiente, entre ellas se incluye: la existencia de normas de participación; los roles, entre los que se destaca el del docente como orientador, guía, mediador en la resolución de conflictos y generador de los procesos de evaluación; las interacciones, y sobre ellas se propone que han de ser permanentes estudiante-profesor, privilegiando el trato individualizado, y realizarse bajo la estrategia de trabajo cooperativo entre estudiante-estudiante.

Iglesias Forneiro define el ambiente como "un todo indisociado de objetos, olores, formas, colores, sonidos y personas que habitan y se relacionan en un determinado marco físico que lo contiene todo y, al mismo tiempo, es contenido por todos estos elementos que laten dentro de él como si tuviesen vida". Plantea que en esa medida, "el ambiente "habla», nos transmite sensaciones, nos evoca recuerdos, nos da seguridad o nos inquieta, pero nunca nos deja indiferentes". Por esta razón identifica el ambiente como una estructura de cuatro dimensiones claramente definidas e inter-relacionadas entre sí, que son respectivamente: Dimensión física, Dimensión funcional, Dimensión temporal y Dimensión relacional.

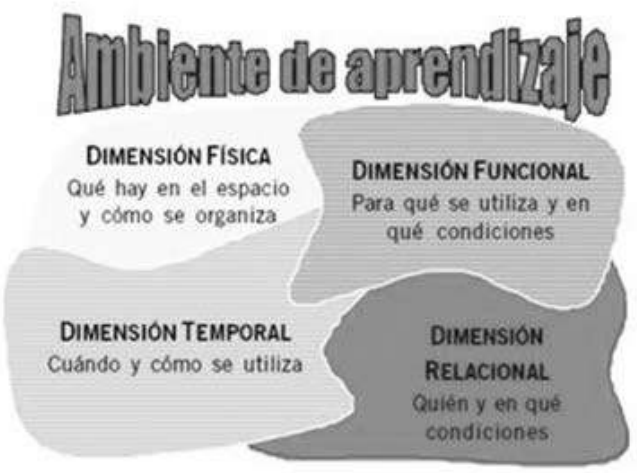

(Tomado de Iglesias Forneiro (sf), pág. 2). 
Parafraseando las dimensiones propuestas por Iglesias Forneiro, propo$\mathrm{n}$ emos los siguientes elementos por dimensiones del ambiente:

- Dimensión física. Alude al aspecto material del ambiente. El espacio físico (o virtual) elegido para la configuración del escenario; comprende todas las características y condiciones con que cuenta el espacio (dimensiones, estructuras arquitectónicas, iluminación, temperatura, mobiliario disponible, etc.), organización del espacio, del mobiliario y de los materiales. En cuanto a esta dimensión, cabe considerar la importancia del análisis que el docente realice a estas condiciones, con el fin de poder prever la potencialidad del espacio físico en relación con las funciones necesarias para el cumplimiento de los propósitos de aprendizaje. También, para prever los posibles riesgos y carencias o la articulación con otros espacios físicos.

- Dimensión funcional. Refiere al modo de utilización de los espacios y de los recursos existentes en él. Existen funciones preestablecidas y funciones reasignadas, dependiendo del tipo de actividad para la que están destinados. En cuanto al modo de utilización, los espacios pueden ser empleados por el estudiante con cierta autonomía o totalmente bajo la dirección del profesor. La polivalencia hace referencia a las distintas funciones que puede asumir un mismo espacio físico (por ejemplo, la alfombra es el lugar de encuentro y comunicación durante la asamblea y más tarde es el rincón de las construcciones). En general es importante definir la función de los espacios y de los materiales y recursos para cada ambiente, de tal manera que se articule una dimensión simbólica y cultural con una funcional del ambiente; por ejemplo, lugares como el rincón de las construcciones, del juego simbólico, de la música, de la biblioteca, de lectura, etc., adquieren una importancia capital para los participantes en un ambiente y para el desarrollo de hábitos y de modos de relación y de comprensión de las actividades.

En general, los ambientes de aprendizaje han de estar dotados con material de apoyo, que se tendrá que considerar en una relación estrecha con el entorno en el cual se desarrolla dicho ambiente y con los niveles e intereses de aprendizaje de los estudiantes involucrados en el proceso. El volumen de complejidad brindado por los materiales depende del número de opciones que estos presenten. Los materiales complejos brindan muchas opciones a la actividad mientras que los simples pueden llegar a ofrecer una sola posibilidad. Es necesario contextualizar estos materiales con los contenidos curriculares y con los propósitos del aprendizaje; en este sentido, es de gran utilidad plantear estrategias y dispositivos tendientes a dinamizar los procesos de aprendizaje, tales como el proyecto de aula, los talleres, los grupos de trabajo, entre otros, de tal manera que se faciliten, en el desarrollo del ambiente, tanto los aprendizajes como el monitoreo que sobre el proceso ha de realizar el profesor. 
- Dimensión temporal. Refiere a la organización del tiempo, a la duración del ambiente $y$, por lo tanto, a los momentos en que los espacios van a ser utilizados bajo una intencionalidad didáctica. En las distintas actividades el tiempo está necesariamente ligado al espacio en que se realiza cada una de ellas: el tiempo de los talleres, el tiempo de la lectura, el tiempo de la discusión, el de jugar, el de contar cuentos, etc. En un ambiente de aprendizaje es importante que todos los participantes reconozcan las condiciones temporales de las actividades y su relación con el logro de los propósitos de cada actividad; por ejemplo, el tiempo de la actividad libre y autónoma, el de la actividad dirigida. Este aspecto resulta fundamental en el desarrollo de hábitos y de responsabilidades para los estudiantes y en la posibilidad de planificar, de manera coherente, el ritmo de las actividades en relación con el de los aprendizajes, por parte del maestro. De igual modo, se podrán observar clases que requieren tiempos más fugaces y otras que requieren más tiempo.

- Dimensión relacional. Este aspecto compromete las distintas relaciones que se establecen en el ambiente del aula e incluyen las que se generan en la relación interpersonal (profesor y estudiantes) y las que se producen por los distintos modos de acceder a los espacios y a los saberes (Calderón y León, 2001). En este campo de relaciones se generan las normas de interacción social del aula y las normas de relación con los campos de saberes y los instrumentos y las herramientas que median estas relaciones. Muchas de estas relaciones se dan de manera dirigida por el docente o consensuadas en el grupo. De uno u otro modo, es vital que el maestro, en los distintos espacios y en las actividades que realizan los estudiantes, pueda sugerir, estimular, observar, dirigir los procesos, en la perspectiva vigotskyana de la zona de desarrollo proximal. Todas estas cuestiones, y otras más, son las que configuran una determinada dimensión relacional del ambiente del aula.

En la combinatoria de las cuatro dimensiones habrá de generarse el diseño de las actividades que se realizarán en un ambiente determinado y de las estrategias metodológicas por las que se optará para su desarrollo. En este sentido, se habla de la elección de dispositivos didácticos para el ambiente de aprendizaje. Es importante señalar que los diseños de las actividades obedecerán a una estructura impuesta por el dispositivo elegido, pero en general han de tener en cuenta mínimo los siguientes aspectos:

-El cronograma de trabajo.

-Los propósitos didácticos y sus indicadores.

-Los procesos que se pretende desarrollar en los estudiantes.

-Los contenidos conceptuales y procedimientos que se trabajarán.

-Los indicadores actitudinales que se tendrán en cuenta.

-El sistema de evaluación con sus correspondientes valores. 
Este conjunto de aspectos habrán de tener un lugar en el sistema del ambiente didáctico propuesto. En este sentido, el carácter didáctico del ambiente se sitúa en la experiencia del profesor: en el conjunto de relaciones epistemológicas, metodológicas, socio-culturales e interpersonales que configuran su experiencia de profesor. Para los estudiantes, los ambientes de aprendizaje serán los que vive a diario en el aula y que, por ser parte de los ambientes didácticos, han sido diseñados para su bienestar en sus aprendizajes. A continuación presentamos un esquema que visualiza la estructura del diseño didáctico como ambiente didáctico.

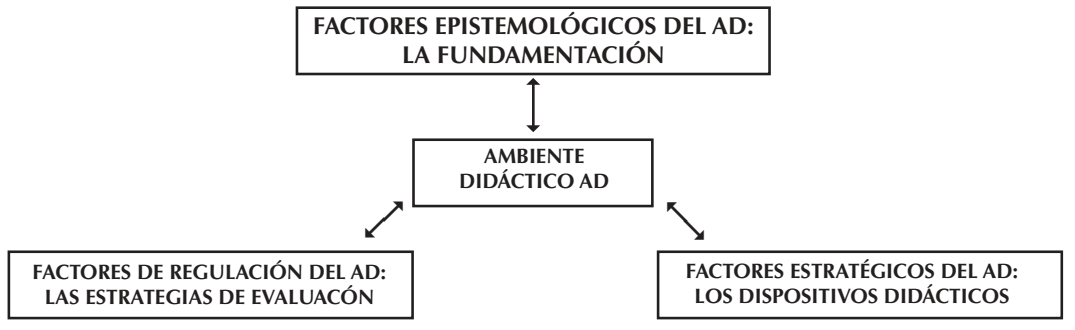

Esquema No 1.

Desde el esquema anterior, el ambiente didáctico está configurado por los distintos elementos que hacen posible sustentar una propuesta de ambiente de aprendizaje, así:

- Los factores epistemológicos, corresponden a la base teórica que soporta una propuesta de ambientes de aprendizaje. Esta base ha de considerar requerimientos de tipo cognitivo (una teoría del aprendizaje y del sujeto), de tipo disciplinar (una teoría del saber escolar puesto en juego: de las matemáticas, del lenguaje, de las ciencias sociales, etc.), de tipo comunicativo (la propuesta de formas de lenguaje que se requiere para el desarrollo de las competencias comunicativa y cognitiva en el campo de saber comprometido) y de tipo socio-cultural del aula (la comprensión de las normas y de las reglas que subyacen a la interacción en el aula y con los saberes puestos en juego) (Calderón y León, 2001). Se destaca en este factor la necesidad de que el profesor disponga de distintos soportes teóricos que le permitan acudir a explicaciones y profu ndizaciones cuando lo requiera. En el contexto del presente ambiente didáctico, este factor estará configurado por los documentos de profundización disponibles para este ambiente, relacionados con los distintos aspectos involucrados en el desarrollo de los ambientes de aprendizaje: la discursividad, el bilingüismo, el sentido numérico y las trayectorias en el aprendizaje matemático.

- Los factores estratégicos, hacen alusión a la elección de los dispositivos didácticos como opciones para el desarrollo del aprendizaje. En esta medida se involucran las distintas posibilidades metodológicas que el profesor seleccione 
para dinamizar las experiencias de aprendizaje, por ejemplo, el proyecto de aula, la clase magistral, el taller, la estrategia de portafolio, los juegos, las salidas de campo, entre otros. En cuanto a este factor, es necesario recordar que en el desarrollo de un ambiente didáctico pueden surgir distintas opciones y generarse combinatorias interesantes para el trabajo en el aula. Lo importante será el diseño de las articulaciones entre los distintos dispositivos y el análisis de sus potencialidades para el desarrollo de los aprendizajes previstos. En este ámbito es en el que se desarrollan los ambientes de aprendizaje para los estudiantes. Es decir, son los escenarios de interacción social en el aula y, por ello, configuran tipos de ambientes para el aprendizaje. Todos los aspectos descritos para la conformación de ambientes de aprendizaje tendrán su lugar en el desarrollo de este factor.

- Los factores de regulación del ambiente didáctico. En este componente se sitúa la dimensión evaluativa del proceso e incluye dos niveles: la valoración del mismo sistema didáctico propuesto y de las relaciones entre sus componentes; por ejemplo, el profesor podrá valorar y ajustar teorías, dispositivos, materiales, estrategias de evaluación de los procesos, entre otros. El otro nivel será el de la propuesta de evaluación en el ambiente de aprendizaje; es decir, la relación entre propósitos de aprendizaje, actividades, recursos y procesos desarrollados por los estudiantes. Ambos niveles de evaluación requieren el diseño de instrumentos y de criterios de evaluación y el soporte en los dos anteriores factores.

Como resultado, este proyecto diseñó un sistema de Ambiente Didáctico como ambientes de aprendizaje, que se representa en el siguiente esquema:

Esquema No 2

AMBIENTES DIDÁCTICOS CREADOS PARA EL DESARROLLO DE COMPETENCIA COMUNICATIVA EN MATEMÁTICAS EN ESTUDIANTES SORDOS DE NIVELES INICIALES

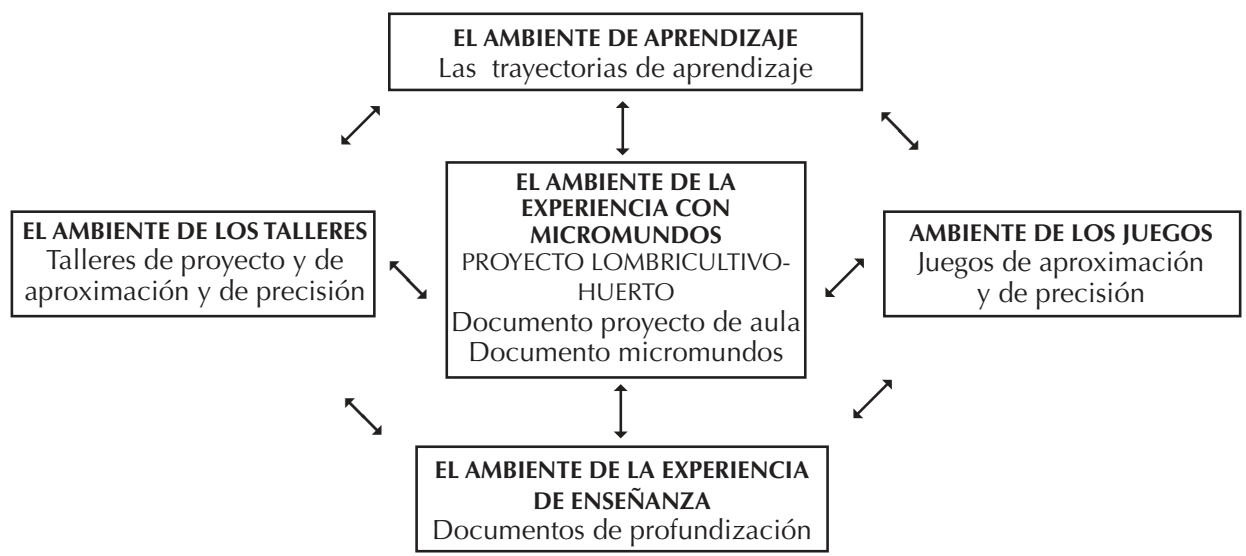


En este Esquema No 2 se visualizan las relaciones propuestas en el diseño de un sistema de AMBIENTE DIDÁCTICO como ambiente de aprendizaje; el desarrollo de estas relaciones se realiza a largo de esta obra. 


\section{El desarrollo del lenguaje y de la discursividad en la formación inicial en matemáticas en estudiantes sordos}

Dora Inés Calderón

Un punto de partida de esta reflexión es el reconocimiento del lugar preponderante que tienen, el lenguaje en general y las lenguas en particular, en el desarrollo sociocultural, cognitivo y afectivo de los sujetos; es decir, en sus procesos de enculturación. Situamos la reflexión específicamente en los primeros niveles de escolaridad, con miras a presentar una articulación entre el desarrollo del lenguaje y la discursividad en los primeros años de vida de niños y niñas y su iniciación en los aprendizajes escolares. Esto, para proporcionar elementos teóricos que soporten una didáctica del lenguaje y de las lenguas y su relación con el desarrollo de competencia comunicativa en los campos disciplinares escolares; en este caso en matemáticas. Aclaramos que el carácter discursivo de la lengua está inscrito en cualquier lengua (oral o de señas) y que por ello, los elementos que presentamos aquí se consideran como elementos que se explican para el desarrollo tanto de la lengua de señas (LS) como de la lengua oral.

Nos situamos en el marco de los estudios sobre el lenguaje y el pensamiento (Vigotsky, 1987; Oléron, 1985; Rogoff, 1993), en los que se considera que la experiencia social del individuo resulta fundamental para el desarrollo de su pensamiento, de su conocimiento y con ellos, de su lenguaje. En este sentido, destacamos el carácter semiótico del lenguaje que lo reconoce, según Halliday (1982), como "un potencial de conducta en un potencial de significado"; así, el lenguaje es acción humana cuya expresión por excelencia es la lengua y cuyas dos grandes funciones son la significación y la comunicación.

Con esta base es posible plantear que el desarrollo del lenguaje, a través de las lenguas y su discursividad, implica, en primera instancia, el desarrollo de la lengua natural ${ }^{3}$ (lengua primera). Es decir, la apropiación y el uso de las reglas de producción sintáctica, semántica y pragmática de los discursos y de los registros y de las lógicas socioculturales de las interacciones, desde un punto de vista polifónico y dialógico (Bajtín, 1982/1998; Martínez, 1997, 2001, 2005; Calderón, 2005, 2010, 2012). En esta perspectiva, se hace necesario identificar y desarrollar, tanto para los estudiantes como para los profesores, los modos discursivos propios del aula y los que se desarrollan en los campos particulares

3 No utilizaremos aquí la expresión "lengua materna" dado que para las personas sordas la lengua materna, la de sus padres, no siempre es la lengua de señas, que sí sería su lengua natural. 
de conocimiento, como en este caso el de las matemáticas escolares (Calderón, 2012).

\subsection{Modos discursivos y sujeto escolar}

Desarrollar competencia lingüístico-discursiva en el aula exige, entre otras condiciones, la participación activa de los estudiantes en la vida escolar: en las actividades propuestas en las clases (objetivadas por los aprendizajes propuestos curricularmente), en las que se realizan fuera del aula (en el descanso, en las celebraciones, en las salidas pedagógicas, en las reuniones con padres de familia, etc.). Es decir, se requiere que niños y niñas tengan la oportunidad de actuar como interlocutores en los distintos ambientes escolares. Más, cuando en este escenario sociocultural se realizan distintos modos discursivos (maneras de hablar, formatos de las interacciones, rituales lingüísticos, discursivos y textuales), actividades que privilegian la oralidad o la visogestualidad y la escucha, y otras que necesitan de la lectura y la escritura. Tales modos del discurso se articulan o, más bien, son la expresión de las prácticas socioculturales que se llevan a cabo en los distintos contextos sociales. Por esta razón, desarrollar lenguaje es apropiarse de estas formas del discurso.

En la perspectiva anterior, y considerando la importancia de que la escuela se convierta en un espacio privilegiado para el desarrollo de lenguaje y de la lengua, a continuación presentamos una relación entre los modos discursivos que naturalmente hacen parte de las formas de interacción espontánea en la vida de niños y niñas, que son la base de su desarrollo lingüístico- discursivo a lo largo de su vida, y las formas académicas y sociales del espacio escolar. Tales formas permiten la apropiación de la comunicación social y de las estrategias para construir sus propios conocimientos y ser partícipes y co-constructores de cultura. Además, en el espíritu del proyecto de aula "Criando lombrices y sembrando plantas", ${ }^{4}$ estas formas discursivas sustentan tanto la apropiación del conocimiento relacionado con los micromundos de la aproximación y de la precisión que se han propuesto a lo largo de los talleres, en sus tres fases, como de las formas de interacción propias de un taller, del trabajo en equipo y de lo que representa convivir en un ambiente en el que se tienen metas comunes, como por ejemplo, construir un lombricultivo y una huerta escolar.

MODOS DISCURSIVOS EN LA INTERACCIÓN EN EL AULA

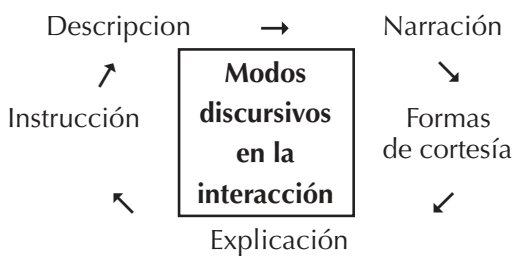

Diagrama No 1.

4 Ver la tercera parte de este libro que presenta el Proyecto y los talleres respectivos y consultar el Repertorio Léxico y el lexicón desarrollados en el proyecto de aula. 
Previo a la caracterización de los modos discursivos seleccionados, es importante aclarar que en las producciones discursivas de los estudiantes y de los profesores, tanto en la vida cotidiana como en los momentos de realización de las clases y de las tareas, estas modalidades se combinan constantemente. Difícilmente empleamos alguno de los modos en puro; no obstante, sus cualidades son importantes tanto para la valoración que puede hacer el profesor sobre su relación con el tipo de conocimiento que permite elaborar, como con el desarrollo del pensamiento, del conocimiento y del mismo lenguaje que potencia cada uno de los modos.

Hacemos, con las palabras, un cuadro que represente la realidad perceptiva e intuitiva, con el cual nuestro interlocutor pueda llegar a comprender la idea que se está tratando de comunicar. Todo lo que percibimos a través de nuestros cinco sentidos es susceptible de ser descrito. Cualquier objeto, real o imaginario, puede ser detallado a través de las palabras. Nuestras emociones, sentimientos y estados de ánimo también pueden ser descritos. En este sentido, la descripción, como forma del discurso, genera una situación de comunicación en la que un sujeto expone su punto de vista sobre el objeto (físico, virtual, mental, real, o imaginario) o sobre el fenómeno (una situación, un hecho, un evento) que está describiendo. Para ello hace uso de la lengua natural y de sus herramientas gramaticales (las palabras que permiten describir y las construcciones adecuadas), semánticas (el significado de las palabras y de las expresiones con función descriptiva) y pragmáticas (reconocer en qué casos se describe o se responde describiendo, porque eso es lo que se me ha solicitado). En el Proyecto de aula "Criando lombrices y sembrando plantas", se sugiere instaurar formas de interacción discursiva orientadas a poner al niño o a la niña en la situación de focalizar y describir. Veamos ejemplos:

\subsubsection{La descripción como un modo discursivo}

La descripción es "...una "pintura" hecha con palabras... que provoca en el receptor una impresión semejante a la sensible, de tal forma que ve mentalmente la realidad descrita." (Álvarez, 1993: 39).

a) Características: Es una respuesta a la pregunta explícita o implícita ¿Cómo es? Focaliza el objeto. La persona que describe se convierte en el que "ve" y da razón de lo que ve.

Hacemos, con las palabras, un cuadro que represente la realidad perceptiva e intuitiva, con el cual nuestro interlocutor pueda llegar a comprender la idea que se está tratando de comunicar. Todo lo que percibimos a través de nuestros cinco sentidos es susceptible de ser descrito. Cualquier objeto, real o imaginario, puede ser detallado a través de las palabras. Nuestras emociones, sentimientos y estados de ánimo también pueden ser descritos. En este sentido, la descripción, como forma del discurso, genera una situación de comunicación en la que un sujeto expone su punto de vista sobre el objeto 
(físico, virtual, mental, real, o imaginario) o sobre el fenómeno (una situación, un hecho, un evento) que está describiendo. Para ello hace uso de la lengua natural y de sus herramientas gramaticales (las palabras que permiten describir y las construcciones adecuadas), semánticas (el significado de las palabras y de las expresiones con función descriptiva) y pragmáticas (reconocer en qué casos se describe o se responde describiendo, porque eso es lo que se me ha solicitado). En el Proyecto de aula "Criando lombrices y sembrando plantas", se sugiere instaurar formas de interacción discursiva orientadas a poner al niño o a la niña en la situación de focalizar y describir. Veamos ejemplos:

-¿Qué sabor consideras que tiene esa fruta?

- ¿Qué color tiene esa fruta?

-¿Cuál de las frutas que coloreaste te gusta más?

(Taller 1, Fase 1)

Tales preguntas exigen identificar un objeto (fruta) y emitir características como sabor y color; además, expresar una relación personal con tal objeto (gusto).

En muchas ocasiones la descripción sirve para reconstruir: volviendo a construir o dando otra versión (deformada o caricaturizada) del objeto de la descripción. Esto depende de la intención que tenga la persona que describe.

b) Aspectos que desarrolla la descripción

Podemos señalar dos tipos de aspectos, que van unidos, pero que podemos separar para mayor comprensión, dado el impacto de la actividad de describir sobre ellos:

1) Cognitivos: La capacidad de representar en nuestra mente a través de las cualidades que emergen del fenómeno descrito. Construir imágenes lingüísticas que se convierten en imágenes sensibles a nuestra comprensión. Favorece la objetivación de la realidad física, virtual, mental... en este sentido, realizar descripciones propicia una manera de conocer la realidad, de comprender su forma, sus cualidades, sus características, sus funciones, etc. Todos estos aspectos se identifican lingüísticamente. Veamos la siguiente situación del Proyecto de aula:

Mientras se encuentran dibujando (los niños y las niñas), se sugiere al docente formularles preguntas del siguiente tipo

-¿Qué estas dibujando?

-¿Por qué te interesó eso del video?

-¿Qué otra cosa del video te gustó?

(Taller 2, Fase 1)

* Para el empleo de convenciones par citar los talleres, es importante tener en cuenta que el en proyecto de aula de diseñaron tres fases y cada fase presenta un determinado número de talleres. 
El dibujo es una experiencia de representación descriptiva, caracterizadora que propiciará la objetivación del interés de niños y niñas. Las preguntas del profesor orientan tal objetivación, generando una situación que favorece la posibilidad de construir la imagen evocada.

2) Lingüísticos: emplear la lengua para describir, hace exigencias de uso de nuestro sistema lingüístico. Por ejemplo, exige reconocer la existencia del objeto o del fenómeno que se va a describir; en este caso se hace necesario:

-Nominar: nombrar objetos y fenómenos. Cuando se nombra se instaura el objeto y se le reconoce a través de la categoría lingüística del sustantivo o nombre. Generalmente este acto de nombrar los objetos o fenómenos va acompañado de un acto deíctico de tipo lingüístico (uso de pronombres demostrativos como éste, ese aquel...) o de tipo corporal (señalar con el dedo, con la boca, con los ojos), acto que permite identificar al objeto como particular y ser al que se refiere el sujeto que describe. Por ejemplo, preguntas como: ¿Cuáles animales conoces?, ¿Cuál animal de los propuestos en el taller es más pequeño? (Taller 2 , Fase 1), exigen respuestas directas de tipo nominativo; exigen al niño o a la niña acudir a un nombre de una especie de animal y, generalmente acompañar este acto con la deixis corporal. Una actividad más compleja que privilegia la nominación es la siguiente:

Poniendo el nombre: Luego el estudiante deberá escoger una tarjeta (de las disponibles para esta actividad) que considere presenta el nombre del sabor; es decir, la tarjeta que tenga el valor que es más característico en los alimentos de esa mesa. Cuando el estudiante acierta a escoger la tarjeta correspondiente, el docente marca la tarjeta con el nombre del estudiante, se la obsequia y le solicita guardarla, para que al final de la ronda completa, cuando todos los estudiantes hayan pasado por todas las mesas, todos los estudiantes tengan seis tarjetas con los seis tipos de sabores degustados.

(Taller 3, Fase 1).

Clasificar: diferenciar en el objeto o fenómeno sus respectivas características como el género (masculino o femenino), el número (singular o plural), el tipo (animal, persona, objeto, lugar, etc.), la clase (parte de una especie), entre otras. Por ejemplo, para responder a preguntas del profesor como: ¿Cuáles animales conoces?, ¿Cómo es un perro? (Taller 2, Fase 1), el estudiante tendrá que clasificar al menos más de un tipo de animal (perro, gato, ratón...), dar cualidades como cantidad de patas, de ojos, color, acciones, etc., aspectos todos que revelan una relación entre el conocimiento del objeto y la forma de construir su descripción con las palabras.

-Adjetivar: asignar cualidades físicas, actitudinales, funcionales a los objetos descritos. Decir cómo es: ponerse fuera, como espectador, como el que ve, observa, y registra. En este sentido, realizar descripciones permite comprender 
esta función de la lengua e identificar los formatos descriptivos: orales/ visogestuales, digitales, etc., que se usan para llevar a cabo esta actividad. También, propicia la comprensión de que existen palabras que permiten decir algo de cómo son los objetos y los fenómenos: los adjetivos (calificativos, demostrativos, ordinales) y los adverbios (de cantidad como muy; de modo cansadísimo). Veamos una experiencia de adjetivación en el Proyecto de aula:

El profesor preguntará a cada uno de los niños y niñas sobre las cualidades físicas de los elementos que observaron en el video (sembrador, frutos, tierra): ¿cómo era el agricultor?, ¿qué frutos vieron?, ¿de qué color era la tierra?, ¿cuántos frutos distintos vieron?, ¿había mucha o poca tierra?

(Taller 2, Fase1)

De acuerdo con los propósitos de la fase y de la actividad, se pretende verificar si los estudiantes tienen ciertas dudas sobre el acto de describir. Insistir en la producción de las señas para cada objeto y sus cualidades (forma, color, estado...). Si bien la descripción pretende decir cómo son los objetos, también permite decir cómo nos gustaría que fueran; es decir, desarrolla capacidad creativa para construir otros mundos. No obstante, toda descripción cuenta con un referente de partida: el mundo conocido o el mundo visto.

-Desarrollar capacidad deíctica lingüística y gestual: es decir, la posibilidad de que el sujeto que describe se sitúe fuera del objeto descrito y lo señale, en un acto de reconocimiento, bien sea con un gesto lingüístico (pronombre como éste (a), ese (a) aquel (a), o bien sea mediante el gesto corporal que señala (el dedo índice, la mano, los ojos, la boca, el cuerpo). Un ejemplo de este tipo de experiencia en el proyecto de aula es la siguiente actividad:

Como se advirtió, la organización de los alimentos se hará de acuerdo con el valor del descriptor "olor" que es más característico en cada uno de ellos. Tan pronto cada estudiante perciba el olor del o los alimentos de una mesa, el docente le preguntará: ¿Qué olor tiene el alimento? El estudiante deberá tratar de expresar con su cuerpo el olor del alimento. Si se dispone de una cámara, es conveniente grabar las expresiones de cada estudiante.

(Taller 4, Fase 1)

La deixis, en principio, es un acto de posicionamiento espacio temporal del sujeto con relación a un objeto. Implica el reconocimiento de la existencia del objeto; es la descentración del niño que sabe que existen objetos fuera de sí. No obstante, en el curso del desarrollo del lenguaje y del pensamiento, este aspecto también se desarrolla permitiendo la representación gestual y corporal de los objetos como una manera de darlos a conocer.

c) Tipos de descripción y usos

Siendo la descripción una forma privilegiadamente discursiva que se realiza cuando se quiere dar a conocer ¿cómo es algo o alguien?, también se pueden 
reconocer otras formas de descripción, no necesariamente discursivas, pero que también se trasladan al discurso. Veamos:

1) Descripción lingüística (oral o escrita): es aquella que emplea la lengua natural y sus recursos; por ejemplo, las lista de deberes, la toma de notas, los horarios, la agenda, la lista de cualidades, la información sobre cómo es un objeto, un lugar o un fenómeno. Por ejemplo, la propuesta de identificación de formas de nariz y animales respectivos en el proyecto de aula:

En la siguiente tabla se presentan formas de nariz y los animales que las presentan:

\begin{tabular}{|l|l|}
\hline Tipos de nariz en los animales & \multicolumn{1}{|c|}{ Animal } \\
\hline Largas & elefante, oso hormiguero \\
\hline Cortas & murciélago, gato persa, paloma \\
\hline Grandes & delfín de nariz botella, mono narigudo \\
\hline Pequeñas & Mosca \\
\hline Con un orificio & pez lamprea \\
\hline Varios orificios & perro(2), caballo(2), serpiente cuatro narices (4) \\
\hline
\end{tabular}

(Taller 4, Fase 1)

Los estudiantes encuentran la necesidad de enlistar palabras- cualidad y relacionarlas con palabras-nombre, permitiendo la comprensión del formato lista de cualidades y el valor de relacionar las dos categorías de palabras: nombre-adjetivo.

2) Descripción Icónica: es la que privilegia la imagen del objeto sobre las palabras. El carácter icónico radica en que se ofrece una representación física (cualidades de forma) del objeto o del fenómeno que se describe. Ejemplos de este tipo de descripción son los frisos, las fotos, los dibujos, los afiches, las pinturas, las caricaturas... Para el caso de niños y niñas que inician su aprendizaje escolar y que aún no dominan el código escrito, esta forma descriptiva es muy útil.

Para el caso de los niños sordos el valor de la descripción icónica es doble: es la posibilidad de aprehender objetos y cualidades tal y como lo hacen niños y niñas oyentes y configurar representaciones de imágenes, como un tipo de aproximación al objeto, anterior a la escritura, que realizan todos los niños y niñas. También, de manera singular, la descripción icónica se convierte para la persona sorda en el puente entre la lengua de señas (LS) y la lengua oral, en la posibilidad de interlocución con el oyente; en el espacio para la construcción de nominaciones y de adjetivaciones en LS. Veamos manifestaciones de este tipo de descripción en el Proyecto de aula. 
“...Después de cualquiera de las actividades anteriores, el profesor entregará las láminas de lombrices en diferentes estados, para que entre todos los estudiantes vayan identificando los elementos necesarios para las lombrices, de los que aparecen en las láminas".

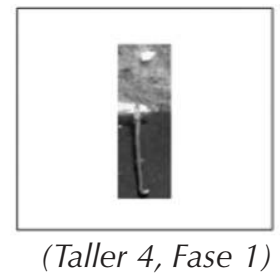

3) Descripción Icónico-lingüístico: son descripciones que combinan los anteriores tipos, con preponderancia de alguno de los dos (la lingüística o la icónica). Para el caso del proceso de iniciación de los niños a la lengua escrita o al desarrollo de su lengua oral o viso-gestual, este tipo de descripción es fundamental, pues se convierte en un escenario que permite visualizar a los niños (as) al menos dos tipos de representación y distinguirlas: la icónica (formas) y la lingüística (letras y palabras); con ello se inicia un conocimiento sobre la relación de significación entre los dos registros y la diferenciación de los mismos. Veamos un ejemplo de este uso en el Proyecto de aula.

*En una hoja de papel periódico pinta a tu lombriz y escribe su nombre. Luego haz una lista de dibujos de las cosas que necesita la lombriz para vivir. Presenta a tus compañeros (a) a tu lombriz y lo que ella necesita para vivir.

(Taller 1, Fase 2, actividad 3)

Colorea los siguientes dibujos y dibuja una cama de lombriz para ellos. Dibuja los alimentos que consumirán. Ponle un nombre a cada uno en LSC
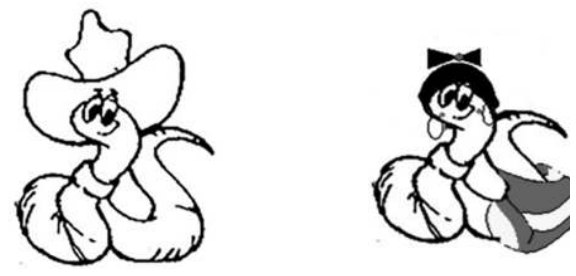

(Taller 2, Fase 2 Actividad 3)

Como se observa, el ejercicio solicitado a los niños (as) exige: combinar la representación icónica como un acto de instaurar su objeto (lombriz); nominarlo no solamente como animal sino como mascota (nombre propio), lo que representa un avance en la función nominadora; y realizar el listado de cosas que la lombriz requiere para vivir. Este ejercicio incrementa el carácter descriptivo, hacia la comprensión de ¿cómo es el hábitat de la lombriz?

\subsubsection{La narración como un modo discursivo}

\section{a) Características:}

Responde a la pregunta explícita o implícita ¿Qué pasó? Focaliza el hecho. 
Fundamentalmente es una reconstrucción de eventos, de hechos ocurridos, reales o ficticios. Es una forma de construcción reconocible por los sentidos mediante un relato, que intenta contar, informar, hacer saber o convencer a un interlocutor de lo sucedido. Se caracteriza por ser una organización cronológica de los sucesos; este orden puede ser lineal o no, dependiendo del interés del narrador y de los objetivos de su relato.

Como secuencia discursiva, "la narración se estructura en fases como: antes (situación inicial) - proceso (transformación o nudo) - después (resolución)" (Calderón, 2005: 25). Para realizar una narración o para contar una historia, el narrador requiere establecer una relación entre actores (o personajes del relato), que son quienes realizan o realizaron las acciones, los tiempos o momentos de ocurrencia de las acciones y los lugares de los acontecimientos. También ofrece una evaluación de los hechos, a través de sus puntos de vista y de su modo de contar. Así, el relato puede contarse en una secuencia diferente a la que ocurrió realmente o a la que presentó una historia leída o sabida con anterioridad. Es decir, el narrador tiene libertad en la organización cronológica; pues la presentación del tiempo en el que sucedieron las acciones puede variar en su orden, dependiendo de lo que quiera transmitir el narrador y en qué aspectos o hechos quiera focalizar la atención.

Vale la pena destacar que en el mundo contemporáneo se ha dado un cambio de la narrativa lineal a la narrativa digital: convergente, hipertextual; es decir, la temporalidad toma otras características distintas a los sucesos lineales para proponer otras relaciones y otras combinaciones, por ejemplo, entre literatura, tecnología, creatividad y pensamiento convergente. Los sucesos pueden tener bifurcaciones (otros relatos derivados), ir y volver, ser presentados con alternativas musicales, visuales (imágenes), entre otros; los personajes pueden cambiar de roles, establecer interacciones con el lector; el lector puede intervenir las historias, construir otros órdenes temporales, otros roles... Un buen ejemplo de este tipo de narrativas son los nuevos relatos literarios propuestos en formatos digitales.

La narratividad es una de las experiencias lingüístico-discursivas más importante en la vida de las personas y, en especial, en la vida de niños y niñas. Según Bruner (2004: 25) la modalidad narrativa trata de situar la experiencia en el tiempo y en el espacio y se ocupa de las intenciones, de las acciones y de las vicisitudes humanas. Podemos decir, entonces, que la experiencia narrativa permite al sujeto situarse "organizar la experiencia espacio-temporal, afectiva y cognitivamente en la posición de "contar" algo a alguien. Se narra para dar razón de nuestras propias vivencias o de las de los otros, generando una relación de poder sobre la propia historia y de ser "el que narra". La narración como experiencia humana permite saber del pasado inmediato, del mediato y del remoto. Posibilita el contacto con los sucesos de la vida diaria y con 
los que imaginamos. Propicia la construcción de mundos posibles. Al mismo tiempo, es una fuente de evaluación de nuestra propia vida y de la de nuestros antepasados.

En el desarrollo del Proyecto de aula "Criando lombrices y sembrando plantas", el acto narrativo se convierte en una experiencia importante para poner en evidencia la comprensión y la apropiación de los micromundos de la aproximación y de la precisión de cantidades, en tanto ofrece momentos para la reconstrucción de hechos (videos, salidas, acciones de días anteriores, etc.).

\section{b) Aspectos que desarrolla la narración}

Al igual que en el caso de la descripción como modo discursivo, podemos señalar dos tipos de aspectos que la narración potencia en su desarrollo; tales aspectos son inseparables; los presentamos de manera separada en aras de ampliar su posibilidad de comprensión, dado el impacto de la actividad de narrar sobre ellos:

1) Cognitivos. Aquí nos referimos a los procesos que favorece la experiencia de narrar, aunque naturalmente se expresan en lenguaje.

- Organizar narrativamente la experiencia, implica realizar procesos de categorización evenimencial (eventos o hechos), de manera temporal y causal, en una ubicación espacial; es decir, organizar secuencias temporales tendientes a construir el panorama de la acción (Bruner, 2004) o el conjunto de acciones que hacen parte del relato.

- Personificar, exige construir los personajes, es decir producir agentividad (decidir el o los personajes que realizan la acción y el o los que la reciben). Este acto mental implica la comprensión y/o la asignación de condiciones emocionales (enojado, alegre...), actitudinales (solidarios, envidioso...), de personalidad (espontáneo, tímido); asignar o reconocer intenciones (encontrar un lugar, fundar una ciudad, etc.) y roles (padre de familia, estudiante...) a los personajes que participan en la historia. En este sentido, personificar es construir el panorama de la conciencia (Bruner, 2004). El narrador conoce los sentimientos, los pensamientos y los conocimientos de sus personajes $\mathrm{o}$, puede evaluar o inferir los de los actores de su historia narrada; reconoce y diferencia roles sociales de los personajes.

- Construir el ambiente de la acción, es decir que en este aspecto se requiere el concurso de la representación descriptiva que permita recuperar o imaginar el ambiente espacial en el que se sitúa la acción narrada; es decir, cómo eran o cómo imagina que fueron los lugares en que ocurrieron los hechos.

- Construirse como narrador; es decir, desarrollar la capacidad narrativa que implica la experiencia lingüístico-cognitiva y afectiva de: i) situarse como narrador (el que cuenta algo a alguien), de evocar sucesos (lejanos o cercanos) 
y de reconstruirlos y contarlos a otro (Bruner, 2004): escoge las palabras, las expresiones gestuales y corporales, sabe que es para otros y le dirige el discurso; ii) a la vez, la capacidad de construir criterios para lograr verosimilitud con la realidad, en la historia contada: quien narra puede valorar si su historia será creída por su interlocutor; iii) generar una intencionalidad para con su acto de narrar: contar una historia para entretener (cuentos), para informar qué se hizo, para obtener un beneficio, etc.

2) Lingüísticos. Emplear la lengua para narrar hace exigencias de uso de nuestro sistema lingüístico y de las formas del discurso que expresen las condiciones cognitivas descritas anteriormente. A continuación destacamos algunos aspectos lingüístico-discursivos.

La construcción del relato: la organización temporal, espacial, agentiva e identificación del inicio, del nudo, del climax y del desenlace. Organizar la secuencia de acciones exige emplear verbos en pretérito, pues las acciones que se narran son pasadas y establecer una relación entre ellas (temporal o causalmente). Los tiempos verbales desarrollan formas según la temporalidad a la que hagan alusión. Por ejemplo:

\section{Tabla 1. Construcción de relato}

\begin{tabular}{|l|l|}
\hline Había una vez... & $\begin{array}{l}\text { El verbo haber se conjuga en pretérito imperfecto simple y da la idea de que } \\
\text { la acción pasó pero aún no ha terminado. Por eso, cada vez que se inicia un } \\
\text { cuento, la acción parece tomarse en un pasado que aún no concluye o que } \\
\text { es simultánea, pero anterior, al tiempo en el que se habla, se vincula al } \\
\text { presente. }\end{array}$ \\
\hline Se encontró al príncipe. & $\begin{array}{l}\text { El verbo encontrar se conjuga en pretérito perfecto simple y da la idea de } \\
\text { una acción terminada, que ya no se vincula al presente (parece más remota } \\
\text { que la acción imperfecta). }\end{array}$ \\
\hline $\begin{array}{l}\text { Se enojaba cada vez que veía a } \\
\text { la bruja... }\end{array}$ & $\begin{array}{l}\text { Verbo enojar en pretérito imperfecto simple. Al lector le da la sensación de } \\
\text { que se vuelve a enojar, pues es parte de su emoción. }\end{array}$ \\
\hline
\end{tabular}

Como se observa, los juegos temporales son una rica fuente para saber cómo se dan las acciones y ayudan a comprender cómo son los personajes, de acuerdo con lo que hacen. En este sentido, no sólo se refieren a acciones pasadas, sino que permiten saber cómo son esas acciones y las personas que las realizan, qué intensidad tienen. La lengua española tiene gran variedad de tiempos verbales simples y compuestos. ${ }^{5}$

Si no se tiene un dominio de la lengua natural, por ejemplo de la lengua de señas, la organización de las acciones puede hacerse con secuencias de

5. Se recomienda ver gramáticas españolas con el tema de conjugación verbal o por ejemplo Larousse de la conjugación. $6^{\text {a }}$ Edición. París. Ediciones Larousse. 
dibujos, de láminas, con frisos, etc., que expresen las acciones realizadas y los personajes o agentes que las realizan, pero ayudando en la construcción de los verbos y sus usos en la lengua respectiva (LSC o en español). En el proyecto de aula, existen distintos momentos que fomentan la construcción de relatos. Por ejemplo, los registros de acciones mediante el "Diario del Semillero" en la Fase 3, Taller 1, en donde se propone:

Después de realizar la organización de los grupos, se sugiere al profesor elaborar carteleras como las siguientes6 y pegarlas en lugar visible, para apoyar a los grupos en sus registros:

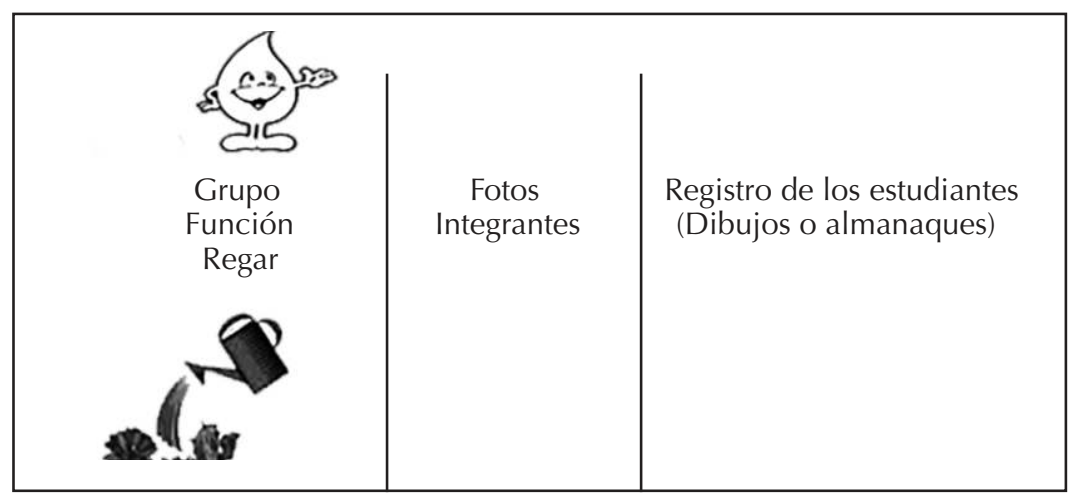

La actividad exige identificar responsables, funciones y formas de registro. Dado que cada día se debe registrar el cumplimiento de la acción de regar (en este caso del semillero), el ambiente del proyecto genera un espacio de experiencia que proporciona elementos para la creación posterior de un relato, en donde el tema será la construcción del semillero y las acciones girarían en torno al riego (regar), el crecimiento (crecer), la temporalidad estará definida por los días de la semana, las semanas y el tiempo transcurrido para la obtención del semillero; los actores serán los estudiantes, los beneficiarios las plantas y el espacio de la acción, el semillero y el aula de clase. Se destaca como importante, la observación y el registro como insumos básicos para la obtención de datos que posteriormente puedan alimentar una descripción y un relato.

-Uso de marcadores de relato: temporalidad (verbos en pasado o pretérito y adverbios de tiempo), de secuencialidad (conectores conjuntivos y preposicionales: antes, después, ahora). Este es un aspecto lingüístico y lógico fundamental en el desarrollo de una lengua, pues los marcadores de tiempo, de relaciones causales, de agentividad, van a permitir la expresión de la lógica del relato en todos sus aspectos. En el caso de la lengua española, las formas verbales, expresiones prototípicas, las preposiciones, las conjunciones, las interjecciones y los pronombres permiten marcas de relato: "había una vez" es la clásica entrada a los cuentos tradicionales infantiles. "Te voy a contar una historia...", "Esta es la historia de...", son expresiones de entrada a un relato

6 Imágenes tomadas de: educared.org, articulos.infojardin.com 
que ponen de antemano la situación narrativa para el interlocutor; "y fueron felices y comieron perdices" es la marca de finalización de los cuentos de hadas. Preguntas como ¿qué te pasó ayer?, ¿qué hiciste en vacaciones?, instauran una solicitud de contar acciones pasadas que requieren convertirlas en un relato. En el Proyecto de aula, la Fase III recupera la gran experiencia descriptiva de las fases I y II e ingresa al estudiante en la experiencia plenamente narrativa; ejemplo de ello es la siguiente actividad:

Momento uno: ¡construyo mi friso!

El profesor entrega a cada niño (a) hojas grandes de papel bond o cuartos de cartulina, con divisiones de cuadrados y colores, crayolas o tijeras. Entrega fotos en las que aparece el niño (a) haciendo el proceso. Entrega copias de los registros de actividades de cada niño (a) realizadas en el salón o con los padres. Pregunta a los estudiantes si les gustó hacer el lombricultivo y si les gustaría contar a otros niños (as) cómo los hizo. Con base en las respuestas, les pide realizar una historieta, con el material que les entregó, formando la secuencia de cómo hizo o cómo participó en la construcción del lombricultivo.

(Taller 3, Fase 3, Actividad 1)

En este caso, se espera que los marcadores de relato estén dados: por la secuencialidad de las ilustraciones (temporalidad), la agentividad a través de la expresión de los modos de participación. Observemos cómo estos marcadores se construyen en la lengua de señas (LSC) y para los niños (as) está muy ligado a la relación con las narrativas icónicas.

-Construcción de distintos formatos: oral/visogestual (en español oral o en lengua de señas), escrito (español escrito), digital (escrito, icónico, tecnológico). Este aspecto tiene que ver con la construcción de prototipos o guiones de relato: diferenciar lingüísticamente entre cuentos, historietas, anécdotas. Para ello se ha de proporcionar a los niños siluetas o formatos de cuentos (Jolibert, 1996) de recetas, etc.; pero sobre todo, dar la oportunidad de visualizar (en LSC), historias, anécdotas y de participar como narrador. En el proyecto de aula, los diarios de alimentación de la lombriz y de cuidados de la planta; los videos y las salidas pedagógicas son una rica fuente para diferenciar formatos o modos en que se narran acciones.

\section{c) Tipos de narración y usos}

1) Narración lingüística: (oral/visogestual o escrita). Esta es la clásica forma narrativa que emplea una lengua y se expresa en los cuentos, las historietas, las leyendas, las fábulas, las anécdotas, las noticias... esta forma narrativa es una poderosa entrada de los niños al conocimiento de su lengua. Se recomienda que en principio el adulto cuente al niño (a), les lea cuentos, noticias, etc. Esta actividad se convierte en un modelado de los formatos o guiones narrativos y de uso de la lengua y del vocabulario en general y del papel de la corporalidad 
en la expresión de acciones y emociones. En el Proyecto de aula "Criando lombrices y sembrando plantas" actividades como la propuesta para el Taller 1 de la Fase 3, son espacios de construcción de actividad narrativa:

Grupo verde:

Dibuja la comida que se recoge para la lombriz cada día.

Cuéntale a los otros grupos qué tipo de comida es la que debe darse a las lombrices.

Esta actividad parte del dibujo, pero pide evocar un objeto y una situación: he ahí la génesis del relato, en espacial, por cuanto aparece la solicitud de "contar", que hará la exigencia de elegir datos qué contar, de organizarlos y de dirigirlos a los interlocutores. Con respecto a la posibilidad de desarroIlar esta capacidad en los niños (as), Macchi y Veinberg (2005: 91) destacan la importancia de la lectura de cuentos a los niños sordos. Sugieren realizar el equivalente a la "lectura en voz alta" (lectura sonora) en LS, siguiendo la lectura con la mirada y realizando la traducción en LS. Esta actividad permite establecer al niño (a) la relación entre el acto de leer la letra y su significación en lengua de señas.

2) Narración Icónica: se trata de narraciones que emplean propuestas no verbales como historietas sin texto escrito (tiras cómicas), secuencia fotográfica... La narración no sólo se realiza a través de las palabras, también se construye con imágenes que estructuran una historia secuencialmente. El dibujo, los frisos, la pintura y los medios interactivos ayudan a realizar este tipo de narraciones, pues además de estar apoyados de animaciones (imágenes y algunas veces imágenes en movimiento) sintetiza la acción y la pone en evidencia para su mejor comprensión. La narración icónica es la entrada más sencilla a la narración lingüística, pues, de manera natural, concreta y universal, presenta al lector (de imágenes) una propuesta narrativa, sin importar la lengua de ese lector.

En el Proyecto de aula, encontramos que, en la experiencia propuesta para niños y niñas de primeros grados de escolaridad, de construir un lombricultivo y un semillero, suelen quedar varias emociones y sensaciones sin registrar. Por ello se hace oportuno la creación de un "diario comunitario" en el que se consignen en forma de historias breves lo que han descubierto, desarrollado y no menos importante, la respuesta al cómo se han sentido al realizar la acción del lombricultivo y el semillero. La creación literaria, con imágenes, cuentos, frisos, contribuirán a ampliar el campo semántico y lexical relacionado tanto con los micromundos de la aproximación y de la precisión, como de la comprensión de los hábitats de la lombriz y de las plantas y del compromiso de las personas para con la naturaleza. Está en manos del profesor establecer vínculos entre la experiencia de comprensión temática y la literaria e imaginativa. Veamos una actividad del Proyecto de aula que proporciona la experiencia de narración icónica. 
¿Recuerdas cómo construiste semillero? Ahora dibuja en el orden que lo hiciste

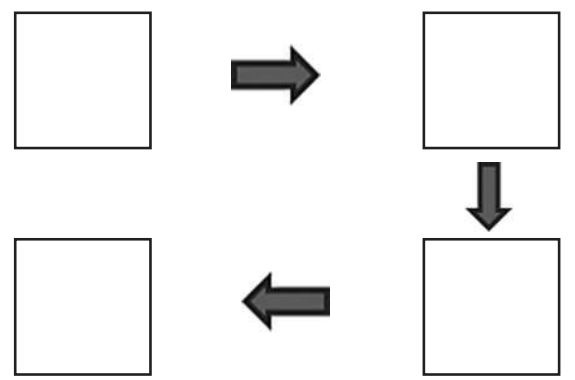

(Taller 4, Fase 2, Actividad de evaluación)

3) Narración Mímica: son las narraciones que acuden a la expresión corporal, no en lengua de señas, en un intento por emplear gestos y movimientos para representar acciones; para no emplear las palabras. Acude al empleo de formas onomatopéyicas de la acción (imitaciones). Ejemplos de este tipo de narrativa son los relatos con gestos: las actuaciones de los mimos, el cine mudo, los juegos de adivinanza. Este tipo de experiencia narrativa es altamente lúdica y permite el desarrollo de la expresión corporal, ganar en confianza en sí mismo, integración grupal y recursividad y creatividad. En el proyecto de aula, en los talleres de la Fase 1 se solicita, frente a la experiencia del sabor, representar estos sabores con el cuerpo; esta sería una entrada a este tipo de narratividad.

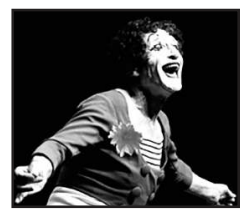

Ver en: http://www.youtube.com/watch?v=UPBoVM8xiSQ, el video del MiMo Chispa MiMe Dancing

4) Narración icónico-lingüístico: Combina las anteriores y puede presentarse en formato digital. En general, para las narraciones infantiles este es el tipo de narración más potente, en cuento ofrece la relación entre las dos formas: lingüística e icónica, presentando una relación de significación entre los dos formatos y, por ello, un acceso más natural a la comprensión del contenido lingüístico, al significado y al uso de las palabras o, a la escritura, tanto en su forma (de las palabras y de las frases) como a su significación.

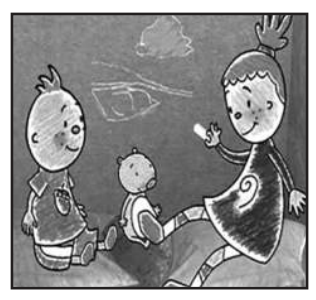


Un ejemplo que señala la importancia de narrar, en la vida de un niño o niña pequeño (a) y cómo de esta manera puede desarrollar confianza en sí mismo, su lenguaje y su imaginación, es el programa infantil que tiene una manera particular de contar historias. Su finalidad va más allá de entretener, pues fija su interés en el desarrollo lexical y semántico del niño o niña que le observa.

Nuevas palabras, refuerzo de ellas, mundos posibles entre varios imaginarios, todo a partir de un cuento que es dibujado por Pinki Dinki Do y el señor Coballan a Tayler (hermanito de Pinki Dinki Do) al interior de una caja de cartón.

Esta experiencia muestra que no importan los medios que se emplean para que una historia sea narrada, o si tiene un fin determinado, tampoco si se conocen o no las letras y las palabras, para poder realizar una narración o un relato. Lo realmente importante es vivir la experiencia de narrar. Se puede contar por medio de imágenes, palabras u otros signos; lo importante es vivir el acto narrativo y aprender con él otros aspectos como las formas, las palabras, los recursos; ir modificando las propias narraciones, mejorándolas, para dar a entender mejor lo que contamos, pero sobre todo, para ser un narrador.

Finalmente, destacamos las actividades propuestas en el taller 3 de la Fase 3 del Proyecto de aula. Reconstruir el lombricultivo y el semillero se convierten en la oportunidad de vivir la experiencia directa de evocar y de organizar la experiencia. Desatacamos, por ello la recomendación hecha al profesor sobre la necesidad de aprovechar para llamar la atención sobre el uso de la lengua de señas colombiana (LSC) en la construcción de los hechos (uso de verbos, descripciones, léxico, etc.) y observar la comprensión de la propuesta de contar historias, las emociones de los niños (as), el nivel de trabajo en equipo. Todo esto es la materia prima del desarrollo de una competencia narrativa en niños y niñas.

\subsubsection{Otros modos discursivos en el aula}

Sobre los modos explicativo, instruccional y de cortesía, presentaremos brevemente sus funciones e implicaciones en el desarrollo lingüístico discursivo de niños y niñas. Partimos de considerar que estos tres modos discursivos constituyen el circuito de la interacción en el aula, dadas sus funciones (tabla2):

Así pues, el contexto escolar ha de convertirse en un espacio rico en expe- 
Tabla 2. Formas discursivas de la interacción en el aula

\begin{tabular}{|c|c|c|c|}
\hline $\begin{array}{c}\text { FORMA } \\
\text { DISCURSIVA }\end{array}$ & CARACTERÍSTICA & $\begin{array}{c}\text { FUNCIÓN } \\
\text { COMUNICATIVA }\end{array}$ & TIPOS /USOS \\
\hline $\begin{array}{l}\text { Las reglas de } \\
\text { cortesía }\end{array}$ & $\begin{array}{l}\text { Son las formas discursi- } \\
\text { vas que expresan situa- } \\
\text { ciones de comunicación } \\
\text { orientadas a sostener } \\
\text { las relaciones sociales, } \\
\text { los afectos, los reconoci- } \\
\text { mientos: por ejemplo, los } \\
\text { saludos, las despedidas, } \\
\text { las celebraciones, los } \\
\text { cumplidos, los agradeci- } \\
\text { mientos, etc. Se expresan } \\
\text { formas lingüístico-discur- } \\
\text { sivas ritualizadas: como } \\
\text { saludar y dar la mano } \\
\text { o dar un beso; corear y } \\
\text { aplaudir, al finalizar un } \\
\text { concierto). Son formas } \\
\text { conversacionales. }\end{array}$ & $\begin{array}{l}\text { Mantener la convi- } \\
\text { vencia socio-cultural } \\
\text { en los distintos con- } \\
\text { textos de comuni- } \\
\text { cación. Cada esfera } \\
\text { de la comunicación } \\
\text { desarrolla formas de } \\
\text { cortesía que expre- } \\
\text { san la identidad de la } \\
\text { esfera y el hecho de } \\
\text { que la persona asu- } \\
\text { me el rol social que } \\
\text { le corresponde en esa } \\
\text { esfera. Por ejemplo, el } \\
\text { profesor habla como } \\
\text { profesor. }\end{array}$ & $\begin{array}{l}\text { Celebraciones: cumpleaños, } \\
\text { día del niño (a), del profesor } \\
\text { (a), de la tierra, fiestas patrias } \\
\text { y religiosas... } \\
\text { Saludos y despedidas: diarios, } \\
\text { definitivos. } \\
\text { Las fórmulas de cortesía: el } \\
\text { trato de respeto y de distan- } \\
\text { cia que se debe dar a las per- } \\
\text { sonas, según la profesión y la } \\
\text { relación jerárquica: profesor, } \\
\text { estudiante, médico... }\end{array}$ \\
\hline Instrucción & $\begin{array}{l}\text { Responde a una solici- } \\
\text { tud o a una necesidad de } \\
\text { aclaración ante una no } \\
\text { comprensión y requiere, } \\
\text { para responder, el aná- } \\
\text { lisis y la síntesis (Adam } \\
\text { (1991). Es una forma ex- } \\
\text { positiva declarativa (una } \\
\text { certeza). Por esta razón } \\
\text { acude a fundamentos } \\
\text { teóricos o empíricos para } \\
\text { dar a conocer qué y por } \\
\text { qué, en ese sentido ge- } \\
\text { nera relaciones causales } \\
\text { y de informatividad. }\end{array}$ & $\begin{array}{l}\text { Esclarecer, hacer in- } \\
\text { teligible a otros algo. } \\
\text { Se manifiesta como } \\
\text { una experiencia so- } \\
\text { cio-lingüística ligada } \\
\text { al desarrollo natural } \\
\text { del lenguaje de nom- } \\
\text { brar, adjetivar, asignar } \\
\text { funciones, relaciones } \\
\text { y establecer causa- } \\
\text { lidades. Es decir, de } \\
\text { objetivar y de com- } \\
\text { prender en un univer- } \\
\text { so empírico, teórico, } \\
\text { discursivamente. En el } \\
\text { aula puede realizarse } \\
\text { mediante: fichas de } \\
\text { registro en ciencias } \\
\text { naturales, en sociales, } \\
\text { protocolos de labora- } \\
\text { torios, informes, ins- } \\
\text { trucciones, etc. }\end{array}$ & $\begin{array}{l}\text { Académica: la realizada por el } \\
\text { profesor o por los estudiantes } \\
\text { para desarrollar asignaturas. } \\
\text { Tiene como base los libros de } \\
\text { texto y las teorías. Desarrolla } \\
\text { el lenguaje académico de los } \\
\text { campos disciplinares. Requiere } \\
\text { la lectura y la escritura } \\
\text { Científica: similar a la acadé- } \\
\text { mica, pero desarrollada por los } \\
\text { investigadores en los distintos } \\
\text { campos del conocimiento. } \\
\text { Técnica: loas manuales de uso } \\
\text { de equipos, de instrumentos } \\
\text { de juegos, etc. Exige la lectura. } \\
\text { Empírica: la que se hace en si- } \\
\text { tuaciones cotidianas para dar } \\
\text { a conocer procedimientos o } \\
\text { comportamientos. }\end{array}$ \\
\hline
\end{tabular}


riencias de lenguaje que permita desarrollo de discurso académico relacionado con pautas de acción para la experiencia escolar. En esta perspectiva, y teniendo en cuenta el marco epistemológico de los micromundos de la aproximación y de la precisión y el marco metodológico de los tres dispositivos elegidos para el proyecto de aula "Criando lombrices y sembrando plantas", se hace necesario identificar y desarrollar, tanto para los estudiantes como para los profesores, los modos discursivos propios del aula y los que se desarrollan en estos campos particulares de conocimiento (Calderón, 2005), como en este caso el de las matemáticas escolares relacionadas con el micromundo de la aproximación y el de la precisión. Entonces, desarrollar competencias para la lectura, la escritura, la oralidad y la escucha, en contextos académicos (en este caso matemático); aumentar el repertorio léxico relacionado con la matemática escolar; aprender y diferenciar la producción de narrativas, explicaciones, justificaciones, etc., acerca de lo matemático, resulta ser un imperativo para el desempeño socio-cultural del estudiante sordo de matemáticas.

\subsection{El desarrollo de la lengua de señas como lengua primera en los procesos de formación discursiva de la persona sorda}

Con respecto a lo expuesto en el apartado anterior a cerca del desarrollo lingüístico- discursivo en el aula, Marchesi (1995) concluye que el uso de la lengua de señas (en este caso LSC) se constituye en el uso de un código pleno, de una lengua en pleno desarrollo, al que es necesario complementarle sistemas alternativos de comunicación (español escrito, sistemas de representación numérico, etc.), para propiciar condiciones en el aprendizaje de contenidos escolares, de normas sociales y para el desarrollo de habilidades cognitivas básicas y de capacidad discursiva suficiente para un desempeño más efectivo en el aula, en una ambiente de aprendizaje matemático.

Desde el punto de vista anterior, destacaremos la necesidad de que en el aula de niños sordos se considere que el discurso es el eje del proceso escolar (Macchi y Veinberg, 2005) y el criterio bilingüe como necesario. Es decir, que se requiere de una perspectiva educativa que sitúe el desarrollo del lenguaje, y en particular de la lengua de señas colombiana (LSC), como principio básico de la comunicación escolar y como soporte del aprendizaje, y a la escritura como aprendizaje de segunda lengua (lengua española) y como soporte del desarrollo académico de los saberes escolares. En este sentido es fundamental asumir la relación entre los espacios de desarrollo lingüístico discursivo en LSC (instrucciones cotidianas, conversaciones, debates) y los momentos que necesariamente exigen la presencia de la escritura.

En particular, la competencia comunicativa en matemáticas requiere, como uno de sus factores fundamentales, del desarrollo procesos cognitivos como la visualización como una forma de representación que organiza en esquemas y en estructuras mentales dos tipos de aspectos: los aprehendidos de manera perceptual a partir de actividades sensoriales y los reflexionados desde la 
relación hombre-entorno. En esta perspectiva, existe una función básica de la visualización en la elaboración del conocimiento matemático y en la constitución de intuiciones básicas (como la de la noción de número natural y de forma geométrica), que depende de la relación con la actividad sensorial que permite la aprehensión, por medio de los sentidos, de los objetos del mundo físico. Tenemos una forma de percepción que puede ser visual, táctil, gustativa, auditiva y olfativa y que guía la necesaria búsqueda de respuestas a preguntas que surgen de la interacción niño (a)- entorno.

Para el caso particular de la aritmética es posible identificar tres instancias fundamentales que disponen una interacción niño (a)-entorno muy productiva en la formulación de cuestionamientos: i) La constitución de relaciones cuantitativas, ii) La elaboración de formas de representación para la comunicación y el manejo de las cantidades y iii) La constitución de un sentido numérico desde las múltiples experiencias con cantidades. Las tres instancias establecen diversos procesos semióticos que hacen de la visualización una forma de representación determinada por el uso de registros de representación semiótica y orientada a modelar situaciones (León, 2005). En este horizonte de configuración de competencia comunicativa en matemáticas, los procesos de discursivización, necesarios para la comunicación, adquieren una dimensión semiótica que incluyen el uso de la lengua como uno de los registros de representación semiótica involucrados en la visualización.

Desde estas exigencias, observamos que la investigación en educación matemática para estudiantes sordos, además de identificar una brecha en la calidad del aprendizaje entre estudiantes oyentes y estudiantes sordos (Augusto et. al, 2002), revela la necesidad de asumir tanto el desarrollo de la lengua de señas para la comunicación de lo matemático, como de propiciar las condiciones didácticas para el desarrollo en los estudiantes en, por lo menos, tres sistemas semióticos (SS): la lengua de señas, el español y un registro matemático. Más, cuando, como se dejó planteado al comienzo, el desarrollo del lenguaje, a través de las lenguas y su discursividad, implica la apropiación y el uso de las reglas de producción sintáctica, semántica y pragmática de los discursos y de los registros y de las lógicas socioculturales de las interacciones. En este sentido, se hace necesario desarrollar la LS no sólo hacia las interacciones naturales entre profesor y estudiantes, sino hacia los modos discursivos que se desarrollan en los campos particulares de conocimiento, como en este caso el de las matemáticas escolares (Calderón, 2009),como se ha descrito anteriormente. El siguiente apartado sobre el bilingüismo en el aula de niños sordos, complementario a este apartado, profundizará en este fenómeno necesario para la educación de las personas sordas. 


\subsection{El bilinguiismo como factor de desarrollo linguíístico-discursivo en el aula de niños sordos}

En la perspectiva de considerar la educación de las personas sordas, presentamos dos hipótesis de trabajo: I) un adecuado desarrollo lingüístico-discursivo de la lengua de señas, en este caso la colombiana, en el contexto escolar, es garantía de "una educación plena, significativa, justa y participativa" para los sordos (Skliar, 1999: 3); esto, en tanto que se asegura un desarrollo de la lengua natural de las personas sordas, con propósitos académicos. II) El bilingüismo es una condición necesaria para la formación escolar de las personas sordas, por cuanto es un factor de necesidad ontológica y epistemológica. A continuación desarrollaremos las dos hipótesis como un sustento del Proyecto de Aula "Criando lombrices y sembrando plantas".

\subsubsection{El desarrollo lingüístico-discursivo de la lengua de señas (LS) como factor de escolarización de las personas sordas}

La discusión sobre el carácter de lengua natural de las lenguas de señas para las personas sordas, teórica y empíricamente se considera superada. A estas alturas del siglo XXI, son innumerables las investigaciones que avalan el estatuto lingüístico de las lenguas de señas como lenguas naturales y diferenciadas estructuralmente de las lenguas habladas. Así, por ejemplo, desde 1993 en la "International Bibliography of Sign Language" publicada por Signum Press reporta estudios de lingüística de la lengua de señas ("sign linguistics") como una disciplina de la lingüística general con objeto de estudio y métodos propios. ${ }^{8}$

Desde una perspectiva socio-antropológico en la educación de los sordos y discursiva en el desarrollo del lenguaje, la lengua natural, que en este caso es la lengua de señas, se convierte en el factor de los procesos de enculturación y, por ello, de la configuración de identidad individual y colectiva del sordo (al respecto ver Skliar, 1999; Massone, 1995; Macchine y Veinberg, 2005; entre otros). En este sentido, un punto de partida es la consideración de la necesidad de que el contexto educativo contribuya a un desarrollo de la lengua de señas (LS) como lengua natural en todos los ambientes de la escolaridad (Calderón, 2010; León y Calderón, 2008), de tal manera que podamos considerar la LS como un factor de alfabetización para la comunidad sorda.

No obstante, a partir de la observación de procesos de escolarización de niños sordos en niveles iniciales, ${ }^{9}$ se encontró que, si bien los discursos y los

7. Este apartado es uno de sus soportes de fundamentación en el tema de lenguaje y Discursividad para el Proyecto de Aula "Criando lombrices y sembrando plantas".

8. Al respecto se recomienda consultar el trabajo de Robert Johnson de la Universidad de Gallaudet en Washington (1995, 2006, 2008, 2009, 2010); el de Alejandro Oviedo y la producción de Apuntes para una Gramática de la Lengua de Señas Colombiana (2001); los trabajos de Lionel Tovar en la Universidad del Valle en Colombia, entre otros.

9. Ver resultados de etnografías del Proyecto "Desarrollo de competencia comunicativa en matemáticas en estudiantes sordos" Colciencias-Universidad Distrital, en la fase anterior a este Diseño didáctico, en León y Calderón (2008). 
pronunciamientos políticos sobre la LS para la comunidad sorda, la directriz de su incorporación al aula y el reconocimiento del papel de esta lengua en la educación, son abundantes y datan de comienzos de la década de los $90,{ }^{10}$ las prácticas escolares distan mucho de promover un adecuado desarrollo lingüístico-discursivo de la lengua de señas. Esto, por cuanto se identifican dos problemáticas particulares y vigentes en las aulas de niños sordos: la dificultad de desarrollar académicamente la lengua de señas y el problema de la enseñanza de la lengua escrita como segunda lengua para una formación bilingüe de los estudiantes sordos.

En cuanto a la primera problemática, asumir discursivamente la lengua de señas (LS) implicaría considerar su relación con los distintos contextos de comunicación, o como lo denomina Bajtín (1982), con las diferentes esferas de la comunicación que generan distintos géneros discursivos y el posicionamiento, y por ello, la participación de las personas sordas en tales contextos y de sus respectivos géneros del discurso. Por el contrario, observamos que, en su gran generalidad, los niños sordos comienzan su escolaridad sin una lengua que les permita entender normas sociales, expresar sentimientos y deseos o comprender su entorno más cercano. ${ }^{11}$ Es decir, sin el adecuado desarrollo de su lengua natural para la edad en que se inicia la escolaridad; aspecto que se constituiría en la base de un posterior desarrollo de la lengua en el ámbito escolar.

Como lo señalan distintos autores (Skliar, 2005, Macchi y Veinberg, 2005, entre otros) los sordos desarrollan la lengua de señas como su lengua natural; es decir, la que adquieren sin enseñanza sistemática - como adquiere el niño oyente la lengua hablada de su entorno- dada su condición de persona sorda. Así, la LS constituye su modo de aproximación al mundo, el medio de construcción de su identidad y el mecanismo para significar y "decir" sobre el mundo. Las lenguas viso-gestuales son, entonces, la modalidad por la que las personas sordas estarán plenamente habilitadas para la interacción social, ya que como sordos no oyen la lengua hablada. A través de esta lengua el sordo desarrolla su potencial de lenguaje (Halliday, 1983, Bruner, 1983, 2004) con la que nace por el hecho de ser humano. La comunidad, los padres o los agentes socializadores del niño - los adultos- serán los encargados de hacer entender

10. Al respecto, ver los pronunciamientos de políticas educativas en Colombia: Ley General de Educación de 1994 (Ley 115). Reconocimiento de la lengua de señas como lengua de las personas sordas (Ley 324 de 1997). Nacimiento del proyecto conjunto entre: INSOR, MINCO, con el apoyo de la Red de Solidaridad (1996 - 1997), Compra de los primeros equipos 1997, Compra de equipos segunda etapa 1999. Moreno, Rojas, Jones y Franklin. 1998. Proyecto de educación a distancia. Vida Ciudadana para los sordos. Instituto Nacional para Sordos. INSOR. Congreso de la República de Colombia. (1997). Ley № 361 por la cual se establecen mecanismos de integración social de las personas con limitación.

11. De este problema dan razón distintos trabajos reportados como investigaciones o como observaciones cotidianas de profesores. Ver por ejemplo, los reportes en el Congreso Nacional de LSE, Valladolid, 15 - 17 de septiembre de 2005; los trabajos de Carlos Skliar (1995, 1999) y Massone (1999, 2005, 2009), entre otros. 
al niño sordo las intenciones de los otros y darán la oportunidad para que él pueda hacer claras sus propias intenciones comunicativas. De esta manera, el niño sordo no solo adquiere el sistema de la lengua de señas, sino también las complejas reglas de la interacción social, de la participación, de tal manera que pueda construir los significados y la realidad compartidos. Todo esto de manera más potente cuando los niños sordos son hijos de padres sordos, como lo señalan con Behares, Massone y Curiel (1990), puesto que se garantizaría un entorno natural de la lengua de señas -al igual que los entornos de la lengua oral para padres y niños oyentes.

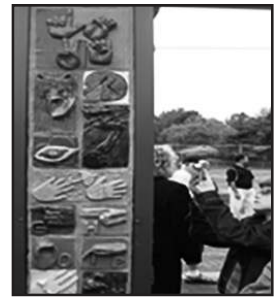

Foto de la entrada a la Indiana Deaf School de Indianápolis (EEUU) inaugurada el 25 de septiembre de 2009 como el símbolo de la puerta que une la escuela de sordos con la comunidad oyente que habita el entorno. Símbolo de la convivencia natural de las dos comunidades y de la invitación de los sordos hacia los oyentes a conocer su escuela.

\section{Foto 1.}

No obstante lo anterior, sobre todo para el caso de niños sordos de padres oyentes, esta posibilidad de desarrollo está seriamente limitada durante sus primeros años de vida familiar, pues sus padres, al menos en nuestro contexto nacional, poco se preocupan por aprender lengua de señas o por generar una estrategia para una comunicación más efectiva con su hijo sordo. En consecuencia, la llegada a la escolaridad de estos niños sordos los sitúa en una condición de déficit, frente a los niños oyentes; pero este déficit ha sido ocasionado por factores socio-culturales de no acceso a su lengua natural, no por factores cognitivos del mismo niño -en particular, en los casos en que éste tan sólo tiene la condición de sordera y no problemas cognitivos asociados-.

Por la razón anterior, la escuela se convierte, en la mayoría de los casos, en el lugar donde el estudiante sordo comienza sus primeras aproximaciones comunicativas auténticas. Desde este punto de vista, consideramos la necesidad de que la escuela asuma, con mayor énfasis, estrategias que según los estudios sobre adquisición de LSE serían propias del contexto familiar entre padres e hijos sordos. Tales estrategias tenderán a proporcionar experiencia lingüístico-discursiva natural y en cooperación con el contexto familiar. ${ }^{12}$ En este sentido se consideró que el dispositivo proyecto de aula es una estrategia que, de suyo, involucra la vida en la escuela y que naturalmente Ilama a la cooperación de padres de familia. Veamos un pronunciamiento de este proyecto al respecto:

"La propuesta de proyecto de Aula, adquiere dos funciones articuladas y articuladoras: Ser el escenario de las relaciones socio-culturales entre los estudiantes, el profesor y los padres de familia, a propósito de la meta de construir y mantener un criadero de lombrices y un huerto escolar. En este sentido, se diseñan fases y

12. Ver en la Tercera Parte de este libro el Proyecto de Aula "Criando lombrices y sembrando plantas y sus respectivas actividades para padres y para estudiantes. 
momentos que conllevan a lograr paulatina y colectivamente esta meta; adicionalmente, se considera el concurso de los intereses y la motivación de los niños (as) para con este propósito y la cooperación de los padres de familia en todos los momentos requeridos."

(Introducción al proyecto de Aula "Criando lombrices y sembrando plantas").

De igual manera, este proyecto se propone como uno de sus objetivos:

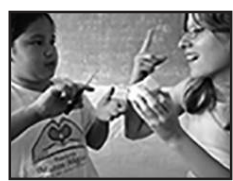

Conformar un equipo solidario formado por profesores, niños y padres, cuya interacción permita la construcción del criadero y de la huerta.

Foto 2 .

Es evidente, entonces, que se ha considerado, de manera importante, la participación de los padres, como parte de la estrategia de configuración de un Ambiente de Aprendizaje ${ }^{13}$ para los micromundos de la aproximación y de la precisión, a través del proyecto de aula y de sus talleres. De igual manera, como se propone en el siguiente apartado, refiriéndonos al desarrollo del lenguaje y de la discursividad en la formación inicial en matemáticas estudiantes sordos, las modalidades discursivas prioritarias del aula (descripción, narración, explicación, fórmulas de cortesía) han de ser consideradas como base para la formulación de estrategias de trabajo en el aula y para el diseño de sus interacciones. En particular, se requiere considerar el desarrollo de la LSC en estos formatos, de manera natural, y no como un puente con la oralidad del español.

Esto, por cuanto en la educación de los sordos se ha observado que las expectativas de los profesores $y$, en general del sistema educativo, frente a las potencialidades de la persona sorda son bajas. Según Johnson, Erting y Liddell (1989) "el educador parte de la idea de que sus alumnos ya poseen un límite natural en sus procesos de conocimiento, planifica por debajo de esas capacidades, obtiene los resultados que concuerdan con esa percepción y justifica el fracaso en el hecho de que los niños sordos no pueden vencer su propia naturaleza". Es decir, parece considerarse, de entrada, que la lengua de señas es un impedimento para el desarrollo natural de la discursividad y, más aún para el discurso requerido en el ámbito escolar.

Con base en lo anterior, destacamos en este momento la necesidad de proponer estrategias de trabajo en el aula que privilegien la experiencia sociocultural del aula de manera natural, con la puesta en marcha de formatos discursivos propios de las interacciones que se generan en la comunicación en contextos

13. Ver el apartado 1 de esta primera parte, que explicita una teoría sobre Ambientes de Aprendizaje y luego los dispositivos didácticos en la Parte 2 del libro. 
socio-escolares: por ejemplo, formatos para la interacción regulativa orientada a la conformación de rituales escolares (saludos, despedidas, de participación en los juegos), hábitos de aseo, de uso de los materiales, etc. Todo esto, atendiendo a la naturaleza gramatical, semántica y pragmática de la lengua de señas colombiana (LSC): interacciones que privilegien la atención visual y el uso del espacio o las referidas al estilo comunicativo y la adaptaciones lingüísticas de la LS, que permitan avanzar posteriormente hacia una enseñanza de la LSC, desde formatos más complejos como la narración, la descripción y la explicación. De este modo, el niño sordo estará en condiciones de arriesgar hipótesis lingüísticas para construir la gramática de su lengua con base a los datos del "input" y de interiorizar y emplear funcionalmente la LS: pedir, expresar, pensar socialmente al interactuar, "ser socialmente, mediante la interacción" (Behares, 1990) en su lengua natural o desarrollar competencia comunicativa en LSC. Al respecto, las actividades propuestas en el Proyecto de Aula se caracterizan por establecer momentos de experiencia lingüístico -discursiva que desarrolla formatos de pregunta-respuesta, de descripción y de búsqueda y registros de vocabulario que llevará al niño (a) a un necesario aprendizaje de aspectos gramaticales y pragmáticos de la LSC.

A continuación presentamos una síntesis de la relación entre características lingüísticas de la LS y aspectos que, desde el Proyecto de Aula "Criando lombrices y sembrando plantas" proponemos como base del desarrollo lingüístico- discursivo en los micromundos de la aproximación y de la precisión. No realizamos un estudio gramatical de la LS, por considerar que ese no es el propósito del presente trabajo; no obstante, Ilamamos la atención sobre elementos estructurales de la LS, con el fin de establecer la diferencia y complejidad de su desarrollo frente a la lengua oral y el necesario cuidado que ha de tener el profesor para promover su adquisición y su desarrollo.

Así pues, destacamos la necesidad de que los profesores desarrollen intencionadamente, tanto desde el punto de vista lingüístico-discursivo como desde el epistemológico (los contenidos en matemáticas y otras posibles áreas escolares involucradas), las actividades comprometidas en el Proyecto de Aula. Sobre todo, porque, como se observa en la tabla 3., los distintos aspectos de la lengua de señas estarán siendo puestos en juego en las actividades y los recursos que se han propuesto para este proyecto. Por ejemplo, la interiorización de formas de preguntas y respuestas que se elaboran para el trabajo en los distintos talleres, se convierte en el inicio de la configuración de las formas discursivas propias de la interacción estudiante-profesor, en el marco de las "tareas" escolares. De igual manera, la toma de registros, la consulta de vocabulario en diccionarios, en libros y en videos, establece estrategias de estudio, maneras de búsqueda del conocimiento y de registro del mismo, formalizando modos discursivos académicos que respondan a: cómo organizar respuestas escolares, cómo presentar el resultado de las tareas... 
Tabla 3. Características de la Lengua de Señas

\begin{tabular}{|c|c|c|}
\hline & Características de la LS & Aplicaciones en el Proyecto de aula \\
\hline $\begin{array}{l}\text { (Componentes articulatorio } \\
\text { y de movimiento de las LS } \\
\text { manuales y no manuales: } \\
\text { cara, manos, cuerpo) }\end{array}$ & $\begin{array}{l}\text { Configuración de la mano y dedos } \\
\text { (CM) para cada seña. } \\
\text { Ubicación en el espacio: las señas se } \\
\text { producen en el espacio del señante } \\
\text { con límites establecidos. } \\
\text { Movimiento (en arco, lineal, circular, } \\
\text { en zigzag, en forma de siete, detenido } \\
\text { meneante, oscilante, progresivo, } \\
\text { vibrante, rozando el cuerpo. } \\
\text { Orientación (en relación con el suelo). } \\
\text { Rasgos no manuales (RNM): de partes } \\
\text { distintas del cuerpo a la mano (ceja, } \\
\text { nariz, boca, etc.) }\end{array}$ & 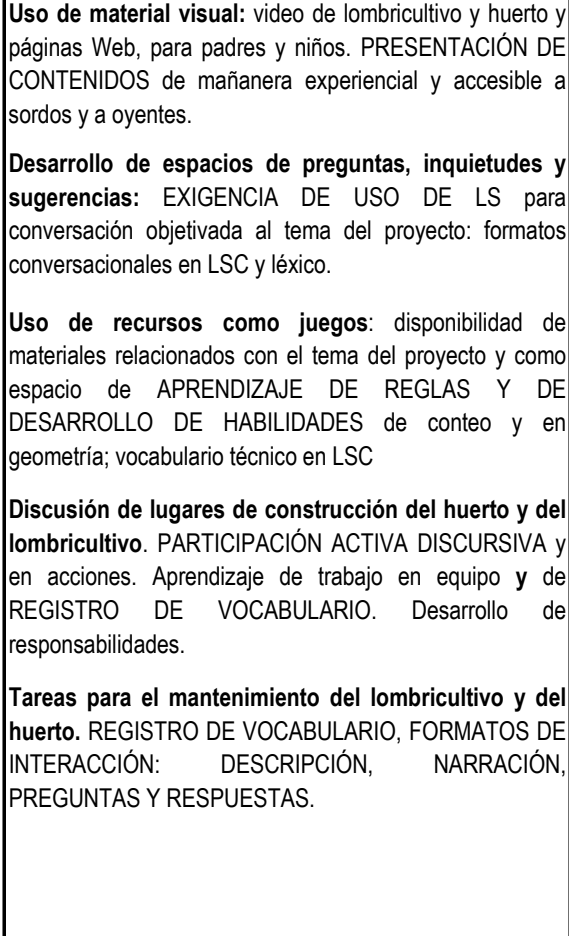 \\
\hline $\begin{array}{l}\text { El componente } \\
\text { morfosintáctico } \\
\text { Estructuración de unidades } \\
\text { de la lengua: verbos, } \\
\text { clasificaciones, } \\
\text { enunciados... }\end{array}$ & $\begin{array}{l}\text { Raíces de incorporación numeral: } \\
\text { indican el número de elementos que se } \\
\text { van a contar. } \\
\text { Clasificadores: tipo de pronombre que } \\
\text { incluye en su significado información } \\
\text { acerca del objeto al que se refiere. } \\
\text { Palabras compuestas: combinación de } \\
\text { segmentos de una seña con los de otra } \\
\text { seña, para formar una nueva. } \\
\text { Flexiones verbales: modificaciones } \\
\text { espaciales, temporales o dinámicas } \\
\text { para indicar número, aspecto, tiempo, } \\
\text { modo... } \\
\text { Sintaxis: preferiblemente el orden es } \\
\text { SOV (sujeto- objeto-verbo). }\end{array}$ & \\
\hline El factor discursivo & $\begin{array}{l}\text { La mirada juega un papel } \\
\text { preponderante en este aspecto, para } \\
\text { marcar turnos de conversación y los } \\
\text { marcadores de uso de la lengua, según } \\
\text { contextos de comunicación. }\end{array}$ & \\
\hline
\end{tabular}

* Hemos tomado los aportes de Macchi y Veinberg, 2005 y de Oviedo, 2001. 
Consecuentemente, los momentos de explicación del profesor, bien sea para aclarar significados, para describir configuraciones de señas, para ayudar a establecer relaciones entre cuidado de las lombrices y del semillero y fenómenos que ocurren con ellos, se configuran como la génesis de la explicatividad en el aula; aspecto relevante tanto para aprehender formas de conocer como para elaborar una relación jerárquica con el profesor, con el adulto, en términos de la autoridad epistémica: el que sabe (el profesor, el adulto, el libro, el experto, etc.). Este último aspecto, es fundamental en la conformación de un sentido para la interacción en el aula y de poder diferenciar el contexto escolar de otros contextos sociales y aprender a actuar efectiva y satisfactoriamente en él.

Complementariamente, en una perspectiva antropológica de la educación, retomamos la recomendación de Ramírez (2003) que se potenció en la propuesta de participación de los padres de familia en el Proyecto de Aula: "con el objetivo de que los padres de los niños sordos se interesen cada vez más por el aprendizaje de la LSC y el conocimiento de las personas sordas, se debe promover la realización de actividades de tipo social, recreativo, cultural o educativo dentro y fuera de la institución con participación de personas sordas de la comunidad".

Adicionalmente, estar atento a las inquietudes de los padres y abrir espacios de comunicación para escuchar sus interrogantes y ofrecer oportunamente el apoyo necesario, es la estrategia que se propone en el Proyecto de Aula "Criando lombrices y sembrando plantas", para los propósitos de involucrar activamente a la familia en el desarrollo educativo del niño sordo y, en especial, de su competencia comunicativa en LSC. El contacto de los padres de los niños sordos con sordos adultos, con otros padres de niños sordos y con otros niños sordos, facilitará la aceptación de la sordera de sus hijos y les generará mejor disposición para su participación activa en el contexto escolar. De igual manera, se hace necesario garantizar la presencia de adultos sordos con buena competencia comunicativa en LSC, bien como cuidadores o como profesores, de tal manera que se promueva activamente el desarrollo de todas las potencialidades de los niños (as) y, particularmente, cooperen en su construcción lingüístico-discursiva. El adulto sordo se convierte en el modelo lingüístico de la cultura y puede ser, para los niños y sus familias, el representante de la comunidad sorda, de su estilo de vida, en beneficio de la construcción de una sana identidad y de un sentido de pertenencia necesario para todo ser humano.

\subsubsection{El bilingüismo en el aula de sordos: un factor necesario}

El tema del bilingüismo, en términos generales, hace alusión a una situación de convivencia de dos lenguas en una misma región o en una misma persona. Adicionalmente, la condición de bilingüe implica que las dos lenguas son dominadas con suficiencia por la o las personas que las emplean. Para el caso del bilingüismo de las personas sordas, la situación será la convivencia de una lengua de señas (la propia del país, empleada por su comunidad sorda) y de 
una lengua oral en su expresión escrita (la lengua de la comunidad oyente del mismo país). Para un análisis de la situación de bilingüismo de las personas sordas en el contexto escolar, partiremos de tres condiciones, a nuestro juicio, importantes en términos de su valor para un desarrollo efectivo de competencia bilingüe y de aprendizajes académicos en los estudiantes sordos; competencia que también conlleva una apropiación del ambiente escolar en general.

a) El bilingüismo ha de ser considerado desde un punto de vista socio-antropológico.

b) El bilingüismo de la lengua de señas y de la lengua escrita es necesario para la educación de las personas sordas.

c) Un desarrollo competente de la lengua de señas será un factor potenciador de un buen desarrollo de las competencias lectora y escritora. Las dos competencias son garantía de una escolarización efectiva para la persona sorda.

Estas tres condiciones configurarían un escenario propicio para la educación de las personas sordas, en condiciones de equidad, de acceso a los saberes y a las prácticas escolares y de respeto por las condiciones particulares de esta comunidad. A continuación se explicitan elementos para cada uno de las tres condiciones y se relacionan con el Proyecto de Aula "Criando lombrices y sembrando plantas".

\section{1) El bilingüismo de los sordos desde un punto de vista socio-antropológico}

El punto de vista socio-antropológico en la educación de las personas sordas ha sido posicionado por distintos autores como Skliar y Massone (1990, 1999, 2002, 2009), Veimberg (1995, 2004), entre otros. Esto, reconociendo, en primera instancia, que el sujeto sordo históricamente ha sido discriminado tanto en sus derechos como en las formas de realización de la interacción social y educativa; en particular por considerar la sordera como una condición de inferioridad intelectual y social. Ante este hecho ha surgido una perspectiva crítica instaurada desde el Discurso Pedagógico de la Educación de los Sordos (DPES), que proclama la necesidad de un discurso y unas prácticas educativas de tipo bilingüe-bicultural y que tiene como punto de partida una nueva valoración de las categorías "sordo", "educación especial de sordos", "idioma gestual", e introducen el signo "cultura sorda" (Massone y Johnson, 1990), con la intención de cuestionar el discurso dominante oralista en el contexto educativo y de abrir el espacio para la emergencia de prácticas socio-educativas orientadas por principios antropológicos de la condición de sordo.

Este discurso se sustenta en una concepción intercultural de las relaciones entre grupos sociales y desde el paradigma de la aceptación y respeto por la diversidad. Se considera que los sordos son miembros de una minoría lingüística con su propia lengua y cultura y que, por ello, se hace necesaria la existencia de un modelo educativo bilingüe-bicultural, que permita, con su desarrollo, 
poner a la comunidad sorda en una condición de interlocutor válido, de participante y actor social, en los distintos escenarios sociales y en la red discursiva socio-cultural (Massone, 2009), mediante su participación lingüístico-discursiva empleando efectivamente tanto la lengua de señas colombiana (LSC) como el español escrito.

Así pues, reconociendo que la construcción de las identidades no depende de una mayor o menor limitación biológica, sino de complejas relaciones lingüísticas, históricas, sociales y culturales, tanto desde el punto de vista de la investigación como desde las prácticas pedagógicas para la educación de los sordos, se llega a la conclusión de que la lengua de señas es la primera lengua -o la lengua natural- y las lenguas de los oyentes, en este caso el español escrito, son segundas lenguas para la persona sorda (Sánchez, 1990). Las Investigaciones sobre la enseñanza de la lengua escrita como segunda lengua (Quiñónez, Ramírez, y Valbuena, 2000, 2006; MEN-INSOR, 2003; Tovar, 2004), han permitido generar una serie de lineamientos sobre los procesos fundamentales, los principios y los espacios de trabajo para enseñar la lengua escrita desde preescolar hasta quinto de primaria en propuestas de educación bilingüe y bicultural para sordos. Adicionalmente, proponemos observar prácticas educativas concretas que dan cuenta de cómo el bilingüismo en el aula es una realidad que se desarrolla desde el preescolar. Citamos el caso de la Indiana Deaf School en Indinápolis (EEUU) y de la Elementary Kendall School en la Universidad de Gallaudet en Washington (EEUU)..$^{14}$ Estas dos escuelas exclusivas para sordos desarrollan modelo bilingüe y bicultural en toda la escolaridad de niños sordos, generando una clara convivencia de las dos lenguas y promoviendo el desarrollo de la lengua de señas americana (ASL) como lengua natural en los contextos escolares, a la par con la inglés escrito para los procesos académicos.

Esta mirada socio-antropológica a la educación de las personas sordas, que posiciona una propuesta bicultural y bilingüe, exige que el trabajo en el aula privilegie prácticas educativas orientadas a la generación de Ambientes de Aprendizaje, en el sentido en que se ha considerado esta categoría para el presente sistema didáctico. ${ }^{15}$ Tales prácticas se han de caracterizar por: exigir la interacción natural en la primera lengua, que en este caso es la lengua de señas colombiana (LSC), con el fin de resolver la convivencia diaria; requerir de la lengua escrita para resolver aspectos puntuales de la convivencia, que naturalmente se encuentra en formatos escritos (libros, afiches, registros, etc.).

En esta perspectiva, generar un ambiente de aprendizaje implica diseñar sistemas de prácticas que promuevan la participación activa y natural de la co-

14 Ver videos sobre observaciones de clases de primer grado en estas dos escuelas y modelos de libros de texto empleados para el trabajo en lenguaje y en matemáticas en los archivos del Grupo de Investigación Interdisciplinaria en Pedagogía del Lenguaje y las Matemáticas, Universidad Distrital Francisco José de Caldas, Bogotá, Colombia.

15 Ver el apartado 1. "El sistema didáctico como un Ambiente Didáctico" de la Parte 1 de este libro. 
munidad educativa; en este caso, de los estudiantes, de los profesores, de otros actores de la institución y de los padres de familia. El Proyecto de Aula "Criando lombrices y sembrando plantas" parte de estos principios de un ambiente de aprendizaje; en ese sentido propone, como punto de partida, el desarrollo de una convivencia socio-cultural y discursiva alrededor de la meta común de construir un lombricultivo y un huerto escolar. Así por ejemplo, en la introducción al Proyecto de Aula se declara que:

"En general, como escenario, este proyecto de aula propicia el desarrollo de aprendizajes y de valores relacionados con la convivencia, la cooperación, la responsabilidad, el respeto por los otros y por el entorno natural y social (los animales, las plantas, las personas y la naturaleza en general) y el valor del trabajo en equipo. Consecuentemente, propicia el necesario desarrollo de conocimientos relacionados con las prácticas de convivencia y de trabajo conjunto y las formas de expresión lingüístico-discursiva en lengua de señas colombiana LSC y en español escrito.

Como se observa, se plantea el proyecto de aula como un escenario para la permanente interacción entre profesores, estudiantes y padres y para el desarrollo de convivencia social; a la vez, se considera que el proyecto pretende el desarrollo de lengua de señas y de español escrito. Los objetivos y las actividades planteados para cada fase ratifican este carácter de ambiente de aprendizaje, veamos un ejemplo:

\section{Tabla 4. Ambiente de aprendizaje bilingüe}

\begin{tabular}{|c|c|c|}
\hline Objetivos & Actividades & Desarrollo bilingüe \\
\hline $\begin{array}{l}\text { Revisar con cada equipo los } \\
\text { materiales necesarios para el } \\
\text { lombricultivo. } \\
\text { Conseguir materiales necesarios } \\
\text { para la construcción del criadero. } \\
\text { Construir el semillero y el } \\
\text { lombricultivo. } \\
\text { (Objetivos Fase 2) }\end{array}$ & $\begin{array}{llrr}\text { Se recomienda } & \text { al profesor } & \text { hacer } \\
\text { una lectura } & \text { previa } & \text { de } & \text { los } \\
\text { documentos } & \text { vinculados a } & \text { la } \\
\text { construcción del lombricultivo y } & \text { de la } \\
\text { huerta escolar. También, revisar los } \\
\text { videos y } & \text { realizar } & \text { sus } \\
\text { adecuaciones a lengua de señas } \\
\text { colombiana (LSC). Algunos de } \\
\text { estos materiales se sugieren en la } \\
\text { parte dedicada a materiales en esta } \\
\text { fase. }\end{array}$ & $\begin{array}{l}\text { Como se observa, la situación } \\
\text { bilingüe es planteada por el profesor, } \\
\text { de manera natural. Se dan prácticas } \\
\text { socio-culturales relacionadas con } \\
\text { construir un lombricultivo y una huerta } \\
\text { escolar, prácticas que para el profesor } \\
\text { se apoyan con documentos escritos. } \\
\text { Durante tales prácticas, se hace } \\
\text { necesario hablar (opinar) en LSC, ver } \\
\text { videos (comentar en LSC) y comparar } \\
\text { con expresiones escritas; jugar exige } \\
\text { preguntar comparar, observar las } \\
\text { señas conocidas y preguntar por las } \\
\text { no conocidas o no existentes. En fin, } \\
\text { se desarrolla la LSC tanto para } \\
\text { estudiantes como para los profesores. }\end{array}$ \\
\hline
\end{tabular}


Así pues, del cambio de la mirada de un enfoque más clínico hacia uno social- antropológico, surge el concepto de bilingüismo y el del sordo como sujeto bilingüe. El niño sordo bilingüe puede compararse con otros niños pertenecientes a minorías bilingües que utilizan y desarrollan dos lenguas, y a la vez se diferencia de éstas por su condición específica, ya que los bilingües no son la suma de dos monolingües sino que presentan una configuración lingüística única y específica (Veinberg, 2002: 5). De la misma manera, una persona bicultural no es la suma de dos monoculturas, sino que es la combinación de los aspectos de ambas culturas que producen una única configuración cultural. Debido a que las necesidades y usos de las dos lenguas son generalmente diferentes, la persona bilingüe es raramente igual de fluida y competente en ambas lenguas. Los niveles de competencia en una lengua dependerán de la necesidad y de la oportunidad que la persona tenga de utilizarla.

\section{2) El bilingüismo de la lengua de señas y de la lengua escrita es necesario para la educación de las personas sordas.}

Un punto de partida para esta premisa es la consideración de que cuando se habla de la necesidad de una situación bilingüe para los sordos en la escuela, no estamos aludiendo al bilingüismo decretado por las leyes por los decretos expresados desde los pronunciamientos legales en la educación; no obstante reconocemos que este es un aspecto fundamental en el desarrollo de condiciones institucionales para un bilingüismo en la educación de las personas sordas. Como lo plantea Masson, se trataría de los objetivos que debería tener una educación bilingüe creada y desarrollada dentro de las escuelas para sordos y, sobre todo, con los sordos (Massone, 2009: 7), a partir de la necesidad comunicativa y epistemológica de la condición de la persona sorda para acceder efectivamente a la escolaridad.

Como punto de partida, es importante hacer dos reconocimientos: la escritura se hace necesaria por cuanto la lengua de señas no posee un sistema de escritura; sistema en el que se ha desarrollado y en el que circula el legado científico, artístico, tecnológico y socio-cultural de la humanidad letrada. Por lo anterior, para un desenvolvimiento socio-cultural intelectual y profesional adecuado, la persona sorda se ve obligada a emplear la lengua escrita. Ella se convierte en el medio privilegiado de acceso a la información, al conocimiento simple y complejo y, al intercambio, en todos los órdenes, con los oyentes de la sociedad en la que vive. No todos los sordos usan las dos lenguas y las razones para que esto suceda varían de una persona a otra y están relacionadas con la educación que recibieron, con situaciones familiares y con la facilidad con la que puedan desenvolverse solo con la lengua de la mayoría. No obstante, todos los sordos necesitan ambas lenguas cuando llega el momento de comprender la totalidad de un mensaje (Veinberg, 2002: 7 y 8).

En el sentido anterior, el bilingüismo aparece como necesidad contextual escolar: se requiere aprender una primera lengua LSC como base de la comuni- 
cación y de la significación natural en el universo socio-cultural del individuo y como base del desarrollo de una segunda lengua. Adicionalmente, se necesita aprender la escritura del español, que es la segunda lengua de bases estructurales diferentes y cuyo uso aparece para el mundo letrado: dar y circular información, conocer y desarrollar los temas académicos, etc.

Así, el bilingüismo del niño sordo exige el uso de la lengua de señas, empleada por la comunidad sorda y el de la lengua oral, en su modalidad escrita, de la mayoría oyente. Esta última puede ser adquirida por el sordo en su modalidad escrita y, cuando es posible, en su modalidad hablada. En cada niño sordo las dos lenguas jugarán papeles diferentes: en algunos predominará la lengua de señas, en otros predominará la lengua oral y en otros habrá en un cierto equilibrio entre ambas lenguas, dependiendo del desarrollo de sus contextos familiar, educativo y social.

Adicionalmente, este tipo de bilingüismo pone en juego factores distintos que aumentan la complejidad de tal situación: la relación entre diferentes niveles de sordera y la compleja situación de contacto entre ambas lenguas. En algunos casos la situación puede privilegiar modalidades lingüísticas como: la oral y la escrita de la lengua oral; la escrita y la viso-gestual de la lengua de señas), exigiendo dos sistemas de producción de las lenguas (la articulación oral y el sonido por una parte, y la articulación mano-expresión gestual y corporal, por otra) y dos sistemas de recepción (el oído y la vista).

Así, es posible encontrar diferentes tipos de bilingüismo; es decir, la mayoría de los niños sordos adquirirá niveles distintos de bilingüismo y de "biculturalismo". En este sentido, es posible concluir al respecto, que los niños sordos no se diferenciarán de la mitad de la población mundial que, aproximadamente, convive con dos o más lenguas (se estima que actualmente en el mundo hay tantas personas si- no- más- bilingües como monolingües). Como otros niños bilingües, los niños sordos emplearán ambas lenguas en sus vidas cotidianas como miembros integrantes de dos mundos, en este caso, el mundo oyente y el mundo sordo (Grosjean, 1999). Es importante destacar aquí, que la discusión sobre este tipo de bilingüismo ha de ser más desarrollada, sobre todo al tenor del tipo de contacto que se produce en el encuentro de la LS y la lengua oral. No obstante, desde un punto de vista didáctico, es relevante considerar que las dos lenguas constituyen canales naturales y necesarios para el desarrollo lingüístico comunicativo y de los saberes escolares en los niños sordos. Desatacamos aspectos para tener en cuenta en esta relación de necesidad entre las dos lenguas: LSC y español escrito en el aula.

i) Las implicaciones de aprender las particularidades de cada lengua. Es necesario que se consideren las características estructurales y contextuales de cada una de las dos lenguas, pues esa diferencia hace exigencias cognitivas y 
comunicativas distintas. Por ejemplo, el hecho de que la LS sea viso-gestual, más ideográfica, más contextualizada, altamente deíctica, a diferencia de la lengua española en su modalidad escrita, que se caracteriza por ser lineal, secuencial, tendiente a la descontextualización, altamente simbólica. No obstante, un enfoque comunicativo en la enseñanza de las lenguas será fundamental, para garantizar un aprendizaje natural y en contexto de las dos lenguas. Al respecto se recomienda considerar una didáctica de la lengua de señas colombiana (que no existe hasta el momento) y una didáctica de la lengua escrita (Solé, 2001; Goodman, 1995; Lerner, 2001, Tolchinsky, 1993; Ferreiro, 1989, entre otros).

Proponer actividades para el trabajo en el aula que partan de, al menos, dos criterios: el aprendizaje de la lengua en uso: en los distintos formatos discursivos y contextos de comunicación variados; y el desarrollo de las lenguas: esto es, que las interacciones en el aula han de ser exigentes para avanzar en la lengua, ofrecer modelos más desarrollados de la lengua, del que cotidianamente tiene a disposición el estudiante. La escuela es, en este sentido, modelo de uso académico y científico de las lenguas. El hecho de que los niños sean bilingües hace que también posean una percepción metalingüística más aguda que influye positivamente en el rendimiento escolar. El argumento consiste en que el ser bilingüe se traduce en un aumento de las capacidades metacognitivas y metalingüísticas que, a su vez, facilita todo aprendizaje lingüístico y conduce a mejores logros escolares (Veinberg, 2002: 9). Al respecto, se recomienda ver la propuesta de talleres del proyecto de aula "Criando lombrices y sembrando plantas", como propuesta de entrada a la relación LSC- español escrito en primeros grados de escolaridad; por ejemplo:

*Escoge la lombriz que más te gusta de todas las que viste y colócale un nombre en LSC. Pide al profesor que te ayude a buscar el nombre en español y escríbelo en la lámina.

*En una hoja de papel periódico pinta a tu lombriz y escribe su nombre. Luego haz una lista de dibujos de las cosas que necesita la lombriz para vivir. Presenta a tus compañeros (a) a tu lombriz y lo que ella necesita para vivir.

*Con la ayuda de tu profesor, escribe en español las cosas que tu lombriz necesita para vivir.

\section{(Actividad 3, Fase 2)}

También se ha construido un Repertorio léxico para el campo semántico del conteo y un Lexicón de términos que aparecen en el Proyecto de aula, referidos a la experiencia en el micromundo de la aproximación y en el de la precisión, durante la construcción del lombricultivo y del huerto escolar. Elementos que representan, en la idea del bilingüismo en el aula, referentes para y un desarrollo efectivo de las dos lenguas en el aula de matemáticas de primeros grados .

ii) La necesidad de una didáctica de los saberes escolares en las aulas de sordos, en este caso de las matemáticas. Didáctica que, desde un enfoque lin- 
güístico-discursivo y bilingüe, ha de centrar la atención, entre otros aspectos, en el desarrollo lingüístico-discursivo del lenguaje y de los sistemas de representación propios de ese campo de saber escolar. Por ejemplo, la complejidad de la producción de sistemas de numeración, para el niño sordo, pasa por la construcción de tales sistemas en las dos lenguas: el sistema de numerales en LSC y el sistema de numerales en español escrito. En este caso, es importante destacar el cuidado de que la convivencia de las dos lenguas mantenga la naturaleza de cada una. La tendencia a emplear la lengua señada (aplicar reglas de la escritura lo de la oralidad a la producción de la lengua de señas) como medio de transmisión de contenidos en las escuelas que decidieron incluir la utilización de señas en el ámbito escolar, puede llegar a ser una forma de dialectización, ya que al usar las señas sin respetar su gramática, se la transforma en una variante de la lengua dominante (Veinberg, 2002: 8).

En este sentido, el sistema didáctico construido en esta obra, y que se explicita en la acción propuesta como proyecto de aula "Criando lombrices y sembrando plantas", articula el sistema de Documentos de profundización que constituyen la Parte 1 del libro ${ }^{16}$ y que para fundamentar y para profundizar en los saberes matemáticos contiene: El micromundo de la aproximación y el Micromundo de la precisión y su sistema de trayectorias del número y la cantidad en niveles iniciales de escolaridad. La productividad de la lengua hace que los estudiantes puedan referirse a los contenidos de los programas académicos aunque no existían previamente señas para designar algunos conceptos específicos. A medida que se desarrollan los temas, se van creando nuevas señas que se irán utilizando y convencionalizando en el uso cotidiano del aula. La expansión del vocabulario permite el acceso a otros ámbitos académicos, a medida en que se avanza en la escolaridad: exposiciones, cursos, salidas pedagógicas, intercambios con otros colegios, etc. (ver Veinberg, 2002: 13).

iii) La disposición de buenos modelos de lengua de señas y de español escrito en las aulas. La construcción de procesos de educación bilingüe y el respeto por la situación de bilingüismo, inherente a las personas sordas, es un asunto de responsabilidad pedagógica, puesto que actualmente en Colombia la única opción con que cuentan los niños sordos para acceder, de manera natural, a una primera lengua es en el espacio escolar. El hecho de que en el contexto familiar no existan hablantes de una lengua, que como la LSC, privilegia los canales de expresión y recepción en los cuales el niño sordo no tiene ninguna restricción sensorial, genera serias implicaciones sociales, educativas, comunicativas y emocionales, dado que la mayoría de ellos pasa sus primeros seis años de vida sin la oportunidad de configurar y simbolizar el mundo a través de las interacciones genuinas y naturales que se dan en el seno de la familia y que son mediadas por la lengua de los padres.

16. Se recomienda consultar estos capítulos como la estrategia de profundización para el profesor y como el insumo para la planeación de la evaluación y de nuevas actividades. En esta perspectiva, se configuran en parte del ambiente didáctico para el profesor. 
La sordera es un factor crítico dentro de las aulas con maestros oyentes y alumnos sordos. Este factor se reduce ostensiblemente en interacciones entre maestros sordos y alumnos sordos. Por ello, las escuelas que han tomado conciencia de este factor han incorporado adultos sordos competentes en lengua de señas en sus aulas, con el fin de favorecer la comunicación de sus alumnos con los docentes, pero no han tenido en cuenta que si los adultos sordos no están adecuadamente entrenados para participar de la actividad educativa, los resultados académicos no serán diferentes de los que obtenían sin la presencia de los sordos (Veinberg, 2002: 9). En este sentido, resulta fundamental la toma de conciencia del sistema educativo para los sordos, de que no basta con usuarios nativos de lengua de señas en el aula. Se requiere el criterio pedagógico y didáctico de que sean personas formadas como educadores. Por supuesto, la mejor opción es la formación de profesores en las áreas de los saberes escolares competentes en LS, independientemente de que sean sordos u oyentes. ${ }^{17}$

En condiciones deficitarias de uso de LSC o de comprensión didáctica de los saberes, los niños sordos se encuentran en situación de desventaja frente a la cantidad y calidad de temas escolares en relación con sus pares oyentes. Cuando se dificulta la comunicación maestro oyente-estudiante sordo, la tendencia es a simplificar los conceptos y los contenidos en general, de tal manera que se considere comprensibles para el niño. De esta forma, el niño sordo recibe sólo una parte de la información, filtrada no por su incapacidad de comprensión del mensaje, sino por su poca habilidad con una lengua que no le es natural. Estos niños son privados de contenidos curriculares interesantes y desafiantes debido a que el maestro no está en capacidad de comunicarlos eficientemente. La pregunta inmediata será ¿de quién es la responsabilidad? (Veinberg, 2002: 4).

Adicionalmente, y para mayor complejización del problema, es necesario reconocer que otro modelo importante en el aula bilingüe de sordos, es el de la escritura. Se requiere, tanto para oyente como para sordos, la presencia de modelos claros, correctos (en el sentido gramatical), pertinentes y adecuados de escritura. También la comprensión de los niveles de elaboración del código escrito en los primeros años de escolaridad. El niño sordo, como el oyente, se hallan ante un código diferente cuando se enfrentan a la escritura. La diferencia es que el niño oyente posee una base que es la oralidad, que permitirá un acceso menos difícil a este nuevo código. La recomendación es acudir a una teoría de la adquisición del código escrito, como se dijo antes, desde un enfoque comunicativo y desde una perspectiva más semiótica y sociocultural: la lengua escrita en uso y bajo necesidad real. Se recomienda, entonces, escribir bien, acudir a modelos escritos de tamaño adecuado, de frases cortas, a visualizar permanentemente el nombre de los niños, los días de la semana, es decir, a establecer un contacto natural con el mundo letrado y a establecer estrategias

17. Al respecto, se recomienda ver propuesta de Proyecto Académico Transversal de Formación de Profesores para Poblaciones con Necesidades Educativas Especiales, de la Universidad distrital Francisco José de Caldas (2008), Bogotá. Colombia. 
de trabajo que vinculen naturalmente las dos lenguas, en donde la escritura cobre funcionalidad y necesidad. En el Proyecto de Aula "Criando lombrices y sembrando plantas" se proponen numerosas actividades que proporcionan experiencia con la escritura inicial.

"Un desarrollo competente de la lengua de señas será un factor potenciador de un buen desarrollo de las competencias lectora y escritora. Las dos competencias son garantía de una escolarización efectiva para la persona sorda".

La competencia lingüística desarrollada por la persona bilingüe permitirá que haga un uso de una lengua o de la otra o una mezcla de ambas, dependiendo de la situación, del tema, del interlocutor, etc. Siguiendo a Veinberg (2002) podemos decir que las personas bilingües son capaces de cambiar, en diferentes situaciones, de una lengua a otra. Es posible hablar una lengua en casa y cambiar a una segunda lengua en la escuela o en el trabajo; emplear nuevamente la primera lengua en contextos más familiares (el almuerzo, la intimidad) y así sucesivamente. Las razones para cambiar de lengua y de repertorio lingüístico están relacionadas con las características del interlocutor, del mensaje que se va a comunicar y del ámbito en el que se utilizar cada lengua.

El sordo bilingüe, presenta una configuración lingüística que resulta de la conjugación de una lengua que pertenece a la sociedad mayoritaria que se transmite en una modalidad oral y auditiva, cuyo acceso será la modalidad escrita y otra lengua que se transmite en una modalidad visual y gestual. Además de la cohesión de las dos modalidades, el hecho de que estas lenguas no posean el mismo estatus social agrega rasgos que caracterizan a este sujeto bilingüe (Veinberg, 2002: 7).

Para una comprensión de la dificultad del aprendizaje de la escritura en los estudiantes sordos, Andrews y Mason (1991) apuntan tres posibles causas. La primera es la falta de conocimientos del medio y las pocas experiencias previas con los principales temas de los textos. El hecho de que los sordos inician el aprendizaje formal de la lectura con un repertorio lingüístico y conceptual reducido. La segunda, es la pobreza en las habilidades lingüísticas orales de los lectores sordos, ya que presentan un léxico limitado, un menor conocimiento de palabras polisemánticas, un desconocimiento de expresiones idiomáticas e igualmente tienen dificultades con el lenguaje figurado, con las formas sintácticas y con las inferencias. Una tercera causa planteada por los investigadores, hace referencia a que la forma del lenguaje de signos, comúnmente el más usado entre la población sorda, es estructuralmente diferente del lenguaje oral.

Otros autores han señalado que una posible causa es que los niños sordos no formulan suficientes preguntas cuando se enfrentan a un texto escrito o que tienen menos interacciones con el significado de la lectura durante sus años preescolares (LaSasso, 1993, citado por Herrera, 2005). Por consiguiente, el 
déficit en la competencia lingüística se postula como uno de los principales factores del fracaso lector de los estudiantes sordos (Herrera, 2005: 137).

En consecuencia, se hace evidente que para aprender a leer y escribir son necesarias ciertas habilidades lingüísticas de las cuales los sordos carecen al iniciar este aprendizaje. En este momento señalaremos los principales factores que garantizarían un desarrollo de competencia lingüística general de los sordos en el aprendizaje de la lectura ${ }^{18}$ y que se refiere a habilidades léxicas: repertorio léxico vocabulario y semántico (Herrera, 2005: 140) y a la comprensión y apropiación de formatos discursivos de la escritura.

iv) La necesaria relación entre representaciones icónicas y lingüísticas, como un modo de iniciación a la relación entre los códigos escritos y no escritos, pero con la mediación de las palabras-seña. Este se convierte en un principio de construcción semántica, por cuanto la presencia del dibujo o de la pintura revela, de manera general, un contenido semántico, susceptible de ser asimilado al universo semántico de la persona que observa el dibujo, en primera instancia mediante la representación lingüística en lengua de señas. No obstante, es importante tener en cuenta que es una estrategia inicial y que no resuelve la configuración de la semántica ofrecida por la palabra escrita o por la misma seña. Paul (1998) elaboró una prueba que consistía en presentar dibujos que representaban distintas palabras, donde los sujetos debían elegir la opción correcta entre cinco alternativas. En algunos casos existía más de una respuesta correcta. Las conclusiones del estudio señalan que los estudiantes sordos tienen un nivel de comprensión de palabras inferior al de los oyentes, que en ambos grupos es más difícil enfrentarse a palabras que presentan polisemia y que la pobreza de vocabulario produce dificultades en la comprensión lectora (Herrera, 2005: 141).

El principal problema, al respecto, es la escasa disponibilidad léxica de la persona sorda. Si el vocabulario es limitado, presentan pobres expresiones escritas. Los autores concluyen que el conocimiento de vocabulario es un indicador de las habilidades en lectura, que la falta de vocabulario no puede ser compensada ni sintáctica ni semánticamente, que el desempeño de los sordos es mejor con palabras con un solo significado y, finalmente, que los sordos que poseen un lenguaje fluido y natural desde el nacimiento, obtienen mejores resultados en las pruebas de conocimiento de vocabulario que los sordos que no tienen un lenguaje consolidado (Herrera, 2005:143). Observemos actividades propuestas en el Proyecto de aula "Criando lombrices y sembrando plantas" en donde se propone una relación ícono- seña-letra:

En un comienzo, la presencia visual de los tres registros de representación (icónico, seña y letra) ofrece una propuesta de configuración de significado,

18 Se recomienda consultar "Ios principales aspectos del lenguaje que han sido señalados como causantes del fracaso lector de los estudiantes sordos" en Herrera (2005). 
Tabla 5. Actividad 4, Fase II.

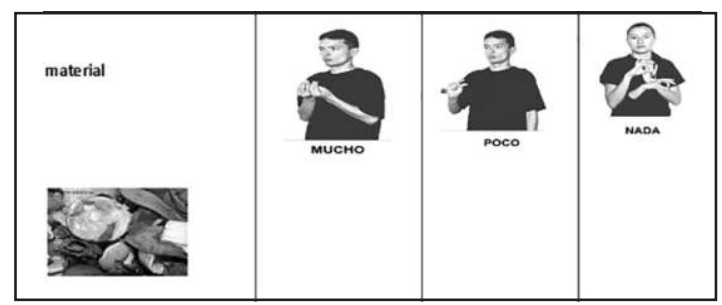

pero desde un punto de vista de la idea-palabra. Se requerirá un desarrollo posterior al enunciado o a la proposición: decir algo de...

v) El desarrollo morfológico y sintáctico de las dos lenguas. Mies (1992) observó la dificultad de los niños sordos de emplear el léxico escrito en la comprensión lectora, e identificó errores como: inserción de la palabra en grupos de palabras o en frases; errores en la creación de palabras por derivación o por familiaridad de palabras; errores por omisión de palabras que no considera pertenecientes a ningún grupo. Por ejemplo: para la palabra insectos, el sujeto considera que puede agruparla junto con insecticida, innecesario, inefectivo. El sujeto atribuye el mismo lexema a campesina y campesino, pero forma un grupo aparte con campo y acampar que no considera que formen parte del grupo inicial. El sujeto agrupa la palabra especie junto con especialidad y especialista, pero considera que la palabra especialización no forma parte ni de este grupo ni de ninguno de los propuestos. La autora señala que en este estudio se observó una relación directa entre la familiaridad en el reconocimiento de la palabra y la ejecución correcta de la tarea (Herrera, 2005:142).

En el anterior panorama, se pone en emergencia la necesidad de partir de un desarrollo adecuado y suficiente de la lengua de señas como base, sobre todo semántica y pragmática. Para la adquisición de la lengua escrita. La morfología de cada una de estas lenguas es bien distinta, pero una base (la de la LSC) permitirá comprender la diferencia de la otra base (la de la escritura). Un estudio realizado en Chile (Herrera, 2003) concluye que los lectores sordos que utilizan la LSCh como primera lengua, y poseen buenos niveles en ella, utilizan códigos dactílicos, signados, ortográficos y articulatorios (todos ellos de base visual) para extraer información lingüística del texto escrito. Se concluye, desde ahí, que la habilidad léxica (signada) contribuye significativamente al éxito lector de los estudiantes sordos. (Herrera, 2005: 143).

El desarrollo sintáctico involucra morfología y sintaxis. Así, cuando los niños aprenden las formas del lenguaje están descubriendo implícitamente las reglas que las gobiernan. De este modo, los morfemas (la unidad más pequeña de significado de las formas gramaticales) se combinan en las palabras (morfología) y éstas en oraciones (sintaxis). Por ello, "la sintaxis se ha convertido en una 
de las variables más investigadas en el campo de la sordera. Al respecto, Paul (1998) plantea que para los sordos, y posiblemente para los aprendices de una segunda lengua, el conocimiento sintáctico es un buen indicador de la habilidad lectora, porque requiere la destreza para integrar información a través de unidades lingüísticas como palabras, frases y oraciones." (Herrera, 2005: 148).

En este contexto, se destaca como uno de los factores que más genera brecha en el desarrollo de la escritura en personas sordas, son las tareas relacionadas con la formulación de preguntas, la complementación, la pronominalización, la disyunción y la alternación. Estas tareas exigen el desarrollo de la lógica morfológica y sintáctica de la lengua escrita, sus modos de elaboración de relaciones entre sus elementos, que no coinciden con la morfología de la LS y que, de todas maneras, también resulta complejo para el oyente que está aprendiendo a escribir. Por ello, es posible observar un desempeño más efectivo entre sordos y oyentes en construcciones relativamente simples, como oraciones activas, afirmativas, negativas y uso de conjunciones. Al respecto, distintas investigaciones concluyen que el patrón de errores de los sordos es similar al de los oyentes, por tanto, ambos grupos comparten estrategias sintácticas, aunque no la misma habilidad para usarlas (Herrera, 2005: 149).

Por lo anterior, vale la aludir a los resultados de Marschark (1993) y de Brasel y Quigley (1977) que indican que una combinación de lenguaje de signos y entrenamiento en lenguaje oral es el medio lingüístico más adecuado para que los niños sordos aprendan a leer, al menos respecto a la adquisición de las habilidades sintácticas y la comprensión escrita. Según estos autores, los factores que más benefician el desarrollo de las habilidades sintácticas son la exposición a la sintaxis y la adquisición de un vocabulario extenso (Herrera, 2005: 145), eso sí, dependiendo del nivel de escolaridad y de los contextos de uso de las dos lenguas. Al respecto, recomendamos ver la propuesta de desarrollo descriptivo y narrativo en las fases II y III del proyecto de Aula "criando lombrices y sembrando plantas".

Según la investigación de Herrera (2005), los datos indican que los lectores sordos presentan un retraso de 10 años aproximadamente con respecto a los oyentes, en el uso de habilidades sintácticas. Destaca que uno de los principales factores de un buen nivel sintáctico en los estudiantes sordos, es la exposición al lenguaje (oral o manual) desde el nacimiento y una combinación de lenguaje de signos y destrezas en el lenguaje oral como método educativo (pág. 147). En este sentido el DELETREO se convierte en un vínculo natural entre la lengua de señas y el español escrito en su base mínima y en el camino hacia la configuración de una relación entre palabra-seña y palabra-grafía. Veamos la actividad 1 propuesta en la Fase II del Proyecto de aula "Criando lombrices y sembrando plantas".

Actividad 1 
Seleccionar el tipo de semillas de la cajas de semillas del salón que quieres sembrar y registrar en la cartelera, según el ejemplo que te muestra:

Como se observa, la actividad exige un desarrollo consciente de la cons-

\section{Tabla 6. Relación expresión manual de las grafías españolas en la configuración de palabra}

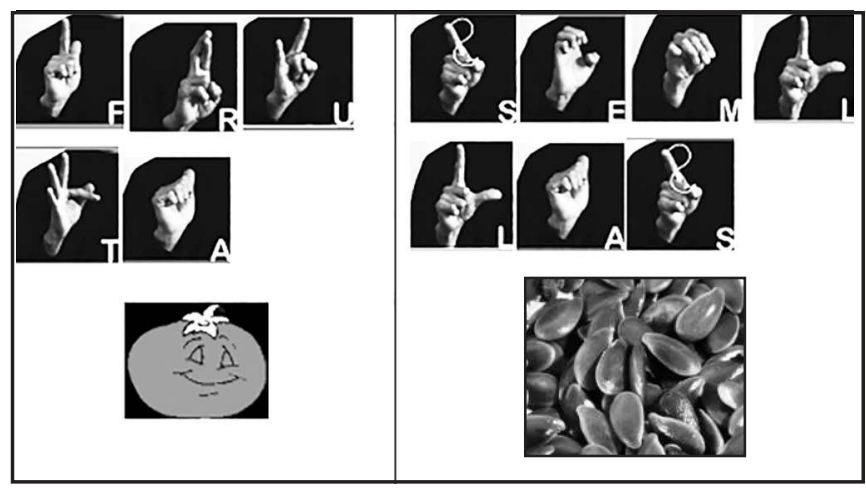

trucción de la palabra vía la escritura. La existencia del alfabeto señado se convierte en el puente que permite a las personas sordas un contacto, no sólo físico sino intelectual, con el código de la escritura española, por cuanto aparece la experiencia de la producción secuencial de la escritura en relación con la configuración de la unidad palabra y con un contenido semántico. Desde este punto de vista, se destaca el valor de los videos de grabaciones de clases en la Indiana Deaf School, que muestran cómo los niños simultáneamente producen señas (con una mano) y deletrean con la otra, mientras observan la palabra escrita en el tablero o en el cartel disponible. Así, la simultaneidad de códigos, si bien es exigente cognitivamente, es también el escenario social de la construcción de los códigos en las dos lenguas y de la comprensión de sus relaciones.

Los estudios de Herrera (2205), Fuentes y Tolchinsky (1999) muestran que los sordos son sensibles a la estructura ortográfica y que esta habilidad es adquirida a través de un medio visual como la dactilología. Las habilidades en dactilología pueden proveer una herramienta para aquellos lectores novatos que inician el aprendizaje de la lectura, aportando un elemento para la codificación. De este modo, las reglas de correspondencia grafema-fonema y las habilidades de segmentación permiten el establecimiento de una estrategia alfabética de lectura. De ello se puede inferir que el desarrollo de códigos visuales, como los códigos dactílicos y ortográficos en los sordos, está relacionado a partir de un sistema de equivalencia entre queiremas y grafemas que se aprende durante la enseñanza de la lectura y que al mismo tiempo se relaciona con los buenos niveles en lenguaje de signos. Asimismo, el deletreo dactílico supone desarroIlar competencias para secuenciar y segmentar grafemas y, por lo tanto, mayor 
conocimiento fonológico y ortográfico. Planteamos que la dactilología proporciona a los lectores sordos que emplean la lengua de signos una herramienta que posibilita ver las relaciones de correspondencia entre grafemas y queiremas, a partir del establecimiento de relaciones entre ortografía y dactilología más próximas a su experiencia viso-espacial del lenguaje (Herrera, 2005:150).

vi) El desarrollo de habilidades semánticas y pragmáticas en ambas lenguas. Como se ha reiterado, el desarrollo de la competencia lingüístico-discursiva en una lengua exige habilidades semánticas y pragmáticas del lenguaje. Este énfasis en la pragmática centra la atención en unidades mayores del lenguaje como el discurso, más que en las palabras y las oraciones. Un aspecto importante del discurso es el análisis de la comprensión global de la estructura del texto, como la estructura de la gramática de las historias. Algunos estudios han demostrado que los estudiantes sordos parecen comprender la estructura sintáctica más fácilmente si está conectada a un discurso, que cuando es presentada en oraciones simples y, que en algunos casos, la comprensión de una estructura particular no es necesaria para la comprensión de una unidad mayor del discurso.

Según distintos estudios, los lectores sordos, al igual que los lectores novatos y los malos lectores, utilizan principalmente estrategias de lectura descendentes que les llevan a quedarse con una idea general del texto. Respecto del contexto, Ewoldt (1997) señala que estos lectores pueden desviar la sintaxis e ir directamente al significado y que la comprensión de estructuras particulares no es imprescindible para comprender el discurso (Herrera, 2005: 147). Este tipo de estrategias también son empleadas por los oyentes que aprenden a leer o que leen como lectores novatos (Cassany, 1994). Así pues, la comprensión de estructuras sintácticas sencillas, por parte de los lectores sordos, resultará más fácil si están conectadas a un discurso. Las oraciones activas en contexto son más fáciles de comprender que las oraciones presentadas en forma aislada. La introducción de estructuras nuevas resulta más simple y beneficiosa, si se utiliza el contexto. Debemos, por tanto, hacer hincapié en que el contexto es muy relevante para la construcción del significado por parte de cualquier lector, sea sordo u oyente.

Por lo anterior, volvemos sobre la necesidad de propiciar una experiencia rica con vocabulario nuevo y con el desarrollo de una conciencia léxica, ortográfica y gramatical en general, acompañada de actividades de predicción de los contenidos textuales, como base de las estrategias de comprensión lectora. Respecto al nivel semántico y pragmático, se ha comprobado que los lectores sordos pueden usar la información contextual para quitar ambigüedad a algunas estructuras oracionales sencillas (ver Herrera, 2005: 49). Al respecto Ilamamos a un análisis de las actividades propuestas en las tres fases del Proyecto de Aula "Criando lombrices y sembrando plantas", para observar esta relación de desarrollo pragmático de las dos lenguas de LSC y español escrito 
y del valor de las preguntas formuladas o sugeridas por los padres de familia y por las conversaciones entre niños y entre profesor y estudiantes. Es decir, el valor de considerar el proyecto de aula como un ambiente de aprendizaje para los micromundos de la aproximación y de la precisión.

De igual manera, tener en cuenta que la enseñanza de la lectura en los sordos debería comenzar de forma temprana y que, si una buena habilidad en lenguaje oral es prerrequisito para aprender a leer, entonces los niños sordos deberían tener un cierto grado de dominio de estas habilidades en la lengua de señas, antes de comenzar la instrucción lectora. Sin embargo, también es importante reconocer que los problemas de aprendizaje de la lectura para algunos sordos no resultan simplemente de deficiencias en el desarrollo de su lengua natural, sino que pueden estar asociadas a deficiencias en los procesos cognitivos específicos implicados en la lectura. En este sentido, se ha descubierto que la habilidad para reconocer palabras de forma rápida y exacta está relacionada con el logro lector. Existe consenso entre los investigadores en que la relación entre reconocimiento de palabras y logro lector no está suficientemente desarrollada en los sordos (Herrera, 2005: 149-150).

Finalmente, aunque se reconoce la falta de suficiente evidencia empírica, es un hecho que los sordos pueden usar las reglas de correspondencia entre grafemas y fonemas y que esta base puede aportar de manera importante a la configuración lingüístico-discursiva de la experiencia tanto en lengua de señas como en español escrito. La literatura, la lectura de cuentos, la organización de celebraciones (cumpleaños, día de la madre, del profesor, del colegio, etc.), la elaboración de solicitudes, serán los escenarios socio-culturales que el aula puede recrear para el desarrollo de competencia comunicativa, lectora y escritora en los niños sordos. 



\title{
3. El ambiente de las experiencias: micro-mundo de la aproximación
}

\author{
Olga Lucía León Corredor
}

La percepción de la cantidad, fundamento del conocimiento general de las cantidades en el mundo y del desarrollo de un sentido numérico para modelar problemas cuantitativos y para tomar decisiones, es una etapa que la escuela debe considerar en los campos de formación que propone a la sociedad. De manera complementaria, las instancias sociales asignan a la escuela como una de sus metas más importantes "desarrollar en los estudiantes la habilidad para hacer razonamientos inteligentes con información cuantitativa" (Fey, 1999). La mutua valoración (sociedad-escuela) del aspecto cuantitativo, incluye la consideración de lo que se ha llamado el sentido numérico y que en su génesis cuantitativa compromete: acciones, desde, con, y sobre cantidades presentes en situaciones de relación del niño(a) con su entorno y condiciones semióticas y discursivas para describir, interpretar y operar empleando representaciones simbólicas, verbales y gráficas.

\subsection{La cantidad y el micromundo de la aproximación}

La experiencia primaria de los niños con la cantidad es una experiencia de necesidad de conocimiento de entornos de vida y de creación y recreación de pequeños mundos en los que se organiza su comprensión de su forma de estar y de ser como persona, en relación con "lo otro" y con "el otro". Esa experiencia primaria con las cantidades se desarrolla a partir de la percepción de las variaciones de cantidades en diversos contextos y consolida procesos de objetivación de referentes sobre tamaños de cantidades y tipos de relaciones entre tamaños de cantidad. ¿Qué tanto? Es una pregunta que informa sobre el tamaño de una cantidad, con una exigencia de un referente de comparación conformado previamente. El ambiente que fomenta estas experiencias es el de la aproximación de cantidades. Aunque el término aproximación está implícito en el concepto de estimación, en sí mismo tiene un carácter impreciso y puede ser utilizado en cualquier contexto. En matemáticas, la acción de aproximar está en la base de muchos procesos: las áreas de formas irregulares son aproximadas por áreas internas y externas de figuras regulares, las integrales son aproximadas por sumas finitas, las líneas tangentes a las curvas son aproximadas por secantes (Mac Lane, 1986), aproximar es entonces, una acción de sustituir un objeto matemático por otro lo suficientemente próximo en magni- 
tud o en definición, al segundo se le llama una aproximación del primero. En el micromundo de la aproximación de cantidades, aproximar es dar un valor cercano a un número o cantidad.

Son múltiples los contextos y las situaciones en las que no es necesario conocer los valores exactos de las cantidades que en ellas intervienen. Esa multiplicidad de contextos y de experiencias conforma lo que denominamos el micromundo de la aproximación. En este micromundo, la percepción de la variación de los tamaños de cantidad se articula al desarrollo de reflexividad en el niño (a) para consolidar juicios para tamaños de cantidad; expresiones como mucho, poco, son el indicador de la presencia de un juicio de tamaño. Las relaciones globales entre tamaños de cantidades, se constituyen en el tipo de relaciones básicas que surgen de la experiencia con las cantidades. Este es un micromundo donde se propician condiciones para experiencias entre los diferentes tipos de cantidades.

La experiencia con la cantidad en el niño sordo tiene su génesis en la experiencia con "lo otro", en la interacción con diversidad de contextos y en la necesidad de actuar con los objetos de su entorno. La experiencia temprana de los niños de agrupar objetos no es ajena a un niño (a) sordo (a); y el desarrollo de esta experiencia en procesos de comparación y clasificación no es ajeno al desarrollo de un sentido numérico o de un sentido espacial o geométrico en el niño (a). Sin embargo, las acciones de comparar los objetos entre sí, bien sea para agruparlos en una misma clase, o para combinarlos con la intención de obtener un objeto o conjunto nuevo e interesante, además de constituir actividades de comparación y de clasificación de objetos en el primer caso y de composición de objetos complementarios en el segundo caso, no son las mismas desde el punto matemático. "La matematización de esta actividad de composición de objetos complementarios es muy diferente de la matematización de las actividades de comparación y clasificación" (Vergnaud, 1995 p 77). La actividad de comparación y clasificación se vincula a un desarrollo de la cantidad en general y en particular al desarrollo de la cantidad en los niños (as) sordos (as). Veamos aspectos involucrados en esta actividad:

\section{a) Comparación y clasificación de objetos: Percepciones de tipos de can-} tidad. Consideramos en profundidad la matematización de las actividades de comparación y de clasificación de objetos a partir de la identificación de propiedades o atributos. La forma de percepcion de los objetos (visual, auditiva, tactil, olfativa o gustativa) determina la identificación de las categorías de propiedades como: forma, color, sabor, olor, tamaño, textura, grosor, peso, entre otras, y la identificación de propiedades que pertenecen a esas categorías como: redonda, azul, dulce, floral, grande, liso, delgado, liviano respectivamente. Así: "color" es la categoría conformada por un conjunto de propiedades como: azul, rojo, amarillo,...; "forma" es la categoría formada por un conjunto de propiedades como: alargada, redonda, cuadrada,.... La función que cum- 
plen esas categorías para la identificación de un objeto particular según las propiedades que tiene, es una función fundamentalmente descriptiva; por consiguiente, este conjunto de categorías se denominan descriptores de los objetos $y$, a las propiedades que pertenecen al descriptor, se les denomina valores del descriptor.

El desarrollo de la experiencia con los objetos es inicialmente una experiencia con el mundo desde lo sensible y lo aprehensible (lo que se percibe por los sentidos y por la razón). Desde los sensible, destacamos el valor de los sentidos y de su estimulación para la identificación de los descriptores de los objetos y de sus propiedades asociadas.

A través de los sentidos se reciben los estímulos del entorno, que se convierten en sensaciones y percepciones que, a la vez, conforman y hacen parte de los procesos del conocimiento del ser humano. Viendo, percibiendo con el tacto, tomando olores y explorando el lugar que le rodea, el niño (a) va integrando experiencias y constituyendo los objetos, como objetos lingüísticos y objetos mentales. El proceso de pensamiento que se lleva en el ser humano desde su niñez hasta la vejez es evolutivo, transforma y problematiza las percepciones y las sensaciones de su medio, para construir y reconstruir procesos conceptuales obtenidos con anterioridad. Este proceso conceptual, como lo presenta Vygotski (1982), no es aislado; las experiencias y las percepciones vinculadas a cada momento de la vida se constituyen en fundamento vital de dicho proceso "... las ideas generales como fase superior al desarrollo y significado de las palabras, no surgen de la generalización de las ideas aisladas, sino de la generalización de las percepciones, es decir, de las generalizaciones que predominan en la fase anterior..." (Vygotsky, 1982: 265). Los procesos de matematización de la clasificación y de la comparación de objetos, son procesos que requieren la generalización de las percepciones de las propiedades.

Existen descriptores de objetos, con sus respectivas propiedades, que son identificados por la mediación directa de los sentidos y tienen un efecto muy importante en los procesos de identificación de las cantidades y de matematización de las actividades de clasificación y de comparación. Los dispositivos elaborados en este ambiente diáctico ${ }^{19}$ privilegian condiciones para identificar descriptores de objetos y sus propiedades (valores del descriptor), vinculados a las experiencias sensoriales con los objetos. La tabla 7 presenta la relación descriptores valores que provienen de esa experiencia.

19 Se refiere al diseño de los dispositivos didácticos presentados en la Parte 2 de esta obra y que, junto con la Parte 3 "Proyecto de Aula", configuran la estructura del ambiente didáctico desarrollado por el proyecto "Desarrollo de competencia comunicativa en matemáticas en estudiantes sordos". 
Tabla 7. Descriptores de objetos y sus propiedades

\begin{tabular}{|c|c|c|c|c|c|c|}
\hline Descriptor & \multicolumn{6}{|c|}{ Valores de los descriptores } \\
\hline Sabor & Ácido & Amargo & Picante & Salado & Dulce & Agrio \\
\hline Olor & Frutal & Herbal & Floral & Picante & Neutro & Pútrido \\
\hline Color & Negro & Amarillo & Azul & Verde & Blanco & Rojo \\
\hline Textura & Suave & Áspero & Blando & Duro & Liso & Rugoso \\
\hline
\end{tabular}

El olfato, el sentido de la vista, el tacto, el gusto, y el oído, ayudan a desarrollar las primeras nociones en el infante. Vygotski (1982) señala la relación existente entre las sensaciones y las percepciones con el desarrollo del pensamiento; por eso, retomamos las palabras de este autor al respecto: "... en este primer estadio del lenguaje infantil, resulta totalmente imposible el pensamiento, como actividad libre e independiente de la percepción... (p.272).

La constitución de los objetos, a partir de la experiencia con sus descriptores, propicia las condiciones para agrupar y comparar objetos. En el esquema 1 presentamos las relaciones entre los procesos de identificación de propiedades y de categorías de propiedades y las dos acciones de agrupación y comparación de objetos.

Claramente situamos la experiencia con los objetos como un experiencia básica en el micromundo de la aproximación de cantidades. El desarrollo de los procesos de clasificación en el niño sordo requiere la identificación y la descripción de las operaciones de clasificación elementales y la manifestación de su efecto en un proceso de desarrollo de habilidades con las cantidades en el niño sordo.

\section{Esquema 2. El desarrollo perceptual y las acciones sobre los objetos}

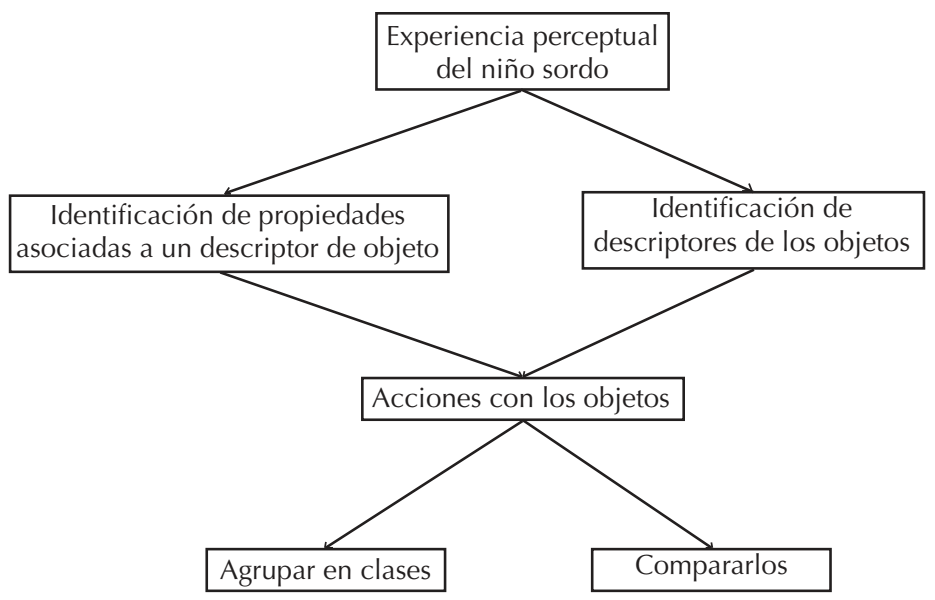


b) La importancia de la expresión "lo mismo que" y el cuidado con la expresión "se parece a". En primer lugar, la matematización de la actividad de agrupación se manifiesta en el desarrollo de las dos operaciones clasificatorias más elementales (Vergnaud, 1985):

-Agrupar objetos que tienen la misma propiedad.

-Agrupar objetos que son equivalentes entre sí por una relación determinada por un descriptor.

Las anteriores operaciones clasificatorias se realizan sobre conjuntos de objetos y en ellas no intervienen de manera directa operaciones y relaciones sobre clases. ${ }^{20}$ Profundizaremos en las operaciones clasificatorias elementales, considerando fundamentalmente la pertenencia de los objetos a unas clases específicas y el razonamiento directo sobre esas clases.

La experiencia con las propiedades de los objetos determina la acción de agrupar objetos. Se pueden agrupar objetos más por propiedades que se complementan, que por la búsqueda de propiedades comunes; como un ejemplo tendríamos la agrupación por colores que combinan o por formas que encajan como se lustra en la foto 2. Este uso de las propiedades para agrupar objetos no determina la generación de clases y, por consiguiente, no consolidan una actividad de clasificación plena.

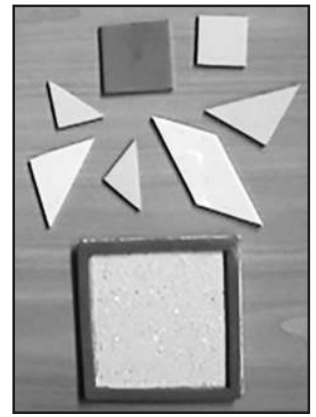

Foto2. Agrupación por complementación de propiedades

El uso de expresiones como "agrupar los objetos que combinen" o "agrupar objetos que se parecen" privilegian la identificación y el uso de propiedades que se complementan y no la búsqueda de propiedades comunes. De otra parte, expresiones como "agrupar los objetos que son iguales", permiten la consideración de múltiples propiedades que no son manifiestas en la agrupación; por ejemplo, forma y tamaño, sólo forma, sólo tamaño; es decir, no es posible obtener clases bien diferenciadas.

20 El desarrollo en detalle de operaciones sobre clases puede encontrarse en el capítulo 5 del libro: "El niño las matemáticas y la realidad" de Gerard Vergnaud, referenciado en la bibliografía de esta obra. 
La realización plena de la clasificación exige la enunciación explícita de una propiedad como en: "agrupar los objetos que son grandes", "agrupar los objetos verdes", "agrupar los niños que tienen los mismos años". En todos los casos se exige identificar la propiedad común que identifica al grupo; así un objeto pertenece al grupo si tiene la propiedad que se pide, y queda por fuera del grupo si no tiene la propiedad, es decir que determinan clases que no comparten objetos, como en la foto3.

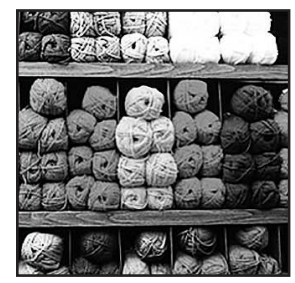

Foto 3. Agrupación por una propiedad común

Otro aspecto identificado en el uso de las propiedades y las acciones con los objetos, es el de determinar sus parecidos según las propiedades que comparten. Se requiere un análisis de las propiedades para hacer un desarrollo del "ser parecido a" a "estar en la misma clase de" o "tener la misma propiedad que". Propiciar las condiciones para ese desarrollo es una exigencia para promoverlas habilidades de clasificación en los niños (as). El desarrollo de un proyecto de aula como el lombricultivo y el semillero, responde al Ilamado a que la escuela cumpla una función muy importante en el uso riguroso de las propiedades de los objetos y, en el paso entre los parecidos globales, a las verdaderas equivalencias que determinan las clasificaciones de los objetos. "Es necesario, entonces, desarrollar sistemáticamente en la escuela los ejercicios de clasificación, con signos verbales no ambiguos, con materiales cada vez más complejos: bloques lógicos animales, prendas de vestir, números" (p.83).

Los siguientes niveles propician los elementos para orientar el seguimiento de un desarrollo de la semejanza global de objetos a la organización en clases:

-Nivel de la equivalencia simple: Los objetos comparten algunas propiedades y son equivalentes por esa propiedad que es comun como en el caso de la foto 4 .

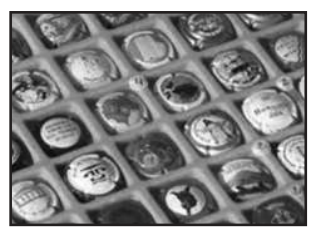

Foto4. Equivalencia por una propiedad (forma)

-Nivel de la cuasiidentidad o multiples equivalencias: Los objetos comparten todas las propiedades pero son objetos distintos como enla foto 5 . 


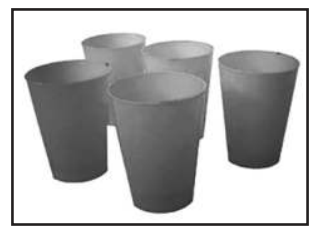

Foto 5. Equivalencias por varias propiedades

Nivel de la identidad. Se comparten todas las propiedades posibles. Es decir, solo existe un objeto como en la foto 6.

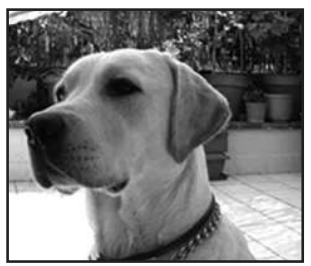

Foto 6. Equivalencias por todas las propiedades posibles

En el desarrolllo de procesos de clasificación con niños (as) pequeños se recomienda iniciar con objetos cuasiidenticos; pero en las trayectorias de desarrollo de las habilidades, se sugiere considerar posteriormente los de equivalencia simple: "Unicamente los ejercicios que sugieren el agrupamiento en una misma clase de objetos diferentes entre sí, conducen al niño a analizar distintas propiedades" (Vergnaud, 1985: 83).

c) La importancia de las diferencias. Las agrupaciones de objetos por propiedades que comparten y el surgimiento de las clasificaciones, es un aspecto del desarrollo de la percepción de los objetos y sus atributos. El otro aspecto es el de análisis de las diferencias entre los objetos y el análisis de descriptores de objetos, determinado fundamentalmente por la posibilidad de establecer un orden a los valores del descriptor, en este caso, el análisis se realiza entre el descriptor y sus propiedades. Vergnaud (1995) propone los siguientes niveles:

El nivel de los descriptores cualitativos. Las propiedades que pertenecen a estos descriptores no pueden ser ordenadas: Tenemos como ejemplos los descriptores color, sabor, olor, textura, forma, nacionalidad. Ver foto 7.

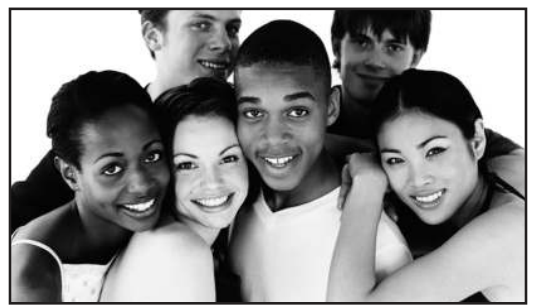

Foto 7 Diferencias no ordenables como las propiedades del descriptor raza 
El nivel de los descriptores ordinales. Las propiedades que pertenecen a estos descriptores son ordenables pero no mensurables: descriptor: Tonalidad de un color (clara, obscura, media).Ver foto 8 y 9.
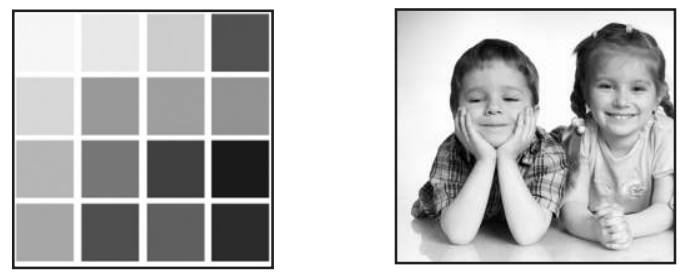

Fotos 8 y 9. Diferencias ordenables no medibles, descriptores tonalidad de color y estado de alegría

El nivel de los descriptores cuantitativos. Las propiedades que pertenecen a estos descriptores se pueden ordenar en una escala de medida numérica, como el tamaño, la superficie, el volumen, el peso. Ver foto 10 y11.
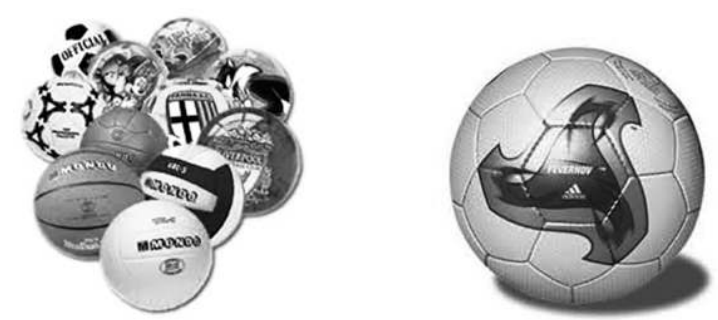

Fotos 10 y 11 Diterencias numéricas, decriptor: Tamaño de la colección

El análisis adecuado del tipo de descriptores según las posibilidades de ordenación de sus valores es el que detemina el paso de la percepción de la cantiadad al desarrollo del sentido numérico. Las relaciones comparativas que se establecen entre los objetos son del tipo: "este objeto es más pequeño que...".

Inicialmente para los niños (as) la mayoría de descriptores son del tipo cualitativos. El desarrollo de trayectorias en este aspecto está fundamentado en el paso de descriptores que sólo permiten la comparación de diferencias, a los descriptores que permiten el desarrollo de las operaciones, como los descriptores cuantitativos.

En el micromundo de la aproximación de las cantidades, los descriptores que se priviligian son los ordinales, que permiten comparaciones tempranas entre los objetos. Vergnaud (1995) asigna un gran valor a esas comparaciones, por cuanto se situan en la génesis de las dos relaciones fundamentales para el desarrollo de la noción de número, las de orden y las de equivalencia. Deter- 
minar el: "más grande", "el mejor sabor", "el de mejor olor", "el más amistoso", "el más agradable" son todas actividades propias de este micromundo. En este micromundo algunos descriptores cuantitativos son considerados ordinales, como el tamaño. Es posible establecer diferencias por tamaños en objetos, pero no es posible desarrollar operaciones entre las cantidades de los tamaños.

En el esquema 3 se presentan los niveles de análisis de las diferencias y de las semejanzas entre los objetos.

\section{Esquema 3. Niveles en la comparación de objetos}

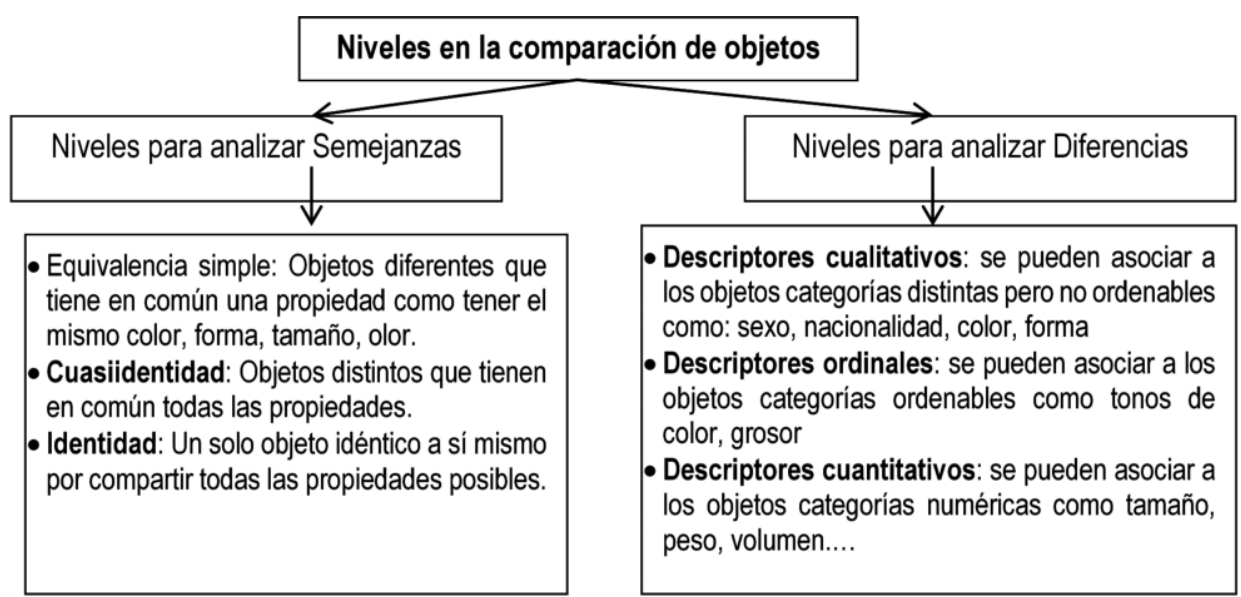

Las acciones con los objetos y las acciones con propiedades de los objetos se destacan como fundamentales en para el manejo de la cantidad en los niños sordos, estas acciones se encuentran implícitas en las caracterizaciones que se hacen de la cantidad por diversos autores:

"característica o cualidad de un objeto que se puede valorar numéricamente, siempre en relación con una unidad. Por redundancia, también los números son cantidades." (Castro \& Rico, 1989: 120).

"el objeto de la matemática, aquello por lo cual una cosa se dice mayor, menor, o igual a otra; y la razón es, porque todo su empleo consiste en averiguar y demostrar las propiedades y atributo" (Tosca, 1757).

En el diccionario de María Moliner (Moliner, 2002):

"Aspecto por el que se diferencia entre sí las porciones de la misma cosa o los conjuntos de la misma clase de cosas, por el cual esas porciones o esos conjuntos se pueden medir o contar".

"porción de una cosa, de cierta magnitud, peso o número"(p 499)

Aunque se proponen caracterizaciones para la cantidad aparentemente diferentes, encontramos que comparten ser un atributo con una condición de 
valoración numérica o pre-numérica. Se deja ver una idea de cantidad, como aquello que puede ser comparado con otro de su misma especie mediante una relación de orden con propiedades y atributos particulares.

Las cantidades pueden ser discretas o continuas. En las cantidades discretas es posible separar los tamaños de cantidad, como tres lápices, cuatro lápices, dos niños, un niño etc. Las cantidades discretas pueden ser contadas con los números naturales y reciben por ello el nombre de contables. Las cantidades continuas, por el contrario, no están formadas por partes separadas entre sí. "Continuo" significa "sin interrupción", entre dos tamaños de cantidad siempre es posible encontrar un tercer tamaño de cantidad. Las cantidades continuas que se pueden evidenciar en descriptores asociados a objetos como el agua, el tiempo, la superficie etc. no son contables, es decir, que no existe de manera inmediata una correspondencia entre objetos y números naturales, estas cantidades requieren la búsqueda de una unidad de medida, por ejemplo, dos litros de agua, tres vasos de vino. En otras palabras podemos decir que lo discreto puede ser contado por los números naturales, mientras que los objetos continuos requieren de otros sistemas numéricos como los reales. La percepción de estas cantidades discretas y continuas es un aspecto básico para el desarrollo aritmético de magnitudes en los niños.

El siguiente cuadro relaciona tipos de cantidad que se perciben a partir de los sentidos, dando ejemplos de cantidades continuas y discretas.

\section{Tabla 8. Formas de percepción y tipos de cantidad}

\begin{tabular}{|c|c|c|}
\hline $\begin{array}{c}\text { Formas de } \\
\text { percepción }\end{array}$ & \multicolumn{2}{|c|}{ Tipos de Cantidad } \\
\hline & Continua & Discreta \\
\hline Tacto & Intensidad de la textura & Tipo de texturas \\
\hline Gusto & Intensidad de sabor & Tipo de sabores \\
\hline Olfato & Intensidad de olor & Tipo de olores \\
\hline Vista & Intensidad de luz & Tipos de colores \\
\hline Oído & Intensidad del sonido & Tipos de sonido \\
\hline
\end{tabular}

Los niños entran al micro mundo de la aproximación de la cantidad, por actividades de comparación en las que predomina la percepción de descriptores ordinales: empiezan a utilizar adverbios para su expresión, como por ejemplo: muy, poco, muy poco, cada vez más, mucho, bastante, más, menos, algo, demasiado, casi, sólo, solamente, tan, tanto, todo, nada, aproximadamente. En lengua de señas colombiana LSC tenemos expresiones correspondientes como: ${ }^{21}$

21 Tomadas del Diccionario Básico de la Lengua de Señas Colombiana. 2006. 


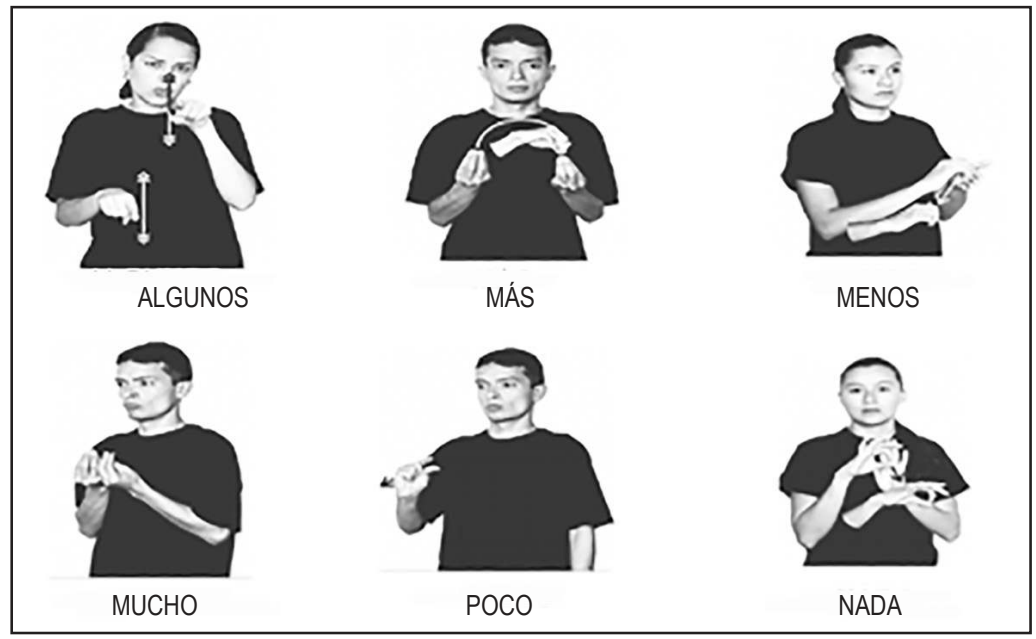

Fotos 12-16 expresiones cantidad en LSC

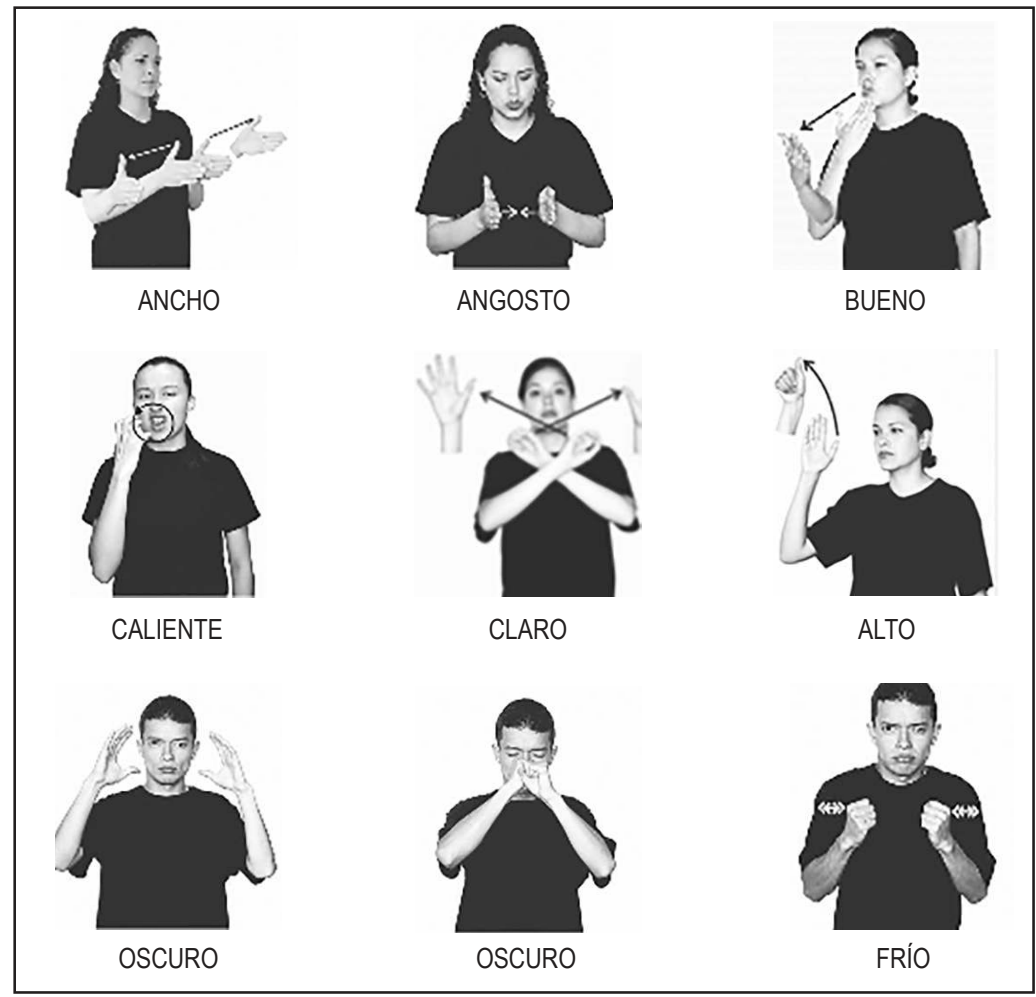

Fotos 17-25 Propiedades de descriptores ordinales

Se consideran tambien las expresiones asociadas a propiedades de descriptores que en su origen se usan como ordinales: 
d) Formulación de Juicios sobre tamaños de cantidades y formulación de relaciones cuantitativas. El camino por recorrer será el de las experiencias y el de los ejemplos, experiencias que permitan expresiones como: "en esta olla cabe más líquido que esta otra"; "este atleta demoró más tiempo que su compañero en llegar a la meta"; "la puerta estaba más abierta antes que ahora", "el café está más caliente que la sopa" "la habitación está más clara que la sala". La percepción de las cantidades se vincula con la experiencia de establecer relaciones entre los objetos: así al desarrollo de las cantidades discretas y continuas vinculamos las experiencias de relacionar. El siguiente cuadro presenta los diferentes tipos de relaciones que se establecen para cantidades discretas y continuas.

Tabla 9. Relaciones entre cantidades discretas y continuas

\begin{tabular}{|l|l|l|}
\hline Tipos de cantidades & Relaciones de orden & Relaciones de equivalencia \\
\hline \multirow{2}{*}{ Discretas } & Tiene más tíos que... & Nació el mismo mes que... \\
\cline { 2 - 3 } & Hay más niños que... & Tiene el mismo color que... \\
\hline \multirow{3}{*}{ Continuas } & Es más grande que... & Llego al mismo tiempo que... \\
\cline { 2 - 3 } & Es más claro que... & Es tan alto como... \\
\cline { 2 - 3 } & & Es tan largo como... \\
\hline
\end{tabular}

Las trayectorias de desarrollo de habilidades para identificar relaciones de comparación requieren considerar que las relaciones formuladas para contextos de cantidades continuas, son más complejas que para cantidades discretas. El establecimiento de clasificaciones en contextos de cantidades continuas requiere el desarrollo de unidades de medida para ese tipo de cantidades. El uso de descriptores ordinales y de descriptores cuantitativos, propician en el niño (a) el uso de procesos de razonamiento, por cuanto se implican decisiones sobre tamaños de cantidad, que pueden ser menos exigentes como en el caso de los tamaños de cantidades discretas o más exigentes como en los tamaños de cantidades continuas: "Decidir si dos niños pertenecen a un mismo equipo o a equipos diferentes, es más fácil que decidir si tienen o no la misma estatura" (Vergnaud, 1995: 105).

En el micromundo de la aproximación de cantidades las expresiones del tipo "está tan frio como el otro", "tiene el mismo sabor que", "es tan alto como" estan dadas fundamentalmente por juicios de proximidad. Según Sarama \& Clements (2009) el niño puede usar tres tipo de juicios en la valoración de las cantidades:

Perceptual. Los objetos son comparados con otro objeto fisicamente presente, como en "el carro rojo esmás grande que el amarillo. 
Normativo. La comparación se hace con la referencia de una clase de objetos guardada en la memoria, como "la semilla de la naranja es más pequeña que la del aguacate".

Funcional. La comparación se hace con la referencia de un uso que pueda tener el objeto, como "es el largo ideal de la lombriz de tierra".

En los niños (as) la relación de orden se desarolla en forma precoz, paralelamente a las actividades de comparación (Vergnaud, Sarama\&Clements). En el caso de propiedades espaciales de los objetos, se desarrollan simultaneamente discretas y continuas. Las relaciones de equivalencia presentan mayores exigencias y su desarrollo depende de la experiencia y de la reflexión propiciada en las formas de agrupaciones. La experiencia con las propiedades de los dos tipos de relaciones se requiere para las nociones de número y de formas geométricas. En el texto anterior se han evidenciado condiciones para trayectorias de aprendizaje que pretendan desarrollar habilidades en el manejo de cantidades en el micromundo de la aproximación, continuamos con la profundización para el desarrollo de habilidades geométricas en este micromundo.

\subsection{La forma y el micro-mundo de la aproximación}

La experiencia en el espacio es otro tipo de experiencia que desarrolla el micromundo de la aproximación. Retomamos el descriptor forma considerado inicialmente como un descriptor cualitativo que identifica disposiciones de los objetos en el espacio, su matematización exige pasar de la percepción de la forma al desarrollo de la figura geométrica o de la forma geométrica (usadas indistintamente por algunos autores). La forma geométrica se considera como una abstracción de la forma física (Sarama \& Clements, 2009).

Para el caso de todos los niños (as) pero en particular de los niños (as) sordos es importante retomar los resultados de Johnson (1987), citados por Clements y Samara (2009), quienes identifican los componentes no verbales, ricos en imágenes, es decir, cada objeto geométrico mental incluye uno o más sistemas de imágenes periódicas, patrones dinámicos de las acciones cinestésica y visuales. Aspecto que también desarrolla Duval (1999), al considerar los tres niveles de visualización que caracterizan el desarrollo visual del estudiante.

1) Nivel global de percepción visual: Es el nivel más elemental en la visualización en el cual se destaca la forma total de la imagen, se asocian figuras geométricas a objetos físicos y predominan aspectos no matemáticos como la posición (boca arriba, boca abajo) entre otros; por esta razón este nivel debe dar paso a la enseñanza geométrica que permita una mirada a las figuras de manera más matemática para que se active la búsqueda de objetos geométricas y sus relaciones. Ver foto 26. 


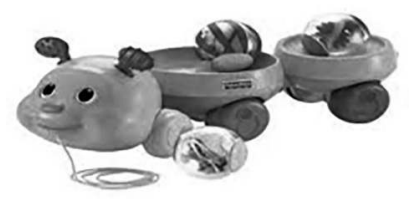

Foto 26 . Nivel global de la percepcion visual

2) Nivel de percepción de elementos constitutivos: Es el siguiente nivel en el cual no solamente se observa el total de la imagen, sino que se observa que la imagen está constituida de elementos de una misma dimensión o de dimensiones inferiores; es decir, que en una imagen tridimensional se puede ver que está formada por figuras tridimensionales o bidimensionales, o en la imagen bidimensional se verá que está formada por figuras bidimensionales o unidimensionales; es en este sentido que se consideran las relaciones entre los elementos integrantes. Ver foto 27.

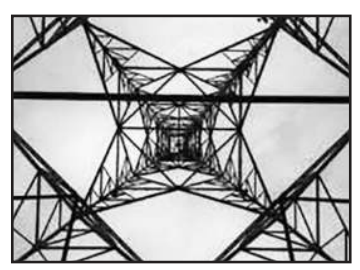

Foto 27. Nivel de percepción de elementos constitutivos

3) Nivel operativo de percepción visual: Se opera sobre las figuras, es decir que se realizan transformaciones visuales.

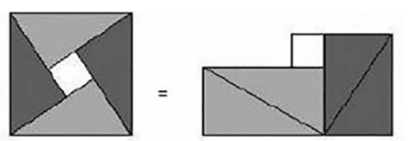

Tomada de Nelsen, R (1993). Proofs without words:

Exercises invisual thinking. Washington, USA: The

Mathematical Association of America, p. 4

\section{Foto 28 Nivel operativo de la percepción visual}

El paso de los nivel 1 al nivel 3 exige a la escuela una organización de condiciones que propicien los ambientes para el desarrollo de la visualización. Godino (2002) propone trabajar primero las figuras geométricas, para lo cual el docente debe tener presente:

-Es necesario aclarar de qué trata esta rama de las Matemáticas y reflexionar sobre la naturaleza de sus objetos. 
-Los entes geométricos no tienen ninguna consistencia material, ningún peso, color, densidad, etc.

-Un problema didáctico crucial es que con frecuencia usamos la misma palabra para referimos a los objetos perceptibles con determinada forma geométrica ("el triángulo es un instrumento de percusión") y al concepto geométrico correspondiente (el triángulo isósceles).

-La Geometría estudia las formas de las figuras y los cuerpos geométricos.

-El objetivo de la geometría será explorar, clasificar estudiar y usar las propiedades de las figuras geométricas.

Asimismo, en el proceso de enseñanza es fundamental saber proponer actividades para el desarrollo de los diferentes conceptos en geometría como:

- Componentes elementales de las figuras geométricas (Puntos, rectas, planos y espacio, segmentos y ángulos).

- Curvas y polígonos en el plano (Curvas y regiones, Curvas poligonales y polígonos)

- Los triángulos y su clasificación (Definiciones y propiedades, Clasificación de triángulos, Elementos notables de un triángulo. Construcción de triángulos).

- Los cuadriláteros y su clasificación (Situación introductoria: Clasificación de los cuadriláteros, Descripciones y propiedades de los cuadriláteros, Rectángulo, Rombo, Cuadrado, Trapecio y Trapezoides, Trapecio, Clasificación de los trapecios, Trapezoide, Cometa,)

- Recubrimientos del plano con polígonos (Teselaciones poligonales del plano, Teselaciones semirregulares)

- Figuras en el espacio (Planos y líneas en el espacio, Curvas, superficies y sólidos, Los poliedros y su clasificación, Poliedros regulares, Dualidad de poliedros, Deltaedros, Poliedros semirregulares o Arquimedianos, Conos y cilindros).

Clements y Samara (2009) explican que las formas bidimensionales empiezan a formarse en preescolar, razón por la cual las primeras experiencias son relevantes y, en este proceso, es crucial el desarrollo del lenguaje. Así pues, a continuación se presentan las caracterizaciones propuestas por estos autores para las formas de 2D como un efecto de la experiencia con los objetos. 
Tabla 10. Definiciones básicas de figuras geométricas

\begin{tabular}{|c|c|}
\hline Forma & Definición \\
\hline & Dos líneas que se juntan para hacer una esquina o vértice. \\
\hline & $\begin{array}{l}\text { Una figura bi-dimensional que consta de todos los puntos fijos a una } \\
\text { distancia desde un punto llamado centro. Los círculos son "perfecta- } \\
\text { mente redondos" es decir, tienen una curvatura constante. }\end{array}$ \\
\hline $\begin{array}{l}\text { Una figura cerrada de dos } \\
\text { dimensiones }\end{array}$ & $\begin{array}{l}\text { Una figura bidimensional es cerrada, cuando está constituida por } \\
\text { segmentos de línea que se conectan entre sí, en puntos llamados } \\
\text { vértice. En cada vértice sólo se conectan dos segmentos y todos los } \\
\text { segmentos tienen sus dos extremos conectados. Los segmentos de } \\
\text { línea son llamados lados, los lados no se cruzan entre sí. }\end{array}$ \\
\hline Congruente & exactamente iguales en forma y tamaño, coinciden por superposición \\
\hline & Una forma de (polígono) con seis lados rectos. \\
\hline & $\begin{array}{l}\text { Una figura de cuatro lados con dos pares de lados adyacentes que } \\
\text { tienen la misma longitud. }\end{array}$ \\
\hline Línea de simetría & $\begin{array}{l}\text { Las figuras planas tienen una línea que refleja la simetría. Cuando su } \\
\text { forma se invierte sobre los lados opuestos de una línea, como: Я I R. }\end{array}$ \\
\hline Una forma de octógono & (Poligono) con ocho lados rectos. \\
\hline & Cómo una figura puesta en comparación con una línea de referencia. \\
\hline líneas paralelas & Líneas que siguen la misma distancia, como las vías del ferrocarril. \\
\hline Paralelo & Cuadriláteros con los dos pares de lados opuestos paralelos. \\
\hline Pentá & Polígonos con cinco lados rectos. \\
\hline Plano & Una superficie plana. \\
\hline Un polígono & Figura plana limitada por tres o más lados rectos. \\
\hline cuadrilátero & Una forma (Poligono) con cuatro lados rectos. \\
\hline Rectángulo & $\begin{array}{l}\text { Un polígono con cuatro lados rectos (es decir, un cuadrilátero) y cuatro } \\
\text { ángulos rectos. Como todos los paralelogramos, los lados opuestos } \\
\text { de un rectángulo son paralelos y de la misma longitud. }\end{array}$ \\
\hline & $\begin{array}{l}\text { Figura plana con cuatro lados rectos (es decir, un cuadrilátero) y de la } \\
\text { misma longitud. }\end{array}$ \\
\hline Ángulo recto & $\begin{array}{l}\text { Dos líneas que se encuentran como en una esquina de un edificio. A } \\
\text { menudo, informalmente llamada "esquina de la cuadra". Los ángulos } \\
\text { rectos miden de } 90 \text { grados. Las líneas que se cortan en ángulo recto } \\
\text { son perpendiculares. }\end{array}$ \\
\hline
\end{tabular}




\begin{tabular}{|c|l|}
\hline Simetría de rotación & $\begin{array}{l}\text { Una figura tiene simetría de rotación cuando se le puede girar sobre } \\
\text { sí misma una parte una vuelta completa y hacerla coincidir exacta- } \\
\text { mente con la figura de partida. }\end{array}$ \\
\hline Forma & $\begin{array}{l}\text { Nombre informal para una figura geométrica de dos o tres dimensio- } \\
\text { nes formada por puntos, líneas o planos. }\end{array}$ \\
\hline Trapecio & $\begin{array}{l}\text { Polígono que tiene cuatro lados iguales y todos los ángulos rectos. } \\
\text { Tenga en cuenta que un cuadrado es a la vez un tipo especial de } \\
\text { rectángulo y un tipo especial de rombo. }\end{array}$ \\
\hline Triángulo & $\begin{array}{l}\text { Un cuadriátero con un par de lados paralelos (Algunos insisten en } \\
\text { que tienen sólo un par de lados paralelos, Otros dicen que tienen que } \\
\text { tienen por lo menos un par, que a su vez haría que los paralelogra- } \\
\text { mos fueran un subconjunto de los trapecios). }\end{array}$ \\
\hline & Polígono con tres lados. \\
\hline
\end{tabular}

Trayectorias de aprendizaje de Formas. Considerando las exigencias del micromundo de la aproximación de cantidades para el desarrollo de habilidades geométricas en niños (as) sordos, seleccionamos la trayectoria de aprendizaje propuesta por Clements y Samara (2009). Se hablará de trayectoria de aprendizaje, al proceso seguido por los estudiantes para desarrollar la noción de forma, que llega a ser complejo, debido a las distintas habilidades y avances conceptuales que se deben lograr. En este proceso existen cuatro subtrayectorias que están relacionadas y que se pueden desarrollar de manera independiente,

a. Comparación: Se tiene en cuenta los diferentes niveles de principios de congruencia e identificación.

b. Clasificación: Incluye el reconocimiento, identificación y análisis para clasificar las formas.

c. Reconocimiento de componentes: Implica distinguir, nombrar, describir y cuantificar los componentes de las formas como los lados y ángulos.

d. Representación: Implica la construcción o dibujo de las formas.

Clements \& Samara (2009) explican que el objetivo es aumentar la capacidad de los niños en nombrar, describir, analizar y clasificar.

\section{Ejemplo de actividades que se deben proponer}

1) Identifica los círculos de la figura y descríbelos.

2) La figura siguiente muestra variedad de triángulos y no triángulos, con los cuales se puede generar un debate en la clase, se podría preguntar ¿Qué nombres reciben estas figuras? ¿Qué similitudes tienen? ¿Cuáles son sus diferencias?

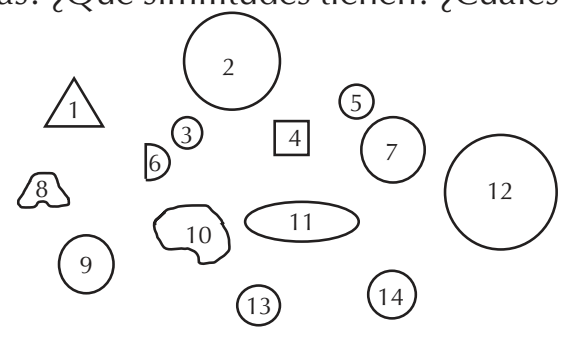


Si observamos las representaciones de las figuras, se identifica que las de la tabla de la derecha difieren en un solo atributo respecto a los de la izquierda. El maestro puede utilizar estas comparaciones para centrarse en la definición de cada atributo de un triángulo.

El desarrollo de la forma exige que el entorno educativo incluya:

\section{Triángulos}

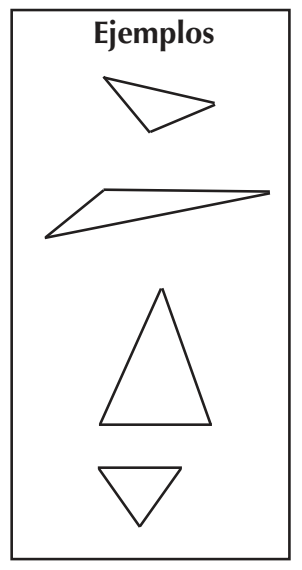

a. Variados ejemplos y contraejemplos.

b. Discusiones sobre las formas y sus atributos.

c. Mayor variedad de clases de formas.

d. Amplia gama de tareas geométricas.

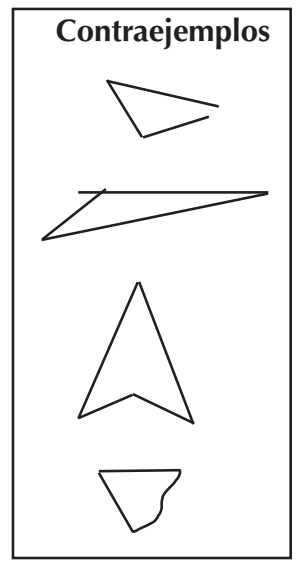

Los anteriores ítems garantizan que los niños experimenten diversos tipos de formas y no se desarrollen ideas erróneas, además el uso de prototipos puede iniciar el aprendizaje, cuando se muestran ejemplos y no ejemplos que luego se comparan, centra la atención de los niños en ejemplos críticos de las formas.

\subsection{El sentido numérico: micromundo de la precisión en cantidades discretas}

La precisión hace referencia a la medida y exactitud en las cantidades. Los atributos de información precisos pueden especificar las características de los elementos con gran detalle. La necesidad o la exigencia de la precisión es el efecto de otro tipo de experiencias con los objetos y sus propiedades. El micromundo de la aproximación ${ }^{22}$ profundiza en las acciones sobre los objetos y la percepción y comparación de las cantidades. Sin embargo, el desarrollo de la experiencia con la cantidad integra otras formas de interacción con los objetos, que da origen a uno de los objetos matemáticos más útiles en la experiencia del hombre con el mundo: el número. Complementariamente, la experiencia con los números desarrolla la experiencia de la precisión de las cantidades y

22 Este documento está integrado a todo el ambiente didáctico propuesto por el proyecto desarrollo de competencia comunicativa en matemáticas en niños sordos que se integra tanto con los fundamentos de la Parte I como la propuesta diseñada para la Parte III (proyecto de aula). 
su manejo a través de las operaciones aritméticas, en el caso particular de los primeros números, conocidos como los números para contar o los números para medir, conjuntos de objetos separables. "Las relaciones entre números no son independientes de las relaciones entre objetos y, muy particularmente, en lo que concierne a los primeros números comprendidos por el niño, de las relaciones entre conjunto" (Vergnaud, 1995; 115).

En el micromundo de la aproximación surge la necesidad de comparar objetos y de enunciar relaciones como: "lo mismo que", "tiene más que". Pero comparar los objetos no es suficiente para determinar los tamaños de colecciones de objetos aislables; se requiere, por los menos, articular cuatro planos de acción: el de los objetos, el de las colecciones de objetos, el de los tamaños de esas colecciones y el de las representaciones de esos tamaños.

En el plano de los objetos se requieren acciones de agrupaciones entre ellos para formar colecciones físicas (los objetos se agrupan en una misma región del espacio) o mentales (todos los objetos son considerados en mismo conjunto). En el plano de acción de los tamaños de colecciones, se requiere el desarrollo de la acción de contar; esta acción es a su vez el vínculo con el plano de acción de las representaciones de tamaños.

En las cantidades discretas el conocimiento numérico es el efecto de la relación entre, el reconocimiento y nominalización de pequeñas cantidades de objetos según su configuración (subitizaciones); el aprendizaje de una lista ordenada de palabras denominadas palabras número; el uso de esa lista para numerar objetos y la comprensión de que el último término de la lista es el que informa el tamaño de la colección. Se profundizará en el conteo como una actividad esencial para el desarrollo de la precisión de cantidades discretas.

El conteo, siendo una de las actividades más investigadas, no deja de ser necesaria en la reflexión sobre una didáctica de las matemáticas. Ese proceso de asociar objetos con números, además de tener una larga historia en el desarrollo de cada cultura, está naturalmente vinculado a las condiciones de expresión de la misma. Las necesidades primarias de identificar tamaños (numerosidad) de colecciones de objetos y de indicar la posición de un objeto en una colección ordenada de objetos, no sólo propician condiciones para desarrollar el concepto de número natural en sus dimensiones cardinal y ordinal, sino tambien, originan técnicas que tienen como mediación semiótica cultural el tipo de representación numérica, consideradas además transculturales, porque comparten los mismos principios en sus procesos. Entre los principios que comparten tenemos:

1) Principio de abstracción: cualquier colección de objetos aislables es suceptible de ser contada. (Fotos 27 y 28). 


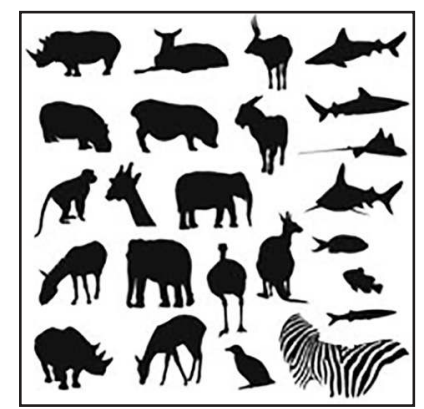

Fotos 27 y 28 principio de abstracción

2) Principio de la correspondencia uno a uno: a cada objeto contado de la colección de objetos debe asignarse a uno y un sólo término de la colección que cuenta (ver foto 29).

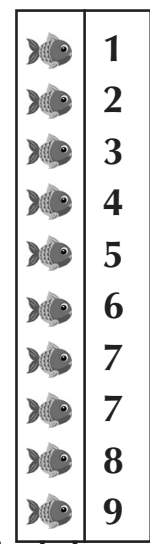

Foto 29. principio de la correspondencia uno a uno

3) Principio de la irrelevancia del orden. El objeto por el que se inicie el conteo y el orden que se siga para los demás objetos es irrelevante para determinar el tamaño de la colección (ver foto 30).

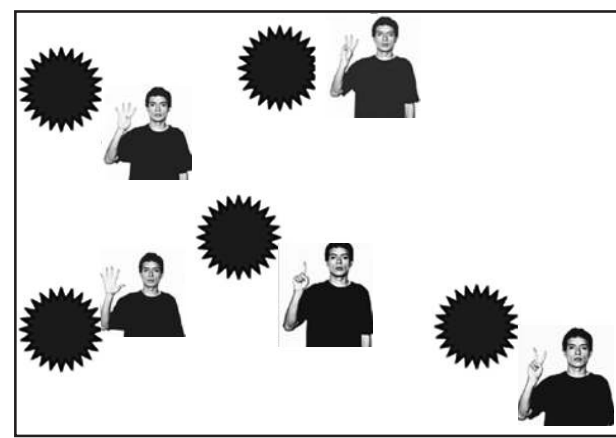

Foto 30 principio de irrelevancia del orden 
4) Principio de orden estable: los signos del sistema que se use para el conteo deben producirse con un orden establecido sin omitir ninguno de ellos (ver foto 31 ).
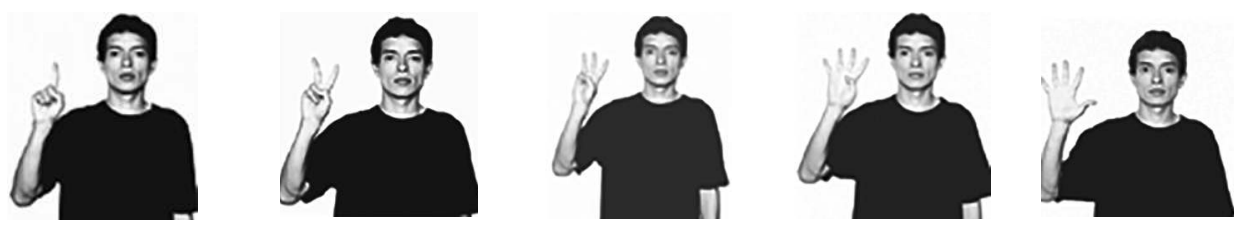

Foto 31 principio del orden estable

5) Principio de la cardinalidad: El último término usado de la colección que cuenta, indica el tamaño de la colección, se denomina el cardinal de la colección (ver foto 32).

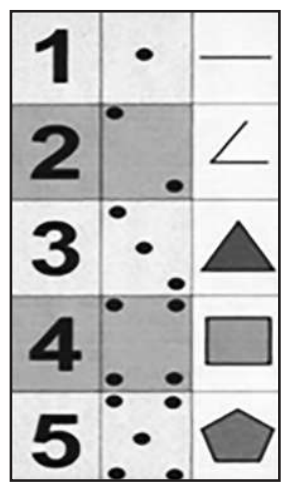

Foto 32. Principio de la cardinalidad

Los principios 1, 2 y 5 se desarrollan a partir de la experiencia de relacionar dos colecciones como experiencia fundamental del conteo. El principio 1 determina la percepción de la numerosidad, como un invariante de las colecciones, aspecto determinante en la idea de número cardinal. El principio 2 consolida la estrategia fundamental de conteo en la matemática y es el dispositivo para determinar las relaciones de equinumerosidad o de coordinabilidad de conjuntos. Finalmente, el principio 5 vincula la experiencia del conteo con experiencas mentales de inclusión de clases, elemento importante para consolidar las ideas de ordinal y de cardinal.

Los principios 3 y 4 se desarrollan a partir de las experiencias con las dos colecciones que privilegian en el conteo: la colección contada y la colección contadora. El principio 3 se vincula a la relación que el conteo establece con la colección de objetos que se va a contar (colección contada) y el princi- 
pio 4 se vincula con la colección de objetos que realiza el conteo (colección contadora). Se evidencia una etapa importante para el proceso del conteo, la discriminación de dos tipos de colecciones.

Sin embargo, la aplicación de tales principios con las herramientas y mediaciones simbólicas que cada cultura ofrece, hace emerger difrentes tipos de técnicas como la siguientes:

- Técnicas para asociar objeto-término: recitar sucesiones de términos (o producir sucesiones de términos); adjudicar cada término a cada objeto contado, hasta agotar los objetos de la colección; enunciar el término final.

- Técnicas para el organizar el conteo: trazar un camino a seguir para el conteo; distinguir (mental o fisicamente) los objetos ya contados; sustituir la colección por otra colección equinumerosa, contando esta última.

- Técnicas para abreviar el conteo: contar de dos en dos, de tres en tres, etc; contar hacia adelante o hacia atrás desde un cardinal dado; contar hacia adelante o hacia atrás desde un cardinal dado hasta otro cardinal dado, contar hacia adelante o hacia atrás tanto como lo indique un cardinal dado.

El desarrollo de la técnica responde a requerimientos del conteo como acción física. La producción de una técnica es la elaboración reflexionada de procesos asociados a la experiencia del conteo. Es decir, el conteo se convierte en un macro proceso que articula:

- Aspectos de desarrollo sensorial: visual, tactil, auditivo, olfativo, gustativo,

- Aspectos de desarrollo lingüístico-discursivo: interpretación y producción de signos, producción de significados y de sentidos,

- Aspectos cognitivos:diferenciar el conjunto de objetos que se va a contar del conjunto de objetos con el que se realizar el conteo, abstraer los principios del conteo,

- Aspectos culturales: formas convencionales de expresar cantidades y de usar simbolos número,

- Aspectos matemáticos: relaciones de equinumerosidad, correspondencias biunívocas de colecciones, relaciones de coordinabilidad de conjuntos, relaciones de orden, relaciones ternarias...

La presentación de las trayectorias de subitización y conteo evidencia que el proceso de desarrollo de la técnica está inmerso en los procesos de desrrollo de habilidades numéricas en los niños y niñas sordos.

\subsubsection{El proceso de subitización y la numerosidad}

Subitizar es reconocer la numerosidad de una colección pequeña de objetos $<<$ de una ojeada $>>$, el número surge en la mente de forma instantánea. En la 
subitización perceptual se percibe la numerosidad de la colección de objetos intuitiva y simultáneamente, mientras que en la subitización conceptual percibe un todo como un conjunto de partes. Las ideas y el desarrollo de las habilidades de subitización inician en edades tempranas para el niño y "la subitización introduce ideas de cardinalidad, ideas de partes y todo con sus relaciones, son el inicio de la aritmética, y, en general, ideas de cantidad" (Clements \& Sarama, 2009: 10).

Se denomina trayectoria de aprendizaje al proceso seguido por los estudiantes para desarrollar la subitización. La trayectoria de la tabla 11 es una propuesta para el desarrollo de la subitización en niños (as) sordos. ${ }^{23}$

Cabe recordar que las edades en los cuadros de la trayectoria son aproximadas porque la edad de adquisición de la noción, por lo general, depende en gran medida de la experiencia previa que se proporcione a los niños (as).

\subsubsection{El proceso de conteo}

El macro proceso de conteo se manifiesta como un tipo de actividad matemática primaria vinculada al hacer cultural y con un profundo efecto en la elaboración del número natural, que se constituye a partir de la identificación de los conceptos de cardinal y ordinal:

Identificación que se realiza mediante el postulado fundamental de la aritmetica: "El número cardinal de un conjunto coincide con el número ordinal del último elemento, y es siempre el mismo cualquiera que sea el orden en que se haya efectuado el recuento" (Cid \& Díaz Godino, 2003, pág. 25).

La dimensión cardinal considerará el tamaño del conjunto sin tener en cuenta la naturaleza de los elementos que los componen ni el orden en el que se presentan. La dimensión ordinal no considerá la naturaleza de los objetos y sí el orden en el que se presentan. La primera dimensión se manifiesta al responder preguntas como: cuánto hay, cuánto ganó, cuánto vale, cuánto más, cuánto menos... La ordinalidad se manifiesta cuando se responde a preguntas como: en qué puesto está, qué puesto ocupó, en qué posición llegó...cuál es el quinto.

Se podría pensar que el proceso de contar, se genera de una forma natural y rápida en los niños de tres años, debido a la relación establecida cuando el niño recita de forma ascendente los primeros tres o cuatro números naturales. Sin embargo, el proceso de contar involucra aspectos como: qué elementos ya contó en una colección dada, para que este elemento no vuelva a ser contado; realizar conteos de dos en dos, tres en tres; comenzar a contar en un número natural diferente de 1. La trayectoria presentada en la tabla 12 es una propuesta para el desarrollo del conteo en niños (as) sordos. ${ }^{24}$

23. La trayectoria de subitización fue adaptada de la que proponen los autores Clements y\& Sarama en Learning and Teaching Early Math, pág. 15-18.

24 La trayectoria de subitización fue adaptada de la que proponen los autores Sarama y Clements en Early Childhood Mathematics Education Research, páginas 73-79 


\section{Tabla 11. Traducción y Adecuación de la Tabla 2.1 de Learning and Tea- ching Early Math: The Learning Trajectories Approach pp. 15-17}

\begin{tabular}{l} 
Descripción del nivel \\
\hline $\begin{array}{l}\text { En el primer año, el niño (a) no está habituado al número, no tiene conocimiento explícito e intencional del número. Para los } \\
\text { niños, están primero las colecciones de un objeto rígido. }\end{array}$
\end{tabular}

II NIVEL: Nominador de Pequeñas Colecciones. Edad 1-2

Descripción del nivel

Nombra grupos de 1 a 2 , algunas veces de 3 .

Construye expresiones en LSC relacionadas con cantidades con función nominativa

Al mostrarle una pareja de zapatos, expresa en LSC "dos zapatos".

III NIVEL: Constructor de Pequeñas Colecciones. Edad 3

Descripción del nivel

Construye una colección pequeña no verbalmente (no más que 4, frecuentemente 1-3). Con el mismo número de otra colección (siguiendo modelo mental, es decir, no necesariamente por emparejamiento para este proceso, ver "Comparación Numérica"). También puede ser verbal (LSC).

Relaciona los objetos que ve con la expresión que interroga ¿cuántos?

Cuando le muestran una colección de 3 hace otra colección de 3.

IV NIVEL: Subitizador Perceptual hasta 4. Edad 4

Descripción del nivel

Reconoce instantáneamente colecciones hasta 4, mostradas por un tiempo breve, y expresa en (LSC) los números que corresponden a los puntos.

Cuando le muestran por un tiempo breve 4 objetos, dice "cuatro".

Evoca expresiones número en LSC hasta 4.

V NIVEL: Subitizador Perceptual hasta 5. Edad 5

Descripción del nivel

Reconoce instantáneamente colecciones hasta 5, mostradas por un tiempo breve, y expresa en (LSC). los números

Cuando le muestran por un tiempo breve 5 objetos, dice "cinco".

VI NIVEL Subitizador Conceptual hasta 5 . Edad 5

Descripción del nivel

Expresa nombres en LSC para todos los arreglos de 5, cuando son mostrados por un tiempo breve.

“ 5 ! ¿Por qué? Yo veo 3 y 2 y entonces dije 5. (LSC)"

VII NIVEL: Subitizador Conceptual hasta 10. Edad 5

Descripción del nivel

Expresa en LSC nombres para todos los arreglos de 6 a 10, usando grupos.

"En mi mente, yo hago 2 grupos de 3, y 1 más, entonces 7. (LSC)"

Nominan tamaños de cantidades, hasta diez, en profunda relación con los objetos que ve y que puede evocar.

Establece relaciones entre los nombres de las cantidades en LSC y los numerales indo-arábigos

VIII NIVEL: Subitizador Conceptual hasta 20. Edad 6

Descripción del nivel

Verbaliza, expresa nombres de tamaños de cantidades en (LSC) estructurando arreglos hasta 20 , mostradas por un tiempo breve, y usando grupos.

Nomina tamaños de cantidades, hasta veinte, en profunda relación con los objetos que ve y que puede evocar.

Establece relaciones entre los nombres de las cantidades en LSC y los numerales indo-arábigos

Construye otras secuencias de numerales, de acuerdo con los grupos que ve:

"Vi tres cincos, entonces 5, 10, 15. (LSC)" 


\section{Tabla 12. Trayectoria de conteo, adaptada de la tabla $3.1 \mathrm{~A}$ developmental Progession for counting in (Sarama \& Clements, 2009, pp. 73-79).}

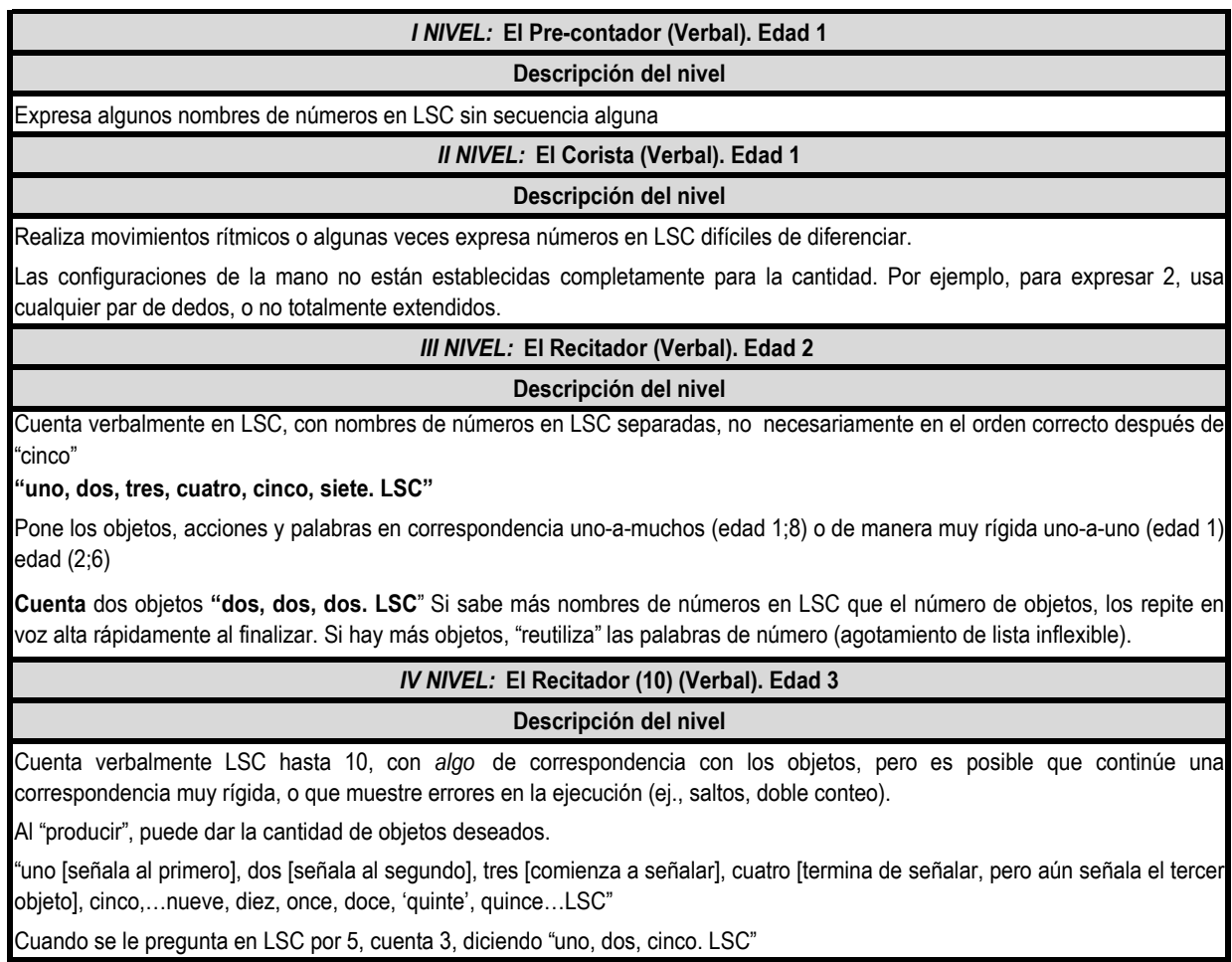

Cuando se le pregunta en LSC por 5 , cuenta 3 , diciendo "uno, dos, cinco. LSC"

\section{NIVEL: El Correspondedor. Edad 3}

\section{Descripción del nivel}

Mantiene correspondencias uno-a-uno entre nombres de números de conteo en LSC y objetos (cada nombre para cada objeto), por lo menos para grupos pequeños de objetos puestos en fila.

$$
\text { ㅁㅁ }
$$

\section{"1, 2, 3, 4 LSC"}

Es posible que conteste a la pregunta en LSC “¿cuántos?” re-contando los objetos, o violando la asociación 1-1 o el orden de los nombres de los números en LSC para hacer que la última nombre de número sea aquel deseado o predicho

\section{NIVEL: El Contador (Números Pequeños) . Edad 4}

Descripción del nivel

Cuenta objetos en fila hasta 5 con precisión y responde la pregunta en LSC "cuántos" con el último número contado. Cuando los objetos son visibles, y especialmente con números pequeños, comienza a entender el concepto de cardinal.

$$
\text { प्वप्र }
$$

"1, 2, 3, 4... ¡ cuatro! (LSC)"

\section{NIVEL El Contador (10). Edad 4}

\section{Descripción del nivel}

Cuenta arreglos de objetos hasta 10 en LSC. Es posible escribir numerales para representar 1 - 10

Cuenta de manera precisa una fila de 9 bloques y expresa en LSC que hay nueve.

Puede estar en capacidad expresar en LSC que el número justo antes o justo después de otro número, pero solamente cuanto comienza a contar desde 1 .

¿Qué sigue después de 4? “1, 2, 3, 4, 5. ¡5! (LSC)”

El conteo verbal en LSC hasta 20 está desarrollándose. 
VIII NIVEL: El Productor (Números pequeños). Edad 4

Descripción del nivel

Cuenta objetos en LSC uno a uno hasta 5. Reconoce que el conteo es relevante en situaciones en las cuales cierto número debe ser reconocido.

Produce un grupo de 4 objetos.

IX NIVEL: Contador y Productor (10+). Edad 4

Descripción del nivel

Cuenta en LSC y produce por conteo grupo de objetos de forma precisa hasta 10, después cantidades más altas (hasta 30 ).

Tiene una comprensión explícita de lo cardinal (cómo los números determinan cantidad). Hace seguimiento a los objetos que

han y no han sido contados, incluso en diferentes arreglos. Escribe y dibuja las representaciones 1 a 10 (posteriormente, 20,

finalmente 30).

Cuenta en LSC un grupo disperso de 19 trozos manteniendo el conteo con el movimiento de separación de cada trozo contado.

Produce el siguiente número (usualmente hasta la decena 20 - 30 o hasta la siguiente decena). Separa las decenas y las unidades de una palabra número, y comienza a relacionar cada parte de una palabra número/numeral con la cantidad a la cual éste se refiere.

Reconoce los errores en los conteos de los otros y es capaz de eliminar la mayoría de los errores en su propio conteo (señalar objeto) si se le pide en LSC que haga un esfuerzo mayor.

X NIVEL Contador regresivo desde 10 (Verbal y Objeto). Edad 4

Descripción del nivel

Cuenta un LSC regresivamente desde 10 hasta 1 verbalmente, 0 al removiendo objetos de un grupo.

"10, 9, 8, 7, 6, 5, 4, 3, 2, 1! LSC"

XI NIVEL Contador desde N (N+1, N-1) (Verbal y Objeto)

Descripción del nivel

Cuenta verbalmente en LSC y con objetos desde números diferentes a 1 (pero no puede mantener el número de conteos).

Si se le pide que "cuente de 5 a 8," cuenta " $5,6,7,8$ !" LSC

Determina los números justo antes o justo después inmediatamente.

Si se le pregunta en LSC, "¿Qué va justo antes de 7?" contesta, "iSeis!"

La trayectoria desarrollada y adaptada con sugerencia de actividades para el profesor se presenta en el apartado 5.

\subsubsection{Los sistemas de numeración y la LSC}

La trayectoria del conteo presenta un desarrollo que parte de las acciones sobre los objetos físicos, hasta llegar a la constitución de unos objetos mentales denominados números, que permiten operar cantidades. Los procesos representativos se presentan como inherentes al desarrollo numérico. Es decir, el desarrollo del sistema numérico es también el desarrollo del sistema de numeración y viceversa. Retomamos de Bourbaki citado por Gómez (1993) que el propósito para usar unos sistemas de numeración es: "asignar a cada número natural individual (con un límite que depende de las necesidades prácticas) un nombre y una representación escrita, formada por combinaciones de un reducido número de signos, efectuadas siguiendo leyes más o menos regulares". (Gómez, 1993: 31). Esas posibilidades de producción y de combinación simbólica determinan el carácter sistémico de los sistemas de numerales y les 
confieren potencia inventiva al sistema de numeración y potencial heurístico para procesos matemático (León, 2006).

Los sistemas de numeración pueden tener naturaleza física o naturaleza lingüística. Para el primer caso, el sistema de numeración es otra colección de objetos (como las partes del cuerpo, ábacos...), en el segundo caso, es un sistema de representación semiótica. La existencia de diversos sistemas de numeración es determinada por los siguientes características de los sistemas de numeración considerados como sistemas de representación semióticos:

Tabla 13. Características de los sistemas de numeración

\begin{tabular}{|l|l|}
\hline $\begin{array}{l}\text { Características de los sistemas de } \\
\text { numeración }\end{array}$ & \multicolumn{1}{|c|}{ Descripción de las características } \\
\hline El carácter de sistema linguístico & $\begin{array}{l}\text { Sistemas de signos con función comunicativa y de tratamiento constituido por: } \\
\text { Dos tipos de signos: la signos básicos y los compuestos. } \\
\text { Reglas para la conformación de los signos, reglas simples y reglas } \\
\text { compuestas. } \\
\text { Reglas para la expresión (oral, escrita, gestual) y para el uso del sistema } \\
\text { (convencionales, o no convencionales). } \\
\text { El carácter de sistema de numeración } \\
\text { Ejemplo, en el campo de la aritmética, cada signo expresa un número, un } \\
\text { tamaño de una colección, una posición. Cada signo recibe el nombre de } \\
\text { numeral. }\end{array}$ \\
\hline El carácter aritmético del sistema & \begin{tabular}{l} 
La producción de los signos está determinada por factores aritméticos. \\
\hline
\end{tabular} \\
\hline
\end{tabular}

Las características anteriores de los sistemas de numeración los constituyen en registro de representación semiótica (Duval, 1999), debido a que es posible realizar con ellos tres tipos actividades cognitivas fundamentales:

1) La producción de otros numerales a partir de los ya existentes y de las reglas del sistema.

2) La transformación de las representaciones a partir de reglas que permiten pasar de un numeral a otro y

3) La transformación de la representación en otra representación dentro de otro sistema de numerales.

Para Duval (1999: 43-44) las posibilidades de combinación en los sistemas semióticos son los que otorgan su potencia inventiva, permitiéndole efectuar en su interior transformaciones de expresión o de representación, y las reglas son las que determinan el funcionamiento del sistema, todos los sistemas no poseen las mismas reglas. El siguiente esquema presenta elementos comunes en la producción de los sistemas semióticos. 


\section{Esquema 3. Elementos para la producción de los signos en los sistemas de numeración}

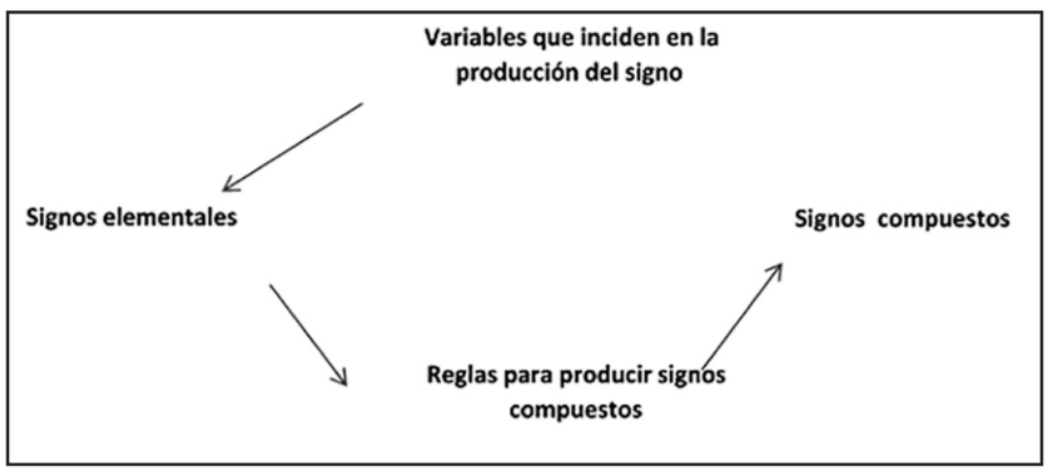

Tres sistemas de numeración, para el desarrollo de un sistema numérico. Para el caso de poblaciones sordas la coexistencia de tres sistemas de númeración con el mismo nivel de importancia es imprescindible. Los subsistemas de numerales que provienen de dos lenguas naturales (LS y español) y el sistema de numeración internacional arábigo.

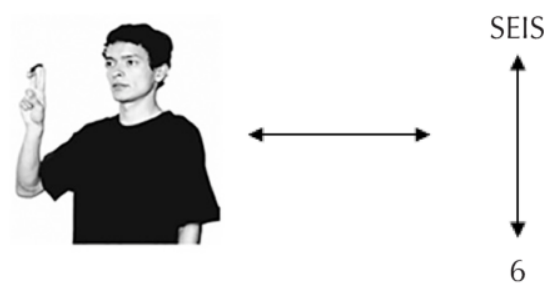

Las características de los tres sistemas de numeración y las necesidades de interrelación entre los mismos inciden en el uso simultáneo de los mismos. a continuación se describen estos sistemas:

1) El sistema de numeración de la Lengua de Señas Colombiana como subsistema lingüístico. Para el caso de la estructura de los numerales en la Lengua de Señas Colombiana LSC, se identifican cinco (5) variables que inciden en la producción de los numerales según Oviedo (2001):

- Configuración. Se refiere a como se colocan los dedos y el pulgar de la mano para formar la seña.

- Movimiento. Informa sobre el cambio en algún aspecto de la configuración, ubicación, dirección o en la orientación de la mano.

- Dirección. Informa hacia donde se dirige la mano con respecto a una locación en el cuerpo o plano de superficie. 
- Ubicación. Informa acerca del lugar que la mano ocupa en el espacio, así como la posición que adopta en relación con ese lugar.

- Orientación. Da cuenta de la posición relativa de la mano articuladora en el espacio.

La Lengua de Señas Colombiana tiene la característica de emplear solo una mano para los diez primeros numerales, lo que permite, en el proceso de conteo, usar la otra mano para separar los objetos ya contados de los no contados. Esta característica se presenta, además en otros numerales como se muestra en la tabla 14.

Tabla 14. Algunos numerales en LSC y sus variables de producción

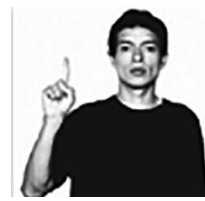

Numeral uno

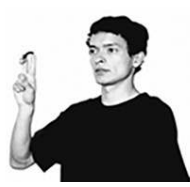

Numeral seis

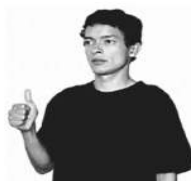

Numeral diez

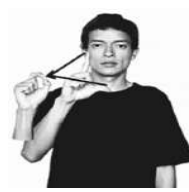

Numeral cien

La mano con la palma La mano con la palma hacia La mano cerrada con el La mano en "L" se mueve hacia adelante 0 hacia adelante extiende y flexiona pulgar extendido y la palma hacia afuera al tiempo que atrás se coloca con el el dedo índice mientras los hacia adentro se mueve une las yemas de los dedos dedo índice extendido y demás dedos permanecen varias veces hacia adentro y índice y pulgar. los demás recogidos. hacia afuera.

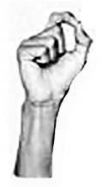

Numeral cero

La mano en configuración "o"

Los signos simples son aquellos que no son efecto de la composición de otros signos del sistema, en términos de Duval (1995/2004) se pueden Ilamar numerales elementales. La tabla 15 presenta las unidades elementales del sistema de numeración de la LSC.

Estos signos elementales ayudan a la creación de signos compuestos (ver tabla 16) basados en tres reglas mencionadas por (Chaves, 2006):

- Reiteración. Se repite la configuración de la mano para crear otros numerales.

- Combinación. Se forma un nuevo numeral a partir de dos o más signos elementales.

- Movimiento. A una seña compuesta se le adiciona el movimiento. 
Tabla 15. Signos elementales de la Lengua de Señas Colombiana

\begin{tabular}{|l|l|l|l|}
\hline Numeral cero & Numeral uno & Numeral seis & Numeral diez \\
\hline Primera forma & & \\
\hline segundo signo elemental & tercer signo elemental & cuarto signo elemental & \\
\hline Numeral cien & Numeral mil & Numeral un millón & \\
\hline sexto signo elemental & séptimo signo elemental & octavo signo elemental \\
\hline
\end{tabular}

2) El susbsistema de numerales en el español escrito. El español escrito tiene tres tipos de unidades elementales: palabras, las sílabas y las letras. La tabla 17 presenta la discriminación de las unidades elementales de este sistema.

En cuanto a la producción de signos compuestos. Las reglas que permiten determinar la producción de signos compuestos en español escrito son:

TIPO 1. Unidad superior de una sola palabra.

REGLA 1. Constitución de una sola palabra por tratamiento simple de acumulación de unidades elementales.

Seis cientos $\Rightarrow$ Seiscientos

Dos cientos $\Rightarrow$ Doscientos

REGLA 2. Constitución de una sola palabra por acumulación por unidades elementales, con una acción de tratamiento, sustitución, eliminación, o agregación.
Dos ce
do(s)
$\Rightarrow$ Doce
Diez seis
$\operatorname{die}(z) c i$
$\Rightarrow$ Dieciséis
Cuatro enta
cua(tro) enta
$\Rightarrow$ Cuarenta 
Tabla 16. Producción de signos compuestos en la LSC

\begin{tabular}{|l|l|}
\hline Reiteración & \\
\hline Numerales: seis, siete, ocho, nueve & Combinación \\
\hline $\begin{array}{l}\text { Seis: La mano con la palma hacia adelante } \\
\text { extiende y flexiona el dedo índice mientras los } \\
\text { demás dedos permanecen recogidos. }\end{array}$ \\
$\begin{array}{l}\text { Siete: La mano con la palma hacia adelante } \\
\text { extiende y flexiona los dedos índice y medio } \\
\text { mientras los demás dedos permanecen }\end{array}$ \\
recogidos.
\end{tabular}

TIPO 2. Unidad superior de dos palabras o más.

REGLA 1.Adjunción de dos unidades de una sola palabra.

Mil doscientos

Ciento cincuenta
$\Rightarrow$ Mil doscientos

$\Rightarrow$ Ciento cincuenta

REGLA 2. Adjunción de unidades elementales de una sola palabra y sílabas con acción de tratamiento. 
Tabla 17. Unidades elementales del español

\begin{tabular}{|c|c|c|}
\hline $\begin{array}{c}\text { Palabras } \\
\text { Números }\end{array}$ & Letras & Silabas \\
\hline Cero & $\mathrm{R}$ & $\mathrm{Ce}$ \\
\hline Uno & $\mathrm{U}$ & $\mathrm{Ci}$ \\
\hline Dos & $\mathrm{S}$ & Enta \\
\hline Tres & $\mathrm{Y}$ & Un \\
\hline Cuatro & & \\
\hline Cinco & & \\
\hline Seis & & \\
\hline Siete & & \\
\hline Ocho & & \\
\hline Nueve & & \\
\hline Diez & & \\
\hline Catorce & & \\
\hline Quince & & \\
\hline veinte & & \\
\hline Treinta & & \\
\hline Cien & & \\
\hline Ciento & & \\
\hline Quinientos & & \\
\hline Mil & & \\
\hline Millón & & \\
\hline & & \\
\hline
\end{tabular}

Cinco milló(n)

Uno millón

Uno billón

Uno trillón

Uno cuatrillón
Millones

Uno millón
Uno billón
Uno trillón

REGLA 3. Adjunción con uso de unidades de una sola palabra o letra y por adjunción de una de las 10 primeras en una palabra.

Treinta ocho y

Cuarenta nueve y
Treinta y ocho

Cuarenta y nueve

La escritura de los numerales en español es el efecto de las siguientes variables:

La complejidad del sistema de numeración del español escrito no puede ignorarse cuando se trata de considerar trayectorias de aprendizaje del conteo. 
Tabla 18. Variables de la producción del signo

\begin{tabular}{|c|c|c|}
\hline Variable & Valores & Determinación \\
\hline \multirow[t]{2}{*}{$\begin{array}{l}\text { a. Orientación } \\
\text { Indica el lugar desde donde } \\
\text { debe empezar a escribirse } \\
\text { teniendo en cuenta los valores } \\
\text { que determinan la escritura. }\end{array}$} & $\begin{array}{l}\text { Izquierda -derecha } \\
\text { Arriba - Abajo }\end{array}$ & $\begin{array}{l}\text { Esta muestra la escritura en palabras número bajo la regla } \\
\text { de derecha a izquierda pero en la escritura de signos } \\
\text { número se realiza por valor posicional de izquierda a } \\
\text { derecha. } \\
\text { En los signos número cuando de escribe en vertical u } \\
\text { horizontal. } \\
\text { Las diferentes combinaciones como se pueden escribir las } \\
\text { cantidades o cifras y palabras número. }\end{array}$ \\
\hline & - Linealidad & Ir en renglón. \\
\hline b. Tipos de signos & $\begin{array}{l}\text { Vocales } \\
\text { a,e,i,o,u. } \\
\text { Silabas: Ci, enta, un, ce } \\
\text { Palabras: Uno, die, ciento }\end{array}$ & $\begin{array}{l}\text { Están para articular en el tratamiento o reglas de } \\
\text { conformación de adjunción y constitución. } \\
\text { Que se utilizan para los diferentes tratamientos que se } \\
\text { presentan en la representación semiótica }\end{array}$ \\
\hline c. Ortografía & $\begin{array}{l}\text { UnO - uNo } \\
\text { dosClentos } \\
\text { DosciENTOS } \\
\text { No dejaría de ser la cifra nombrada. } \\
5720 \text { - Cinco miL seTEcientos vEinte } \\
\text { es la misma cantidad que se nombra }\end{array}$ & $\begin{array}{l}\text { En la objetivación matemática no son importantes sus reglas } \\
\text { ortográficas ya que la misma palabra número es } \\
\text { independiente de que sean mayúsculas o minúsculas. } \\
\text { Pero en la producción lingüística si no se toman en cuenta } \\
\text { las reglas de construcción, se dar un error en su escritura. }\end{array}$ \\
\hline \multirow[b]{2}{*}{ d. Tamaño de la letra } & Mayúsculas & \\
\hline & $\begin{array}{l}\text { Minúsculas } \\
\text { se objetiva en lo matemático } \\
\text { TRESCIENTOS - trescientos; } \\
\text { CUATROCIENTOS - cuatrocientos }\end{array}$ & $\begin{array}{l}\text { Se utilizan para dimensión significante en la función de } \\
\text { objetivación matemática. }\end{array}$ \\
\hline $\begin{array}{l}\text { e. Por posición de unidades } \\
\text { elementales (izquierda - } \\
\text { derecha): }\end{array}$ & $\begin{array}{l}\text { Mil } \longrightarrow \text { Uno } \\
\text { Un mil } \\
\text { Doscientos } \longrightarrow \text { mil } \\
\text { Mil doscientos }\end{array}$ & $\begin{array}{l}\text { La posición de las unidades elementales o compuestas } \\
\text { cambia las cantidades }\end{array}$ \\
\hline $\begin{array}{l}\text { f. Por orden y cantidad de } \\
\text { una palabra en su escritura. }\end{array}$ & $\begin{array}{l}\text { SEIS MIL MILLONES DOSCIENTOS } \\
\text { CINCO } \\
\text { CINCO MIL MILLONES DOSCIENTOS } \\
\text { SEIS } \\
\text { DOSCIENTOS CINCO MIL MILLONES } \\
\text { SEIS }\end{array}$ & $\begin{array}{l}\text { Orden en las palabras número principio y final. } \\
\text { Nombra cantidades diferentes. } \\
\text { Se pueden organizar por jerarquías y según la necesidad del } \\
\text { número que se requiere. }\end{array}$ \\
\hline
\end{tabular}


3) El sistema de numerales en la numeración decimal Hindú-arábiga. Las unidades elementales en el sistema de numeración decimal, están conformadas por los numerales llamados dígitos y el (.) punto:

\section{Tabla 19. Símbolos numéricos básicos del SND}

\begin{tabular}{|l|}
\hline 0 \\
\hline 1 \\
\hline 2 \\
\hline 3 \\
\hline 4 \\
\hline 5 \\
\hline 6 \\
\hline 7 \\
\hline 8 \\
\hline 9 \\
\hline. \\
\hline
\end{tabular}

Las reglas para la producción de las unidades compuestas son muy simples desde el punto de vista lingüístico, pues los signos compuestos están determinados por la acumulación lineal de signos simples: 11111222222389, 12, 320, entre otras representaciones En algunas culturas se acostumbra a colocar el punto cada tres unidades para apoyar la lectura de la cantidad, que se hace en sentido contrario a la lectura de palabras.

4) Los sistemas aritméticos de los sistemas de numerales. La producción de los signos en el sistema de numeración decimal (SND), está determinada por principios aritméticos vinculados a valores de los signos elementales. Se destacan los siguientes aspectos (Barrera, 2008):

- La cantidad que se utiliza para realizar las agrupaciones sucesivas es el mismo cardinal del conjunto de símbolos generadores. En el SND los signos básicos son diez, las agrupaciones se realizan de diez en diez, esto es lo que construye la base del sistema.

- Lo que se registra en forma escrita es el residuo. En la forma de representar el valor posicional, lo que no se alcanza agrupar en base diez es lo que se registra, así como el resto de las cantidades de objetos, como por ejemplo para: (573)

Tabla 20. Formas de representación en el valor posicional

\begin{tabular}{|c|l|l|}
\hline CENTENAS & \multicolumn{1}{|c|}{ DECENAS } & \multicolumn{1}{c|}{ UNIDADES } \\
\hline 5 grupos de diez de diez. & $\begin{array}{l}7 \text { de diez que no completan } \\
\text { grupos de diez de diez. }\end{array}$ & $\begin{array}{l}\text { 3 objetos, que no completan el } \\
\text { grupo de diez y se registran en } \\
\text { esta casilla. }\end{array}$ \\
\hline
\end{tabular}


- La cantidad que refiere cada cifra, que compone un numeral, depende de la posición en que se encuentre. La lectura de cantidades en la que se realiza la identificación del valor relativo y los registros se realizan de derecha a izquierda, teniendo en cuenta el agrupamiento, observando el ejemplo anterior.

- La cantidad está asociada con las potencias del cardinal del conjunto de signos utilizados para la representación. Cada posición del símbolo de cada cifra en un numeral representa una cantidad de grupos conformados de diez, por ser un residuo de secuencia de una agrupación de diez, indica que representa una potencia de 10. Siguiendo con el ejemplo 573, el tres está asociado a $10^{\circ}$, el siete con $10^{1}$ el cinco con $10^{2}$.

- La cantidad relativa, corresponde a un múltiplo, de la potencia que representa la posición: el numeral y su posición representan las veces que la potencia de 10 asociada a la posición se presenta. Siguiendo con el ejemplo 573 , el tres en primera posición representa tres veces $10^{\circ}$, el siete en segunda posición representa 10 veces $10^{1}$ y el cinco, cinco veces $10^{2}$.

- El residuo de cada orden de agrupación se representa con alguno de los numerales empleados para la representación: para el registro se utiliza el signo del conjunto base.

- Cada representación sintetiza una combinación lineal de las potencias de la base: a través de un polinomio numérico, representado en forma abreviada las potencias de diez en el SND, la cantidad total es la suma de cada una de las cantidades multiplicadas por la potencia que indica cada posición; 573 representada $5 \times 10^{2}+7 \times 10^{1}+3 \times 10^{\circ}=5 \times 100+7 \times 10+3 \times 1=500+70+3^{25}$

- Entonces la suma y multiplicación hacen parte de la significación de números en el SND: se aplican siempre de una misma condición, multiplicando por la potencia de la base que le corresponde y luego se suman los productos.

Según Kamii (1995), los niños de primer grado conocen y escriben números grandes, sin poder comprender que uno deriva del otro y que se organizan de diez en diez, aquí es donde el niño empieza la noción de adición y sustracción, de mayor que, y menor que. "Existe una relación entre edades y niveles al interpretar la cifra, se destacan cuatro niveles de desarrollo, cada uno con características particulares, que permiten establecer cuándo hay comprensión del valor de posición" (p 64).

- Nivel1: Los números de dos cifras representan la cantidad total de objetos de una colección, para el niño cada cifra de un número de dos cifras no tiene significado numérico.

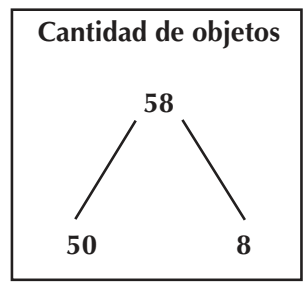

25 Lo referente a las reglas del SND es tomado de lo elaborado por el grupo de matemática Básica de la Universidad Distrital Francisco José de Caldas. 
Nivel 2: El número representa la cantidad total, el niño puede inventar significados numéricos para cada cifra; estos inventados no guardan relación con el valor de las posiciones ni agrupamientos en decenas ni unidades.

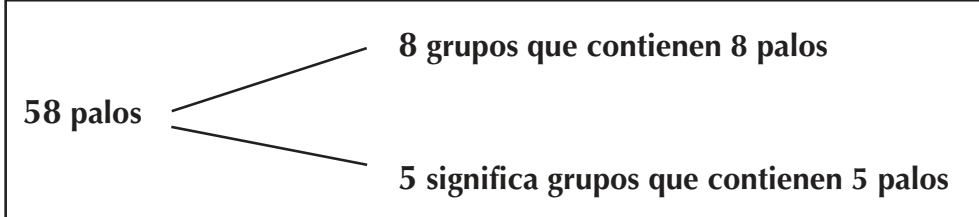

Nivel 3: El número representa la totalidad y cada parte tiene relación con decenas o unidades, según su posición, pero el niño no llega a identificar que es lo que sucede, ni lo puede interpretar.

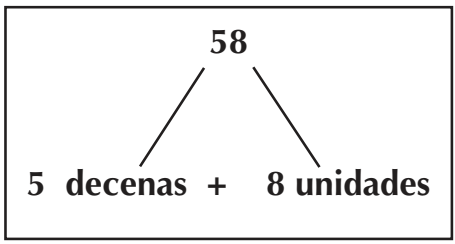

Nivel 4: El número de dos cifras muestra la totalidad de los objetos de la colección, donde se define que la cifra de la izquierda muestra las decenas (grupos de diez) y la de la derecha las unidades (proceso aditivo).

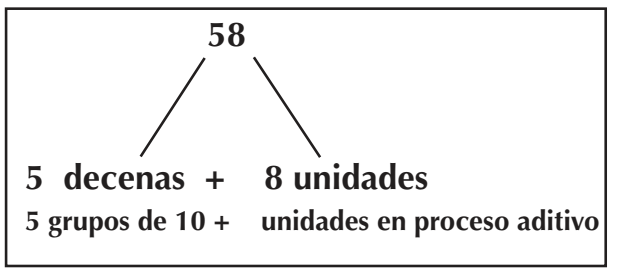

5) El sistema de numerales en el español escrito. Las dos operaciones que determinan el uso y producción de los signos escritos son la adición y la multiplicación de los valores de los numerales. Para la escritura de SND convencional de números, la cantidad de signos tiene una composición más complicada, cada palabra representa un valor que debe ser adicionado a los valores de las otras palabras para obtener el valor total que representa la expresión como en

Diez seis $\operatorname{die}(z)$ ci $\Rightarrow$ Dieciséis

La composición de los signos compuestos está determinada por aspectos multiplicativos como en:

Cuatro enta cua(tro) enta $\Rightarrow$ Cuarenta

Cinco enta $\operatorname{cinc}(0)$ uenta $\Rightarrow$ Cincuenta 
Donde el sufijo enta (grupo de diez) con el prefijo de la palabra cuatro conforma para cuarenta el valor de cuatro dieces, cinco dieces para cincuenta, seis dieces para sesenta.

6) El sistema de numerales de la lengua de señas. Como para el español escrito en algunos de sus signos se manifiesta la dimensión aditiva como en
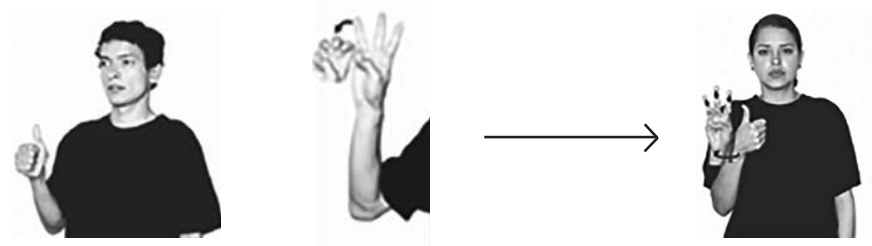

Donde la composición de los signos diez y ocho, conforma el valor de diez más ocho para el nuevo signo. Pero también se tienen dos aspectos muy importantes que marcan agrupaciones y multiplicación por potencias de diez, el primero corresponde al movimiento y el segundo al desplazamiento. Los signos que marcan agrupaciones con tipos de movimientos reiterativos o con el movimiento de una segunda mano son:
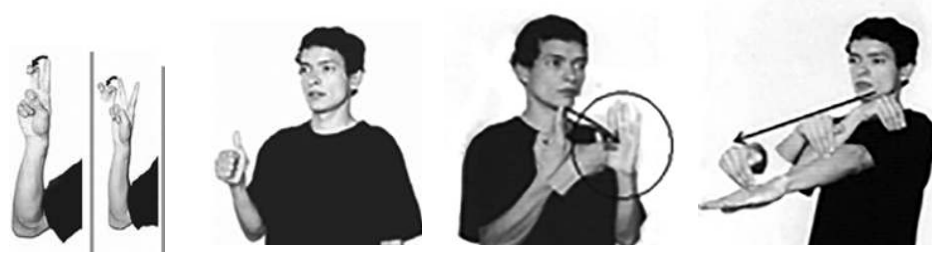

Que corresponden a seis (registra con el movimiento una agrupaciones de cinco y uno), siete (registra con el movimiento una agrupaciones de cinco y dos, diez (agrupaciones de diez), mil (agrupaciones de mil), un millón (agrupaciones de un millón).

Los movimientos tipo desplazamiento indican potencias de diez como

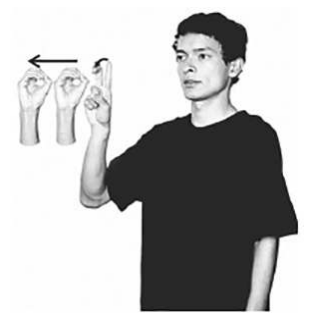


La seña: setecientos, la primera posición de izquierda a derecha marca el mayor valor de la potencia (siete por $10^{2}$, cero por $10^{0}$ y cero por $10^{\circ}$ ) la última posición marca la menor potencia de $10\left(10^{\circ}\right)$.

7) La conversión entre sistemas. Las características de los tres sistemas de numerales evidencian las exigencias para su elaboración, de ahí que las trayectorias de subitización y conteo requieren para su desarrollo un tiempo de experiencia en cada nivel.

Por su estructura el sistema de numerales de la lengua de señas se consolida de forma parecida al de numeración decimal indo-arábigo y la conversión entre los dos sistemas hasta el numeral novecientos noventa y nueve. En ambos sistemas el cero es visible en las denominaciones, esas razones harían que la escritura privilegiara el sistema de numeración decimal en primera instancia y en un segundo momento del sistema de numerales del español escrito, cuando su desarrollo con la lengua escrita le brinde las condiciones necesarias para la producción significativa.

\subsection{Trayectorias para el aprendizaje en matemáticas}

La expresión "Trayectorias Hipotéticas de Aprendizaje" (THA) refiere a las predicciones del profesor sobre el camino por el que el aprendizaje puede movilizarse. Son hipotéticas debido a que las trayectorias reales de aprendizaje de los estudiantes sordos (como de cualquier estudiante) dependen de la condición de existencia de cada individuo y a que el aprendizaje de los individuos tiene ciertas regularidades. Las THA le proporcionan al profesor un criterio racional para decidir el diseño que él considera, la mejor conjetura de cómo puede avanzar el aprendizaje (Simon, M. \& Tzur R. (2004).

Las THA de geometría analizadas por Sarama, Clements \& Vulkelic (1996), "ayudan a los maestros a entender la variedad de niveles de conocimiento y de pensamiento de sus clases y de los individuos dentro de ellas, como fundamentales para satisfacer las necesidades de todos los niños" (p.16). La propuesta de las THA busca dar respuestas a preguntas tales como: ¿qué metas o propósitos se deben establecer en el aprendizaje de la geometría y la aritmética inicial en niños sordos?, ¿por dónde empezar el aprendizaje de las matemáticas en cada momento de desarrollo de la población sorda?, ¿cómo podemos favorecer el aprendizaje para que la población sorda vaya alcanzando las mismas metas o propósitos que la porblación oyente?

En Clements \& Sarama (2009: 17) se consideran tres partes de las THA:

a) Las metas o propósitos matemáticos, entendido como el conjunto de los conceptos y habilidades que son matemáticamente centrales y coherentes, consistentes con el pensamiento de los niños y generadoras de futuros aprendizajes. 
b) La ruta de desarrollo a lo largo de la cual los niños progresan, constituída por los niveles de pensamiento, cada uno más sofisticado que el anterior y que conducen a la meta geométrica.

c) Un conjunto de actividades instruccionales o tareas, relacionadas para cada uno de los niveles de pensamiento, que fomentan el paso de un nivel a otro.

Las experiencias de aprendizaje con la aritmética y la geometría se pueden dar en número espacio, forma y magnitud. La trayectorias hipotéticas de aprendizaje centradas en nociones específicas (Clements \& Samara, 2009), parten del hecho que el aprendizaje se da a partir del desarrollo progresivo, el cual guarda una fuerte relación con la complejidad de las tareas que se le asignan a los niños. A medida que los aprendices viven, se establecen diferentes estrategias, que suelen ser influenciadas por las tareas que les propone el profesor. Este desarrollo refleja una jerarquización progresiva, permitiéndole organizar estructuras previas y construir un plan mental para construcciones más complejas.

A partir de las THA propuestas por (Clements \& Sarama, 2009), se consolidaron tres THA con aspectos del desarrollo de la LSC. Cada una de las tres THA que se presentan a continuación: Forma, Subitización y Conteo, se vincula a dispositivos didácticos como juegos y talleres. Aunque se indica unas edades para el seguimiento de trayectorias reales de aprendizajes, el aspecto fundamental de desarrollo es el progreso en los niveles que se presenta independiente de la edad del aprendiz.

\subsubsection{Trayectoria hipotética de aprendizaje de la forma}

Tabla 21. Trayectoria Hipotética de aprendizaje de la forma, adaptada de Clements, \& Sarama, 2009. Tabla 8.1 de FORMAS, Capítulo 8, pp. 137-147.

\begin{tabular}{l}
\hline \multicolumn{1}{|c|}{ I NIVEL: Comparador de "la Misma Forma" (Comparación). Edad 0-2 } \\
\hline Comparar "las mismas Figura" Comparación de objetos del mundo real \\
Expresa en LSC si las casas en dos fotos son la misma o diferentes \\
Igualar Formas - Idénticas. Comparación Emparejar figuras que le sean familiares y que tengan el mismo tamaño y \\
orientación (círculos, cuadrados, triángulos típicos) \\
Compara $\square$ con $\square$ \\
Tamaños Iguala figuras que le sean familiares pero con diferentes tamaños. \\
Empareja \\
Orienta figuras que le sean familiares pero con diferente orientación. \\
Empareja
\end{tabular}




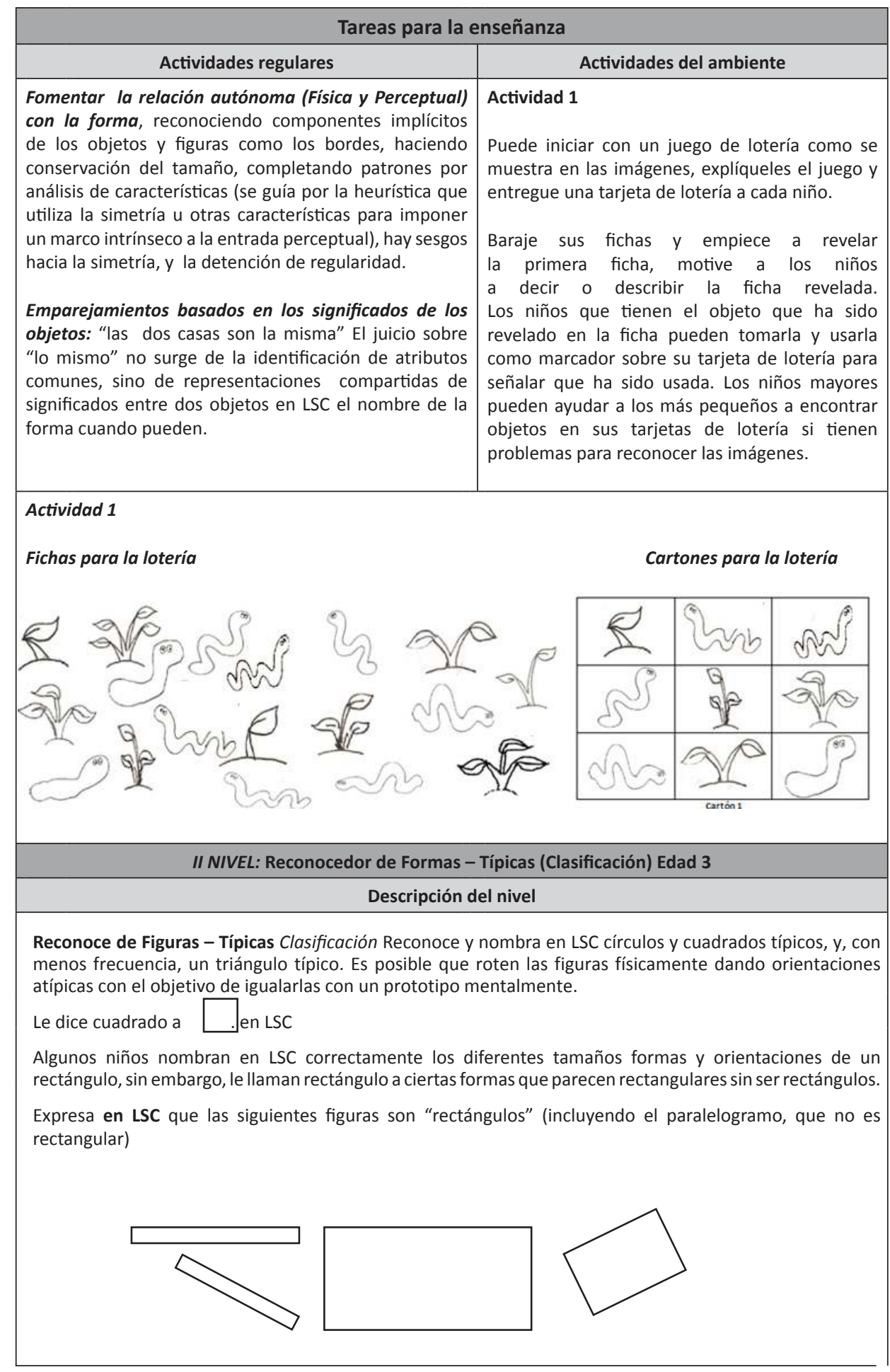




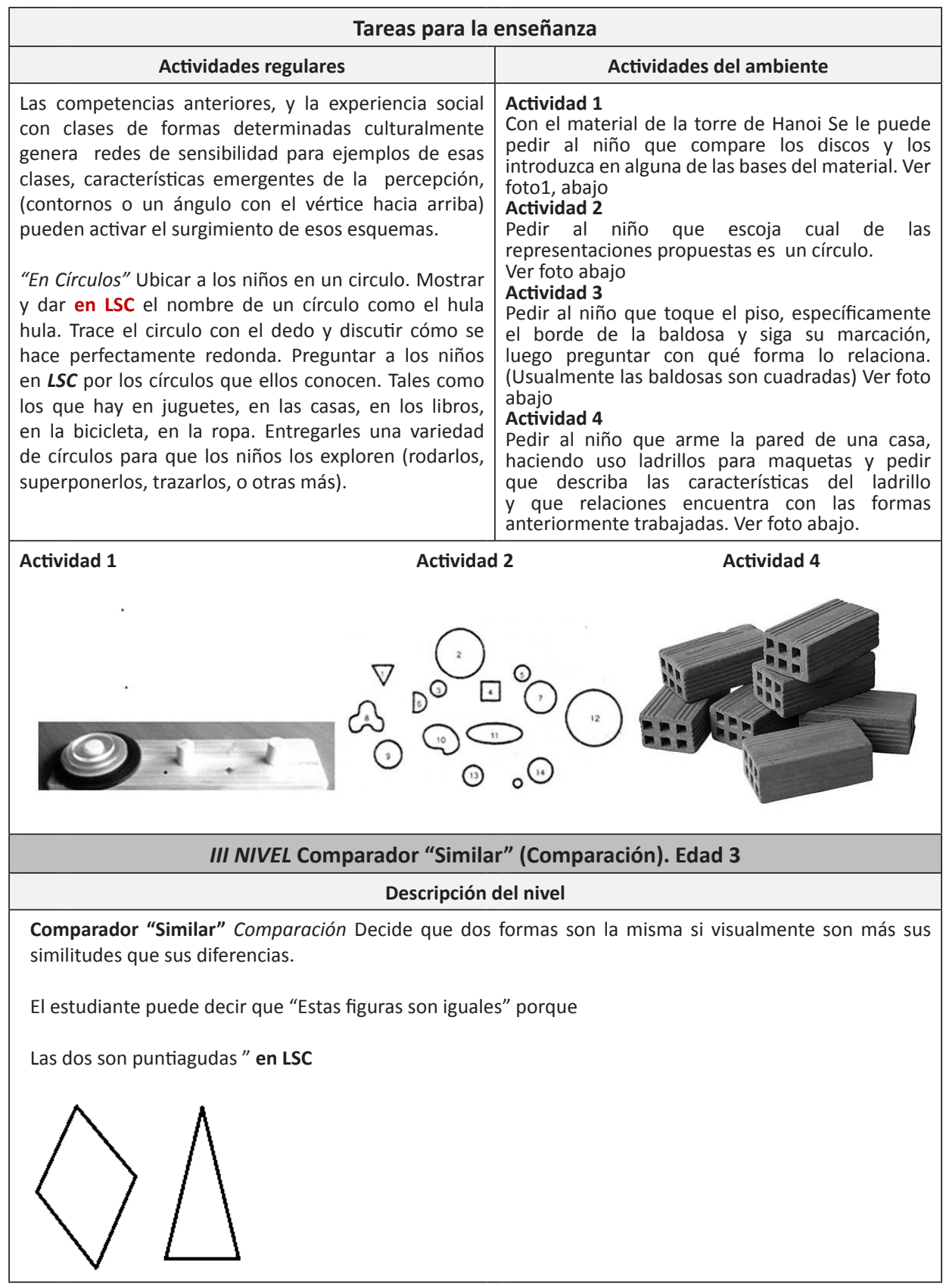




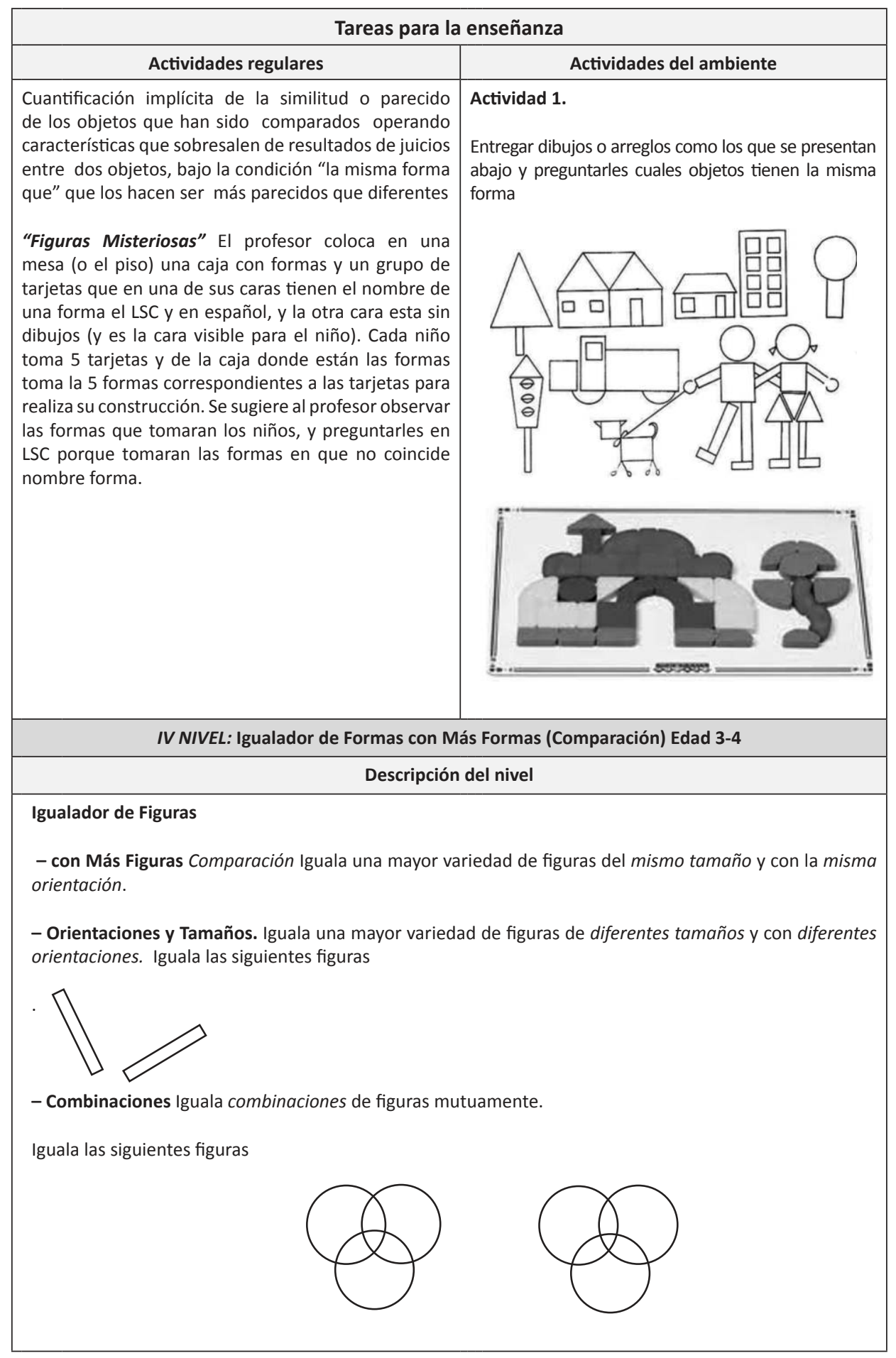




\section{Tareas para la enseñanza}

"Emparejar y Nominar Formas" Usa la misma actividad pero usando una amplia variedad de formas en diferentes orientaciones.

“Figuras Misteriosas" Usa la misma actividad pero usando nuevas formas, y seleccionar más tarjetas (como 10).

V NIVEL: Reconocedor de Formas Círculos, Cuadrados y Triángulos (Clasificación). Edad 4

\section{Descripción del nivel}

Reconocedor de Figuras (Círculos, Cuadrados y Triángulos) Clasificación, reconoce algunos cuadrados y triángulos que son menos típicos y es posible que reconozca algunos rectángulos, usualmente no reconoce rombos (diamantes). Normalmente no diferencia entre un lado y una esquina.

Reconoce algunos cuadrados y triángulos que son menos típicos y es posible que reconozca algunos rectángulos, usualmente no reconoce rombos (diamantes). Normalmente no diferencia entre un lado y una esquina.

Expresa en LSC que estos son triángulos
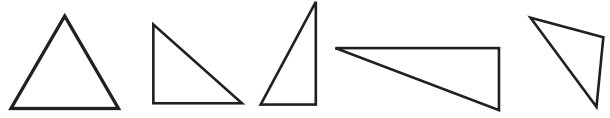

\section{Tareas para la enseñanza}

Amplía los esquemas a formas que incluyen múltiples prototipos los hace más flexibles, pero sin embargo, operan dentro de las limitaciones. Cada nombre de la forma dirige la atención a características que son cada vez más representacionales descriptivamente

"Es o No Es" (Círculos). Dibujar un círculo sobre una superficie donde toda la clase pueda verlo. Preguntar a los niños el nombre de la forma dibujado en LSC, y después decirles porque es un círculo. Dibujar un elipse (un ovalo) sobre la misma superficie. Preguntar a los niños a que se les parece, y preguntarles en LSC porque no es un círculo.

Dibujar otros círculos y otras formas que no son círculos pero que pueden ser confusas para ellos, y discutir sus diferencias. Concluir la actividad que un círculo que es perfectamente redondo, y formado por un línea que siempre se curva de la misma manera.

"Es o No Es" (Triángulos). Como arriba, incluir otros variantes (ej., "triángulos delgados") y, distractores como:
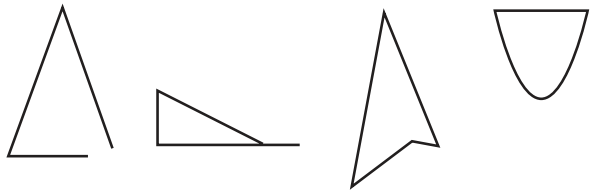

\section{NIVEL: Comparador de Partes (Comparación). Edad 4}

\section{Descripción del nivel}

Comparador de Partes Comparación Dice en LSC que dos formas son la misma después de haber igualado uno de los lados de cada una "Estas figuras son iguales" en LSC

(Igualando los dos lados).

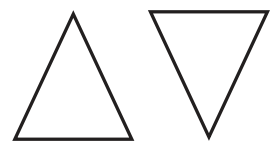




\section{Tareas para la enseñanza}

Analiza los resultados de las imágenes de lados de aproximadamente la misma longitud. Esto orienta los emparejamientos de bordes de formas físicas, y si coinciden aproximadamente, se determina una igualación(inadecuada matemáticamente para indicar congruencia de formas) si la coincidencia física es rechazada, el proceso se repite.

Modelos perceptualmente accesibles(o, en formas familiares, imágenes mentales globales y estáticas), implícitamente analizados, orientan manipulaciones físicas para crear configuraciones aproximadas de una forma dada. Inicialmente el análisis implícito considera cada componente de manera separada. Gradualmente se va integrando a un todo coherente

"Geometría Instantánea" La profesor entrega a cada niño 4 formas. Mostrar una forma a los niños por 2 segundos, ellos seleccionan su pareja de un grupo de 4 formas. Realice varias veces la actividad. Cuando presente una forma que no corresponde, pregunta en LSC porque presenta esa forma.

\section{NIVEL: Constructor de Formas - a partir de Partes - Como Lucen (Partes). Edad 4}

\section{Descripción del nivel}

Constructor de Figuras - a partir de Partes - Como Lucen Partes. Usa manipuladores que representa las partes de las figuras, tales como sus lados, para formar una figura que "luzca como" la figura en cuestión. Es posible que piense que los ángulos son esquinas (las cuales son "puntiagudas").

Si se le pide que haga un triángulo con palos, el resultado puede ser el siguiente.

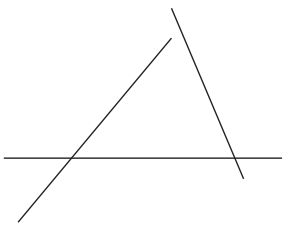

Tareas para la enseñanza

Actividades regulares

Actividades del ambiente

"Construcción de Formas" Incluir los nombres de esas formas. Proporcionar a los niños pitillos de varias longitudes para hacer formas que ellos conocen. El profesor observará que los niños construyan formas con los atributos correctos, tales como lados de las mismas longitudes y todos los ángulos rectos para cuadrados. Todo las pitillos deben que conectarse (tocar) en sus extremos.

Discutir los atributos en las construcciones de los niños. Si los niños necesitan ayuda, proporciona un dibujo para que ellos coloquen sobre él. Si los niños no tienen problemas con el ejercicio, entonces presentarles 3 pitillos de longitudes que no permiten a construir triángulos.

Preguntarles si es posible construir triángulos. Después entregar los pitillos para que los construyan.

VIII NIVEL: Comparador de Algunos Atributos (Comparación). Edad 4

Descripción del nivel

Comparador de Algunos Atributos.

Busca las diferencias en cuanto a atributos, pero es posible que solo examine cierta parte de la figura.

"Estas figuras son la misma" en LSC (indicando que las partes superiores de las figuras son similares al ponerlas una sobre la otra).
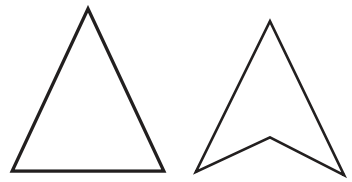


\section{Tareas para la enseñanza}

Hay análisis de los objetos para comparar atributos o propiedades. Un resultado para "lo mismo" es producido es producido en ausencia de diferencias relevantes, y "no es lo mismo" por presencia de al menos una diferencia relevante. Sin embargo el análisis no necesariamente se realiza sobre todo el objeto. No todos los atributos son comparados

"Formar Parejas" Entregarles un colección de formas y hacen todas las parejas que tienen la misma forma.

\begin{tabular}{c|}
\hline IX NIVEL: Reconocedor de Formas - Todos los Rectángulos (Clasificación). Edad 4-5 \\
\hline Descripción del nivel \\
\hline
\end{tabular}

Reconocedor de Formas - Todos los Rectángulos (Clasificación)

Reconoce más formas tamaños y orientaciones de los rectángulos.

Expresa en LSC acertadamente que las siguientes formas son "rectangulares".
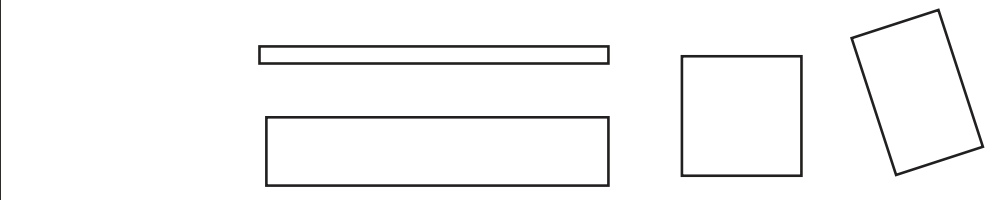

Tareas para la enseñanza

Los ángulos rectos se incorporan con más fuerza en los esquemas para los rectángulos.

"Adivina Mi Regla" El profesor solicita a los niños observar cuidadosamente como el clasifica formas en dos grupos con base en una regla que hace que esas formas están en cada grupo. Preguntar a los niños si adivina cuales la regla que uso, círculos versus cuadrados, o formas de 4 lados de redonda. Clasificar formas una a la vez, continuando hasta tener el menos 2 formas en cada grupo.

Cada vez que vaya a colocar una forma, solicitar la atención de los niños, y con un gesto de confusión solicitar que le indiquen a qué grupo corresponde la forma, y colocar la forma en su grupo. Después de que todas las formas están clasificadas, preguntan los niños que piensan los niños que es la regla de clasificación.

Repetir con otras formas y otras reglas.

"Figuras Misteriosas" El profesor coloca en una mesa (o el piso) una caja con formas y un grupo de tarjetas que en una de sus caras tienen el nombre de una forma el LSC y en español, y la otra cara esta sin dibujos (y es la cara visible para el niño). Cada niño toma 5 tarjetas y de la caja donde están las formas toma la 5 formas correspondientes a las tarjetas para realiza su construcción. Se sugiere al profesor observar las formas que tomaran los niños, y preguntarles en LSC porque tomaran las formas en que no coincide nombre forma.

X NIVEL: Reconocedor de Lados (Partes). Edad 4-5

\section{Descripción del nivel}

\section{Reconocedor de Lados (Partes)}

Identifica los lados como objetos geométricos de distinción.

Cuando se le pregunta en LSC qué forma es esta

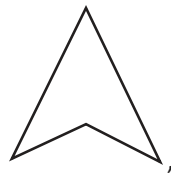
que tiene cuatro lados) después de contar los lados uno a uno moviendo su dedo índice a lo largo de cada uno. 


\section{Tareas para la enseñanza}

Puede explícitamente sacar cada lado como un objeto conceptual separado, mientras simultáneamente lo considera como parte de la forma como un todo.

"Rectángulos y Cajas" Dibujar un rectángulo grande para que toda la clase lo vea, contar cada lado en LSC, trazándolo con el dedo. Solicitar en LSC a los niños a dibujar un rectángulo en el aire, recordándoles que los deben ser rectos. Mostrar cajas a los niños, como, las de la crema dental, el cereal, caja de gelatina, y otras que tienen formas diferentes. Destacar las caras de las cajas, que deben ser rectángulos. Hablar sobre los lados y los ángulos rectos. Sobre un papel, colocar las cajas, y trazar todas sus caras. Solicitar en LSC a los niños emparejar los rectángulos. Trazar más caras y repetir. Ayudar a los niños a buscar cajas con otras formas en sus caras, como triángulos, octágonos, circulo/cilindro.

\section{NIVEL: Comparador de la Mayoría de Atributos (Comparación).Edad 4-5}

\section{Descripción del nivel}

Busca las diferencias en los atributos, examinando totalmente las formas, pero es posible que ignore algunas relaciones espaciales.

"Estas formas son iguales." LSC

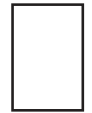

Tareas para la enseñanza

Analiza comprensivamente las formas comparando más atributos. Después de analizar las formas, la mayoría de los componentes son seleccionados y físicamente emparejados o igualados. Si todos los componentes son emparejados o igualados el resultado es "la misma forma". Sin embargo, los emparejamientos físicos y especialmente los visuales pueden no ser exactos y las relaciones espaciales entre los componentes pueden ser ignoradas.

"Nombrar Caras de Bloques" Organizar a los niños en una forma circular, y solicitarles en LSC los nombres de caras de bloques. Decirles en LSC cuales objetos tienen la misma forma en el salón.

XII NIVEL Reconocedor de Esquinas (Ángulos) (Partes). Edad 4-5

\section{Descripción del nivel}

Reconoce ángulos como objetos geométricos separados, por lo menos dentro del contexto limitado de "esquinas."

Cuando se le pregunta en LSC por qué es esto un triángulo, expresa en LSC, "tiene tres ángulos" y los cuenta, señalando claramente cada uno de los vértices (puntos en las esquinas).

Tareas para la enseñanza

Puede explícitamente sacar un ángulo como un objeto conceptual separado, mientras simultáneamente lo considera como parte de la forma como un todo.

\begin{tabular}{c} 
XIII NIVEL Reconocedor de Formas - Más Formas Clasificación. Edad 5 \\
\hline Descripción del nivel \\
\hline
\end{tabular}

Reconoce la mayor parte de las formas que le son familiares y los ejemplos típicos de otras formas, tales como los hexágonos, rombos (diamantes), y trapecios.

Identifica y enuncia en LSC de manera acertada todas las formas a continuación:

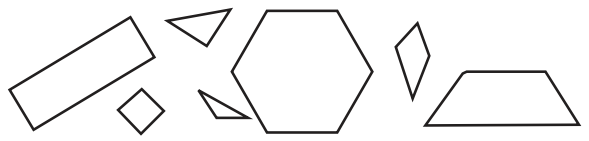




\section{Tareas para la enseñanza}

Los esquemas de formas tienen pocos prototipos (círculo y cuadrado), son desarrollados sobre la base de combinaciones sinérgicas de experiencias constructivas de mucha riqueza visual, y conocimientos declarativos verbales que limitan los componentes visuales al esquema.

"Pisa Formas" Hacer formas sobre el piso con cintas o tiza de colores. Solicitar a los niños pisar en una cierta clase de formas (por ejemplo, rombos). Colocar un grupo de 5 niños sobre los rombos, y preguntar a los otros niños si están seguros que el grupo está pisando en todos los rombos. Preguntarles en LSC ¿por qué ellos están seguros de estar en la forma correcta? (¿Cómo sabe usted que es un rombo?" LSC. Remitir la actividad hasta que todos los grupos hayan pisado las formas.

\section{NIVEL: Identificador de Formas (Clasificación). Edad 6}

\section{Descripción del nivel}

Enuncia en LSC las formas más comunes, incluyendoc los rombos, sin cometer errores

tales como decir que los óvalos son

Círculos.

Reconoce (por lo menos) los ángulos rectos, por lo tanto distingue entre un rectángulo y un paralelogramo que no tenga ángulos rectos.

Nombra en LSC acertadamente todas estas figuras:

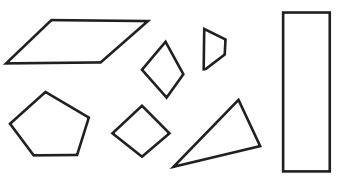

\section{Tareas para la enseñanza}

Hay evocaciones en el conocimiento declarativo verbal en contextos restringidos a aspectos espaciales y visuales de los esquemas de formas y de análisis de formas geométricas. El conocimiento visual y especial es más diferenciado y específico. Los niños son más cuidadosos en las clasificaciones \}

"El Señor Equivocado" Disfrazarse o llevar un asistente disfrazado y presentarlo como el Señor Equivocado. Decirles en LSC a los niños que ordenen El Señor Equivocado hacer formas en el tablero. Corregirlo cuando se equivoca. Usar formas del juego de formas. Solicitarle El Señor Equivocado en LSC los nombres de las formas. El confunde los nombres de formas, como la de cuadrado con la de rombo. Preguntar a los niños en LSC por el nombre correcto, y explicar porque sus ángulos son diferentes (Los cuadrados deben tener todos sus ángulos rectos; los rombos pueden tener diferentes ángulos). Revisar que los cuadrados y rombos tienen también los 4 lados igual de longitud. Repite con otras formas como trapezoides y hexágonos.

\section{NIVEL: Reconocedor de Ángulos - Más Contextos (Partes). Edad 7}

\section{Descripción del nivel}

Puede reconocer y describir contextos en los cuales el conocimiento de los ángulos es relevante, incluyendo esquinas (puede hablar de ángulos más "puntudos"), cruces (Ej., unas tijeras), y, más adelante, objetos doblados y curvas (algunas veces curvas en caminos y pendientes). Solamente un tiempo después podrá entender explícitamente en LSC cómo el concepto de ángulo se relaciona con estos contextos (Ej., es posible que inicialmente no conciba las curvas de una calle como ángulos; podría no estar en capacidad de sumar cantidades horizontales o verticales para completar un ángulo en el contexto de las pendientes; incluso podría observar esquinas que son más o menos "puntudas" sin representar las líneas que los constituyen). No es frecuente que relacione estos contextos y es posible que represente solo algunas características de los ángulos en cada uno (Ej., una línea oblicua para una rampa en el contexto de pendientes). 


\section{Tareas para la enseñanza}

"El Señor Equivocado" Como arriba, pero ahora confunde lados y esquinas. Asegurase explican en LSC cuál es cuál.

\section{NIVEL: Identificador de Partes de Formas (Clasificación). Edad 7}

\section{Descripción del nivel}

El conocimiento declarativo verbal es evocado deliberadamente para analizar las formas geométricas. El conocimiento visual espacial está incrementando lo específico y bajo control metacognitivo, Cognitivamente los componentes son separados explícitamente de la figura mientras son integrados con otros componentes

Identifica formas con respecto a sus componentes.

“No importa que tan delgado luzca, eso es un triángulo porque tiene tres lados y tres ángulos". en LSC

\section{Tareas para la enseñanza}

"Tienda de Formas" Los estudiantes identifican formas por sus atributos o numero de partes (Ej., Numero de lados, y ángulos).

XVII NIVEL: Determinador de Congruencias (Comparación). Edad 7

\section{Descripción del nivel}

Determina la congruencia mediante la comparación de todos los atributos y todas las relaciones espaciales.

Expresa en LSC que dos formas tienen la misma forma y el mismo tamaño después de comparar cada uno de sus ángulos y lados.

\section{Tareas para la enseñanza}

Analiza formas y compara atributos comprensivamente.

Aumenta la revisión visual de lados y ángulos integrados a una totalidad produciendo una estrategia de superposición, es decir, es un sistema directo de mover físicamente los objetos para producir la superposición, si todos los componentes coinciden el resultado es la determinación de la congruencia ("Io mismo" y "no es lo mismo" permanecen en estructuras separadas)

XVIII NIVEL: Determinador de Congruencias por Superposición (Comparación). Edad 7

\section{Descripción del nivel}

Mueve y coloca objetos, unos sobre los otros, para determinar su congruencia.

Expresa en LSC que dos formas tienen las mismas formas y el mismo tamaño dado que pueden ser puestas una sobre la otra.

\section{Tareas para la enseñanza}

Actividades regulares

Actividades del ambiente

XIX NIVEL: Constructor de Formas a partir de Partes - Exactas (Representación). Edad 7

\section{Descripción del nivel}

Usa manipuladores que representan partes de formas, tales como "conectores" de lados y de ángulos, para formar una forma que totalmente correcta, basándose en el conocimiento de componentes y relaciones.

Si se le pide que forme un triángulo con palos, hace lo siguiente:

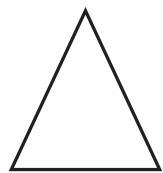




\section{Tareas para la enseñanza}

Modelo disponible perceptualmente con explicito conocimiento de propiedades geométricas, orienta la manipulación física para crear una configuración de una forma buscada. Con la edad y la experiencia los componentes de las relaciones tales como intersecciones y orientaciones oblicuas, aumentan las organizaciones jerárquicas.

"La Forma Secreta (Partes de Formas)" Proporcionar algunos palillos o palitos de varios longitudes. Secretamente hacer una forma como un rectángulo usando los palillos, y cubrirlo. Decir en LSC a los niños que los miran cuidadosamente y la guarden en sus mentes cuando usted lo muestra por 2 segundas, y cubrirla nuevamente. Solicitar a los niños en LSC construir con sus palillos lo que ellos vieron. Mostrar otra vez la forma por 2 segundas o más para que los niños puedan cambiar sus formas si es necesario. Después, los niños describen en LSC lo que ellos vieron y como lo construyeron. Repetir con otras formas más difíciles.

\section{NIVEL: Representador de Ángulos (Partes). Edad 8+}

\section{Descripción del nivel}

Representa varios contextos de ángulos en forma de dos líneas, incluyendo de manera explícita la línea de referencia (horizontal o vertical para una pendiente; una "línea de vista" para contextos de giro) y, por lo menos de manera implícita, representa el tamaño del ángulo como la rotación entre dichas las líneas. (es posible que aun tenga concepciones herradas de la medida de un ángulo, tales como relacionar el tamaño del ángulo con la longitud de la distancia entre los extremos de los lados y puede que no aplique este entendimiento en múltiples contextos).

\begin{tabular}{|c|c|}
\hline \multicolumn{2}{|c|}{ Tareas para la enseñanza } \\
\hline Actividades regulares & Actividades del computador \\
\hline $\begin{array}{l}\text { "Girar el Mundo" Los estudiantes estiman, y } \\
\text { después meden y dibujan diferentes ángulos } \\
\text { talles como, de una puerto abriéndose, las } \\
\text { tijeras abiertas, girar una perilla, girar la } \\
\text { cabeza, y otros. }\end{array}$ & $\begin{array}{l}\text { Sitio del Web con la programa de Logo, algunos gratis de } \\
\text { libre acceso: } \\
\text { http://scratch.mit.edu/ } \\
\text { http://www.cs.bham.ac.uk/ sjv/macroturtles/ } \\
\text { TurtlesApplet.html } \\
\text { http://www.mathsnet.net/logo/turtlelogo/index.html } \\
\text { http://illuminations.nctm.org/ActivityDetail.aspx?ID=83 }\end{array}$ \\
\hline \multicolumn{2}{|c|}{ XXI NIVEL: Representador de Congruencia (Comparación). Edad 8+ } \\
\hline \multicolumn{2}{|c|}{ Descripción del nivel } \\
\hline
\end{tabular}

Se refiere a las propiedades geométricas y las explica mediante transformaciones.

"Estas formas deben ser congruentes porque tienen sus lados iguales, todas las esquinas cuadradas, y las puedo colocar una sobre la otra de manera exacta." en LSC

Tareas para la enseñanza

\begin{tabular}{|cc|}
\hline Actividades regulares & Actividades del ambiente \\
\hline XXII NIVEL: Identificador de Clases de Formas Clasificación. Edad 8+ \\
\hline Descripción del nivel \\
\hline
\end{tabular}

Usa el nombre distintivo de la clase (Ej., para separar), sin basarse en sus propiedades de manera explícita.

“pongo los triángulos por aquí, y los cuadriláteros, incluyendo a los cuadrados, rectángulos, rombos y trapecios por acá" en LSC 


\section{Tareas para la enseñanza}

Actividades regulares

Los esquemas de formas están organizados jerárquicamente, basados en combinaciones de imágenes visuales y otras ayudas lingüísticas como la doble nominación (un cuadrado es un tipo especial de rectángulo.

"Adivina Mi Regla" Como arriba, pero con reglas apropiadas para este nivel, incluyendo otras clases de formas.

XXIII NIVEL: Identificador de Propiedades de Formas Clasificación. Edad 8+

\section{Descripción del nivel}

Usa las propiedades de manera explícita. Puede ver las permanencias en los cambios de estado o forma, pero manteniendo las propiedades de la forma.

"Pongo las formas con lados opuestos paralelos por aquí, y aquellas que tienen cuatro lados pero no sus pares de lados paralelos por acá." en LSC

\section{Tareas para la enseñanza}

Los esquemas de formas están organizados jerárquicamente, basados en combinaciones de imágenes visuales flexibles y especialmente en el análisis de formas y no formas, componentes y propiedades.

"Adivinar Mi Forma" Antes, colocar varias formas en lugares visibles del salón. Nombrar una propiedad de algún objeto del salón, como: "3 lados". Pedir en LSC a adivinen la forma que usted escogió. El niño que adivina la forma correcta selecciona la forma siguiente para que sea adivinada. Como variaciones, comunicar en LSC una forma en que la está pensando para que los niños busquen objetos que tengan esa forma. En este nivel hay que incluir variaciones como: pienso en una forma con 4 lados con lados opuestos con lo mismo longitud, pero no tiene ángulos rectos.

\section{NIVEL: Identificador de Clases de Propiedades Clasificación. Edad 8+}

\section{Descripción del nivel}

Usa la pertenencia a las clases para formas (Ej., para separarlas o considerarlas "similares") basándose explícitamente en sus propiedades, incluyendo las medidas de sus ángulos. Es consciente de las restricciones tanto al hacer transformaciones como definiciones y puede además integrarlas. Separa por jerarquías, basándose en las propiedades.

“Pongo los triángulos equiláteros por aquí, y los triángulos escalenos por acá. Los triángulos isósceles son todos estos... incluyendo los equiláteros." en LSC

\section{Tareas para la enseñanza}

"El Señor Equivocado" Como arriba, pero ahora enfatizar en definir propiedades y nombres en LSC de clases de formas (Ej., El Señor Equivocado expresa en LSC que un rectángulo tiene 2 pares de lados iguales, y paralelos, pero [equivocado] no tiene ángulos rectos).

"Cuál Forma Puede Ser" Lentamente, presentar una forma detrás de una pantalla. En cada paso, preguntar en LSC a los niños que clase formas puede ser, que tanto están seguros.

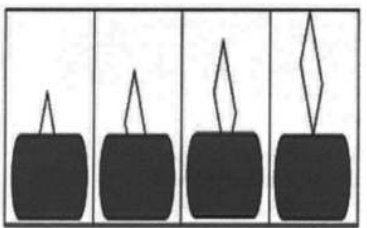

XXV NIVEL: Sintetizador de Ángulos Partes. Edad 8+

Combina varios significados de ángulo (giro, esquina, inclinación), incluyendo la medida del ángulo.

"Esta rampa esta en un ángulo de $45^{\circ}$ con respecto al suelo." en LSC

\section{Tareas para la enseñanza}

Establece una red de significados de ángulos interrelacionados 


\subsubsection{Trayectoria Hipotética de aprendizaje de Subitización}

\begin{tabular}{|c|c|c|c|}
\hline \multicolumn{4}{|c|}{ I NIVEL Numérico Pre-Explicito. Edad 0-1 } \\
\hline \multicolumn{4}{|c|}{ Descripción del nivel } \\
\hline \multicolumn{4}{|c|}{$\begin{array}{l}\text { En el primer año, el niño (a) no está habituado al número, no tiene conocimiento explícito e intencional del } \\
\text { número. Para los niños, están primero las colecciones de un objeto rígido. }\end{array}$} \\
\hline \multicolumn{4}{|c|}{ Tareas para la enseñanza } \\
\hline $\begin{array}{l}\text { Actividades } \\
\text { regulares }\end{array}$ & \multicolumn{2}{|c|}{ Actividades del ambiente } & $\begin{array}{l}\text { Actividades con el } \\
\text { computador }\end{array}$ \\
\hline $\begin{array}{l}\text { Proporciona un am- } \\
\text { biente rico sensorial- } \\
\text { mente para la manipu- } \\
\text { lación de objetos, y el } \\
\text { uso de Lengua de Se- } \\
\text { ñas Colombiana (LSC) } \\
\text { para expresar "más" y } \\
\text { acciones de adición de } \\
\text { objetos dirigiendo la } \\
\text { atención a las compa- } \\
\text { raciones. }\end{array}$ & \multicolumn{2}{|c|}{$\begin{array}{l}\text { Actividad } 1 \\
\text { Tomar frutas, para oler, tocar saborear y expresar en } \\
\text { LSC sus olores y sabores. } \\
\text { Presentarle varios objetos de textura suave para que } \\
\text { lo tome con sus manos, (repetir la acción con otras } \\
\text { texturas) } \\
\text { Presentarle objetos que al ser tocados emitan luces, o } \\
\text { que produzcan vibraciones hacerlo tocar varias veces } \\
\text { cada objeto. } \\
\text { Jugar con los dedos del niños } \\
\text { Actividad } 2 \\
\text { Mecerlos suavemente varias veces, } \\
\text { Presentarles movimientos rítmicos con las manos. } \\
\text { Jugar a hacer expresiones con la cara } \\
\text { Jugar a presentar-ocultar- presentar objetos } \\
\text { Mostrarle plantas, } \\
\text { Mostrarle animales } \\
\text { Actividad } 3 \\
\text { Expresarle al niño lo que ve en las siguientes imáge- } \\
\text { nes }\end{array}$} & $\begin{array}{l}\text { Mostrar imágenes en } \\
\text { el computador donde } \\
\text { hayan colecciones de } \\
\text { uno o dos, se sugieren } \\
\text { las siguientes páginas } \\
\text { porque contienen imá- } \\
\text { genes de donde hay } \\
\text { uno o dos animales: } \\
\text { http://www.123ima- } \\
\text { genes.com/u-image- } \\
\text { nes-animales.html } \\
\text { http://fotosdeanima- } \\
\text { les.net/ }\end{array}$ \\
\hline \multicolumn{4}{|c|}{$\begin{array}{r}\text { Hay una manzana, Hay dos } \\
\text { manzanas, Hay tres manzanas }\end{array}$} \\
\hline \multicolumn{4}{|c|}{ Hay una lombriz } \\
\hline \multicolumn{4}{|c|}{ II NIVEL Nominador de Pequeñas Colecciones. Edad 1-2 } \\
\hline \multicolumn{4}{|c|}{ Descripción del nivel } \\
\hline \multicolumn{4}{|c|}{$\begin{array}{l}\text { Nombra grupos de } 1 \text { a } 2 \text { algunas veces, } 3 \text {. } \\
\text { Construye expresiones en LSC relacionadas con cantidades con función nominativa } \\
\text { Al mostrarle una pareja de zapatos, expresa en LSC "dos zapatos" }\end{array}$} \\
\hline
\end{tabular}




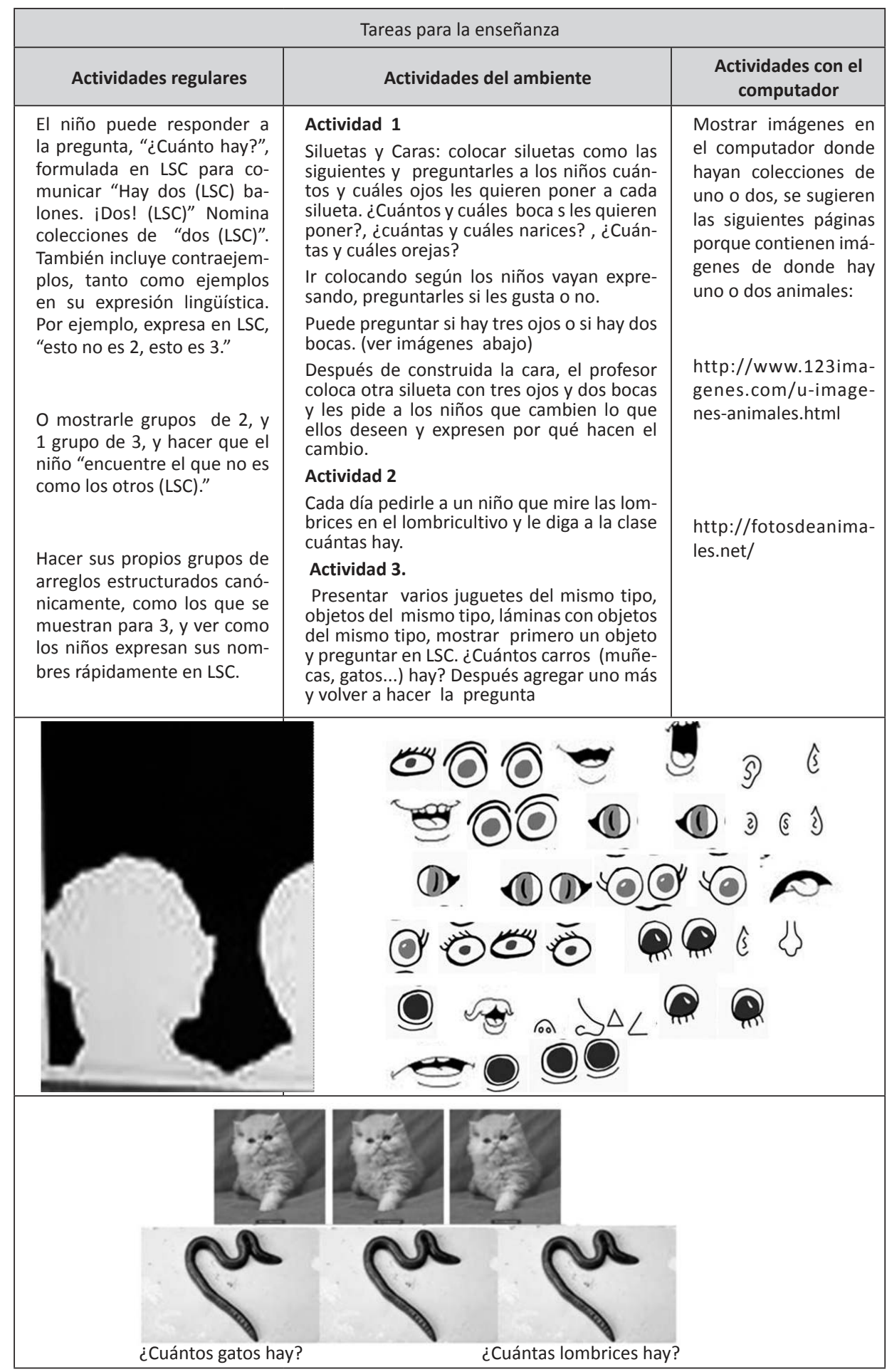


III NIVEL: Constructor de Pequeñas Colecciones. Edad 3

Descripción del nivel

Construye una colección pequeña no verbalmente (no más que 4, frecuentemente 1-3). Con el mismo número de otra colección (siguiendo modelo mental, es decir, no necesariamente por emparejamiento para este proceso, ver "Comparación Numérica”). También puede ser verbal (LSC).

Relaciona los objetos que ve con la expresión que interroga ¿cuántos?

Cuando le muestran una colección de 3 hace otra colección de 3.

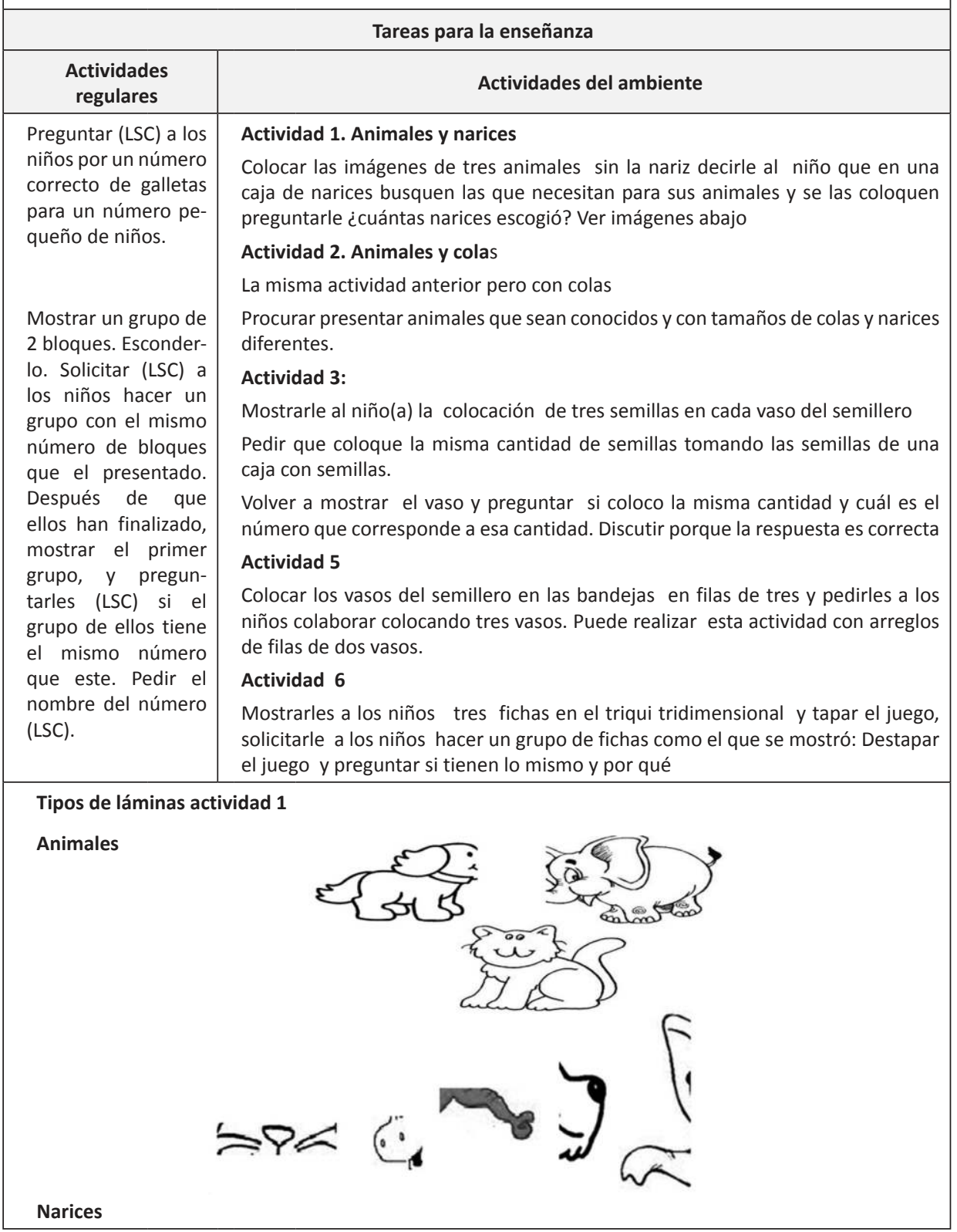



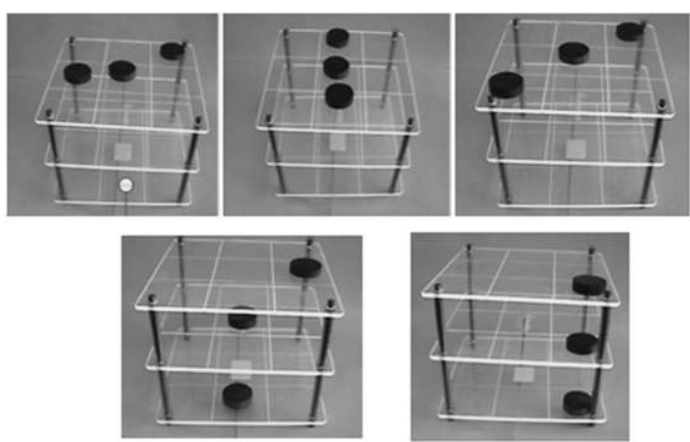

IV NIVEL: Constructor de Pequeñas Colecciones. Edad 4

Descripción del nivel

Reconoces instantáneamente colecciones hasta 4, mostradas por un tiempo breve, y expresar en (LSC) los números que corresponden a los puntos.

Cuando le muestran por un tiempo breve 4 objetos, dice "cuatro".

Evoca expresiones número en LSC hasta 4.

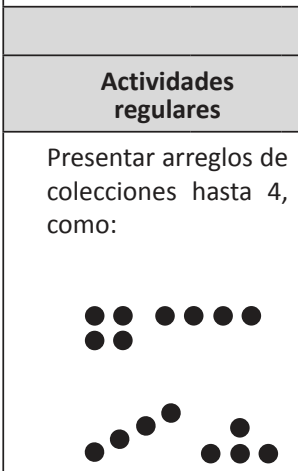

Preguntar en (LSC) cuántos puntos hay para que niño responda en lengua de señas con el nombre del número.

Tareas para la enseñanza

Actividades del ambiente

\section{Actividad 1}

Organizar 4 fichas de un juegos como las que se muestran abajo. Mostrarlas solo para 2-3 segundos, y ocultarlas. Preguntarles a los niños en LSC ¿Cuántos fichas hay?

Mostrar láminas como las siguientes por 2 o 3 segundos y preguntar

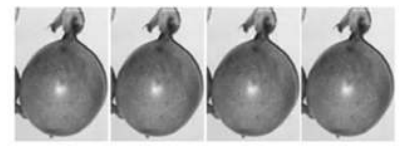

¿Cuántas granadillas hay?

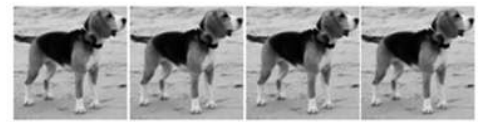

¿Cuántos perros hay?

\section{Actividad 2}

Entregar a los niños (as) cuatro fichas de un juegos y solicitar a cada niño realizar diferentes arreglos con las cuatro fichas

\section{Actividad 3}

Presentar la siguiente lámina solo para 2-3 segundos, y ocultarlas. Preguntarles los niños en LSC ¿Cuántos tomates hay? Después, mostrar la lámina otra vez, para que los niños pueden ver si sus respuestas son correctas.

Discutir en LSC las posibles respuestas

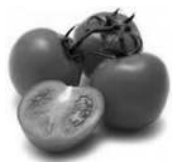




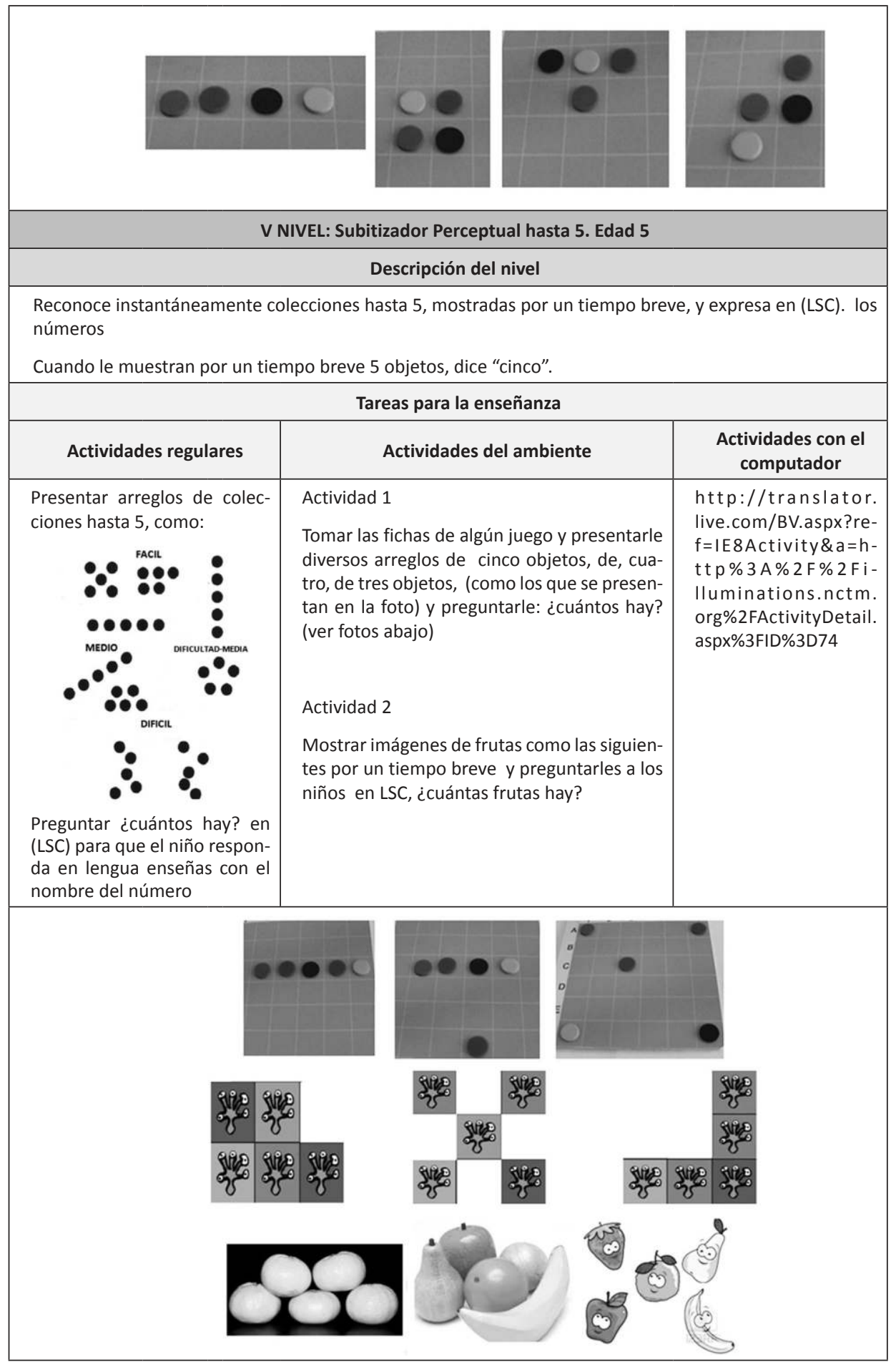




\begin{tabular}{|c|c|c|}
\hline \multicolumn{3}{|c|}{ VI NIVEL: Subitizador Conceptual hasta 5. Edad 5} \\
\hline \multicolumn{3}{|c|}{ Descripción del nivel } \\
\hline \multicolumn{3}{|c|}{$\begin{array}{l}\text { Expresan nombres en LSC para todos los arreglos de 5, cuando son mostrados por un tiempo breve. } \\
\text { “i5! ¿Por qué? Yo veo } 3 \text { y } 2 \text { y entonces dije 5. (LSC)" }\end{array}$} \\
\hline \multicolumn{3}{|c|}{ Tareas para la enseñanza } \\
\hline Actividades regulares & Actividades del ambiente & $\begin{array}{l}\text { Actividades con el } \\
\text { computador }\end{array}$ \\
\hline $\begin{array}{l}\text { Usar diferentes arreglos } \\
\text { que desarrollan subitiza- } \\
\text { ción conceptual con ideas } \\
\text { de adición y sustracción. } \\
\text { El objetivo es fomentar en } \\
\text { los estudiantes "ver dos } \\
\text { partes y la suma, como '2 } \\
\text { galletas y } 3 \text { galletas son } 5 \\
\text { galletas". }\end{array}$ & $\begin{array}{l}\text { Actividad } 1 \\
\text { Colocar las piezas o fichas de un juego en } \\
\text { arreglos de tres y dos, cuatro y uno, dos- dos } \\
\text { y uno. Cubrir cada arreglo con una cartulina, } \\
\text { destapar uno por uno por un tiempo breve } \\
\text { para que los niños lo vean, volver a tapar y } \\
\text { ¿preguntarles cuántas fichas hay ? Repetir la } \\
\text { actividad con otros juegos en otros días. } \\
\text { Actividad } 2 \\
\text { Presentar por un tiempo breve (2-3 segun- } \\
\text { dos), un arreglo de dos dados que corres- } \\
\text { ponda a cinco puntos, y ocultarlas. Preguntar } \\
\text { ¿cuántos puntos hay? Tapar uno de los dados } \\
\text { y preguntar cuántos puntos hay en el otro } \\
\text { dado, destapar el dado y volver a preguntar } \\
\text { cuántos hay. } \\
\text { Repetir la actividad con otros arreglos para } \\
\text { cinco, cuatro, tres... } \\
\text { Actividad } 3 \\
\text { Mostrar imágenes de frutas como las de las } \\
\text { fotos de abajo por un tiempo breve ( } 2 \text {-3 se- } \\
\text { gundos), y ocultarlas. Preguntar a los niños en } \\
\text { LSC lo que se indica debajo de cada imagen. }\end{array}$ & $\begin{array}{l}\text { buenísima, conteo } \\
\text { hasta } 5 \\
\text { http://www.vedoque. } \\
\text { com/juegos/conjun- } \\
\text { tos.htm }\end{array}$ \\
\hline 9 & $\begin{array}{l}\text { ortamos una fruta, ¿cuántas frutas quedarían? } \\
\text { ortamos dos frutas, ¿cuántas frutas quedarían? } \\
\text { ibujamos otro mono ¿cuántos monos vemos? }\end{array}$ & \\
\hline
\end{tabular}



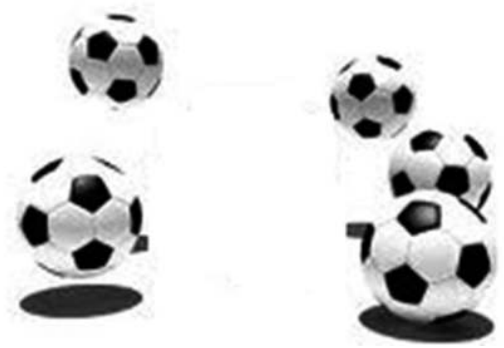

Si cortamos dos balones ¿Cuántos balones quedan?

\section{NIVEL: Subitizador Conceptual hasta 10. Edad 5}

\section{Descripción del nivel}

Expresan en LSC nombres para todos los arreglos de 6 a 10, usando grupos.

"En mi mente, yo hago 2 grupos de 3, y 1 mas, entonces 7. (LSC)"

Nominan tamaños de cantidades, hasta diez, en profunda relación con los objetos que ve y que puede evocar.

Establece relaciones entre los nombres de las cantidades en LSC y los numerales indo-arábigos

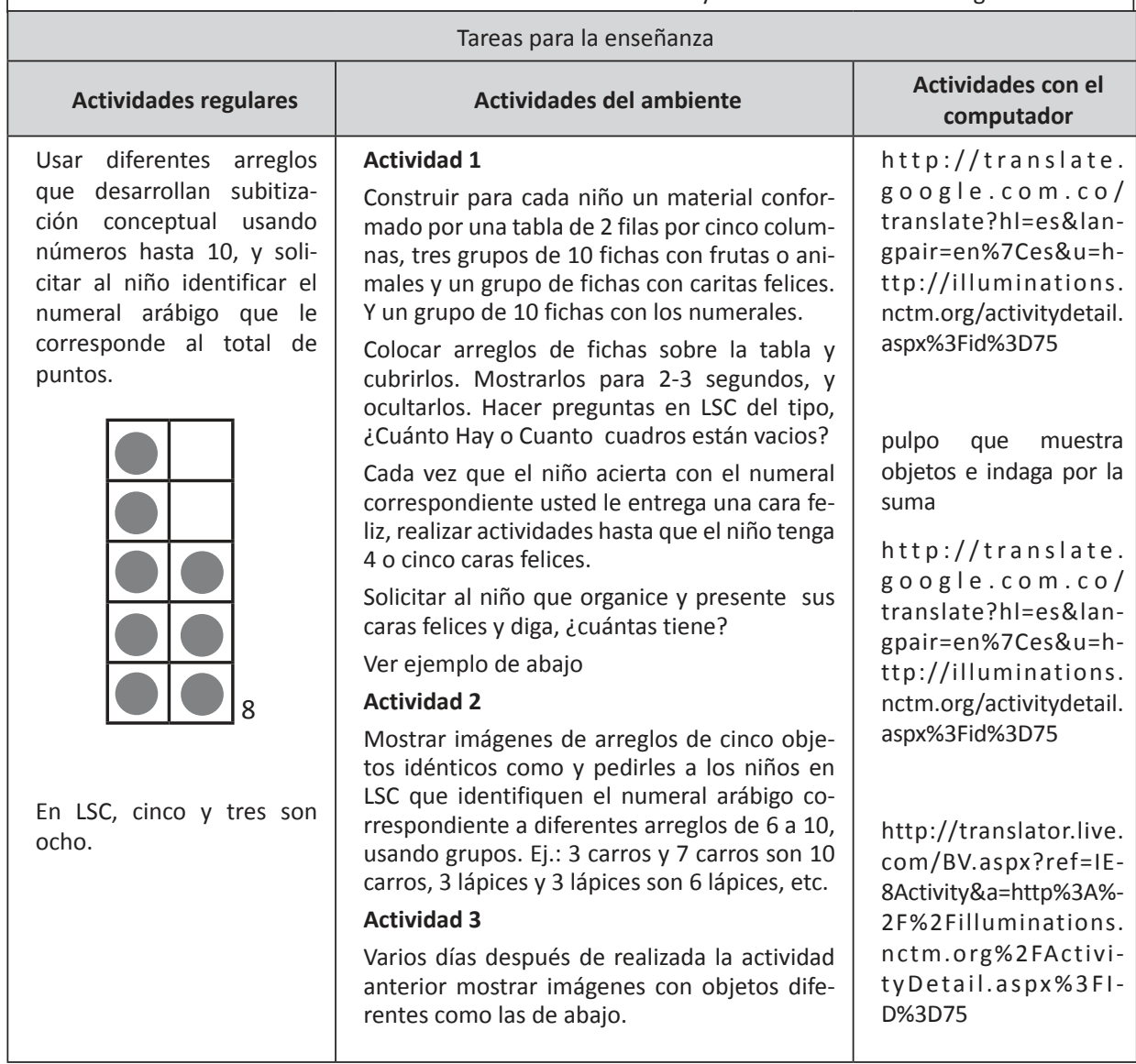




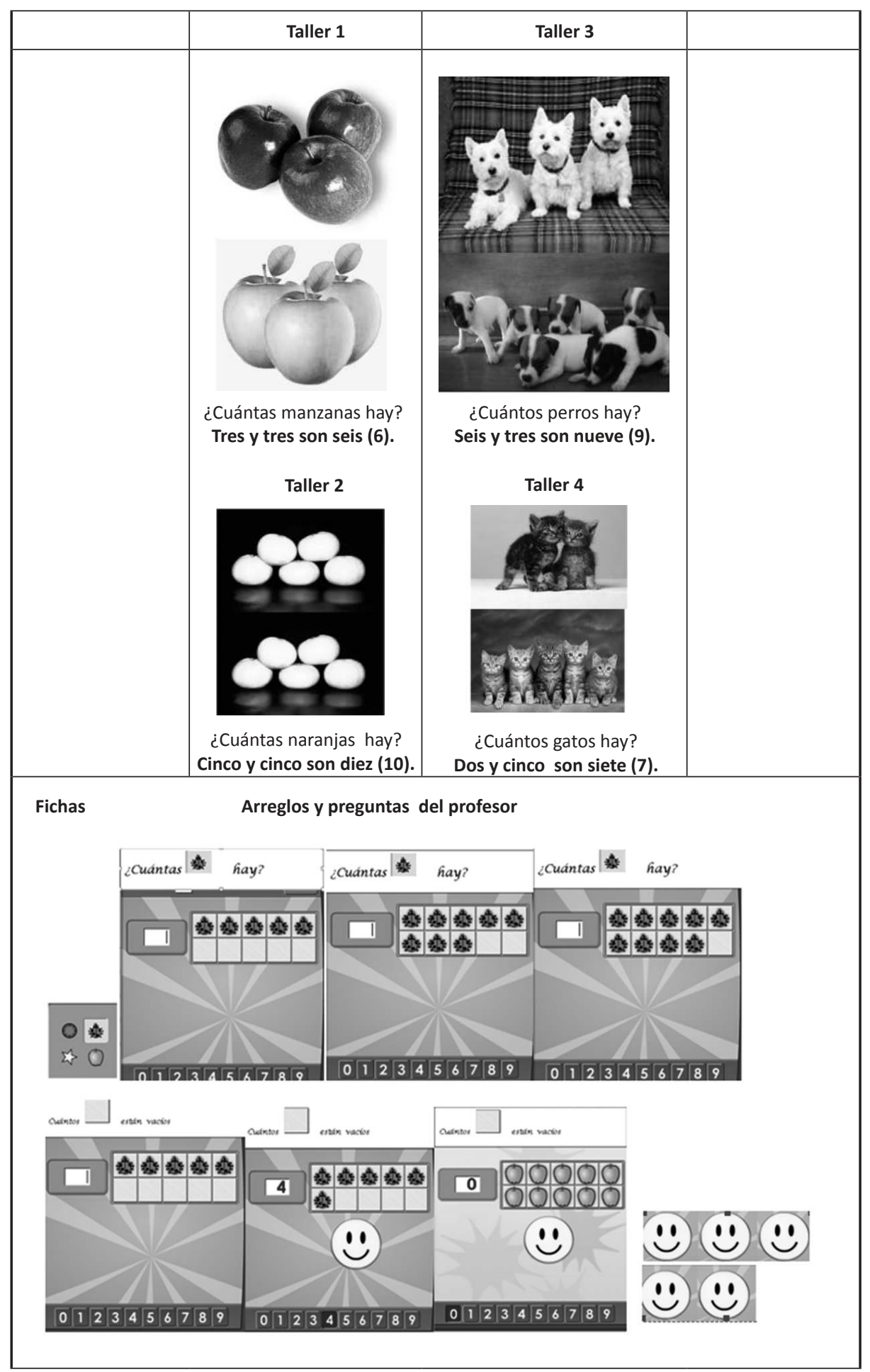




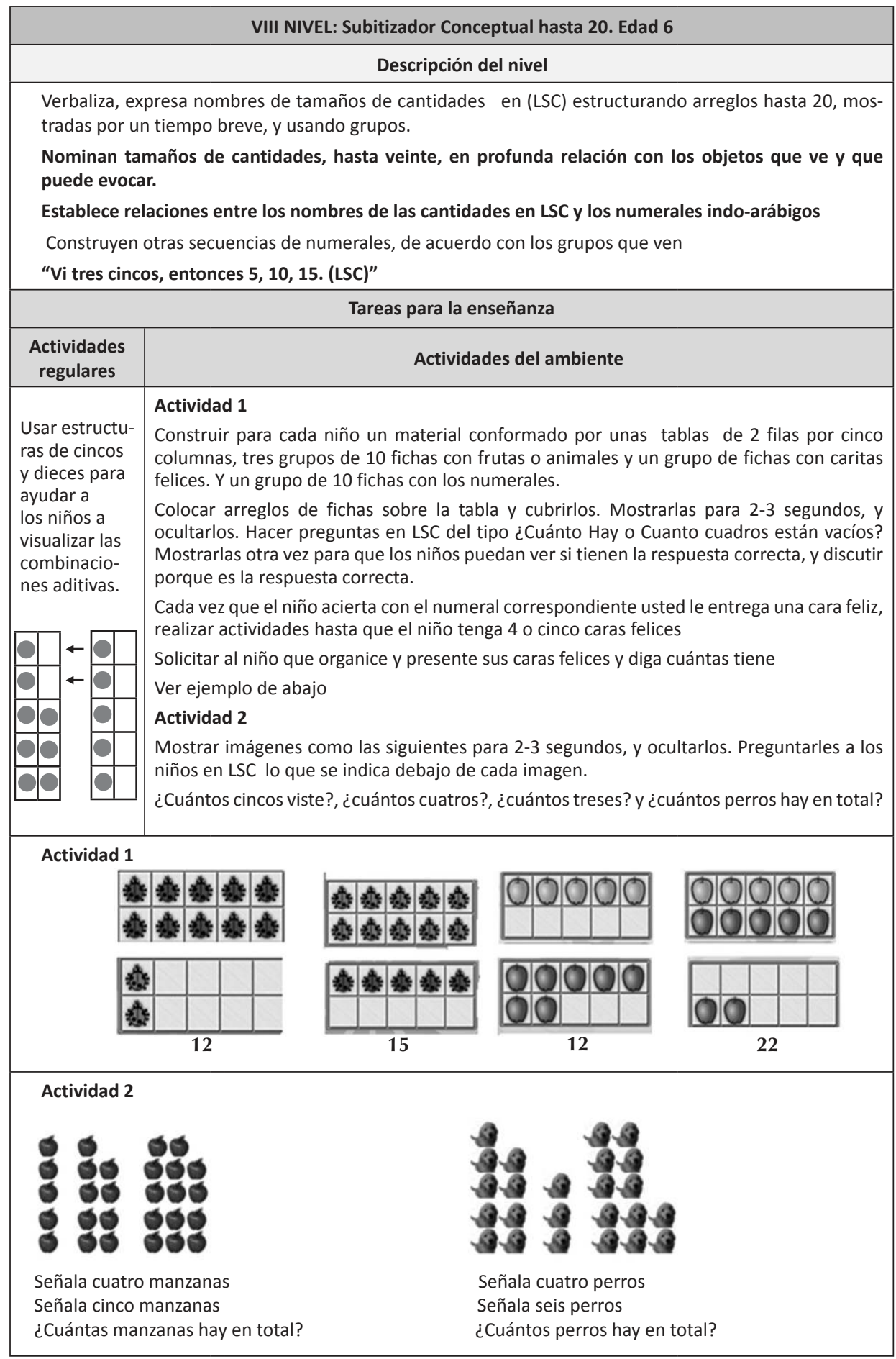


IX NIVEL: Subitizador Conceptual con Conteo de Saltos, y Valor Posicional. Edad 7

\section{Descripción del nivel}

Expresa en (LSC) nombres de arreglos estructurados mostrados por corto tiempo, usando grupos contando por saltos, y con valor posicional.

"Vi grupos de diez y dos, entonces 10, 20, 30, 40, 42, 44, 46...j46! (LSC)"

Nomina tamaños de cantidades, hasta cincuenta, en profunda relación con los objetos que ve y que puede evocar.

Establece relaciones entre los nombres de las cantidades en LSC y los numerales indo-arábigos

Construyen otras secuencias de numerales, de acuerdo a los grupos que ven

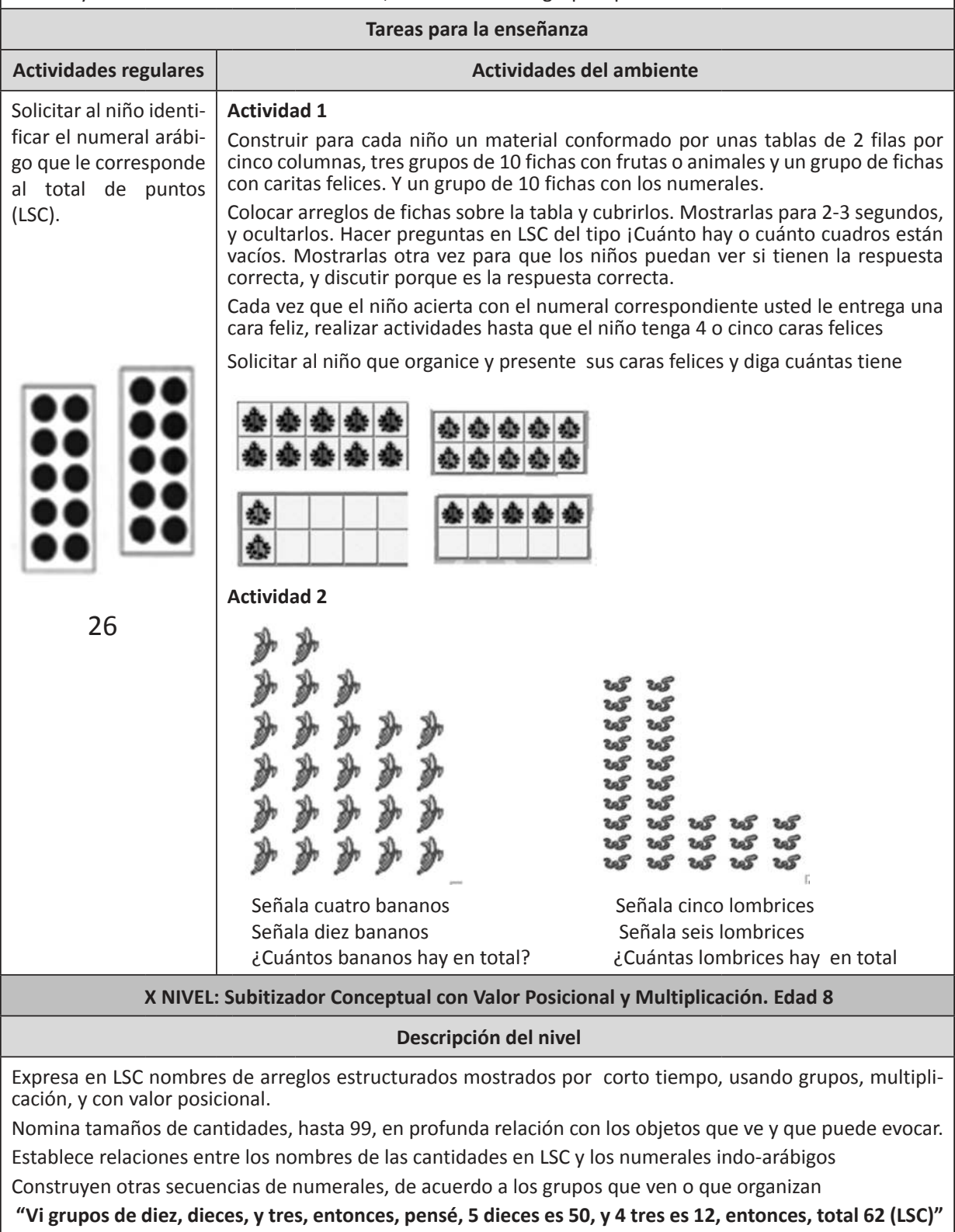




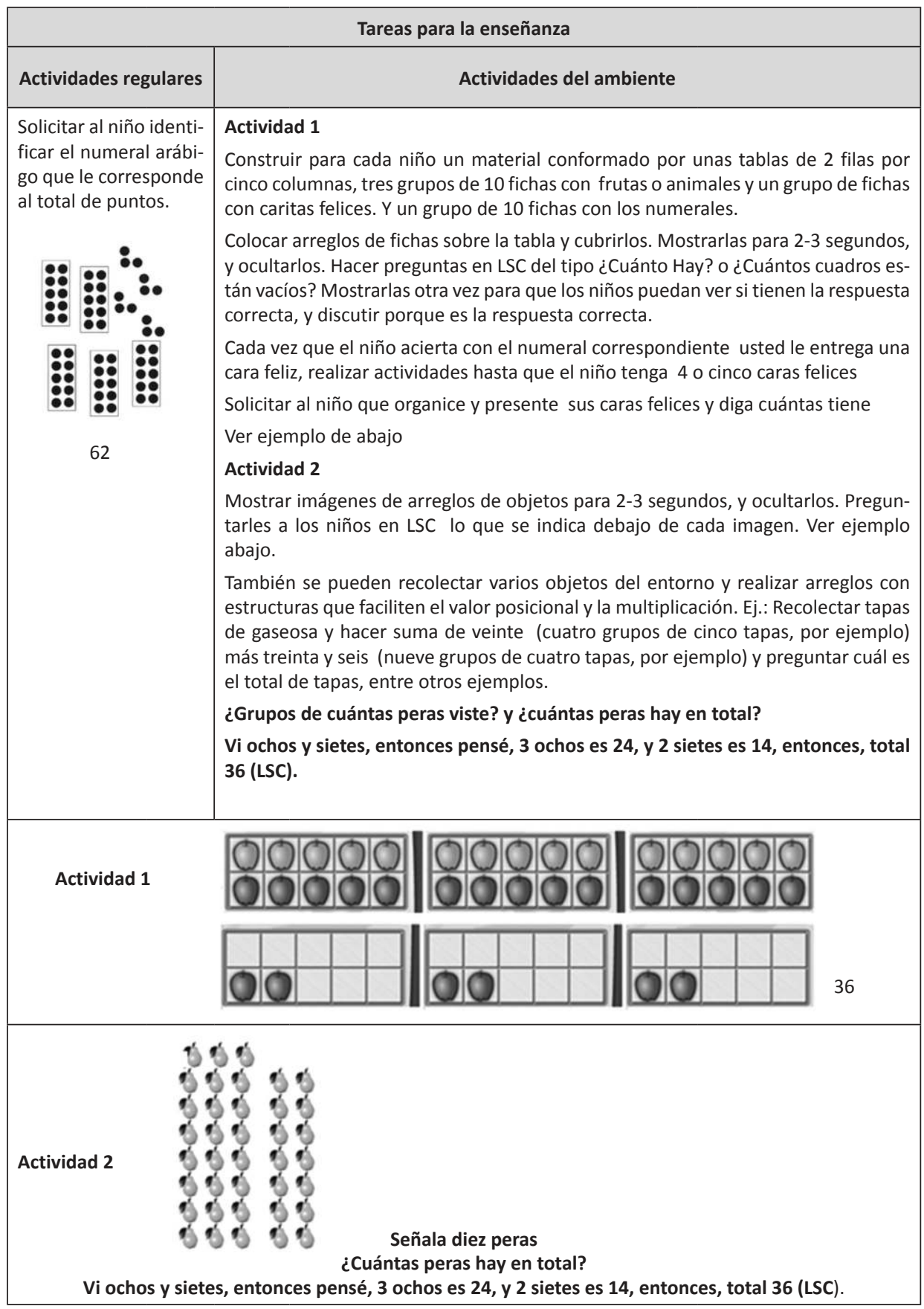

Tabla 22. Trayectoria Hipotética de aprendizaje de Subitización, adaptada de Clements, \& Sarama, 2009. Tabla 2.1 de CANTIDADES, NÚMERO, Y SUBITIZACIÓN, Capítulo 2, pp. 15-17 Tabla 8.1 de FORMAS, Capítulo 8, pp. 137-147. 


\subsubsection{Trayectoria Hipotética de aprendizaje de Conteo}

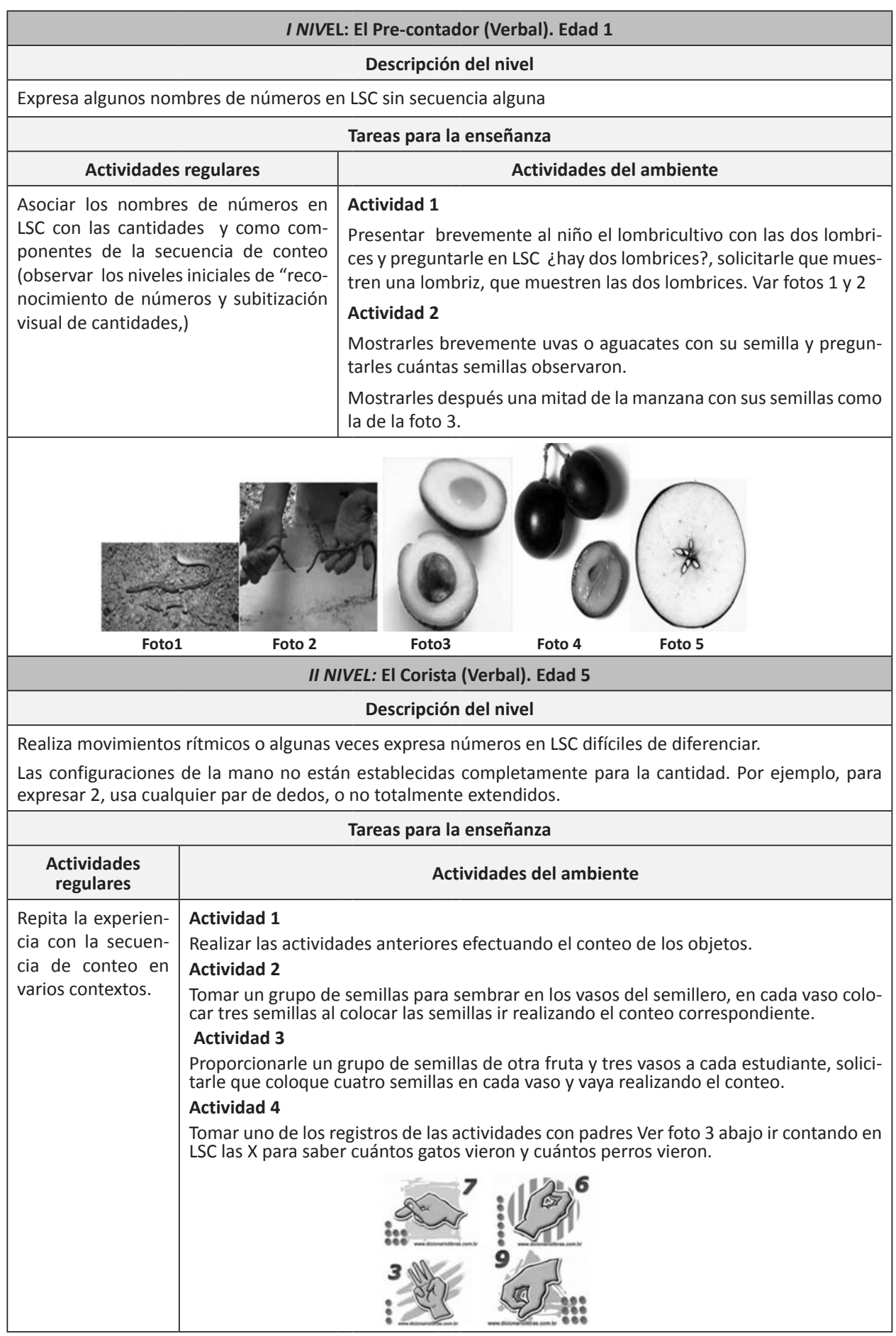




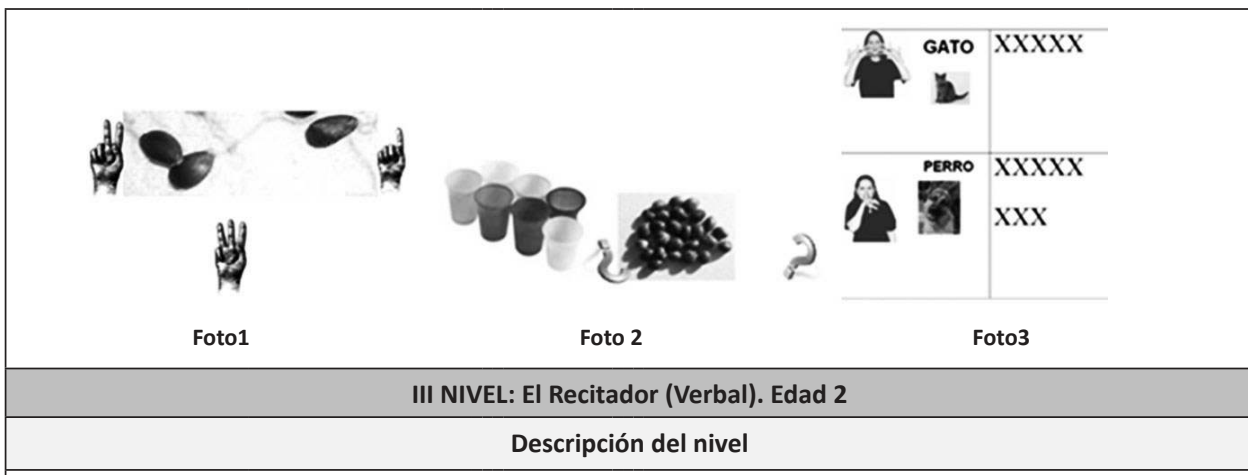

Cuenta verbalmente en LSC, con nombres de números en LSC separadas, no necesariamente en el orden correcto después de "cinco".

"uno, dos, tres, cuatro, cinco, siete. LSC"

Pone los objetos, acciones y palabras en correspondencia uno-a-muchos (edad $1 ; 8$ ) o de manera muy rígida uno-a-uno (edad 1) edad $(2 ; 6)$.

Cuenta dos objetos "dos, dos, dos. LSC" Si sabe más nombres de números en LSC que el número de objetos, los repite en voz alta rápidamente al finalizar. Si hay más objetos, "reutiliza" las palabras de número (agotamiento de lista inflexible).

\begin{tabular}{|c|c|}
\hline \multicolumn{2}{|c|}{ Tareas para la enseñanza } \\
\hline Actividades regulares & Actividades del ambiente \\
\hline $\begin{array}{l}\text { Genere experiencias repetidas y frecuentes con la se- } \\
\text { cuencia de conteo en varios contextos. } \\
\text { Observar el paso en el conteo de LSC del numeral cinco } \\
\text { al numeral seis. Es muy probable que use las dos manos } \\
\text { para expresar seis. Puede ayudarle con el numeral con- } \\
\text { vencional dejándole que extienda el dedo en la segun- } \\
\text { da mano, escondiéndole la mano de los cinco dedos } \\
\text { extendidos y bajándole simultáneamente el índice de } \\
\text { la segunda mano. Este ejercicio es conveniente hacerlo } \\
\text { varias veces pues la situación se puede presentar con } \\
\text { los numerales siete ocho, siempre al bajarle la mano } \\
\text { de cinco, bajar simultáneamente los dedos extendidos } \\
\text { de la otra mano. }\end{array}$ & $\begin{array}{l}\text { Actividad } 1 \\
\text { Se toma cada uno de los vasos del semillero y se pro- } \\
\text { cede a sembrar una cantidad determinada para cada } \\
\text { uno, de } 1 \text { hasta } 5 \text { semillas como máximo por vaso, los } \\
\text { estudiantes a medida que se va sembrando las semi- } \\
\text { llas, deben ir contando los vasos que quedan con la } \\
\text { cantidad de semillas listas. } \\
\text { Actividad } 2 \\
\text { Se toma el registro de actividades de los grupos agua } \\
\text { sol y flor. El profesor le dice si recuerdan el día que em- } \\
\text { pezaron con el semillero, luego les presenta el registro } \\
\text { de los grupos y pide a los niño contar: } \\
\text { ¿Cuántos días tenía la primara semana?, ¿cuántos } \\
\text { días fueron a estudiar ellos en la primera semana? } \\
\text { ¿Cuántos días el grupo flor cuidó el semillero? }\end{array}$ \\
\hline
\end{tabular}




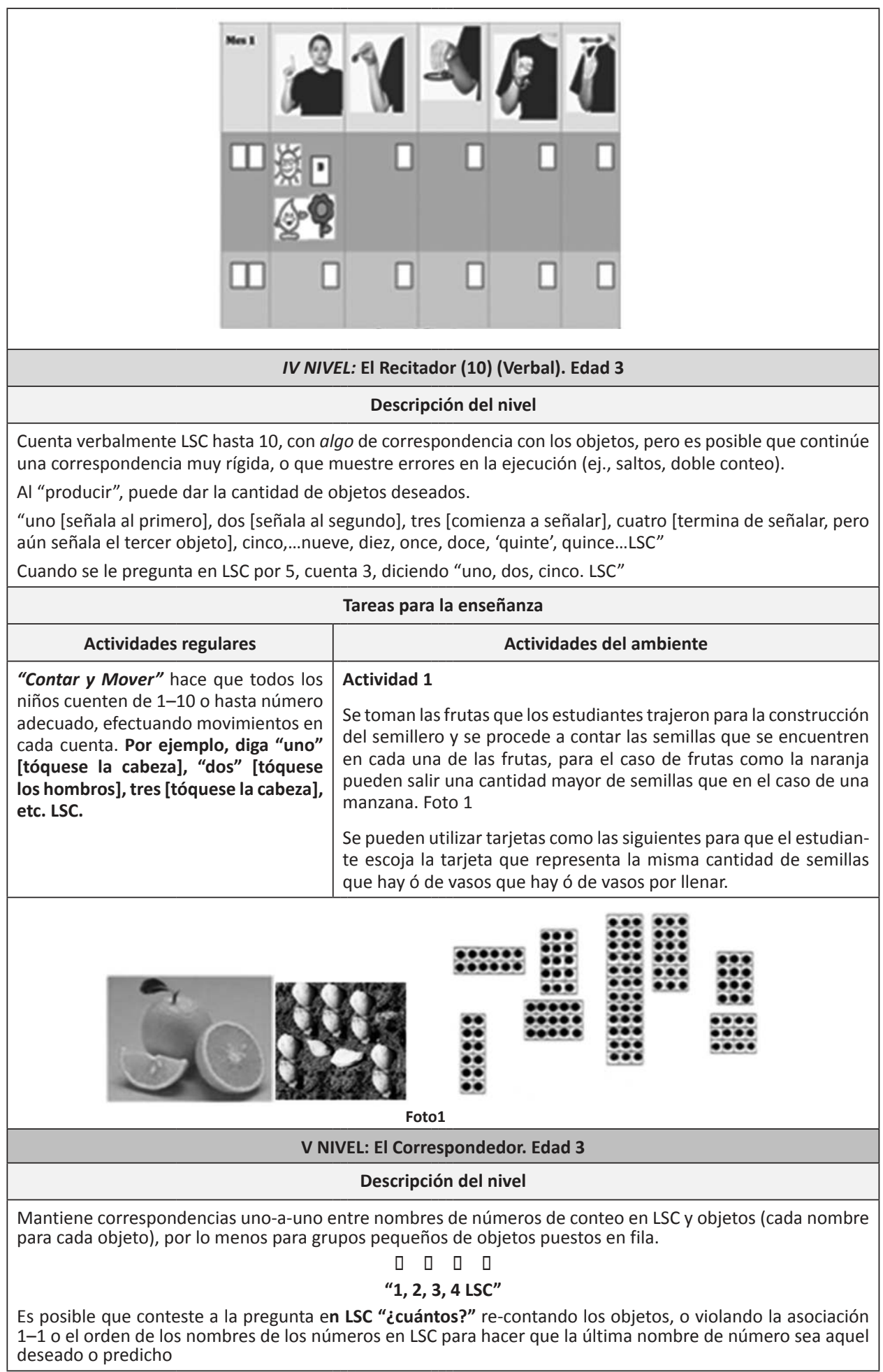


Tareas para la enseñanza

“Contar y Mover" también desarrolla esta competencia.

En "Contador en la Cocina" los estudiantes hacen clic en los objetos uno a uno a medida que el video presenta los números de 1 a 10 en LSC. Por ejemplo, hacen clic en las porciones de comida y se toma un mordisco a medida que se cuenta.

\section{NIVEL: El Contador (Números Pequeños). Edad 4}

\section{Descripción del nivel}

Cuenta objetos en fila hasta 5 con precisión y responde la pregunta en LSC "cuántos" con el último número contado. Cuando los objetos son visibles, y especialmente con números pequeños, comienza a entender el concepto de cardinal.

$$
\begin{array}{llll}
\hline \quad 0 & 0 & 0
\end{array}
$$

\section{“1, 2, 3, 4... icuatro! (LSC)"}

\begin{tabular}{|l|}
\hline \multicolumn{1}{|c|}{ Actividades regulares } \\
\hline “Cubos en la Caja" hace que el niño cuente un con- \\
junto de cubos pequeño. Póngalos en la caja y tápe- \\
los. Después pregúntele al niño cuántos cubos están \\
escondidos. Si el niño está listo, haga que escriba el \\
numeral. Saque los cubos de la caja y cuéntelos con \\
el niño para revisar.
\end{tabular}

En "Juego de Pizzas 2" estudiantes cuentan objetos hasta 5, poniendo ciertos ingredientes en una pizza hasta cumplir con el número objetivo.

En "Juego de Pizzas de Exploración Libre" los estudiantes exploran el conteo y los temas relacionados con números mediante la adición de ingredientes a una pizza. ¡Asígnele a los niños proyectos y retos! Haga que un niño le dé un modelo al otro y así sucesivamente.

“¿Qué Color Falta?” le asigna un color diferente a cada niño en grupos pequeños. Haga que cada niño escoja 5 crayones de ese color. Una vez que los niños han revisado los colores de los otros, haga que pongan todos los crayones dentro de un mismo recipiente. Entonces escoja un niño para ser el "ratón furtivo". Ante los ojos cerrados de todos, el ratón furtivo toma un crayón en secreto y lo esconde. Los otros niños deben contar los crayones para ver cuál color fue el que el ratón escondió.

En "Carrera de Conteo" los estudiantes identifican cantidades de números (desde 1 hasta 5) en un dado (juego de mesa físico) o en un marco de puntos (versión de computador) y avanzan un número correspondiente de espacios en un juego de mesa.

En "Juego Pon Tus Naves" los estudiantes identifican números de las caras $(3,4,05)$ de un dado y avanzan un correspondiente número de espacios en el juego.

\section{Actividades del ambiente}

Se presenta a los estudiantes en una hoja dos columnas $A$ y $B$, en las cuales se encuentran diferentes cantidades de puntos en cada uno de los recuadros de la columna $A$, como se muestra en la imagen. El profesor da la instrucción que en la columna B dibuje la misma cantidad de puntos que se encuentran en la columna.

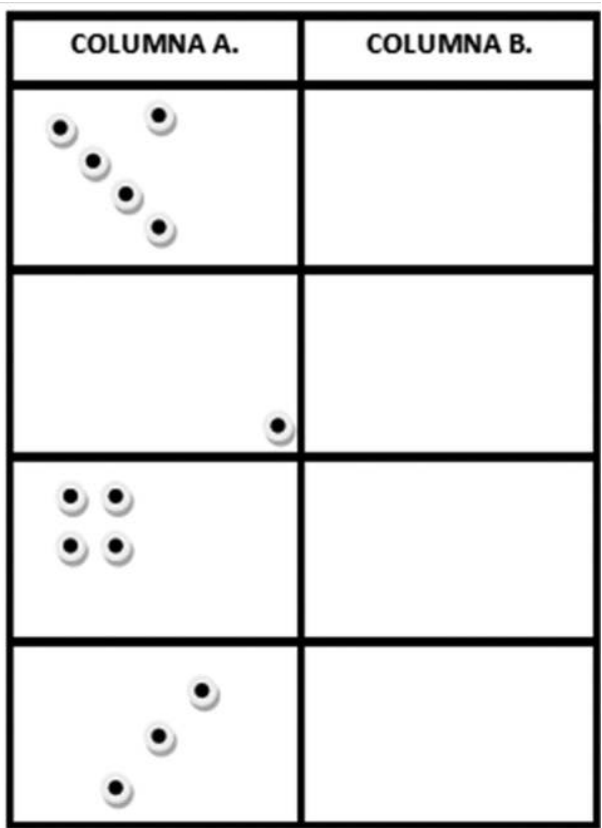


VII NIVEL: El Contador (10). Edad 4

\section{Descripción del nivel}

Cuenta arreglos de objetos hasta 10 en LSC. Es posible escribir numerales para representar $1-10$.

Cuenta de manera precisa una fila de 9 bloques y expresa en LSC que hay nueve.

Puede estar en capacidad expresar en LSC que el número justo antes o justo después de otro número, pero solamente cuanto comienza a contar desde 1.

¿Qué sigue después de 4? “1, 2, 3, 4, 5. i5! (LSC)”

El conteo verbal en LSC hasta 20 está desarrollándose.

Tareas para la enseñanza

\begin{tabular}{|c|l|}
\hline Actividades regulares & \multicolumn{1}{|c|}{ Actividades del ambiente } \\
\hline \hline "Torres de Conteo [hasta 10]" Jugar a construir torres & Actividad 1
\end{tabular}

con el Tricubo. Pregunte qué formas funcionan bien en qué partes de una torre (ej: ¿puede ser la punta del bloque triangular una buena base (LSC)?). Organice estaciones con diferentes objetos para apilar. Anime a los niños a apilar tantos objetos como puedan, cuente los objetos para saber cuántos pudieron ser exitosamente apilados.

Pregúnteles en LSC a los niños si alguna vez han contado cuántos bloques pueden apilar en una torre. Haga que los niños trabajen en una estación y construyan torres tan altas como puedan. Pídales en LSC que estimen el número de bloques por torre. Cuente los bloques con los niños antes de derribarlas. Procure que haya un número considerable de bloques en la torre. Después de esto, los niños cambian de estación.

"Tarro para Contar" contiene un número específico de objetos para que los niños cuenten en LSC sin tocar dichos objetos. Use el mismo tarro todo el año cambiando el reducido número de objetos semanalmente. Haga que los niños vacíen el tarro para contar los objetos.

"Construir Escaleras 1" los estudiantes adicionan escalones a una base en forma de escalera para alcanzar cierta altura.

"Tienda de Dinosaurios 1" los estudiantes identifican el numeral que representa un número dado de dinosaurios dentro de un marco de números.

En "Exploración Libre" los estudiantes exploran el conteo y otros temas relacionados con números poniendo en una tabla elementos alusivos a lombricultivo, a la huerta, a una fiesta, a los juegos. ¡Asígnele a los niños proyectos y retos! Haga que un niño de un "modelo" para que otros lo sigan y así sucesivamente.

"Memoria Numérica 1" mediante el conteo de cartas los estudiantes forman parejas de cartas de números (cada carta tiene un numeral y su respectivo conjunto de puntos) en el marco de un juego de cartas de "Concentración".
Retomar los talleres de la fase tres del proyecto lombricultivoi

\section{CONSTRUIMOS EL SEMILLERO!}

Para el momento de llevar a cabo esta actividad, el profesor habrá dispuesto en el salón de clase cuatro cartulinas de colores marcadas con la palabra-gesto referida a los siguientes materiales: una para los vasos, otra para la tierra, otra para las piedras y otra para las semillas. Luego pedirá a los estudiantes que depositen los materiales traídos en las cartulinas correspondientes. Así, en cada una de las cartulinas quedarán grupos con el mismo elemento. Cada estudiante debe registrar, en la cartulina correspondiente, el material que entrega, empleando algún símbolo.
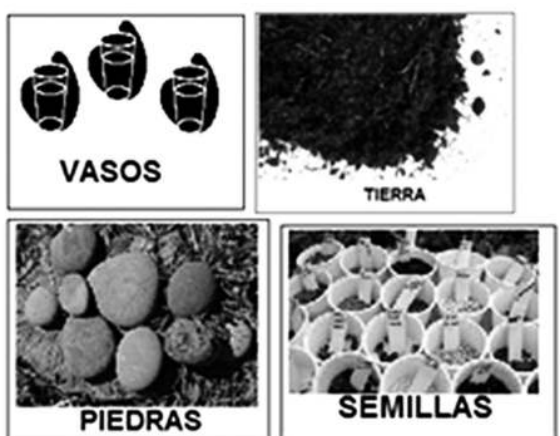

A continuación el profesor preguntará a los estudiantes: ¿Cuántos elementos hay en cada cartulina? $Y$ colocan el correspondiente numeral arábigo, ¿En cuál cartulina hay menos elementos?, ¿Cuál fue la cartulina donde más niños depositaron elementos?, ¿Cuál fue la cartulina donde menos niños depositaron elementos? Es importante destacar las señas de más, menos y su relación con el objeto al que se refiere la expresión. 
"Correr sobre la Fila de Números" les ofrece a los niños un número de filas de diferentes colores. El jugador 1 arroja un dado y le pide en LSC al banco el número de fichas en cuestión. El banco le da las fichas correspondientes al jugador 1 , quien debe colocarlas en orden a lo largo de su línea de número a medida que las cuenta. Entonces el jugador 1 mueve su figura de juego sobre la fichas, contando de nuevo en voz alta, hasta que la figura se encuentre sobre la última ficha. Eventualmente, pregúnteles en LSC a los niños quién está más cerca de la meta, y cómo lo saben.

En "Antes y Después", los estudiantes identifican y seleccionan números que están o justo antes o justo después del número en cuestión.
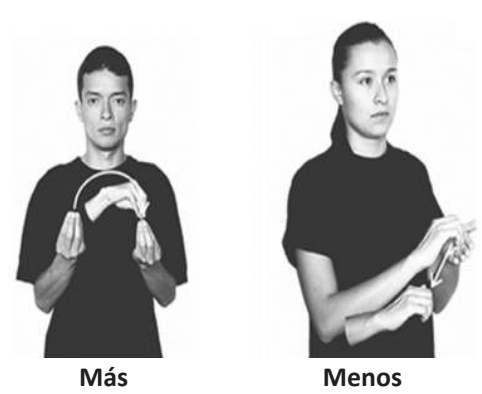

Menos

VVIII NIVEL: El Productor (Números pequeños). Edad 4

\section{Descripción del nivel}

Cuenta objetos en LSC uno a uno hasta 5. Reconoce que el conteo es relevante en situaciones en las cuales cierto número debe ser reconocido.

Produce un grupo de 4 objetos.

Tareas para la enseñanza

\section{Actividades regulares \\ Actividades del ambiente}

“Conteo de Movimientos" Mientras se está esperando en momentos de transición, haga que los niños cuenten cuántas veces usted salta o aplaude, o hace cualquier otro movimiento. Después, haga que los niños repitan los mismos movimientos el mismo número de veces. Inicialmente, cuente en LSC los movimientos con los niños. Después, haga los movimientos pero esta vez explicando en LSC y dando un modelo de cómo se puede contar mentalmente. Los niños que entiendan el número de movimientos se detendrán, mientras que los otros seguirán haciendo los movimientos.

En "Juego de Pizzas 3" los estudiantes le ponen ingredientes a una pizza (hasta 5) para igualar los numerales en cuestión.

En "Juego de Pizza/Galleta 1" los niños juegan en parejas. El jugador 1 lanza un cubo de números, y coloca la cantidad indicada de ingredientes (fichas) sobre su plato. EI jugador Uno le pregunta al jugador Dos, "¿estoy en lo correcto (LSC)?" el jugador Dos debe estar de acuerdo en que el jugador Uno respondió correctamente en LSC. En este punto del juego, el jugador Uno pone las fichas en los espacios circulares para ingredientes de su pizza. Los jugadores se turnan hasta que todos los espacios en sus pizzas tienen ingredientes. Antes de realizar esta actividad, se recomienda un actividad previa, que puede ser con ayuda de páginas web de pizzerías de la ciudad para conocer tipos de ingredientes y pizzas, vocabulario de los ingredientes y de los tipos de pizzas en LSC.

Si los niños no tienen mucha experiencia con el consumo de una pizza, puede ser conveniente realizar una celebración que incluya como comida pizzas.

En "Tren de los Numerales" los estudiantes identifican numerales (1-5) en un cubo numeral (juego de mesa físico) o en la pantalla de un computador (consultar las páginas web que ofrece este tipo de juegos) y avanzan un número correspondiente de espacios en un tablero de juego.

En "Tiempo para Fiesta 3" los estudiantes ponen objetos en una bandeja (hasta 10) para hallar ciertos numerales.
Juego: "Pon tus naves"

Materiales: Induxor, 1 dado.

Número de participantes: De 2 a 4.

Descripción de la actividad: Cada participante tiene un color de fichas, y cada ficha representa una nave, por lo cual cada participante tiene nueve naves en total, el objetivo del juego es quedar con la menor cantidad posible de fichas (o naves).

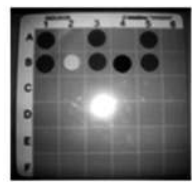

Por turnos, los participantes deberán lanzar el dado para ubicar la primera ficha en el tablero del Induxor, teniendo como orden cada espacio y siguiendo la regularidad de empezar de izquierda a derecha (como si estuviéramos leyendo un libro), si el espacio ya está ocupado por otra nave no se toma en cuenta dicho espacio, es decir, solo contamos los espacios que haya en blanco del tablero.

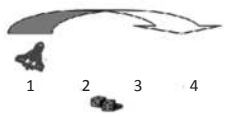

Cada participante cuenta el lanzamiento del dado de acuerdo a la última nave que aterrizó en el tablero de su tropa, es decir, del mismo color y sólo se dispone de una ronda para poder aterrizar la mayor cantidad de naves.

Aunque la estrategia del juego es obtener el menor valor en cada lanzamiento con el dado, el maestro ó quien esté dirigiendo la actividad, puede realizar preguntas como: ¿Cuántas naves te faltan para ganar? ¿Cuántos espacios en blanco necesitas para aterrizar todas tus naves?, permitiendo que los participantes realicen relaciones entre los espacios en blanco, los turnos que faltan por el lanzamiento del dado o la cantidad de naves para aterrizar. 
IX NIVEL Contador y Productor (10+) . Edad 4

\section{Descripción del nivel}

Cuenta en LSC y produce por conteo grupo de objetos de forma precisa hasta 10, después cantidades más altas (hasta 30). Tiene una comprensión explícita de lo cardinal (cómo los números determinan cantidad). Hace seguimiento a los objetos que han y no han sido contados, incluso en diferentes arreglos. Escribe y dibuja las representaciones 1 a 10 (posteriormente, 20, finalmente 30).

Cuenta en LSC un grupo disperso de 19 trozos manteniendo el conteo con el movimiento de separación de cada trozo contado.

Produce el siguiente número (usualmente hasta la decena 20 - 30 o hasta la siguiente decena). Separa las decenas y las unidades de una palabra número, y comienza a relacionar cada parte de una palabra número/ numeral con la cantidad a la cual éste se refiere.

Reconoce los errores en los conteos de los otros y es capaz de eliminar la mayoría de los errores en su propio conteo (señalar - objeto) si se le pide en LSC que haga un esfuerzo mayor.

\begin{tabular}{l}
\hline \multicolumn{1}{|c|}{ Tareas para } \\
\hline \multicolumn{1}{|c|}{ Actividades regulares } \\
\hline "Torres de Conteo [más de 10]" (lea las instrucciones \\
básicas ya mencionadas) Con el objetivo de permi- \\
tirle a los niños contar hasta 20 o más, haga que \\
construyan torres con otros objetos (monedas por \\
ejemplo). Los niños construyen una torre tan alta \\
como puedan, poniendo más monedas, sin acomo- \\
dar las monedas que ya estén en la torre. El objetivo \\
es estimar y después contar en LSC para saber cuán- \\
tas monedas hay en la torre más alta. Para contar \\
en LSC más alto, los niños deben elaborar muros de \\
bloques siguiendo un patrón. Ellos deben construir \\
un muro bloque como patrón tan largo como sea \\
posible. Esto les permite contar en LSC números \\
más grandes.
\end{tabular}

\section{Alternativos:}

1. En parejas, pueden jugar a formar torres con monedas

2. Colocar monedas en la torre según el número que indique el dado.

"Salta Numérico con Numerales" Se muestra una tarjeta con un numeral, y niños deben que expresar el numeral en LSC, y tienen que realizar el numero de movimientos que indiquen el numeral. Repite con numerales diferentes. Asegúrese de usar el cero.

\section{Actividades del ambiente}

\section{Actividad 1}

Retomar el registro de un mes de los grupos del semillero y contar los días donde se registraron cambios para cada tipo de semillas, contar los días en que no hubo cambios, pedirles buscar el númeral que corrresponde a la cantidad de días en que las semillas cambiaron y el númeral de la cantidad de días sin cambios en cada semilla. Discutir con ellos porqué son diferentes las cantidades: preguntarles cuántos días han observado las semillas.

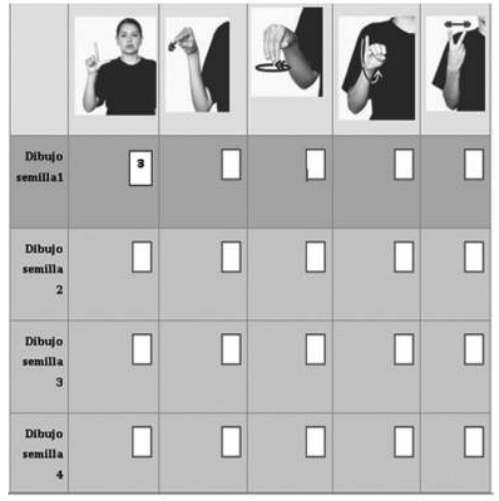

X NIVEL: Contador regresivo desde 10 (Verbal y Objeto). Edad 4

\section{Descripción del nivel}

Cuenta un LSC regresivamente desde 10 hasta 1 verbalmente, o al removiendo objetos de un grupo.

“10, 9, 8, 7, 6, 5, 4, 3, 2, 1! LSC"

\begin{tabular}{|c|c|}
\hline \multicolumn{2}{|c|}{ Tareas para la enseñanza } \\
\hline Actividades regulares & Actividades del ambiente \\
\hline $\begin{array}{l}\text { “Contar y Mover - Progresivo y Regresivo" Los } \\
\text { niños cuentan LSC de uno a diez haciendo movi- } \\
\text { mientos en cada conteo. Después, ellos cuentan } \\
\text { en LSC a diez a cero. }\end{array}$ & Realizar uno de los juegos tipo tren del triominó \\
\hline
\end{tabular}


XI NIVEL: Contador desde N (N+1, N-1) (Verbal y Objeto). Edad 6

\section{Descripción del nivel}

Cuenta verbalmente en LSC y con objetos desde números diferentes a 1 (pero no puede mantener el número de conteos).

Si se le pide que "cuente de 5 a 8," cuenta " $5,6,7,8$ !" LSC

Determina los números justo antes o justo después inmediatamente.

Si se le pregunta en LSC, “¿Qué va justo antes de 7?” contesta, “iSeis!”

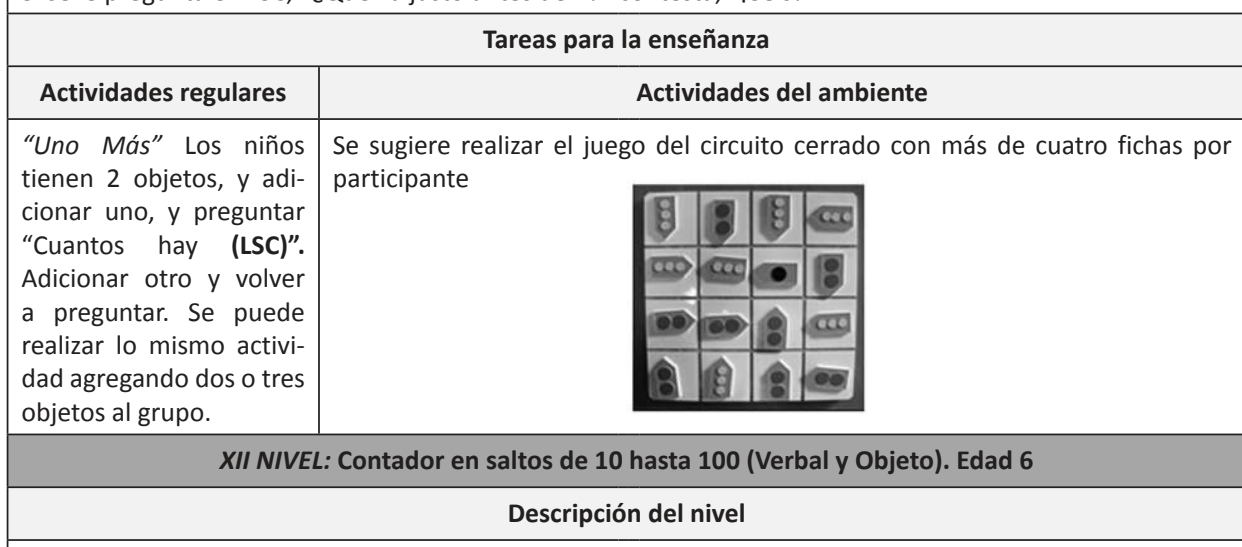

Cuenta en LSC de decena en decena con comprensión hasta 100 o más; ej. "puede ver" los grupos de diez dentro de una cantidad y contar dichos grupos de diez en diez (esto se relaciona con la multiplicación y el pensamiento algebraico; ver capítulos 7 y 13 )

“10, 20, 30... 100." LSC

Tareas para la enseñanza

\begin{tabular}{|c|c|c|c|c|c|}
\hline Actividades regulares & \multicolumn{5}{|c|}{ Actividades regu } \\
\hline $\begin{array}{l}\text { "¿Cuánto Hay Ahora } \\
\text { en la Caja?" Acerca los } \\
\text { niños cuentan los objetos } \\
\text { que hay en una caja. Pre- }\end{array}$ & \multicolumn{5}{|c|}{$\begin{array}{l}\text { Se puede proponer el trabajo con tarjetas de } \\
\text { estudiantes que cuenten en cada tarjeta, ter } \\
\text { conteo que utiliza, se puede comenzar la acti } \\
\text { muestra a continuación: }\end{array}$} \\
\hline $\begin{array}{l}\text { guntarles: ¿cuántos hay } \\
\text { en LSC en la caja ahora? }\end{array}$ & & 0 & 0 & 0 & 0 \\
\hline Adicionar uno y repetir & & 0 & 0 & 0 & 0 \\
\hline la pregunta. Revisar si los & & 0 & 0 & 0 & 0 \\
\hline $\begin{array}{l}\text { niños responden en LSC } \\
\text { contando todos los obje- }\end{array}$ & & 0 & 0 & 0 & \\
\hline tos. Cuando los niños son & & & & & \\
\hline
\end{tabular}

listos, pueden agregar dos objetos.

"Construir Escaleras

3" Construir escaleras de cubos omitiendo un escalón. El niño debe identificar el numeral que corresponde a la cantidad de cubos del escalón.

En el siguiente momento se pueden plantear tarjetas como la siguiente:

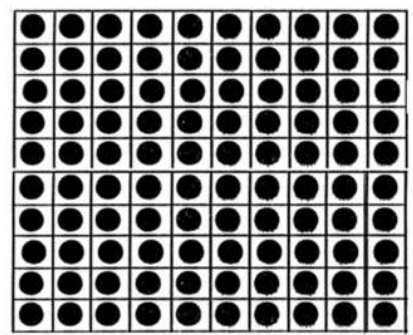


XIII NIVEL: Contador hasta 100 (Verbal). Edad 6

Descripción del nivel

Cuenta en LSC hasta 100.

Hace transiciones entre decenas (ej., de 29 a 30) comenzando en cualquier número.

“...78, 79... $80,81 . . . "$

Tareas para la enseñanza

"Contando Todos los Días de Colegio" Durante todo del año.

XIV NIVEL: Contador Progresivo Usando Patrones (Estrategia). Edad 6

Descripción del nivel

Mantiene un registro de algunas acciones de conteo, únicamente cuando utiliza patrones numéricos (espacial, auditivo, o rítmico).

“¿Cuánto es 3 mas cinco?” El niño siente tres “pulsos” a medida que cuenta, “5... 6, 7, 8!” (LSC)

Tareas para la enseñanza

"Cuánto Hay Ahora en la Caja” Mira los instrucciones arriba.

"Buen Idea" Entregar a los estudiantes un numeral y una estructura de puntos. Ellos cuentan los puntos usando LSC a partir del número representado en el numeral. Se puede usar en juego de mesa que requieran desplazamientos en un tablero.

\begin{tabular}{|c|}
\hline \multicolumn{1}{|c|}{ XV NIVEL: Contador en Saltos (Verbal y Objeto). Edad 6} \\
\hline Descripción del nivel \\
\hline Cuenta en LSC con manejo de saltos de cinco y de dos. \\
El niño cuenta objetos, “2, 4, 6, 8... 30.” (LSC) \\
\hline Tareas para la enseñanza \\
\hline
\end{tabular}

"Cuento en Saltos" Usa el conteo de saltos en LSC para contar objetos, talles como pares de zapatos para saltos de dos, o de números de dedos en la clase para salta de cinco.

\begin{tabular}{c}
\hline XVI NIVEL Contador de objetos imaginarios. Edad 6 \\
\hline Descripción del nivel \\
\hline
\end{tabular}

Estrategia cuenta en LSC imágenes mentales de objetos ocultos.

Si se le pregunta, "hay 5 trozos acá y 5 bajo la servilleta, ¿cuántos hay en total?” responde ciiiinco... después señala la servilleta en cuatro lugares distintos, [esquinas de un cuadrado imaginario] diciendo "6, 7, 8, 9." (LSC)

\section{Tareas para la enseñanza}

“¿Cuántos Objetos Escondidos?” Esconder algunos objetos, y decirles en LSC a los niños, ¿cuántos objetos están escondidos?, y mostrar otros objetos. Preguntar: ¿cuánto hay en total?

\section{NIVEL: Contador Progresivo Manteniendo el Numero de Conteos (Estrategia): Edad 6}

\section{Descripción del nivel}

Mantiene un el número de conteos, primero con los objetos, después mediante el "conteo de conteos." Cuenta en LSC de 1 a 4 a partir de un número dado.

¿Cuánto es 3 más 6? "Seis... 7 [levanta un dedo], 8 [levanta otro dedo], 9 [levanta un tercer dedo], 9."

¿Cuánto es 8 si le quitamos 2? “Ocho... 7 es uno, y 6 es dos. 6." 


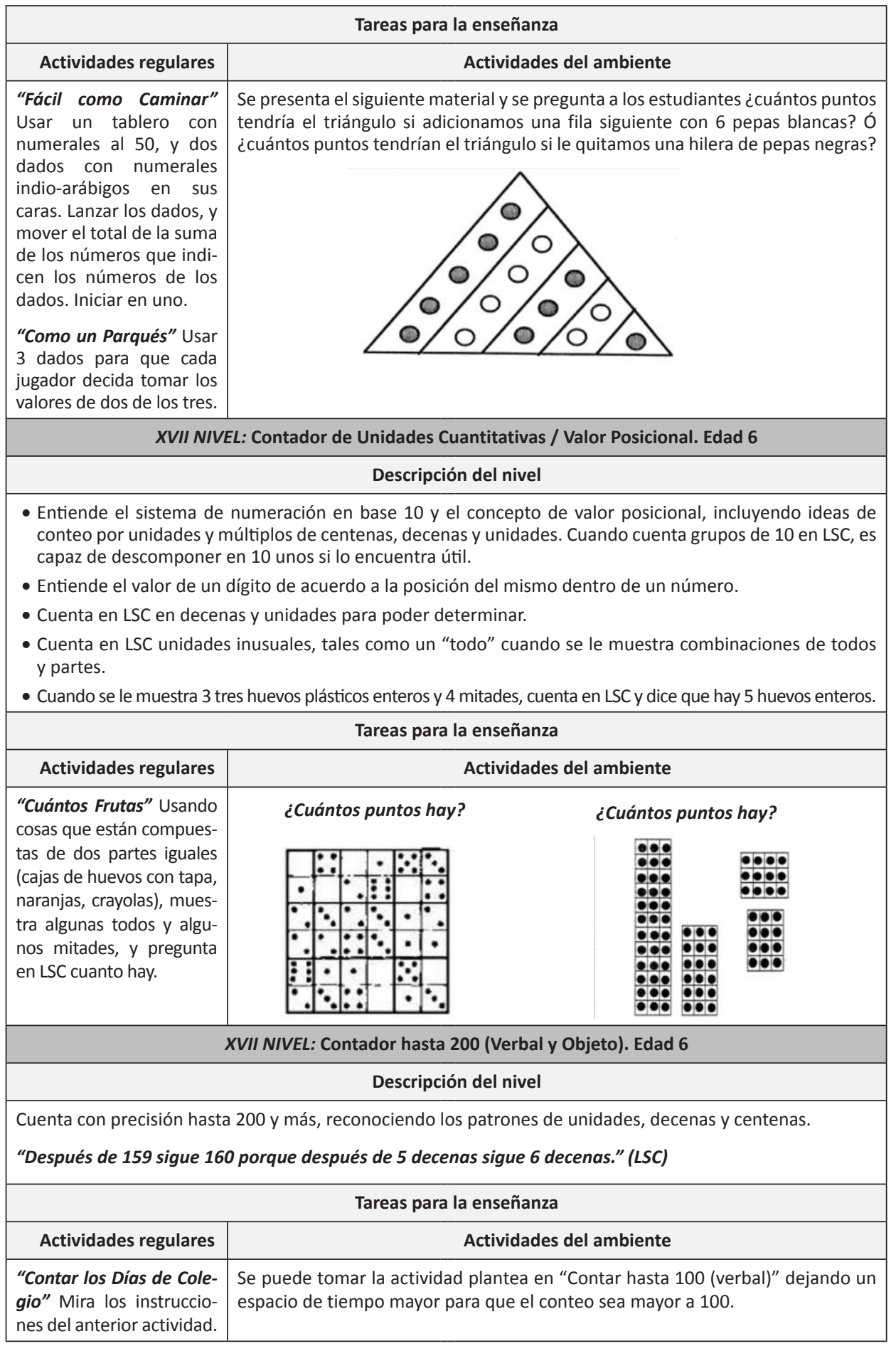




\section{NIVEL: Conservador de Número. Edad 7}

\section{Descripción del nivel}

Conserva el número de forma consistente (ej., cree que el número no ha sido cambiado) incluso al enfrentar distracciones de tipo perceptivo tales como la dispersión de los objetos de una colección.

Cuenta en LSC 2 filas que están dispuestas una en frente de la otra y verbiliza en LSC que son iguales. El adulto dispersa los objetos de una fila. Responde en LSC "Las dos aún tienen el mismo número de objetos, simplemente una es más larga que la otra."

\section{Tareas para la enseñanza}

\begin{tabular}{|c|c|}
\hline Actividades regulares & Actividades del ambiente \\
\hline $\begin{array}{l}\text { "La Lombriz Astuta" } \\
\text { Contar una historia usan- } \\
\text { do una lombriz y otros } \\
\text { animales de juguete. La }\end{array}$ & $\begin{array}{l}\text { Para el desarrollo inicial se propone realizar una serie de tarjetas como las mos- } \\
\text { tradas en la imagen } 1 \text {. Estas tarjetas estarán distribuidas en una superficie de tal } \\
\text { manera que los estudiantes estén alrededor de éstas. El profesor se encargará } \\
\text { de proponer ciertas situaciones para cada uno de los estudiantes, tales como: }\end{array}$ \\
\hline lombriz es astuta, y dice & Toma la más grande. ¿Por qué es la más grande? \\
\hline $\begin{array}{l}\text { a los otros anımales que } \\
\text { ellos deben tomar la }\end{array}$ & Toma la más pequeña. ¿Por qué es la más pequeña? \\
\hline fila que tenga más por- & ¿Cuál tiene más puntos? \\
\hline ciones de comida, pero & ¿Cuál tiene menos puntos? \\
\hline
\end{tabular}
ella hace dos filas: una con menos porciones de comida pero con más distancia entre porciones de comida, y la otra con más porciones de comida pero con menos distancia entre de porciones. Preguntar a los niños en LSC como evadir las astucias.

5. El profesor tomando una de las tarjetas puede proponer encontrar otra que tenga los mismos puntos, en el momento que alguno de los estudiantes muestre una tarjeta, que él considere es igual a la que el profesor está mostrando, se procede a preguntar, señalando otra tarjeta, ¿̇por qué esta no es igual?

6 . Se les propone a los estudiantes que organicen las tarjetas de menor a mayor, desarrollando en ellos la transitividad.

\section{NIVEL: Contador Progresivo y Regresivo (Estrategia). Edad 7}

\section{Descripción del nivel}

Cuenta en LSC "palabras de conteo" (secuencias unitarias o conteos con saltos) en cualquier dirección. Reconoce que las secuencias de decenas son un reflejo de las secuencias de unidades.

¿Cuánto es 4 menos que 63? “62 es 1, 61 es 2, 60 es 3, 59 es 4, entonces 59."

¿Cuánto es 15 más 28? “2 decenas y una decena es 3 decenas. 38, 39, 40, y tres más, 43.” (LSC)

Pasa con facilidad de la visión de secuencia a la visión de composición de los números de múltiples dígitos. Cuenta en LSC descendentemente desde 20 o más con significado. 


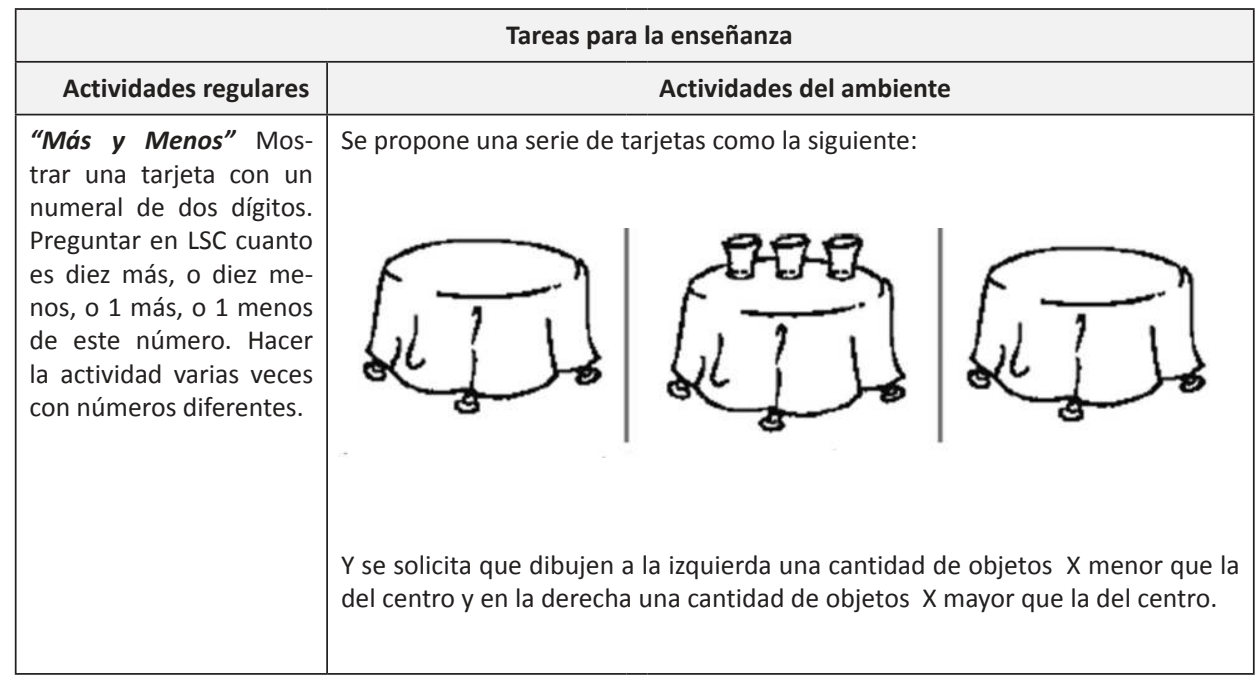

Tabla 23. Trayectoria Hipotética de aprendizaje de Conteo, adaptada de Clements, \& Sarama, 2009. Tabla 3.1 de CONTEO, Capítulo 3, pp. 30-41 



\section{Parte II:PROPUESTAS PARA EL DESARROLLO DIDÁCTICO: LOS DISPOSITIVOS DIDÁCTICOS}





\title{
1. Dispositivos didácticos para el desarrollo de competencia comunicativa en matemáticas
}

\author{
Dora Inés Calderón- Olga Lucía León
}

El diseño didáctico configurado teóricamente en la parte I, se completa como un ambiente didáctico para el aprendizaje en esta segunda parte, a través de la propuesta de trabajo para el aula que se desarrolló en el proyecto ${ }^{261}$ y se cristaliza en la parte III con el proyecto de aula "Criando lombrices y sembrando plantas". Para este efecto se estudió la situación de desarrollo lingüísticodiscursivo y matemático de los niños sordos de niveles iniciales, tanto desde el punto de vista curricular, como desde el punto de vista real. ${ }^{272}$ Con esta base se realizó un estudio de dispositivos didácticos más apropiados para el desarrollo lingüístico discursivo y matemático en estos grados y en las condiciones de los niños sordos.

Así, se optó por un sistema de dispositivos didácticos que favorecen la experiencia discursiva y matemática: como macro dispositivo el proyecto de aula y como dispositivos complementarios el juego y el taller. Como resultado, se obtiene un diseño didáctico que, en su dimensión práctica es una propuesta de trabajo para el profesor, es el escenario de las relaciones didácticas propuestas teóricamente, para ser puestas en juego en un ambiente didáctico susceptible de ser ejecutado, observado y valorado. Así mismo, configura un ambiente de aprendizaje para el estudiante. A continuación se describen los tres dispositivos construidos y sus relaciones.

\subsection{El proyecto de aula como estrategia pedagógica y como dispositivo didáctico}

\begin{abstract}
"En la medida en que se vive en un medio sobre el cual se puede actuar, en el cual se puede discutir con otros, realizar, evaluar, se crean situaciones más favorables para el aprendizaje...
\end{abstract}

"(Jolibert, 1998)

26 Como se ha enunciado en la introducción, esta propuesta es uno de los resultados del proyecto "Desarrollo de competencia comunicativa en matemáticas, en estudiantes sordos de niveles iniciales".

27 Para este efecto se estudiaron las propuestas curriculares y planes de área de tres colegios de niños sordos de Bogotá. También se realizaron observaciones etnográficas en clases de primer grado en los tres colegios. 
La pedagogía como campo de reflexión teórica y como espacio de producción de conocimiento sobre la educación, se ha ocupado permanentemente del análisis de las implicaciones de la aplicación de modelos de enseñanza y de aprendizaje en la formación de los sujetos sociales. En esta perspectiva, un análisis de la propuesta de proyecto de aula como opción didáctica, nos sitúa en un enfoque de orientación constructivista del aprendizaje (Piaget, Vigotsky, Bruner, etc.), dado que la pedagogía ha considerado como fundamental encontrar estrategias pedagógicas y didácticas que puedan potenciar aprendizajes más significativos, más procesuales, más efectivos y más contextualizados, para el desempeño sociocultural y científico de los estudiantes de cualquier nivel de escolaridad (León y Calderón, 2004).

En concordancia con el planteamiento anterior, la pedagogía por proyectos aparece en el escenario pedagógico como una opción epistemológica (Vassileff, $1995)^{28}$ enmarcada en la pedagogía de corte constructivista. Se reconoce que esta opción pedagógica potencia el proceso de construcción de conocimiento, pues su aplicación moviliza, de manera significativa, las condiciones cognitivas, comunicativas, afectivas y volitivas de los sujetos, dado el tipo de participación social que le impone esta dinámica a los estudiantes. Adicionalmente, se observa que el sujeto puede ser partícipe de su propio aprendizaje, dada la complejización cada vez mayor de las actividades de aprendizaje. En este contexto, cobra gran valor el carácter tutorial del acompañamiento del profesor, como garantía de un desarrollo legítimo, orientado y efectivo del aprendizaje. De acuerdo con Rodríguez (2001, citada por León y Calderón, 2004), la pedagogía de proyectos permite fundamentalmente:

- Insertar la escuela en la vida. Es decir, lograr que los aprendizajes escolares adquieran una utilidad en las exigencias de desempeño social. Que los estudiantes logren emplear los saberes que construye en la escuela en la resolución de problemas que la vida les plantea. Por lo anterior, que se pueda comprender la "necesidad de ir a la escuela" para ser "mejor ciudadano", mejor sujeto social y para tener la posibilidad de aplicar permanentemente los saberes escolares porque "se necesitan". En últimas, que se desarrolle un aprendizaje significativo. Además, favorecer una "interpretación holística de la realidad" (Rodríguez (2001) y el valor de los saberes interdisciplinares para dar respuestas a las exigencias de esa realidad, en tanto que la orientación para el aprendizaje serán los problemas y no los contenidos curriculares; problemas que, para ser resueltos, requieren de diversos saberes y de varias miradas.

- Cristalizar los intereses de los estudiantes frente al conocimiento. Esto es, lograr que se dé una verdadera motivación por el aprendizaje escolar, por parte

28 Para una ampliación del tema, ver autores como Vassileff, Jean (1989, 1995); Touchon, Francois (1994); Rodríguez, María Elvira (2001); Ordóñez, Carlos (1995); entre otros. 
de los estudiantes, ya que lo que se va a realizar en un proyecto de aula permite alcanzar metas que los aprendices quieren lograr frente a una situación elegida. Esta cualidad de los proyectos de aula garantiza una condición necesaria en el aprendizaje significativo: la motivación intrínseca como factor necesario para orientar internamente el aprendizaje en los individuos: el estudiante indaga, soluciona problemas, etc., porque tiene un reto cognitivo y un interés personal que cumplir. Como efecto de esta característica, se favorece el desarrollo de la autonomía en el educando, en tanto que elige no sólo el proyecto que quiere realizar sino que tiene un espacio para el desarrollo de tareas de acuerdo con sus roles, responsabilidades y acuerdos en el grupo. Complementariamente, se cualifica el trabajo en equipo, dado que el proyecto de aula es, para los estudiantes, una meta compartida, que requiere de acciones conjuntas e individuales, pero todas orientadas al alcance colectivo de la meta.

- Organizar y cohesionar los conocimientos y los aprendizajes. Esto significa que los contenidos escolares y los procesos de aprendizaje dejan de ser atomizados, como se planteaban tradicionalmente en los currículos por contenidos, puesto que se estructuran para responder a aprendizajes significativos y a la solución de problemas que se plantean en el proyecto de aula. Se hablará, desde esta perspectiva, de un currículo por objetivos más que por contenidos o también de currículos problémicos y de currículos flexibles. Esta posibilidad de los proyectos de aula, genera exigencias de tipo didáctico y pedagógico a los docentes, de tal manera que implicará también, un desarrollo de competencia didáctica en el profesor.

Según León y Calderón (2004), como estrategia didáctica el proyecto de aula interpreta y realiza tres tipos de propósitos: los de formación curricular, los del plan de área y los que pretenden alcanzar los estudiantes mediante el desarrollo de un plan común. Requiere adecuaciones del plan de área a las exigencias del aula y determina una forma de relación con el conocimiento: aprender haciendo; y una forma de relación con los otros: cooperación para alcanzar metas. Como meta para los estudiantes, se convierte en el espacio de realización de intereses que pueden tener frente a un campo de conocimiento o frente a un espacio de prácticas escolares; por ejemplo, realizar una salida de campo, una visita a museos, un festival de cuentos, una olimpiada de matemáticas, montar un periódico mural, una emisora, un club de juego, etc.

En su configuración, el proyecto de aula se estructura en fases que particularizan roles, responsabilidades, acciones, métodos, estrategias, todos en función del logro del propósito del proyecto. Pone de manifiesto comprensiones sobre las relaciones didácticas y genera criterios para la regulación de las acciones didácticas en función de la relación profesor- estudiante saber.

En términos generales es el proyecto compartido entre profesores y estudiantes, en el aula de clase. Pretende desarrollar procesos de aprendizaje situados 
curricularmente. De ahí que se considere como una ESTRATEGIA DIDÁCTICA empleada por el docente para mejorar los aprendizajes de los estudiantes $y$, para ellos, como una META compartida.

Se reconoce aquí la responsabilidad e importancia que asume el profesor en este tipo de proyectos y el papel preponderante que juegan los estudiantes en la formulación y el desarrollo de las propuestas que surgen en el proyecto. También, se hace necesario valorar el efecto que pueden llegar a tener en el desarrollo de los planes de área y en los procesos curriculares relacionados con el desarrollo de un proyecto de aula. En este sentido, no ha de olvidarse que se trata de proyectos micro, de corto plazo, que atienden a propósitos de aprendizaje concretos en una o varias áreas y en un tiempo determinado. Así, los proyectos de aula adquieren en sí mismos dimensiones de tipo didáctico, curricular y estratégico que el profesor tendrá que articular en el ambiente didáctico y en el ámbito curricular de un grado de escolaridad y de un campo de conocimiento específico o de un conjunto de campos relacionados.

\subsection{El taller como dispositivo didáctico}

"El taller... formas de establecer
puentes y conexiones entre los
conocimientos que se transmiten en
el aula y la vida que desarrollan los
niños"

(C Freinet, citado por E. AnderEgg.)

El taller será asumido aquí como dispositivo didáctico en términos sistémicos. Es decir, comprende la organización de un conjunto de elementos para facilitar un proceso de aprendizaje o para generar una situación de aprendizaje. En ese sentido, el dispositivo puede ser aplicado en distintos momentos, con diferentes actores y variar los intereses de aprendizaje. La idea de dispositivo recoge aquí la de "organización para acometer una acción" propuesta en el DRAE, ${ }^{29}$ pues se trata de la disposición de los distintos elementos involucrados en una relación didáctica. Así, el taller, como el proyecto de aula, se convierte en un modo de organización para el trabajo en el aula, por ello genera unas formas de relación y unos efectos en los procesos de aprendizaje de quienes participan en él.

Para avanzar en la comprensión de este tipo se dispositivo, diremos que la noción de taller configura su significación a partir de su sentido etimológico que reporta su origen así: "...la palabra 'taller', que el castellano tomó del francés 'atelier', y la palabra 'astilla' tienen la misma raíz. Antiguamente (siglo XIV) la voz francesa se escribía 'astelier' designando 'un montón de astillas de madera' y luego 'obra al aire libre' de carpintero". ${ }^{30}$ Así, se observa que el

29 Diccionario de la Real academia Española. Vigésima primera Edición. Madrid, 1992.

30 Etimología de taller. http://etimologias.dechile.net/?taller 
término "taller", tiene su raíz en el contexto del "hacer un oficio", de realizar obras con las manos, de preparar a las personas para la adquisición de ciertas capacidades manuales propias de un determina oficio, o para designar ciertas actividades como lo son las artes manuales y demás oficios que involucren la creatividad, el desarrollo manual y cognoscitivo.

Desde el punto de vista didáctico, la noción de taller recoge los anteriores aspectos referidos en su noción general e histórica y las potencia en aras de considerar el valor de la APLICACIÓN DEL CONOCIMIENTO como un factor importante en el proceso de aprendizaje. Como técnica de trabajo grupal (Calderón y Molina, 1999), el taller tiene asidero en la teoría de las dinámicas de grupo (Beal, 1970). Desde el punto de vista de su descripción, consiste en una actividad (realizada individual o grupalmente) diseñada para la discusión de un tema o de una situación o para el descubrimiento de relaciones, aplicaciones o factores asociados a un tema o cuestión. Por esta razón, como acción comunicativa, exige centrar la interacción entre los talleristas y las actividades presentadas en el taller, con el fin de alcanzar los objetivos propuestos en el tiempo estipulado; y como acción cognitiva exige situar la relación de los sujetos participantes con el conocimiento en discusión. Como resultado de estas exigencias, opera bajo los criterios de aplicación del conocimiento previo y de verificación de los resultados obtenidos en la aplicación. Por lo tanto, no constituye un espacio para la construcción inicial de conocimiento; es decir, se propone un taller, cuando se tiene un conocimiento previo sobre el que se quieren desarrollar aspectos como: aplicaciones, relaciones, proyecciones, entre otros (Calderón, 2005).

Freinet (1993) empleó el taller en la escuela libre experimental, en donde se privilegió la acción educativa bajo el criterio de: "el conocimiento, la manipulación y la exploración directa del entorno que rodea al estudiante". Así, una de las bases de la educación era el taller, como herramientas básicas para la presentación y construcción del conocimiento. Freinet propuso una clasificación de la categoría taller: una ligada al trabajo manual (artes manuales) y la segunda, a la actividad intelectual: la evolución y socialización del conocimiento. Así, en la perspectiva de taller, se recogen múltiples trabajos generados en el aula, tales como: el análisis de textos (aplicando saberes anteriores o buscando en diccionarios), la observación del entorno (experimentaciones), la creación de periódicos escolares, las actividades artísticas como la danza y el teatro, la creación artística (experimentación, elaboración de murales, etc.). En todo caso, esta multiplicidad de actividades realizadas como talleres se convierten en factores del desarrollo cognitivo, afectivo, social y cultural de los estudiantes y contribuyen a la elaboración significativa del conocimiento, en tanto que se caracterizan por involucrar las actividades con el entorno sociocultural del estudiante. 
El taller hace una referencia al establecimiento de "puentes de conexión" entre los conocimientos que se trasmiten en el aula y la vida que desarrollan los niños. En este sentido, comporta el principio constructivista del aprendizaje en interacción con el entorno, del aprendizaje significativo; es decir, el aprendizaje es bidireccional pues el ejecutor del taller, en el caso del aula quien es el profesor, aprende de los hechos realizados por los estudiantes en los que ambos actores actúan e interactúan frente al hecho o situación.

El taller, como dispositivo didáctico, se constituye en una propuesta de acción organizada e intencionada que ha de ser desarrollada bajo las siguientes condiciones:

- Para el profesor: analizar previamente los aspectos teóricos y metodológicos que incluirá en el taller, a través de la identificación de los objetivos de aprendizaje y del diseño de las actividades. Identificar el potencial del taller como una herramienta para evaluar el proceso que llevan a cabo los estudiantes.

Desde las dos anteriores condiciones, el profesor podrá considerar las actividades desde el punto de vista de su utilidad para la persona que está aprendiendo; podrá identificar la relación entre del desarrollo de la estrategia de trabajo propuesta en el taller y los conocimientos y habilidades puestas en juego para quien realiza el taller. Podrá diseñar un modo de generar el análisis, la síntesis y la sistematización de los resultados del taller. De igual manera, el profesor ha de diseñar cuidadosamente las instrucciones (enunciados) que orientarán las actividades a los estudiantes. Es necesario tener en cuenta que estas instrucciones sean explícitas y que las reglas estén bien establecidas: qué hacer, cómo hacerlo, cuánto tiempo se tiene, qué resultado se espera. Así pues, las indicaciones para las acciones tendrán que asegurar el proceso que ha de realizar el (los) tallerista (s) para responder a la solicitud general.

En general, para el profesor aparece la exigencia de desarrollar su propia capacidad de diseñar talleres: de construir una estructura consistente y realizable que articule actividades para el desarrollo de conocimiento; por ejemplo, establecer objetivos de aprendizaje alcanzables; proponer una metodología y unas actividades concordantes para el avance del conocimiento y el cumplimiento de tales objetivos, en un tiempo y en unas condiciones determinadas; explicitar criterios de evaluación para el desarrollo del taller, de tal manera que los talleristas tengan opción de regular sus propias actividades (Calderón, 2005).

- Para el estudiante: constituirse en un momento de aprendizaje que implique la aplicación de conocimientos: para solucionar problemas, para construir propuestas con base en un conocimiento anterior. Comprometerse a desarrollar las actividades, de acuerdo con las indicaciones del profesor y, con ello a participar activamente en todos os momentos del taller. Observar 
una actitud cooperativa y respetuosa para con los compañeros y el profesor y cuidadosa para con los materiales y los distintos elementos involucrados en la realización de las actividades.

Desde el punto de vista de los principios pedagógicos y didácticos que subyacen a la estrategia de taller, señalamos las siguientes: hace presente con fuerza el "aprender haciendo en grupo". La aplicación de este principio propicia el desarrollo de habilidades y la aplicación de conocimientos aprendidos previamente. Genera condiciones de desarrollo de creatividad y capacidad de investigación, pues propicia la actitud de búsqueda de información en distintas fuentes para consolidar sus conocimientos y certezas sobre lo que va construyendo como resultado de las actividades y de las solicitudes del taller. En general, el aprender haciendo encarnado en la estrategia de taller, puede convertirse en la puesta en marcha de un proyecto relacionado con una asignatura o con una disciplina en donde el aprender es una experiencia vivencial formadora, que permite cultivar la acción y reflexiva como un proceso formativo en el estudiante. Implica la superación de una educación centrada en la teoría hacia una centrada en la relación teoría-práctica pues en el taller ellas no son inseparables.

Otro principio pedagógico del taller es la "metodología participativa", en la que se enseña y se aprende a través de la experiencia conjunta (profesor - estudiante- estudiante); en donde todos y cada uno de los participantes se constituyen en agentes del proceso, dado su protagonismo en el desarrollo de las actividades.

Un tercer principio del taller es la "pregunta como factor de aprendizaje" y de relación entre el estudiante y el profesor, contrapuesta a la respuesta como el comportamiento esperado del estudiante y del profesor. En esta dinámica, el conocimiento se produce como respuesta a las preguntas formuladas explícita e implícitamente en el taller. Es decir, las actividades se diseñan desde las preguntas que se espera resolver; en este proceso, para el estudiante y, también para el profesor, emergen nuevas preguntas que generan nuevas y posiblemente más refinadas búsquedas. Esto quiere decir que la dinámica del desarrollo de un taller propende por el desarrollo de una actitud científica, en la capacidad de formular una serie de problemas y tratar de resolverlos. Lo difícil no es resolver dichos cuestionamientos, lo verdaderamente arduo es la formulación de las preguntas ya que esto implica apropiarse del saber y cuestionar solo aquello que no comprendamos. Este procedimiento de la construcción de preguntas implica la documentación por parte del profesor y del estudiante. El docente, entonces, será el guía el que oriente en la búsqueda de so- luciones a los cuestionamientos surgidos a través de la experiencia de indagación. 
Por último, el taller como estrategia didáctica sustenta un carácter interdisciplinario y sistémico. Interdisciplinario en el sentido en que convoca la articulación de diferentes campos de conocimiento o áreas del saber escolar. Para la formulación de un taller habrá que identificarse los distintos saberes implicados, su función en el proceso de aprendizaje que va a poner en escena y la articulación que tales saberes exigen. Esta condición del taller pone en evidencia que los procesos de aprendizaje, al igual que el conocimiento, son complejos, sistémicos y exigen ser considerados de este modo, de tal manera que se alcancen como desarrollos de conocimiento más efectivos, más útiles y aplicables a la vida misma.

Teniendo en cuenta lo anterior, en el marco del diseño de situaciones didácticas, y en especial de ambientes de aprendizaje, el taller ha de ser considerado como una de las estrategias necesarias para promover el aprendizaje, pero no la única ni la más importante; además, su uso habrá de estar relacionado con el análisis de los procesos necesarios para el desarrollo del conocimiento escolar.

\subsection{El juego como dispositivo didáctico}

"Si consideramos que el juego es uno de los primeros lenguajes del niño y una de sus primeras actividades, a través del cual conoce el mundo que lo rodea incluyendo las personas, los objetos y el funcionamiento de los mismos y la forma de manejarse de las personas cercanas, no podemos excluir el juego del ámbito de la educación formal."

(Öfele, 1999:4)

El juego, tomado fundamentalmente como actividad humana, como forma de relación con el mundo interno y externo, refiere a una acción, a un ejercicio, al despliegue de habilidades, de actitudes, al modo de disponer un conjunto de objetos y de relaciones, generalmente, con funciones de divertimento, de competición, de mimetizar, de reto intelectual, físico, estratégico, etc. Consecuentemente, en esta acción se manifiestan el ingenio, la creatividad, las habilidades y las destrezas relacionados con las exigencias y las reglas del juego. Otro sentido para "juego" es el de objeto o disposición de un conjunto de elementos de cierto modo y con cierta función. ${ }^{31}$ Esta última acepción no es la que analizaremos aquí, pues la primera es la que nos sitúa en las relaciones didácticas.

31 Ver acepciones en el Diccionario de la Real Academia Española de la Lengua (DRAE). 22ª Edición, 2001. 
Así pues, considerar el juego como dispositivo didáctico nos exige tener en cuenta que éste ha sido un tema ampliamente estudiado por psicólogos, antropólogos y educadores, dado su papel, bien en el desarrollo del sujeto, bien en la configuración de la cultura y de lo social o bien, en la educación, la pedagogía y la didáctica. En cada una de estas tres perspectivas, los aportes son prolíficos, resultado de largas investigaciones y, también, obedecen a enfoques epistemológicos distintos. No obstante, y dado que las tres principales fuentes de explicación son relevantes en la consideración del juego como dispositivo didáctico, o mejor, en la configuración del discurso pedagógico y didáctico acerca del juego, tomaremos aportes de estas perspectivas para proponerlo en términos de un objeto con características de dispositivo didáctico. El criterio con el que se toman los autores es en cuanto a la influencia de su teoría del juego en la educación.

Adicionalmente, situar el juego Como dispositivo didáctico, implica asumirlo de acuerdo con las características de un dispositivo de este tipo; por ejemplo como "la propuesta didáctica que busca estimular un tipo de acción en los estudiantes para favorecer la movilización de sus procesos cognoscitivos y comunicativos" (Vergel, Rocha y León, 2006: 1). En este sentido, adquiere el carácter de propuesta intencionada y estructurada con fines educativos $y$, en particular, para ser implementada en una relación de enseñanza y aprendizaje. Por esta razón, asume las condiciones que se exigen a un diseño didáctico, que en términos generales son: de tipo macroestructural y de tipo microestructural. En las condiciones de tipo macro consideramos las relacionadas con la misma naturaleza del juego y su vínculo pedagógico y curricular y, en las condiciones microestructurales situamos una relación entre las posibilidades de acción del juego y su papel en la estructura de la interacción natural entre estudiante-saber-profesor. A continuación explicitamos el conjunto de aspectos relacionados para la configuración del juego como dispositivo didáctico.

\section{1) Aspectos macroestructurales en el dispositivo juego}

En la relación entre la naturaleza del juego como actividad humana y la dimensión curricular y didáctica acudimos a una fundamentación general del juego proveniente de dos perspectivas teóricas, a nuestro juicio complementarias para la educación: una de corte cultural-antropológico y otra de corte psicológico. Ambas permiten comprender la actividad del juego en el desarrollo humano, en una dimensión histórico-cultural y social y en una dimensión individual del desarrollo. Desde allí, se considerará su relación en una perspectiva pedagógica.

En primera instancia, destacamos la explicación de la actividad de juego como aspecto fundamental en la configuración de la cultura. Situamos aquí los aportes del clásico filósofo e historiador holandés Johan Huizinga y su 
planteamiento de partida: "el hombre es un animal que ha hecho de la cultura su juego" (Homo Lu- dens, 1933/1990). Es en este sentido que la actividad de jugar demuestra que la cultura humana brota del juego; que la cultura misma ofrece un carácter de juego" (1990: 8). En general, este autor plantea que el juego es un fenómeno cultural en el que intervienen aspectos biológicos, psicológicos y etnográficos y también es una función humana tan esencial como la reflexión y el trabajo, pero diferente de ellas porque va más allá de los actos de supervivencia inmediata o de la reflexión intelectual para conocer. Se juega por placer; el juego significa algo para el que juega, es el jugador quien "llena de sentido" su propio acto de jugar.

De acuerdo con lo anterior, el acto de jugar adquiere un carácter inmaterial y simbólico que se realiza en la experiencia humana de tipo cultural, desarrollada como proceso histórico-social. Así, el juego no es sólo una de las manifestaciones de la cultura, sino que el acto de "jugar" es inherente a la experiencia cultural; es una experiencia de búsqueda de sentido personal y colectivo.

En la interpretación de Huizinga sobre el juego, se identifica una explicación de la naturaleza humana, de su capacidad racional, de orientar su actuar en relación con su entorno, pero también, de su capacidad "irracional" de jugar; pues como lo plantea él mismo, "desde el pensamiento de la irresponsabilidad estructural, el hombre es un animal que está agradablemente condenado a jugar" (1990: 256). Así, según nuestro autor, en su aspecto formal el juego es una acción libre ejecutada "como si" y sentida como situada fuera de la vida corriente, pero que, a pesar de todo, puede absorber por completo al jugador, sin que haya en ella ningún interés material ni se obtenga en ella provecho alguno. Es una acción que tiene un fin en sí misma y que va acompañada de un sentimiento de tensión; se ejecuta dentro de un determinado tiempo y un determinado espacio; se desarrolla en un orden sometido a reglas (aunque libremente asumidas) y da origen a asociaciones que propenden por rodearse de misterio o a disfrazarse para destacarse del mundo habitual (1990). Permite la experiencia de la mimesis, de la expansión creativa de la conciencia y, de manera singular, relaciona aspectos culturales en solidaridad con la parte espiritual; o como lo explicita Fröebel (1912), la categoría juego puede ser considerada como uno de los elementos espirituales más fundamentales de la vida.

Adicionalmente, y desde el punto de vista de la acción de jugar, Huizinga amplía la experiencia de juego más allá de la niñez, hasta el conjunto de las manifestaciones humanas como las competencias (deportivas), la máscara (en la expresión teatral), los mitos (configurados en la tradición oral y en la literatura en general), los intercambios (diarias formas de relaciones lúdicas), etc. De igual manera, establece una relación de la profunda dimensión de juego con la estética, el arte barroco, la "fantasía" romántica y lo que podría denominarse como la ruptura del ser fuera de su arraigo natural o social. Por 
lo tanto, en sus palabras, el «homo ludens»-el hombre que juega- expresa una función también esencial y debe estar junto al «homo faber» y al <<homo sapiens $>>$. El juego, entonces, es testimonio de la inteligencia del hombre y, generalmente, el modelo y la imagen de la vida del hombre, de la vida interna, natural y misteriosa. En este sentido, el juego original es el gozo, la libertad, la satisfacción, la paz consigo mismo y con el mundo. En consecuencia, el juego es experiencia interna, individual y, a la vez expresa la experiencia sociocultural configuradora de tradiciones, de modos, fundamentalmente lúdicos, de ser y de estar en la cultura. Esto último, en tanto todos los pueblos juegan, y muchas veces de mane- ras semejantes; el juego puede considerarse como universal en términos de condición humana y particular en expresiones externas socio-culturales que se transmiten y se desarrollan en el devenir cultural.

En la perspectiva anterior, identificamos una primera relación entre el juego y la educación y tiene que ver con su función en los procesos de enculturación. Como lo plantea Fröbel (1912), "hay una dimensión política en el juego. El niño, en cualquier lugar en que se encuentre sabe siempre asegurarse un lugar para jugar con sus camaradas, y esos juegos en común producen frutos utilísimos para sociedad misma, pues ellos se manifiestan en el seno de la comunidad, de sus leyes y de sus exigencias". Desde una perspectiva sociológica, cercana a la antropológica, los juegos disciplinan los instintos por ser, por un lado, espacios para el placer y la diversión, y por otro, acatamiento de una serie de restricciones proporcionando un modelo controlado de la realidad. Así, una propuesta pedagógica y curricular tendría que otorgar un lugar al juego y su papel enculturizador, tanto en el diseño y la declaración de políticas y de lineamientos para la formación de niños, jóvenes y profesionales, como en la configuración y la previsión de marcos teóricos y metodológicos dedicados al juego en y de espacios para el desarrollo de la actividad de jugar.

Por otra parte, desde una perspectiva psicológica, distintos y prolíficos autores han caracterizado el juego y su papel en la experiencia individual y en la dimensión del desarrollo del sujeto. Tomaremos los aportes del psicólogo suizo Jean Piaget (1986) y su caracterización del juego. Su teoría explica, esencialmente, el desarrollo cognoscitivo del niño, haciendo énfasis en la formación de estructuras mentales. Su idea central es que "resulta indispensable comprender la formación de los mecanismos mentales en el niño para conocer su naturaleza y funcionamiento en el adulto. El desarrollo es... en cierto modo una progresiva equilibración, un perpetuo pasar de un estado de menor equilibrio a un estado de equilibrio superior, tanto si se trata en el plano de la inteligencia, de las operaciones lógicas, de las nociones de número, de espacio y tiempo, como, en el plano de la percepción de las constancias perceptivas, de las ilusiones geométricas, la única interpretación psicológica válida es la interpretación genética, la que parte del análisis de su 
desarrollo". Esa equilibración progresiva se modifica continuamente debido a las actividades del sujeto, y éstas se amplían de acuerdo con la edad. Por lo tanto el desarrollo cognitivo sufre modificaciones que le permiten consolidarse cada vez más.

En la comprensión piagetiana del desarrollo está inscrita la idea de los estadios de desarrollo y, es en ese proceso, en el que sitúa la aparición del juego en el niño. Así, considera que, por ejemplo, en la edad preescolar, la principal actividad de los niños es jugar: "El juego, con su énfasis en el cómo y el por qué se convierte en el instrumento primario de adaptación, el niño transforma su experiencia del mundo en juego con rapidez" (Landeira, S., $\mathrm{s} / \mathrm{f}$ ). En este sentido, las repercusiones del juego en el desarrollo integral del niño son importantes. Para Piaget "el juego es una relación entre el niño y el entorno, es un modo de conocerlo aceptarlo y construirlo". Con esta base presenta una clasificación orientada a dar razón de la naturaleza de la actividad de jugar, del siguiente modo:

- El ejercicio: Es el primero en aparecer en la vida del niño (estadio II de la etapa pre-verbal) hasta el estadio VI, en el que aparece poco a poco el juego simbólico. Según este autor, en este ámbito de la experiencia de juego, no requiere un gran desarrollo del pensamiento ni ninguna estructura representativa especialmente lúdica.

- El símbolo: Requiere estructura representativa de un objeto ausente, comienza por las conductas individuales que hacen posible la interiorización de la imitación.

- La regla: La aparición de esta condición del juego implica la aprehensión de regularidades por parte del grupo. Se reconoce que la violación de las reglas representa una falta. Para algunos casos se transmiten las reglas de generación en generación.

Como se puede observar, para Piaget el juego no tiene que ver mucho con el carácter lúdico, con la felicidad o con la enseñanza. Más bien, y desde una perspectiva psicológica, caracteriza el juego como una asimilación de lo real al yo; se trata de una relación sujeto - mundo en donde predomina la asimilación. El niño no se adapta al mundo, sino que lo deforma en el marco del juego, conforme a sus deseos, asimilando así lo real al yo. Piaget afirma que el acto intelectual persigue siempre una meta que se halla fuera de él, mientras que el juego, en cambio, tiene el fin en sí mismo. Entonces, la actividad lúdica no es una conducta adaptativa, no persigue el equilibrio entre asimilaciones y acomodaciones. En este sentido, el aporte fundamental para este trabajo, desde la teoría de Piaget, es el reconocimiento de procesos que intervienen en el desarrollo del juego y del papel preponderante de su carácter de ejercicio, de simbolización y de construcción de reglas. 
Con respecto al ejercicio de simbolización que engendra el juego, según Piaget éste es una conducta; como tal "comparte con todas las conductas el hecho de ser solidarias de la estructura intelectual que en cada momento del desarrollo marcará sus límites y posibilidades. Es así que el juego simbólico recibe el carácter de tal por dos razones solidarias: a) la estructura intelectual que lo determina y b) la utilización excluyente que hace del símbolo, es decir, de uno de los dos instrumentos que engendra la función semiótica... que consiste en representar algo por medio de un significante diferenciado, y que engendra dos clases de instrumentos: los símbolos, significantes motivados, construidos por el sujeto, y que guardan alguna semejanza con sus significados; y los signos, arbitrarios o convencionales, necesariamente colectivos, recibidos por el canal de la imitación" (Landeira, 1998: 2).

Con base en los planteamientos psicológicos sobre el juego, encontramos que el aporte fundamental para la educación está en la identificación de su papel en el desarrollo intelectual, afectivo, socio-cultural y lingüísticodiscursivo de los sujetos. En este sentido, la conclusión de Bruner resulta profundamente esclarecedora y sintetizadora: "El juego no es sólo juego infantil. Jugar, para el niño y para el adulto..., es una forma de utilizar la mente e, incluso mejor, una actitud sobre cómo utilizar la mente. Es un marco en el que poner a prueba las cosas, un invernadero en el que poder combinar pensamiento, lenguaje y fantasía". (Bruner, 1984: 219). De ahí que, así como consideramos anteriormente la necesidad de que la pedagogía y el currículo tomen en cuenta el papel enculturizador del juego, será necesario que también involucren, en sus fundamentos curriculares, en sus planes de estudio y en sus propuestas didácticas generales, el juego como un dinamizador del desarrollo socio-afectivo e intelectual de los estudiantes.

\section{2) Aspectos microestructurales en el dispositivo juego}

Desde una perspectiva didáctica se identifican numerosos estudios sobre el juego y su utilidad en el desarrollo del trabajo en el aula. Aquí destacaremos los aspectos que surgen de la necesaria relación entre las posibilidades de acción del juego y su papel en la estructura de la interacción entre estudiante-saberprofesor; es decir, en el marco de las relaciones didácticas. A continuación explicitamos exigencias para el juego cuando se asume como configuración de un diseño didáctico; para ello partimos del análisis de los requerimientos didácticos de un diseño (Calderón y León, 2001).

\section{a. En la dimensión epistemológica.}

Todo diseño didáctico ha de construir un componente de fundamentación teórica, de tipo disciplinar e histórico. En este lugar se desarrolla la reflexión epistemológica del campo de conocimiento puesto en juego en el diseño (proviene de las áreas de saber escolar); es decir, del marco de contenidos 
por desarrollar en el aula. Con respecto al dispositivo juego, se requiere considerar, en esta dimensión, un análisis de la tradición lúdica o de juego en el desarrollo socio-cultural e histórico del saber en cuestión. La pregunta será por el tipo de prácticas de juego y de juegos relacionados con ese saber. Por ejemplo, en el campo de las matemáticas (olimpiadas, juegos lógicos, etc.); en el de lenguaje (rondas, juegos y retahílas, adivinanzas, etc.)... A partir de allí, se hace necesario establecer el marco teórico de referencia que permita explicar las decisiones y las elecciones del profesor en cuanto a la relación: campo de saber escolar - prácticas de juego asociadas -juegos identificados.

\section{b. En la dimensión cognitiva.}

Un diseño didáctico ha de construir al quién del aprendizaje (Calderón y León, 2001).Esta construcción requiere un análisis de las condiciones cognitivas y afectivas que el conocimiento puesto en juego impone. Por ejemplo, aprender a sumar, fracciones; aprender a leer y a escribir, exigen, cada uno, el desarrollo de procesos intelectuales y de condiciones actitudinales y afectivas particulares. En este orden de ideas, cuando el dispositivo es el juego, requerirá la identificación de actividades de juego y de juegos relacionados con el desarrollo del campo de conocimiento por desarrollar. Adicionalmente exigirá la reflexión sobre las condiciones cognitivas, afectivas, aptitudinales y actitudinales que impone la actividad de jugar diseñada para el aula.

\section{c. En la dimensión comunicativa.}

Un diseño didáctico ha de considerar, en esta dimensión dos grandes aspectos: los modos discursivos y textuales que el campo de conocimiento impone (Calderón, 2010) y las formas de la interacción en el aula que el profesor elige como estrategia para desarrollar la clase. En cuanto al primer aspecto, por ejemplo, si se enseña matemáticas y específicamente el conteo, ha de considerarse el campo léxico relacionado, la forma de los enunciados referidos a la actividad de contar, los usos del lenguaje para comunicar y para expresar este conocimiento, tanto por parte del profesor como en los textos escolares. De igual manera, si el saber es, por ejemplo, la narrativa de cuentos, el lenguaje que impone este campo estará relacionado con el universo de los cuentos, de la literatura, de la personificación, etc., tanto en el plano de la oralidad como en el de la escritura. Estos modos discursivos y textuales son un factor de la comunicación en el aula que el profesor ha de considerar y analizar para el diseño didáctico, pues imponen aprendizajes y prácticas particulares.

En cuanto al segundo aspecto, el profesor elige estrategias de comunicación en el aula (o dispositivos) de acuerdo con los contenidos y con los aspectos cognitivos relacionados (Calderón y León, 2001), por ejemplo, taller, juego, clase magistral, etc. Tales estrategias imponen exigencias comunicativas particulares. Así, cuando es el juego el que se toma como estrategia, se 
requiere analizar y planear cuidadosamente los aspectos relacionados con los modos de interacción que esta estrategia exige. La identificación de las reglas y del desempeño de los roles requeridos en el juego será fundamental, así como el lenguaje que la actividad realizada en el juego permite desarrollar: requiere, por ejemplo, ¿registrar datos?, ¿reconstruir jugadas?, ¿argumentar procedimientos?, ¿inventar otros modos de proceder? A través del juego se conoce el mundo que rodea al estudiante, incluyendo las personas, los objetos y el funcionamiento de los mismos. Hay una sociología en el desarrollo de los juegos, tal sociología es fuente de aprendizaje en la dimensión de comunicación y de cultura y ha de ser un factor de análisis didáctico para el profesor, en tanto será factor de aprendizaje para el estudiante.

\section{d. En la dimensión socio-cultural del aula.}

El aula como cualquier otro escenario socio-cultural, es un espacio de interacción social y genera una cultura propia. Fundamentalmente se considera, en esta dimensión, la existencia e incidencia de las reglas y de las normas socio-culturales del aula que surgen de varias fuentes: de la relación natural de los actores que intervienen en ella y de la función de este espacio: profesoresestudiantes en función de la enseñanza y el aprendizaje. Aquí surgen las normas socioculturales del aula relacionadas con los roles de los actores y de sus naturales interacciones: el profesor enseña, instruye, orienta, evalúa; el estudiante pregunta, copia, es evaluado, etc. (Calderón, 2010). Otra fuente de normas y reglas, es el campo de saber escolar puesto en juego: si se trata, por ejemplo de las matemáticas o del lenguaje, emergen reglas y normas matemáticas y socio-matemáticas o reglas y normas lingüísticas y sociolingüísticas. Ellas también son objeto de la reflexión didáctica y fuente de enseñanza y de aprendizaje.

Así pues, cuando el dispositivo es el juego, en esta dimensión sociocultural del aula aparecen con fuerza las características del juego tales como: ser una actividad reglamentada, libre y con meta propia. Estas características, preponderantes y reconocidas en las distintas explicaciones, tanto psicológicas como socio-antropológicas y filosóficas destacan que: "todo juego, incluso representativo es mantenido por una regla " (Gutton, 1982: 189); "no hay juego sin reglas" (Vigostky, 1989: 144) y (Öfele, 1999: 4). En general, se considera que ni el más elemental de los juegos carece de reglas; sobre todo porque una vez nos desprendemos del orden de la vida cotidiana, se hace necesario fundar un nuevo orden: el del juego y, en él, las reglas son las que ponen limitaciones a la libertad dentro del mismo. Callois (1986, citado por Navarro Adelantado, 2002) considera que el juego es una actividad que tiene las siguientes cualidades:

- Libre: a la cual el jugador no podría estar obligado sin que el juego perdiera al punto su naturaleza de diversión atractiva y alegre; 
- Separada: Circunscrita en límites de espacio y de tiempo precisos y determinados por anticipado;

- Incierta: cuyo desarrollo no podría estar determinado ni el resultado dado de antemano, por dejarse obligatoriamente a la iniciativa del jugador cierta libertad en la necesidad de inventar;

- Improductiva: por no crear ni bienes, ni riqueza, ni tampoco elemento nuevo de ninguna especie; y salvo desplazamiento de propiedad en el círculo de los jugadores, porque se llega a una situación idéntica a la del principio de la partida;

- Reglamentada: sometida a convenciones que suspenden las leyes ordinarias e instauran momentáneamente una nueva legislación, que es la única que cuenta;

- Ficticia: acompañada de una conciencia específica de la realidad secundaria o de una franca irrealidad en comparación con la vida corriente (Callois, 1986: 37-38).

Tales cualidades aparecen como un marco de relaciones socio-culturales y comunicativas para el aula que incluye el juego como un dispositivo didáctico. Con respecto al carácter reglado del juego, Navarro Adelantado (1995: 19) considera que existen juegos sin reglas (juegos simbólicos, juegos configurativos, juegos de personajes, juegos de entrega, juegos funcionales, etc.). Otros autores como Rüssel (1970: 226) diferencian entre el «juego infantil» y el "juego», considerando que el primero no tiene un curso fijado y se desarrolla sin formas delimitadas de antemano, mientras que el segundo responde a un modo de actuar conocido, que puede repetirse de forma análoga, porque está sometido a reglas y, en este sentido, está ligado a la tradición considerando que se transmite de una generación a otra, en parte manteniéndose tenazmente en su integridad y en otra parte modificándose de modo lento pero continuo.

De cualquier modo, en una perspectiva del papel del juego como dispositivo didáctico, vale la pena destacar con Öfele (1999,) y Moyles (1990) la necesidad de garantizar que la formación de profesores incluya un componente sobre el papel vital del juego en el desarrollo de los estudiantes; tendiente a la comprensión de la función educadora y auto educadora del juego y a su capacidad didáctica de favorecer la creación de espacios y de grupos de juego, de responder a las preguntas que le hagan espontáneamente los estudiantes con ocasión de esos juegos y de aportar los materiales que ellos puedan pedirle" (Krou citado por Raabe, 1980: 19).

En general, las implicaciones prácticas del juego en la educación tienen que ver con distintos e importantes aspectos que destacamos aquí. Tales 
implicaciones las tomamos de las palabras de Bruner (1983). Desde un punto de vista ontológico, dado que el juego es una actividad que se justifica por sí misma y cuya relación entre medios y fines es débil, se convierte en un excelente medio de exploración e invención que, de por sí, infunde estímulo y que permite la experiencia de omnipotencia, de diversión y embriaguez en el acto de "vencer obstáculos". Según lo anterior, tiene implicaciones de tipo intelectual y emocional en el desarrollo del niño (a). Su realización tiende a reducir la gravedad de las consecuencias de los errores y de los fracasos, permitiendo al niño (a) cambiar los objetivos y las posibilidades combinatorias cuando lo desee, de manera jubilosa. Los "jugadores "auténticos" consideraron la tarea como una invitación a jugar con un problema, sin preocuparse de aparentar eficacia y sin miedo por su amor propio, pues pueden obrar libre y creativa-mente. El juego genera la experiencia de aprender a jugar roles, a seguir reglas a construir jugadas, a comprender procedimientos y estrategias y, por ello, aprender cada juego en sí mismo. Por las mismas razones anteriores, el juego tiene un papel considerable en el dominio del milagro del lenguaje por parte del niño: en una situación lúdica se exige poner en juego el ejercicio y la experimentación con la lengua materna; es decir, aprenderla más rápidamente. En muchos casos, las expresiones idiomáticas gramaticalmente más complicadas, la metaforización, la comparación, aparecen primero en actividad de juego. Así "el niño no solamente está aprendiendo el lenguaje sino también su utilización combinatoria como instrumento de pensamiento y de acción" (Bruner, 1983).

Otras implicaciones, que se relacionan con las anteriores, son de tipo sociocultural y ético-político, el papel del juego en la constitución de formas de relación social, de valores, de formas de simbolizar y de trascender la realidad es innegable; es un hecho que los juegos revelan ideales y valores de la sociedad adulta. Además, ofrecen naturalmente la experiencia de la convivencia social, del reconocimiento de la otredad y del carácter trascendente del juego, en tanto no es la misma realidad, pero puede relacionarse con ella. En todo este panorama surge una implicación de tipo metodológico que es cómo organizar las actividades de juego de los niños en los grupos de juego para ayudarles a desarrollar su potencial y vivir más plenamente.

Desde la anterior perspectiva, también es importante reconocer que el profesor requiere estar preparado para afrontar otras discusiones con respecto al juego en la escuela. Algunas consideran que el juego, en su desarrollo natural (en la calle, sin la vigilancia del adulto) conlleva un aspecto educativo; que la estructuración, la aceptación de normas por parte de los jugadores y el estricto cumplimiento de las decisiones arbitrales del grupo, se ven afectados cuando el profesor interviene para modificar las reglas por causas como el agotamiento de un jugador, el aburrimiento del grupo, etc.; se considera, entonces, que se estaría contraviniendo la esencia misma del juego. Así también en una 
perspectiva crítica frente a la relación juego-espacio escolar distintos autores consideran que las características de la actividad de juego hacen de ella una experiencia ajena a la escuela. Por ejemplo Scheines, en una expresión radical al respecto, opina que el juego no tiene cabida en la escuela: "sólo cuando jugamos juegos inútiles, cuando jugamos simplemente, el juego resulta "útil" en una dimensión trascendente, ontológica: nos hace crecer como seres humanos. Pero poner contenidos pedagógicos en los juegos de los chicos para que aprendan, es algo horroroso" (Scheines, 1999: 3).

Este tipo de posturas han de ser consideradas cuidadosamente cuando se toma la decisión de involucrar el juego en el aula y mucho más cuando se configura como un dispositivo didáctico. Se tendría que establecer una diferencia clara entre el juego en su dimensión estrictamente lúdica y el juego en su dimensión de dispositivo. Nosotros consideramos que el tiempo que el niño (a) pasa en la escuela no deja de ser parte de su vida y el juego no se puede sacar de la vida de los niños y niñas; siempre que no se realice un abuso y/o un mal uso del mismo, coincidiendo con Lavega cuando afirma: "no deberíamos prostituir su uso presentándolo de cualquier manera, como actividad complementaria y poco importante" (Lavega, 1995: 12). 


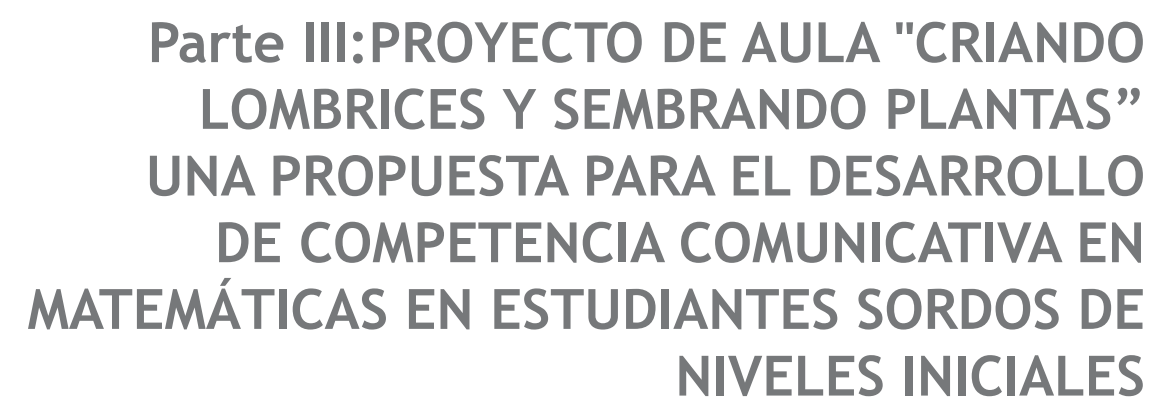





\title{
1. Proyecto de aula "criando lombrices y sembrando plantas"
}

\author{
Dora Inés Calderón- Olga Lucía León
}
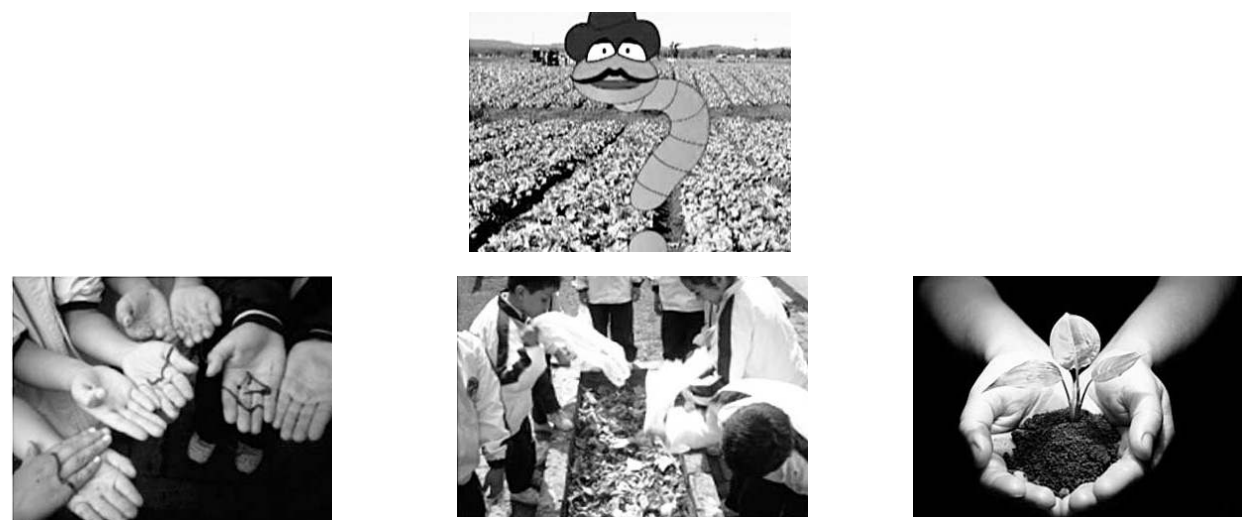

\subsection{Introducción}

La propuesta de Proyecto de Aula "Criando lombrices y sembrando plantas", se plantea como el dispositivo didáctico macroestructural que configura un ambiente en el que niños sordos de primeros grados de escolaridad desarrollarán experiencia bio-psicosocial y discursiva en los micromundos de la aproximación y de la precisión. Por esta razón, adquiere dos funciones articuladas y articuladoras:

Ser el escenario de las relaciones socio-culturales entre los estudiantes, el profesor y los padres de familia, a propósito de la meta de construir y mantener un criadero de lombrices y un huerto escolar. En este sentido, se diseñan fases y momentos que conllevan a lograr paulatina y colectivamente esta meta; adicionalmente, se considera el concurso de los intereses y la motivación de los niños (as) para con este propósito y la cooperación de los padres de familia en todos los momentos requeridos. Así, en cuanto escenario, el proyecto de aula es el espacio del encuentro de todos los actores para experimentar, juntos, el proceso de obtener un criadero de lombrices que produzca humus y un semillero cuyas semillas puedan ser abonadas con el humus proveniente de las lombrices y germinen y se conviertan en plantas.

En este sentido, la existencia de materiales adecuados y de apoyos que permitan "aprender más" o tener ejemplos de cómo hacer un lombricuario, de montar un semillero y de cómo cuidar y obtener un lombricultivo y de cómo cuidar el proceso de germinación, serán fundamentales. Naturalmente, también son lugares de aprendizaje. 
En general, como escenario, este proyecto de aula propicia el desarrollo de aprendizajes y de valores relacionados con la convivencia, la cooperación, la responsabilidad, el respeto por los otros y por el entorno natural y social (los animales, las plantas, las personas y la naturaleza en general) y el valor del trabajo en equipo. Consecuentemente, propicia el necesario desarrollo de conocimientos relacionados con las prácticas de convivencia y de trabajo conjunto y las formas de expresión lingüístico-discursiva en lengua de señas colombiana LSC y en español escrito.

La segunda función para este dispositivo proyecto de aula, es ser el ambiente para el desarrollo de experiencias en los micromundos de la aproximación y de la precisión, que ancla aprendizajes relacionados con el contexto de las cantidades: procesos, operaciones, representaciones, formas de expresión y de uso de cantidades. En esta perspectiva, el proyecto se convierte en el lugar para la articulación de las intencionalidades curriculares y didácticas en las áreas que intervienen prioritariamente y en las que el profesor pueda relacionar. Como se concibe este proyecto de aula, se articulan fundamentalmente las áreas de matemáticas y de lenguaje, en tanto que se considera el desarrollo de aprendizajes relacionados con el contexto de las cantidades y con las dimensiones gramatical y discursiva de las dos lenguas involucradas en la educación de los niños sordos: la lenguas de señas colombiana LSC y el español, en su modalidad escrita.

Desde este punto de vista, las distintas actividades propuestas y los otros dos dispositivos sugeridos: taller y juego, se configuran como microambientes relacionados con el macroambiente proyecto de aula. En esta perspectiva, a continuación se describe el proyecto, recomendando, de antemano, no desarticular la dimensión estratégica (el propósito de construir el lombricultivo y el huerto) de la dimensión didáctica (desarrollar aprendizajes relacionados con las cantidades en los micromundos de la aproximación y de la precisión y desarrollar lenguaje desde el punto de vista de la significación y de la comunicación de tales aprendizajes).

\subsection{Objetivos}

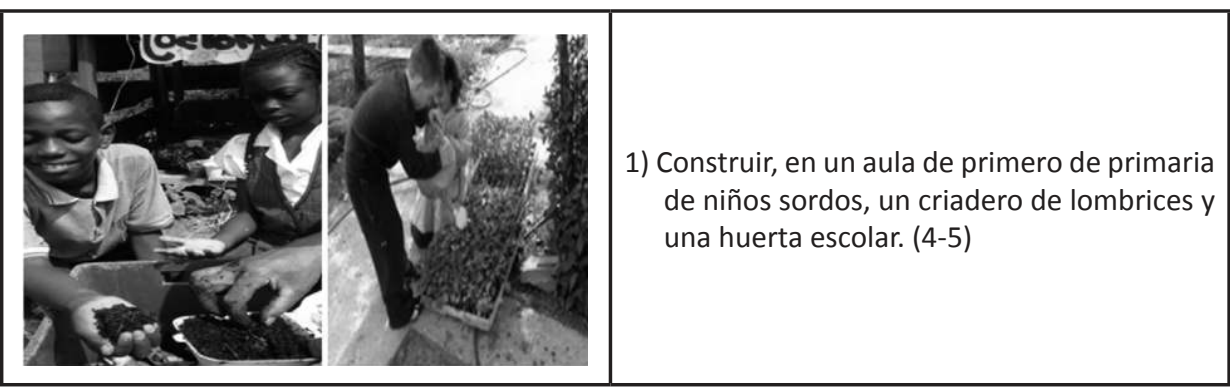




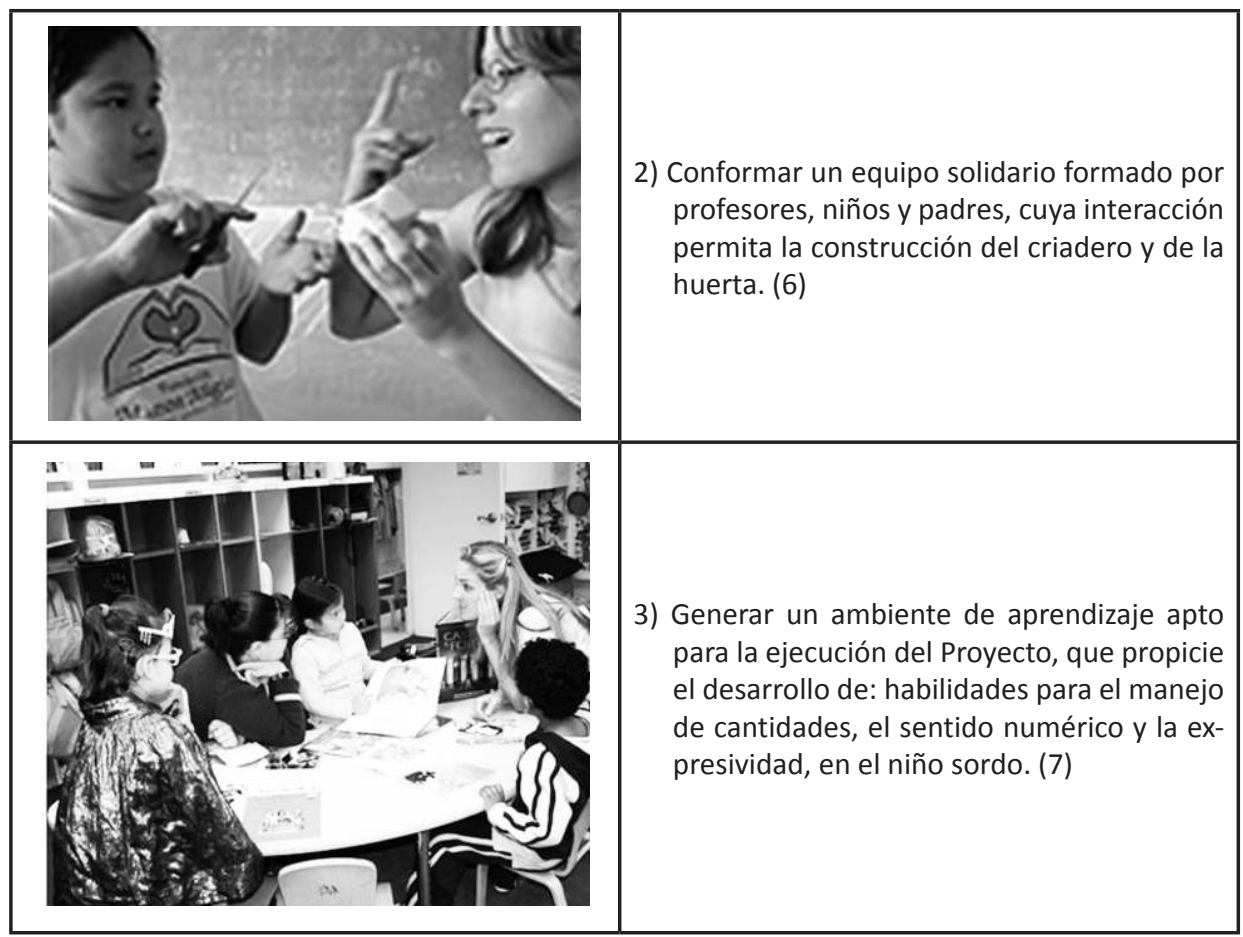

\subsection{Descripción del proyecto}

El proyecto consiste en la construcción y el mantenimiento de un criadero de lombrices y la construcción de una huerta escolar. Como proyecto de aula, se estructura en tres fases que son respectivamente: "Cultivemos la vida", "La vida para las plantas y las lombrices" y "El crecimiento de las plantas y las lombrices". A la vez, en cada una de las fases se identifican cinco componentes básicos que permiten la estructura de la fase como un ambiente de aprendizaje. Estos componentes son:

- Las actividades de la fase.

- Los recursos necesarios para el desarrollo de la fase.

- Los responsables de las funciones de cada fase (profesores, estudiantes y padres de familia).

- La duración aproximada para la ejecución de la fase.

- El producto de la fase con su respectiva evaluación

El producto de una fase también puede indicar la culminación de la misma. Para el presente proyecto las fases son: 


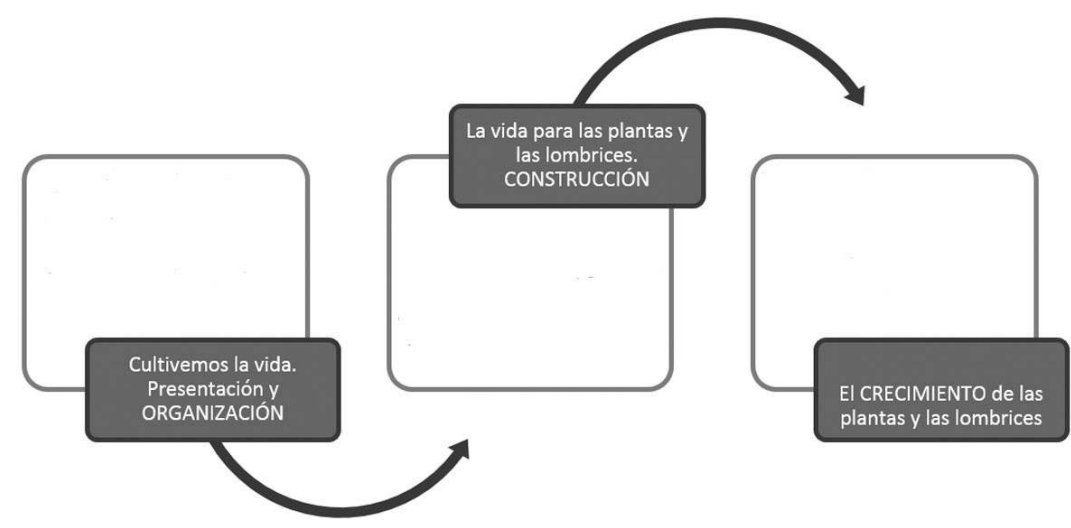

Esquema 4. Fases del proyecto

En la siguiente tabla se presentan las tres fases con la descripción de sus respectivos componentes:

\begin{tabular}{|c|c|c|c|}
\hline \multirow[b]{2}{*}{$\begin{array}{l}\text { COMPONENTES } \\
\text { DE CADA FASE }\end{array}$} & \multicolumn{3}{|c|}{ FASES } \\
\hline & $\begin{array}{l}\text { 1. Cultivemos la vida } \\
\text { PRESENTACIÓN- } \\
\text { ORGANIZACIÓN }\end{array}$ & $\begin{array}{l}\text { 2. La vida para } \\
\text { las plantas y las } \\
\text { lombrices } \\
\text { CONSTRUCCIÓN }\end{array}$ & $\begin{array}{l}\text { 3. CRECIMIENTO } \\
\text { de las plantas y las } \\
\text { lombrices }\end{array}$ \\
\hline Actividades & $\begin{array}{l}\text { Presentar el proyecto a los } \\
\text { estudiantes y a los padres } \\
\text { de familia. } \\
\text { Organizar a los estudiantes } \\
\text { en grupos para conseguir } \\
\text { materiales. }\end{array}$ & $\begin{array}{l}\text { Revisar con cada } \\
\text { equipo los materiales } \\
\text { conseguidos. } \\
\text { Conseguir materiales } \\
\text { necesarios para la } \\
\text { construcción del criadero. } \\
\text { Construir el semillero y el } \\
\text { lombricultivo. }\end{array}$ & $\begin{array}{l}\text { - Mantener el criadero de } \\
\text { lombrices y el crecimien- } \\
\text { to de las plantas. } \\
\text { - Recoger el humus como } \\
\text { abono para las plantas. } \\
\text { - Trasplantar las plantas } \\
\text { germinadas. }\end{array}$ \\
\hline Recursos & $\begin{array}{l}\text { Salón de proyecciones de } \\
\text { los videos, o instrumentos } \\
\text { que permitan la proyec- } \\
\text { ción del mismo como un } \\
\text { computador y video beam. } \\
\text { Planillas de registros. }\end{array}$ & $\begin{array}{l}\text { De acuerdo con el } \\
\text { espacio disponible en la } \\
\text { institución, el maestro, } \\
\text { junto con los estudiantes, } \\
\text { construirán el criadero de } \\
\text { lombrices. } \\
\text { Planillas de registros }\end{array}$ & $\begin{array}{l}\text { - Agua } \\
\text { - Alimentos para las lom- } \\
\text { brices. } \\
\text { - Planillas de registro de ac- } \\
\text { tividades de los equipos. }\end{array}$ \\
\hline Responsables & $\begin{array}{l}\text { El profesor presentar a } \\
\text { estudiantes y a padres el } \\
\text { Proyecto: los parámetros } \\
\text { para la organización del } \\
\text { trabajo, el video. Estable- } \\
\text { cer trabajo individual o } \\
\text { grupal. Orientar el trabajo. } \\
\text { Los estudiantes y padres } \\
\text { en esta fase se comprome- } \\
\text { ten con el Proyecto. }\end{array}$ & $\begin{array}{l}\text { El profesor y los estu- } \\
\text { diantes Trabajo en equipo } \\
\text { para la construcción del } \\
\text { criadero y del huerto. } \\
\text { Padres cooperación y } \\
\text { apoyo en la construcción } \\
\text { del criadero y del huerto. }\end{array}$ & $\begin{array}{l}\text { Después de establecer el } \\
\text { cronograma los estudian- } \\
\text { tes se encargan de dar de } \\
\text { comer a las lombrices y dar } \\
\text { el abono a las plantas. } \\
\text { El profesor será una guía } \\
\text { del Proyecto. }\end{array}$ \\
\hline
\end{tabular}




\begin{tabular}{|c|c|c|c|}
\hline $\begin{array}{l}\text { Productos y } \\
\text { evaluación }\end{array}$ & $\begin{array}{l}\text { El producto que se } \\
\text { espera de esta fase es el co- } \\
\text { nocimiento por parte de los } \\
\text { profesores, los estudiantes } \\
\text { y los padres del proyecto, } \\
\text { así como la conformación } \\
\text { de los equipos con sus fun- } \\
\text { ciones establecidas. }\end{array}$ & $\begin{array}{l}\text { Al culminar con esta fase } \\
\text { se debe tener la ubicación } \\
\text { de los espacios y la cons- } \\
\text { trucción del criadero y del } \\
\text { semillero. }\end{array}$ & $\begin{array}{l}\text { Un lombricultivo que pro- } \\
\text { duce humus y unas plantas } \\
\text { que producen frutas. }\end{array}$ \\
\hline
\end{tabular}

Tabla 24. Descripción de los componentes del Proyecto de Aula "Criando lombrices y sembrando plantas"

\subsection{Descripción de las fases}

A continuación se profundizan algunos aspectos de las fases anteriormente señaladas, como orientaciones para el maestro.

\section{FASE 1: CULTIVEMOS LA VIDA}

Esta es una fase de Presentación - Organización:

\section{Actividades:}

Se recomienda al profesor hacer una lectura precia de los documentos vinculados a la construcción del lombricultivo y de la huerta escolar. También, revisar los videos y realizar sus adecuaciones a lengua de señas colombiana (LSC). Algunos de estos materiales se sugieren en la parte dedicada a materiales en esta fase.

La actividad presentar el proyecto a los estudiantes y a los padres de familia, se propone a través de un video que muestre el lombricultivo y el uso de humus para una huerta. Posteriormente, propiciar un espacio para preguntas, inquietudes y sugerencias. Aunque la finalidad del video es la misma, tanto para padres de familia como para estudiantes, se recomienda tener en cuenta los siguientes parámetros de escogencia del mismo:

- Duración. El video no debe superar los 25 minutos para los estudiantes y 35 para padres.

- Estructura. El video para los estudiantes debe tener una estructura y una propuesta comunicativa concordante con sus edades; en lo posible, a través de dibujos animados, de títeres o de secuencias de imágenes que cambien constantemente. Para los padres puede presentarse a modo documental o entrevistas con expertos.

- Calidad. El video deberá tener una calidad que permita la proyección en un videobeam, si es el caso.

- Idiomas y subtítulos. Para los estudiantes debe contener presentación en lengua de señas colombiana (LSC) en un recuadro que avance con el video. 
Para los padres, según se observe la necesidad, puede tener la opción de subtítulos o LSC.

Como alternativa al video (en caso de no conseguirlo o de querer complementarlo), se recomienda realizar una salida pedagógica a lugares en donde se realice el proceso del lombricultivo o se cultive una huerta. Esto, con el fin de que los estudiantes puedan tener un contacto directo con lo que se espera realizar en el proyecto.

Para la organización de los grupos y sus funciones, se sugiere tener en cuenta los gustos y las preferencias de los estudiantes; por ejemplo, los que deseen conseguir recursos para la construcción del lombricultivo o los que prefieran hacerlo para la construcción del huerto.

Se sugiere realizar los talleres 1, 2, 3 y 4, propuestos como apoyo a la fase durante las distintas actividades: la presentación del video, la identificación de materiales y la organización de los equipos que buscarán los materiales.

\section{Recursos:}

Se identifican tres tipos de recursos para la fase: los que empleará el profesor, los que se requieren para las actividades y los dispositivos didácticos que se vinculan a esta fase, tales como los talleres y los juegos.

En lo que concierne a los recursos para el profesor, sugerimos consultar los siguientes tipos de documentos cuando el profesor lo considere necesario durante el desarrollo del proyecto:

1) Documentos de profundización. Elaborados por el equipo proponente (presentados en la parte I de esta obra), entre los que se proponen: "Ambientes didácticos: Micromundo de la aproximación y la precisión de cantidades"; "Desarrollo del sentido numérico en los micromundos de la aproximación y la precisión de cantidades"; "Desarrollo de relaciones con el espacio y las formas"; "Desarrollo del lenguaje y la discursividad en el niño"; "El dispositivo juego".

2) Documentos virtuales relacionados con temáticas del proyecto. Se consideran las páginas Web sugeridas en este proyecto o las búsquedas personales que pueda hacer el profesor.

3) Documentos virtuales elaborados por el equipo, como los videos sobre vocabulario del campo semántico del conteo en lengua de señas y el repertorio léxico de este campo.

En lo que concierne a los materiales requeridos para las actividades, en los talleres se detallan este tipo de materiales. 
En lo que concierne a los materiales asociados a los dispositivos didácticos, se cuenta con el conjunto conformado por los documentos de profundización y los materiales para la manipulación de estudiantes, como los juegos.

Como ejemplos de recursos para el profesor, encontramos páginas Web que ofrecen documentos de profundización sobre el lombricultivo y el huerto como las siguientes:

En:

http://www.manualdelombricultura.com/manual/index.html

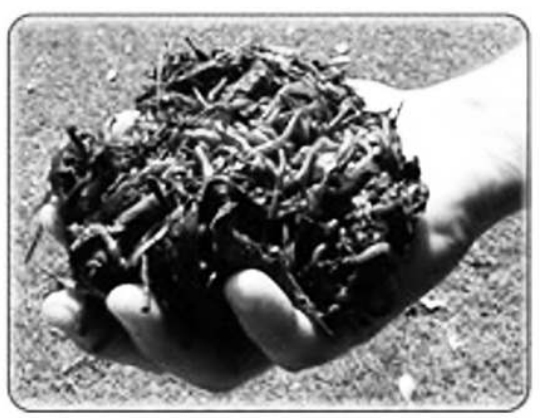

Se encuentra: Historia, conceptos recomendaciones

En:

http://www.scribd.com/doc/14746751/Manual-de-Lombricultura-2003:

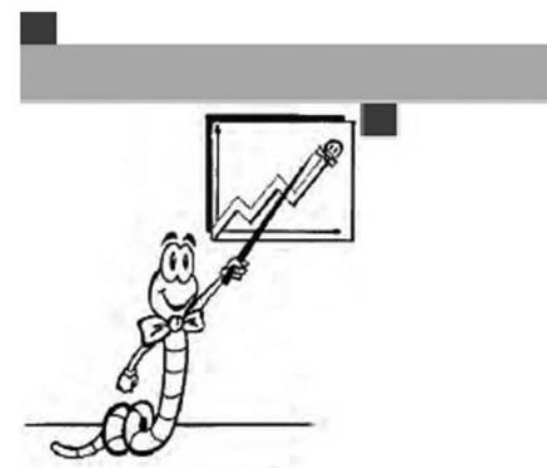

Manual de Lombricultura 2003
En:

http://huertasescolares.wordpress.com se encuentra la siguiente experiencia

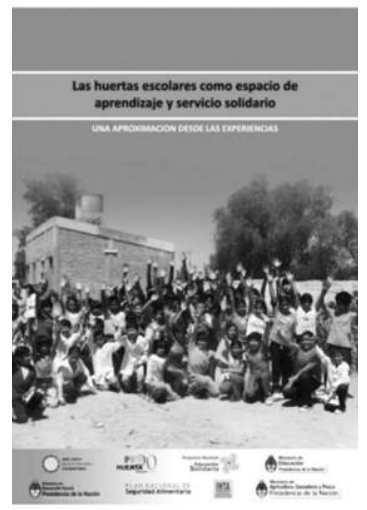

En:

http://www.fao.org/docrep/009/a0218s/ a0218s00.HTM: Crear y manejar un huerto escolar

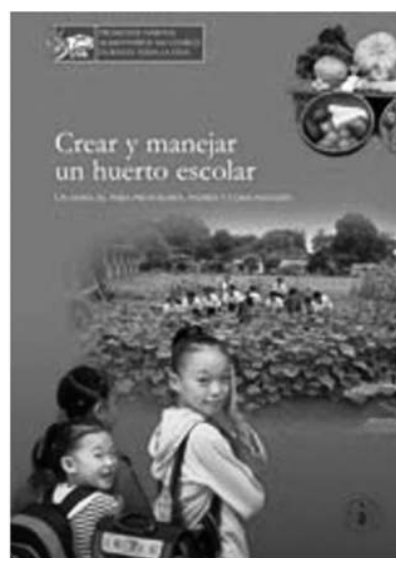


En:

http://concursos.colombiaaprende.edu.co/expediciones_botanicas/ver_proyecto_de_aula. php? $\mathrm{id}=193$

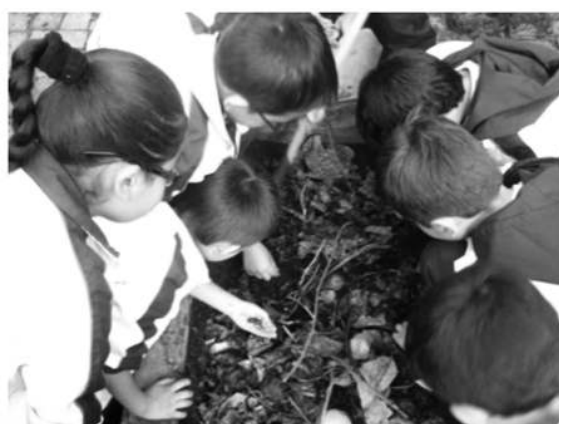

Descripción de proyecto de aula en Madrid Colombia
En:

http://www.ingurumena.ejgv.euskadi.net/ r49-6172/es/contenidos/publicaciones/huerto_ escolar/es_10677/adjuntos/huerto_escolar.pdf

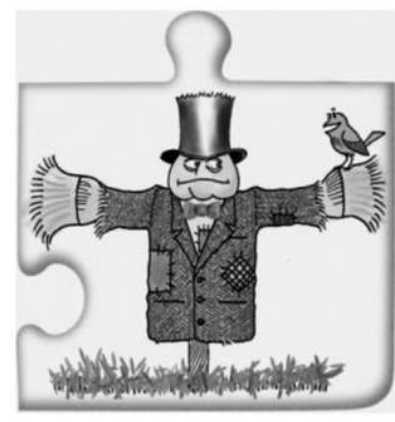

Guía para desarrollo curricular de un huerto

Otras páginas donde se pueden encontrar videos de lombricultivo o de semillero son:

\begin{tabular}{|c|c|c|}
\hline $\begin{array}{c}\text { Tipo de } \\
\text { construcción }\end{array}$ & Página web & Sugerencias \\
\hline Lombricultivo & $\begin{array}{l}\text { http://www.youtube.com/wat- } \\
\text { ch?v=AbQNcTky3X8 }\end{array}$ & $\begin{array}{l}\text { Adecuado para la construcción del lombricultivo } \\
\text { con caja de icopor. }\end{array}$ \\
\hline Lombricultivo & $\begin{array}{l}\text { http://www.youtube.com/wat- } \\
\text { ch?v=9MWzWCO8_o4 }\end{array}$ & $\begin{array}{l}\text { Adecuado para la organización de la fase de cre- } \\
\text { cimiento. }\end{array}$ \\
\hline Lombricultivo & $\begin{array}{l}\text { http://www.youtube.com/wat- } \\
\text { ch?v=3WLXfuMoFCE }\end{array}$ & $\begin{array}{l}\text { Adecuado para la presentación para padres } \\
\text { oyentes. }\end{array}$ \\
\hline & $\begin{array}{l}\text { http://il.youtube.com/watch?- } \\
\text { v=tPZUJdad34U }\end{array}$ & $\begin{array}{l}\text { El lumbricario adecuado para otro tipo de lombri- } \\
\text { cario fase de construcción. }\end{array}$ \\
\hline & $\begin{array}{l}\text { http://www.youtube.com/wat- } \\
\text { ch?v=H9ZiGBekZ7Y }\end{array}$ & $\begin{array}{l}\text { Adecuado para mirar el tipo de comida que se le } \\
\text { debe dar a las lombrices. }\end{array}$ \\
\hline & $\begin{array}{l}\text { http://www.youtube.com/wat- } \\
\text { ch?v=GHdOHbJHsXg }\end{array}$ & $\begin{array}{l}\text { Adecuado para la presentación para padres y pro- } \\
\text { fesores. }\end{array}$ \\
\hline \multirow[t]{2}{*}{ Semillero } & $\begin{array}{l}\text { http://www.youtube.com/wat- } \\
\text { ch?v=HuEFodx-qrU }\end{array}$ & $\begin{array}{l}\text { Adecuado para niños sordos, hay video en LSC de } \\
\text { apoyo. }\end{array}$ \\
\hline & $\begin{array}{l}\text { http://www.youtube.com/wat- } \\
\text { ch?v=ZmzaS89f4nY }\end{array}$ & $\begin{array}{l}\text { Adecuado para la fase de construcción puede ir } \\
\text { acompañado de un video con indicaciones pre- } \\
\text { vias y posteriores. }\end{array}$ \\
\hline
\end{tabular}

Tabla 25. Páginas web recomendadas para Fase 1.

En cuanto a recursos como el juego se pueden considerar juegos adquiridos por el Proyecto y adaptados por el equipo investigador, tales juegos fueran 
estudiados desde el punto de vista didáctico para ver su capacidad de propiciar actividad matemática y $\operatorname{son}^{32}$ :

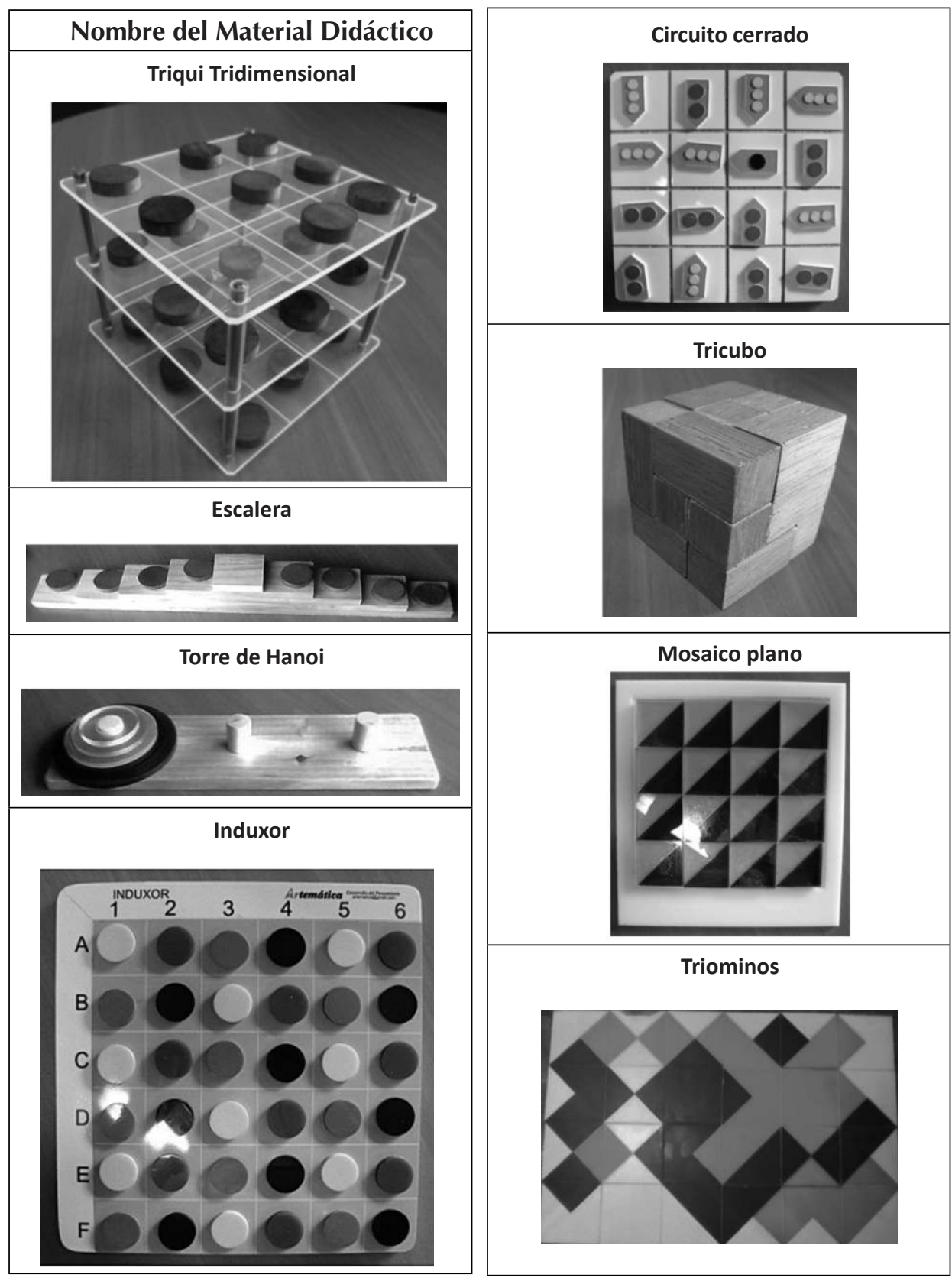

32. Estas fotos corresponden a juegos adquiridos por el Proyecto y adaptados por el equipo investigador. Están disponibles en el Grupo de Investigación Interdisciplinaria en Pedagogía del Lenguaje y las MatemáticasGIIPLyM, sede Universidad Distrital FJC, Bogotá, Colombia. 
Roles: El papel del profesor se centra en organizar y en orientar la realización del proyecto y la definición de los responsables del proyecto.

Los estudiantes y padres de familia, pueden generar todo tipo de inquietudes y sugerencias del video o la salida pedagógica y adquirir responsabilidades para las funciones que sean designadas por el profesor.

\section{FASE 2: LA VIDA PARA LAS PLANTAS Y LAS LOMBRICES}

Esta es una fase de construcción colectiva.

\section{Actividades:}

Para la construcción del criadero se recomienda tener en cuenta los siguientes aspectos: en lo posible, realizar una salida pedagógica a un centro de producción de lombrices o a un huerto escolar en funcionamiento. Esta actividad contribuirá a enriquecer aún más el proyecto, dado que posibilita la interacción del estudiante con el entorno natural de semilleros y lombricultivos.

Para la actividad de construcción del lombricultivo, se deben tener en cuenta los siguientes aspectos:

- Lugar de construcción. Entre los integrantes del proyecto se escogerá el lugar más adecuado, dentro de la institución, para la construcción del criadero.

- Materiales necesarios para la construcción del criadero. Para este momento es fundamental el trabajo en equipo y la coordinación de todos los estudiantes, para distribuirse y comprometerse a traer al colegio los materiales necesarios para la construcción del lombricuario.

- Lugar de almacenamiento de la comida para las lombrices. El grupo que quede a cargo del almacenamiento de la comida, establecerá el lugar, con aprobación del profesor.

Para la actividad de construcción del semillero, se deben tener en cuenta los siguientes aspectos:

- Lugar de construcción. Debe tener una iluminación mínima para el cultivo y tener un área en proporción con el espacio y el número de semillas y de lombrices. Esto, con el fin de evitar que después haya mucho humus y pocas plantas o poco humus y muchas plantas.

- Materiales necesarios para la construcción. Se proponen las mismas recomendaciones dadas en la construcción del criadero, pero en relación con en semillero.

- Trasplante de las plantas cuando se vea la necesidad. Si el cultivo empieza con semillas individuales en recipientes que contienen agua y algodón, éstas en algún momento deben trasplantarse a tierra húmeda. 


\section{Recursos:}

A continuación se visualizan los más necesarios:

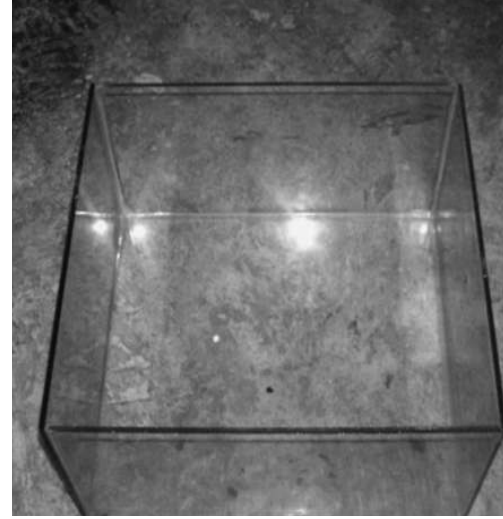

Imagen 1. Acuario.

- Un criadero de lombrices, una construcción por parte de todo el grupo, guiado por el profesor, como una de las primeras etapas del Proyecto. Se puede tomar como ejemplo, y en caso de contar con poco espacio para la realización del Proyecto, un acuario de dimensiones $30 \times 20 \times 25 \mathrm{~cm}$. Como se muestra en la imagen 3.

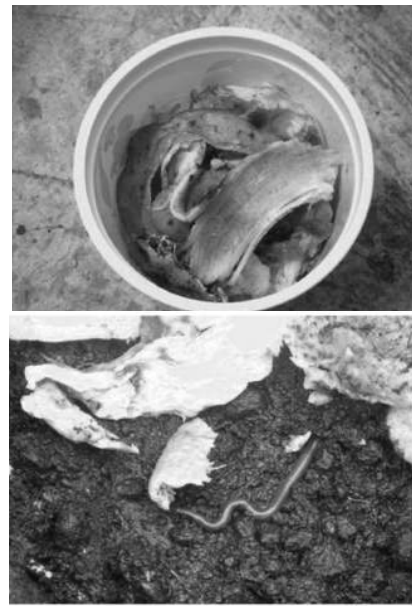

- Comida. La comida de la lombriz con la cual se sugiere trabajar.

- Incluye cualquier desecho orgánico; sin embargo, podemos escoger cinco clases de desecho que contengan ciertas características (uno por cada día), que se incluirán en el cronograma de alimentación diaria de la lombriz (ver tabla 3). Esta se colocará sobre la tierra como se muestra en la siguiente imagen:

Imagen 3. Alimento y abastecimiento. 
Para el semillero se requiere:

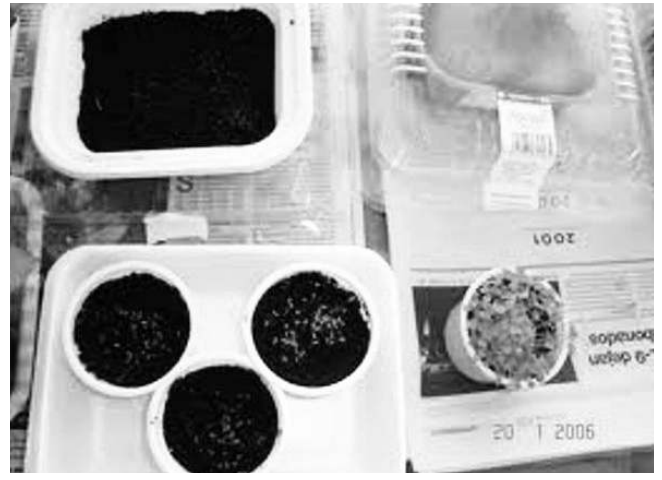

Imagen 4. Materiales

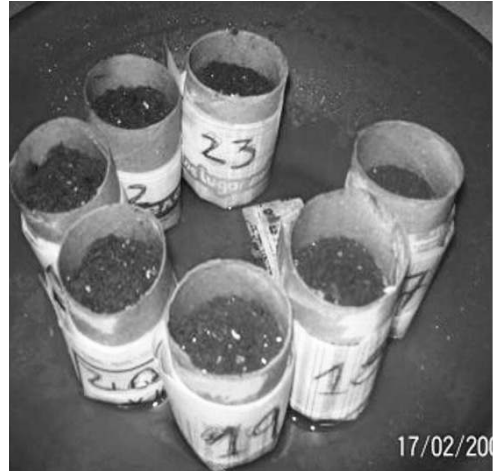

Imagen 5. Otro tipo de materiales no plásticos.

Tierra, vasos plásticos, semillas, bandejas para colocar los vasos.

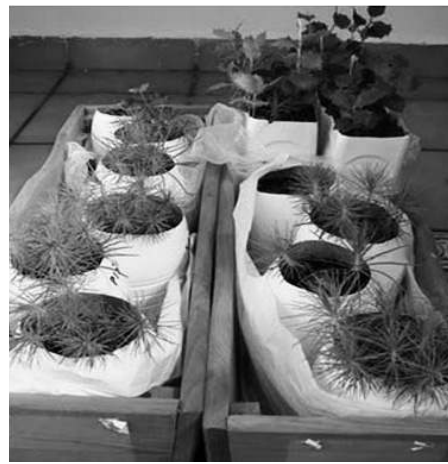

Imagen 6. Bandejas donde se pueden colocar

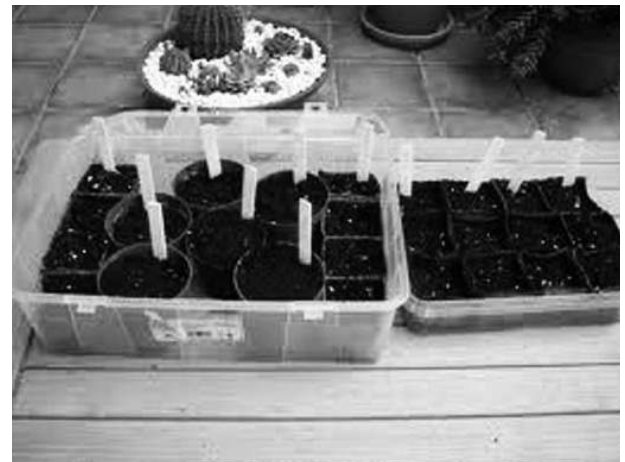

Imagen 7. Etiquetas para marcar los semilleros

Se sugiere construir primero el lombricultivo, porque a partir del espacio que abarque éste, se puede identificar el tamaño de la huerta escolar, la cual se puede construir a la siguiente semana de construir el lombricultivo. Es importante conocer las condiciones mínimas para crear un ambiente óptimo en el criadero de lombrices y determinar, con los estudiantes, cuál sería el espacio para su construcción. Además, es necesario conocer el proceso que se debe llevar a cabo para la extracción del humus, así como también las decisiones que se tomen cuando las lombrices superen en cantidad el espacio destinado para ellas.

Para el semillero, se sugiere realizar un estudio previo de los tipos de frutas que se cultivan en Bogotá o en la región donde se construye el semillero; identificar las que germinan más rápido y proporcionan cosecha en menos tiempo. 
Roles:

En esta fase el profesor y los estudiantes estarán a cargo de la construcción del lombricultivo y la huerta escolar. Para ello, se pueden conformar grupos de trabajo con responsabilidades específicas para cada construcción; por ejemplo, nombrar el grupo que se encargará de traer las lombrices, el grupo que se encargará de traer las semillas para la huerta y, el grupo que se encargará de traer materiales, en caso que la institución no los tenga.

\section{FASE 3: CRECIMIENTO DE PLANTAS Y LOMBRICES}

Esta es una fase de atención y cuidado del lombricuario y del semillero-

\section{Actividades:}

Dado el momento de sostenimiento de esta fase, es importante llevar un registro de todas las funciones que se cumplan a diario con respecto al mantenimiento del lombricultivo (tipo y cantidad de comida que se les suministra a diario a las lombrices); también, el registro del proceso de crecimiento de la huerta (cambios en torno al crecimiento de la planta). Los estudiantes, de acuerdo con el nivel escolar, pueden llevar un diario escrito o también utilizar marcas simbólicas que representen alguna de estas funciones. El profesor deberá establecer, junto con los estudiantes, el tipo de marca que se asociará con cada una de las funciones del día, de tal manera que se logre una comprensión de las actividades necesarias para mantener el lombricultivo y la huerta y una conciencia de la responsabilidad individual y colectiva, en este proceso.

El profesor puede solicitar, al final de la semana, que los estudiantes realicen un resumen de la cantidad de frutas que se le proporcionó a las lombrices durante esa semana, especificando cuántas veces a la semana se les dio esa fruta. A continuación se visualiza el caso de una semana de alimentación con las frutas especificadas en las ilustraciones por día de la semana. El registro se propone con dibujos de la fruta, en caso de que los estudiantes no puedan escribir o si el profesor considera más conveniente este tipo de representación.

\begin{tabular}{|l|l|l|l|l|}
\hline LUNES & MARTES & MIERCOLES & $\underline{\text { JUEVES }}$ & $\underline{\text { VIERNES }}$ \\
\hline 0 & 0 & 0 & 0 \\
\hline
\end{tabular}

Tabla 26. Registro de alimentación diaria. 
Así, a partir de esta ilustración, el profesor puede preguntar:

$\checkmark$ ¿Cuál fue la fruta que más se le dio a las lombrices?

$\checkmark$ ¿Cuál fue la fruta que menos se le dio a las lombrices?

$\checkmark$ ¿Qué día de la semana se les dio más frutas?

$\checkmark$ ¿Qué día de la semana se les dio menos frutas?

\section{Recursos:}

La fase exige el empleo articulado de materiales y la realización de actividades y de procedimientos para el mantenimiento del criadero y de la huerta. Por ejemplo, seguir el cronograma establecido para la cría de lombrices, utilizar el humus para la huerta y, con la ayuda de padres, garantizar el buen uso de todos los componentes que se puedan generar al realizar este tipo de proyectos: el crecimiento de las lombrices, la producción del humus y los cultivos de la huerta.

El cronograma ha de ser un instrumento visible y accesible para todos los estudiantes. Se recomienda ubicarlo en el salón de clase, o donde se considere pertinente, para que todos estén al tanto de la alimentación que se les provee a las lombrices. El estudiante encargado de suministrar el alimento, puede escribir o registrar diariamente en el cronograma algunas características del mismo (textura, olor o sabor). Este registro puede variar; por ejemplo, a cambio de escribir en el cronograma la comida que se le suministra a la lombriz, pueden realizar dibujos alusivos.

A continuación se muestra un ejemplo de la forma como se puede organizar dicho cronograma: se especifica el día, las características del abono de la lombriz, el o la (s) responsable (s), en caso que se decida trabajar en grupos y, una alternativa de presentación del abono a la lombriz.

\begin{tabular}{|l|l|l|l|l|l|}
\hline & Lunes & \multicolumn{1}{|c|}{ Martes } & Miércoles & Jueves & Viernes \\
\hline $\begin{array}{l}\text { Características } \\
\text { del abono a la } \\
\text { lombriz. }\end{array}$ & $\begin{array}{l}\text { Cáscara de manzana. Fruta } \\
\text { dulce de textura suave y } \\
\text { color rojizo, entre otras ca- } \\
\text { racterísticas que evidencien } \\
\text { los estudiantes. }\end{array}$ & & & \\
\hline Responsable. & $\begin{array}{l}\text { Estudiante 1 o grupo de } \\
\text { estudiantes. }\end{array}$ & & & \\
\hline $\begin{array}{l}\text { Forma de } \\
\text { presentar a } \\
\text { los demás } \\
\text { estudiantes } \\
\text { el abono a la } \\
\text { lombriz. }\end{array}$ & $\begin{array}{l}\text { Un cuento en el que pre- } \\
\text { sente la forma de adquirir } \\
\text { la cáscara de la manzana. } \\
\text { "el día de ayer compré en la } \\
\text { esquina de la cuadra..." }\end{array}$ & & & \\
\hline
\end{tabular}

Tabla 27. Cronograma de alimentación 
También se puede considerar llevar un tipo de diario para registro y conclusiones. Este será Ilenado, en la medida de lo posible, por los estudiantes, o también por el profesor, de acuerdo con las preguntas que el profesor proponga para responder. Estas preguntas estarán enfocadas a la construcción de la cantidad.

Para la construcción del huerto se propone considerar el espacio, que bien puede ser reducido. Por ejemplo, se puede utilizar una maceta o un espacio con zona verde de 1.30 por $1.30 \mathrm{~cm}$. En cualquier caso, el objetivo es utilizar el humus de las lombrices para propiciar el crecimiento del huerto. También se puede manejar el espacio de acuerdo con la cantidad de humus que se produzca, conservando una proporción entre en éste y la cantidad de plantas por abonar.

\section{Roles:}

En esta fase el maestro debe establecer un cronograma de alimentación para las lombrices y de riego para las semillas, en cada día de la semana (lunes a viernes). Los alimentos han de contener características físicas específicas (olor, sabor, textura) y es responsabilidad de cinco estudiantes, uno por cada día, traer el sustento de las lombrices. En esta fase se espera una comunicación con los padres de familia, ya que al tener ciertas características de alimentación por días, va a depender de ellos que los alimentos lleguen de acuerdo con la especificación establecida por el cronograma.

A partir de este momento los estudiantes estarán registrando, en una especie de diario, todo lo referente a la cría de las lombrices. Por ejemplo, cualquier cambio de volumen o de longitud de la lombriz, o de los desechos que se les proporcionen como comida a las lombrices. En lo posible, se sugiere registrar cambios externos en los alimentos (más dulce o menos dulce).

Por último, a medida que el abono sea destinado para las plantas, también se deben registrar los cambios que se puedan observar. Todo esto, con el fin de generar las características más apropiadas, tanto para la crianza de la las lombrices como para el proceso de extracción de humus y el abastecimiento para las plantas.

\section{PRODUCTO FINAL Y EVALUACIÓN DEL PROYECTO}

Con el desarrollo del Proyecto de Aula, se espera como ya se mencionó, la construcción y mantenimiento de un criadero de lombrices y un semillero. Sin embargo, durante este proceso, se espera que los estudiantes relacionen los cambios de longitud de la lombriz o de las plantas a factores externos; por ejemplo: "la lombriz crece más rápido cuando le damos de comer frutas más dulces" ó "la planta crece más lenta cuando no tiene la suficiente luz". 
Cuando se logra relacionar este tipo de cambios a factores como la luz o la alimentación, el estudiante ve la necesidad de describir esos factores a través de algunas características que perciben con los sentidos; por ejemplo, al hablar de luz se asocia con la intensidad; para el caso de la comida, con el sabor y el olor; además de otros factores como la longitud o la rapidez de crecimiento con la cantidad de comida o con el abono que se proporciona. Así, en toda esta experiencia, aparece la cantidad en cada uno de estos aspectos.

La evaluación del Proyecto de Aula se relaciona principalmente con el objetivo planteado para el mismo: "Construir un criadero de lombrices apto para la producción de humus, destinado a utilizarse como abono en una huerta". Este componente debe dar cuenta de la formulación, ejecución, producto y seguimiento del criadero. Así, se trata de un proceso que acompaña al Proyecto desde el comienzo y que puede estipularse para cada fase de manera particular, estableciendo un tiempo en cual se muestre el alcance que ha tenido el criadero y la huerta.

El Proyecto debe evaluar el proceso llevado a cabo y los resultados obtenidos por cada fase. En este proceso, es el profesor quien identifica los obstáculos y los logros que aparecen en cada una de las fases. Para la valoración de los resultados obtenidos, se puede utilizar como complemento la autoevaluación; con ella se espera que los estudiantes reconozcan y señalen sus propios logros y las dificultades que se presentaron para el desarrollo de cada una de las fases.

Otros aspectos que se proponen como parte de la evaluación del proyecto son los siguientes:

- Relación con la enseñanza de las matemáticas: identificar y valorar aspectos acerca de la noción de cantidad que se pueden evidenciar en cada uno de los estudiantes que hicieron parte del Proyecto de Aula.

- Desarrollo de lenguaje en los estudiantes: identificar el avance en la comprensión y apropiación de recursos léxicos y discursivos en lengua de señas colombiana LSC y en español escrito, alrededor de la experiencia de construir un lombricultivo y un huerto y en relación con los micromundos de la aproximación y de la precisión.

- Interés por el desarrollo personal y colectivo: observar y valorar destrezas y actitudes que se desarrollan al realizar un Proyecto como éste, que beneficie no sólo al estudiante sino también a su entorno.

- Relaciones grupales y con la comunidad: establecer y valorar las relaciones interpersonales que generaron los estudiantes, su trabajo en equipo y su liderazgo, así como la responsabilidad para la realización de las actividades.

- El docente deberá registrar los inconvenientes que surjan durante la realización del Proyecto, además del trabajo por parte de los estudiantes, enfatizando en sus compromisos y el trabajo en grupo, teniendo en cuanta la participación y los compromisos de cada uno de los estudiantes. 


\section{RECOMENDACIONES PARA LA ARTICULACIÓN DEL PROYECTO DE AULA CON LOS OTROS DISPOSITIVOS Y CON EL SISTEMA DE PROFUNDIZACIÓN}

Dado que el dispositivo proyecto de aula hace parte de un sistema didáctico y configura un componente del ambiente didáctico general, en la perspectiva del profesor, y un ambiente de aprendizaje, en la experiencia de los estudiantes, se reitera la necesidad de articular su desarrollo a los demás elementos del sistema. Por ello, se propone que el proyecto de aula, como dispositivo didáctico, exige, para su desarrollo, considerar otros elementos didácticos que lo complementan de distintas maneras, tales como: en profundización teórica sobre los contenidos o sobre los mismos dispositivos o el sistema didáctico (documentos de profundización); en opciones de desarrollo de objetivos de aprendizaje y estratégicos (el sistema de talleres y el conjunto juegos). Veamos estas formas de complemento y de relación.

\section{1) Proyecto de aula y su articulación a los otros dispositivos}

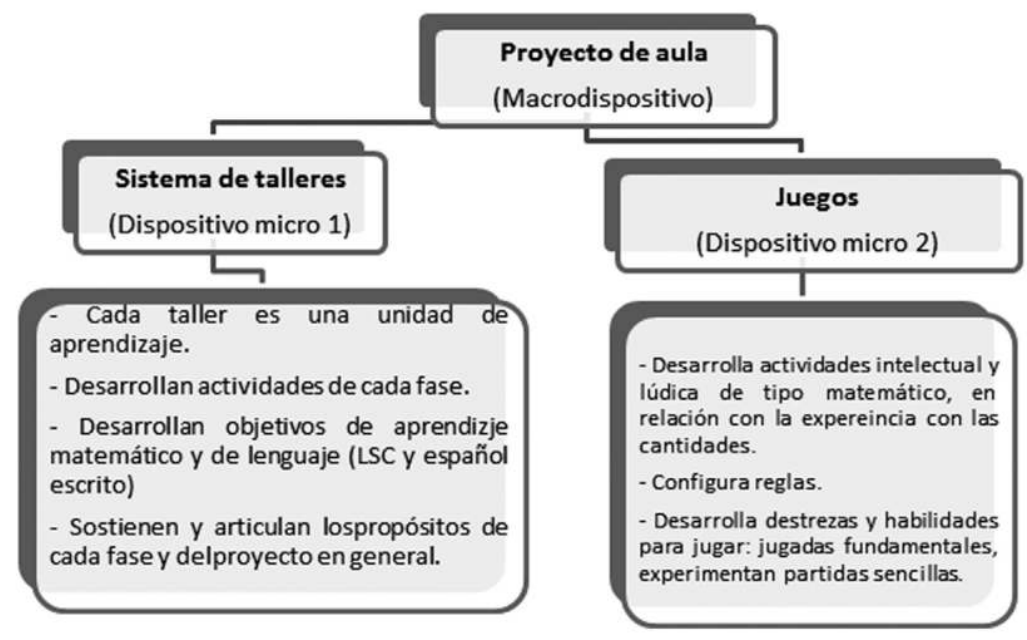

Esquema 5. Proyecto de aula en relación con dispositivos

En su conjunto, se propone una estructura de relaciones entre los tres dispositivos, considerando el Proyecto de Aula el dispositivo articulador y el taller y el juego, como los dispositivos que, aunque independientes, se articulan al proyecto para su desarrollo efectivo y para hacer concretas las experiencias que permiten alcanzar objetivos didácticos (realizar experiencia matemática y de

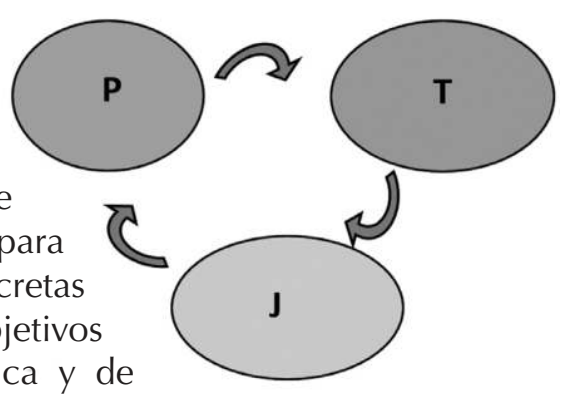


lenguaje y discurso en el aula de niños sordos). A continuación se presentan relaciones particulares entre los tres dispositivos.

En primera instancia, la dinámica de trabajo propuesta en la relación talleres -proyecto de aula, configura el desarrollo de unidades de aprendizaje, a través de cada taller y en relación con la misma fase y entre fases. Es decir, cada conjunto de talleres de una fase constituyen una gran unidad y todos los talleres de las tres fases establecen una macrounidad de aprendizaje orientada a:

- Hilar hacia y conservar el propósito del dispositivo principal, potenciando la profundización en aspectos de aprendizaje de los micromundos de la aproximación y de la precisión.

- Implementar actividades particulares e independientes, mediadas por los propósitos particulares de cada taller, pero complementarias con el dispositivo principal y susceptibles de ser aplicadas a la par con ese dispositivo (el proyecto de aula). En este sentido, resulta ventajoso aplicar los talleres, puesto que han sido pensados para que se apoyen entre sí, de modo tal que al ser activados conjuntamente, sea más probable obtener mejores resultados, gracias a su carácter complementario.

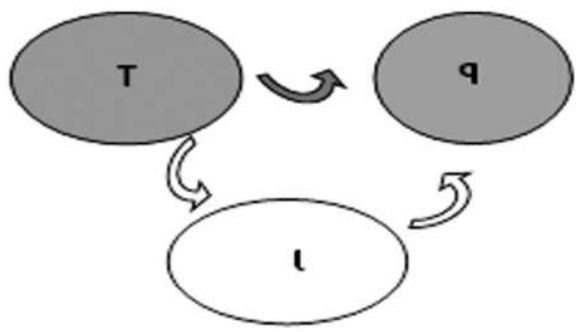

La figura ilustra la relación entre Proyecto de Aula (PA) y talleres

Cabe aclarar que no necesariamente hay que utilizar juntos todos los talleres. Así, en caso de no tener disponibilidad de tiempo, recursos, o cualquier otra condición que sea ineludible para implementar alguno de los dispositivos, el otro pueda actuar por sí solo, o acompañado de las acciones o dispositivos que el profesor considere constituyan un aporte. Se subraya que aunque se pueda implementar el proyecto de aula sin el sistema de talleres, o viceversa, se recomienda utilizarlos juntos, ya que de cierta manera, el proyecto de aula justifica a los talleres y los talleres permiten reflexionar acerca del proyecto de aula. En el transcurso de los talleres se resaltan los aspectos en los cuales el profesor puede realizar modificaciones. También se sugieren algunas opciones y posibilidades para hacerlo, dándole así una estructura flexible al sistema de talleres que posibilita su aplicación en diferentes contextos.

En segunda instancia, la relación proyecto de aula- dispositivo juego nos permite observar que el juego cambia el aula y cambia las formas de interacción en el aula. Además, permite la introducción y articulación con otros dispositivos como: el taller, el proyecto de aula, la resolución de problemas, para el 
desarrollo y la consolidación de conocimiento. Así, el juego como dispositivo didáctico, involucra varias dimensiones (Vergel et al., 2006): la dimensión matemática: relación entre el juego como actividad cultural y la matemática como una actividad cultural desarrollada" (Vergel et al., 2006: 3). Establecer relaciones entre contenido matemático en la actividad desarrollada (aritmético, geométrico, algebraico, estadístico, entre otros) y diversas actividades matemáticas y culturales como: los jugadores, las jugadas, las reglas, los juguetes y las marcas de tiempo. Presentándose la relación coexistente entre el jugador y el resolutor, (cuando el jugador procura resolver el problema que propone el juego desde su accionar).

La dimensión cognitiva: la relación entre el desarrollo del sujeto y el juego genera procesos dinamizados por los juegos y su efecto en el aprendizaje de las matemáticas" (Vergel et al., 2006: 5). Involucra también, dado que no tiene restricción para presentarse en la vida del hombre, aspectos de su desarrollo tales como: la afectividad, la actividad simbólica y la experiencia con la realidad, la motricidad y el uso de instrumentos que intervienen en el juego. Todos estos aspectos implican que el juego cumpla una función muy importante en el desarrollo cognitivo del sujeto. "Las formas de significación se elaboran por un progresivo ejercicio de representación, que desde el "hacer como si" hasta el producir un dibujo o una palabra: la representación simbólica en el juego es esencialmente una determinada forma de lenguaje en un estadio temprano, una forma que nos conduce directamente al lenguaje escrito" (Vergel et al., 2006: 7) eh ahí la importancia de usar diversos registros semióticos.

La dimensión comunicativa: necesita de organizaciones discursivas como la narración, que permite la presentación del juego con sus reglas y e instrumentos; la explicación que ayuda para la comunicación de las estrategias empleadas; la argumentación que concede justificar la legitimidad de sus estrategias y la demostración que garantiza el resultado pretendido en la jugada final (como los juegos que exigen el menor número de movimientos) (Vergel et al., 2006).

Finalmente, la dimensión sociomatemática que considera el sujeto en un contexto social con necesidades de interacción. Diversas formas de interacción son promovidas de acuerdo al juego puesto en escena" (Vergel et al., 2006: 8).

Desde el punto de vista anterior, el juego es un microambiente altamente propicio para el desarrollo de aspectos matemáticos y lingüísticos en relación con los propósitos del proyecto de aula y su esquema de relación con éste sería la que se visualiza aquí.

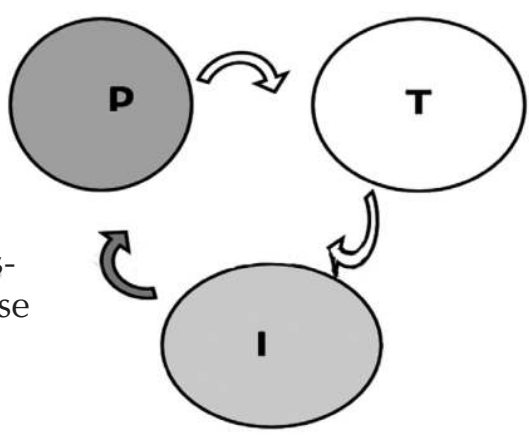




\section{2) Proyecto de aula y su articulación con los documentos de profundización}

Hemos denominado como profundización al componente del sistema didáctico dedicado a soportar teórica y epistemológicamente el proyecto de aula como ambiente de aprendizaje y como estrategia pedagógica y didáctica (Parte I de esta obra). Este componente se presenta en forma de documentos digitales y físicos, y contiene planteamientos teóricos tendientes a explicar los distintos aspectos involucrados en el proyecto de aula y referencias para el trabajo en el aula de matemáticas de niños sordos de niveles iniciales, tales como:

\begin{tabular}{|c|c|c|}
\hline \multicolumn{3}{|c|}{ PROYECTO DE AULA } \\
\hline $\begin{array}{l}\text { PROFUNDIZACIÓN } \\
\text { EN SISTEMA } \\
\text { DIDÁCTICO }\end{array}$ & $\begin{array}{c}\text { PROFUNDIZACIÓN EN } \\
\text { APRENDIZAJE MATEMÁTICO }\end{array}$ & $\begin{array}{l}\text { PROFUNDIZACIÓN DESARROLLO } \\
\text { DE LENGUAJE }\end{array}$ \\
\hline \multirow{3}{*}{$\begin{array}{l}\text { El sistema didácti- } \\
\text { co como un "ambiente } \\
\text { didáctico". }\end{array}$} & $\begin{array}{l}\text { Las trayectorias sobre el paso } \\
\text { de las cantidades al sentido nu- } \\
\text { mérico y del micro-mundo de las } \\
\text { cantidades a la adición. }\end{array}$ & $\begin{array}{l}\text { - El desarrollo del lenguaje y de la discursi- } \\
\text { vidad en el aula. } \\
\text { - Desarrollo lingüístico-discursivo y bilin- } \\
\text { güismo en niños sordos. }\end{array}$ \\
\hline & $\begin{array}{l}\text { - El micromundo de la aproxima- } \\
\text { ción de cantidades. } \\
\text { - El micromundo de la precisión en } \\
\text { cantidades discretas. } \\
\text { - De los micromundos de la apro- } \\
\text { ximación y de la precisión a las } \\
\text { operaciones aditivas. } \\
\text { - Micromundo de la aproximación } \\
\text { y de la precisión de la forma. }\end{array}$ & $\begin{array}{l}\text { - Repertorio léxico: El campo semántico } \\
\text { del conteo. } \\
\text { - Lexicón en LSC: de los micromundos de la } \\
\text { aproximación y de la precisión. }\end{array}$ \\
\hline & $\begin{array}{l}\text { Juego y desarrollo aritmético y } \\
\text { geométrico. }\end{array}$ & $\begin{array}{l}\text { Referencias para la experiencia literaria } \\
\text { en el aula. }\end{array}$ \\
\hline
\end{tabular}

Tabla 28. Proyecto de aula y su articulación con profundización

- El propósito de profundizar en el sistema didáctico se orienta a fundamentar la propuesta didáctica y a comprender las relaciones entre los dispositivos propuestos: proyecto de aula, taller y juego. Básicamente se fundamenta la opción didáctica del diseño por la categoría "ambiente": didáctico y de aprendizaje y establecer, desde allí, la configuración de dispositivos didácticos.

- El propósito de profundizar en matemáticas y su aprendizaje, es ofrecer un referente epistemológico que dé soporte a las decisiones y a las acciones de enseñanza de las matemáticas por parte del profesor y que disponga de un referente para la evaluación de las actividades propuestas y de los resultados 
con los estudiantes. Se presentan elementos que orientan el desarrollo de procesos matemáticos, mediante la articulación de trayectorias identificadas como rutas que sigue el proceso de desarrollo del sentido numérico y del sentido geométrico y el mundo de las experiencias en el micromundo de la aproximación y de la precisión. Se complementa con una reflexión sobre el juego como dispositivo didáctico y su papel en el desarrollo aritmético y geométrico.

El propósito de la profundización en lenguaje y discursividad es ofrecer al profesor un referente sobre el desarrollo de lenguaje en el niño (a) en una perspectiva lingüístico-discursiva y en un contexto bilingüe y cultural de la persona sorda en el aula. Se pretende que la reflexión sobre la importancia del lenguaje en los procesos de enculturación social y académica, sea un aspecto relevante en las decisiones didácticas del profesor. Por ejemplo, que se analice la relación entre desarrollo de lenguaje, procesos de subjetivación e intersubjetividad y elaboración de conocimiento matemático en el aula. Por esta razón, la profundización en este campo también ofrece un panorama semántico del campo del conteo, orientado a consolidar un repertorio de términos susceptible de ser consultado por los profesores y, en la medida de las posibilidades, por padres y estudiantes. Adicionalmente y como complemento al repertorio léxico, se ofrece un Lexicón elaborado a partir de la recopilación de las expresiones naturales relacionadas con los micromundos de la aproximación y de la precisión, que aparecen en los talleres; esta compilación se realizó bajo dos criterios: la necesidad de generar lexicones aclaratorios para el desarrollo de estos temas y, la no existencia de señas en los diccionarios de Lenguas de Señas (consultados el de Colombia y uno de EEUU). Finalmente, se incluye un conjunto de referencias sobre literatura infantil, con destino a los profesores que quieran ampliar recursos para generar experiencia narrativa-estética con sus estudiantes.

En términos generales, el presente proyecto se configura como, como se dijo anteriormente, un ambiente de aprendizaje para estudiantes, padres y profesores y un ambiente didáctico para el profesor, pues es el escenario en el que pone en juego su propuesta didáctica, la puede observar, seguir, valorar y evaluar para una nueva puesta en escena. Así mismo, articula, naturalmente, tanto las estrategias metodológicas y los momentos de desarrollo, como los llamados teóricos y las necesidades de profundización en temáticas y en aspectos particulares que el desarrollo del proyecto permite evidenciar. 



\title{
2. Sistema de talleres del proyecto de aula
}

\author{
Dora Inés Calderón- Olga Lucía León \\ “El taller... formas de establecer puentes y conexiones \\ entre los conocimientos que se transmiten en el aula \\ y la vida que desarrollan los niños" \\ (C Freinet, citado por E. Ander Egg.)
}

\section{INTRODUCCIÓN}

El presente sistema de talleres se comporta como un dispositivo didáctico anexo al dispositivo principal (proyecto de aula). En el espíritu del sistema didáctico que se propone, se ha diseñado un sistema de talleres relacionado con las tres fases del proyecto de aula, de tal manera que se consolidó un total de 11 talleres. A la vez, configuran, por sí mismos, un ambiente de aprendizaje que se relaciona con el ambiente generado por los otros dos dispositivos: el proyecto de aula y el juego. En particular, los talleres articulan actividades cuya realización exige la participación de estudiantes, padres y profesores, desde la posibilidad de experimentar un ambiente de aprendizaje alrededor de la construcción de un lombricultivo y un huerto escolar. Con respecto al modo en que se relaciona con el proyecto de aula, se reconocen múltiples aspectos; a continuación se destacan algunos de los más importantes:

- Conservan el propósito del dispositivo principal, pero profundizan en aspectos de aprendizaje relacionados en el proyecto de aula.

- Constituyen una macrounidad de aprendizaje en su conjunto de los 11 talleres; al interior de cada fase también son una unidad de aprendizaje con respecto a los propósitos de la fase y, en su individualidad, conservan su naturaleza de unidad de aprendizaje.

- Configuran microambientes de aprendizaje, en tanto que permiten relaciones entre los actores educativos (estudiantes, profesores, padres de familia) a propósito de actividades y aprendizajes inscritos en ellas.

- Han sido diseñados para apoyar el proyecto de aula y para ser apoyados por él. De esto modo, al ser activados conjuntamente será más probable obtener mejores resultados, gracias a que se complementarían y se completarían. En el anterior sentido, es posible implementarlos a la par con el dispositivo principal.

Con respecto al diseño y la estructura del sistema de talleres se destaca que: 
- En el transcurso de los talleres se resaltan los aspectos en los cuales el docente puede realizar modificaciones, además se sugieren algunas opciones y posibilidades para hacerlo, dándole así una estructura flexible al sistema de talleres que posibilita su aplicación en diferentes contextos.

De acuerdo con sus exigencias, los talleres están compuestos por:

$\checkmark$ Orientaciones para el profesor.

$\checkmark$ Actividades para los padres de familia.

$\checkmark$ Actividades para los estudiantes: en este tipo de taller el docente debe leer el enunciado de las actividades y orientar a los estudiantes en su realización.

$\checkmark$ Actividades de evaluación para los estudiantes.

El siguiente esquema será empleado para indicar el tipo de relación entre dispositivos que se privilegia en el documento.

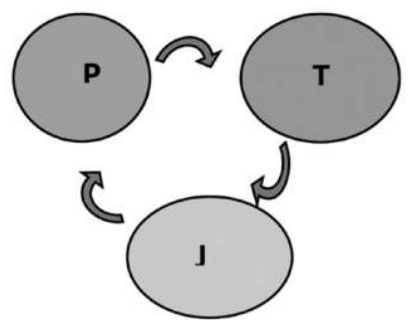

El círculo con el signo "P y está coloreado de verde, significa "Proyecto de Aula"; El círculo con el signo "T", es definido como "Taller" y el círculo en el que se encierra el signo "J", significa "Juego". Las flechas demuestran la dirección y la fuerza que posee cada dispositivo con respecto al otro. Por ejemplo, el siguiente esquema indica que en esta parte del documento, se privilegia la relación proyecto - taller.

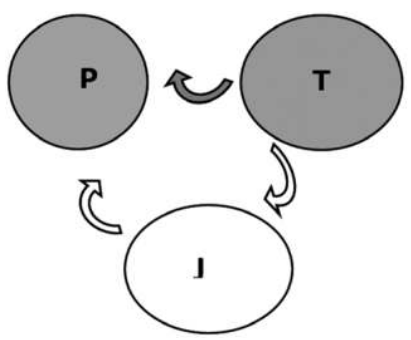

Las relaciones del dispositivo juego, frente a los otros dos, son débiles. La flecha sombreada indica que las actividades del taller fortalecen las actividades del proyecto, sin desconocer que existe una baja intensidad en la fuerza del dispositivo juego frente al proyecto o por parte del dispositivo taller frente al dispositivo juego. 


\section{RELACIÓN TALLER-PROYECTO DE AULA}

Presentamos a continuación las relaciones generales que se establecen entre el proyecto de aula y las fases y los talleres.

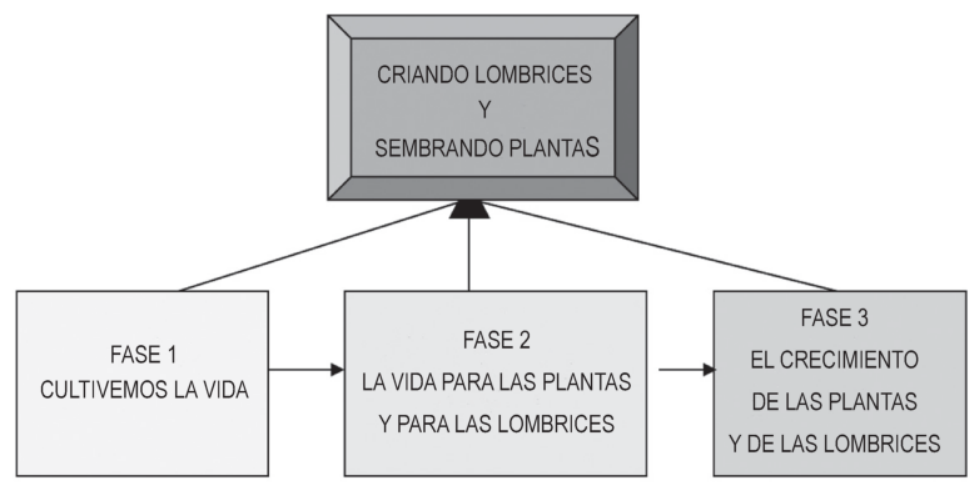

Esquema 6. Relación proyecto de aula y fases

Cada fase cuenta con un sistema de actividades que organizan sus componentes, según las exigencias que provienen de los propósitos de la fase y que, a la vez, determinan lo necesario para alcanzar los productos exigidos por ella. La evaluación de la fase está determinada por la valoración de las relaciones entre los componentes, la calidad de los productos obtenidos y el logro de los propósitos formativos, en el contexto de la experiencia en los micromundos de la aproximación y de la precisión. Es en esta perspectiva formativa que se articulan los talleres en cada fase, estableciendo y una relación entre las actividades de la fase y la experiencia en los dos micromundos aludidos.

\subsection{Organización de los talleres en el micromundo de la aproximación de la cantidad. Fase I}

Para el desarrollo de este micromundo en la Fase 1, se diseñó un conjunto de cuatro talleres. El siguiente esquema ilustra la relación de talleres.

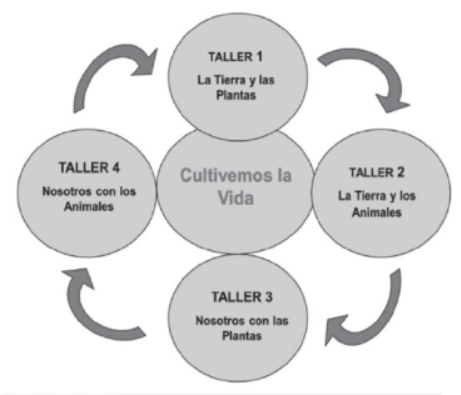

Esquema 6. Talleres del micromundo de la aproximación a la cantidad, Fase 1.

A continuación se presentan los cuatro talleres. 

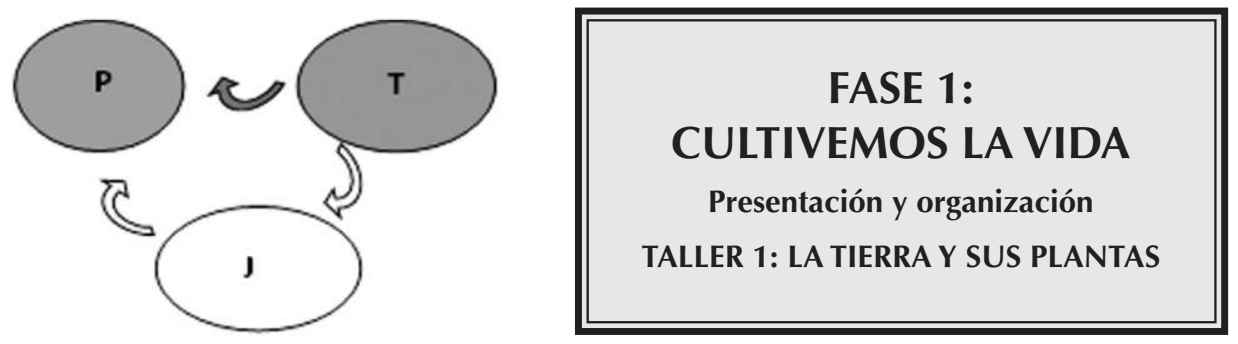

\section{A. ORIENTACIONES PARA EL PROFESOR}

\section{Objetivos}

- Presentar el semillero como un proyecto para ser construido conjuntamente por el grupo de estudiantes y con el aporte de su familia.

- Crear un ambiente de cooperación entre la familia y la escuela, para que los estudiantes sordos desarrollen procesos de percepción de la tierra y sus plantas y procesos de identificación de atributos de personas y de elementos vinculados a un semillero.

- Crear un ambiente para desarrollar experiencias que propicien condiciones para el reconocimiento de conjuntos de propiedades con sus elementos respectivos, a partir del desarrollo de la expresividad lingüístico-discursiva de la relación niño (a)-naturaleza.

\section{Presentación}

Partimos de reconocer que un trabajo mediado por el interés propio tiene mayores probabilidades de obtener resultados óptimos. Por ello, el trabajo que los estudiantes van a realizar a lo largo del sistema de talleres requiere de su interés y motivación.

Si el sistema de talleres se está implementando a la par con el proyecto de aula, la proyección de los videos sugeridos se constituirá en el inicio de esa motivación requerida. A partir de lo que los estudiantes observen en estos videos, de sus interpretaciones y de sus nociones previas, cada estudiante realizará las actividades del taller. A la vez, las actividades pretenden crear un ambiente lúdico que aporte a la motivación de los estudiantes. Se requiere que el docente oriente permanentemente la realización de las actividades.

\section{Actividades sugeridas:}

Recomendación: El taller para padres se debe enviar con mínimo una semana de anticipación a la clase en la que se van a implementar las actividades para los estudiantes, dando así la oportunidad y el tiempo para que puedan reali- 
zarlo y enviar los resultados sugeridos. Además, es importante disponer de un espacio para atender y orientar a los padres que lo soliciten.

En la sesión con los estudiantes se aconseja:

Disponer los materiales necesarios para la proyección del video.

Crear un ambiente ameno vinculado a la temática, utilizando elementos importantes, por ejemplo, elementos que se relacionen con el video del semiIlero (semillas, plantas, frutas, afiches relacionados con la temática, entre otros).

$\checkmark$ Orientar y organizar a los estudiantes para iniciar la proyección del video.

$\checkmark$ Realizar la ambientación del video y proyectarlo. Si es necesario, y se cuenta con la disposición de los estudiantes y con el tiempo, se presenta nuevamente el video.

$\checkmark$ Entregar a cada niño el formato de las actividades para el estudiante.

$\checkmark$ Presentar en Lengua de Señas Colombiana (LSC) las actividades, señalando los enunciados escritos de las actividades para el estudiante. Es importante que los estudiantes observen que lo explicado en LÑSC corresponde al enunciado escrito en la hoja de trabajo.

Luego, orientar cada actividad: en primer lugar las actividades para el estudiante proponen que ellos dibujen algo interesante del video que observaron. Mientras se encuentran dibujando, se sugiere al docente formularles preguntas del siguiente tipo:

¿Qué estas dibujando?

¿Por qué te interesó eso del video?

¿Qué otra cosa del video te gustó?

Posteriormente deben pintar con diferente color el recorrido de cada semilla por su único camino que conduce a su respectiva planta. Es importante que el profesor subraye con los estudiantes en la relación que se establece aquí: cada semilla con su respectiva planta.

Por último, las actividades para los estudiantes sugieren colorear las frutas que les gustan. Este es un momento propicio para que el docente haga preguntas del siguiente tipo:

¿Cada cuánto comes esa fruta?

¿Qué sabor consideras que tiene esa fruta?

¿Qué color tiene esa fruta? 
¿Cuál de las frutas que coloreaste te gusta más?

Es importante que el profesor presente cuidadosamente y de manera diferenciada las señas referidas a los interrogativos ¿qué tanto?, ¿qué?, ¿cuándo?, a los sustantivos fruta, color y a los verbos comer, colorear, gustar. De igual modo, en las respuestas de los estudiantes, realizar correcciones y orientaciones en la producción y uso de las señas, con el fin de que ellos amplíen el vocabulario.

Al finalizar las actividades para el estudiante, se sugiere implementar las actividades de evaluación.

NOTA: es primordial que el docente registre las reflexiones y consideraciones que le inciten las respuestas, acciones y observaciones de los estudiantes, e identifique las expresiones que son difíciles o desconocidas para los niños (as). Para ello se puede disponer de un cuaderno de registro y se debe estar atento a cada suceso de la clase y a los comportamientos de los estudiantes. Si es posible tomar imágenes fotográficas o realizar grabaciones en video, se aconseja hacerlo, pues se obtendrá un registro más completo que se podrá utilizar posteriormente, bien para evaluar, bien para continuar el tema.

A continuación se ofrece una propuesta de un tipo de registro de procesos de los estudiantes. Se presenta un ejemplo de un posible registro que realizaría el profesor con respecto a un estudiante, durante el desarrollo del taller 1. Así, el docente observa que el niño (a) identifica tres (3) conjuntos de propiedades (p.e.: color, sabor y olor). Del primer conjunto (color), reconoce dos valores (p.e.: amarillo, rojo); del segundo (sabor) solo reconoce uno (p.e.: dulce); y, del tercero (olor), no reconoce valores asociados (no discrimina olores). Se puede obtener un registro de esta observación como el que se presenta en la siguiente tabla.

\section{REGISTRO DEL ESTUDIANTE XXXXXX}

\begin{tabular}{|l|c|c|c|c|c|c|c|c|c|c|c|c|}
\hline $\begin{array}{c}\text { Fechas del registro/ forma } \\
\text { de observación }\end{array}$ & \multicolumn{6}{|c|}{$\begin{array}{c}\text { Identificación de Descriptores (Conjuntos de } \\
\text { propiedades) }\end{array}$} & \multicolumn{6}{c|}{$\begin{array}{c}\text { Número de valores (una propiedad del conjunto) identifi- } \\
\text { cados para cada atributo }\end{array}$} \\
\hline & 1 & 2 & 3 & 4 & 5 & 6 & 1 & 2 & 3 & 4 & 5 & 6 \\
\hline $25-09-2010-T a l l e r 1$. & $\mathrm{X}$ & $\mathrm{X}$ & $\mathrm{X}$ & & & & 2 & 1 & 0 & & & \\
\hline & & & & & & & & & & & & \\
\hline & & & & & & & & & & & & \\
\hline
\end{tabular}

Tabla 29. Registro de observaciones

\section{Materiales:}

- Videos: sugerido http://www.youtube.com/watch?v=HuEFodx-qrU

- Guías de talleres 
- Colores

- Elementos decorativos: afiches de plantas, plantas, afiches de alimentos, entre otros.

Tiempo: Una hora aproximadamente.

\section{B. ACTIVIDADES PARA LOS PADRES DE FAMILIA}

\section{Objetivos}

- Colaborar, acompañar y orientar al niño (a) en la experiencia con las plantas. La experiencia requiere el uso de los sentidos (vista, tacto, gusto, olfato) durante las visitas a las tiendas de mercado, en la organización del mercado en la cocina, en la selección de alimentos para la preparación de las onces del colegio o de la comida familiar.

- Fomentar el desarrollo léxico del mundo de las frutas y de las plantas y la competencia comunicativa del niño (a), a partir de la interacción con los padres, los tenderos, los hermanos, etc.

\section{Presentación}

Generalmente utilizamos nuestros sentidos para determinar el estado de un alimento o para comprobar si se encuentra en buen estado: tocándolo, oliéndolo, mirándolo, probándolo y, en ocasiones, hasta escuchando ruidos que se producen al moverlos de cierta manera. Señores padres de familia o cuidadores de los niños (as), es importante contar con su colaboración para que ellos adquieran este conocimiento, que es necesario y elemental.

\section{Actividad}

1) Asistir en pareja, o con otro miembro de la familia cercano al estudiante, a la presentación de los videos vinculados al proyecto. Preguntar al profesor lo que no entiendan o, si lo consideran, sugieran al profesor actividades con los niños (as), de acuerdo con su experiencia de padres.

2) Llevar al niño a un supermercado donde haya variedad de frutas y alimentos. Puede aprovechar la ocasión para hacer mercado o comprar las frutas que se necesitan para las loncheras de la semana o para la comida del día.

3) Con paciencia, enseñar a su hijo (a) algunos de esos conocimientos que usted tiene y que pone en práctica cuando va de compras; estos conocimientos son necesarios le ayudarán a identificar estados de los alimentos. La idea es que ustedes le enseñen a conocer el buen estado de algunos alimentos, para poder comprarlos: color, olor, textura y, si es posible, el sabor también. 
Se recomienda tener paciencia al dar las indicaciones: hágalo con claridad, bien sea en LSC o hablando despacio y gesticulando y señalando los productos, de tal manera que el niño (a) comprenda lo que ustedes le quieren enseñar.

Ejemplo: en la siguiente tabla ustedes encuentran una lista de alimentos y características de ellos cuando se encuentran en buen estado o en mal estado. En caso dado puede registrar expresiones que no conozca y consultar al profesor o en diccionarios.

\begin{tabular}{|c|l|l|}
\hline \multicolumn{1}{|c|}{ ALIMENTO } & \multicolumn{1}{|c|}{ EN BUEN ESTADO } & \multicolumn{1}{c|}{ EN MAL ESTADO } \\
\hline BANANO & $\begin{array}{l}\text { SABOR A DULCE } \\
\text { COLOR AMARILLO } \\
\text { OLOR FRUTAL O NEUTRO } \\
\text { TEXTURA DURA }\end{array}$ & $\begin{array}{l}\text { COLOR NEGRO } \\
\text { OLOR PUTRIDO } \\
\text { TEXTURA BLANDA }\end{array}$ \\
\hline \multirow{5}{*}{ NARANJA } & $\begin{array}{l}\text { SABOR AGRIOY DULCE } \\
\text { COLOR VERDE O ANARANJADO } \\
\text { OLOR FRUTAL O NEUTRO } \\
\text { TEXTURA DURA }\end{array}$ & $\begin{array}{l}\text { COLOR CAFÉ } \\
\text { OLOR PUTRIDO } \\
\text { TEXTURA BLANDA }\end{array}$ \\
\hline MARACUYA & $\begin{array}{l}\text { SABOR AGRIO } \\
\text { COLOR VERDE } \\
\text { OLOR FRUTAL O NEUTRO } \\
\text { TEXTURA DURO }\end{array}$ & $\begin{array}{l}\text { COLOR CAFÉ } \\
\text { TEXTURA FRAJIL } \\
\text { OLOR PUTRIDO } \\
\text { TEXTURA BLANDA }\end{array}$ \\
\hline & $\begin{array}{l}\text { SABOR ACIDO } \\
\text { COLOR AMARILLO } \\
\text { OLOR FRUTAL O NEUTRO } \\
\text { TEXTURA DURA }\end{array}$ & $\begin{array}{l}\text { COLOR CAFÉ } \\
\text { TECTURA QUEBRADIZA } \\
\text { OLOR PUTRIDO } \\
\text { TEXTURA BLANDA }\end{array}$ \\
\hline
\end{tabular}

Tabla 30. Registro estado de los alimentos

Es opcional que ustedes colaboren completando los espacios vacíos con alimentos que conozcan. Esto, reconociendo que algunos padres de familia son buenos conocedores de las condiciones de los alimentos de acuerdo con su estado. Ese conocimiento se puede constituir en un aporte importante para el trabajo que se está realizando en el proyecto de aula.

\section{Sugerencia}

Tratar, al máximo, de conocer las señas correspondientes al vocabulario que se requiere: nombres de alimentos, nombres de frutas, sabores, olores, texturas, colores, entre otros. Usted encontrará un apoyo de este vocabulario en el "Lexicón" y en el "Repertorio léxico del campo semántico del conteo" que se aporta en los documentos de profundización del Proyecto de Aula y lo puede solicitar al profesor. 


\section{ACTIVIDADES PARA LOS ESTUDIANTES}

*Dibuja lo que te pareció interesante en el video.

*Ayuda a llevar la semilla a su semillero
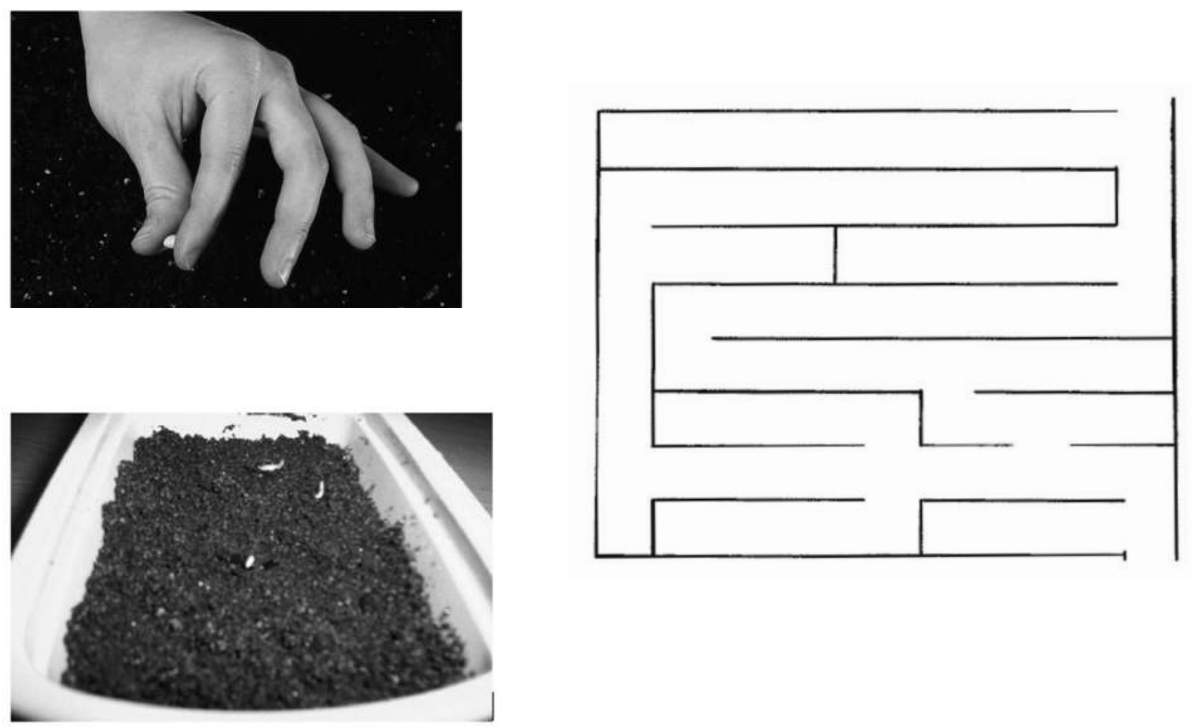

Colorea cada uno de los caminos:
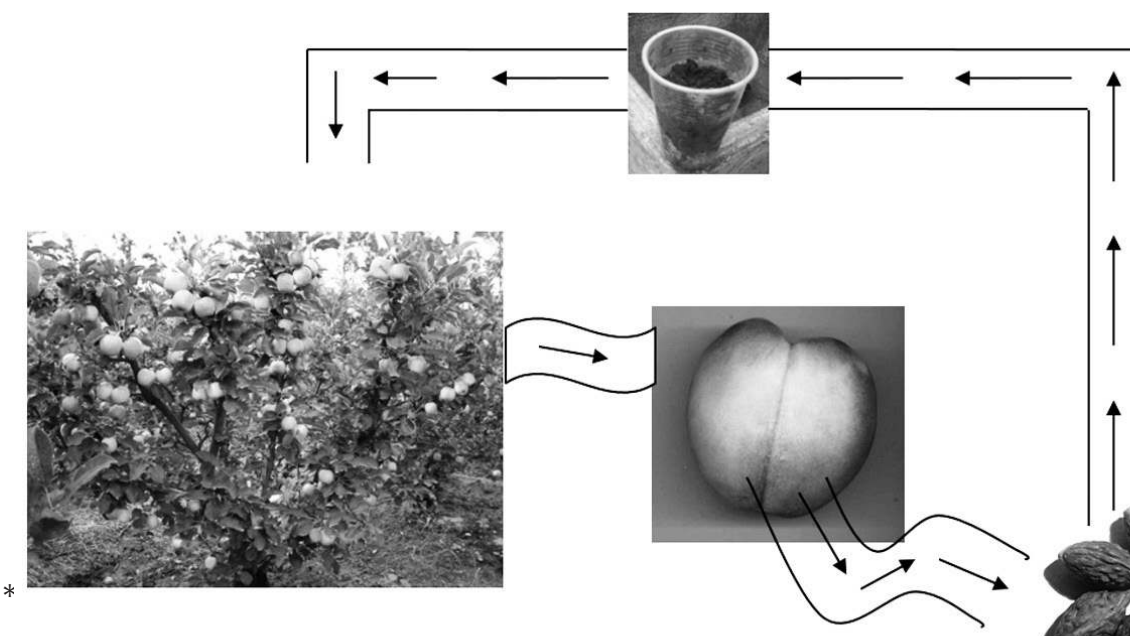
*Dibuja las fotos entre los caminos y corolealos
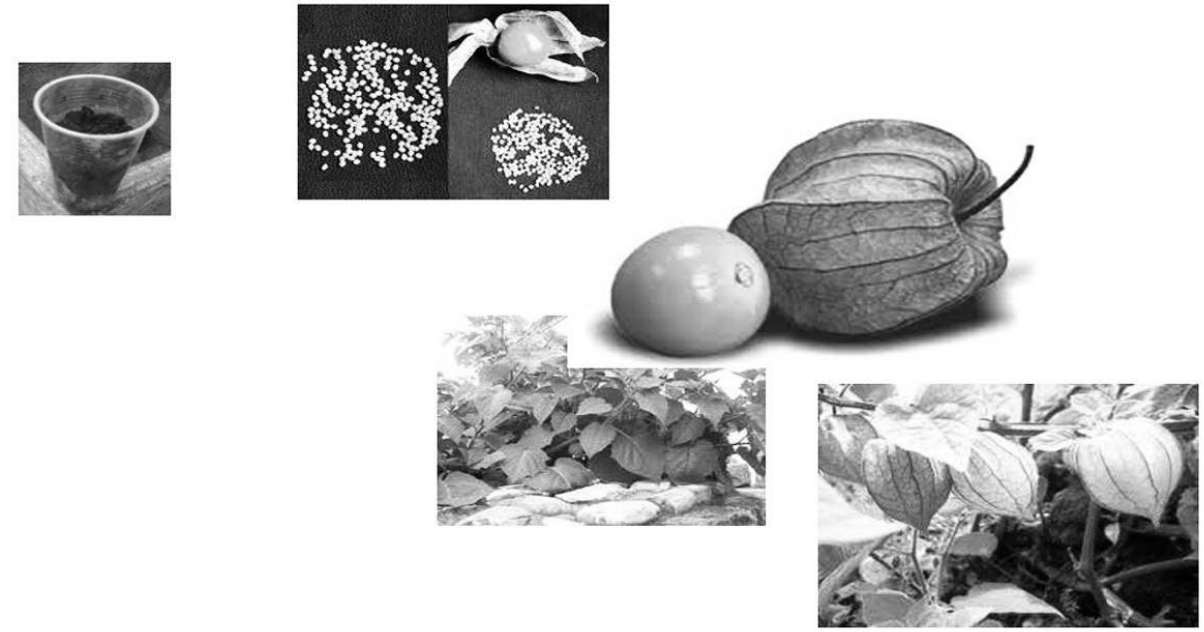

Colorea las frutas que te gustan y dales un nombre en lengua de señas.
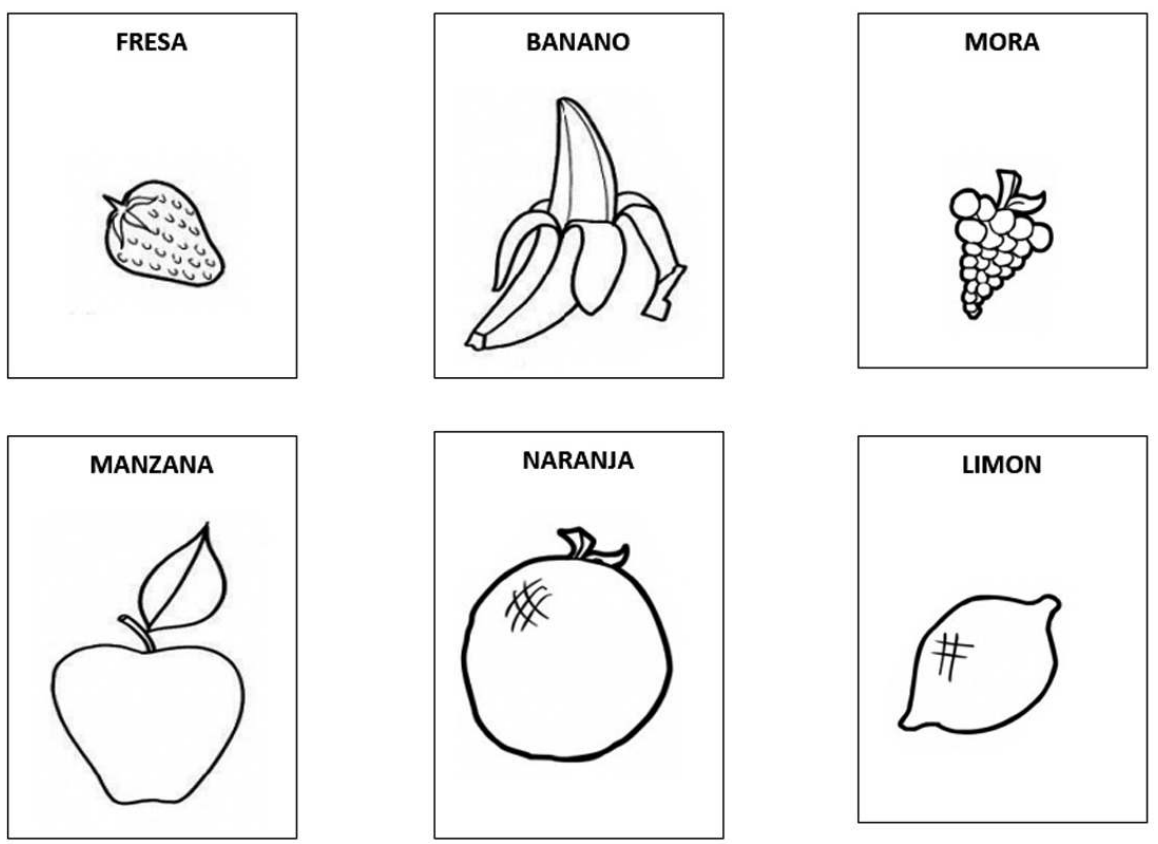


\section{ACTIVIDADES DE EVALUACIÓN PARA LOS ESTUDIANTES}

*Encierra con un círculo cada uno los materiales que se necesitan para sembrar:
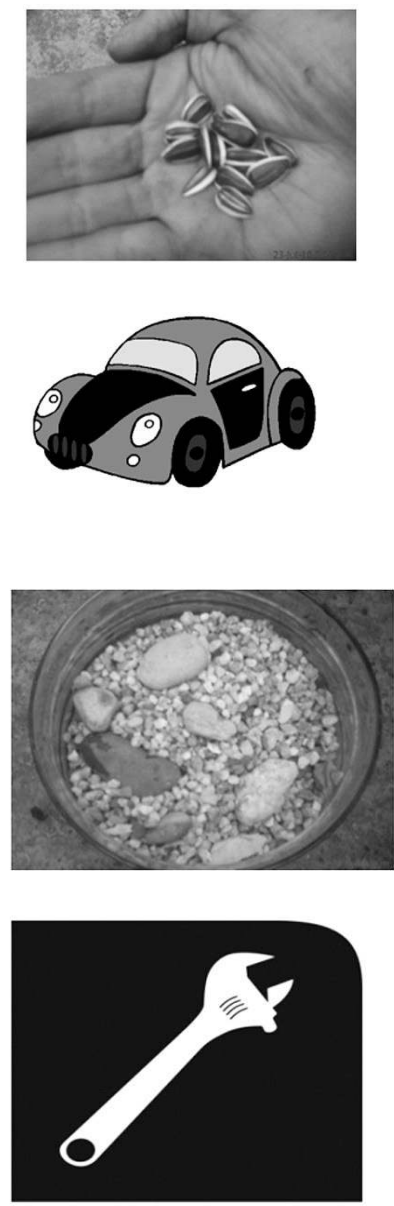
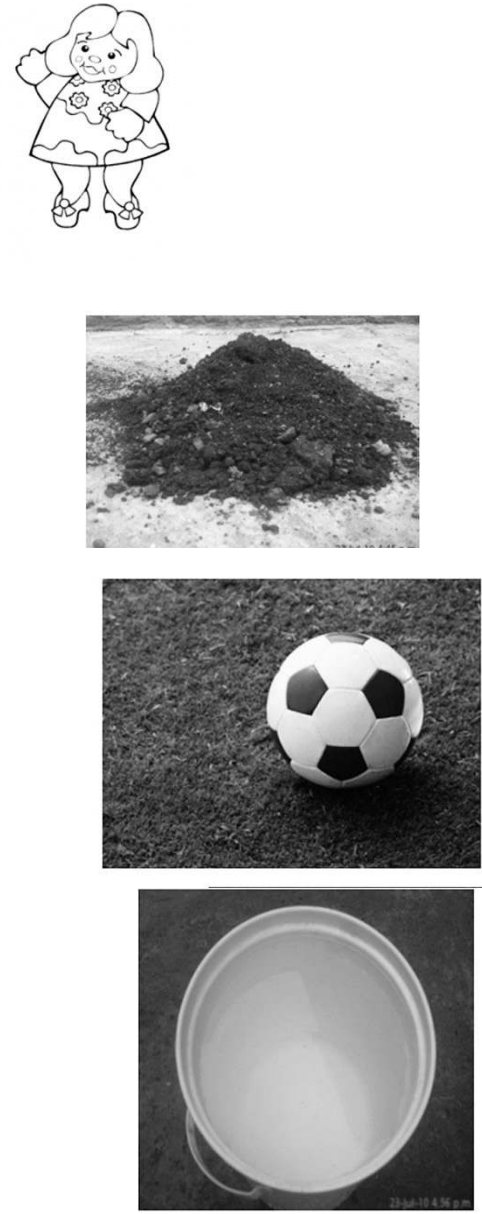

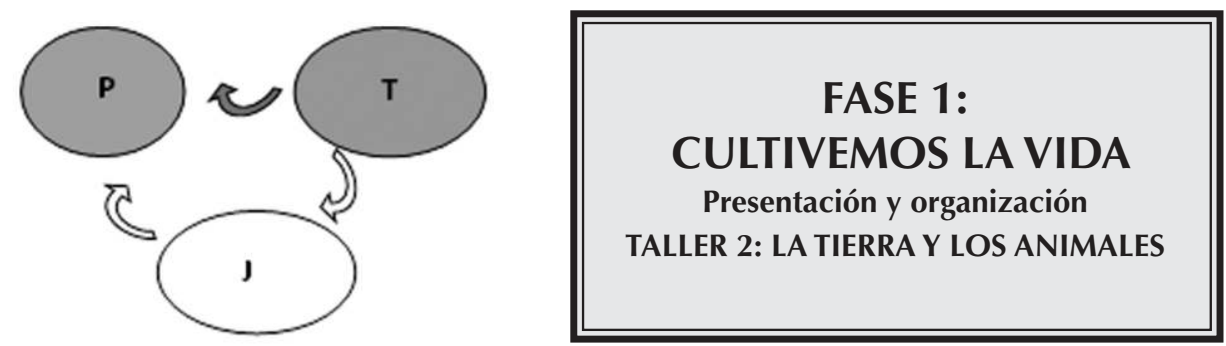

\section{ORIENTACIONES PARA EL PROFESOR}

\section{Objetivos}

- Presentar el lombricultivo como un proyecto para ser construido conjuntamente por el grupo de estudiantes y con el aporte de su familia.

- Crear un ambiente de cooperación entre la familia y la escuela, para que los estudiantes sordos desarrollen procesos de percepción de la tierra y sus animales, así como los procesos de identificación de atributos de personas y de elementos vinculados a un lombricultivo.

- Crear un ambiente para desarrollar experiencias que propicien condiciones para el reconocimiento de conjuntos de propiedades con sus elementos respectivos, a partir del desarrollo de la expresividad lingüístico-discursiva de la relación niño (a)-naturaleza. Enfatizaremos en la descripción y la narración.

Presentación. Partimos de reconocer que un trabajo mediado por el interés propio tiene mayores probabilidades de obtener resultados óptimos. Por ello, el trabajo que los estudiante van a realizar a lo largo del sistema de talleres requiere de su interés y motivación.

Si el sistema de talleres se está implementando a la par con el proyecto de aula, la proyección de los videos sugeridos se constituirá en el inicio de esa motivación requerida. A partir de lo que los estudiantes observen en estos videos, de sus interpretaciones y de sus nociones previas, cada estudiante realizará las actividades del taller. A la vez, las actividades pretenden crear un ambiente lúdico que aporte a la motivación de los estudiantes. Se requiere que el docente oriente permanentemente la realización de las actividades.

\section{Actividades sugeridas}

El taller para padres se debe enviar con mínimo una semana de anticipación a la clase en la que se van a implementar las actividades para los estudiantes, dando así la oportunidad y el tiempo para que puedan realizarlo y enviar los resultados sugeridos. Además, es importante designar un espacio para atender y orientar a los padres que lo soliciten.

En la sesión con los estudiantes se aconseja:

$\checkmark$ Disponer los materiales necesarios para la proyección del video. 
Crear un ambiente ameno vinculado a la temática, utilizando elementos importantes, por ejemplo, elementos que se relacionen con el video del lombricultivo (fotos de lombrices, plantas, animales afiches relacionados con la temática, entre otros).

Orientar y organizar a los estudiantes para iniciar la proyección del video.

$\checkmark$ Realizar la ambientación del video y proyectarlo. Si es necesario, y se cuenta con la disposición de los estudiantes y con el tiempo, se presenta nuevamente el video.

$\checkmark$ Entregar a cada niño (a) el formato de las actividades para el estudiante.

$\checkmark$ Presentar en Lengua de Señas Colombiana (LSC) las actividades, señalando los enunciados escritos de las actividades para el estudiante. Es importante que los estudiantes observen que lo explicado en LSC corresponde al enunciado escrito en la hoja de trabajo.

$\checkmark$ Luego, orientar cada actividad: en primer lugar las actividades para el estudiante proponen que ellos dibujen algo interesante del video que observaron. Mientras se encuentran dibujando, se sugiere al docente formularles preguntas del siguiente tipo:

¿Qué estas dibujando?

¿Por qué te interesó eso del video?

¿Qué otra cosa del video te gustó?

Posteriormente deben pintar con diferente color el recorrido de cada animal por su único camino que conduce a su respectivo alimento. Es importante que el profesor subraye con los estudiantes en la relación que se establece aquí: cada animal con su respectiva alimento.

Por último, en algunas de las actividades para los estudiantes se sugiere colorear las frutas que les gustan. Este es un momento propicio para que el docente haga preguntas del siguiente tipo:

¿Qué tanto comida trajiste de onces?

¿Cuáles animales conoces?

¿Cómo es un perro?

¿Qué colores tienen las palomas?

¿Cuál animal de los propuestos en el taller es más pequeño?

Es importante que el profesor presente cuidadosamente y de manera diferenciada las señas referidas a los interrogativos ¿qué tanto?, ¿qué?, ¿cuándo?, ¿Cuál? a los sustantivos animal, tierra, comida y a los verbos alimentar, cuidar, 
observar. De igual modo, en las respuestas de los estudiantes, realizar correcciones y orientaciones en la producción y uso de las señas, con el fin de que ellos amplíen el vocabulario.

En las actividades de descripción y de narración, se sugiere observar la capacidad expresiva del niño y sus dificultades lingüísticas, para apoyar permanentemente la producción de señas que no se conocen y la corrección de las que se conocen y su relación con carteles escritos. Hacer énfasis en que están construyendo el rincón de las palabras y que lo pueden enriquecer y utilizar cada vez que sea necesario.

Al finalizar las actividades para el estudiante, se sugiere implementar las actividades de evaluación.

NOTA: es primordial que el docente registre las reflexiones y consideraciones que le inciten las respuestas, acciones y observaciones de los estudiantes, e identifique las expresiones que son difíciles o desconocidas para los niños (as). Para ello se puede disponer de un cuaderno de registro y se debe estar atento a cada suceso de la clase y a los comportamientos de los estudiantes. Si es posible tomar imágenes fotográficas o realizar grabaciones en video, se aconseja hacerlo, pues se obtendrá un registro más completo que se podrá utilizar posteriormente, bien para evaluar, bien para continuar el tema. A continuación se ofrece una propuesta de un tipo de registro de procesos de los estudiantes. Se presenta un ejemplo de un posible registro que realizaría el profesor con respecto a un estudiante, durante el desarrollo del taller 2. Así, el docente observa que el niño (a) identifica cuatro (4) conjuntos de propiedades (p.e.: color, sabor, olor, textura). Del primer conjunto (color), reconoce tres valores (p.e.: amarillo, rojo, negro); del cuarto reconoce un valor (suave). Se puede obtener un registro de esta observación como el que se presenta en la siguiente tabla.

\section{REGISTRO DEL ESTUDIANTE XXXXXX}

\begin{tabular}{|l|l|l|l|l|l|l|l|l|l|l|l|l|l|}
\hline $\begin{array}{l}\text { Fechas del registro/ } \\
\text { forma de observación }\end{array}$ & \multicolumn{4}{|l|}{$\begin{array}{l}\text { Identificación de Descriptores (Conjuntos de } \\
\text { propiedades) }\end{array}$} & \multicolumn{3}{l|}{$\begin{array}{l}\text { Número de valores (una propiedad del } \\
\text { conjunto) identificados para cada atributo }\end{array}$} \\
\hline & 1 & 2 & 3 & 4 & 5 & 6 & 1 & 2 & 3 & 4 & 5 & 6 \\
\hline 23-03-2010-Taller 1 & $X$ & $X$ & $X$ & & & & 2 & 1 & 0 & & & \\
\hline $30-03-2010$ Taller 2 & $X$ & & & $X$ & & & 3 & & & 1 & & \\
\hline & & & & & & & & & & & & \\
\hline
\end{tabular}

Tabla 31. Registro de observaciones

\section{Materiales}

- Videos: Se sugieren http://www.youtube.com/watch? $v=A b Q N c T k y 3 X 8$ y el de http://il.youtube.com/watch?v=OQPSfp3GRUg\&p=34A2710ECB1E1A2A\&index=2 adaptado por este equipo. 
- Guías de actividades

- Lápices y colores o témperas

- Elementos decorativos: afiches de animales, afiches de lugares donde habitan los animales, entre otros.

- Hojas de papel periódico para emplear como carteles (un cartel por niño).

- Copias con los dibujos que se encuentran en el taller de descripción.

- Carpeta, folder o cuaderno personales para desarrollo de escritura.

- Tiempo: Dos horas aproximadamente: una por actividad.

\section{B. ACTIVIDADES PARA LOS PADRES DE FAMILIA}

\section{Objetivos}

- Colaborar, acompañar y orientar al niño (a) en la experiencia afectiva y comunicativa con los animales.

- Fomentar el desarrollo léxico del mundo de los animales y de sus lugares de vida y la competencia comunicativa del niño (a), a partir de la interacción con los padres, los tenderos, los hermanos, etc.

La experiencia requiere el uso de los sentidos (vista, tacto, gusto, olfato). Ustedes pueden llevar el niño (a) a una tienda de animales para observar los lugares en los que permanecen o puede ir al supermercado y detenerse en el lugar de comida para animales. Allí pueden observar los tipos de comida para los tipos de animales. Es importante intentar el ejercicio de señalar la comida, señalar el nombre (si lo presenta en los carteles) y producir la seña respectiva (si la conoce); si no la conoce, registrar ese nombre para buscar la seña posteriormente junto con su hijo (a).

Si en casa hay una mascota, pueden enseñarle al niño (a) a conseguir la comida de la mascota. También puede llevar al niño (a) a recorrer el barrio o a caminar por un parque, observando animales que pueden estar en los árboles, en la tierra, en el aire. No olviden observar las reacciones del niño ante los animales y sus alimentos (alegría, temor, asombro, etc.) y conversar con él o ella al respecto. De igual modo, intentar siempre darle a conocer la palabra acompañada de la seña. Recuerden que entre juntos pueden avanzar en el desarrollo de la lengua de señas y en que el niño (a) vaya comprendiendo la lengua oral y su relación con las expresiones faciales y gestuales.

\section{Presentación}

Generalmente utilizamos nuestros sentidos para identificar movimientos, formas texturas. Podemos determinar la edad de un animal por su tamaño o 
por el color de su piel o por su movimiento. Podemos determinar el estado de un animal por sus movimientos, generalmente si se queda quieto por largo tiempo, puede estar enfermo y, en ocasiones, podemos determinar su forma de alimentarse por la forma de su cuerpo y su boca. Señores padres de familia o cuidadores de los niños (as), es importante contar con su colaboración para que ellos adquieran este conocimiento, que es necesario y elemental con los animales que los rodean.

\section{Actividad}

1) Asistir en pareja, o con otro miembro de la familia cercano al estudiante, a la presentación de los videos vinculados al proyecto. Preguntar al profesor lo que no entiendan o, si lo consideran, sugieran al profesor actividades con los niños (as), de acuerdo con su experiencia de padres.

2) Llevar al niño (a) a uno de los siguientes lugares: un supermercado, una tienda de mascotas, un jardín o al parque. La idea es caminar por el barrio buscando lugares donde haya variedad de animales. Puede aprovechar la ocasión para conocer mejor a la mascota (si la hay en la casa) o para revisar si en la casa hay insectos u otros animales perjudiciales o no perjudiciales.

3) Con paciencia, enseñar a su hijo (a) algunos de esos conocimientos que usted tiene y que pone en práctica en el cuidado de su mascota o en el control de plagas en la casa. Estos conocimientos son necesarios y le ayudarán a identificar tipos de animales y sus cualidades. La idea es que ustedes le enseñen a establecer tipos de relaciones con los animales (cuidado, respeto, prevención, etc.).

Se recomienda tener paciencia al dar las indicaciones: hágalo con claridad, bien sea en LSC o hablando despacio y gesticulando y señalando los animales, de tal manera que el niño (a) comprenda lo que ustedes le quieren enseñar.

Ejemplo: en la siguiente tabla ustedes encuentran una lista de animales y características de ellos, para que la completen con su hijo (a) de acuerdo con lo que observen de esos animales cerca de su casa. En caso dado, puede registrar expresiones que no conozca y consultar al profesor o en diccionarios.

\begin{tabular}{|c|c|c|}
\hline ANIMALES & CARACTERÍSTICAS & ALIMENTOS QUE CONSUMEN \\
\hline PERRO & $\begin{array}{l}\text { TAMAÑO: Hay grandes medianos y pequeños } \\
\text { COLOR: Tienen diversidad de colores, como: negro, blan- } \\
\text { Co, amarillo, gris } \\
\text { NÚMERO DE PATAS: cuatro } \\
\text { DOMESTICABLE: SI }\end{array}$ & $\begin{array}{l}\text { CARNE } \\
\text { HUESOS } \\
\text { AGUA } \\
\text { PLANTAS } \\
\text { CONCENTRADO PARA PERROS }\end{array}$ \\
\hline PALOMA & $\begin{array}{l}\text { TAMAÑO } \\
\text { COLOR: } \\
\text { NÚMERO DE PATAS } \\
\text { DOMESTICABLE }\end{array}$ & \\
\hline
\end{tabular}




\begin{tabular}{|l|l|l|}
\hline MOSCA & TAMAÑO & \\
& COLOR: & \\
& NÚMERO DE PATAS & \\
& DOMESTICABLE & \\
\hline ARAÑA & TAMAÑO & \\
& COLOR: & \\
& NÚMERO DE PATAS & \\
\hline
\end{tabular}

Tabla 32. Registro características de animales

Es opcional que ustedes colaboren completando los espacios vacíos con animales que conozcan. Esto, reconociendo que algunos padres de familia son buenos conocedores de diversidad de animales. Ese conocimiento se puede constituir en un aporte importante para el trabajo que se está realizando en el proyecto de aula.

Tratar, al máximo, de conocer las señas correspondientes al vocabulario que se requiere: nombres de anima-

Sugerencia les, nombres de alimentos, nombres de partes del cuerpo de los animales, entre otros. Usted encontrará un apoyo de este vocabulario en el "Lexicón" que aporta el proyecto de Aula y lo puede solicitar al profesor.

\section{ACTIVIDADES PARA LOS ESTUDIANTES}

\section{Actividad 1: Identificando relaciones}

*Dibuja lo que te pareció interesante en el video.

*Realiza un camino que lleve cada animal a su alimento
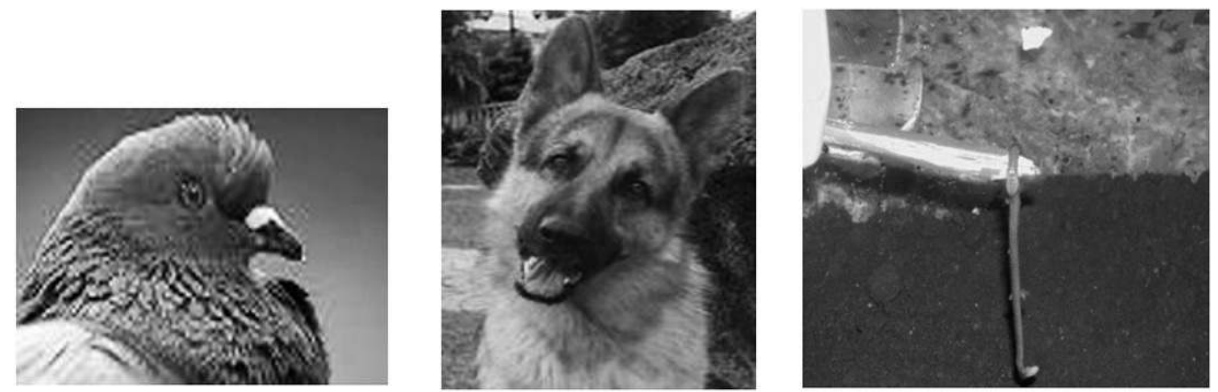

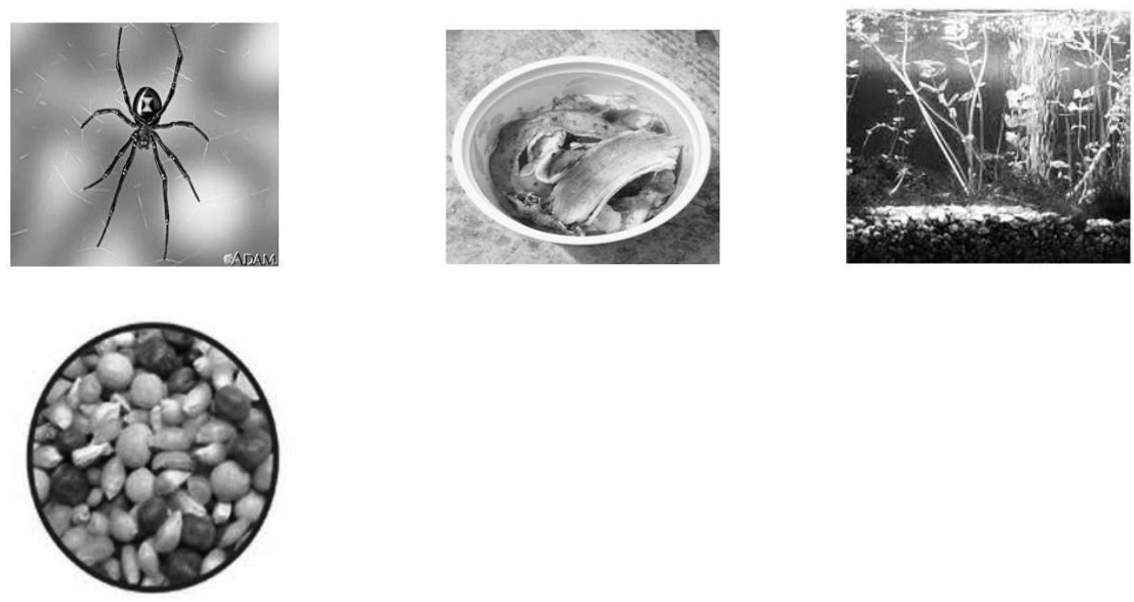

\section{Actividad 2: Describiendo el campo}

\section{Parte A: ;Lo que yo vi!}

1) Se preparará una distribución de forma circular en el salón de clase y se hará uso de unos carteles de papel periódico, ubicados en las paredes, en los que se marcará con el nombre de cada niño (a), para registrar cada una de las intervenciones frente a la temática que se trabaja.

2) El profesor preguntará a cada uno de los niños (as) sobre las cualidades físicas de los elementos que observaron en el video (sembrador, frutos, tierra): ¿cómo era el agricultor?, ¿qué frutos vieron?, ¿de qué color era la tierra?, ¿cuántos frutos distintos vieron?, ¿había mucha o poca tierra? Se pretende verificar si los estudiantes tienen ciertas dudas sobre el acto de describir. Insistir en la producción de las señas para cada objeto y sus cualidades (forma, color, estado...).

3) Cada una de las respuestas (percepciones) de los estudiantes se irá registrando en el respectivo cartel de cada niño (a). Recordar la relación entre señas y escritura en carteles o en el rincón de las palabras.

Parte B: Adivina adivinador: Se pretende jugar a que un estudiante propone una descripción (LSC) y los demás identifican a qué fruta se refiere. El profesor pedirá a cada estudiante que pasen al frente y describan la fruta que más les gusta en L.S.C. Para ello, los estudiantes, pueden valerse de elementos descriptores tales como el sabor, el color, la textura del fruto. Los demás estudiantes adivinarán el nombre del fruto que está describiendo su compañero (a).

Estas intervenciones también deberán ser registradas por el profesor, en el cartel respectivo de cada niño. 


\section{Parte C: Mi personaje el agricultor}

1) El profesor pedirá a los estudiantes que elaboren un dibujo en el cual representen a un agricultor, teniendo eligiendo tres de las siguientes cualidades físicas:

- Gordo

- Delgado

- Grande

- Pequeño

- Fuerte

- Débil

2) Finalizado el dibujo, cada niño (a) le pondrá un nombre en LSC y con ayuda del profesor lo registrará en español escrito y lo presentará a sus compañeros.

3) Guardar en el folder este dibujo.

\section{ACTIVIDADES DE EVALUACIÓN PARA LOS ESTUDIANTES}

*Busca el nombre de cada uno de los materiales que se necesitan para hacer un LOMBRICULTIVO:
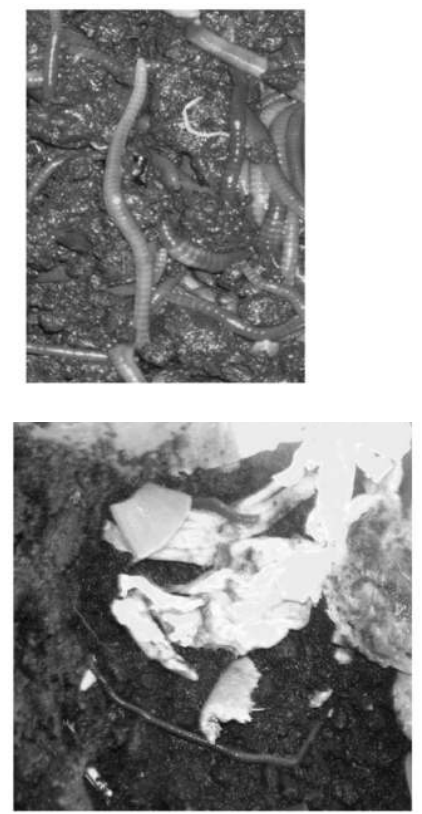
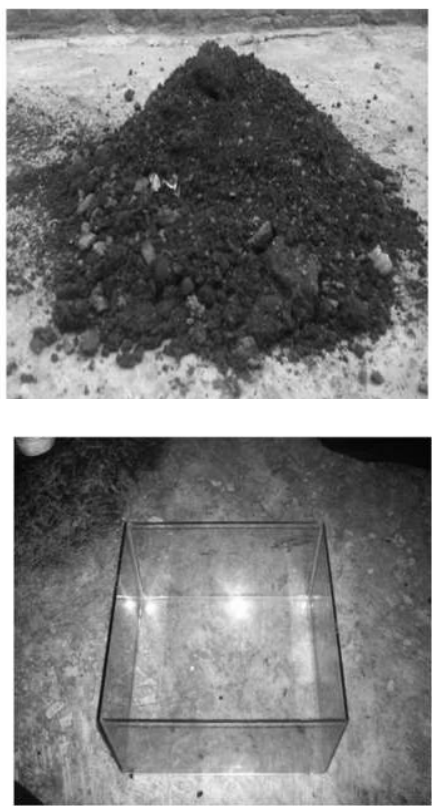
* El profesor entregará a cada niño (a) una hoja con los siguientes dibujos.

- Colorear únicamente aquellos que aparecieron en el video.

- Buscar la seña que corresponde.

- Luego, pedir al profesor ayudar a buscar la palabra escrita correspondiente.
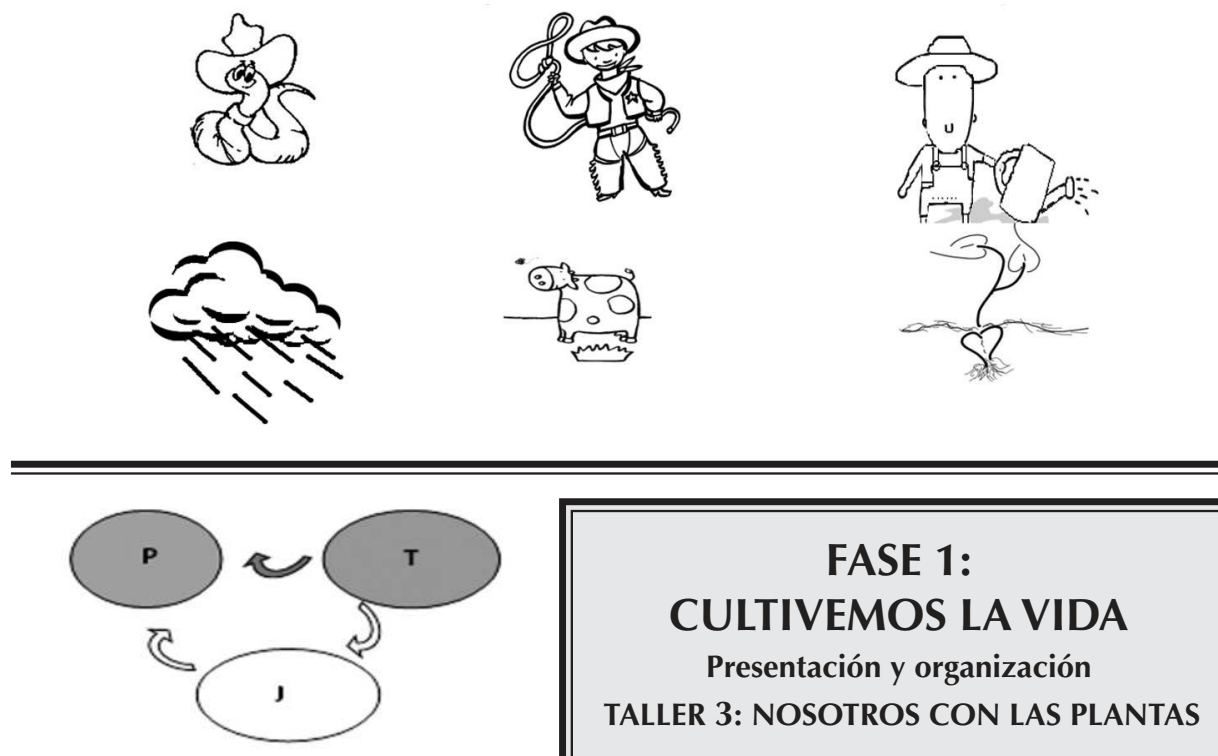

\section{A. ORIENTACIONES PARA EL PROFESOR}

\section{Objetivos}

- Desarrollar experiencias de conocimiento sobre el sabor de alimentos como las frutas, a partir de la percepción de sus diferentes manifestaciones.

- Generar diversas experiencias de representación de las frutas y sus sabores, como un desarrollo de lenguaje y de las lenguas LSC y español escrito.

- Consolidar el conocimiento experiencial y lingüístico acerca del conjunto de propiedades denominadas "sabor" e identificar algunas propiedades de ese conjunto tales como: ácido, amargo, dulce, salado, picante y agrio.

Presentación. La realización de este taller requiere que los estudiantes hagan un trabajo previo extra-clase y que traigan cierto alimento, para lo cual deben contar con la ayuda de sus padres o familiares.

Se pretende que los estudiantes continúen el estudio de descriptores (conjunto de propiedades como sabor) y de valores asociados a ellos (una propiedad del conjunto descriptor, como salado). Este estudio se inició en el taller anterior, 
gracias a la colaboración de los padres en la tarea de visitar el supermercado y determinar el estado de alimentos por medio del análisis sensorial.

En este taller se profundizará el descriptor sabor y los valores acido, amargo, dulce, salado, picante y agrio. Junto con esta profundización, se desarrollará el campo léxico referido al tema y la capacidad expresiva y comunicativa de los estudiantes.

En este sentido se propone disponer de frutas y, si es posible, otros alimentos que tengan sabores diferentes. Por ello se sugiere que el profesor solicite a cada estudiante, en una sesión previa, traer cierta fruta o alimento de su casa. Estas se compartirán en el transcurso del taller. Se recomienda que, si tienen semillas se extraigan, y que los residuos se utilicen para empezar a recolectar el alimento para las lombrices.

A continuación se presenta una relación entre tipos de sabor y alimentos que se caracterizan por contenerlos. Esta información sirve como base para que el profesor, de acuerdo con las condiciones del curso, asigne a cada estudiante el alimento que debe traer.

\begin{tabular}{|l|l|}
\hline $\begin{array}{c}\text { VALORES DEL } \\
\text { DESCRIPTOR SABOR }\end{array}$ & \multicolumn{1}{c|}{ ALIMENTOS ASOCIADOS A CADA VALOR } \\
\hline Ácido & Vinagre, limón, fresas, piña, naranja, cerezas. \\
\hline Amargo & Cabrito, pavo, acelgas, lechuga, té, apio, café. \\
\hline Dulce & Conejo, melón, banano, ahuyama, calabaza, mermelada, azúcar morena, miel. \\
\hline Picante & Cebolla, col china, rábano, nabo, ajo, pimiento, menta, jengibre, tabasco, ají. \\
\hline Salado & Cerdo, embutido, gambas, almejas, mariscos en general, castañas, almendras, nueces. \\
\hline Agrio & $\begin{array}{l}\text { Maíz, yogur, aloe, champiñón, oliva, pepino, patata, tomate, berenjena, alcachofa, col, plátano, setas, } \\
\text { zanahoria, mayonesa, uchuva. }\end{array}$ \\
\hline
\end{tabular}

Tabla 33. Relación tipos de sabor y características

Con respecto a la anterior tabla, se le sugiere al profesor indagar acerca de los alimentos que no son muy conocidos por él o por los estudiantes. Es importante tenerlos en cuenta para ampliar el rango de conocimiento y el vocabulario de todo el grupo. También se recomienda que cada nueva palabra sea puesta en un cartel o construir el rincón de palabras nuevas (el ícono del objeto, la palabra en español y en lengua de señas colombiana).

Una opción para el profesor es solicitar a los estudiantes traer los siguientes alimentos, con el fin de abarcar diferentes valores del descriptor sabor:

Ácidos: limón y naranja.

Amargos: lechuga y apio. 
$\checkmark$ Dulces: banano y miel.

$\checkmark$ Picantes: cebolla cabezona y ají.

$\checkmark$ Salados: sal.

$\checkmark$ Agrios: tomate y uchuva.

Entre los alimentos que se asignen para traer, es necesario decidir cuáles son los que van a degustar los estudiantes durante la sesión, teniendo en cuenta que se den a probar todos los valores del descriptor sabor. De acuerdo con los escogidos, el profesor tendrá que preparar la manera de organizarlos para realizar la degustación. Por ejemplo, quitar la cáscara, picarlos, ubicarlos en una bandeja o plato, entre otros.

Se sugiere al profesor hacer para cada uno de los descriptores: color, olor y textura, el taller correspondiente con los niños. A continuación se presenta un taller como un taller prototipo, pero el profesor podrá proponer otro.

\section{Actividades sugeridas}

Recomendación: El taller para padres se debe enviar con mínimo una semana de anticipación a la clase en la que se van a implementar las actividades para los estudiantes, dando así la oportunidad y el tiempo para que puedan realizarlo y enviar los resultados sugeridos. Además, es importante disponer de un espacio para atender y orientar a los padres que lo soliciten.

En la sesión con los estudiantes se aconseja desarrollar las siguientes actividades:

\section{1) ¡PRESENTO MI FRUTA!}

Dar el espacio para que cada niño (a) presente su alimento a la clase y haga entrega de éste al profesor. Esta actividad se puede realizar durante varias sesiones, al iniciar la clase (la hora de la recolección de alimentos).

Con los datos que los niños aporten y el docente verifique, se propone ir construyendo una tabla que relacione los alimentos con el tipo de sabor correspondiente. Es importante que los estudiantes visualicen el registro que se va llevando y que participen en su realización: sugiriendo dónde va, corrigiendo, aclarando palabras...

\section{2) ¡TENGO EL SABOR!:}

Esta actividad consiste en un festival de degustación e identificación de sabores. A continuación se describe el desarrollo propuesto.

Preparación: Organizar los alimentos que previamente fueron seleccionados para la degustación de los estudiantes. Se recomienda situar una mesa por 
cada uno de los valores del descriptor, pues la actividad que se va a realizar con los niños (as) requiere que los alimentos en los que sobresalen diferentes valores estén separados. Por ejemplo, en una mesa deben estar los alimentos amargos, en otra los ácidos, en otra los dulces, etc. En la mesa correspondiente a cada valor se colocan los alimentos que se van a degustar (deben estar listos en una bandeja o plato) y los que no van por fuera del plato. Por ejemplo, si se decidió que los alimentos agrios que los estudiantes van a traer sean la uchuva y el tomate y que degusten solamente la uchuva, entonces en la mesa del valor agrio se sitúan las uchuvas en un plato, porque van a ser degustadas por los estudiantes; el otro alimento agrio, el tomate, se sitúa al lado del plato tal y como lo hayan traído los estudiantes, porque no va a ser degustado, sólo observado y reconocido dentro de un valor.

Como se advirtió, la organización de los alimentos se hará de acuerdo con el valor del descriptor "sabor" que es más característico en cada uno de ellos. Tan pronto cada estudiante deguste el o los alimentos de una mesa, el profesor le preguntará: ¿Qué sabor tiene el alimento? El estudiante deberá tratar de expresar con su cuerpo el sabor del alimento. Si se dispone de una cámara, es conveniente grabar las expresiones de cada estudiante.

Poniendo el nombre: Luego el estudiante deberá escoger una tarjeta (de las disponibles para esta actividad) que considere presenta el nombre del sabor; es decir, la tarjeta que tenga el valor que es más característico en los alimentos de esa mesa. Cuando el estudiante acierta a escoger la tarjeta correspondiente, el docente marca la tarjeta con el nombre del estudiante, se la obsequia y le solicita guardarla, para que al final de la ronda completa, cuando todos los estudiantes hayan pasado por todas las mesas, todos los estudiantes tengan seis tarjetas con los seis tipos de sabores degustados.

Expresando ideas: Luego, el docente solicita a cada niño (a) que seleccione un alimento de cualquier mesa y exprese con su cuerpo el sabor del alimento. Se les pedirá a los estudiantes dibujar el alimento escogido y marcarlo con su nombre. Luego colocará el dibujo en la cartelera que agrupa los alimentos de ese sabor. Si hay dibujos puestos en carteleras que no correspondan, el profesor buscará un alimento que sí corresponda a esa cartelera y preguntará a los estudiantes si el sabor es el mismo. Así, hará hasta ubicar los dibujos en la cartelera que correspondan.

Nota: Es importante hacer seguimiento de la expresión de las señas y observar el interés de los niños (as) por las palabras en español escrito y su nivel de reconocimiento. Puede aprovechar para señalar alimentos que inicien con la misma letra, por ejemplo: piña, pepino, plátano, pimienta, perejil. 


\section{Materiales}

- Frutas correspondientes a cada sabor.

- Seis mesas organizadas para la degustación.

- Tarjetas con los nombres de los sabores en alfabeto en LSC en una cara y en la otra con alfabeto en español.
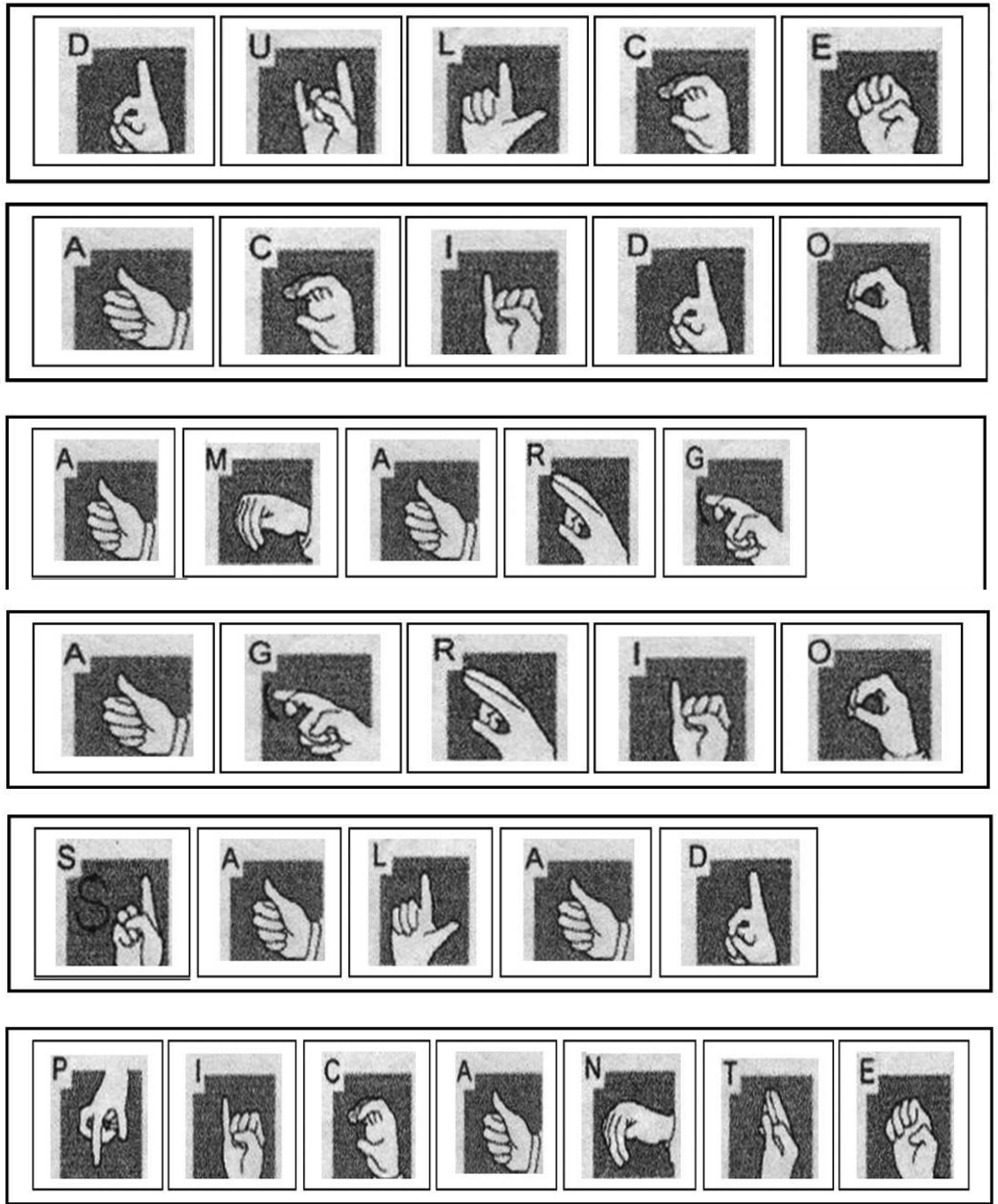

Tiempo: 40 minutos aproximadamente

Se recomienda realizar la actividad de degustación varias veces en el mes, con el fin de ir llenando la cartelera con alimentos nuevos; motivar a los estu- 
diantes para que presenten un alimento nuevo en alguna cartelera y que en ella quede registrado el nombre del aportante con su respectivo alimento. Insistir en el avance del rincón de palabras nuevas completando la relación ícono, palabra en español escrito y en LSC.

\section{3) MUESTRAS TUS SEMILLAS:}

- Dar a cada estudiante un fruto. Presentarle el nombre del fruto en LSC y en español escrito. Es importante que esta información esté visible para los estudiantes durante la clase.

- Cuando estén ingiriendo el fruto, solicitarles buscar sus semillas.

- Después, pedirles representar en dibujos o con plastilina la fruta correspondiente con su respectiva semilla y que la presenten a sus compañeros (as). El profesor puede llevar un dibujo o un modelo de plastilina como referencia.

- Presentar a los estudiantes expresiones cada vez más completas en LSC en la que se describan las frutas, p.e.: "la semilla de la fruta XXXX es pequeña, grande, roja, blanca...). Dar la oportunidad de que los estudiantes repitan las señas o pregunten.

- Finalmente, pedir a los estudiantes formar grupos que tengan la misma semiIla y entregarles una caja que deben marcar con el nombre de las frutas. Acudir a los carteles que visualizan nombres en español escrito y en LSC. Se puede aprovechar la ocasión para recolectar las semillas de la uchuva, en caso de que se esté siguiendo el consejo de crear la huerta con las plantas de esta fruta. Si se decidió que se va a sembrar otro tipo de semillas, se aconseja presentarlas en esta sesión y reflexionar o dejar ver la forma de adquirirlas.

\section{Materiales:}

- Frutas

- Hojas para dibujo

- Plastilina

- Cajas

Tiempo: 40 minutos aproximadamente.

Recomendación: Cuando los estudiantes consuman la fruta, se les puede preguntar por el sabor que tiene. Cada vez que alguien traiga una fruta de onces, se les recordará poner su semilla en la caja correspondiente; si no hay caja para esa fruta se destacará el nuevo aporte.

NOTA: es primordial que el docente registre las reflexiones y consideraciones que le inciten las respuestas, acciones y observaciones de los estudiantes, e 
identifique las expresiones que son difíciles o desconocidas para los niños (as). Para ello se puede disponer de un cuaderno de registro y se debe estar atento a cada suceso de la clase y a los comportamientos de los estudiantes. Si es posible tomar imágenes fotográficas o realizar grabaciones en video, se aconseja hacerlo, pues se obtendrá un registro más completo que se podrá utilizar posteriormente, bien para evaluar, bien para continuar el tema.

A continuación se ofrece una propuesta de un tipo de registro de procesos de los estudiantes. Se presenta un ejemplo de un posible registro que realizaría el profesor con respecto a un estudiante, durante el desarrollo de los talleres de esta fase y lleva el siguiente registro de los talleres precedentes. Recordar que el taller 3 es "sabor" y es el que debe ser registrado en este taller. Se puede obtener un registro de esta observación como el que se presenta en la siguiente tabla.

\section{REGISTRO DEL ESTUDIANTE XXXXXX}

\begin{tabular}{|l|l|l|l|l|l|l|l|l|l|l|l|l|l|}
\hline $\begin{array}{l}\text { Fechas del registro/ } \\
\text { forma de observación }\end{array}$ & \multicolumn{3}{|l|}{$\begin{array}{l}\text { Identificación de Descriptores } \\
\text { (Conjuntos de propiedades) }\end{array}$} & \multicolumn{4}{|l|}{$\begin{array}{l}\text { Número de valores (una propiedad del } \\
\text { conjunto) identificados para cada atributo }\end{array}$} \\
\hline & 1 & 2 & 3 & 4 & 5 & 6 & 1 & 2 & 3 & 4 & 5 & 6 \\
\hline $25-09-2010$ - taller3 & $X$ & $X$ & $X$ & & & & 2 & 1 & 0 & & & \\
\hline & & & & & & & & & & & & \\
\hline & & & & & & & & & & & & \\
\hline
\end{tabular}

Tabla 34. Registro de propiedades

\section{ACTIVIDADES PARA LOS PADRES DE FAMILIA}

\section{Presentación}

En el marco del Proyecto de Aula "Criando lombrices y sembrando plantas", se tiene pensado trabajar con su hijo (a) acerca de los sabores: ácido, amargo, dulce, picante, salado y agrio. Ustedes podrían aportar en este aprendizaje de manera sencilla. Lo único que tienen que hacer es propiciar la reflexión con su hijo (a) con respecto al sabor de algunos alimentos.

\begin{tabular}{|l|l|}
\hline \multicolumn{1}{|c|}{ SABOR } & \multicolumn{1}{c|}{ ALIMENTOS ASOCIADOS A CADA SABOR } \\
\hline Ácido & Vinagre, limón, fresas, piña, naranja, cerezas. \\
\hline Amargo & Cabrito, pavo, acelgas, lechuga, té, apio, café. \\
\hline Dulce & Conejo, melón, banano, ahuyama, calabaza, mermelada, azúcar moreno, miel. \\
\hline Picante & Cebolla, col china, rábano, nabo, ajo, pimiento, menta, jengibre, tabasco, ají. \\
\hline Salado & Cerdo, embutido, gambas, almejas, mariscos en general, castañas, almendras, nueces. \\
\hline Agrio & $\begin{array}{l}\text { Maíz, yogur, aloe, champiñón, oliva, pepino, patata, tomate, berenjena, alcachofa, col, plátano, } \\
\text { setas, zanahoria, mayonesa, uchuva. }\end{array}$ \\
\hline
\end{tabular}

Tabla 35. Relación sabores y alimentos 
Se propone la anterior tabla como una guía para que ustedes tengan un ejemplo de algunos alimentos asociados a cada tipo de sabor. Es decir, alimentos que tienen a ese sabor como el más característico, pues hay que aclarar que generalmente los alimentos tienen más de un sabor, pero entre sus diferentes sabores hay uno que sobresale.

Por otra parte, se requiere de su colaboración enviando para la próxima clase el alimento que le correspondió a su hijo, el cual se indica en las actividades propuestas.

\section{Actividad}

Converse con su hijo (a) acerca del sabor característico de ciertos alimentos. La conversación tendrá mejores resultados si es propiciada cuando el niño (a) tenga a la vista, o mejor aún, se encuentre consumiendo el alimento. Ustedes pueden hacerle preguntas como: ¿Te gusta este sabor?, ¿Qué otro alimento o fruta recuerdas que tenga este sabor?, ¿Cuál sabor te gusta más? Recuerden intentar comunicarse en LSC o hablando despacio y generando buena expresión gestual y corporal que ayude al niño (a) a comprender lo que ustedes quieren compartirle.

Intente que tu hijo (a) pruebe diferentes sabores: haga un esfuerzo para que antes de la próxima clase su hijo (a) haya degustado por lo menos un alimento asociado a cada tipo de sabor. No olviden conversar al respecto de ese sabor cuando estén consumiéndolo o probándolo.

Colabórele a su hijo (a) enviando el alimento que le correspondió y orientándolo en el siguiente trabajo extra-clase, ayudándole a escribir lo correspondiente en cada casilla.

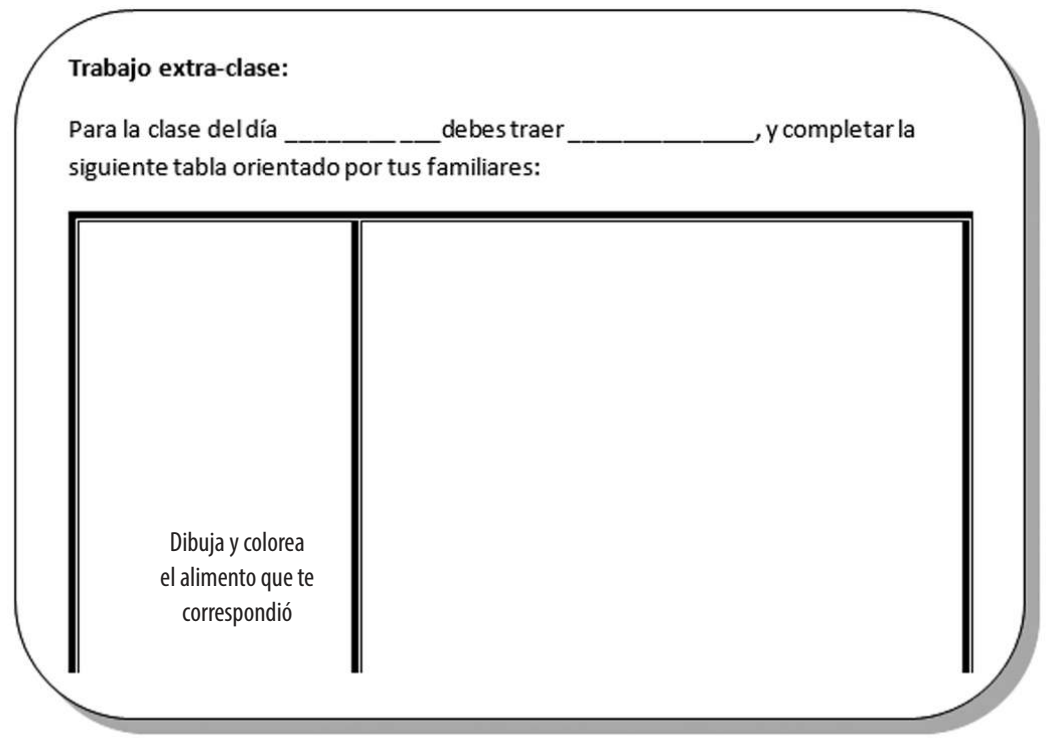


Sugerencia

Amplíe su conocimiento acerca de las señas correspondientes al vocabulario que se requiere: nombres de alimentos, nombres de frutas, sabores, entre otros. Para ello, intente tener disponible las señas de los sabores y de las frutas sobre las que van a conversar. Recuerden que está disponible el diccionario de LSC y el lexicón de este proyecto

\section{ACTIVIDADES PARA LOS ESTUDIANTES}

Actividad 1: Dibujar y colorear la fruta que te dio el profesor. Marca con tu nombre el dibujo. Coloca el dibujo en la cartelera de su sabor.

Actividad 2: Dibujar o hacer en plastilina el fruto que traes para comer

Dibujar o hacer en plastilina la semilla del fruto que te comiste. Busca la seña que corresponde y ponla en tu dibujo. Pide a tu profesor que te escriba el nombre que corresponde.

*Dibujar y colorear la semilla más grande y su respectivo alimento:

\section{ACTIVIDADES DE EVALUACIÓN PARA LOS ESTUDIANTES}

- Unir con su sabor característico

- Expresar en LSC nombre de alimento y nombre de tipo de sabor
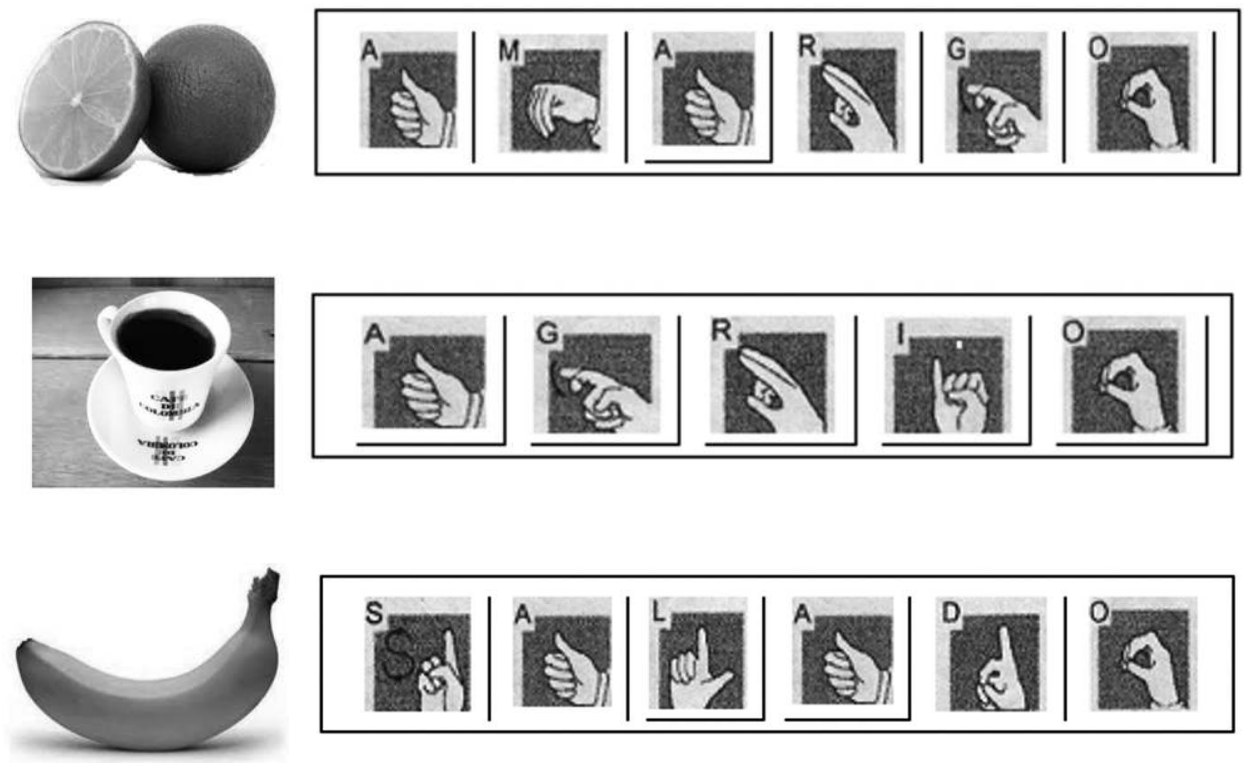

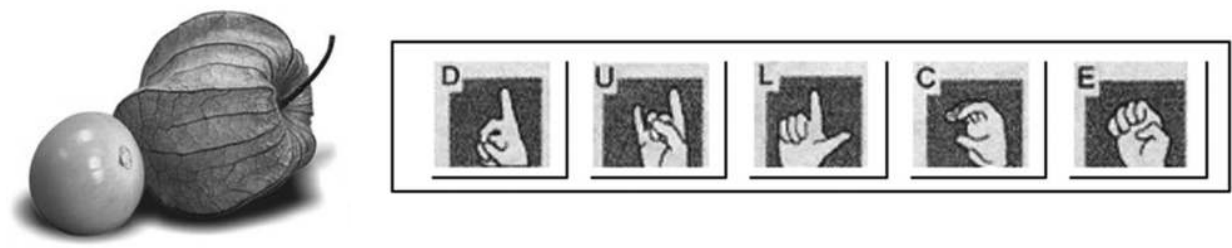

- Juguemos a deletrear:

Escoge un sabor y aprende a deletrearlo.

Cuando el profesor muestre la seña del sabor que tú elegiste, tú lo vas a deletrear.
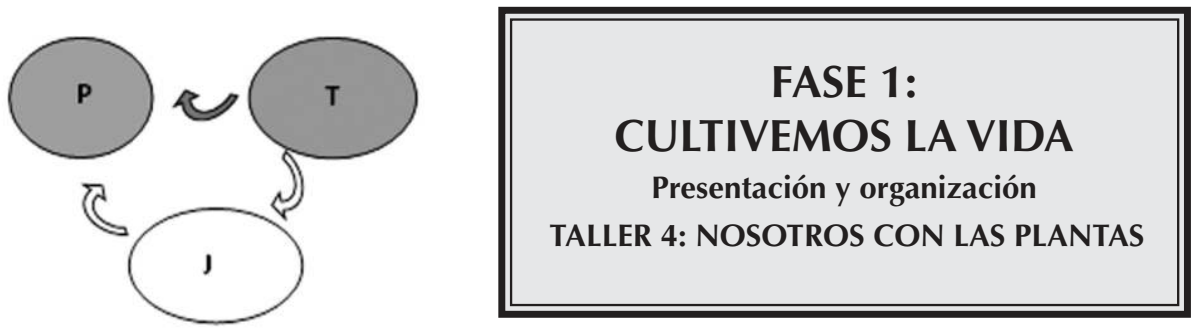

\section{ORIENTACIONES PARA EL PROFESOR}

\section{Objetivos}

- Desarrollar experiencias de conocimiento sobre los tipos de animales, a partir de la percepción de las características de los alimentos que requieren.

- Generar diversas experiencias de representación de las características de los alimentos olores y colores, como un desarrollo de lenguaje y de las lenguas LSC y español escrito.

- Consolidar el conocimiento experiencial y lingüístico acerca del conjunto de propiedades denominadas "olor" e identificar algunas propiedades del conjunto tales como herbal, frutal y pútrido.

\section{Presentación}

La realización de este taller requiere que los estudiantes hagan un trabajo previo extra-clase y que traigan cierto alimento, para lo cual deben contar con la ayuda de sus padres o familiares.

Se pretende que los estudiantes continúen el estudio de descriptores (conjunto de propiedades como olor) y de valores asociados a ellos (una propiedad del conjunto descriptor, como frutal), asignándoles una función como indicadores de estados de alimentos para personas y animales. Este estudio se inició con los talleres 1 y 2 anteriores gracias a la colaboración de los padres en la tarea 
de visitar tiendas, supermercados, parques para comprar, observar o jugar con animales y alimentos.

En este taller se profundizará en los descriptores color y olor y en algunos de sus valores. Junto con esta profundización, se desarrollará el campo léxico referido al tema y la capacidad expresiva y comunicativa de los estudiantes.

En este sentido se propone disponer de información sobre animales (fotos, afiches de animales) y alimentos que tengan olores diferentes. Por ello se sugiere que el profesor solicite a cada estudiante, en una sesión previa, traer dibujos o fotos de animales o empaques de comida de animales. Estas se compartirán en el transcurso del taller. Se recomienda que, en lo posible, cada niño (a) traiga tierra en una bolsita, para empezar a recolectar la tierra para el lombricuario ${ }^{33}$.

A continuación se presenta una relación entre tipos de olor y alimentos que se caracterizan por contenerlos. Esta información sirve como base para que el profesor, de acuerdo con las condiciones del curso, asigne a cada estudiante el alimento que debe traer.

\begin{tabular}{|l|l|}
\hline \multicolumn{1}{|c|}{$\begin{array}{c}\text { VALORES DEL } \\
\text { DESCRIPTOR OLOR }\end{array}$} & \multicolumn{1}{c|}{ ESTADOS DE ALIMENTOS ASOCIADOS A CADA VALOR } \\
\hline Frutal & Frutas en buen estado, miel \\
\hline Herbal & Vegetales en buen estado \\
\hline Floral & Flores recién cortadas, miel \\
\hline Picante & Cebollas rábanos, clavo, pimienta y el ají en buen estado \\
\hline Neutro & Agua \\
\hline Pútrido & Alimentos en estado de descomposición \\
\hline
\end{tabular}

Tabla 36. Relación Descriptores estado de alimentos

Con respecto a la anterior tabla, se le sugiere al profesor indagar acerca de los alimentos o de los vegetales que no son muy conocidos por él o por los estudiantes. Es importante tenerlos en cuenta para ampliar el rango de conocimiento y el vocabulario de todo el grupo. También se recomienda que cada nueva palabra sea puesta en un cartel o construir el rincón de palabras nuevas (el ícono del objeto, la palabra en español y en lengua de señas colombiana).

Una opción para el profesor es solicitar a los estudiantes traer los siguientes alimentos, con el fin de abarcar diferentes valores del descriptor olor:

$\checkmark$ Frutal: frutas frescas, yogures.

$\checkmark$ Herbal: verduras frescas.

33 Lombricuario se refiere al lugar (un acuario, una caja especial, etc.) preparado para que puedan habitar las lombrices. 
Neutro: agua, gelatina sin sabor

Floral: miel

$\checkmark$ Picante: cebolla cabezona y ají

Para percibir el olor Pútrido, se recomienda que sea el profesor quien lleve una naranja o una mandarina en descomposición y les enseñe este olor y este estado a los estudiantes. Se recomienda aprovechar esta situación para aprender la seña de "pútrido" y para describir características como: desagradable, fuerte, maloliente...

En la siguiente tabla se presentan formas de nariz y los animales que las presentan:

\begin{tabular}{|l|l|}
\hline Tipos de nariz en los animales & Animal \\
\hline Largas & Elefante, oso hormiguero \\
\hline Cortas & Murciélago, Gato persa, paloma \\
\hline Grandes & Delfín de nariz botella, mono narigudo \\
\hline Pequeñas & Mosca \\
\hline Con un orificio & Pez lamprea \\
\hline Varios orificios & Perro(2), caballo(2), serpiente cuatro narices (4) \\
\hline
\end{tabular}

Tabla 37. Relación tipo de nariz-animal

El video que se presenta en http://detodounpoco-tag.blogspot.com/2010/01/ delfines-nariz-de-botella-serian-los.html, presenta cómo juegan los delfines de nariz botella con los aros de agua que producen con su nariz.

Entre los alimentos que se asignen para traer, es necesario decidir cuáles son los que van a oler los estudiantes durante la sesión, teniendo en cuenta que se den a oler todos los valores del descriptor olor. De acuerdo con los escogidos, el profesor tendrá que preparar la manera de organizarlos para realizar la detección del olor. Por ejemplo, quitar la cáscara, picarlos, ubicarlos en una bandeja o plato, entre otros.

\section{Actividades sugeridas}

Recomendación: El taller para padres se debe enviar con mínimo una semana de anticipación a la clase en la que se van a implementar las actividades para los estudiantes, dando así la oportunidad y el tiempo para que puedan realizarlo y enviar los resultados sugeridos. Además, es importante disponer de un espacio para atender y orientar a los padres que lo soliciten.

En la sesión con los estudiantes se aconseja desarrollar las siguientes actividades: 


\section{1) ¡PRESENTO MI ANIMAL!}

Dar el espacio para que cada niño (a) presente su animal a la clase y haga entrega de un dibujo de éste al profesor. Con los datos que los niños (as) aporten y el docente verifique, se propone ir construyendo una tabla que relacione los animales con tipos de descriptores como tamaño, número de patas, forma de la boca... Es importante que los estudiantes visualicen el registro que se va llevando y que participen en su realización: sugiriendo dónde va, corrigiendo, aclarando palabras...

\section{2) ¡DIME EL OLOR!:}

Esta actividad consiste en percibir olores. A continuación se describe el desarrollo propuesto.

Preparación: Organizar los alimentos que previamente fueron seleccionados para ser percibidos por el olfato de los estudiantes. Se recomienda situar una mesa por cada uno de los valores del descriptor, pues la actividad que se va a realizar con los niños (as) requiere que los alimentos en los que sobresalen diferentes valores estén separados. Por ejemplo, en una mesa deben estar los alimentos de olor frutal, en otra los florales, en otra los herbales, etc. En la mesa correspondiente a cada valor se colocan los alimentos que se van a oler (deben estar listos en una bandeja o plato) y los que no, van por fuera del plato.

Como se advirtió, la organización de los alimentos se hará de acuerdo con el valor del descriptor "olor" que es más característico en cada uno de ellos. Tan pronto cada estudiante perciba el olor del o los alimentos de una mesa, el docente le preguntará: ¿Qué olor tiene el alimento? El estudiante deberá tratar de expresar con su cuerpo el olor del alimento. Si se dispone de una cámara, es conveniente grabar las expresiones de cada estudiante.

Luego, el estudiante deberá escoger una tarjeta (de las disponibles para esta actividad) que considere presenta el nombre del olor; es decir, la tarjeta que tenga el valor que es más característico en los alimentos de esa mesa. Cuando el estudiante acierta a escoger la tarjeta correspondiente, el docente marca la tarjeta con el nombre del estudiante, se la obsequia y le solicita guardarla, para que al final de la ronda completa, cuando todos los estudiantes hayan pasado por todas las mesas, cada estudiante tenga seis tarjetas de acuerdo con los tipos de sabores olfateados.

Posteriormente el docente solicita a cada niño (a) que seleccione un alimento de cualquier mesa y exprese con su cuerpo el olor del alimento. Se les pedirá a los estudiantes dibujar el alimento escogido y marcarlo con su nombre. Luego colocará el dibujo en la cartelera que agrupa los alimentos de ese olor. Si hay dibujos puestos en carteleras que no correspondan, el profesor buscará un alimento que sí corresponda a esa cartelera y preguntará a los estudiantes si el olor es el mismo. Así, hará hasta ubicar los dibujos en la cartelera que correspondan. 
Es importante hacer seguimiento y corrección de la expresión de las señas y observar el interés de los niños (as) por las palabras en español escrito y su nivel de reconocimiento. Para ello se puede acudir al rincón de las palabras o al lexicón.

\section{Materiales}

- Alimentos correspondientes a cada olor.

- Seis mesas organizadas para la degustación.

- Tarjetas con los nombres de los sabores en alfabeto en LSC en una cara y en la otra con alfabeto en español.
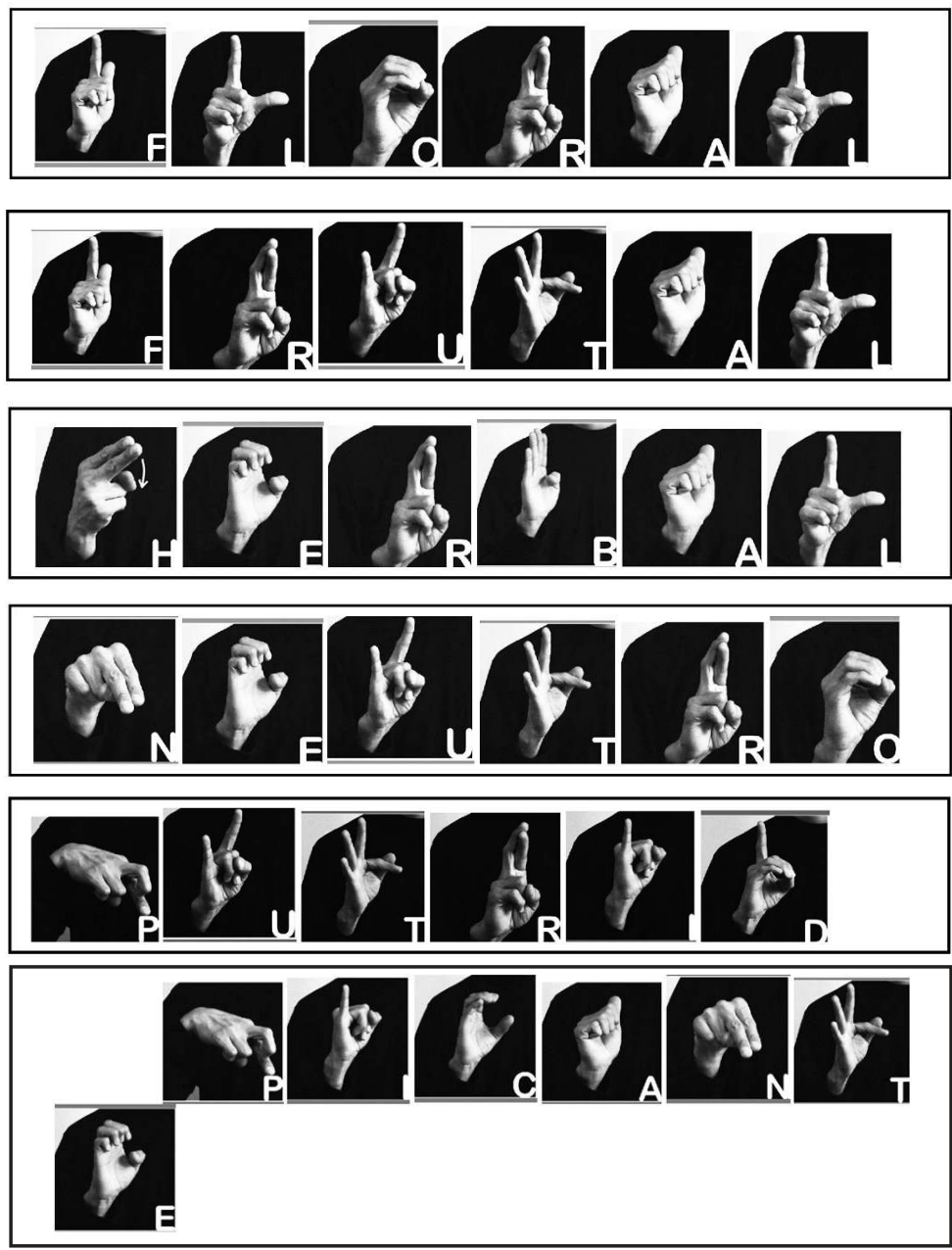

Tiempo: 40 minutos aproximadamente 
Se recomienda realizar la actividad de percepción de olores varias veces en el mes, con el fin de ir llenando la cartelera con alimentos nuevos. Motivar a los estudiantes para que presenten un alimento nuevo en alguna cartelera y que en ella quede registrado el nombre del aportante con su respectivo alimento. Insistir en el avance del rincón de palabras nuevas completando la relación ícono, palabra en español escrito y en LSC.

\section{3) ¿CÓMO ES TU NARIZ?:}

- Dar a cada estudiante una foto de un animal. Presentarle el nombre del animal en LSC y en español escrito. Es importante que esta información esté visible para los estudiantes durante la clase.

- Solicitar a cada estudiante presentar la forma de la nariz de su animal en LSC y después, pedirles representar en dibujos o con plastilina el animal correspondiente. El profesor puede Ilevar un dibujo o un modelo de plastilina como referencia.

Finalmente, pedir a los estudiantes formar grupos que tengan animales cuya nariz sea del mismo tipo. Entregarles una caja que deben marcar con el nombre del tipo de nariz.

Materiales $^{34}$ :

Frutas

Hojas para dibujo

Plastilina

Cajas

Tiempo: 40 minutos aproximadamente.

Recomendación: Cada vez que alguien traiga una fruta en la lonchera, se les recordará percibir su olor, sabor e identificar su color y comunicarlo al grupo. Buscar la seña y la palabra escrita correspondiente en carteles o en el rincón de la palabra.

NOTA: es primordial que el profesor registre las reflexiones y consideraciones que le inciten las respuestas, acciones y observaciones de los estudiantes e identifique las expresiones que son difíciles o desconocidas para los niños (as). Para ello se puede disponer de un cuaderno de registro y se debe estar atento

\footnotetext{
34 L Imagen de lampreas tomadas de http://www.lamarsalao.com/ Imagen de la mosca tomada de :clare120859.blogspot.com imagen de gatos: crisfdez86.blogspot.com imagen de mono: tipete.com oso hormiguero: rescatando-mi-cultura-guaran.blogspot.com imagen de elefante: taringa.net
} 
a cada suceso de la clase y a los comportamientos de los estudiantes. Si es posible tomar imágenes fotográficas o realizar grabaciones en video, se aconseja hacerlo, pues se obtendrá un registro más completo que se podrá utilizar posteriormente, bien para evaluar, bien para continuar el tema.

A continuación se ofrece una propuesta de un tipo de registro de procesos de los estudiantes. Se presenta un ejemplo de un posible registro que realizaría el profesor con respecto a un estudiante, durante el desarrollo de los talleres de esta fase y lleva el siguiente registro de los talleres precedentes. Recordar que el taller 3B es "olor" y es el que debe ser registrado en este taller. Se puede obtener un registro de esta observación como el que se presenta en la siguiente tabla.

\section{REGISTRO DEL ESTUDIANTE XXXXXX}

\begin{tabular}{|c|c|c|c|c|c|c|c|c|c|c|c|c|}
\hline $\begin{array}{l}\text { Fechas del registro/ } \\
\text { forma de observación }\end{array}$ & \multicolumn{3}{|l|}{$\begin{array}{l}\text { Identificación de Descriptores (Conjuntos de } \\
\text { propiedades) }\end{array}$} & \multicolumn{4}{|c|}{$\begin{array}{l}\text { Número de valores (una propiedad del } \\
\text { conjunto) identificados para cada atributo }\end{array}$} \\
\hline & 1 & 2 & 3 & 4 & 5 & 6 & 1 & 2 & 3 & 4 & 5 & 6 \\
\hline 23-03-2010-Taller 1 & $X$ & $X$ & $X$ & & & & 2 & 1 & 0 & & & \\
\hline 30-03-2010 Taller 2 & $X$ & & & $X$ & & & 3 & & & 1 & & \\
\hline 02-04-2010 Taller 3 & $X$ & $X$ & $X$ & $X$ & & & 3 & 3 & 3 & 3 & & \\
\hline & & & & & & & & & & & & \\
\hline
\end{tabular}

Tabla 38. Registro descriptores- propiedades

Recordar, desde el primer taller, que descriptor se asignó a los valores numéricos 1, 2, 3, 4, 5, y mantenerlos en todas las observaciones.

\section{B. ACTIVIDADES PARA LOS PADRES DE FAMILIA}

\section{Presentación}

En el marco del Proyecto de Aula "Criando lombrices y sembrando plantas", se tiene pensado trabajar con su hijo (a) acerca de los olores: frutal, herbal, floral, neutro, picante pútrido. Ustedes podrían aportar en este aprendizaje de manera sencilla. Lo único que tienen que hacer es propiciar la reflexión con su hijo (a) con respecto del olor de algunos alimentos.

\begin{tabular}{|l|l|}
\hline VALORES DEL DESCRIPTOR OLOR & ESTADOS DE ALIMENTOS ASOCIADOS A CADA VALOR \\
\hline Frutal & Frutas en buen estado, miel \\
\hline Herbal & Vegetales en buen estado \\
\hline Floral & Flores recién cortadas, miel \\
\hline Picante & Cebollas rábanos, clavo, Pimienta y el ají en buen estado \\
\hline Neutro & Agua \\
\hline Pútrido & Alimentos en estado de descomposición \\
\hline
\end{tabular}

Tabla 39. Registro valores-estado de alimentos 
Se propone la anterior tabla como una guía para que ustedes tengan un ejemplo de algunos alimentos asociados a cada tipo de olor. Es decir, alimentos que tienen ese olor como el más característico, pues hay que aclarar que generalmente los alimentos tienen más de un olor, pero entre sus diferentes olores hay uno que sobresale.

Por otra parte, se requiere de su colaboración enviando para la próxima clase el alimento que le correspondió a su hijo, el cual se indica en las actividades propuestas.

\section{Actividad}

Converse con su hijo (a) acerca del olor característico de ciertos alimentos. La conversación tendrá mejores resultados si es propiciada cuando el niño (a) tenga a la vista, o mejor aún, se encuentre consumiendo el alimento. Ustedes pueden hacerle preguntas como: ¿Te gusta este olor?, ¿Qué otro alimento o fruta recuerdas que tenga este olor?, ¿Cuál olor te gusta más? Recuerden intentar comunicarse en LSC o hablando despacio y generando buena expresión gestual y corporal que ayude al niño (a) a comprender lo que ustedes quieren compartirle.

Intente que tu hijo (a) perciba el olor de diferentes alimentos. Haga un esfuerzo para que antes de la próxima clase su hijo (a) haya percibido olores de, por lo menos, un alimento asociado a cada tipo de olor. No olviden conversar al respecto de ese olor cuando estén consumiéndolo o probándolo.

Colabórele a su hijo (a) enviando el alimento que le correspondió y orientándolo en el siguiente trabajo extra-clase, ayudándole a escribir lo correspondiente en cada casilla.

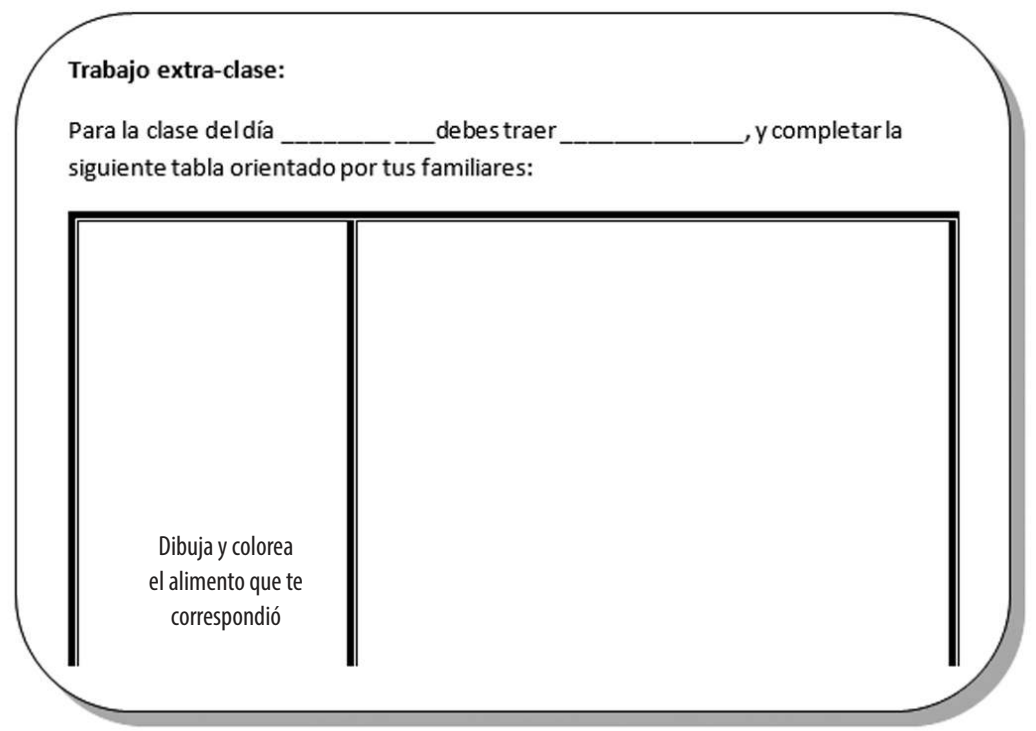




\section{Sugerencia}

Amplíe su conocimiento acerca de las señas correspondientes al vocabulario que se requiere: nombres de alimentos, nombres de frutas, olores, entre otros. Para ello, intente tener disponible las señas de los sabores y de las frutas sobre las que van a conversar. Recuerden que está disponible el diccionario de LSC

\section{ACTIVIDADES PARA LOS ESTUDIANTES}

Actividad 1: Dibujar y colorear el animal que te dio el profesor.

Busca la seña del nombre del animal y la palabra escrita correspondiente y ponlas debajo del dibujo. Marca con tu nombre el dibujo.Coloca el dibujo en la cartelera de su tipo de nariz.

Actividad 2. Dibuja el alimento que traes para oler. Busca la seña del nombre del alimento y la palabra escrita correspondiente y ponlas debajo del dibujo. Marca con tu nombre el dibujo.

Actividad 3. Hacer en plastilina el animal que te dieron para presentarle su nariz.

Presenta tu animal a los otros compañeros, destacando sus características y deja que tus compañeros (as) adivinen de qué animal se trata.

*Coloca el animal que hiciste en la caja que le corresponde por la forma de su nariz. Dibuja los animales que quedaron en esa caja.

\section{ACTIVIDADES DE EVALUACIÓN PARA LOS ESTUDIANTES}

- Encierra con un círculo los anímales de nariz larga y con un cuadrado los animales de nariz corta.

\section{Cuando el profesor}
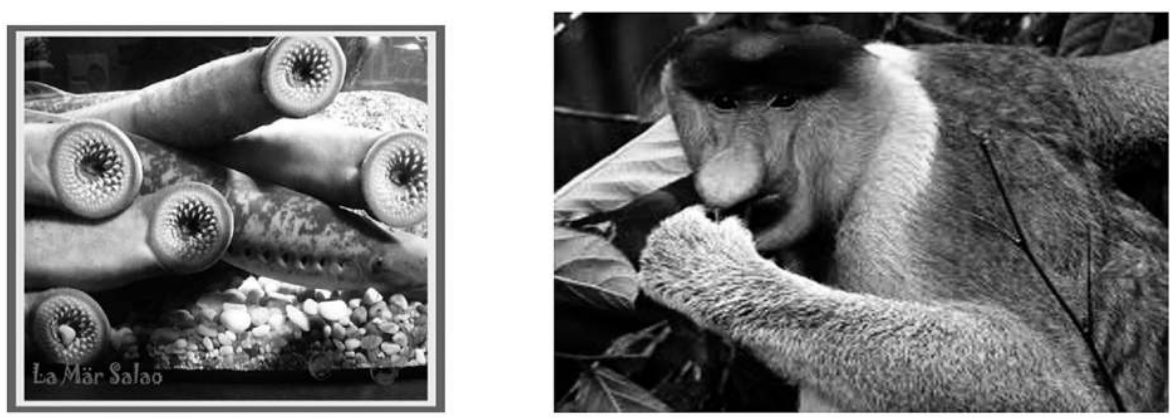
- Juguemos a deletrear:

Escoge un sabor y aprende a deletrearlo.

Cuando el profesor

muestre la seña del sabor que tú elegiste, tú lo vas a deletrear

\subsection{Organización de los talleres en el micromundo de la aproximación de la cantidad Fase 2}

Para el desarrollo de este micromundo en la Fase 2, se diseñó un conjunto de cuatro talleres. El siguiente esquema ilustra la relación de talleres.

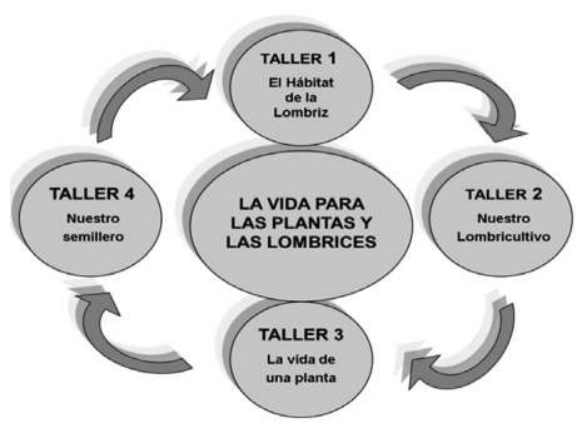

Esquema 7. Talleres del micromundo de la aproximación a la cantidad, Fase 2.

La fase denominada "La vida para las plantas y las lombrices" es una etapa de construcción del lombricultivo y del semillero, a partir de una organización por tres tipos de equipos conformados de la siguiente manera: uno, por estudiantes; dos, por padres y estudiantes y tres, por profesores y estudiantes. Se proponen cuatro talleres como prototipo de talleres para esta fase. Cada profesor puede realizar cambios a la propuesta de talleres, según las exigencias que provienen de las condiciones de los estudiantes.

Es importante considerar los documentos de profundización proporcionados en este ambiente didáctico (Parte I de la obra), para orientarse en la formulación de actividades o en la selección de dispositivos complementarios para la realización de talleres de profundización o de juegos de desarrollo de habilidades numéricas y geométricas. 

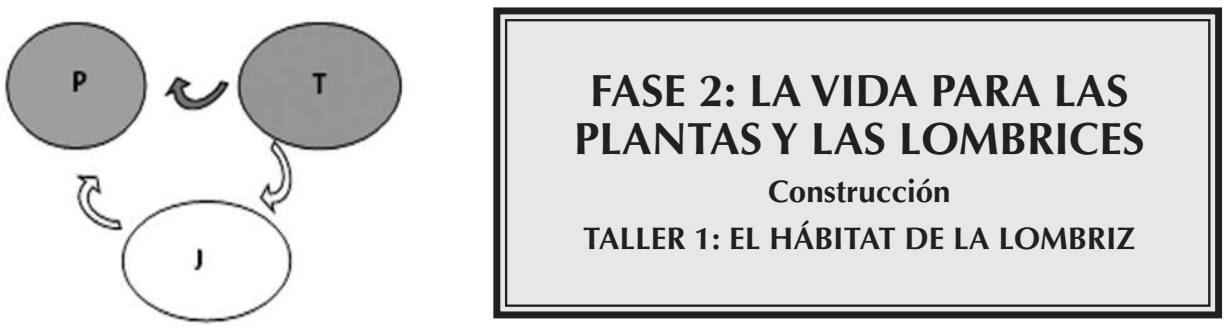

\section{A. ORIENTACIONES PARA EL PROFESOR}

\section{Objetivos}

- Fomentar el trabajo cooperativo entre los estudiantes, y entre padres y estudiantes, para el desarrollo de tareas comunes orientadas a construir el hábitat de la lombriz.

- Comprender las condiciones de vida de una lombriz de tierra e identificar los recursos para su subsistencia.

- Organizar y planear la forma de conseguir los recursos y los espacios para construir el lombricuario en el espacio escolar.

Presentación. Para esta fase es importante que los estudiantes conozcan la lombriz de tierra y las condiciones del ambiente en el que ella se desarrolla. La idea de esta fase es combinar el aprendizaje de cómo hacer y mantener un lombricultivo y desarrollar nociones de aproximación a cantidades y de significación y expresión de las mismas. Así, se requiere propiciar diversas experiencias de conocimiento de la lombriz de tierra, en las que se identifiquen los elementos que se necesitan para preparar el lombricuario como hábitat para la lombriz. También se hace necesario generar experiencias en las que los estudiantes tengan que establecer relaciones de cantidad entre elementos como: espacio necesario, porción de tierra, lombrices, cantidad de comida, cantidad de tiempo y personas que se requieren para hacer un lombricuario. En estas experiencias es fundamental que se haga énfasis en el vocabulario que va surgiendo, por ejemplo palabras referidas a cantidades: mucho, harto, bastante, poco, poquito... y, por supuesto, en el significado de estos términos.

La presentación de videos, ambientada por aclaraciones y ampliaciones del profesor, es muy importante como una experiencia de referencia para los niños. También pueden programarse salidas pedagógicas a lugares donde habitan las lombrices, por ejemplo, a los jardines, los parques, a una granja o a un hogar en donde se cultiven lombrices. Esta puede ser una experiencia complementaria a la del video y puede vincular a los padres.

Finalmente, la experiencia de aula que propicie el profesor, articulando las experiencias que manifiestan los estudiantes sobre lo percibido en cada una de las 
situaciones con sus padres, con el video y con la salida pedagógica (si fue posible), se constituye en el referente básico para la organización de los estudiantes para conseguir los recursos que se requieren para la construcción del lombricuario.

Es importante que la experiencia de aula vincule:

- Emociones de los estudiantes con respecto a la existencia de la lombriz y a las funciones que cumple con la naturaleza.

- Espacios en los que vive la lombriz y elementos importantes en esos espacios.

- Características generales de la lombriz: ¿cómo es?, ¿qué come?, ¿cuánto vive?, ¿cómo se reproduce?, ¿qué cuidados hay que tener con ella?, ¿qué tipos de lombrices hay?, ¿qué función cumplen en la naturaleza?

- Formas representación, significados y expresiones empleadas en LSC y en español escrito.

Las condiciones de la experiencia de aula reconocen que la experiencia con la cantidad en el niño (a) tiene su génesis en la experiencia con "lo otro". Las acciones de comparar los objetos entre sí, bien sea para agruparlos en una misma clase, o para combinarlos con la intención de obtener un objeto o conjunto nuevo e interesante, constituyen actividades de comparación y de clasificación de objetos en el primer caso, y de composición de objetos complementarios, en el segundo caso. Pero, como lo indica Vergnaud, "la matematización de esta actividad de composición de objetos complementarios es muy diferente de la matematización de las actividades de comparación y clasificación" (Vergnaud, 1985: 77).

Sugerimos, entonces, que para el seguimiento de los procesos de comparación entre cantidades, que va a determinar parecidos y diferencias entre los objetos, y que son dinamizados en las actividades de los talleres de esta fase del proyecto de aula, se tengan en cuenta los niveles propuestos por Vergnaud (1985).

NIVELES DE LA COMPARACIÓN DE OBJETOS

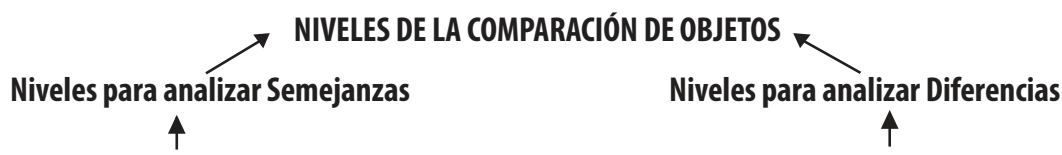

- Equivalencia simple: Objetos diferentes que tiene en común una propiedad, como el vaso de plástico y la botella de plástico

- Cuasi identidad: Objetos distintos que tienen en común todas las propiedades, como las lombrices de tierra, entre ellas son cuasi idénticas.

- Identidad: Un solo objeto idéntico a sí mismo por compartir todas las propiedades posibles; por ejemplo, cada lombriz de tierra que nace es idéntica a sí misma.

- Descriptores cualitativos: se pueden asociar categorías distintas a los objetos, pero no son ordenables. En este caso tenemos los descriptores como: sexo, nacionalidad, color, forma.

- Descriptores ordinales: se pueden asociar categorías ordenables a los objetos, como para los siguientes descriptores: tonos de color, grosor.

- Descriptores cuantitativos: se pueden asociar categorías numéricas a los objetos, como para los siguientes descriptores: tamaño de una colección de objetos, peso, volumen... 
Cuando se desarrolla la percepción en los niños (as), se da paso a la cantidad. Si se observa con detenimiento, encontraremos que en las caracterizaciones que se surgen de "cantidad", se comparten aspectos como:

Identificar la cantidad como un atributo.

Identificar en sus características un proceso de valoración numérica o pre-numérica para dicho atributo.

De este modo, se manifiesta una idea de cantidad como "aquello que puede ser comparado con otro de su misma especie mediante una relación de orden con propiedades y atributos particulares". Este aspecto se desarrolla en la significación de las expresiones de cantidad y en las relaciones que se establecen entre ellas. Por esta razón, es importante que el profesor consulte los documentos de fundamentación y de profundización con respecto a los micromundos de la aproximación y de la precisión y al repertorio léxico del campo semántico de la cantidad.

\section{Actividades sugeridas}

Recomendación: El taller para padres se debe enviar con mínimo una semana de anticipación a la clase en la que se van a implementar las actividades para los estudiantes, dando así la oportunidad y el tiempo para que puedan realizarlo y enviar los resultados sugeridos. Además, es importante disponer de un espacio para atender y orientar a los padres que lo soliciten.

En la sesión con los estudiantes se aconseja desarrollar las siguientes actividades:

\section{1) ¡BUSCO MI LOMBRIZ!}

En esta actividad se le indica al estudiante que va a conocer muchas lombrices, en videos, en fotos, en vivo, en dibujos, en esculturas de diversos materiales (y otras que el profesor presente). Se les solicitará que observen bien y que seleccionen e informen al profesor cuál es la lombriz (o representación de ella) que eligen para cada uno.

El profesor entregará a cada niño (a) su correspondiente representación de lombriz para que le ponga un nombre en LSC a su representación de lombriz y para que luego se busque la palabra en español escrito. En un lugar del salón el profesor habrá adecuado un espacio en una cartelera o en una pared para registrar el desarrollo del lombricultivo. Allí se puede tener el espacio para que cada niño (a) coloque la representación de su lombriz que puede ser bidimensional (foto, dibujo) o tridimensional (una escultura en algún material) o quizás quieran tenerla viva (en ese caso será en el lombricuario). 


\section{2) ¿PARA QUÉ SIRVE UNA LOMBRIZ?}

Para esta actividad se sugieren dos actividades:

El Video: El profesor presenta un video sobre la importancia de las lombrices, sugerimos http://www.youtube.com/watch?v=gR4MYjrfkWs. Después entrega a cada estudiante la primera hoja de actividades para estudiantes, con el fin de que completen la secuencia según el video. Cada niño (a) presenta su secuencia y expresa lo que le gustó del video.

El profesor les puede preguntar si ellos tienen preguntas sobre la información que nos ofreció el video, acerca de la vida de las lombrices. Si es necesario, puede pasarlo de nuevo para que ellos señalen partes que les Ilamaron la atención o que no entendieron. Destacar la importancia de la vida de las lombrices.

La salida pedagógica: Si no hay condiciones para presentar un video, se puede proponer una salida pedagógica a una granja donde cultiven lombrices (cerca Bogotá hay varias), a un jardín o a un parque cercano. Es importante pedir a los estudiantes que observen bien durante la visita y que guarden lo que más les interese para comentarlo después. Al regreso de la salida, se puede solicitar realizar un dibujo o una representación en plastilina de lo que recuerda de la salida. Luego se propone que cada niño (a) presente su dibujo a sus compañeros (as).

\section{3) ¿CÓMO SON LAS LOMBRICES?}

Con el fin de ampliar conocimiento sobre las lombrices y su forma de vida, se propone realizar una salida pedagógica a una granja o a un lombricultivo casero o invitar a un lombricultor para que realice una presentación sobre las lombrices a los estudiantes. En cada caso, es importante hacer énfasis en las condiciones de vida de las lombrices: su alimentación, su forma de reproducirse y los cuidados necesarios.

Si no fuera posible realizar ninguna de las dos actividades anteriores, el profesor podrá llevar una lombriz de tierra en un recipiente, de aquellas que se consiguen en los jardines o debajo de pasto. El recipiente puede ser de vidrio, para que la puedan apreciar.

Después de cualquiera de las actividades anteriores, el profesor entregará las láminas de lombrices en diferentes estados, para que entre todos los estudiantes vayan identificando los elementos necesarios para las lombrices, de los que aparecen en las láminas.

El profesor va seleccionando la lámina que mejor presenta el elemento y la pega en un cartel, indicando la expresión en lengua de señas, y resaltando con un marcador elemento seleccionado en la lámina. El cartel puede tener una presentación como el ejemplo que se muestra aquí, para que alrededor se vayan colocando los elementos que distinguen los niños: 


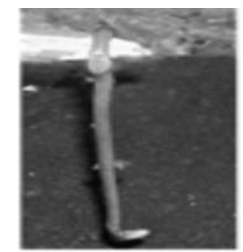

Es importante que el profesor destaque el uso de expresiones de aproximación mencionadas anteriormente, a partir de la pregunta: ¿qué tanto? (¿qué tanta tierra?) Al finalizar las actividades dos y tres, el profesor preguntará a los estudiantes si ya escogieron su lombriz y les pedirá que indiquen dónde se encuentra, para obsequiarle su representación.

\section{Materiales:}

- Videos

- Láminas ${ }^{35}$

- Hojas para trabajo individual y tamaño cartel

- Colores y plastilinas

\section{B. ACTIVIDADES PARA LOS PADRES DE FAMILIA}

Presentación. El taller CULTIVANDO LA VIDA pretende desarrollar conocimiento en los niños (as) sobre las lombrices, sus características y sus condiciones de vida. Por esta razón, es importante que usted acompañe a su hijo (a) en el descubrimiento de espacios donde permanecen las lombrices de tierra, o espacios donde venden el humus que ellas producen, o si les es posible, de fincas donde hay criaderos de lombrices.

En los supermercados pueden observar los alimentos de comidas para animales y mirar si están hechos con harina de lombriz. Acompañe a su hijo (a) a observar en cada espacio la presencia de la lombriz y el efecto que tiene en las personas, en las plantas o en los animales. No olviden la importancia de la conversación con su hijo (a), sea en LSC o en español (hablando despacio y expresándose gestualmente, de tal manera que él o ella pueda comprenderlos y comunicarse con ustedes). Trate de identificar las preguntas de su niño (a) y, en lo posible responderle o averiguar para dar respuesta posteriormente.

Después de esos recorridos, pueden completar, junto con el niño (a), la siguiente gráfica, según la información que encontraron en cada lugar. La gráfica se puede hacer con fotos, recortes de empaques o dibujos. Es importante escribir en el título los nombres de los padres o los familiares que hicieron el recorrido con el niño (a) y el nombre del niño (a).

35 El número de la foto corresponde al sitio Web de donde fue tomada: 1 munieltambo.gob.pe 2 frikinai.spaces. live.com, 7 infojardin.com, 4, hdynaturaleza.blogspot.com, 5 ecologiablog.com , 3 y 6 ooche813.blogspot. com, 8 duggan-lombricultura.blogspot.com, 9residuoslamacarena.blogspot.com, 10 elcolombiano.com 
NOSOTROS: Y

ENCONTRAMOS LO SIGUIENTE SOBRE LAS LOMBRICES
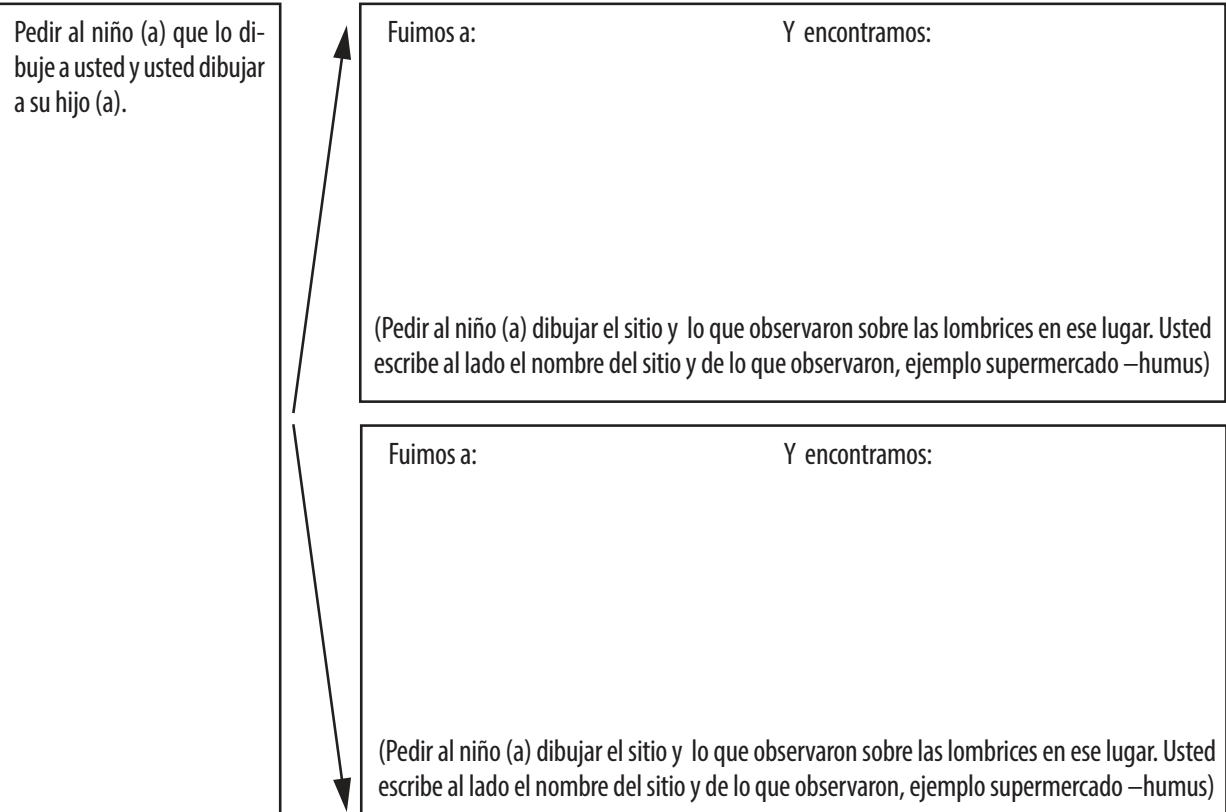

Fuimos a: $\quad$ Y encontramos:

\section{C) . ACTIVIDADES PARA LOS ESTUDIANTES}

Actividad 1: Lleva: al niño, a la planta y al árbol, al sitio que le corresponde según lo visto en el video
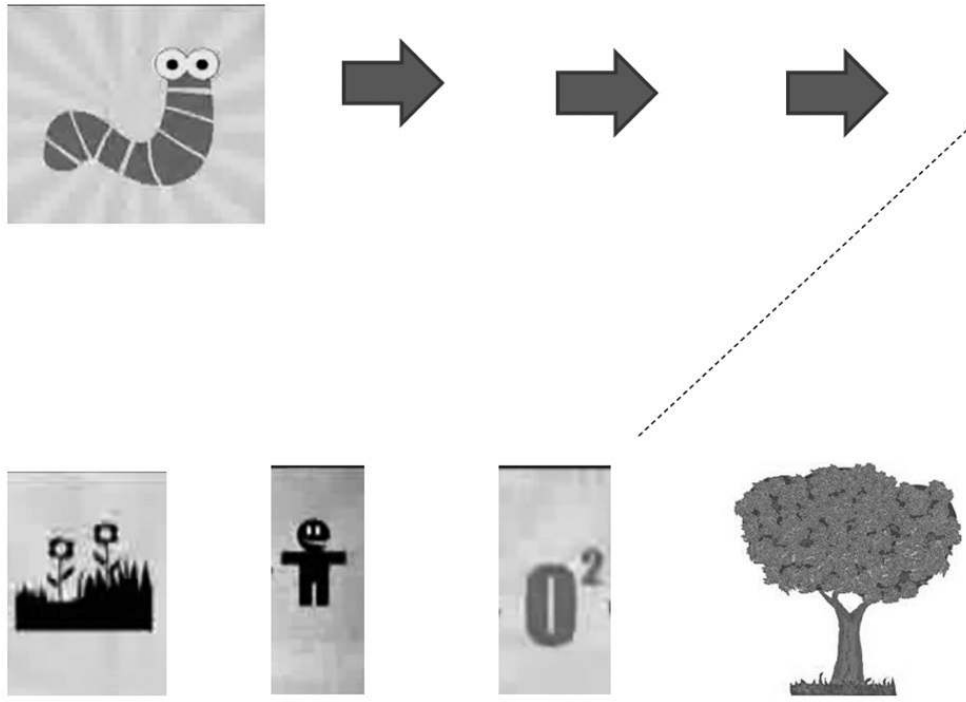


\section{Actividad 2.}

Escoge una de las siguientes láminas, márcala y pídela al profesor.

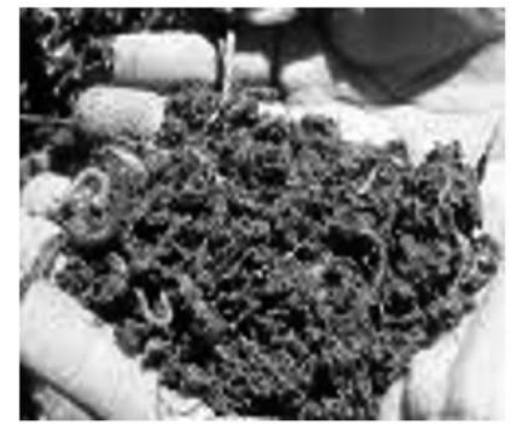

1. munieltambo.gob.pe

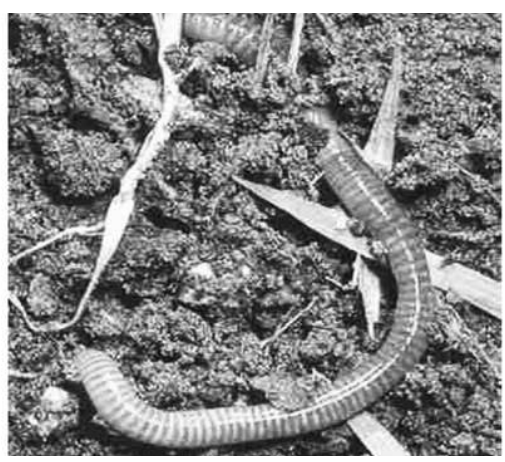

3. ooche813.blogspot.com

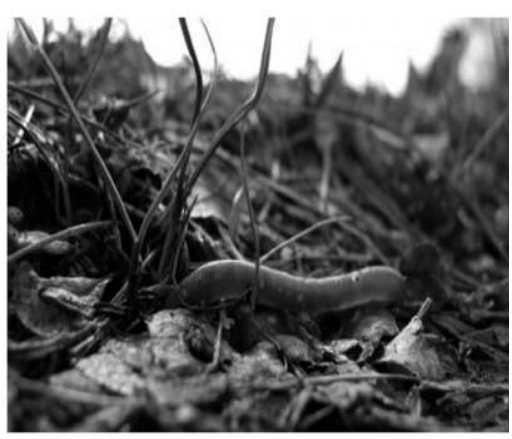

5. ecologiablog.com

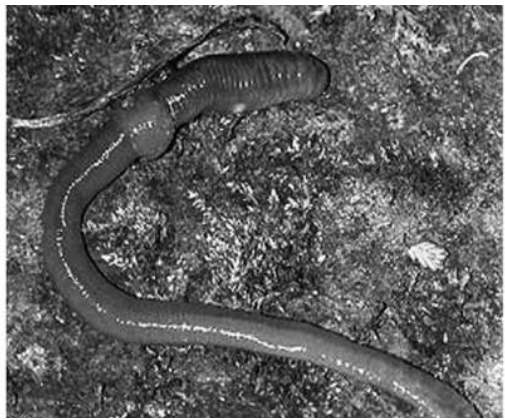

2. frikinai.spaces.live.com

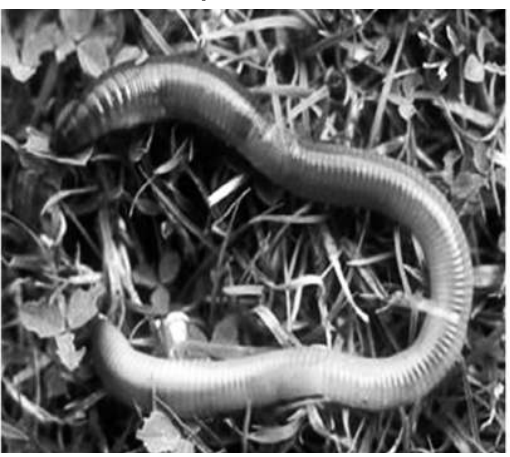

4. dynaturaleza.blogspot.com

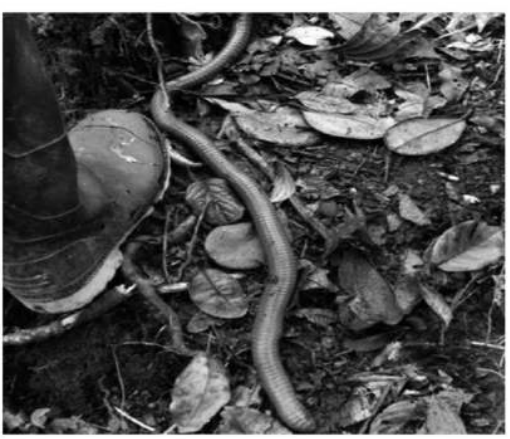

6. Lombriz gigante ecuador ooche813.blogspot.com 


\section{Actividad 3}

*Escoge la lombriz que más te gusta de todas las que viste y colócale un nombre en LSC. Pide al profesor que te ayude a buscar el nombre en español y escríbelo en la lámina.

*En una hoja de papel periódico pinta a tu lombriz y escribe su nombre. Luego haz una lista de dibujos de las cosas que necesita la lombriz para vivir. Presenta a tus compañeros (a) a tu lombriz y lo que ella necesita para vivir.

\section{ACTIVIDADES DE EVALUACIÓN PARA LOS ESTUDIANTES.}

Coloca una $\mathrm{X}$ en el material y cantidad que puedes traer para hacer la cama de las lombrices

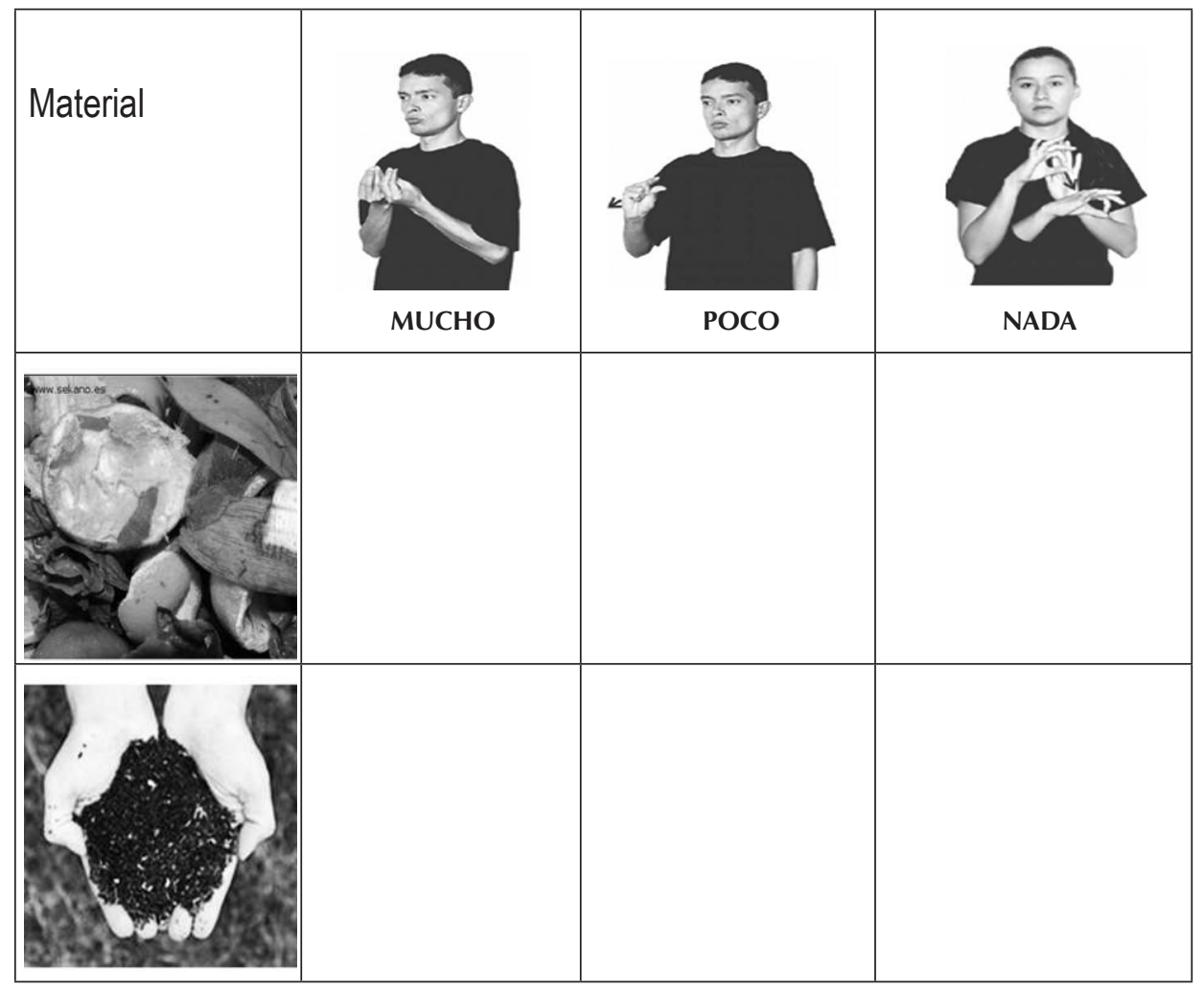




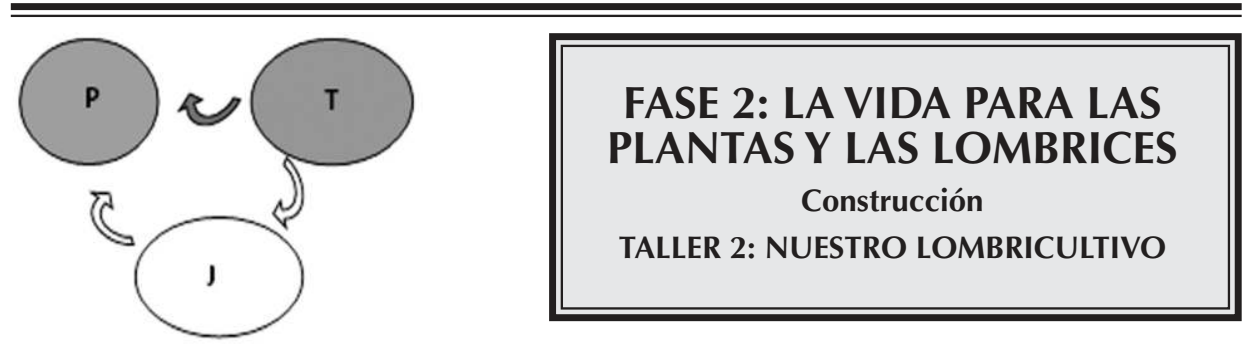

\section{A. ORIENTACIONES PARA EL PROFESOR}

\section{Objetivos}

- Determinar el lugar y los materiales necesarios para la construcción del criadero de lombrices.

- Construir el criadero de lombrices, a través del trabajo en equipo conformado por el profesor y los estudiantes.

- Desarrollar habilidades para comparar cantidades, apreciar tamaños de cantidades y usar expresiones adecuadas para describir y comunicar esos procesos.

Presentación. Para la fase de Construcción es importante que los estudiantes puedan identificar los materiales necesarios que permitirán construir el lombricultivo. En este proceso se realizarán aproximaciones de cantidades de: espacio, superficie, tiempo, tierra, alimento, lombrices, personas, que se requieren $y$, junto con ello, desarrollarán el campo léxico relacionado con la aproximación y una actitud de curiosidad y de respeto por las lombrices.

Por esta razón, las siguientes actividades están diseñadas para que los estudiantes realicen dos aprendizajes relacionados con la construcción del lombricultivo: i) conocer el hábitat de las lombrices: los materiales que se requieren, identificar en qué lugar se puede ubicar el lombricultivo, conseguir la cantidad apropiada de materiales, los tamaños adecuados de los recipientes y de las lombrices, la cantidad apropiada de la comida; y ii) desarrollar la expresividad relacionada con el proyecto de realizar un lombricultivo: el lenguaje (las expresiones en LSC y en español escrito), las significaciones y aplicaciones en la vida diaria, otras formas de expresión (gestos, dibujos, imágenes, otros íconos y símbolos) que vinculen a la LSC con otro tipo de registros.

Se reconocen dos momentos fundamentales en el taller: el de preparación y el de construcción. Por ello se sugiere que sean los estudiantes quienes tengan la elección de su función dentro de esta fase, teniendo en cuenta los gustos de cada uno y las destrezas para manejar uno u otro material. Se recomienda que todos hagan apreciaciones sobre tamaños de cantidad para generar aproximaciones a sus tamaños reales. 
Es importante que la experiencia de aula vincule:

Aportes y emociones de los estudiantes en cada momento de la construcción (sus apreciaciones, reacciones...).

$\checkmark$ Tipos de cantidades y apreciación de tamaños de cantidades (emplear las señas respectivas o intentar otras formas de expresar).

$\checkmark$ Tipos de recursos para hacer un lombricuario y dónde se pueden conseguir (hacer listados).

$\checkmark$ Personas que se requieren para conseguir los materiales y para hacer un lombricuario (insistir en los roles profesionales: jardinero, lombricultor, etc.).

$\checkmark$ Formas representación y expresión empleadas (en LSC, en español escrito o en dibujos e íconos).

Las condiciones de la experiencia de aula reconocen que la experiencia con la cantidad en el niño (a) tiene su génesis en la experiencia con "lo otro". Las acciones de comparar los objetos entre sí, bien sea para agruparlos en una misma clase, o para combinarlos con la intención de obtener un objeto o conjunto nuevo e interesante, constituyen actividades de comparación y de clasificación de objetos en el primer caso, y de composición de objetos complementarios, en el segundo caso. Pero, como lo indica Vergnaud, "la matematización de esta actividad de composición de objetos complementarios es muy diferente de la matematización de las actividades de comparación y clasificación" (Vergnaud, 1985: 77).

Sugerimos, entonces, que para el seguimiento de los procesos de comparación entre cantidades que va a determinar parecidos y diferencias entre los objetos, y que son dinamizados en las actividades de los talleres de esta fase del proyecto de aula, se tengan en cuenta los niveles propuestos por Vergnaud (1985).

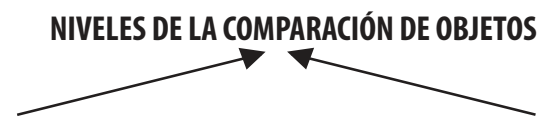

Niveles para analizar Semejanzas

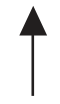

- Equivalencia simple: Objetos diferentes que tiene en común una propiedad, como el vaso de plástico y la botella de plástico

- Cuasi identidad: Objetos distintos que tienen en común todas las propiedades, como las lombrices de tierra, entre ellas son cuasi idénticas.

- Identidad: Un solo objeto idéntico a sí mismo por compartir todas las propiedades posibles; por ejemplo, cada lombriz de tierra que nace es idéntica a sí misma.

\section{Niveles para analizar Diferencias}

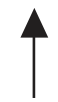

- Descriptores cualitativos: se pueden asociar categorías distintas a los objetos, pero no son ordenables. En este caso tenemos los descriptores como: sexo, nacionalidad, color, forma.

- Descriptores ordinales: se pueden asociar categorías ordenables a los objetos, como para los siguientes descriptores: tonos de color, grosor.

- Descriptores cuantitativos: se pueden asociar categorías numéricas a los objetos, como para los siguientes descriptores: tamaño de una colección de objetos, peso, volumen... 
Cuando se desarrolla la percepción en los niños (as), se da paso a la cantidad. Si se observa con detenimiento, encontraremos que en las caracterizaciones que se surgen de "cantidad", se comparten aspectos como:

Identificar la cantidad como un atributo.

Identificar en sus características un proceso de valoración numérica o pre-numérica para dicho atributo.

De este modo, se manifiesta una idea de cantidad como "aquello que puede ser comparado con otro de su misma especie mediante una relación de orden con propiedades y atributos particulares". Este aspecto se desarrolla en la significación de las expresiones de cantidad y en las relaciones que se establecen entre ellas. Por esta razón, es importante que el profesor consulte los documentos de fundamentación y de profundización con respecto a los micromundos de la aproximación y de la precisión y al repertorio léxico del campo semántico de la cantidad.

Las cantidades pueden ser discretas o continuas. Cantidades discretas son las que constan de unidades o partes separadas unas de otras, como: tres lápices, cuatro mesas, dos niños, etc. Las cantidades discretas pueden ser contadas con los números naturales y reciben por ello el nombre de contables. Las cantidades continuas, por el contrario, no están formadas por partes separadas entre sí. "Continuo" significa "sin interrupción". Las cantidades continuas que se pueden evidenciar en los elementos como el agua, el tiempo, la superficie etc., no son contables, es decir, que no existe manera inmediata de establecer una correspondencia entre objetos y números naturales. Estas cantidades requieren la búsqueda de una unidad de medida; por ejemplo: dos litros de agua, tres vasos de vino... En otras palabras, podemos decir que lo discreto puede ser contado por los números naturales, mientras que los objetos continuos requieren de otros sistemas numéricos como los reales. La percepción de estas cantidades discretas y continuas es un aspecto básico para el desarrollo aritmético de magnitudes en los niños (as).

Cuando los niños (as) entran al micro mundo de la aproximación de la cantidad, comienzan a utilizar adverbios para su expresión, como por ejemplo: Muy, poco, muy poco, cada vez más, mucho, bastante, más, menos, algo, demasiado, casi, sólo, solamente, tan, tanto, todo, nada, aproximadamente...

El siguiente cuadro relaciona tipos de cantidad que se perciben a partir de los sentidos, dando ejemplos de cantidades continuas y discretas. 


\begin{tabular}{|l|l|l|}
\hline Formas de percepción & Tipos de Cantidad & Discreta \\
\hline & Continua & Tipo de texturas \\
\hline Tacto & Intensidad de la textura & Tipo de sabores \\
\hline Gusto & Intensidad de sabor & Tipo de olores \\
\hline Olfato & Intensidad de olor & Tipos de colores \\
\hline Vista & Intensidad de luz & Tipos de sonidos \\
\hline Oído & Intensidad del sonido & \\
\hline
\end{tabular}

Tabla 40. Relación tipos de cantidad-formas de percepción

Los tamaños de colecciones de objetos corresponden a ejemplos de cantidades discretas y los tamaños de los objetos a cantidades continuas. Es importante que el profesor identifique tipos de cantidades en cada taller y propicie las condiciones para la percepción, comparación, representación y expresión de esas cantidades y, en lo posible, para ejemplificar casos en que se utilizan estas expresiones y los posibles cambios de significación de acuerdo con el contexto y la situación; por ejemplo "muy rico", "muy desagradable"...

\section{Actividades sugeridas}

Recomendación: El taller para padres se debe enviar con mínimo una semana de anticipación a la clase en la que se van a implementar las actividades para los estudiantes, dando así la oportunidad y el tiempo para que puedan realizarlo y enviar los resultados sugeridos. Además, es importante disponer de un espacio para atender y orientar a los padres que lo soliciten.

En la sesión con los estudiantes se aconseja desarrollar las siguientes actividades:

\section{1) ¿QUÉ TANTO TRAEMOS?}

Se sugiere retomar la cartelera realizada sobre los materiales necesarios para la vida de las lombrices y recordarlos, presentando la tabla que propone los materiales en varios tamaños de cantidad y:

- Incluir tres tipos de recipientes que pueden servir para el lombricuario, tales como: un acuario, una caja de icopor, materas o jardineras, preferiblemente en tres tamaños (muy pequeño, pequeño y mediano). Todos los recipientes deben cumplir la condición de tener un orificio para desagüe.

- Cada estudiante seleccionará el tamaño y el material que le parezca más adecuado o que le guste. Hará una marca en la cartelera que corresponde al tamaño que escogió. Después de que todos los estudiantes pasen y señalen en la cartelera el recipiente escogido, el profesor retoma la cartelera y cuenta las marcas, destacando cuál obtuvo el mayor número de marcas. Pregunta a 
quienes marcaron en recipientes menos escogidos, si prefieren el recipiente que obtuvo mayor votación para la cama de su lombriz, o de quedan con el elegido por ellos.

- Una vez seleccionado el recipiente, el profesor presentará tres tamaños de bolsas con tierra y solicitará a los estudiantes que seleccionen la bolsa cuyo tamaño les gustaría tener para traer tierra. Les pedirá que dibujen en la cartelera el número de bolsas con tierra que pueden traer para poner en la cama de la lombriz.

- El profesor presentará una lámina con varias lombrices, solicitará a cada estudiante que dibuje en la cartelera las que va a poner en la cama. Tal vez sea conveniente iniciar con esta actividad para la selección del tamaño de la cama. El profesor sugerirá colocar no más de tres lombrices para poderlas atender y observar bien.

- El profesor presentará tres bolsas con un poco de alimento y pedirá a los estudiantes que seleccionen la que consideren conveniente para alimentar a sus lombrices.

\section{2) EL ESPACIO PARA EL LOMBRICULTIVO}

Después de seleccionado el tamaño de la cama, el profesor y los estudiantes recorrerán los espacios del salón para elegir dónde ubicar su cama. Es necesario considerar la altura de los niños (as) para prever que puedan observar, alimentar y cuidar bien a sus lombrices. También hay que considerar la recolección de los líquidos del desagüe y el espacio para colocar la tasa de recolección y reposo de la comida. Teniendo en cuenta que no se colocaran más de dos lombrices, la comida en reposo será poca, por ello, la tasa no debe ser muy grande.

Después de seleccionado el espacio se acondiciona para colocar el lombricultivo. Esta actividad será colectiva, comentando el proceso, ayudando entre todos y de recomienda al profesor formular preguntas como: ¿qué te falta?, ¿qué más vas a poner?, ¿dónde va a quedar tu lombricuario?...

\section{3) HACEMOS EL LOMBRICUARIO.}

En el momento de llevar a cabo la actividad, el maestro habrá dispuesto cuatro cartulinas de colores marcadas con la palabra-gesto asociado al material que se ubicará en cada una de ellas, en el salón de clases. Luego pedirá a los estudiantes que depositen los materiales que trajeron la cartulina correspondiente: una para los vasos, otra para la tierra, otra para las frutas con semilla y otro para las lombrices. Cada estudiante depositará el artículo que le correspondió traer, de tal manera que en cada una de ellas quede el mismo elemento. Cada estudiante debe marcar con algún símbolo en la cartulina en la cual dejó el elemento que le correspondió. 
A continuación el maestro formulará preguntas como: ¿en cuál cartulina hay más elementos?, ¿En cuál cartulina hay menos elementos?, ¿Cuál fue la cartulina donde más niños (as) depositaron elementos?, ¿Cuál fue la cartulina donde menos niños (as) depositaron elementos? Es importante destacar las señas referidas a expresiones de interrogación, haciendo la diferencia entre ellas: ¿en cuál?, ¿cuál? Y expresiones de cantidad: más, menos, intentando que los niños produzcan las señas correctamente y observando la construcción del significado para estos términos por parte de los niños (as).

Los estudiantes deberán generar estrategias para resolver estas preguntas, de acuerdo con lo que consideren más adecuado; por ejemplo, pueden utilizar conteo (en cual cartulina hay más marcas de niños) o pueden basar sus respuestas utilizando otros argumentos (por ejemplo, la cantidad de espacio que se utilizó en cada una de las cartulinas). En este momento el profesor debe estar atento a las estrategias que utilizan los estudiantes para responder a sus preguntas y se sugiere llevar este registro de forma escrita. Posteriormente puede emplear estos registros para ampliar descripciones y para corregir señas.

El siguiente momento consiste en agrupar los elementos que sirvan para la construcción del Lombricultivo (cama, vasos de plástico, tierra y lombrices). Posteriormente se comparará, con la proyección del video, para confirmar si efectivamente los materiales que se pensaron para la construcción del criadero y del semillero son los que los estudiantes escogieron.

Después de organizar el material por construcciones, el profesor puede hacer otra serie de preguntas, tales como: ¿En cuál cartulina hay más elementos? ¿En cuál cartulina hay menos elementos? Nuevamente debe tener en cuenta las estrategias de los estudiantes para este propósito y llevar el registro de su observación.

El profesor proyectará nuevamente el video del lombricultivo para asignar a cada niño (a) un material o materiales que quiera poner en la cama de las lombrices.

Luego procederá a indicar el armando de cada cama, Ilamando a cada niño (a) con sus respectivos materiales según el material que se requiera en cada caso.

Los estudiantes escogerán sus funciones para cada una de las etapas de construcción que serán guiadas en todo momento por el profesor. Cada grupo formado deberá llevar un distintivo, puede ser un brazalete del mismo color o una pequeña marca con tempera en una parte visible del cuerpo.

\section{Materiales:}

- Videos

- Láminas ${ }^{36}$ 
- Cartulinas

- Materiales seleccionados por camas de lombriz

- Colores o témperas

\section{B. ACTIVIDADES PARA LOS PADRES}

Presentación. El taller EL LOMBRICULTIVO pretende desarrollar conocimiento en los niños (as) sobre el espacio propicio para la vida de las lombrices, por esta razón es importante que ustedes acompañen a su hijo (a) en el descubrimiento de espacios donde permanecen las lombrices de tierra, o espacios donde se consiguen los materiales que su hijo (a) va a llevar para la construcción del lombricultivo. Después de realizar los recorridos pueden, entre ustedes y su niño (a), completar la siguiente gráfica, según el material que encontraron en cada sitio. Pueden hacer la gráfica con fotos, recortes de empaques, o dibujos. Es importante escribir en el título los nombres de los padres o los familiares que hicieron el recorrido con el niño (a) y el nombre del niño (a).

- NOSOTROS:

Y

- ENCONTRAMOS LO SIGUIENTE SOBRE LAS LOMBRICES

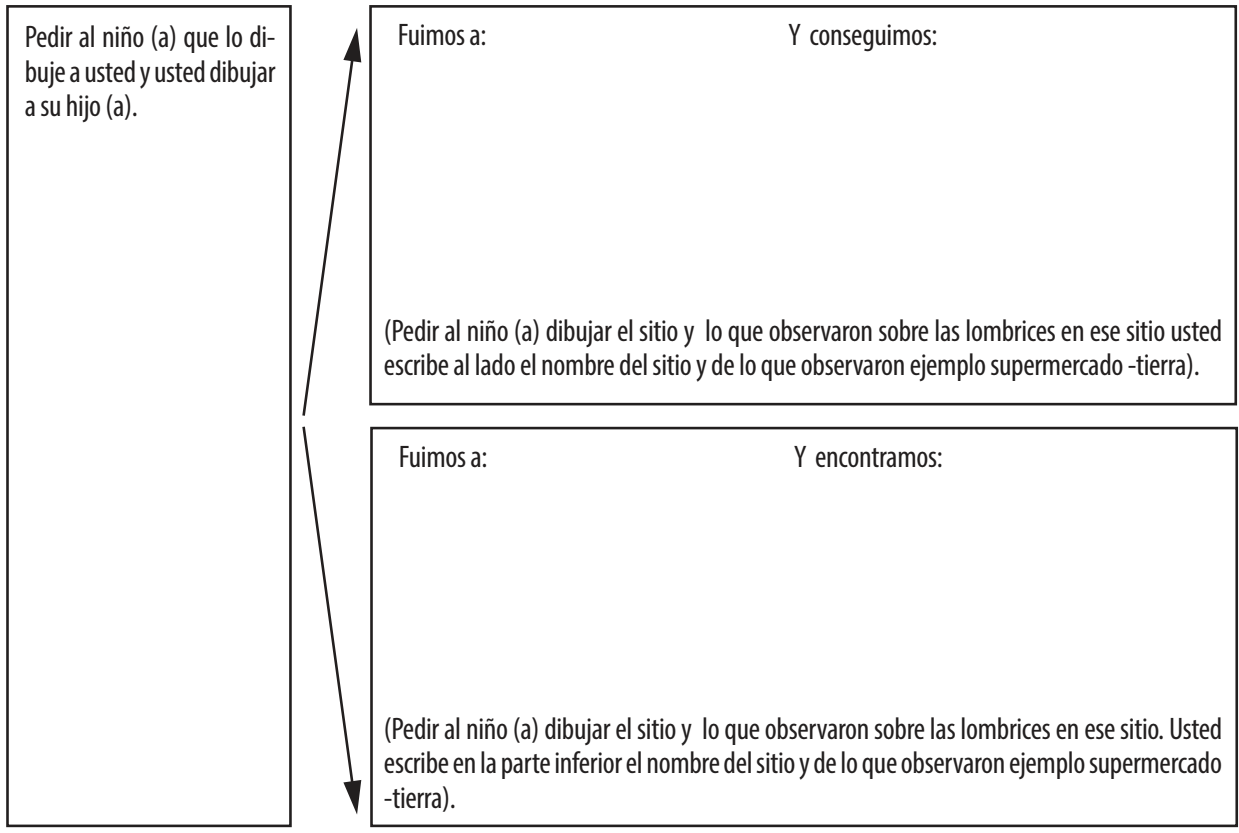

$36 \mathrm{El}$ número de la foto corresponde al sitio Web de donde fue tomada: 1 munieltambo.gob.pe 2 frikinai.spaces. live.com, 7 infojardin.com, 4, hdynaturaleza.blogspot.com, 5 ecologiablog.com , 3 y 6 ooche813.blogspot. com, 8 duggan-lombricultura.blogspot.com, 9residuoslamacarena.blogspot.com, 10 elcolombiano.com 


\section{ACTIVIDADES PARA LOS ESTUDIANTES}

Actividad 1. Seleccionar la cantidad de lombrices que te parece necesaria.

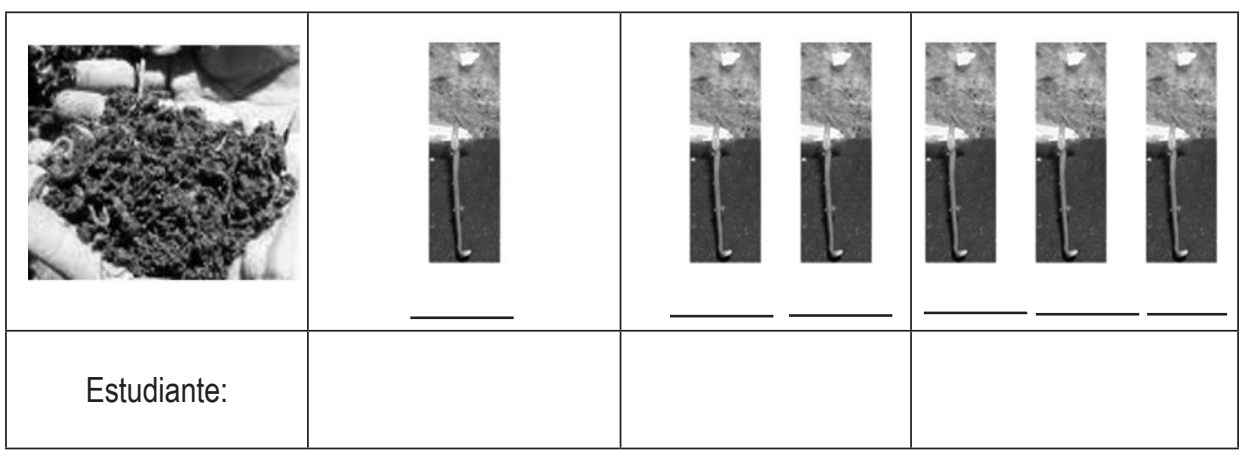

Seleccionar el tamaño de la cama que te pareció más adecuado.

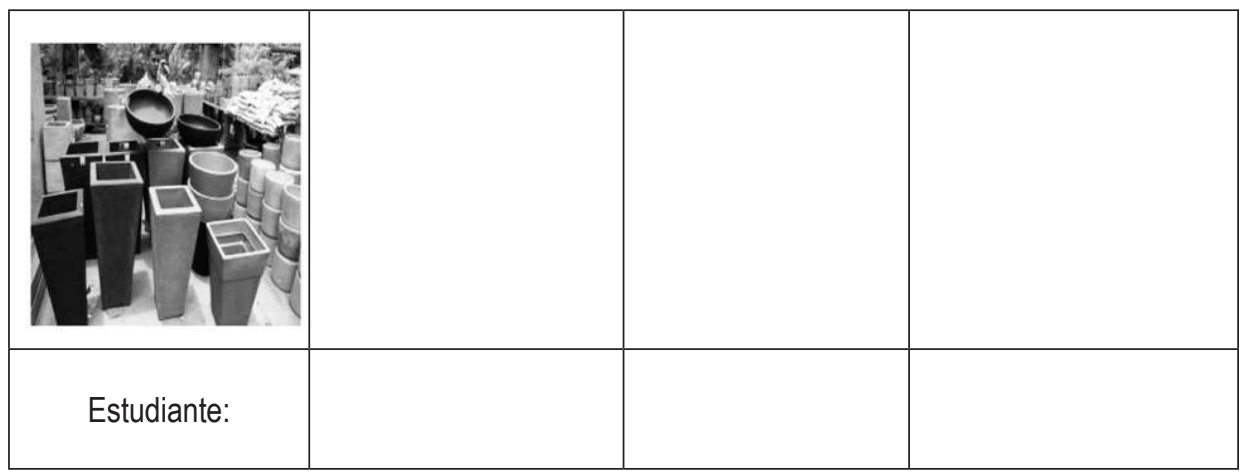

Seleccionar la cantidad de bolsas de tierra que puedes traer. ${ }^{37}$

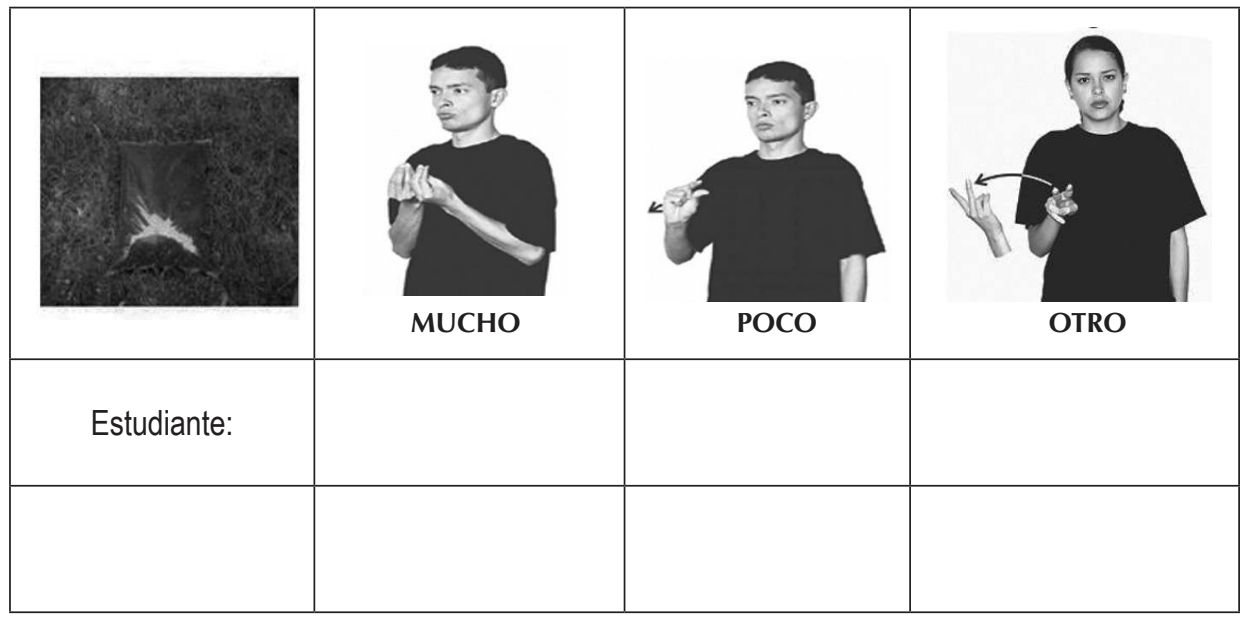

37 Imagen tomada de articulo.mercadolibre.com.uy 
Seleccionar la cantidad de alimento que puedes traer.

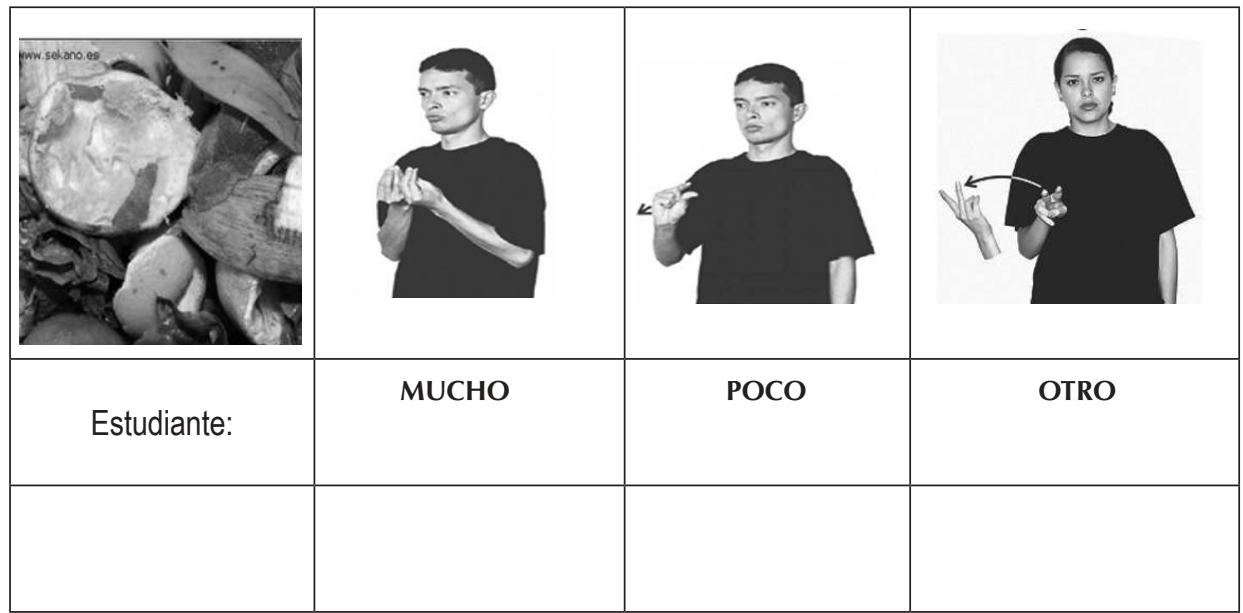

Actividad 2. Ubica en cada una de las cartulinas siguientes el material indicado.
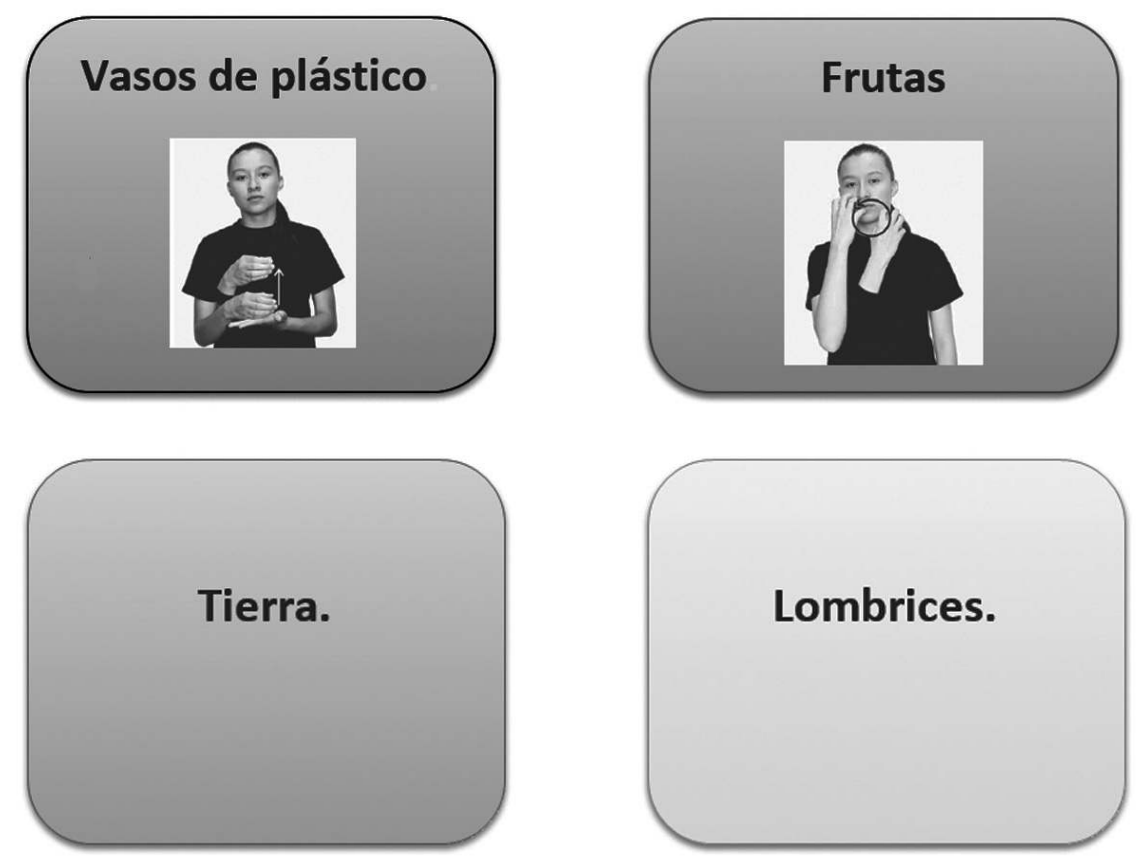

Actividad 3. Colorea los siguientes dibujos y dibuja una cama de lombriz para ellos. Dibuja los alimentos que consumirán: 

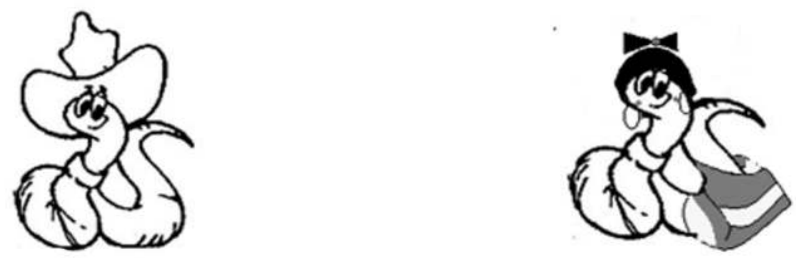

* Ponle un nombre a cada uno en LSC y luego búscalo en español escrito.

* Presenta dos cualidades para cada lombriz, por ejemplo, larga, corta, grande, pequeña.

* Cuéntale a tus compañeros (as) cómo son tus personajes y muestra tu dibujo.

\section{ACTIVIDADES DE EVALUACIÓN PARA LOS ESTUDIANTES}

¿Recuerdas como construiste el criadero de las lombrices? Ahora dibuja en el orden que lo hiciste
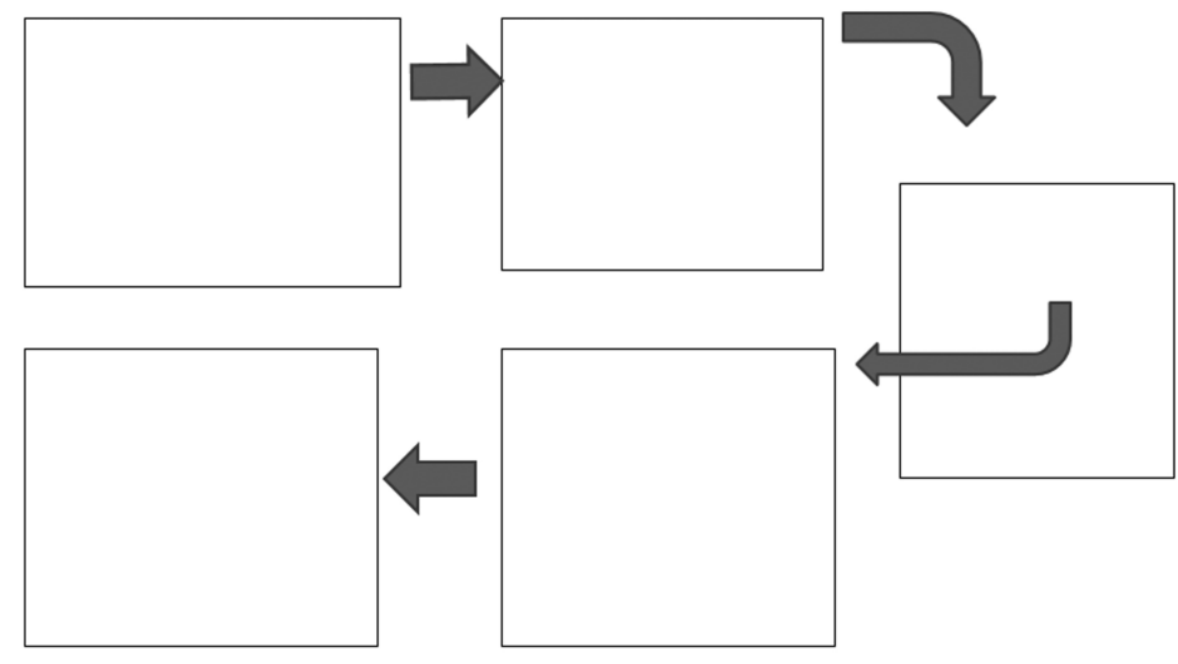
Escoge los materiales que usarías para cada una de las siguientes camas $^{38}$
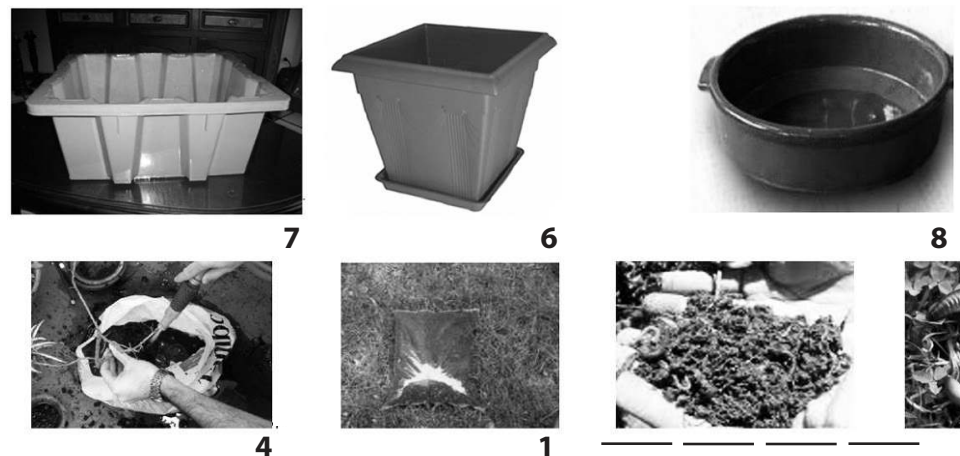

6
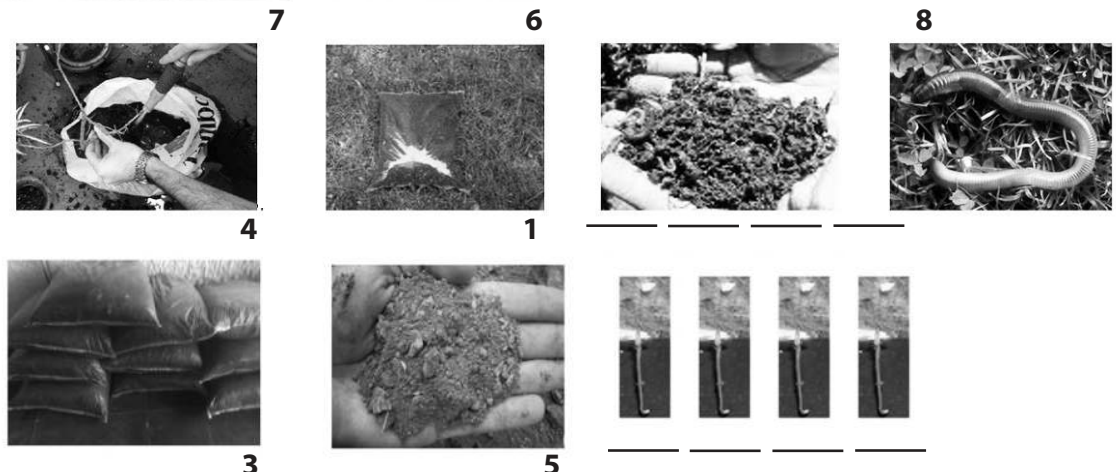

3

Busca la seña que corresponda al recipiente que escogiste para la cama de tus lombrices y pon la marca debajo de la imagen. Pide a tu profesor que te ayude a buscar la palabra en español escrito y también la pones debajo de la seña.

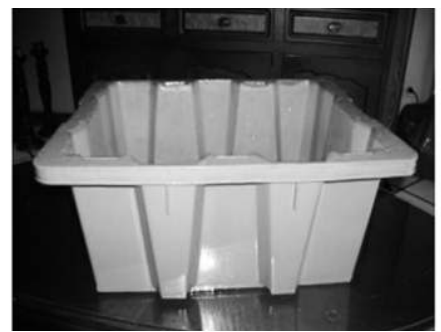

Deletrea el nombre del recipiente que escogiste para la cama de las lombrices. 

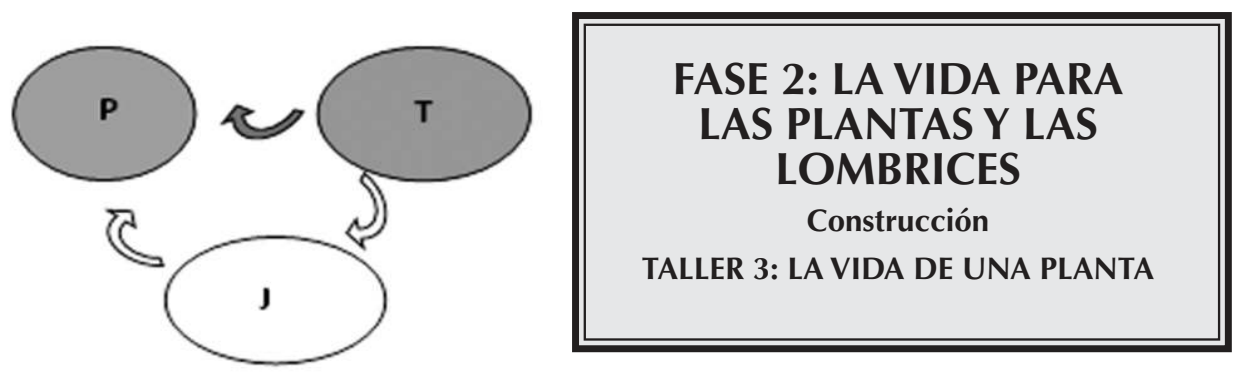

38 1y3 articulo.mercadolibre.com.uy 4 portalbonsai.com. 5 intermundos.org 6 delpino.com.co 7 infojardin. com 8evasworlds.blogspot.com

\section{A. ORIENTACIONES PARA EL PROFESOR}

\section{Objetivos}

- Fomentar acciones de cooperación entre estudiantes, y entre padres y estudiantes, para el desarrollo de tareas comunes orientadas a la identificación del proceso de germinación y de los recursos necesarios para construir un semillero.

- Organizar y planificar colectivamente la forma de conseguir los recursos y los espacios para el semillero.

- Desarrollar habilidades para comparar y apreciar tamaños de cantidades y para describir y comunicar esos procesos.

Presentación. El desarrollo de esta fase exige que los estudiantes se familiaricen con procesos de crecimiento de las plantas (identifiquen los distintos momentos) y con las condiciones del ambiente en el que ellas se desarrollan. Por esta razón, se requiere propiciar diversas experiencias de conocimiento de las plantas, en las que se identifiquen los elementos que se requieren para la germinación de una semilla y, paralelamente, experiencias para establecer relaciones de cantidad entre los elementos requeridos, por ejemplo:

Cantidad de: espacio que se va a utilizar, de tierra necesaria, de vasos para cada semilla, de tierra por cada vaso, de semillas por vaso, de vasos por bandejas.

La presentación de videos ambientada por aclaraciones y ampliaciones del profesor, es muy importante como una experiencia de referencia para los niños. Una salida pedagógica a un vivero, puede ser una experiencia complementaria a la del video y estaría vinculada a la salida con los padres a los jardines o a parques en busca de sitios donde se aprecie el crecimiento y el cuidado de las plantas. Finalmente, la experiencia de aula que propicie el profesor, articulando las experiencias que manifiestan los estudiantes sobre lo percibido en cada 
una de las situaciones con sus padres, con el video y con la salida pedagógica (si se realiza), se constituye en el referente básico para emprender la organización y la planeación, conjuntamente entre el profesor y los estudiantes, para conseguir los recursos necesarios para la construcción del semillero.

Adicionalmente, es importante que la experiencia de aula vincule:

Emociones de los estudiantes con respecto a la existencia de las plantas y a las funciones que cumplen en la naturaleza.

$\checkmark$ Espacios en los que crecen las plantas.

Características generales de las plantas: ¿cómo son?, ¿cómo crecen?, ¿cuánto viven?, ¿qué cuidados hay que tener con ellas?, ¿qué tipos de plantas hay?, ¿qué función cumplen en la naturaleza?

Tipos de recursos para hacer un semillero y dónde se pueden conseguir (hacer listados).

$\checkmark$ Personas que se requieren para conseguir los materiales y para hacer un semillero (insistir en los roles profesionales: jardinero, agricultor, etc.).

$\checkmark$ Formas representación y expresión empleadas (utilizar las señas respectivas, las palabras en español escrito, dibujos e íconos o intentar otras formas de expresar).

Las condiciones de la experiencia de aula reconocen que la experiencia con la cantidad en el niño (a) tiene su génesis en la experiencia con "lo otro". Las acciones de comparar los objetos entre sí, bien sea para agruparlos en una misma clase, o para combinarlos con la intención de obtener un objeto o conjunto nuevo e interesante, constituyen actividades de comparación y de clasificación de objetos en el primer caso, y de composición de objetos complementarios, en el segundo caso. Pero, como lo indica Vergnaud, "la matematización de esta actividad de composición de objetos complementarios es muy diferente de la matematización de las actividades de comparación y clasificación" (Vergnaud, 1985: 77).

Sugerimos, entonces, que para el seguimiento de los procesos de comparación entre cantidades que va a determinar parecidos y diferencias entre los objetos, y que son dinamizados en las actividades de los talleres de esta fase del proyecto de aula, se tengan en cuenta los niveles propuestos por Vergnaud (1985). 


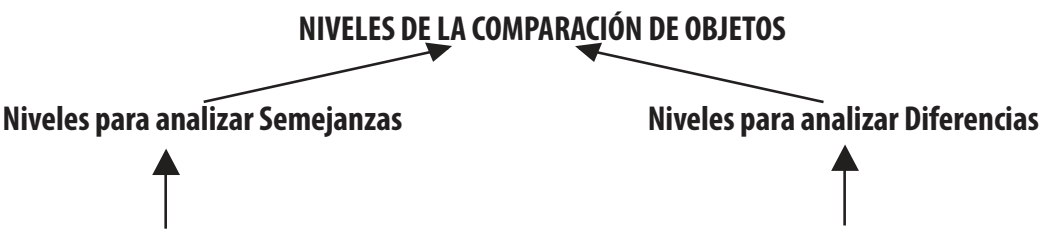

- Equivalencia simple: Objetos diferentes que tiene en común una propiedad, como el vaso de plástico y la botella de plástico

- Cuasi identidad: Objetos distintos que tienen en común todas las propiedades, como las lombrices de tierra, entre ellas son cuasi idénticas.

- Descriptores cualitativos: se pueden asociar categorías distintas a los objetos, pero no son ordenables. En este caso tenemos los descriptores como: sexo, nacionalidad, color, forma.

- Descriptores ordinales: se pueden asociar categorías ordenables a los objetos, como para los siguientes descriptores: tonos de color, grosor.

- Identidad: Un solo objeto idéntico a sí mismo por compartir todas las propiedades posibles; por ejemplo, cada lombriz de tierra que nace es idéntica a sí misma.

- Descriptores cuantitativos: se pueden asociar categorías numéricas a los objetos, como para los siguientes descriptores: tamaño de una colección de objetos, peso, volumen...

Cuando se desarrolla la percepción en los niños (as), se da paso a la cantidad. Si se observa con detenimiento, encontraremos que en las caracterizaciones que se surgen de "cantidad", se comparten aspectos como:

$\checkmark$ Identificar la cantidad como un atributo.

Identificar en sus características un proceso de valoración numérica o pre-numérica para dicho atributo.

De este modo, se manifiesta una idea de cantidad como "aquello que puede ser comparado con otro de su misma especie mediante una relación de orden con propiedades y atributos particulares". Este aspecto se desarrolla en la significación de las expresiones de cantidad y en las relaciones que se establecen entre ellas. Por esta razón, es importante que el profesor consulte los documentos de fundamentación y de profundización con respecto a los micromundos de la aproximación y de la precisión (Parte I de esta obra) y al repertorio léxico del campo semántico de la cantidad.

\section{Actividades sugeridas}

Recomendación: El taller para padres se debe enviar con mínimo una semana de anticipación a la clase en la que se van a implementar las actividades para los estudiantes, dando así la oportunidad y el tiempo para que puedan realizarlo y enviar los resultados sugeridos. Además, es importante disponer de un espacio para atender y orientar a los padres que lo soliciten. En la sesión con los estudiantes_se aconseja desarrollar las siguientes actividades: 


\section{1). BUSCO MI SEMILLA}

En esta actividad se le indica a los estudiantes que van a conocer muchas semillas: en videos, en fotos, en vivo, en dibujos (y otras que el profesor presente). Se les solicitará que observen bien y que seleccionen e informen al profesor cuál es la semilla (o representación de ella) que elijen para cada uno.

El profesor les entregará su semilla o su representación correspondiente, para que cada estudiante asigne un nombre a la semilla y lo registre (en LSC y en español escrito).

En el lugar más adecuado del salón, el profesor habrá adecuado un espacio en una cartelera o en una pared, destinado para registrar el desarrollo del semillero (puede denominarse el Mural del Semillero). En este espacio cada niño puede colocar la representación de su semillero o su semilla: puede ser bidimensional (como foto o dibujo), o tridimensional (como la semilla real).

\section{2). ¿PARA QUÉ SIRVE UNA SEMILLA?}

El profesor presenta un video sobre la germinación de semillas; sugerimos: http://www.youtube.com/watch?v=iFCdAgeMGOA, para observar el proceso de germinación. Después entrega a cada estudiante la primera hoja de actividades para estudiantes, que solicita completar la secuencia, según el video presentado.

Cada niño (a) presenta su secuencia y expresa lo que le gustó del video en LSC. El profesor les puede preguntar si tienen dudas sobre el video y puede pasarlo de nuevo para que ellos señalen partes que les llamaron la atención o que no entendieron.

Si no hay condiciones para presentar un video, sugerimos realizar una salida pedagógica a un vivero. Después de realizada la salida, se puede solicitar realizar un dibujo o una representación en plastilina de lo que recuerda de la salida. Luego cada estudiante presenta a sus compañeros, en LSC, lo representado y el profesor realizará grabación en video de estas presentaciones. Los demás niños (as) pueden preguntar, si no entienden alguna presentación, o si requieren mayor ampliación de algún aspecto.

\section{3). ¿CÓMO SON LAS PLANTAS?}

Se propone realizar una salida pedagógica a un vivero, o recorrer las instalaciones del colegio, buscando plantas. En lo posible se recomienda tomar fotos de las plantas que Ilamen la atención de los estudiantes. En cada caso, será importante hacer énfasis en los tipos de plantas, en sus nombres, y cuidados, empleando las señas respectivas o alguna forma de representación ${ }^{39}$. Las pala-

39 Es posible emplear Álbumes de láminas de vida Natural que circulan en el mercado y que muchas veces los niños llenan. 
bras desconocidas deben ser separadas para indagar buscando en diccionario de LSC o en el español. Recordar aumentar el rincón de las palabras.

Después de cualquiera de las actividades anteriores, el profesor entregará a los estudiantes las láminas de plantas, para que entre todos vayan identificando, en ellas, los elementos necesarios para la germinación de una semilla. es importante observar las expresiones en LSC de los niños y proporcionar vocabulario necesario.

El profesor va seleccionando la lámina que mejor presenta el elemento y la pega en un cartel, indicando la expresión en LSC y resaltando con un marcador elemento seleccionado en la lámina ${ }^{40}$. El cartel puede tener una presentación como el ejemplo que se presenta para que alrededor se vayan colocando los elementos que distinguen los niños (as).

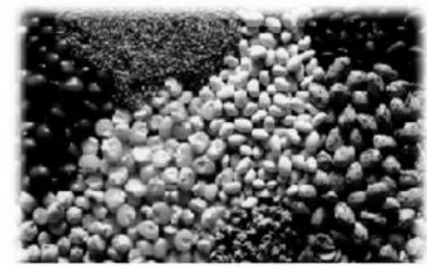

Es importante que el profesor destaque el uso de expresiones de aproximación mencionadas anteriormente, a partir del uso de la pregunta: ¿qué tanto?

Al finalizar las actividades dos y tres, el profesor preguntará a los estudiantes si ya escogieron su lombriz y les pedirá que indiquen dónde se encuentra, para obsequiarle su representación.

\section{Materiales:}

- Videos

- Láminas

- Hojas

- Colores y plastilinas

- Carteles de papel periódico

- Diccionarios y el rincón de la palabra

\section{B. ACTIVIDADES PARA LOS PADRES DE FAMILIA}

Presentación. El taller LA VIDA DE UNA PLANTA pretende desarrollar conocimiento en los niños (as) sobre las plantas, sus características y sus condiciones de vida. Por esta razón, es importante que ustedes acompañen a su hijo (a) en el descubrimiento de espacios donde es posible sembrar plantas, o espacios donde las venden, o donde se venden productos para su cultivo.

40 Imagen tomada de: www.saludpasion.com 
En los supermercados ustedes pueden buscar los sitios donde venden plantas y/o semillas. Una vez allí, se recomienda observar los tipos de semillas y las recomendaciones para su germinación. En este momento es importante que ustedes señalen al niño (a) los empaques y, en ellos, los dibujos o ilustraciones y el texto escrito que ofrece las indicaciones para la siembra. Aunque el niño (a) no sepa leer, podrá aprender sobre la existencia de estos mensajes y textos y reconocer la forma en que se presentan. En lo posible ayúdele a construir las señas necesarias o comprométase en ayudarle a buscar las palabras y sus significados.

Acompañen a su hijo (a) a observar en cada espacio la presencia de plantas y el efecto que su presencia tiene en las personas y en los animales. Conversen con él o ella al respecto y observen qué le interesa.

Después de estos recorridos, sugerimos realizar el siguiente ejercicio, junto con su hijo (a): completar la siguiente gráfica, según la información que encontraron en cada lugar visitado. La gráfica puede hacerse con fotos, recortes de empaques o dibujos. Es importante registrar en el título los nombres de los padres o los familiares que hicieron el recorrido con el niño (a) y el nombre del niño (a).

NOSOTROS: Y

ENCONTRAMOS LO SIGUIENTE SOBRE LAS PLANTAS Y SUS SEMILLAS

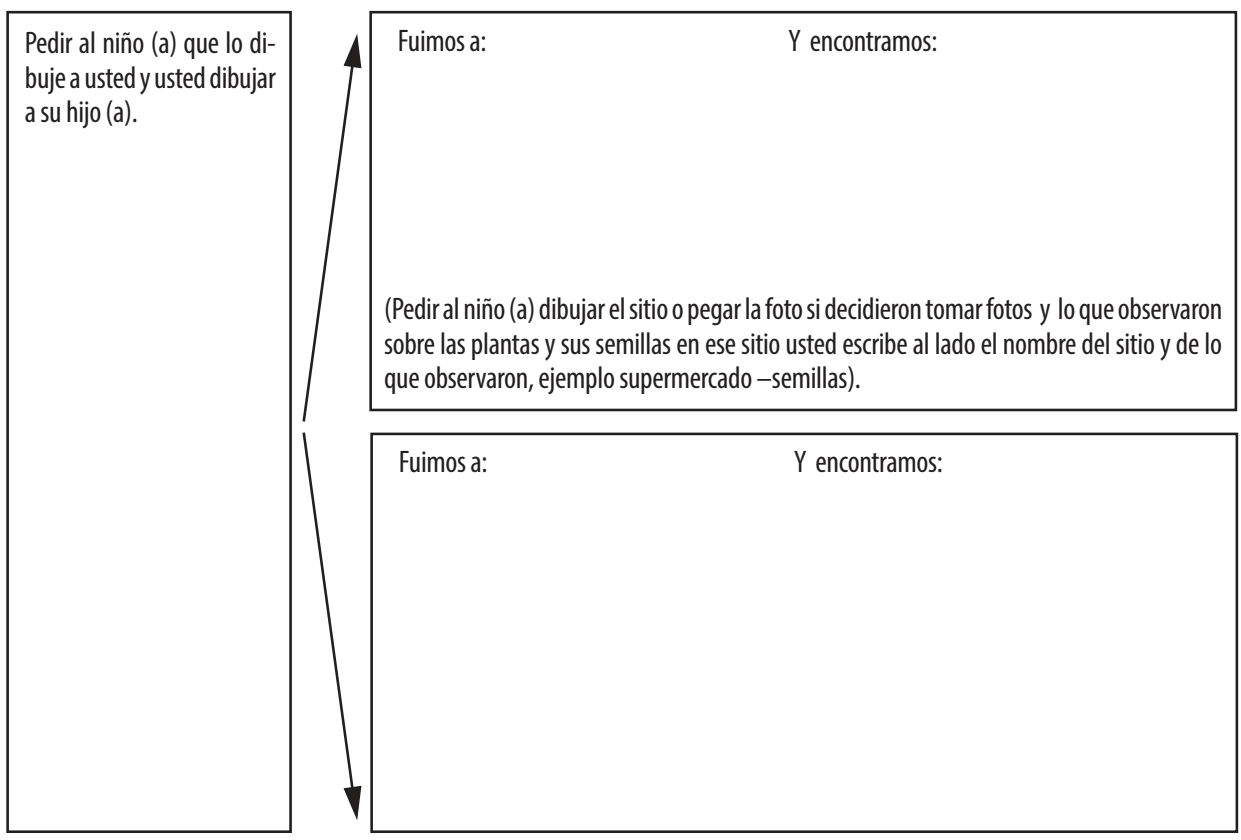




\section{ACTIVIDADES PARA LOS ESTUDIANTES}

Actividad 1: Relaciona cada foto con una flecha al lugar que le corresponde, según lo visto en el video.
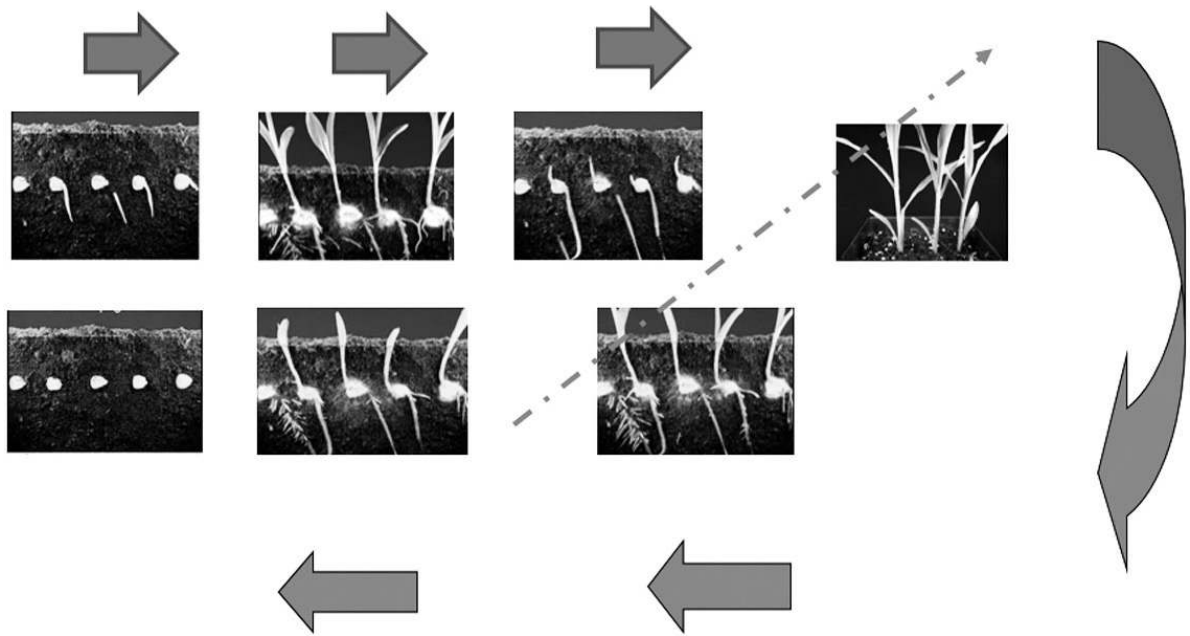

Actividad 2. ${ }^{41}$ Escoge una de las siguientes láminas, márcala y pídela al profesor.
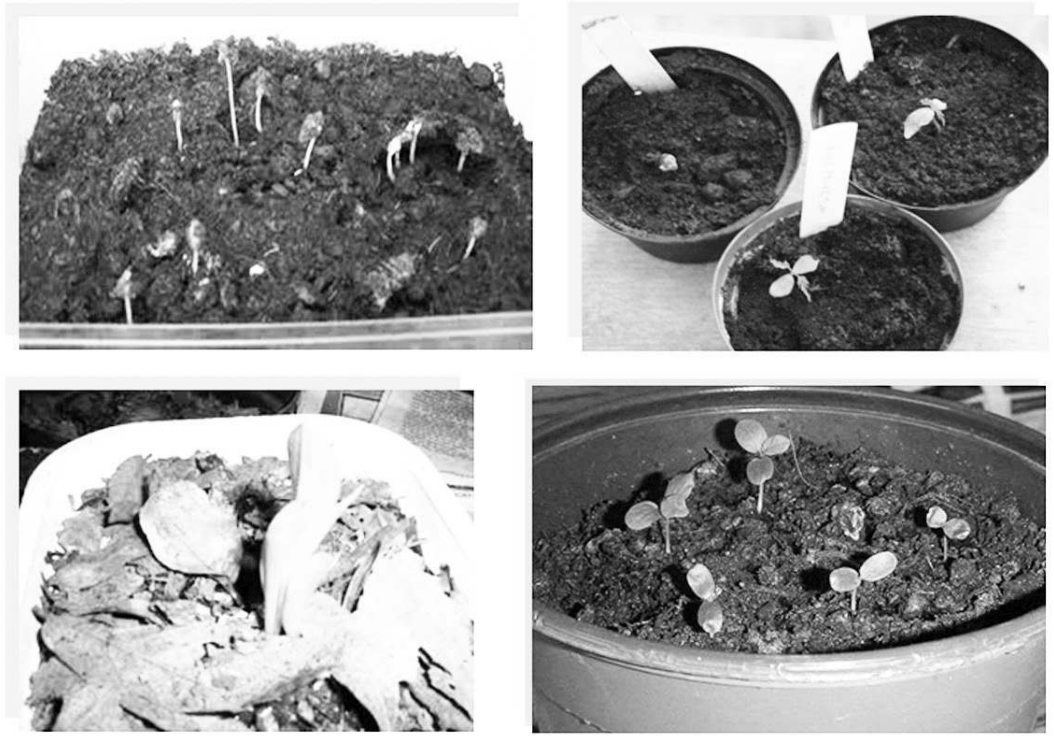

41 Las imágenes según número se tomaron de 1 foroantiguo.infojardin.com 2 oroantiguo.infojardin.com3 nfojardin.com 4passiflora.foroactivo.com5ineteycaballo.blogspot.com 6infojardin.com 


\section{Actividad 3.}

- Dibuja la semilla o pega la foto que seleccionaste.

- Busca la seña que le corresponde, ponla en la lámina y escribe, debajo, ese nombre en español escrito.

\section{Actividad 4.}

* Haz una lista, con dibujos, de los materiales que necesitas para tu semillero.

* Frente a cada dibujo, pon la seña respectiva.

* Frente a la seña, pon la palabra que corresponde, en español escrito.

* Presenta tu lista a tus compañeros (as) y luego pega esta lista en el Mural del Semillero.

La lista de materiales para el semillero

\begin{tabular}{|l|l|l|}
\hline MATERIAL PARA SEMILLERO & SEÑA & PALABRA EN ESPAÑOL \\
\hline & & \\
\hline & & AGUA \\
\hline & & \\
\hline & & \\
\hline & & \\
\hline
\end{tabular}


D. ACTIVIDADES DE EVAlUACIÓN PARA lOS ESTUDIANTES. Coloca una $X$ en el material y cantidad que puedes traer para hacer el semillero de las lombrices.

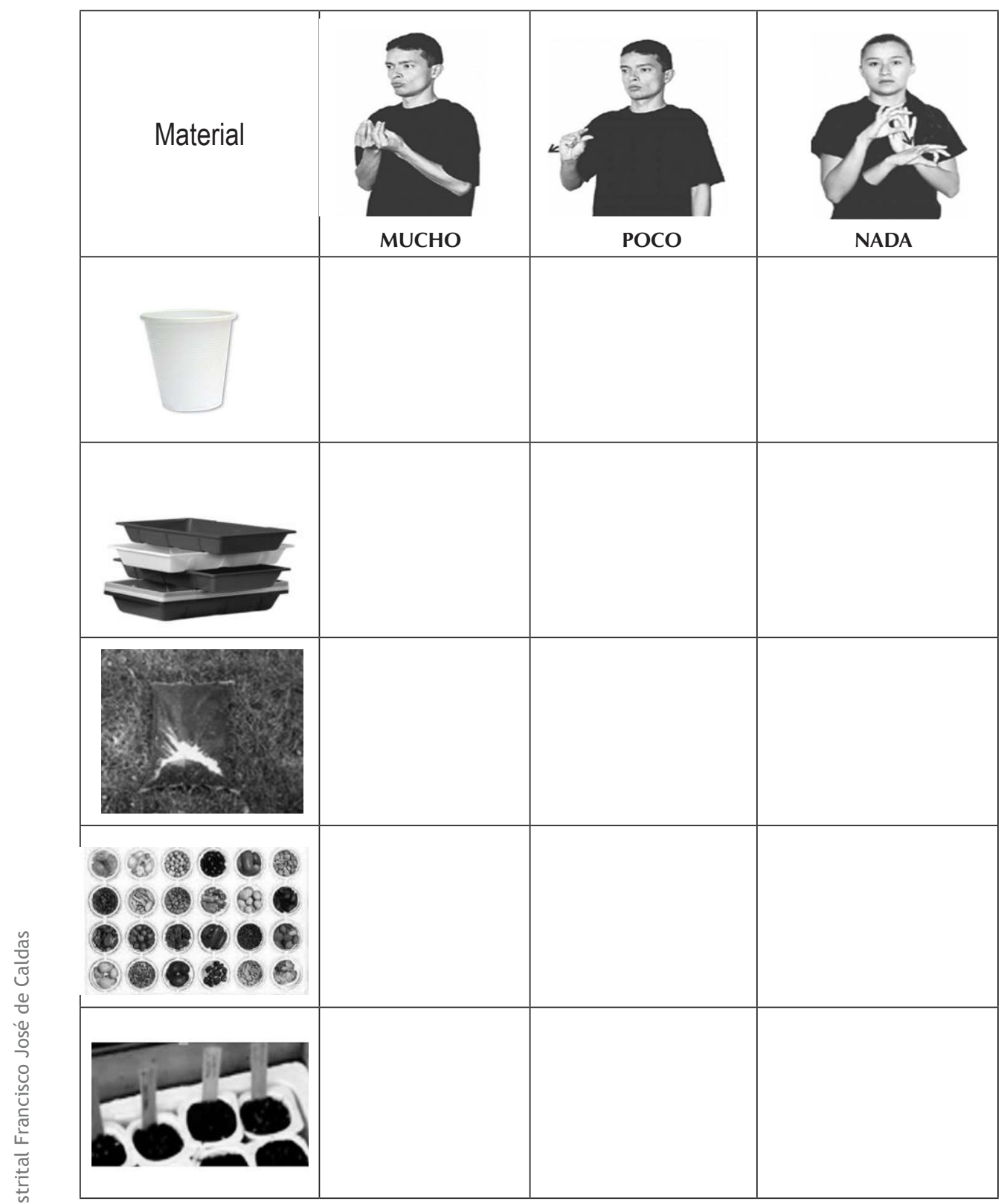

Haz una lista de cualidades que te gustaría para tu semillero con dibujos y señas. Por ejemplo, varias semillas, ¿de cuáles?; muchas o pocas flores o frutos; recipientes grandes o pequeños... 


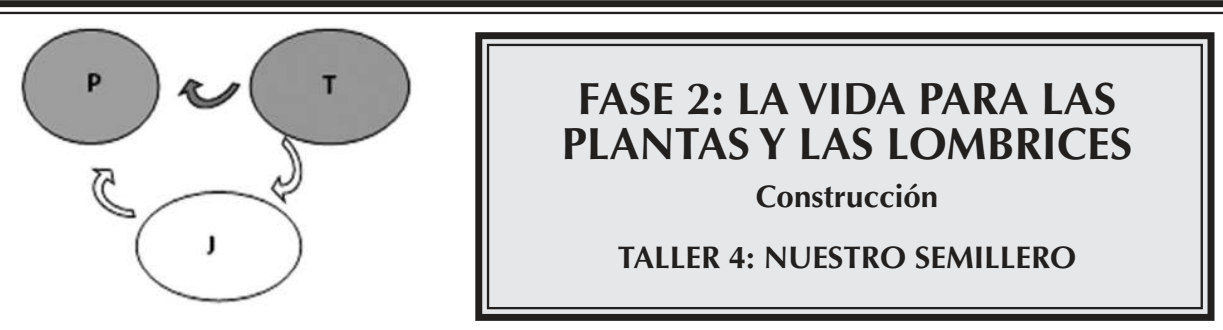

\section{A. ORIENTACIONES PARA EL PROFESOR}

\section{Objetivos}

- Determinar el lugar y los materiales necesarios para la construcción del semillero.

- Construir el semillero a través del trabajo en equipo conformado por el profesor y los estudiantes.

- Desarrollar habilidades para comparar cantidades, apreciar tamaños de cantidades y utilizar y comunicar expresiones adecuadas en esos procesos.

Presentación. Dado que esta es la Fase de Construcción, es importante que los estudiantes puedan identificar los materiales necesarios para la construcción del semillero. Esta experiencia implica hacer aproximaciones de cantidades de: espacio, superficie, tiempo, tierra, alimento, semillas, personas que se requieren... Por ello, las siguientes actividades están diseñadas para que los estudiantes conozcan los materiales que se requieren, identifiquen en qué lugar se puede ubicar el semillero, consigan la cantidad apropiada de materiales, los tamaños adecuados de los recipientes y de las semillas y desarrollen formas de expresión que vinculen la LSC con otro tipo de registros como las imágenes, los dibujos, los símbolos y la lengua escrita.

En el presente taller se reconocen dos momentos fundamentales: el de preparación y el de construcción. Se sugiere que sean los estudiantes quienes tengan la elección de su función para el desarrollo de las actividades de este taller, teniendo en cuenta los gustos propios y sus destrezas para manejar uno u otro material. Adicionalmente, durante la realización de las actividades, todos los niños (as) harán apreciaciones sobre tamaños de cantidad para generar aproximaciones a sus tamaños reales.

Es importante que la experiencia de aula vincule:

Aportes y emociones de los estudiantes en cada momento de la construcción (opiniones, sugerencias, anécdotas, etc.).

Tipos de cantidades y apreciación de tamaños de cantidades, generando las expresiones de las mismas en LSC y en otros registros. 
Tipos de recursos para hacer un semillero y dónde se pueden conseguir (hacer o emplear los listados).

$\checkmark$ Personas que se requieren para conseguir los materiales y para hacer un semillero (insistir en los roles profesionales: jardinero, agricultor, etc.).

Formas representación y expresión empleadas (utilizar las señas respectivas, las palabras en español escrito, dibujos e íconos o intentar otras formas de expresar).

Las condiciones de la experiencia de aula reconocen que la experiencia con la cantidad en el niño (a) tiene su génesis en la experiencia con "lo otro". Las acciones de comparar los objetos entre sí, bien sea para agruparlos en una misma clase, o para combinarlos con la intención de obtener un objeto o conjunto nuevo e interesante, constituyen actividades de comparación y de clasificación de objetos en el primer caso, y de composición de objetos complementarios, en el segundo caso. Pero, como lo indica Vergnaud, "la matematización de esta actividad de composición de objetos complementarios es muy diferente de la matematización de las actividades de comparación y clasificación" (Vergnaud, 1985: 77).

Sugerimos, entonces, que para el seguimiento de los procesos de comparación entre cantidades que va a determinar parecidos y diferencias entre los objetos, y que son dinamizados en las actividades de los talleres de esta fase del proyecto de aula, se tengan en cuenta los niveles propuestos por Vergnaud (1985).

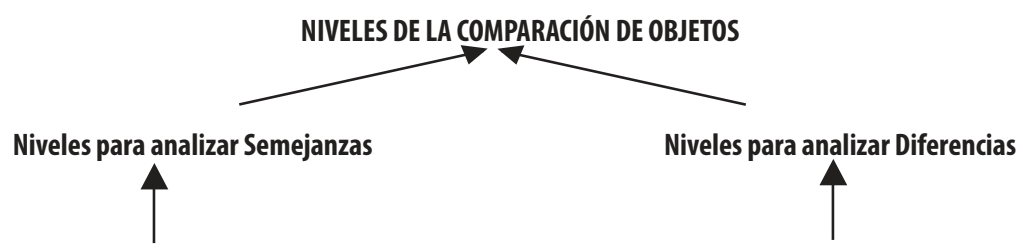

- $\quad$ Equivalencia simple: Objetos diferentes que tiene

- Descriptores cualitativos: se pueden asociar categoen común una propiedad, como el vaso de plástico rías distintas a los objetos, pero no son ordenables. y la botella de plástico

- $\quad$ Cuasi identidad: Objetos distintos que tienen en común todas las propiedades, como las lombrices de tierra, entre ellas son cuasi idénticas.

- Identidad: Un solo objeto idéntico a sí mismo por compartir todas las propiedades posibles; por ejemplo, cada lombriz de tierra que nace es idéntica a sí misma.

En este caso tenemos los descriptores como: sexo, nacionalidad, color, forma.

- Descriptores ordinales: se pueden asociar categorías ordenables a los objetos, como para los siguientes descriptores: tonos de color, grosor.

- Descriptores cuantitativos: se pueden asociar categorías numéricas a los objetos, como para los siguientes descriptores: tamaño de una colección de objetos, peso, volumen... 
Cuando se desarrolla la percepción en los niños (as), se da paso a la Cantidad. Si se observa con detenimiento, encontraremos que en las caracterizaciones que se surgen de "cantidad", se comparten aspectos como:

$\checkmark$ Identificar la cantidad como un atributo.

$\checkmark$ Identificar en sus características un proceso de valoración numérica o pre-numérica para dicho atributo.

De este modo, se manifiesta una idea de cantidad como "aquello que puede ser comparado con otro de su misma especie mediante una relación de orden con propiedades y atributos particulares". Este aspecto se desarrolla en la significación de las expresiones de cantidad y en las relaciones que se establecen entre ellas. Por esta razón, es importante que el profesor consulte los documentos de fundamentación y de profundización con respecto a los micromundos de la aproximación y de la precisión y al repertorio léxico del campo semántico de la cantidad.

Las cantidades pueden ser discretas o continuas. Cantidades discretas son las que constan de unidades o partes separadas unas de otras, como tres lápices, cuatro mesas, dos niños, etc. Las cantidades discretas pueden ser contadas con los números naturales y reciben por ello el nombre de contables. Las cantidades continuas, por el contrario, no están formadas por partes separadas entre sí. "Continuo" significa "sin interrupción". Las cantidades continuas que se pueden evidenciar en los elementos como el agua, el tiempo, la superficie etc., no son contables, es decir, que no existe de manera inmediata una correspondencia entre objetos y números naturales. Estas cantidades requieren la búsqueda de una unidad de medida, por ejemplo, dos litros de agua, tres vasos de vino. En otras palabras, podemos decir que lo discreto puede ser contado por los números naturales, mientras que los objetos continuos requieren de otros sistemas numéricos como los reales. La percepción de estas cantidades discretas y continuas es un aspecto básico para el desarrollo aritmético de magnitudes en los niños.

Cuando los niños entran al micromundo de la aproximación de la cantidad, empiezan a utilizar adverbios para su expresión, como por ejemplo:

Muy, poco, muy poco, cada vez más, mucho, bastante, más, menos, algo, demasiado, casi, sólo, solamente, tan, tanto, todo, nada, aproximadamente.

Los anteriores adverbios, o palabras cantidad, se encuentran en el Repertorio Léxico del campo semántico de la cantidad que el profesor tiene a disposición como documento de profundización.

El siguiente cuadro relaciona tipos de cantidad que se perciben a partir de los sentidos con ejemplos de cantidades continuas y discretas. 


\begin{tabular}{|l|l|l|}
\hline Formas de percepción & Tipos de Cantidad & Discreta \\
\hline & Continua & Tipo de texturas \\
\hline Tacto & Intensidad de la textura & Tipo de sabores \\
\hline Gusto & Intensidad de sabor & Tipo de olores \\
\hline Olfato & Intensidad de olor & Tipos de colores \\
\hline Vista & Intensidad de luz & Tipos de sonido \\
\hline Oído & Intensidad del sonido & \\
\hline
\end{tabular}

Tabla 41. Formas de percepción- tipos de cantidad

Los tamaños de colecciones de objetos corresponden a ejemplos de cantidades discretas; los tamaños de los objetos corresponden a cantidades continuas. Es importante que el profesor identifique tipos de cantidades en cada taller y propicie las condiciones para la percepción, la comparación, la representación y la expresión de esas cantidades. Se sugiere, para ampliar este tema, consultar los documentos de profundización de micromundos de la aproximación y de la precisión.

\section{Actividades sugeridas}

Recomendación: El taller para padres se debe enviar con mínimo una semana de anticipación a la clase en la que se van a implementar las actividades para los estudiantes, dando así la oportunidad y el tiempo para que puedan realizarlo y enviar los resultados sugeridos. Además, es importante disponer de un espacio para atender y orientar a los padres que lo soliciten.

En la sesión con los estudiantes se aconseja desarrollar las siguientes actividades:

\section{1) ¿QUÉ TANTO TRAEMOS?}

Para esta actividad, que es de preparación, se sugiere retomar la cartelera realizada sobre los materiales necesarios para la germinación de una semilla y recordarlos; recuperar los listados de materiales elaborados en el taller No 3 de esta Fase y tenerlos a disposición. Luego, mostrar, en tamaño cartelera, la tabla que presentan los materiales en varios tamaños de cantidad y explicar que las decisiones que se tomen a continuación serán registradas en la cartelera; con esta base:

- Selección de semillas. El profesor solicitará traer las cajas con semillas que se fueron acumulando desde los talleres de la fase anterior. Pedirá a cada estudiante que seleccione las semillas que quiere poner a germinar y la cantidad de ellas. Cada estudiante pasa y dibuja sus semillas seleccionadas en la cartelera dispuesta para ello. El profesor retoma todas las respuestas para organizar por grupos las semillas que se van a poner a germinar; pide a los estudiantes que observen bien en qué grupo van a quedar sus semillas y que tengan en cuenta el total de semillas que se van a poner a germinar. 
- Elección del lugar del semillero. El profesor presenta tres tipos de bandejas que pueden servir para colocar los vasos plásticos que se van a utilizar para poner las semillas. Se recomienda que se cuente con, al menos, tres tamaños de bandeja: muy pequeña, pequeña y mediana. Todas las bandejas deben cumplir la condición de servir para colocar en su interior más de seis vasos. Cada estudiante seleccionará el tamaño y el material que le parezca más adecuado o que le guste y hará la respectiva marca en la cartelera que corresponde al tamaño que escogió. Cuando todos los estudiantes pasen y señalen en la cartelera, el profesor retoma la cartelera y destaca el tamaño que fue elegido por más niños (as). Luego pregunta a los niños (as) cuyos recipientes fueron menos elegidos, si prefieren el recipiente de ellos o el que eligieron la mayoría de sus compañeros para colocar los vasos.

- Elección del tamaño de semilleros. Una vez seleccionado el recipiente-bandeja, el profesor presentará vasos plásticos en tres tamaños: muy pequeño, pequeño y mediano. Solicitará a los estudiantes que seleccionen el tamaño adecuado del vaso, de manera que se puedan colocar varios vasos en las bandejas elegidas y colocar varias semillas en cada vaso. Se le solicita al estudiante hacer una marca en la cartelera, indicando el tamaño seleccionado y el número de vasos que puede traer para la siguiente clase. Se sugiere que cuando todos los estudiantes pasen y señalen en la cartelera, el profesor retome la cartelera y destaque cuál es el tamaño que obtuvo la mayor votación. Con esta base, que pregunte a los estudiantes que propusieron ese tamaño ¿Qué tantos vasos de ese tamaño se pueden acomodar en la bandeja seleccionada? Luego, formular la misma pregunta a los estudiantes que marcaron otros tamaños. Se sugiere revisar con todos los niños (as) las respuestas y comparar con las semillas que van a sembrar para elegir el tamaño más apropiado entre todos.

Este ejercicio exige tener en cuenta las expresiones de las señas tanto del profesor como de los estudiantes, para aprovechar e identificar las que resultan difíciles o las que no se conocen. Con esta base, propiciar la consulta en el rincón de la palabra, en diccionarios o con personas expertas.

- Previsión de la cantidad de tierra. El profesor presentará tres tamaños de bolsas con tierra y solicitará a los estudiantes que seleccionen una bolsa y dibujen en la cartelera el número de bolsas de tierra que pueden traer en la próxima clase, para llenar los vasos.

- Verificación de elementos: El profesor preguntará a los estudiantes ¿qué hace falta? Si ellos consideran que ya está completo todo, se puede revisar el video para identificar las piedras pequeñas. El profesor preguntará quiénes pueden traer algunas piedras y pedirá que pongan en la cartelera el dibujo de la cantidad de piedras que van a traer. 
Nota: Las anteriores actividades se pueden realizar en varios días, así como la recolección y organización de materiales que vayan trayendo los estudiantes. También es importante verificar cada día la responsabilidad de cada uno y cómo se van cumpliendo los compromisos y se va logrando contar con todos los elementos para el semillero. El profesor ha de aprovechar este proceso para que los niños (as) valoren el trabajo en equipo y cómo se logra un mismo propósito con la colaboración de todos.

\section{2) EL ESPACIO PARA EL SEMILLERO}

Después de seleccionado el tamaño de las bandejas y de los vasos y elegidas las semillas y la cantidad de tierra, el profesor y los estudiantes recorrerán los espacios del salón donde pueden colocar sus bandejas. Será necesario considerar las alturas de los niños (as) para que puedan observar, regar y cuidar bien la germinación de las semillas. También habrá que tener en cuenta las condiciones de temperatura; al respecto, es conveniente buscar el sitio más caliente del salón.

Una vez seleccionado el espacio, se procederá a acondicionarlo para colocar el semillero. ¡Manos a la obra!

\section{3) ¡CONSTRUIMOS EL SEMILLERO!}

Para el momento de llevar a cabo esta actividad, el profesor habrá dispuesto en el salón de clase cuatro cartulinas de colores marcadas con la palabra-gesto referida a los siguientes materiales: una para los vasos, otra para la tierra, otra para las piedras y otra para las semillas. Luego pedirá a los estudiantes que depositen los materiales traídos en las cartulinas correspondientes. Así, en cada una de las cartulinas quedarán grupos con el mismo elemento. Cada estudiante debe registrar, en la cartulina correspondiente, el material que entrega, empleando algún símbolo.

A continuación el profesor preguntará a los estudiantes: ¿en cuál cartulina hay más elementos?, ¿En cuál cartulina hay menos elementos?, ¿Cuál fue la cartulina donde más niños depositaron elementos?, ¿Cuál fue la cartulina donde menos niños depositaron elementos? Es importante destacar las señas de más, menos y su relación con el objeto al que se refiere la expresión.

Los estudiantes deberán generar las estrategias que ellos consideren más adecuadas para resolver estas preguntas. Pueden utilizar conteo con los dedos o señalando uno a uno los elementos para decir en cuál cartulina hay más marcas de niños. También pueden basar sus respuestas utilizando otros argumentos, por ejemplo, la cantidad de espacio que se utilizó en cada una de las cartulinas. En este momento el profesor debe estar atento a las estrategias que utilizan los estudiantes para responder a sus preguntas y puede tomar la información para identificar tipos de niveles en la diferenciación y en las semejanzas y en las expresiones (señas y otros recursos empleados por los estudiantes). 
En el siguiente momento se procederá a agrupar los elementos que sirvan para la construcción del semillero: bandejas, vasos de plástico, tierra, piedras y marcas. Posteriormente, se comprobará con la proyección del video, para confirmar si efectivamente los materiales que se pensaron para la construcción del semillero son los que se requieren.

El profesor organizará tres grupos de niños (as) a los que les entregará sus semillas, dejando los demás materiales organizados en una mesa. Desde esta mesa el profesor entregará los materiales que cada grupo vaya pidiendo. Para ello, Ilamará al primer grupo a la mesa y les preguntará: ¿qué tanta tierra necesitan?, ¿qué tantos vasos?, ¿qué tantas piedras?, ¿qué tantas marcas? Entregará la cantidad del material que cada grupo solicite, hasta que pasen todos los grupos. Cuando todos los grupos tengan sus materiales, les pedirá que los organicen en los espacios de cada grupo.

De acuerdo con las semillas y los vasos obtenidos, cada grupo procederá a marcar sus vasos.

Luego el profesor solicitará a todos los grupos realizar paulatinamente lo siguiente: colocar las piedras en los vasos, después la tierra, luego las semillas, posteriormente recubrir con tierra y colocar las marcas y los vasos en las bandejas. En todos los momentos se les estará preguntando a los grupos: si tienen suficiente, si les falta, si quieren más, si les sobro, qué tanto les faltó, qué tano les sobró, qué tanto hay...

Finalmente, se colocarán las bandejas en el espacio del semillero.

\section{B. ACTIVIDADES PARA LOS PADRES}

\section{Presentación.}

El taller NUESTRO SEMILLERO pretende desarrollar conocimiento en los niños (as) sobre el espacio propicio para la germinación de las plantas. Por esta razón, es importante que ustedes acompañen a su hijo (a) a buscar y a seleccionar los materiales que va a aportar al semillero. Proporciónele información sobre la tierra más propicia para las plantas, sobre las condiciones de las materas, sobre la preparación de las semillas...

No olvide incluir en su lonchera frutas que le permitan extraer semillas. Cuando prepare los alimentos, invítelo (a) a extraer semillas. Observe sus reacciones, su interés, sus dudas y trate de conversar con él o ella al respecto.

Después de realizar los recorridos, pueden, junto con su hijo (a), completar la siguiente gráfica, según el material que encontraron en cada lugar. Pueden hacer la gráfica con fotos, recortes de empaques o con dibujos. Es importante marcar la tabla en el título con los nombres de los padres o de los familiares que hicieron el recorrido con el niño (a) y el nombre del niño (a). 
NOSOTROS:

ASÍ BUSCAMOS LOS MATERIALES

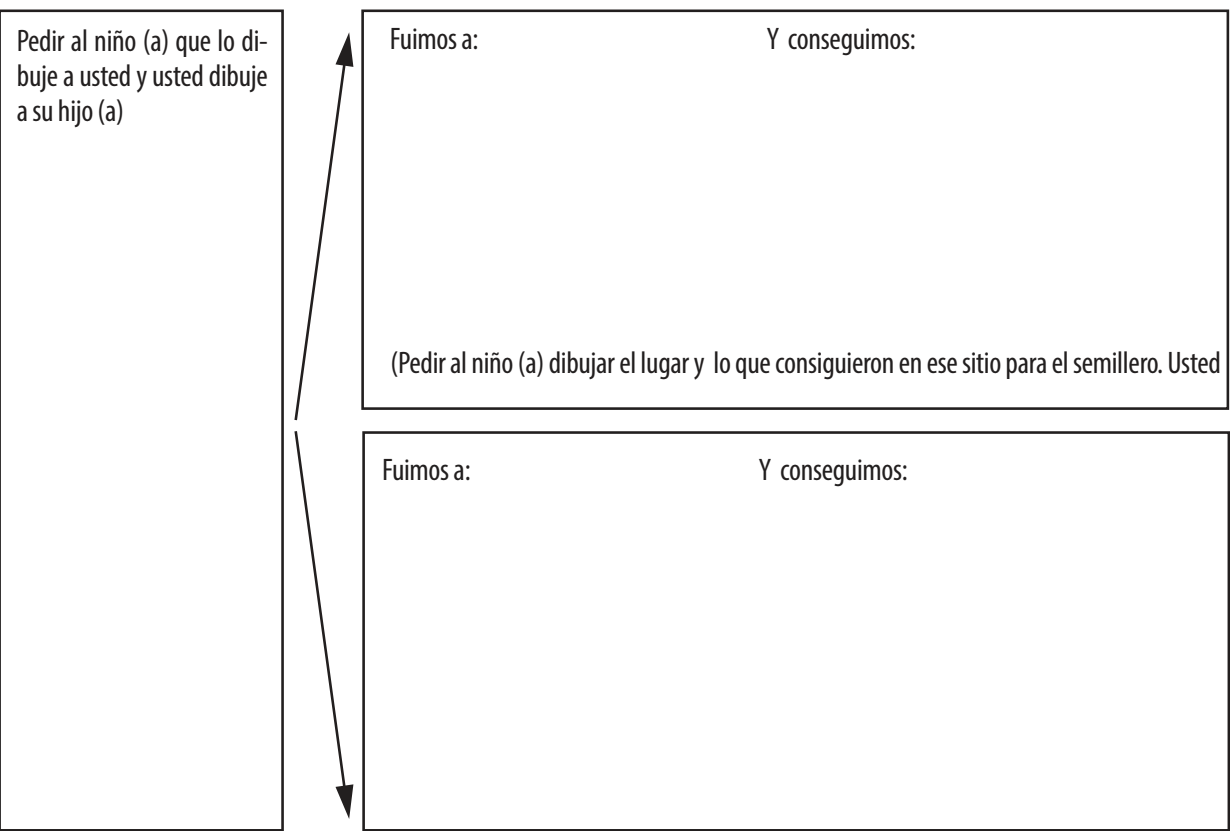

\section{ACTIVIDADES PARA LOS ESTUDIANTES ${ }^{42}$}

\section{Actividad 1}

Seleccionar el tipo de semillas de la caja de semillas del salón que quieres sembrar y registrar en la cartelera, según el ejemplo que te muestra:

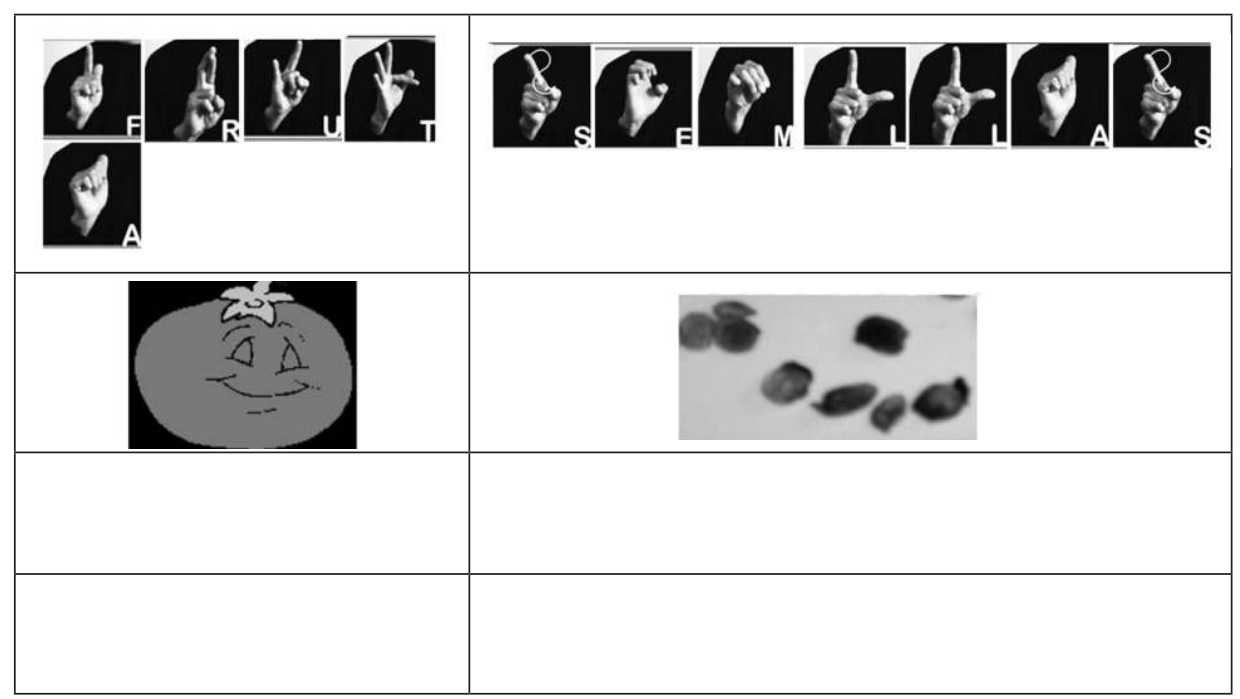

42 Imágenes tomadas de http://mail.colombiaaprende.edu.co:8080/recursos/lengua_senas, ahiva.info 
Seleccionar el tamaño de la bandeja ${ }^{43}$ y la cantidad de bandejas que se necesitan para colocar los vasos. Registrar en la cartelera

\begin{tabular}{|l|l|l|}
\hline & & \\
\hline
\end{tabular}

Debajo de la flecha del vaso que vas a escoger dibuja la cantidad de vasos que puedes traer de ese tamaño ${ }^{44}$

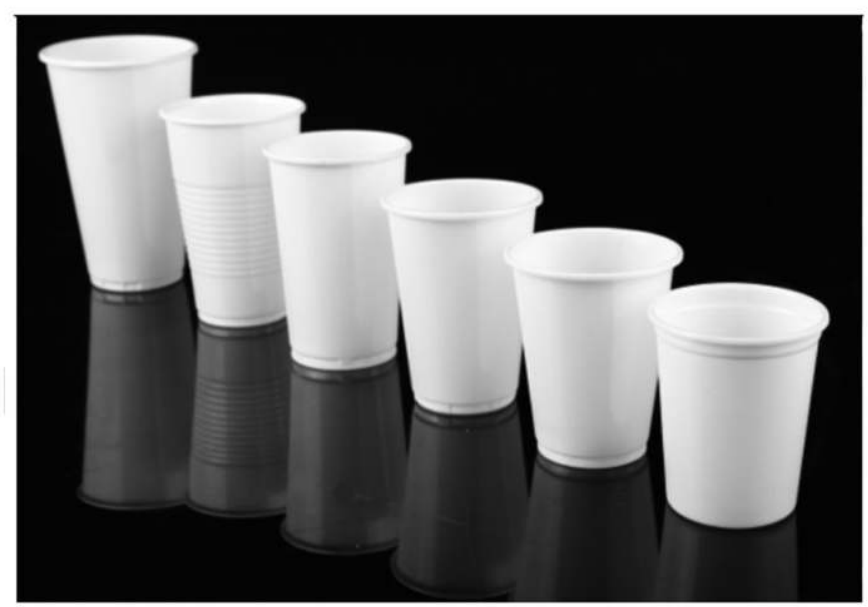

Seleccionar la cantidad de bolsas de tierra que puedes traer $^{45}$

43 Imagen tomadas de: picses.eu, articulo.mercadolibre.com.ar, plasticosacha.com 44 Imagen tomada de plasdiver.com.sv

45 Imagen tomada de articulo.mercadolibre.com.uy 


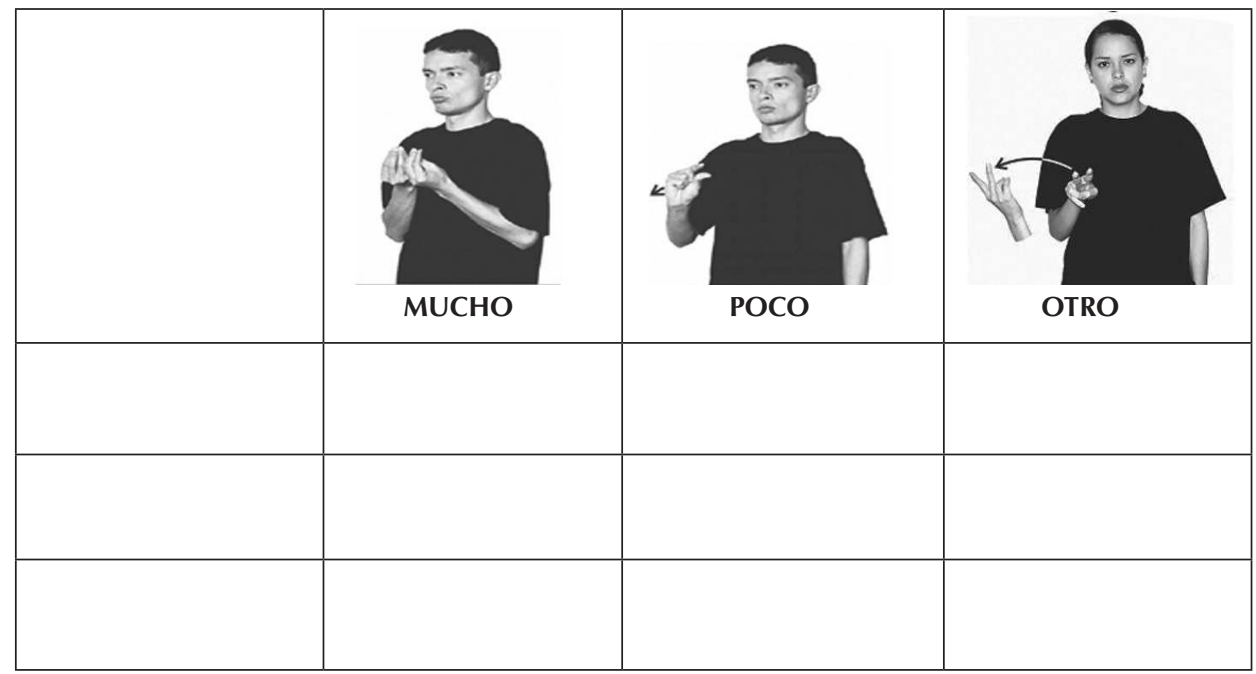

Seleccionar la cantidad de alimento que puedes traer.

\section{Actividad 2}

Ubica en cada una de las siguientes cartulinas el material que trajiste.

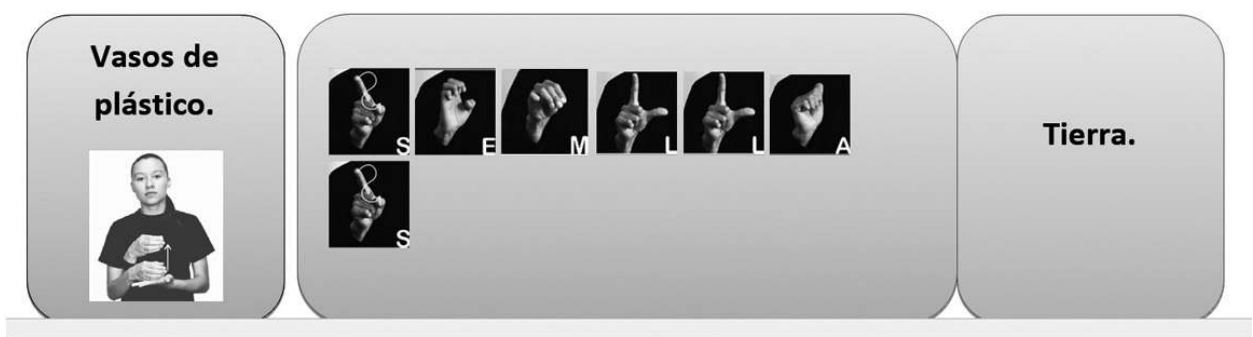

Presenta a tus compañeros tu material y enséñales a deletrearlo 


\section{Actividades de evaluación para los estudiantes}

¿Recuerdas cómo construiste semillero? Ahora dibuja en el orden que lo hiciste
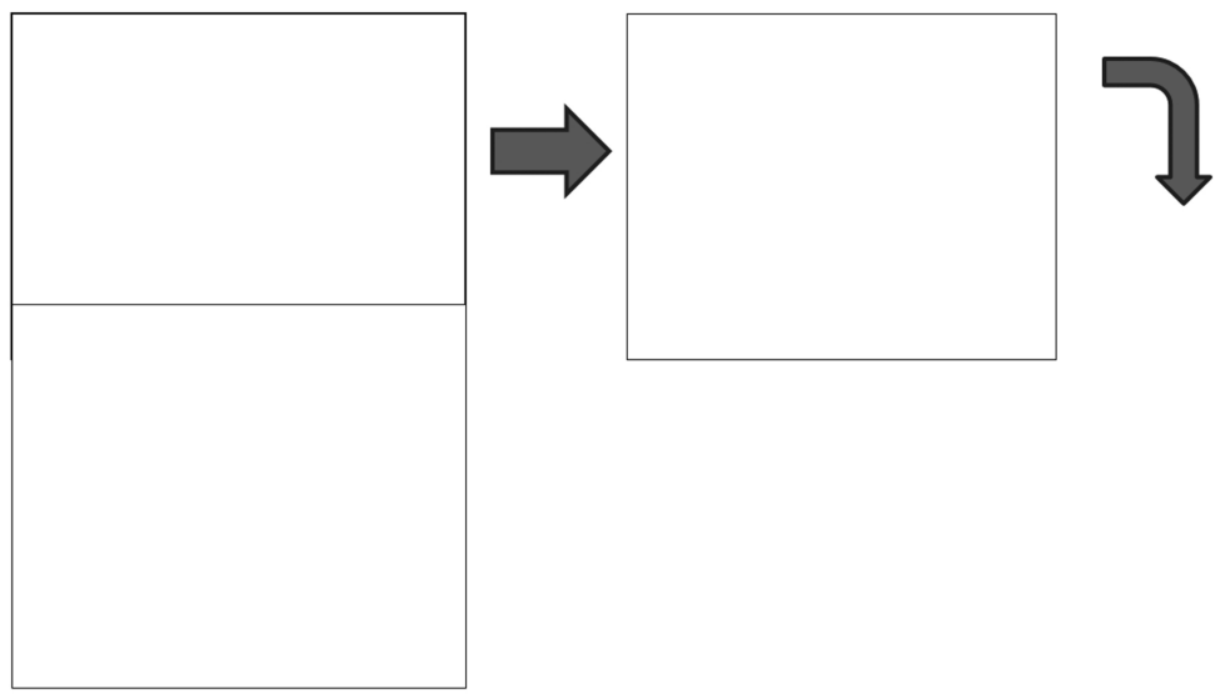

tscoge Ios materiales que usarias para cada una de las siguientes bandejas para el semillero ${ }^{46}$. Marca cuántos vasos necesitas. Si algo hizo falta, completa con un dibujo.
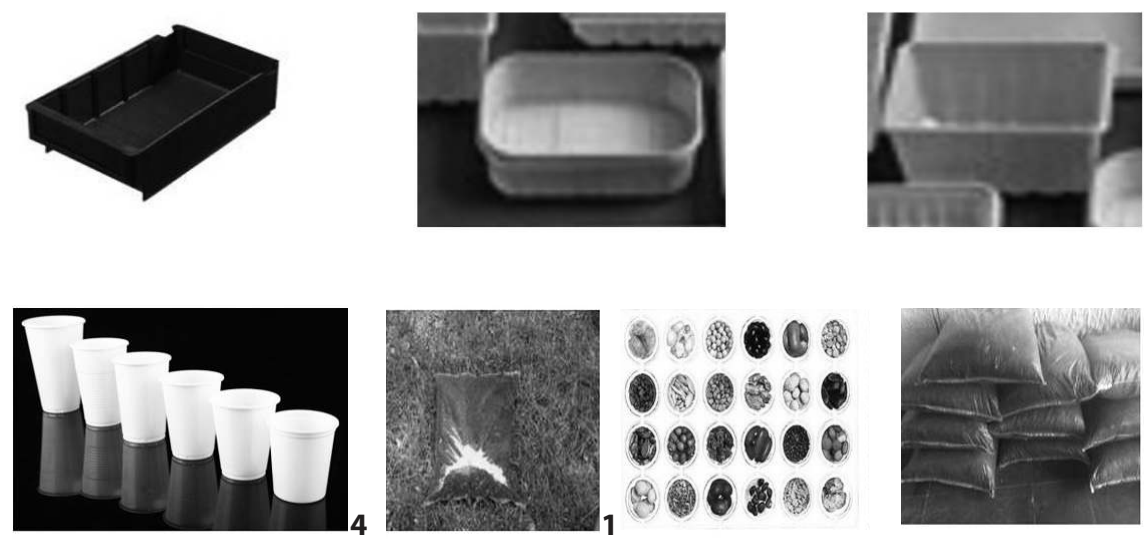

$461 \mathrm{y} 3$ articulo.mercadolibre.com.uy 4 portalbonsai.com. 5 intermundos.org 6 delpino.com.co 7infojardin. com 8evasworlds.blogspot.com 


\subsection{Organización de los talleres en el micromundo de la precisión de la cantidad Fase 3}

Para el desarrollo de este micromundo en la Fase 3 se construyó un conjunto de tres talleres que se visualizan en el siguiente esquema y se presentan a continuación.

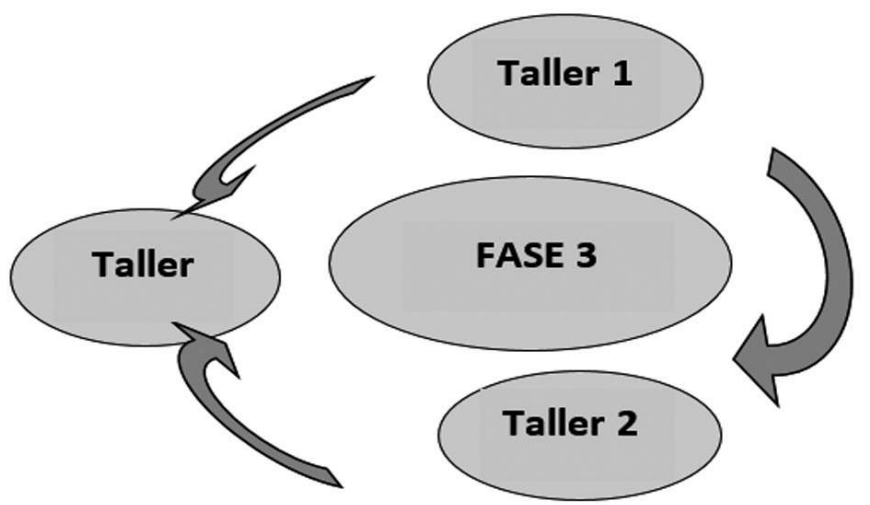

Esquema 8. Talleres de la Relación Fase 3.

La fase de crecimiento, es una etapa de organización para el cuidado y seguimiento del lombricultivo y del semillero, a partir de unas formas de organización del seguimiento y la observación del crecimiento de las lombrices y las semillas. Se proponen tres talleres como prototipo de talleres de esta fase. Cada profesor puede realizar cambios a la propuesta de talleres, según las exigencias que provienen de las condiciones de los estudiantes.

Es importante considerar los documentos de profundización proporcionados en este ambiente didáctico, para orientarse en la formulación de actividades o en la selección de dispositivos complementarios para la realización de talleres de profundización o de juegos de desarrollo de habilidades numéricas y geométricas. 


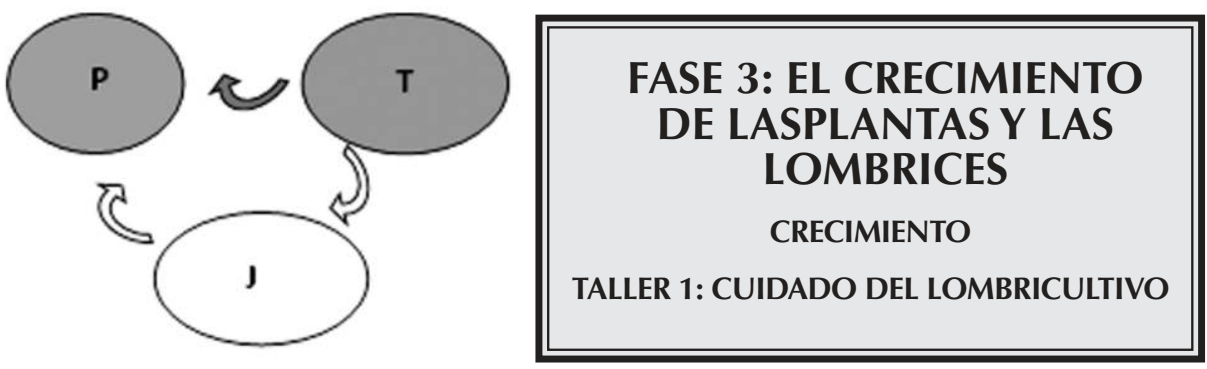

\section{A. ORIENTACIONES PARA EL PROFESOR}

\section{Objetivos}

- Propiciar la reflexión y el desarrollo de acciones de los estudiantes acerca de la responsabilidad y de los cuidados que necesita una mascota y los animales en general.

- Identificar y organizar las funciones que se requieren para desarrollar la Fase de Crecimiento del Proyecto de Aula y para mantener las lombrices en buenas condiciones.

- Desarrollar experiencias del micromundo de la precisión y habilidades de conteo, para la expresión y el manejo de cantidades discretas, a partir del número natural y del sistema de numerales en LSC.

- Desarrollar discursividad acerca del cuidado de las lombrices y de las experiencias de conteo.

Presentación. Una de las intenciones del presente taller es conocer las funciones y las responsabilidades que se adquieren cuando una persona está a cargo de una mascota, cualquiera sea ella y, en particular, cuando la mascota es una lombriz. De este modo, se busca que el grupo de estudiantes, junto con su profesor (a), generen un espacio para la observación, la toma de decisiones y la realización de acciones relacionadas con el cuidado del lombricultivo. En particular, se pretende lograr el desarrollo de acciones como: la selección y la preparación de los alimentos, el suministro de la comida a las lombrices y el registro de su crecimiento.

Estas acciones tienen como propósito organizar a los niños (as) en grupos que asumirán distintas responsabilidades y funciones. Para ello, cada grupo tendrá un color distintivo que los caracterizará en su ambiente de aula, a sí: grupo azul, grupo rojo y grupo verde,

En este ambiente se desarrollará una actividad que relaciona, de manera escencial, el entorno con el desarrollo del conocimiento matemático; tal activi- 
dad es el conteo. Esta es una de las actividades más investigadas, sin embargo, para el profesor no deja de ser necesaria en la reflexión sobre una didáctica de las matemáticas. Ese proceso de asociar objetos con números, además de tener una larga historia en el desarrollo de cada cultura, está naturalmente vinculado a las condiciones de expresión de la misma. Las necesidades primarias de identificar tamaños (numerosidad) de colecciones de objetos y de indicar la posición de un objeto en una colección ordenada de objetos, no sólo propician condiciones para desarrollar el concepto de número natural en sus dimensiones cardinal y ordinal, sino tambien originan técnicas que tienen como mediación semiótica-cultural el tipo de representación numérica. Tales representaciones numéricas pueden ser consideradas transculturales, porque comparten los mismos principios en sus procesos. Entre los principios que comparten podemos señalar:

1) Principio de abstracción: cualquier colección de objetos es suceptible de ser contada.

2) Principio de la correspondencia uno a uno: cada objeto contado de la colección de objetos debe asignarse a uno y un solo término de la colección que cuenta.

3) Principio de la irrelevancia del orden: el objeto por el que se inicie el conteo y el orden que se siga para los demás objetos es irrelevante para determinar el tamaño de la colección.

4) Principio de orden estable: Ios signos del sistema que se usen para el conteo, deben producirse con un orden establecido sin omitir ninguno de ellos.

5) Principio de la cardinalidad: el último término usado de la colección que cuenta, indica el tamaño de la colección, se denomina el cardinal de la colección.

Sin embargo, la aplicación de tales principios con las herramientas y mediaciones simbólicas que cada cultura ofrece, hace emerger difrentes tipos de técnicas como la siguientes:

a) Técnicas para asociar objeto-término: recitar sucesiones de términos (o producir sucesiones de términos); adjudicar cada término a cada objeto contado, hasta agotar los objetos de la colección; enunciar el término final.

b) Técnicas para el organizar el conteo: trazar un camino a seguir para el conteo; distinguir (mental o fisicamente) los objetos ya contados; sustituir la colección por otra colección equinumerosa, contando esta última.

c) Técnicas para abreviar el conteo: contar de dos en dos, de tres en tres, etc; contar hacia adelante o hacia atrás desde un cardinal dado; contar hacia adelante o hacia atrás desde un cardinal dado hasta otro cardinal dado. contar hacia adelante o hacias atrás tanto como lo indique un cardinal dado.

El desarrollo de la técnica responde a las necesidades que el conteo como acción física exige. La producción de una técnica es la elaboración reflexio- 
nada de procesos asociados a la experiencia del conteo. Es decir, el conteo se convierte en un macro proceso que articula: aspectos de desarrollo sensorial (visual, tactil, auditivo, olfativo, gustativo); aspectos de desarrollo lingüístico-discursivo (interpretación y producción de signos, producción de significados y de sentidos); aspectos cognitivos (diferenciar el conjunto de objetos que se va a contar del conjunto de objetos con el que se realizar el conteo, abstraer los principios del conteo); aspectos culturales (formas convencionales de expresar cantidades y de usar simbolos número); aspectos matemáticos (relaciones de equinumerosidad, correspondencias biunívocas de colecciones, relaciones de coordinabilidad de conjuntos, relaciones de orden, relaciones ternarias...).

El macroproceso de conteo se manifiesta como un tipo de actividad matemática primaria vinculada al hacer cultural y con un profundo efecto en la elaboración del número natural, que se constituye a partir de la identificación de los conceptos de cardinal y ordinal: Identificación que se realiza mediante el postulado fundamental de la aritmetica:

"El número cardinal de un conjunto coincide con el número ordinal del último elemento, y es siempre el mismo cualquiera que sea el orden en que se haya efectuado el recuento" (Cid, Díaz Godino, \& Batanero, 2003: 25).

La dimensión cardinal considerará el tamaño del conjunto, sin tener en cuenta la naturaleza de los elementos que lo componen ni el orden en el que se presentan. La dimensión ordinal no considera la naturaleza de los objetos y sí el orden en el que se presentan. La primera dimensión se manifiesta al responder preguntas como: ¿cuánto hay?, ¿cuánto ganó?, ¿cuánto vale?, ¿cuánto más?, ¿cuánto menos?... La ordinalidad se manifiesta cuando se responde a preguntas como: ¿en qué puesto está?, ¿qué puesto ocupó?, ¿en qué posición llegó?... ¿cuál es el quinto?. Como se observa, el desarrollo de la actividad de conteo implica fuertemente una relación con el entorno, con os objetos contados, y también, un desarrollo de lenguaje que exige una apropiación de sistemas de numerales en distintos registros: en lenguas naturales como la lengua de señas colombiana (LSC) o en el español (oral y escrito), en sistemas de numeración como el decimal y en otras formas de representación. Adicionalmente, esta actividad de contar exige el desarrollo de expresiones que permiten realizar la actividad de contar, como las que se presentaron en el párrafo anterior. A todo este conjunto de exigencias lingüísticas se les denomina "desarrollo del campo semántico del conteo". Sugerimos al profesor consultar el documento "Repertorio Léxico del campo Semántico del Conteo" en los documentos de profundización.

\section{Actividades sugeridas}

Recomendación: El taller para padres se debe enviar con mínimo una semana de anticipación a la clase en la que se van a implementar las actividades para 
los estudiantes, dando así la oportunidad y el tiempo para que puedan realizarlo y enviar los resultados sugeridos. Además, es importante disponer de un espacio para atender y orientar a los padres que lo soliciten.

En la sesión con los estudiantes se aconseja desarrollar las siguientes actividades:

\section{1) ¿CÓMO CRECEN LAS LOMBRICES?}

Inicialmente se propone que el profesor entregue a los estudiantes las imágenes tomadas del video ${ }^{47}$ LOMBRICULTURA CASERA CDP 2.wmv, para que las observen y las agrupen según los cuidados que debe hacerse al lombricultivo.

Posteriormente el profesor tomará cada lámina y los estudiantes señalarán en cada una de ellas o expresarán en lengua de señas, el tipo de cuidado que se destaca en la lámina. El profesor va agrupando las láminas según los cuidados señalados y al final puede sugerir conformar tres grandes grupos de mantenimiento del lombricultivo:

i) Alimentación y riego

ii) Cuidado de lombriz

iii) Recolección y Almacenamiento de comida.

El profesor y los estudiantes revisan en qué consisten las actividades de cada uno de esos grupos. Se propone utilizar un color distintivo para cada una de las actividades $(1,2$ y 3 ) que se identifiquen. Así, colocan el distintivo de color rojo para el primer grupo de actividades, el azul para el segundo y el verde para el tercero.

Empleando un almanaque, como el que se propone en la sección de Actividades para Estudiantes, el profesor solicitará a los niños (as) que informen en qué momento del día es conveniente la realización de las actividades de cada grupo. Con las respuestas de todos los estudiantes se acuerda el mejor momento para hacer las actividades por grupos. Se recomienda grabar esta sesión, con el fin de obtener las respuestas en LSC de los niños (as) y emplear el video para realizar correcciones de señas y aclaraciones de significados de señas.

\section{2) ¡TODOS CUIDAMOS NUESTRO LOMBRICULTIVO!}

El profesor recuerda los grupos y sus funciones. Luego solicita a cada estudiante sacar una ficha de una bolsa en la que hay igual número de fichas que de niños (as). El color de ficha indica el grupo en el que estará el estudiante que sacó la ficha. Si el niño (a) no está conforme con su grupo, puede cambiarlo con otro compañero (a) que quiera hacer lo que le correspondió a él o a ella. Vale la pena que en este último caso, se justifique por qué no le gusta la función que le corresponde, según la ficha obtenida. Las funciones que se plantean para cada grupo son las siguientes:

47 Recuperado en http://www.youtube.com/watch?v=9MWzWCO8_o4 
- Grupo azul: Registro de revisión de estado de la lombriz. Todos los días, a primera hora, se debe observar el estado de la lombriz para ver si presenta algún cambio significativo o relevante para el desarrollo del proyecto.

- Grupo rojo: Registro de comida a la lombriz. Este grupo será el encargado de proveer el alimento diario a las lombrices, cuidando la ración que se les dé y cumpliendo con el cronograma de alimentación. Esta actividad se realizará después del descanso, cuidando que el equipo azul haya puesto su marca en el almanaque de ese día.

- Grupo verde: Suministro de la comida de la lombriz. Este grupo estará encargado de proporcionar al grupo rojo la comida de la lombriz. Esta labor se realizará después del descanso. Cada día se recoge un tipo de cáscara de frutas de las que se hayan Ilevado para la lonchera. Al finalizar la jornada escolar, el grupo organiza la comida y registra la nueva comida almacenada. Así, el Grupo Verde almacenará la comida que se entregará al siguiente día. También deben marcar en el calendario que ya realizaron esta labor, con el fin de que los demás grupos lo sepan y continúen con sus funciones. Esta será la última marca del día en el calendario.

En cuanto a la manera de registrar el cumplimiento de cada función, se propone dividir el espacio del día correspondiente en el calendario en tres partes, de tal modo que cada equipo pueda marcar su labor en cada día. Así, al cumplir con su tarea del día, cada grupo dará a conocer a los demás que su función ya fue realizada, coloreando un tercio del día como se muestra a continuación:

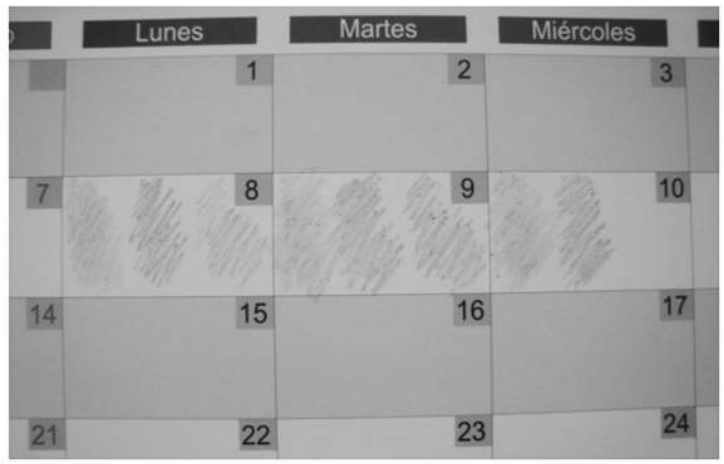

Imagen 8. Ejemplo.

La imagen 8 nos muestra que los días 8 y 9 se realizaron las funciones de cada grupo y que el día miércoles 10 aún no se ha almacenado el alimento de la lombriz. Entre las opciones elegidas para registrar en el almanaque, se pueden emplear caritas felices o alguna figura que se escoja y que indique "cumplimiento" o "incumplimiento". 


\section{3) EL DIARIO DEL LOMBRICULTIVO}

Después de realizar la organización de los grupos, se sugiere al profesor realizar carteleras como las siguientes y pegarlas en lugar visible, para apoyar a los grupos en sus registros:

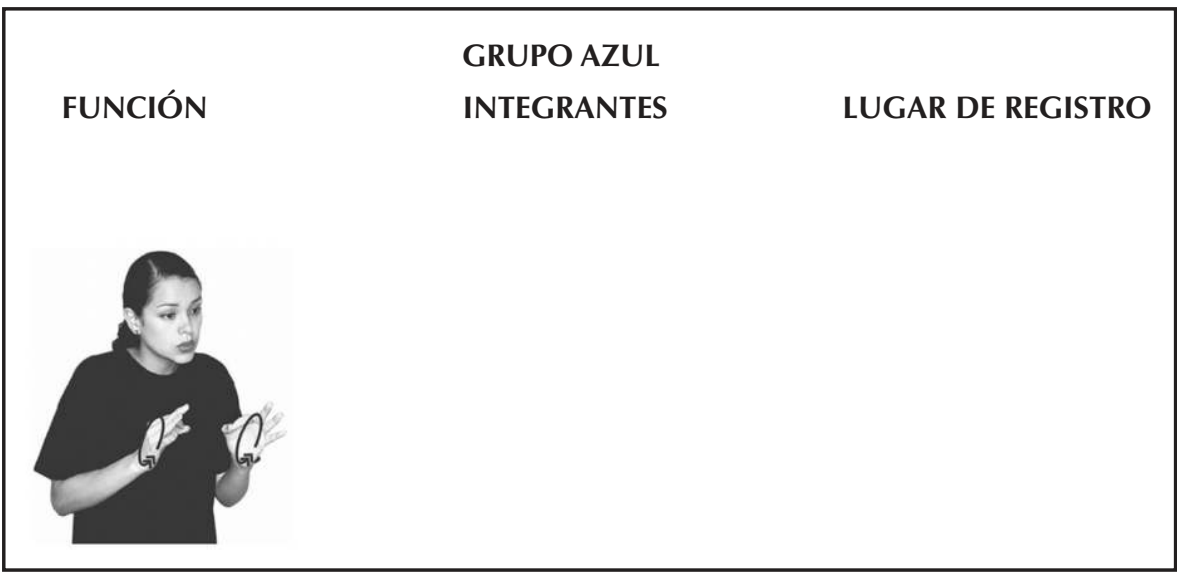

La anterior manera que se sugiere para organizar las carteleras cuenta con tres partes que contienen:

Función: es este lugar de la cartelera el profesor colocará la seña que considera tiene mayor relación con la función principal del respectivo grupo. Esta seña debe ser muy visible.

Integrantes: en esta parte del cartel se sugiere pegar fotos de los integrantes de cada grupo, marcadas con el nombre de cada niño (a) debajo de su foto, a manera de listado de los integrantes del grupo. Es aconsejable que el docente vaya pegando las fotos mientras comunica a los estudiantes la manera como quedaron conformados los grupos. De no ser posible hacerlo en el momento, entonces se realizará posteriormente. Es importante destacar el valor del trabajo en grupo y cómo todos van a contribuir con el mismo propósito.

Lugar de registro: en esta parte del cartel, cada grupo irá pegando el registro más reciente que realizó, reemplazando el inmediatamente anterior. El profesor recogerá el registro que se reemplaza y realizará el respectivo análisis de cumplimiento y de cómo ayuda a mantener el lombricultivo; posteriormente lo archivará. La manera de registro la decidirá el docente; puede estar basada en los dibujos que se sugieren en las actividades del presente taller, para los estudiantes.

Para un manejo más fácil del registro, es importante que la cartelera sea en cartón cartulina, pues se conservará mejor tras el pegado y despegado de cinta cada vez que se cambie el registro. Como se dijo anteriormente, la manera de 
registro la decide el docente; al respecto sugerimos los siguientes modos de registro por grupo:

\section{Grupo azul:}

Dibujar las lombrices a diario teniendo en cuenta si hubo cambio de tamaño, si aparecen huevos o nuevas lombrices.

\section{Grupo rojo:}

Dibujar la comida que se le da a la lombriz cada día y la cantidad que sobró del día anterior.

\section{Grupo verde:}

Dibujar la comida que se recoge para la lombriz cada día.

Nota: el profesor puede dar ejemplos a cada grupo, según la manera en que él decidió realizar el registro, y orientar el registro durante los primeros días, mientras los estudiantes aprenden la forma correcta de hacerlo. Además, destacamos la importancia de dichos registros en el trabajo posterior, pues la información que generan es rica en relaciones matemáticas y en representaciones que constituyen las bases del desarrollo que se pretende al respecto. Ejemplo: más comida, menos comida, más grande, más lombrices, entre otras.

Finalmente, se recomienda no olvidar:

$\checkmark$ Designar en cada grupo el encargado de hacer el registro cada día, para que se turnen y siempre lo haga un integrante del grupo diferente.

$\checkmark$ Informar y recalcar al grupo que deben comunicar al profesor cualquier pregunta, inquietud o problema que se les presente.

Los problemas que se pueden presentar en cada grupo podrían estar relacionados con:

- Cantidad de comida.

- Tipo de comida.

- Sobras de comida.

- Muerte de una lombriz.

- Estado de la comida.

Entre otros. Por ello es importante que el profesor tenga previstas las acciones que va a ejecutar de acuerdo con los posibles problemas o inquietudes que se puedan presentar. Por ejemplo: 
$\checkmark$ Leer, explicar y orientar las actividades para los estudiantes.

$\checkmark$ Consultar en libros y enciclopedias.

$\checkmark$ Hablar con personas expertas...

Materiales:

- Almanaque

- Carteleras de los grupos

- Guías de trabajo

- Colores y marcadores

Tiempo: tres sesiones de máximo una hora

\section{B. ACTIVIDADES PARA LOS PADRES DE FAMILIA}

Presentación. Sabemos que cuando se está a cargo de una mascota es necesario cuidarla: alimentarla, observar su estado de salud, limpiarla, propiciarle un lugar agradable y adecuado para su permanencia, entre otros. De los cuidados que se tengan con una mascota depende su bienestar, ya se trate de un perro, un gato o cualquier otro animal. Además, el responsable de dichos cuidados siempre será el dueño o los dueños de la mascota. Estas acciones, además de favorecer a la mascota, contribuyen a desarrollar, en la familia que la mantiene, actitudes de consideración y de respeto y cariño por los animales y por la naturaleza en general y sentimientos de solidaridad entre los mismos miembros de la familia.

Actividad. Si en su hogar tienen una mascota, podrán realizar las actividades sugeridas en la casa. De no ser así, procure visitar con su hijo (a) la casa de algún familiar o allegado que tenga mascota o visitar una tienda de venta de animales, con el fin de preguntar por los cuidados que se recomiendan para el bienestar de los animales. También se puede observar el estado de animales callejeros y reflexionar sobre su situación y sobre las necesidades que pueden tener y que las personas podrían subsanar. Enséñele a su hijo (a) algunas responsabilidades que se deben asumir al tener un animal como mascota.

Observar en el vecindario qué animales son los que se prefieren como mascotas. Al llegar a casa, acompañe a su hijo (a) a llenar la información que se requiere en la ficha que le entrega el profesor (ver más abajo). No olvidar enviar estos registros al profesor (a) para guardarlos en el diario del niño (a). Si por alguna razón el padre o la madre no pueden acompañar al niño (a) en la salida, sugerimos buscar un familiar adulto que lo acompañe y le colabore en hacer el registro, en compañía de los padres.

En la casilla que queda al lado de las fotos y los nombres de los animales, colocar una $\mathrm{X}$ por cada gato o perro que recuerden haber visto, en la salida a observar mascotas en el barrio. En la siguiente casilla dibujar, o escribir, algún cuidado que necesite el animal. 


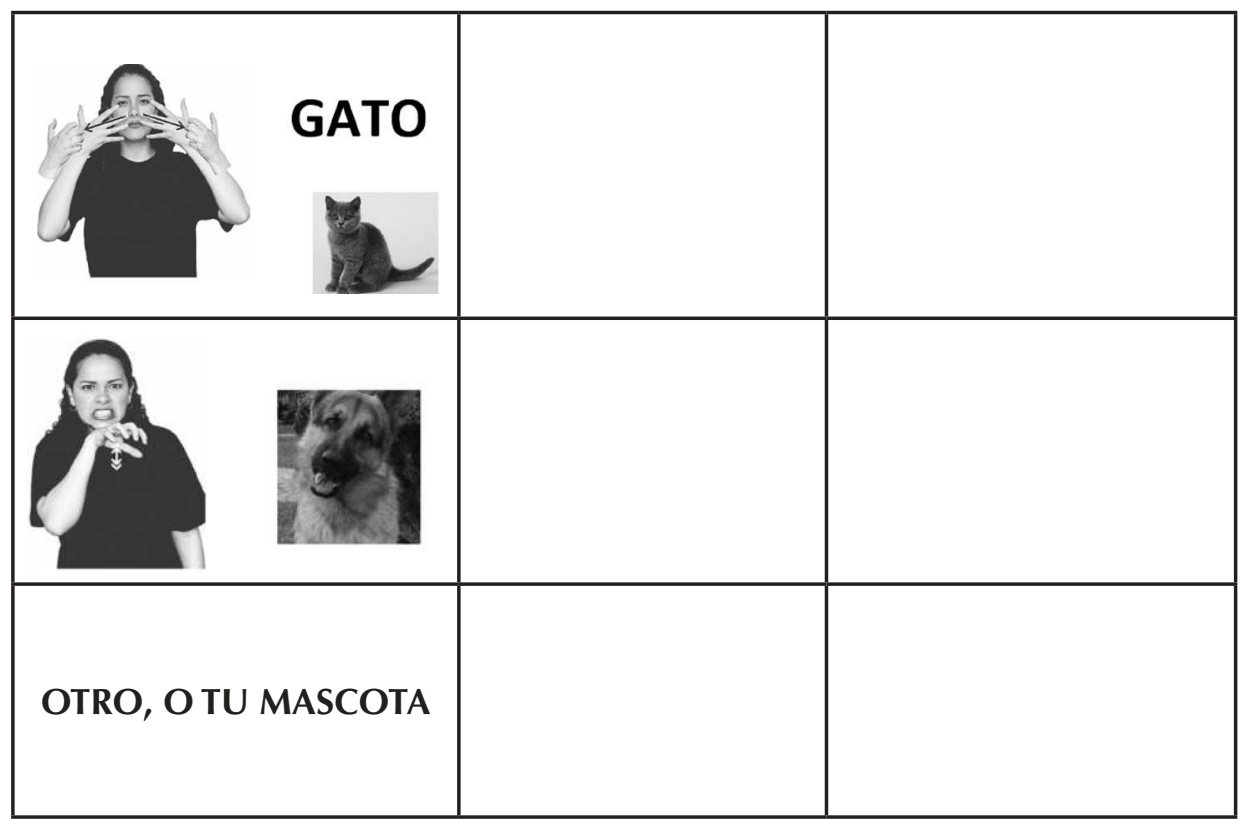

\section{ACTIVIDADES PARA LOS ESTUDIANTES}

Actividad 1: Observa y agrupa las láminas, según los cuidados que deben
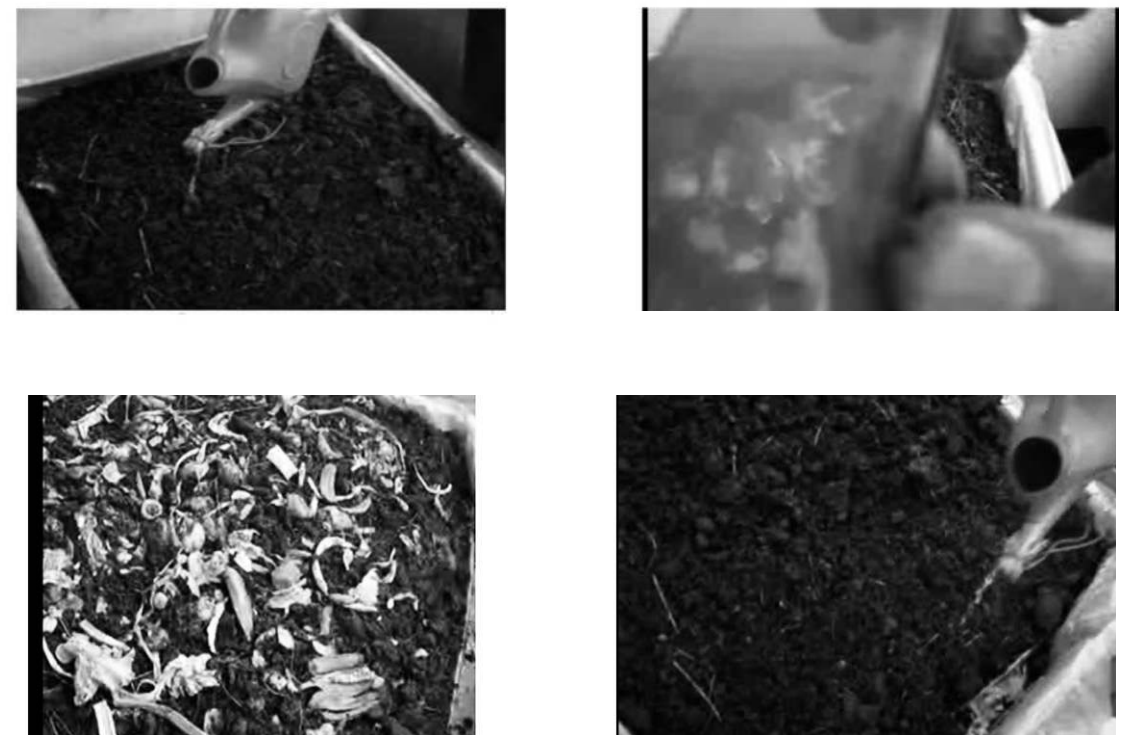

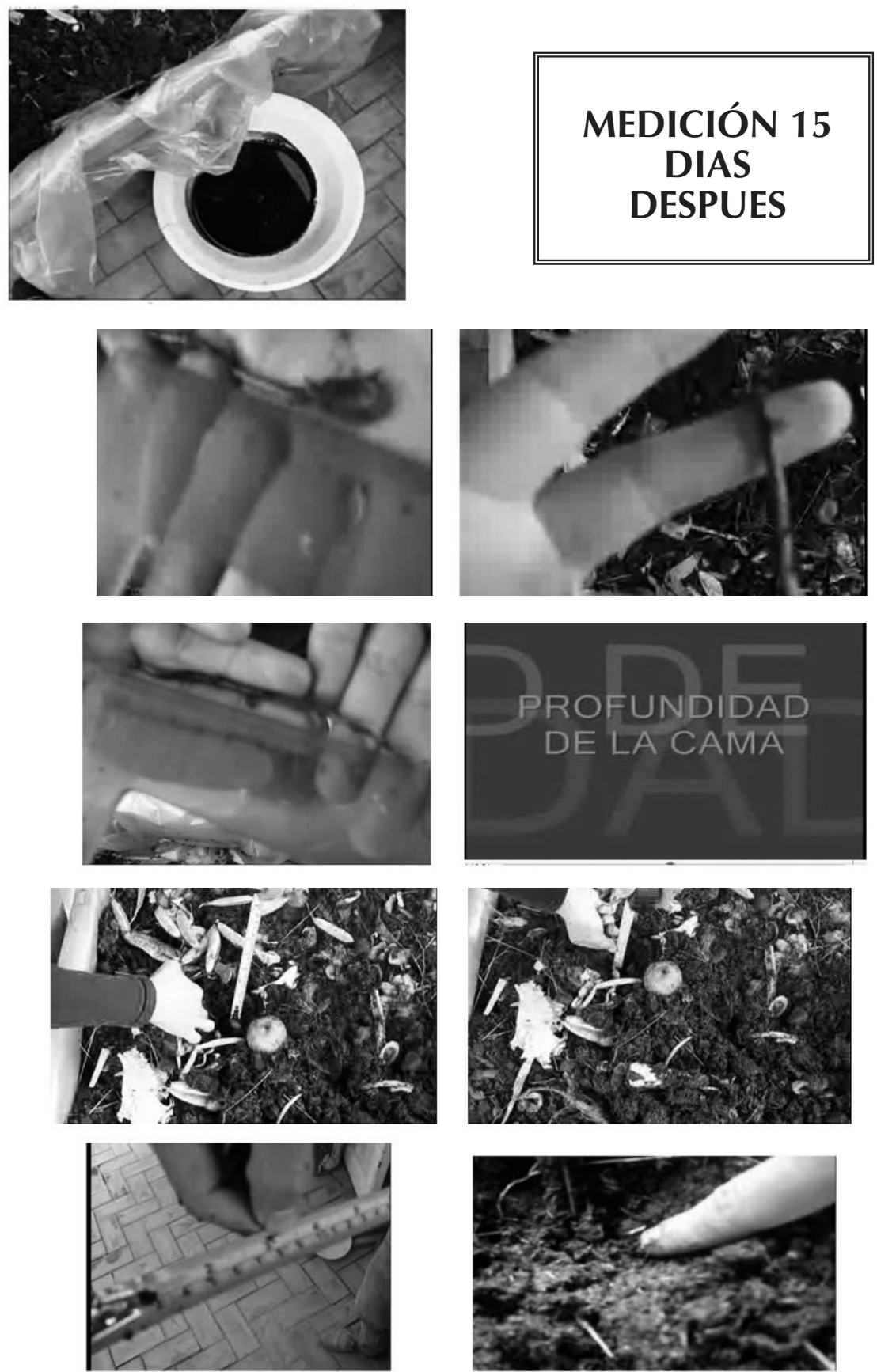

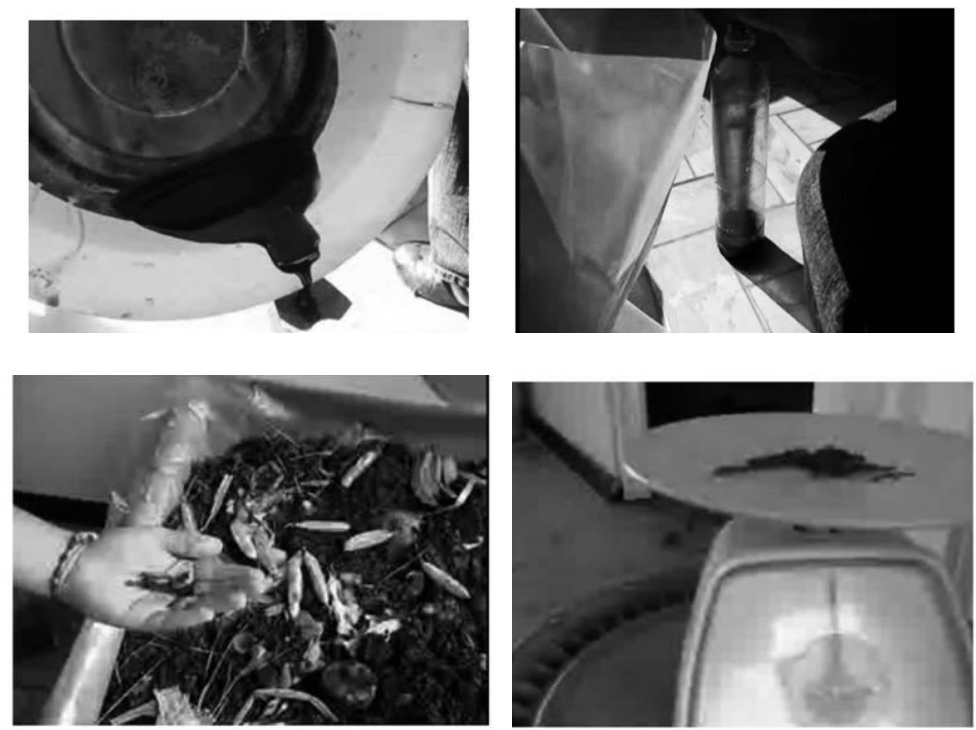

Actividad 2: Emplea los colores de los grupos para colorear el momento del día escolar más conveniente para hacer las actividades de cuidado que le corresponden a tu grupo.
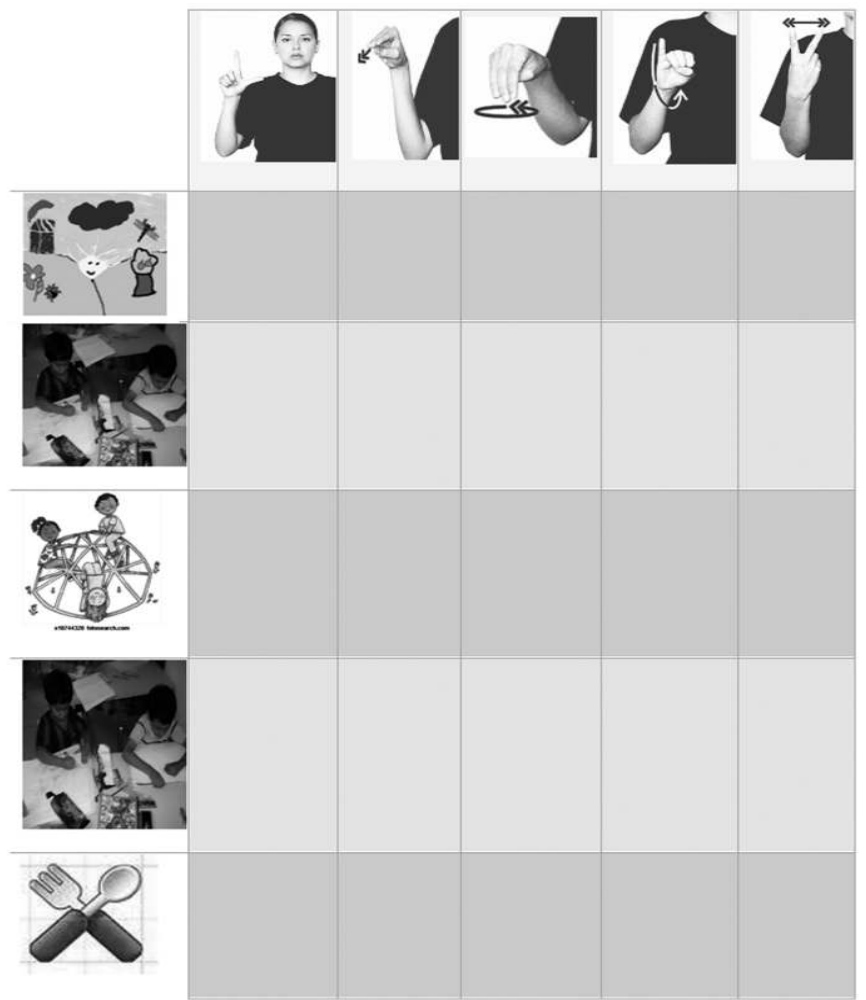
Actividad 3. Teniendo en cuenta los colores para cada función, realiza la labor correspondiente:

Grupo azul: Dibuja las lombrices a diario teniendo en cuenta si hubo cambio de tamaño, si aparecen huevos o nuevas lombrices. Pega tu registro en la cartelera.

Cuéntale a los otros grupos qué pasó con las lombrices.

Grupo rojo: Dibuja la comida que se le da a la lombriz cada día y la cantidad que sobró del día anterior. Pega tu registro en la cartelera.

Cuéntale a los otros grupos cómo hay que alimentar a las lombrices.

Grupo verde: Dibuja la comida que se recoge para la lombriz cada día.

Cuéntale a los otros grupos qué tipo de comida es la que debe darse a las lombrices.

\section{ACTIVIDADES DE EVALUACIÓN PARA LOS ESTUDIANTES}

\section{Actividad 1}

Grupo azul: Registrar en el almanaque proporcionado el número de lombrices que tenían el primer día al inicio del lombricultivo y escribir en el día de la fecha de la evaluación el número de lombrices que hay en el lombricultivo.

Grupo rojo: Registrar en la tabla el número de días en que alimentaron las lombrices con una misma comida. Por ejemplo ¿Cuántos días fueron alimentadas con cáscara de banano?, ¿cuántos días con cáscara de manzana? Y escribir esos numerales al frente del dibujo del banano y de la manzana

Grupo verde: Registrar en la tabla que se entrega qué tipos de comidas entregaron los estudiantes para las lombrices. Al frente de cada comida, escribir el número de días que fue entregada este tipo de comida.

Actividad 2. De acuerdo con el grupo al que perteneces, enséñale a tus compañeros (as) y a tu profesor (a) qué cuidados tener para con las lombrices. Elabora una lista.

* Dibuja tu lombriz,

Ahora ¿qué nombre le pondrás?

Cuando lo hayas puesto, escríbelo utilizando señas y pégalo debajo de tu dibujo. 


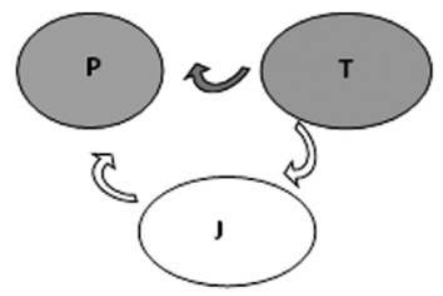

FASE 3: EL CRECIMIENTO

DE LASPLANTAS Y LAS

LOMBRICES

CRECIMIENTO

TALLER 2: CUIDADO DEL SEMILLERO

\section{A. ORIENTACIONES PARA EL PROFESOR}

\section{Objetivos}

- Propiciar, en los estudiantes, la reflexión acerca de la responsabilidad y de los cuidados que se deben tener en la germinación de las semillas.

- Organizar y planear las funciones que se requieren para desarrollar la Fase de Crecimiento del Proyecto de Aula y para mantener el semillero en buenas condiciones.

- Desarrollar experiencias del micromundo de la precisión y habilidades de conteo para la expresión y el manejo de cantidades discretas, a partir del número natural y del sistema de numerales en LSC.

- Desarrollar discursividad acerca del cuidado de las semillas y de las experiencias de conteo.

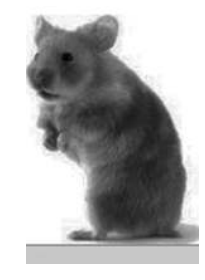

Presentación. Una de las intenciones del presente taller es conocer las funciones y responsabilidades que se adquieren cuando se está a cargo de un cultivo destinado a la alimentación de personas o de animales, cualquiera que sea el tipo de cultivo y, específicamente, apropiar esas funciones y responsabilidades para el cuidado de un semillero. Con este propósito, se generará un espacio para la observación y la toma de decisiones, en relación con el cuidado del semillero: en particular, con el conocimiento y la capacidad de identificar las fases de germinación de las semillas seleccionadas, con el riego, el cuidado y el control de la luz y con el registro de su crecimiento. 
Las anteriores acciones tienen como propósito organizar a los niños en grupos que asuman responsabilidades y funciones para cada una de ellas. Para ello se propone identificar a cada grupo con un distintivo relacionado con su función: grupo agua, grupo luz y grupo semillas. De esta manera, los demás grupos reconocerán la característica de un grupo, según su función en el ambiente de aula.

Para un mejor desarrollo de este taller, es importante retomar las orientaciones presentadas para el profesor en el taller 1 de esta fase (tres) y complementarlas con la siguiente información.

Micromundo de la precisión. La precisión hace referencia a la medida y exactitud de las descripciones en las cantidades. Los atributos de información que se catalogan como "precisos", pueden especificar las características de los elementos con gran detalle; con esto nos referimos a qué tan cercano está un valor individual medido o calculado respecto a los otros. El desarrollo de los procesos de reconocimiento y comparación de tamaños de cantidades, se vincula con las necesidades primarias de identificar tamaños (numerosidad) de colecciones de objetos y de indicar la posición de un objeto en una colección ordenada de objetos. Estos elementos determinan el progresivo desarrollo del número.

La experiencia con las cantidades y sus tamaños se vincula con la experiencia con sistemas de representación. En particular, la experiencia con las cantidades discretas está vinculada con la de construir sistemas de numeración. En la experiencia con los sistemas de representación, se reconoce que toda forma de representación requiere de reglas que orienten la combinación de signos, de manera que el producto de la representación tenga sentido. Esas posibilidades de producción y de combinación simbólica determinan el carácter sistémico de los sistemas de numerales y les confieren potencia inventiva al sistema de numeración y potencial heurístico para procesos matemáticos (León, 2006).

Los sistemas de numeración pueden tener naturaleza física o naturaleza lingüística. Para el primer caso, el sistema de numeración es otra colección de objetos (como las partes del cuerpo, ábacos...). En el segundo caso, es un sistema de representación semiótica.

La existencia de diversos sistemas de numeración es determinada por los siguientes características de los sistemas de numeración considerados como sistemas de representación semióticos: (i) El carácter de sistema linguístico. (ii) El carácter de sistema de numeración. (iii) El carácter aritmético del sistema.

La primera característica determina: en la producción de los signos, unidades básicas y unidades compuestas; en la identificación de las reglas de conformación de los signos, reglas simples y reglas compuestas; en el uso de los 
signos, reglas para la expresión (oral, escrita, gestual) y para el uso del sistema (convencionales o no convencionales). La segunda característica determina una secuencia de signos ordenada y un desarrollo semántico para cada signo; por ejemplo, en el campo de la aritmética, cada signo expresa un número, un tamaño de una colección, una posición. La tercera característica manifiesta una producción de signos vinculada a aspectos aritméticos de tipo aditivo o de tipo multiplicativo, cada signo presenta un potencial operatorio del número que representa.

En el caso de las personas sordas y su relación con los sistemas de nuemeración, es imprescindible la coexistencia de tres sistemas de númeración con el mismo nivel de importancia. Así, los subsistemas de numerales que provienen de dos lenguas naturales (la lengua de señas colombiana LSC y el español, en nuestro caso) y el sistema de numeración internacional arábigo, constituyen tres sistemas que coexisten para una relación integral del niño (a) sordo (a) con las cantidades, en un sistema cultural bilingue. Garantizar la presencia de estos tres sistemas de numerales, para la actividad de conteo de los niños (as) sordos (as) en el aula, será un factor de desarrollo lingüístico y matemátio para esta población. A continuación presentamos algunos signos básicos de los tres sistemas de numeración aludidos:
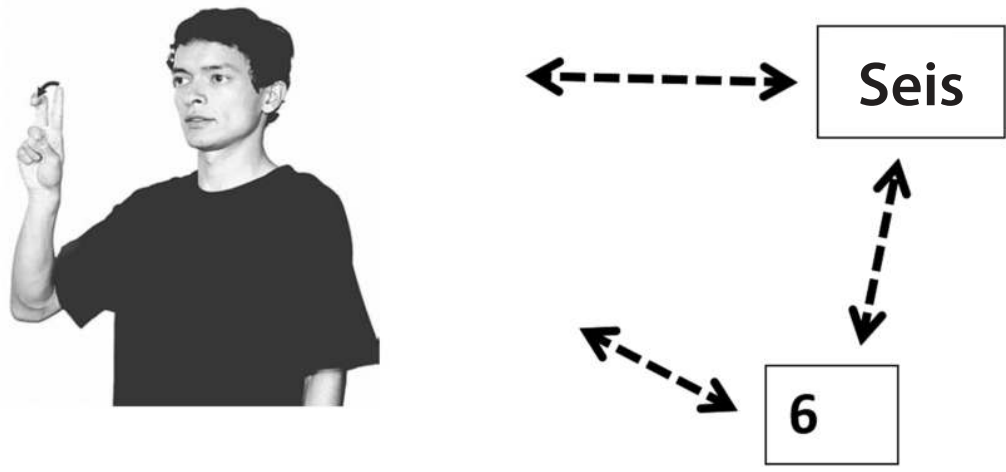

\section{Actividades sugeridas}

Recomendación: El taller para padres se debe enviar con mínimo una semana de anticipación a la clase en la que se van a implementar las actividades para los estudiantes, dando así la oportunidad y el tiempo para que puedan realizarlo y enviar los resultados sugeridos. Además, es importante disponer de un espacio para atender y orientar a los padres que lo soliciten. En la sesión con los estudiantes_se aconseja desarrollar las siguientes actividades: 


\section{1) ¿CÓMO CUIDAR LAS SEMILLAS?}

Se sugiere entregar a los estudiantes las imágenes tomadas de videos sobre el cuidado de semilleros, con el fin de que las observen y las agrupen, según los cuidados que deben proporcionar al SEMILLERO. Posteriormente, el profesor tomará cada lámina y los estudiantes señalarán en ella, o expresarán en LS, el tipo de cuidado que se destaca en la lámina. El profesor va agrupando las láminas según el tipo de cuidado señalado y, al final, puede sugerir que se conformen tres grandes grupos para ocuparse del mantenimiento del semillero, cuyas funciones serán:

i) Riego

ii) Luz y ventilación

iii) Crecimiento de las semillas.

Una vez confirmados los grupos, el profesor, junto con los estudiantes, revisarán en qué consisten las actividades de cada uno de esos grupos. Luego se asignarán un distintivo, de la siguiente manera: el dibujo de una gota de agua para el primer grupo de actividades, el dibujo de un sol para el segundo y, el de una flor para el tercero.

Se solicitará a los estudiantes que informen en qué momento del día es conveniente la realización de las actividades de cada grupo, empleando un almanaque como el que se propone en la sección de Actividades para Estudiantes. Con las respuestas de todos los estudiantes se acordará el mejor momento para hacer las actividades por grupos.

\section{2) ¡TODOS CUIDAMOS NUESTRO SEMILLERO!}

El profesor recuerda los grupos y sus funciones. Luego solicita a cada estudiante sacar una ficha de una bolsa en la que hay igual número de fichas que de niños (as). El color de ficha indica el grupo en el que estará el estudiante que sacó la ficha. Si el niño (a) no está conforme con su grupo, puede cambiarlo con otro compañero (a) que quiera hacer lo que le correspondió a él o a ella. Vale la pena que en este último caso, se justifique por qué no le gusta la función que le corresponde, según la ficha obtenida. Las funciones que se plantean para cada grupo son las siguientes:

Grupo gota de agua: Este grupo llevará el registro de humedad de la tierra. Todos los días a primera hora se debe observar el estado de la tierra: se mirará si presenta resequedad o exceso de humedad. Será necesario poner atención, en caso de identificar que se requiere regarla, controlando la cantidad de vasos de agua que gastan en el riego.

Grupo sol: Este grupo se encargará de registrar de las condiciones de lumi- 
nosidad, de frío o de calor del semillero. No es conveniente poner mucha luz solar o demasiado frío. Es más adecuado mantenerlo en un sitio caliente y alejado de las plagas; además puede cubrírsele en la noche y destaparlo en la mañana.

Grupo flor: Este grupo se encargará de llevar el registro del proceso de germinación. Los integrantes del grupo tendrán la misión de observar constantemente el semillero y estar atentos al surgimiento de los primeros tallos y del desarrollo de su altura.

En cuanto a la manera en que se puede registrar el cumplimiento de una función de un grupo, se propone que cuando cada equipo realice su tarea del día, dé a conocer a los demás equipos ese cumplimiento de alguna manera. Aquí se sugiere hacer el dibujo que represente el cumplimiento de la función y colocar en el recuadro blanco la fecha del día de la tarea, como se muestra a continuación ${ }^{48}$ :

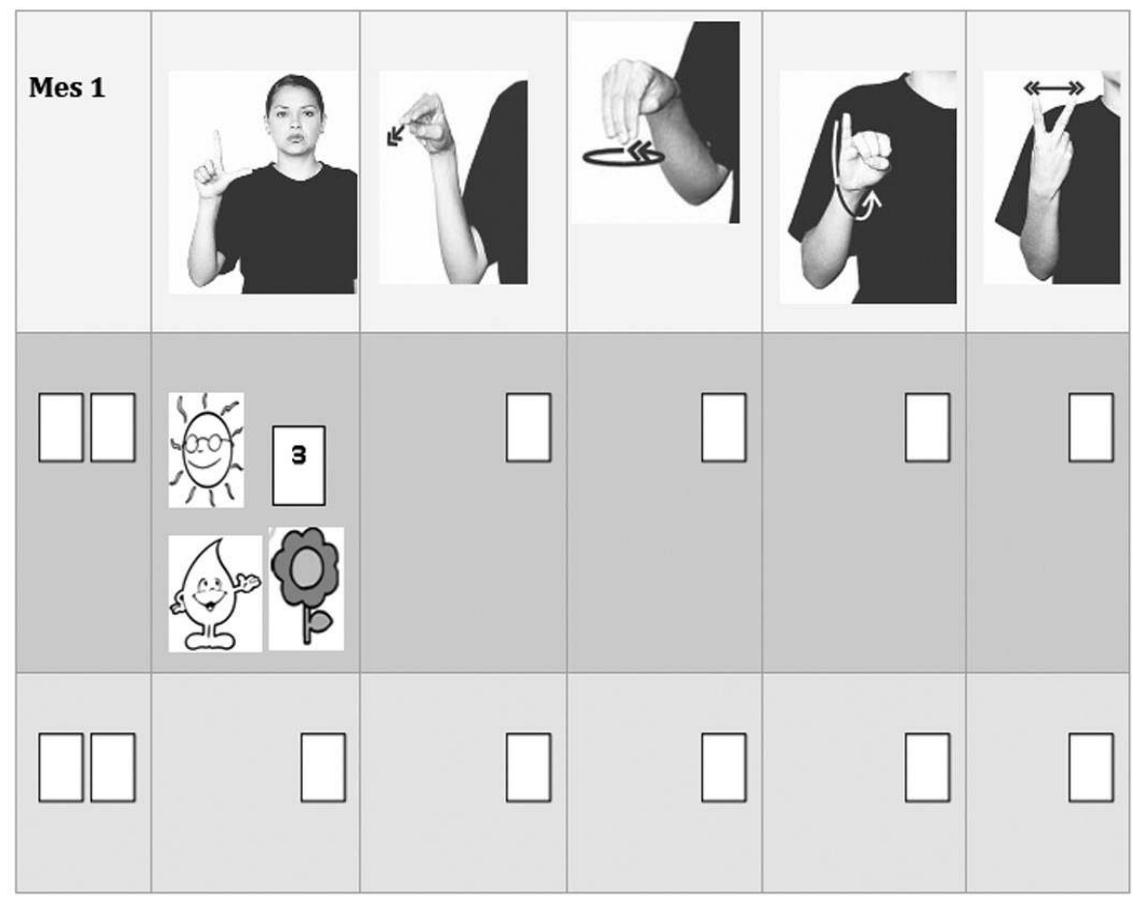

Imagen 9. Ejemplo.

La imagen 9 nos muestra que el día 3 se realizaron las funciones de cada grupo. Entre otras opciones para registrar en el almanaque, se pueden utilizar caritas felices o alguna figura que el equipo escoja.

48 Imágenes tomadas de: educared.org, conmishijos.com, sesamo.com 


\section{3) EL DIARIO DEL SEMILLERO}

Después de realizar la organización de los grupos, se sugiere al profesor elaborar carteleras como las siguientes y pegarlas en lugar visible, para apoyar a los grupos en sus registros:

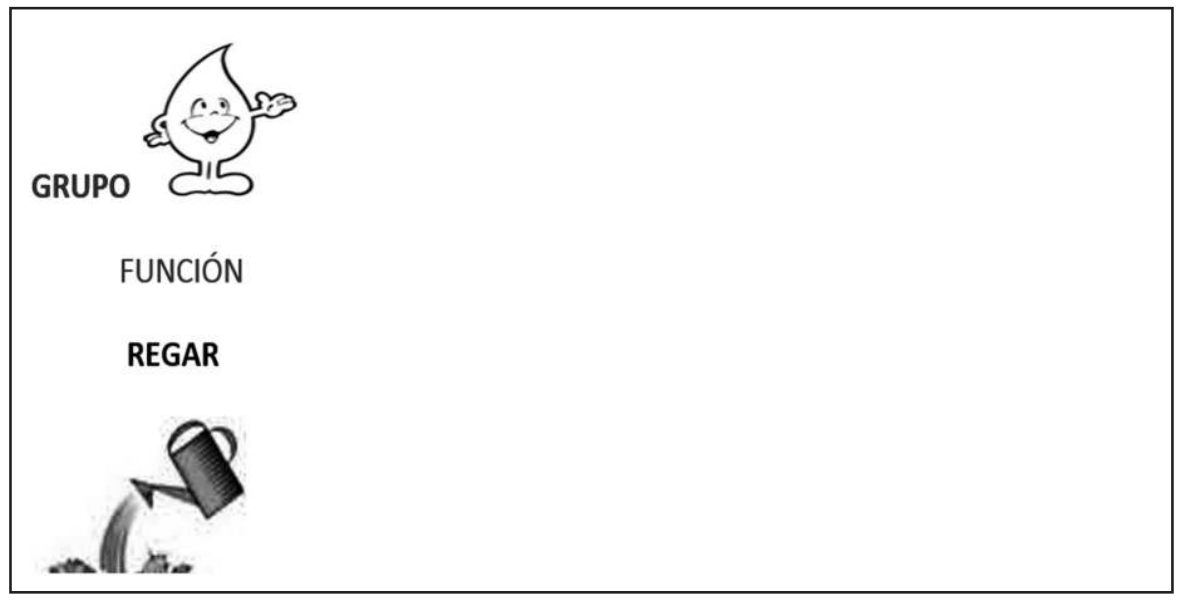

Esta manera sugerida para organizar las carteleras tiene en cuenta los siguientes elementos:

a. Función: es este lugar de la cartelera se coloca la seña que el docente considere tiene mayor relación con la función principal del respectivo grupo.

b. Integrantes: en este lugar se sugiere pegar las fotos de los integrantes de cada grupo marcadas en la parte de abajo con el nombre en español. Es aconsejable que, a medida que el profesor vaya pegando las fotos, comunique a los estudiantes cómo quedaron conformados los grupos. Si no fuera posible hacer esto simultáneamente, será importante informarlo posteriormente.

c. Lugar de registro: en este lugar cada grupo puede ir pegando el registro más reciente, según la realización de cada tarea. Por ello, deben ir reemplazando cada día el registro inmediatamente anterior. El profesor tendrá que recoger el registro reemplazado, para realizar su respectivo análisis y posterior archivo. Se sugiere que el docente tome decisiones sobre el tipo de registro más conveniente; por ejemplo, pueden estar basados en los dibujos que se sugieren en las actividades para estudiantes, propuestas en el presente taller y estar en concordancia con la función de cada grupo.

Para un manejo más fácil, es conveniente que la cartelera sea en cartón cartulina, pues este material se conserva mejor tras el pegado y despegado de cinta que se tendrá que realizar cada vez que se cambie el registro. 
A cada grupo se le puede entregar un registro como el siguiente para que cada uno registre los cambios que considere importante:

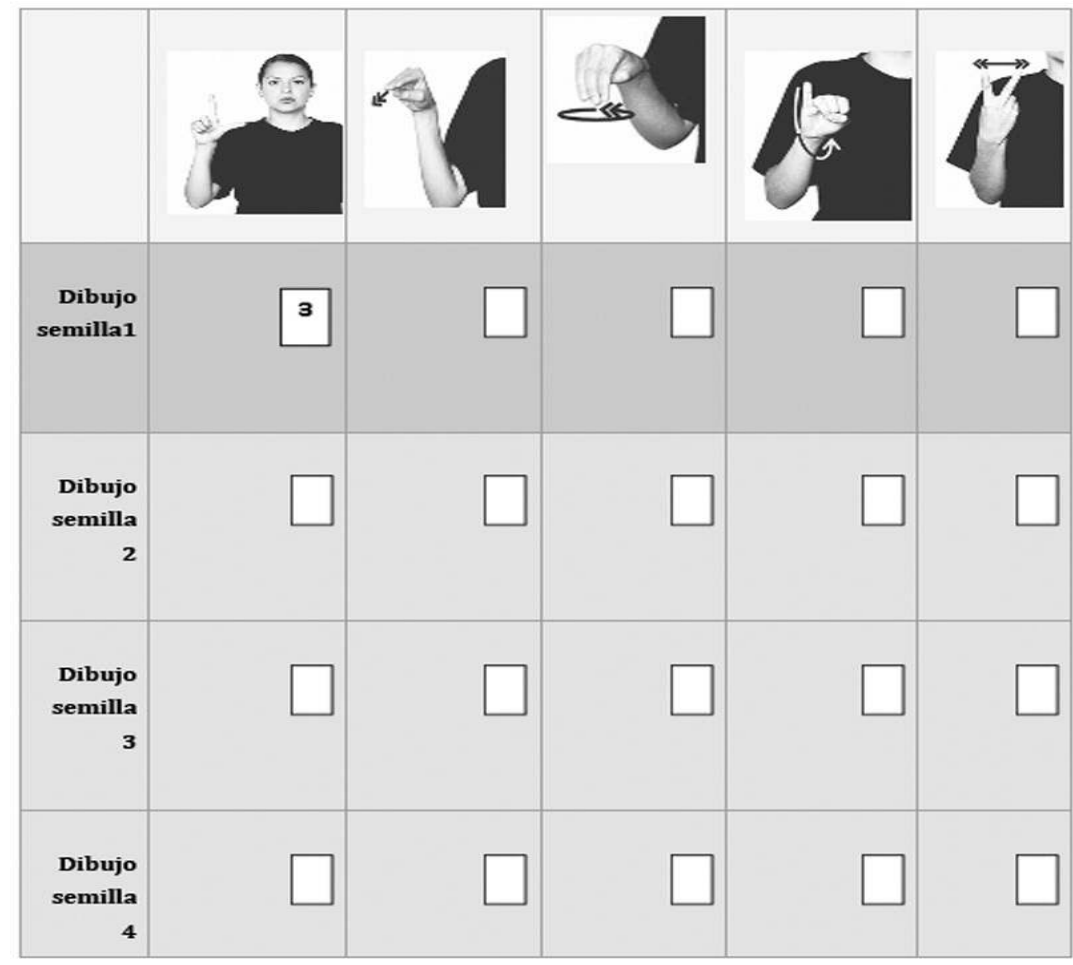

\section{Recomendaciones:}

- El profesor debe dar ejemplos a cada grupo y orientar el registro durante los primeros días, mientras los estudiantes aprenden la forma correcta de hacerlo. Se destaca la importancia de dichos registros en el trabajo posterior, pues la información que generan es rica en relaciones matemáticas y en formas de representación en lengua de señas, en español escrito y en otros registros; aspectos todos que constituyen las bases del desarrollo que se pretende con el proyecto de aula. Por ejemplo: más agua, menos luz, más grande, más tallos, entre otras.

- Para un buen desarrollo del proceso, el profesor tendrá que cuidar que se cumpla:

Designar en cada grupo el encargado de hacer el registro cada día, con el fin de que se turnen y de que no realice siempre la función el mismo integrante del grupo. 
$\checkmark$ Informar y recordar al grupo la necesidad de comunicar al profesor cualquier pregunta, inquietud o problema que se les presente. Los problemas que se pueden presentar en cada grupo podrían estar relacionados con:

- La cantidad de agua empleada.

- La no germinación de las semillas.

- El no crecimiento del tallo.

Entre otros...

Por lo anterior, es importante que el profesor tenga previstas las acciones que va a ejecutar, de acuerdo con los posibles problemas o inquietudes que se puedan presentar. De igual manera, es importante generar espacios de expresión de opiniones, de soluciones, de impresiones sobre la experiencia que se está llevando a cabo. Para ello se proponen algunas acciones como:

$\checkmark$ Leer, explicar y orientar las actividades para los estudiantes.

Acompañar algunas de las actividades relacionadas con el cumplimiento de las funciones.

$\checkmark$ Preguntar cómo va el proceso y la comprensión que se tienen de todos los momentos que van pasando.

Nota: es primordial que el profesor registre las reflexiones y consideraciones que le inciten las respuestas, acciones y observaciones de los estudiantes; también, archivar cada registro de los estudiantes, con el fin de tener a disposición este material para analizar con los niños (as) o para la evaluación. Para ello se puede disponer de un cuaderno de registro y se debe estar atento a cada suceso de la clase y a los comportamientos de los niños (as). Si es posible, se sugiere recopilar imágenes fotográficas o videos; esta forma de registro es más completa para el caso de niños (as) sordos (as).

\section{Materiales:}

d. Almanaque

e. Carteleras de los grupos

f. Guías de trabajo

g. Colores y marcadores

h. Materiales del semillero

Tiempo: tres sesiones de máximo una hora cada una. 


\section{B. ACTIVIDADES PARA LOS PADRES DE FAMILIA}

Presentación. Cuando una persona está a cargo de una planta, se hace necesario cuidar distintos aspectos como: la luz que le conviene, la temperatura adecuada, la cantidad de agua que necesita, el proceso de germinación de las semillas. En general, si queremos obtener plantas saludables, es importante cuidar todo el proceso, desde las semillas hasta el crecimiento y mantenimiento de las plantas.

Actividad. Si ustedes tienen una planta en su casa, pueden encargar a su hijo (a) de regarla; para ello es necesario explicarle cuándo hay que regarla y qué cantidad de agua requiere. También será importante darle a conocer por qué se eligió el lugar de la casa en que se colocó. Intente hacerlo en lengua de señas o mostrándole cómo se hace y luego acompáñelo (a) a realizar esta labor. Es importante que el niño (a) se sienta involucrado (a) en esta responsabilidad y tome conciencia de cómo cada persona puede aportar para cuidar las plantas y de cómo las plantas benefician a las personas y al entorno. Ofrezcan a su hijo (a) el nombre de la o las plantas que tiene (n) en su casa y traten de que se obtenga el nombre en lengua de señas y en español. Si es el caso, se pueden elaborar un cartelito con estos datos y pegarlo en la matera o cerca de la planta.

Otra actividad consiste en visitar con su hijo (a) jardines donde estén creciendo plantas pequeñas. Durante el paseo, pueden observar en el vecindario qué tipos de plantas son las más cultivadas, cuáles están cuidadas y cuáles están deterioradas. Enséñele los signos de que la planta está sana y cuidada o de que está descuidada.

Proponemos el siguiente registro de las salidas o del cuidado de la planta de la casa. No olviden enviar esos registros al profesor, para guardarlo en el diario del niño (a). Si el padre o la madre no pueden acompañar al niño en la salida, se sugiere buscar un familiar adulto que lo acompañe y le colabore en hacer el registro, en compañía de los padres. 
En la casilla que está al lado de las fotos y los nombres de las plantas, colocar una X por cada tipo de planta que recuerden haber visto durante la salida a observar plantas. En la siguiente casilla dibujar o escribir algún cuidado que necesite la planta.

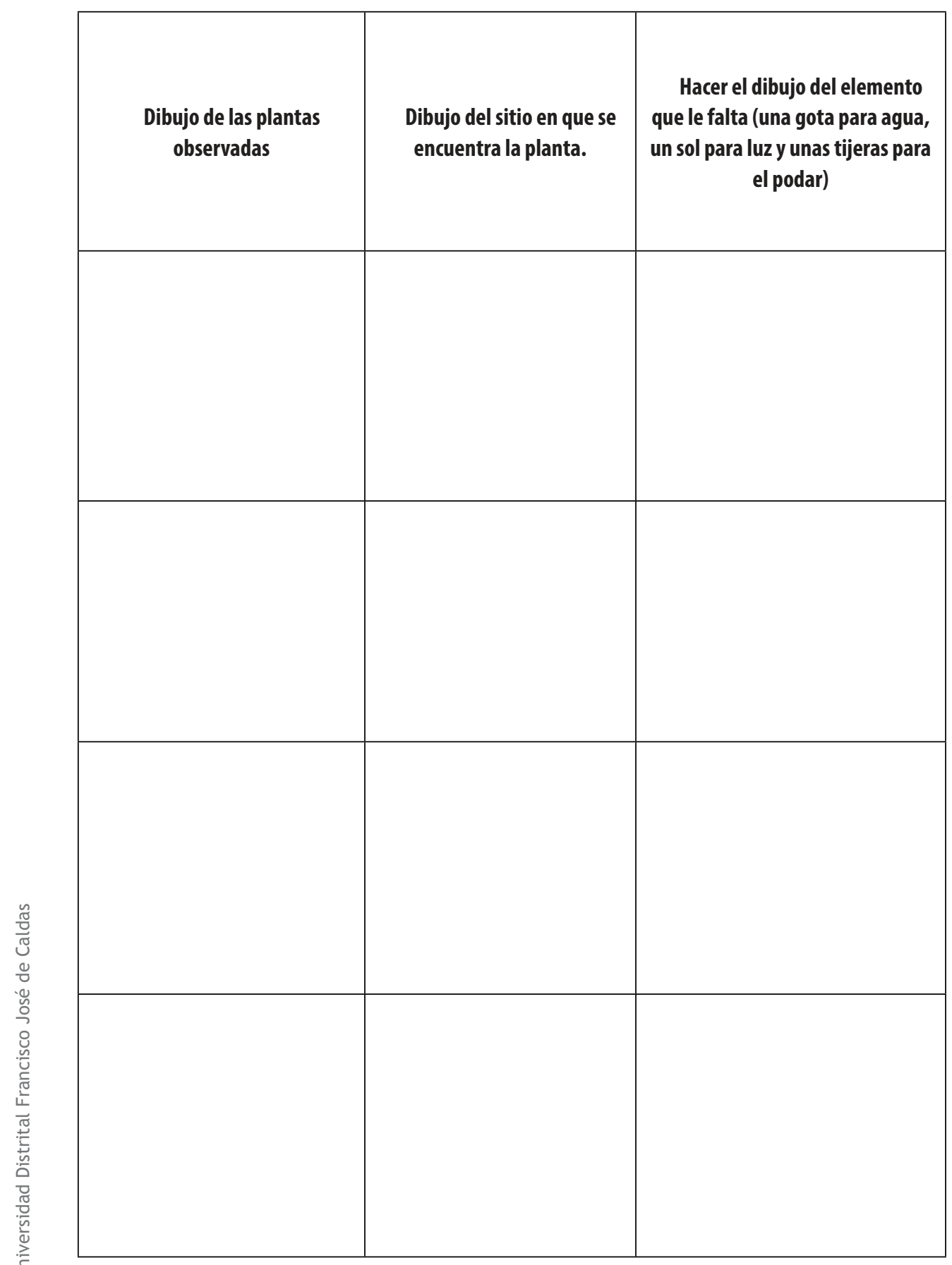




\section{ACTIVIDADES PARA LOS ESTUDIANTES}

Actividad 1: Observar y agrupar las láminas, según los cuidados que deben tenerse con el semillero.
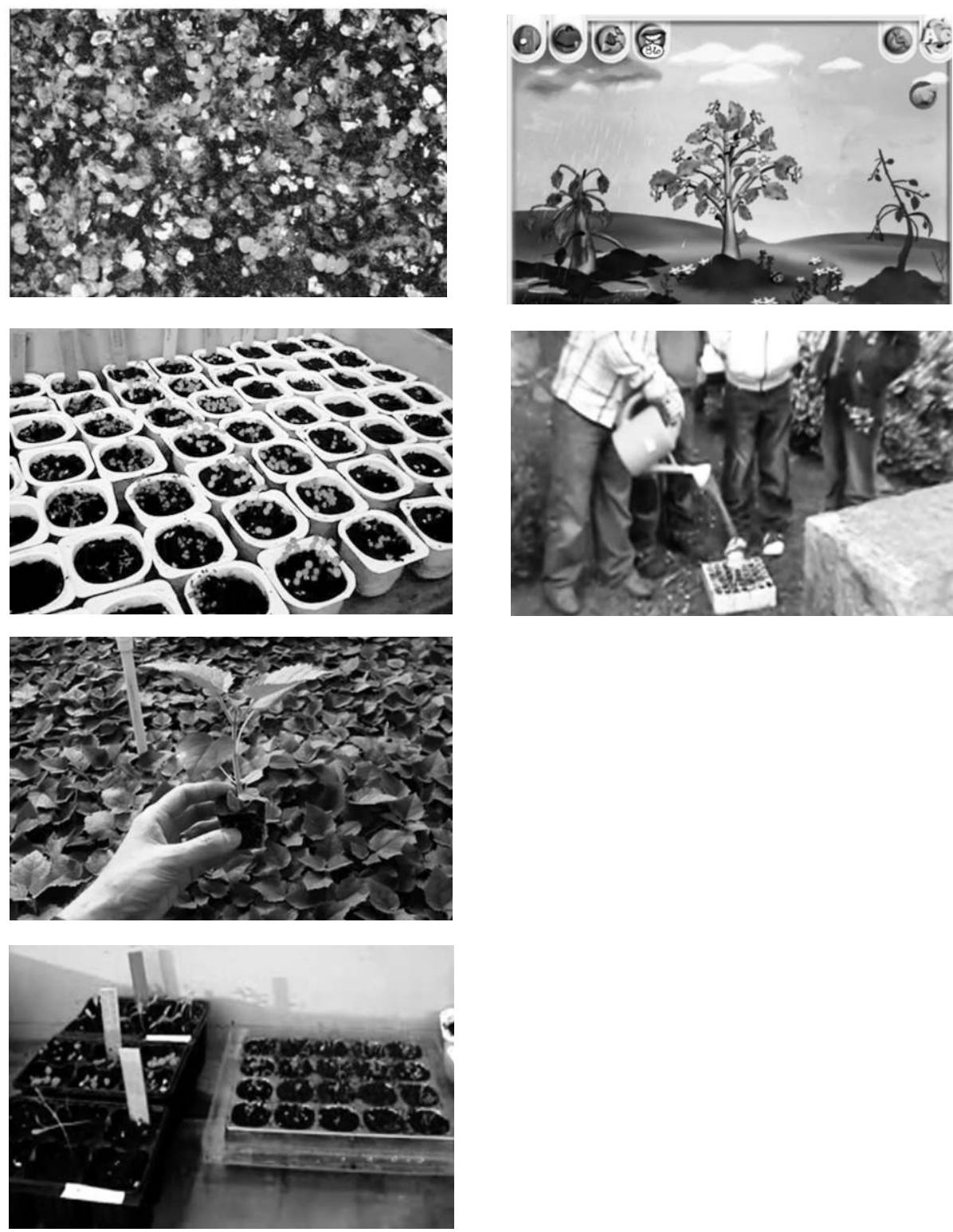
Actividad 2: Usa el distintivo de tu grupo, para indicar el momento del día más conveniente para hacer las actividades de cuidado que le corresponden a tu grupo.

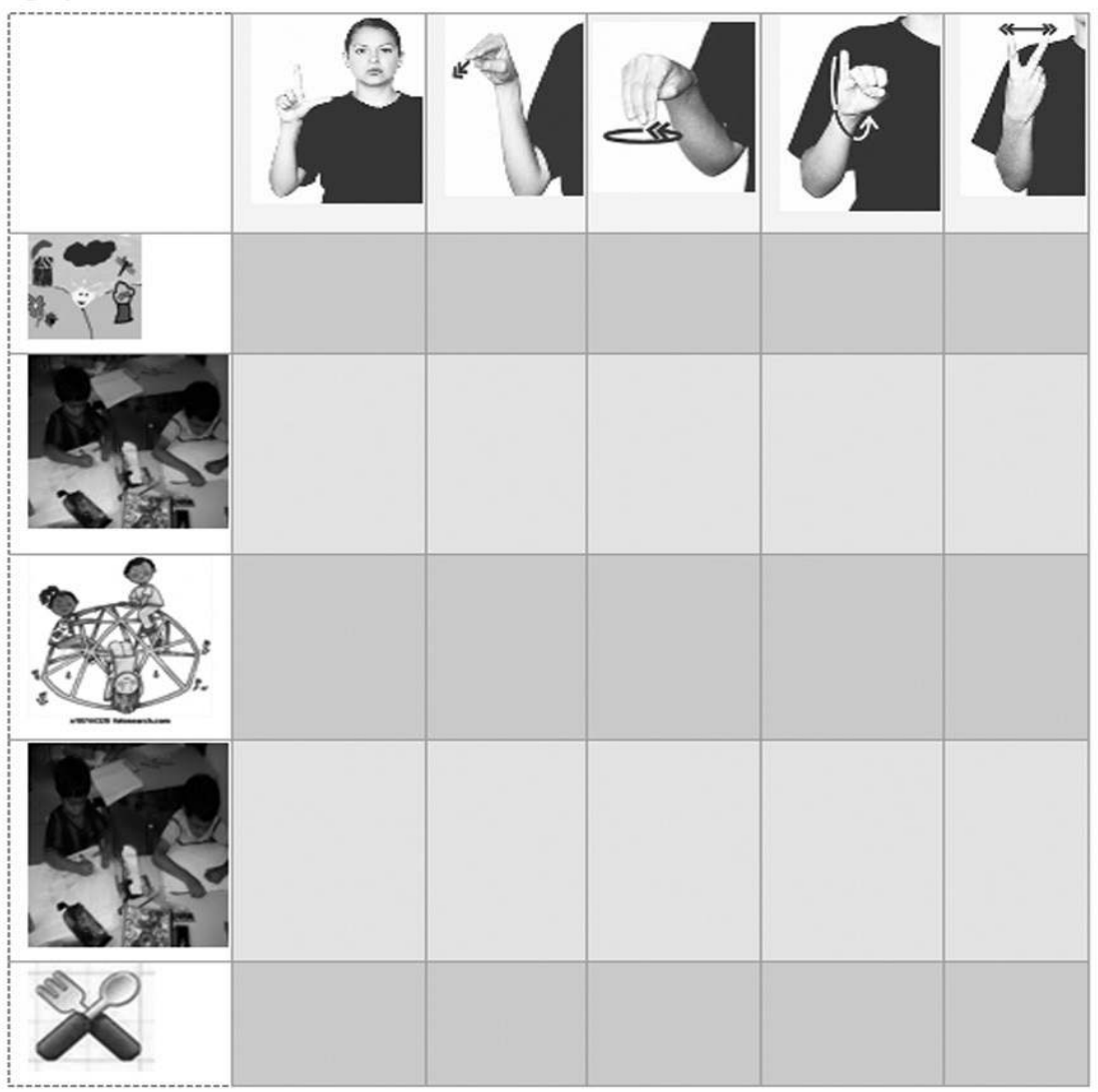

Actividad 3. Marcar con el distintivo del grupo y los nombres de los integrantes el almanaque entregado al grupo para hacer los siguientes registros:

Grupo gota: Días de riego y cantidad de agua.

Grupo sol: Días de protección para calor y días de descubrimiento para luz.

Grupo flor: Día de germinación y seguimiento al crecimiento de los tallos de cada semilla. 
Actividad 4. En el siguiente espacio dibuja la planta que más te gusta de las que has visto. Pon la seña debajo del dibujo. Escribe su nombre en español.

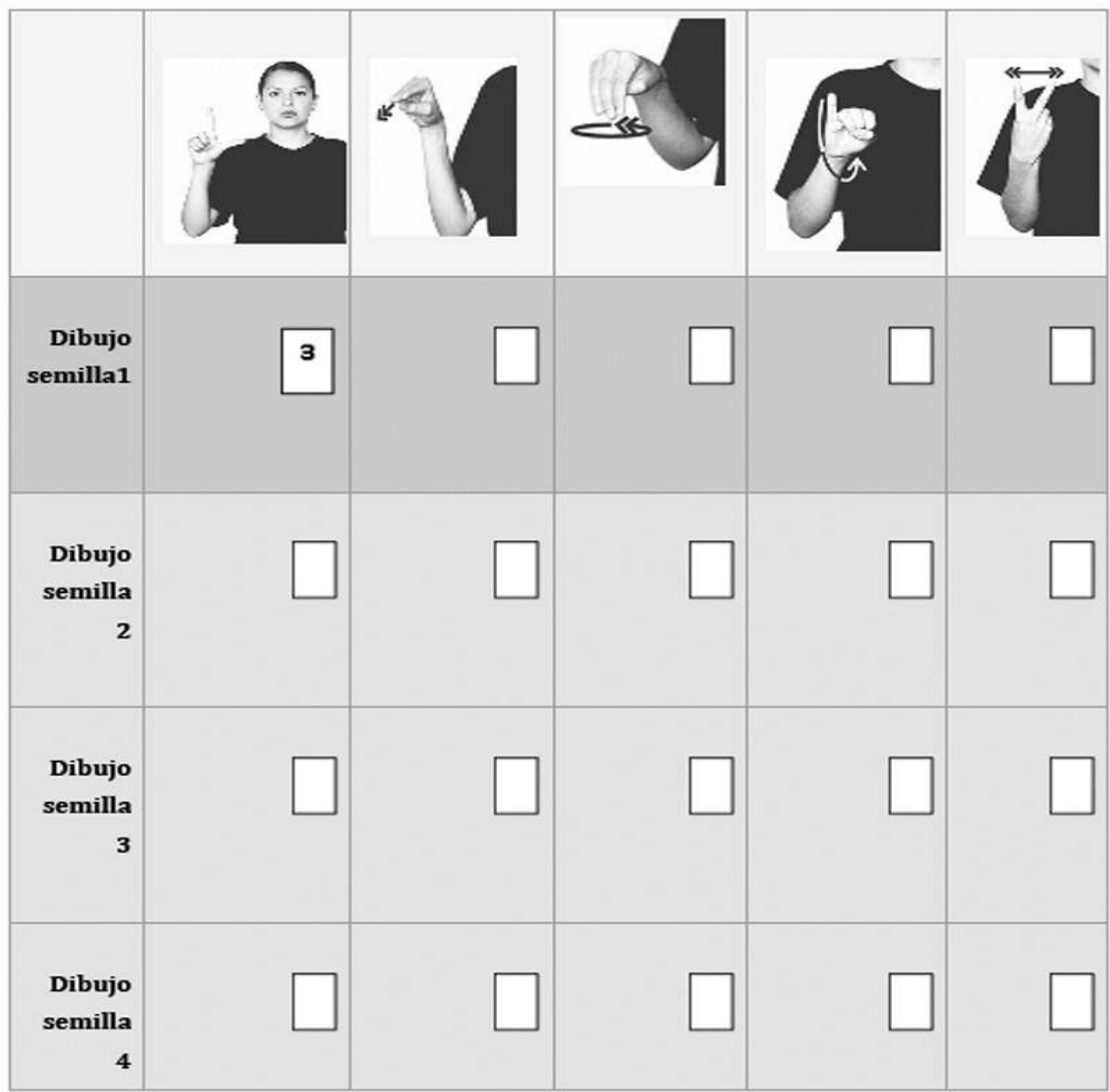

*Presenta, en una lista, tres cualidades de tu planta (color, propiedad, tamaño...) y tres cuidados que debes tener con ella. Presenta tu planta a tus compañeros.

\section{ACTIVIDADES DE EVALUACIÓN PARA LOS ESTUDIANTES}

\section{Actividad}

Grupo gota: Tomar el almanaque de registro y presentar la cantidad total de vasos de agua gastados. Buscar la palabra en español para esa cantidad y deletrearla.

Grupo sol: Tomar el almanaque de registro y presentar la cantidad de días en que se tuvo que cubrir el semillero y la cantidad de días en que permaneció destapado. Buscar la palabra en español para esa cantidad y deletrearla. 
Grupo flor: Tomar el almanaque de registro y presentar la cantidad de días que gastó cada semilla para germinar. Buscar la palabra en español para esa cantidad y deletrearla.

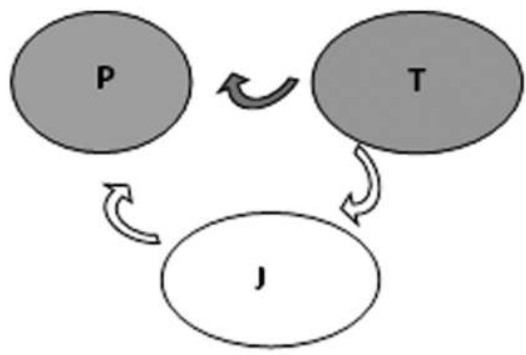

FASE 3: EL CRECIMIENTO

DE LASPLANTAS Y LAS LOMBRICES

CRECIMIENTO

TALLER 3: CONSTRUYENDO

HISTORIAS SOBRE NUESTRAS

LOMBRICES Y NUESTRO SEMILLERO

\section{A. ORIENTACIONES PARA EL PROFESOR}

\section{Objetivos}

- Promover el desarrollo de la narratividad en los estudiantes, a través de la construcción colectiva de historias.

- Ampliar el campo semántico y lexical de los micromundos de la aproximación y de la precisión en lengua de señas colombiana (LSC) y en español como segunda lengua.

- Desarrollar conciencia del cuidado del semillero y del lombricultivo.

Presentación. El presente taller pretende consolidar los conocimientos desarrollados durante el Proyecto de Aula, relacionados con la construcción del semillero y del lombricultivo, a través de un desarrollo lingüístico-discursivo del campo léxico surgido a lo largo de las tres fases, en relación con los micromundos de la aproximación y de la precisión. Partimos de la consideración de que un desarrollo del conocimiento (en este caso matemático) también es un desarrollo del lenguaje (Calderón, 2010; León, 2006; Calderón, 2005; Pimm, 1990) y, a la vez, el lenguaje como condición humana de significación y de comunicación, alcanza mayores desarrollos en tanto permite una evolución de las condiciones discursivas de los sujetos en los distintos campos de saberes y de prácticas socio-culturales. Es decir, en tanto cada individuo logra avanzar en la comprensión y apropiación de las prácticas socio-discursivas relacionadas con los contextos sociales en los que participa a lo largo de la vida. Así, se considera que la experiencia social del individuo resulta fundamental para el desarrollo de su pensamiento, de su conocimiento y, con ellos, del lenguaje y de los lenguajes (Vigotsky, 1987, 1993; Oléron, 1985; Rogoff, 1993). 
En la perspectiva anterior, el papel de las lenguas en la formación de los sujetos en fundamental. La lengua natural representa la posibilidad de la experiencia lingüística, simbólica, interaccional y cultural de la acción humana, con miras a la elaboración de significados y de sentidos sobre el mundo y a la generación de las formas de las relaciones sociales en las distintas esferas de la comunicación humana (Bajtín, 1982). El desarrollo del lenguaje, a través de las lenguas y su discursividad, implica la apropiación y el uso de las reglas de producción sintáctica, semántica y pragmática de los discursos y de los registros y de las lógicas socioculturales de las interacciones, desde un punto de vista polifónico y dialógico (Bajtín, 1982/1998; Martínez, 2004; Calderón, 2005, 2010).

En este sentido, se hace necesario identificar y desarrollar, tanto para los estudiantes como para los profesores, los modos discursivos propios del aula y los que se desarrollan en los campos particulares de conocimiento, como en este caso el de las matemáticas escolares (Calderón, 2009). Así, desarrollar competencias para la lectura, la escritura, la oralidad y la escucha, en contextos académicos (en este caso matemático); aumentar el repertorio léxico relacionado con la matemática escolar; aprender y diferenciar la producción de narrativas, explicaciones, justificaciones, etc., a cerca de lo matemático, resulta ser un imperativo para el desempeño socio-cultural del estudiante de matemáticas.

En el presente taller haremos hincapié en el papel de la narratividad como experiencia básica que permite al sujeto, y en especial al niño (a) situarse en el mundo y frente al mundo (Bruner, 2004). El yo que narra es el yo que ve el mundo, que captura su discurrir, su dimensión evenimencial (eventos que ocurren y transcurren), que reconstruye ese discurrir y puede tomar distancia de él. En el caso de los niños (as), la experiencia narrativa se convierte en la instancia de la reconstrucción de la experiencia; en la posibilidad de la ficción y de la creación de nuevos mundos; y, en una perspectiva didáctica, en el espacio de la evidencia de las comprensiones del niño (a) y de los modo (s) en que se relaciona con el mundo.

Las posibilidades discursivas, de tipo descriptivo y de tipo narrativo en el niño (a) evolucionan en la medida que desarrolla experiencias con el mundo circundante $y$, en ellas, comienza a indagar por aquellas cosas o fenómenos que desconoce y que le gustaría descubrir. Estas manifestaciones de inquietud hacia lo desconocido y el descubrimiento de lo cotidiano, llevan al niño (a) a ampliar su campo lexical enunciativo de su lengua natural para expresar: gustos y estados de ánimo; opiniones y certezas; interrogantes, que surgen sobre el mundo que le rodea. Las preguntas por: "el por qué de las cosas" o el "cómo se hace", son comunes en las primeras etapas de la vida; posteriormente se generan usos de la lengua orientados a generar enunciados para funciones más complejas como el dar razón de, elaborar respuestas a preguntas, comparar situaciones, proponer, inventar, etc. 
Así, relatamos nuestras experiencias empleando la expresión natural de nuestra lengua primera (oral o en lengua de señas); también podemos contar historias de otros (reales o ficticias). Otra alternativa es escribir nuestras vivencias, por ejemplo en un diario (cuando no queremos que sean escuchadas por nadie más que nosotros mismos). Podemos escribir una carta para otra persona, contando muchas, o pocas, historias, solicitando algo, proponiendo algo.... Otro ejemplo de formas de narración es el cine mudo. En esta forma de contar no se necesitan palabras; tan sólo imágenes para relatar un evento o para describir una situación, bien sea cómica, dramática o trágica. Así pues, la narración no sólo se realiza a través de la construcción de una historia con palabras; también puede desarrollarse a través de imágenes, configurando la linealidad y la secuencialidad de los eventos, que pueden ser contadas de la manera en que el narrador lo elija.

Cuando nos encontramos ante personas sordas, observamos que el acto narrativo se da de manera natural como en la lengua oral. La lengua de señas será el recurso más claro y más natural de contar historias. Ella, como cualquier lengua, tiene el potencial de contar y de permitir al sujeto desarrollar una discursividad narrativa, de construir relatos y de incorporar múltiples experiencias del sujeto-narrador, empleando distintos modos y recursos de contar historias. Por ejemplo, comenzar por el final para impactar al escucha; o comenzar por la mitad para aproximar al lector - espectador o tele - audiencia a lo sucedido; saltarse $u$ omitir aspectos que consideramos irrelevantes o de poca importancia, es otro modo de contar historias. Todas estas decisiones son dominio del narrador, del que cuenta la historia, según su intencionalidad narrativa; es decir, qué pretende lograr con lo narrado.

En general, el desarrollo de este taller sitúa la experiencia del proyecto de aula en el ámbito de la reconstrucción y de la creación de lo vivido con el lombricultivo y el semillero, con miras a potenciar un desarrollo de las lenguas (de señas y español escrito) en los niños (as). Para el desarrollo de este proyecto de aula el acto narrativo se convierte en un factor fundamental que pondrá en evidencia la comprensión de la aproximación y de la precisión de la cantidad.

\section{Actividades sugeridas}

\section{Recomendación:}

En el primer taller de la fase 1 del proyecto se le recomendó al profesor hacer un registro fotográfico de todo el proceso con los niños (as), en los talleres anteriores se tomaron varios tipos de registro de los procesos realizados. Este taller requiere que se organice esa información para retomarla con padres y estudiantes.

El taller para padres se debe enviar con mínimo una semana de anticipación a la clase en la que se van a implementar las actividades para los estudiantes, dando así la oportunidad y el tiempo para que puedan realizarlo y enviar los 
resultados sugeridos. Además, es importante disponer de un espacio para atender y orientar a los padres que lo soliciten. En la sesión con los estudiantes se aconseja desarrollar las siguientes actividades:

\section{1) ¡RECONSTRUYO MI EXPERIENCIA CON EL LOMBRICULTIVO!}

- Momento uno: ¡construyo mi friso!

El profesor entrega a cada niño (a) hojas grandes de papel bond o cuartos de cartulina, con divisiones de cuadrados y colores, crayolas o tijeras. Entrega fotos en las que aparece el niño (a) haciendo el proceso. Entrega copias de los registros de actividades de cada niño (a) realizadas en el salón o con los padres. Pregunta a los estudiantes si les gustó hacer el lombricultivo y si les gustaría contar a otros niños (as) cómo los hizo. Con base en las respuestas, les pide realizar una historieta, con el material que les entregó, formando la secuencia de cómo hizo o cómo participó en la construcción del lombricultivo. Como ejemplo de una reconstrucción de la historia con registros tenemos:

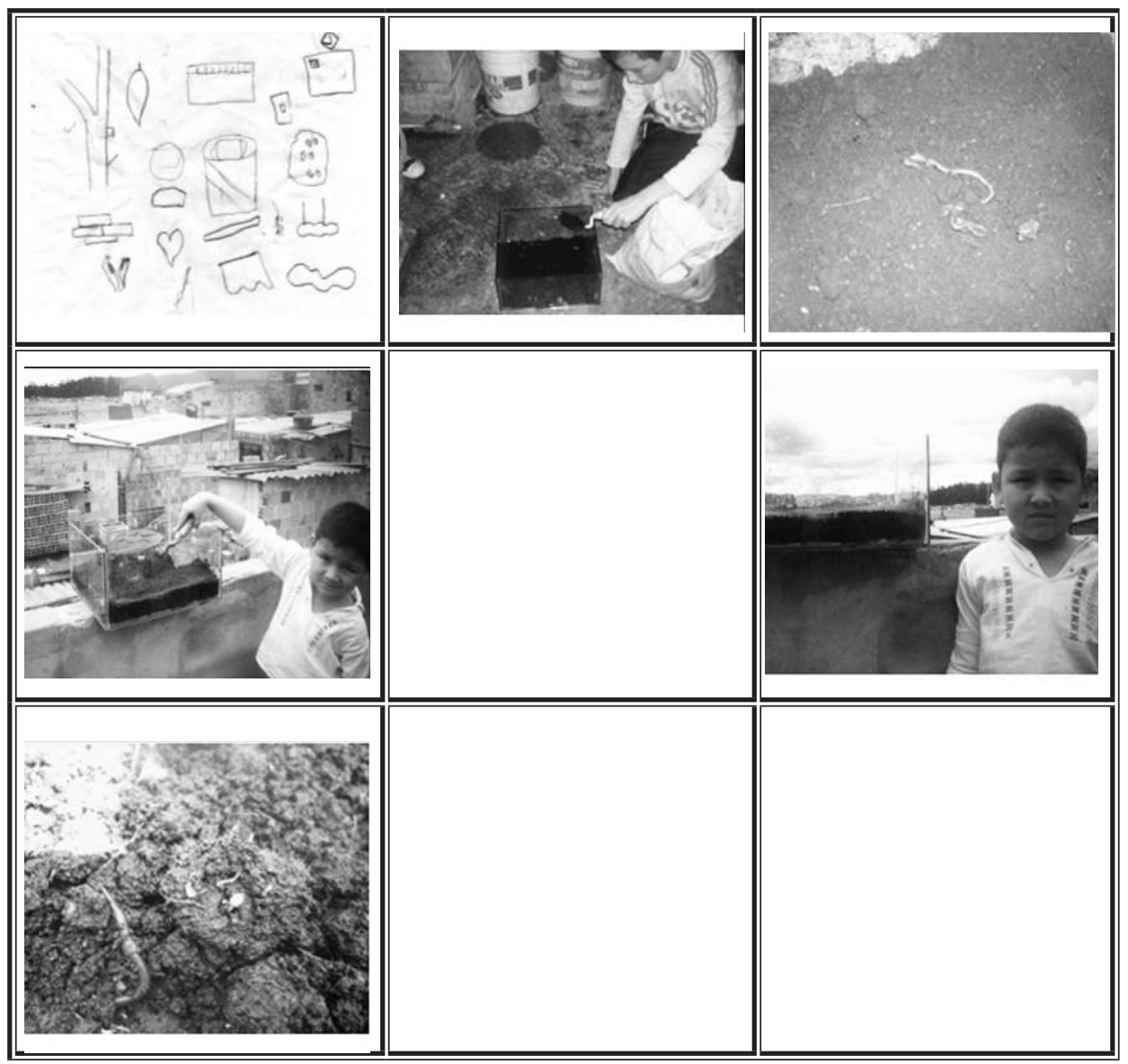


- Momento dos: ¡presento mi friso!

Una vez terminado el dibujo o el friso, cada niño (a) presenta su friso contando su historia. Se recomienda al profesor grabar en video estas intervenciones. Los demás estudiantes pueden preguntar o pedir aclaraciones y expansiones de lo narrado. El profesor aprovechará para llamar la atención sobre el uso de la lengua de señas colombiana (LSC) en la reconstrucción de los hechos (uso de verbos, descripciones, léxico, etc.) y observar la comprensión del proceso, las emociones del niño (a).

- Momento tres: ipongo un nombre a mi historia!Una vez han presentado su historia todos los niños (as), el profesor les pide poner un nombre a su historia y ayuda a los niños (as) a escribir ese nombre o expresión en la parte superior del dibujo, a manera de título. Trata de explicar a los estudiantes que el título ayuda a saber de qué se trata la historia.

\section{2) ¡RECONSTRUIMOS NUESTRA EXPERIENCIA CON EL SEMILLERO!}

- Momento uno: ¡construimos nuestro friso!. El profesor conforma los grupos que se formaron para el taller 2 y entrega a cada grupo hojas grandes de papel bond o cuartos de cartulina, con divisiones de cuadrados y colores, crayolas o tijera. Entrega fotos en las que aparece cada niño (a) haciendo el proceso. Entrega copias de los registros de actividades del niño (a) realizadas en el salón o con los padres. Pregunta a los grupos si les gustó hacer el semillero y si les gustaría contar a otros niños (as) cómo hicieron o cómo participaron. Con base en las respuestas, les pide realizar una historieta, con los materiales entregados, formando la secuencia de cómo hicieron o cómo participaron en la construcción del semillero.

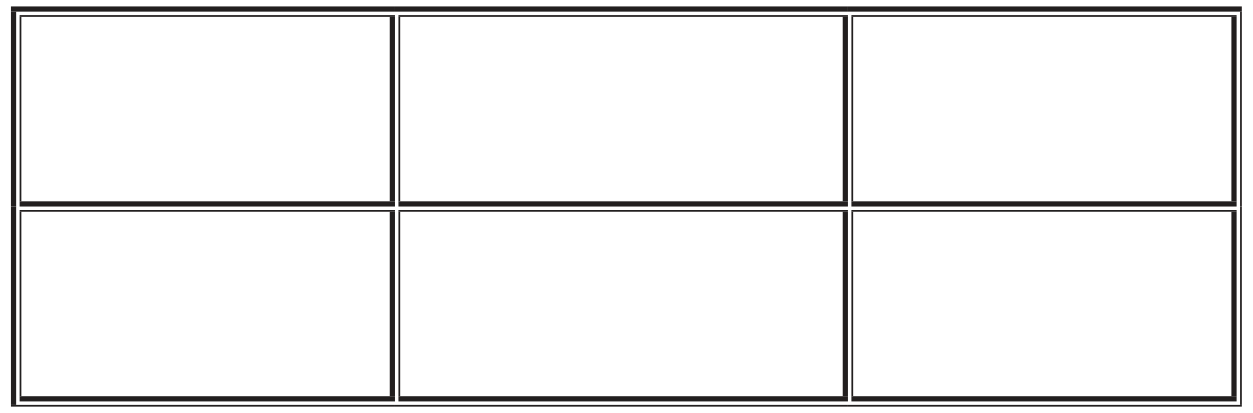

- Momento dos: ipresentamos nuestro friso!. Una vez terminado el dibujo o el friso, cada grupo presenta su friso contando la historia obtenida. Se recomienda que participen todos los integrantes en la narración y que el profesor grabe en video estas intervenciones. Los demás estudiantes pueden preguntar o pedir aclaraciones y expansiones de lo narrado. El profesor aprovechará para llamar la atención sobre el uso de la lengua de señas colombiana (LSC) en la reconstrucción de los hechos (uso de verbos, descripciones, léxico, etc.) y 
observar la comprensión del proceso, las emociones de los niños (as), el nivel de trabajo en equipo...

- Momento tres: iponemos un nombre a nuestra historia!. Una vez todos los grupos han presentado su historia, el profesor les pide poner un nombre a su relato y ayuda a los niños (as) a escribir ese nombre o expresión en la parte superior del dibujo, a manera de título. Trata de explicar a los estudiantes que el título ayuda a saber de qué se trata la historia.

\section{3) ¡INVENTEMOS UN CUENTO!}

El profesor prepara con anterioridad un ambiente para contar cuentos: la hora del cuento. Organiza a los niños de manera circular, sentados en el piso y con un libro de cuentos en el centro. Se recomienda que el libro tenga buenas ilustraciones. Adicionalmente ha colocado los frisos de las actividades anteriores en las paredes del salón.

Como entrada al ejercicio de contar cuentos, el profesor lee a los niños (as) un cuento que trate de animales. Se recomienda seguir la lectura del cuento con los ojos y contar en LSC lo que lee. Una vez terminada la lectura, pregunta por el cuento: ¿qué pasó en esta historia?, ¿cuántos personajes aparecen?, ¿en dónde se realizaron los hechos o dónde ocurrió?, ¿por qué creen que pasó eso?, ¿les gusta la historia o preferían que pasara otra cosa?...

Posteriormente, y con base en los frisos construidos anteriormente, invita a los niños (as) a inventar una historia, de manera colectiva; propone que se trate de las lombrices y del semillero. Pide que, a medida que cada niño (a) interviene, el siguiente trate de continuar la historia. El profesor aprovechará para llamar la atención sobre el uso de la lengua de señas colombiana (LSC) en la construcción de los hechos (uso de verbos, descripciones, léxico, etc.) y observar la comprensión de la propuesta de contar historias, las emociones de los niños (as), el nivel de trabajo en equipo...

Nota: es primordial que el docente registre las reflexiones y consideraciones que le inciten las respuestas, acciones y observaciones de los estudiantes; también, grabar en video todos los momentos, con el fin de evaluar el resultado con los estudiantes y de tener a disposición este material para analizar el desarrollo lingüístico-discursivo de los niños (as) y, en especial el ejercicio narrativo y el uso de léxico referido a los micromundos de la aproximación y de la precisión. Para ello se puede disponer de un cuaderno de registro y se debe estar atento a cada suceso de la clase y a las expresiones de los niños (as).

\section{Materiales:}

- Hojas grandes de papel bond o cuartos de cartulina

- Colores o crayolas 
- Guías de trabajo

- Cuentos infantiles o juveniles.

- Diccionarios o lexicones

- Fotos o registros de talleres anteriores elaborados por los niños o por los padres de los niños.

Tiempo: tres sesiones de máximo una hora cada una.

\section{B. ACTIVIDADES PARA LOS PADRES DE FAMILIA}

Presentación. Esta actividad es muy importante para el desarrollo de su espacio de comunicación con su hijo (a). Narrar o contar cuentos a los niños (as) es un de las principales experiencias de la relación padre-hijo. Recuperar la historia del niño (a), de los hermanos (as), de los padres, tíos o abuelos, contribuye a que se consolide una valoración personal y del la familia. En este tipo de contacto familiar, el adulto construye una relación afectiva, comunicativa y cognitiva con el niño (a), quien se siente importante para su padre o madre, se sabe incluido en el ámbito de la vida de los padres; conoce sobre historias pasadas, reales o ficticias; aprende sobre los comportamientos y las actitudes humanas; inicia una sensibilidad sobre el acto de crear historias.

Actividad. Sugerimos recopilar historias de los abuelos, o de las personas mayores que involucren fotografías, cartas, vestidos u objetos que son significativos para la familia y para el niño (a). Realizar una reunión familiar para ver fotos. La idea es que varias personas participen mostrando fotos y recordando anécdotas relacionadas con ellas. Se sugiere tratar de emplear lengua de señas (LSC) o representaciones con el cuerpo y con los movimientos y los gestos, de tal manera que el niño (a) logre comprender de qué se tratan las historias vinculadas a las fotos. También pueden ver juntos una película o un video de cuentos.

Cuando terminen la hora de contar historias viendo fotografías, pregunten al niño (a) cuál historia y cuál fotografía le gustó más. Realicen un juego elaborando una secuencia tipo friso que recoja una historia de la familia. Al final, pídale a su hijo (a) poner un nombre a su historia. Ayúdele a escribir como título en su friso y póngalo como un afiche en su habitación.

Elaboren con su hijo (a) una o varias secuencias de fotos que muestren alguna historia familiar o alguna secuencia de momentos importantes para el niño (a). Pueden observar la historia de un niño (a) desconocido (a) que se presenta a continuación y después realizar varias historias de la familia empleando las fotografías. 


\section{HISTORIA FAMILIAR DE UN NIÑO DESCONOCIDO}
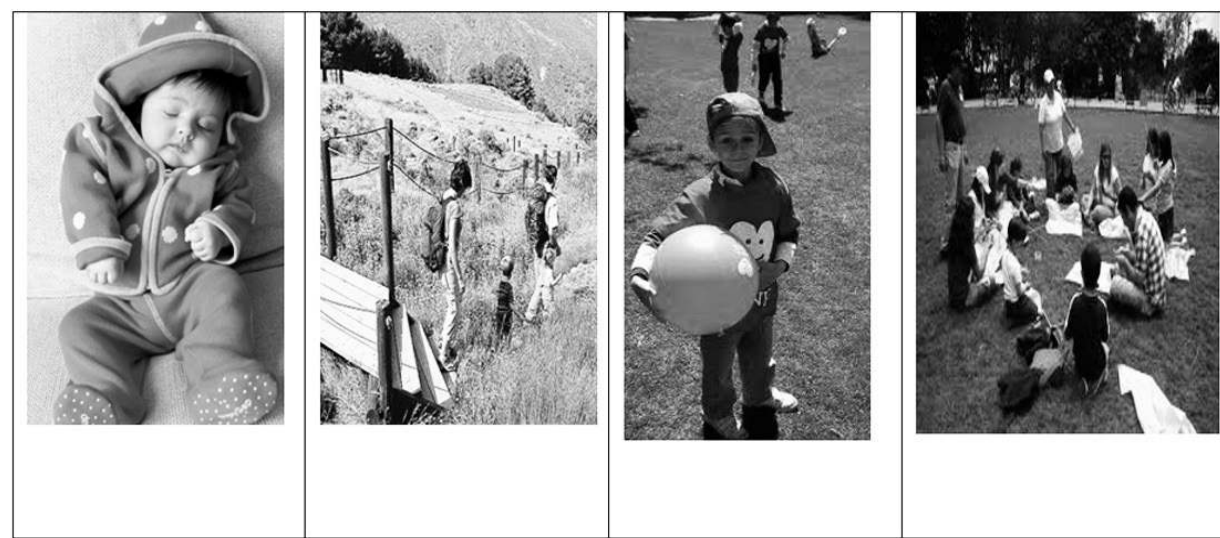

MOMENTOS DE LA HISTORIA FAMILIAR DE

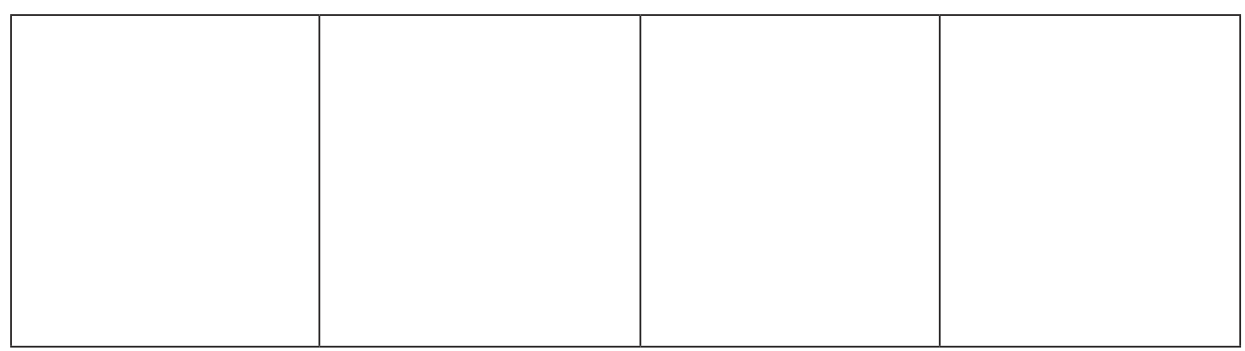

Historia de:

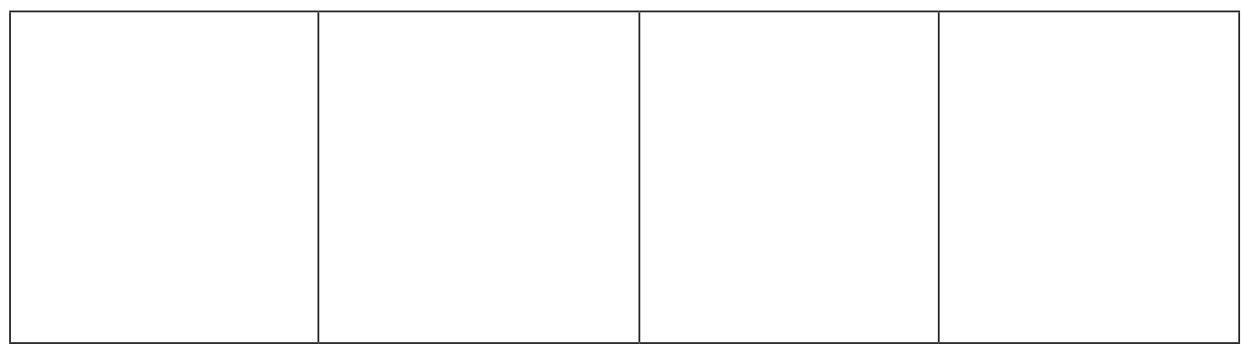

Historia de:

\section{ACTIVIDADES PARA LOS ESTUDIANTES}

CREANDO HISTORIAS. Esta actividad comprende la creación colectiva o individual de historias narradas. Para ello es necesario el desarrollo previo del siguiente material: 
a). Ordenación de secuencias: El profesor entregará a los niños la siguiente instrucción:

Ordena la secuencia, utilizando los números de uno a tres, según el orden que creas conveniente:
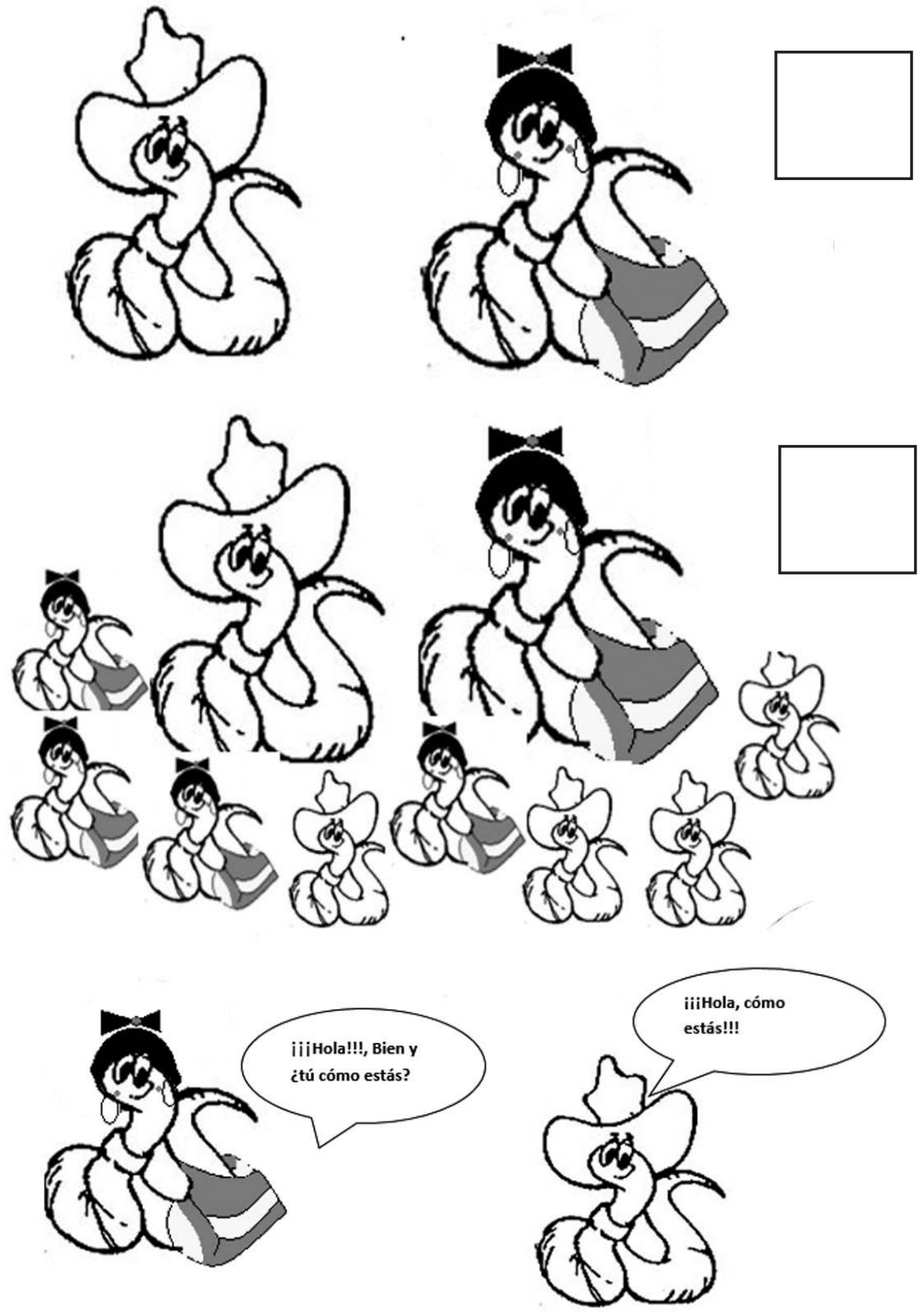
Partiendo del resultado del ejercicio anterior y teniendo en cuenta las respuestas de los estudiantes, se recomienda que el profesor organice grupos que tengan respuestas similares y les asigne un cartel para emplearlo para la escritura o representación de la historia.

A cada grupo, se le pedirá que construya la historia que ocurrió, de acuerdo con el orden que dieron a las láminas: $(1,2,3) ;(1,3,2) ;(2,1,3) ;(2 ; 3,1) ;(3$, $1,2) ;(3,2,1)$.

Se recomienda grabar cada historia. A medida que cada grupo cuenta su historia, el profesor escribirá lo relatado en el cartel de cada grupo.

Para tener un mayor enriquecimiento a la hora de construir la historia, el profesor puede proponer que en ésta se incluyan actos descriptivos de los personajes (las lombrices, entre otros) al igual que de los paisajes, y objetos que hacen parte importante en la trama de la historia.

b) Recreación de la historia: El profesor propondrá a los niños inventar colectiva o individualmente la historia de las lombrices, partiendo de las similitudes o de las diferencias entre las historias anteriores, según las respuestas dadas en el punto "a", se la siguiente manera:

Opción Uno: Si hay similitudes en este primer punto, el profesor puede organizar en pequeños grupos de trabajo que compartan dicha similitud y a partir de ahí construyan una nueva historia.

Opción dos: Si no se encuentran similitudes en las respuestas de los estudiantes, el profesor puede disponer del espacio del salón haciendo un círculo en el que él comience la nueva narración a partir de una posible solución que él proponga, dando la palabra en el orden del movimiento de las manecillas del reloj. En este sentido los estudiantes también pueden hacer uso de recursos utilizados en talleres anteriores, para enriquecer más la historia en construcción.

Para esta actividad, de construcción de historias, el profesor puede proponer palabras-guía, en LSC y en español escrito, en fichas pequeñas. Estas fichas se irán sacando de una bolsa de plástico (preferiblemente negra) a medida que se pase la palabra de uno al otro. Si el niño (a) desconoce el significado de la palabra, el profesor lo aclarará y, en la medida de lo posible, propondrá ejemplos para facilitar la apropiación del término y el aprendizaje del estudiante. Estas palabras se encuentran ligadas al micromundo de la aproximación (ver el repertorio léxico del micromundo de la aproximación), y el profesor dispondrá de ellas de acuerdo con el número de estudiantes que se encuentren en la clase. A medida que vaya transcurriendo la historia, el profesor irá registrado en los carteles lo que dicen los estudiantes.

c) El título de la historia. Después de construida la historia, entre todos (as) propondrán un título para la misma, con la ayuda del profesor. 


\section{ACTIVIDADES DE EVALUACIÓN PARA LOS ESTUDIANTES}

\section{Actividad:}

* Deletrea el nombre de cada una de las historias construidas.

* Cuéntale a tus compañeros de qué se trata la historia que más te interesó y busca el nombre de los personajes.

* Dile a tu grupo cuál es la mayor cualidad de tu personaje favorito de la historia. 


\section{Bibliografía}

Alegría J. \& Leybaert, J. (1987). Adquisición de la lectura en el niño sordo: un enfoque psicolingüístico. Investigación y Logopedia. Madrid: CEPE.

Álvarez, M. (1993). Tipos de Escrito I. En: Cuadernos de la Lengua Española. Madrid: Arco Libros.

Ander - Egg, E. (1999). El taller como una alternativa de renovación pedagógica. Buenos Aires: Magisterio del Río de la Plata.

Bajtín, M. (1982). Estética de la creación verbal. México: Siglo XXI Editores. Bassols, M \& Torrent, A. (1997). Modelos textuales. Teoría y práctica. Barcelona: Eumo Octaedro.

Behares, L.E. y Massone, M. I. (1996). The sociolinguistics of Uruguayan and Argentinian deaf communities as a lenguaje conflict situation. International Journal of the Sociology of Language 117: 99-115.

Behares, L.E., Massone, M.I. \& Curiel, M. (1990). El discurso pedagógico de la educación del sordo. Construcciones de saber y relaciones de poder. Cuadernos de Investigación, Instituto de Ciencias de la Educación, Universidad de Buenos Aires, №. 6: 41-68.

Bishop, A. (2005). Aproximación sociocultural a la educación matemática. Colombia: Universidad del Valle.

Braslavsky, B. (2003). ¿Qué se entiende por alfabetización? En Revista Lectura y Vida, de junio de 2003, año 24. Pág.1 - 17.

Bruner, J. (2004). Dos modalidades de pensamiento. Capítulo II. En: Realidad Mental y Mundos Posibles. Barcelona: Gedisa.

Calderón, D. (2005). La argumentación en el aula. Una perspectiva desde el análisis del discurso. Capítulo III. En: Dimensión cognitiva y comunicativa de la argumentación en matemáticas. Tesis doctoral no publicada. Cali: Universidad del Valle.

Calderón, D. (2012). El lenguaje en las matemáticas escolares. En Perspectivas en la didáctica de la matemáticas. Bogotá: Editorial Universidad Distrital Francisco José de Caldas.

Calderón, D. \& Molina, C. (1999). Institución educativa y técnicas grupales. En Módulo de Comunicación para la Especialización en Docencia Universitaria. Bogotá: Universidad Santo Tomás de Aquino. 
Calderón, D. (2005). Dimensión cognitiva y comunicativa de la argumentación en matemáticas. Tesis doctoral (no publicada). Cali: Universidad del Valle. Cassany, D. (1994). Describir el escribir. Barcelona: Paidós.

Castro, E., \& Rico, L. (1989). Estimación en cálculo y medida. Madrid: Síntesis.

Cid, E., Díaz Godino, J., \& Batanero, C. (2003). Sistemas numéricos y su didáctica. ReproDigital. Facultad de Ciencias: Granada.

Clements, D. H., \& Sarama, J. (2009). Learning and teaching early math: The learning trajectories approach. New York: Routledge.

Clements, D. H., Sarama, J., Spitler, M. E., Lange, A. A., \& Wolfe, C. B. (2011). Mathematics learned by Young children in an intervention base on learning trajectories: A large - scale cluster randomized trial. Journal for Research in Mathematics Education.

Corbalán, F. (2002). Juegos matemáticos para secundaria y bachillerato. Madrid: Síntesis.

De Guzmán, M. (1996). El papel de la visualización. En: El Rincón de la Pizarra. Madrid: Pirámide.

De Guzmán, M. (2005). Juegos matemáticos en la enseñanza. En Revista Suma. Monografía 02: Textos de Miguel de Guzmán. Casalderrey, F. \& Fuentes, I (Eds). Madrid.

Duval, R. (1999). Semiosis y pensamiento humano: Registros semióticos y aprendizajes intelectuales. Cali: Universidad del Valle.

Ferreiro, E. (1989). Los hijos del analfabetismo. México: Siglo XXI.

Fey, J (1999). Cantidad. En Steen, L (Ed.). La enseñanza agradable de las matemáticas. México: Limusa.

Fuentes, L. \& Tolchinsky, L. (1999). La influencia de la lengua en el aprendizaje de los numerales: el caso de los niños sordos profundos prelocutivos. Barcelona: Instituto de Ciencias de la Educación. Universidad de Barcelona.

García Pelayo y Gross, F, \& Durand, M. (1982). Larousse de la conjugación. $6^{a}$ Edición. París: Ediciones Larousse.

Godino, J., \& Ruiz, F. (2002). Geometría y su didáctica para Maestros. Granada: La Mediana.

Gómez, M., Díaz, M., Rodríguez, P., \& García, R. (2005). Primeras estrategias de enseñanza de la LSE: una experiencia en educación infantil. Instituto Hispano Americano de la Palabra. Congreso Nacional de LSE, Valladolid, 15 - 17 de septiembre de 2005. 
Goodman, K. (1995). El lenguaje integral. Edición $1^{\text {a }}$ ed. Publicación Buenos Aires: Aique. $107 \mathrm{p}$.

Grosjean, F. (1999). El derecho del niño sordo a crecer bilingüe. Barcelona: Sección Educación de DifuSord. Asociación de Difusión de la Comunidad Sorda, mayo de 1999.

Herrera, V. (2003). Desarrollo de habilidades lectoras en sujetos sordos signantes, a partir del uso de códigos dactílicos. Tesis doctoral no publicada. Universidad Complutense de Madrid.

Herrera, V. (2005). Habilidad lingüística y fracaso lector en los estudiantes sordos. En: Estudios Pedagógicos. V.31 N.2.: 121-135, Valdivia.

Instituto Nacional para Sordos - INSOR. (2006). Diccionario Básico de la Lengua Señas Colombiana. Bogotá: Imprenta Nacional.

Johnson, R. (2006). Cultural constructs that impede discussions about variability in Speech - Based Educational Models for deaf children with cochlear Implants. Washington D.C.: Perspectiva, Florianópolis, v. 24, n. Especial, p. 29 - 80.

Johnson, R; Erting, C. \& Liddell, S. (1989). Develando los programas: principios para un mayor logro en la educación del sordo. En: Pietrosemoli, Lourdes (ed.) El aula del sordo. Mérida, Consejo de Publicaciones, Universidad de Los Andes, pág. 9 - 59.

Jolibert, J. (1996). Formar niños productores de textos. Santiago de Chile: Dolmen.

León, O \& Calderón, D. (2004). El proyecto de aula en la didáctica de las matemáticas. Bogotá: Corpoeducación-Secretaría de Educación de Pasto.

León, O \& Calderón, D. (2008). Procesos de formación matemática en niveles iniciales en estudiantes sordos. Ponencia en V Congreso Iberdiscap. Aitadis. Cartagena de Indias, Colombia.

León, O. (2006). La relación: Matemática - semiosis - argumentación, en la elaboración de diseños didácticos. En: Revista Científica № .8 de agosto de 2006. Bogotá: Universidad Distrital Francisco José de Caldas.

León, O. Rocha, P. Vergel, R. (2006). El juego, la resolución de problemas y el proyecto de aula como dispositivos didácticos en las didácticas de las matemáticas y de la estadística. Memorias XXII Coloquio Distrital de Matemáticas y Estadística. Bogotá: Universidad Nacional de Colombia.

Lerner, D. (2001). Leer y escribir en la escuela: lo real, lo posible y lo necesario. México: Fondo de Cultura Económica. 
Mac Lane, S. (1986). Mathematics form and function. New York: Springer-Verlag.

Macchi, M \& Veinberg, S. (2005). Estrategias de alfabetización para niños sordos. Buenos Aires: Novedades Educativas.

Marchesi, A. (1995). El desarrollo cognitivo y lingüístico de los niños sordos. (3 ${ }^{\text {a }}$ reimpresión). Madrid: Alianza Psicología.

Martínez, M. (2004). Discurso y aprendizaje. Cali: Cátedra UNESCO.

Massone, M. I. (2009). Reflexiones desde la visión crítica de las formaciones ideológicas del discurso pedagógico de la educación del sordo. Departamento de Lingüística, Centro de Investigaciones en Antropología Filosófica y Cultural - CIAFIC. Consejo Nacional de Investigaciones Científicas y Técnicas - CONI - CET-. Buenos Aires, Argentina.

Massone, M. I; Skliar, C. \& Veinberg, S. (1995). El acceso de los niños sordos al bilingüismo y al biculturalismo. Madrid, vol. 69-70, 85-100, 1995; reimpreso en Ecos Fonoaudiológicos, Buenos Aires, 2, 32-50.

MEN., INSOR \& FENASCOL. (1998). Orientaciones para la integración escolar de estudiantes sordos. Bogotá: MEN.

Mies, B. (1998). Apropiación de la lengua escrita. N. Silvestre (ed). Sordera, comunicación y aprendizaje. Barcelona: Masson.

Moliner, M. (2002). Diccionario de uso del español. Madrid: Gredos.

Oléron, P. (1985). El niño y la adquisición del lenguaje. Madrid: Morata.

Oviedo, A. (2001). Apunte para una gramática de la Lengua de Señas Colombiana. Bogotá: Instituto Nacional para Sordos (INSOR) y la Escuela de Ciencias del Lenguaje de la Universidad del Valle.

Piaget, J. (1986). La formación del símbolo en el niño. México: Fondo de Cultura Económica.

Pimm, D. (1990). El lenguaje matemático en el aula. Madrid: Morata.

Quiñónez, E., Ramírez \& Valbuena. (2006). Representaciones sociales de un grupo de estudiantes sordos frente a la lecto escritura en una fundación para niños con VIH en Cali enero-junio. Medellín: Fundación Universitaria María Cano.

Ramírez, P. (2002). Programa Bilingüe de Atención Integral al niño sordo menor de cinco años. En: Nuevos caminos en educación bilingüe en Colombia. Editado por Anne-Marie de Mejía y Rocío Nieves. Cali: Escuela de Ciencias del Lenguaje. Universidad del Valle. 
Ramírez, P. (2003). Programa bilingüe para niños sordos en Colombia. Bogotá: INSOR.

Rodríguez, M. (2001). Consideraciones institucionales, pedagógicas y didácticas en torno a la pedagogía de proyectos. En Antología de proyectos pedagógicos (pp. 17-44). Cuaderno de trabajo No 2. Bogotá, Colombia: Universidad Distrital Francisco José de Caldas.

Rogoff, B. (1993). Aprendices del pensamiento. Barcelona: Paidós.

Sarama, J., \& Clements, D. H. (2009). Early childhood mathematics education research: Learning trajectories for Young children. New York: Routledge.

Skliar, C. (1999). Un análisis preliminar de las variables que intervienen en el proyecto de educación bilingüe para los sordos: Núcleo de investigaciones en Políticas Educativas para Sordos. Brasil: Universidad Federal de Rio Grande do Sul, Porto Alêgre.

Solé, I. (2001). Estrategias de lectura. Barcelona: Plaza edición.

Tolchinsky, L. (1993). Aprendizaje del lenguaje escrito. Barcelona: Anthropos.

Tosca, V. (1757). Primer tomo del compendio matemático. Valencia Compendio matemático. Tomos I y II.

Tovar, L. (2004). La necesidad de planificar una norma en las lenguas de señas. Mérida: Universidad de Los Andes.

Veinberg, S. (2002). La perspectiva socio antropológica de la sordera. Argentina: Facultad de Filosofía y Letras Universidad de Buenos Aires,.

Vergnaud, G. (1985). El niño, las matemáticas y la realidad. México: Trillas.

Vygotsky, L. (1982). Obras escogidas Vol. II. Moscú: Pedagógica de Moscú. 


\section{Cibergrafía}

Abad, D. [Dante Ricardo Abad Zapata]. (2008, abril 28). lombricultura en casa [Archivo de video]. Recuperado de http://www.youtube.com/watch?v=3WLXfuMoFCE

Acero, D. (2011, mayo 30). 14746751 Manual de Lombricultura 2003[1] Recuperado de https://es.scribd.com/document/56614454/14746751-Manual-de-Lombricultura-2003-1

Carrera, J. [Jorge Carrera]. (2009, septiembre 21). Lombriz de tierra [Archivo de video]. Recuperado de http://www.youtube.com/watch?v=gR4MYjrfkWs.

ElazulitoT 7. [ElazulitoT 7]. (2010, enero 31). Granja de Lombrices [Archivo de video]. Recuperado de http://www.youtube.com/watch?v=H9ZiGBekZ7Y

FAO. (2006). Crear y manejar un huerto escolar. UN MANUAL PARA PROFESORES, PADRES Y COMUNIDADES. Recuperado de http://www.fao.org/ docrep/009/a0218s/a0218s00.HTM

HECHOS TV. [HECHOS TV]. (2010, marzo 18). Deshágase de su basura con ayuda de unas lombrices [Archivo de video]. Recuperado de http://www. youtube.com/watch? $\mathrm{v}=\mathrm{AbQNcTky} 3 \mathrm{X} 8$

Información Alternativa. [Información Alternativa]. (2008, enero 18). Lombricultura [Archivo de video]. Recuperado de http://il.youtube.com/ watch? $v=$ OQPSfp3GRUg\&p=34A2710ECB1E1A2A\&index $=2$

Mindlapse. [mindlapse]. (2007, marzo 18). Time lapse fast growing corn, roots and leaves growing [Archivo de video]. Recuperado de http://www.youtube. com/watch?v=iFCdAgeMGOA

Miracebo. [miracebo]. (2008, enero 18). Semilleros para el germinador [Archivo de video]. Recuperado de http://www.youtube.com/watch?v=HuEFodx-qrU

Miracebo. [miracebo]. (2008, febrero 22). El repicado [Archivo de video]. Recuperado de http://www.youtube.com/watch?v=ZmzaS89f4nY

Museohudson. [museohudson]. (2007, diciembre 12). Taller de Huerta 8 / El lumbricario [Archivo de video]. Recuperado de http://il.youtube.com/ watch?v=tPZUJdad34U

Seba Gabe. [Seba Gabe]. (2007, julio 4). Introducción a la Lombricultura [Archivo de video]. Recuperado de http://www.youtube.com/ watch? $\mathrm{v}=\mathrm{GHdOH} / \mathrm{HsXg}$

YSEMEMANDAESEANIMAL's channel. (2010, junio 7). LOMBRICULTURA CASERA CDP 2.wmv [Archivo de video]. Recuperado de http://www.youtube. $\underline{\mathrm{com} / \text { watch? } \mathrm{v}=9 \mathrm{MWzWCO} 8 \mathrm{o} 4}$ 


\section{Sobre las Autoras}

Olga Lucía León Corredor. Doctora en Educación, en el área de Educación Matemática de la Universidad del Valle (2005). Profesora de planta de la Universidad Distrital Francisco José de Caldas, adscrita al Doctorado Interinstitucional en Educación en el énfasis de Matemáticas. Es miembro fundadora del Grupo de Investigación Interdisciplinaria en Pedagogía del Lenguaje y las Matemáticas -GIIPLyM, adscrito a las Universidades Distrital Francisco José de Caldas y del Valle. Entre sus líneas de investigación están: Lenguaje y construcción de conocimiento matemático, Formación de educadores (as) matemáticos (as), Argumentación en lenguaje y matemáticas, Didáctica del lenguaje y las matemáticas, Argumentación y semiosis en didáctica de las matemáticas, entre otras. Ha sido editora de diferentes publicaciones destacándose los siguientes títulos: Referentes curriculares con incorporación de tecnologías para la formación del profesorado de matemáticas en y para la diversidad; Pensamiento, epistemología y lenguaje matemático y, Elementos para una didáctica del lenguaje y las matemáticas en estudiantes sordos de niveles iníciales. Actualmente hace parte del equipo coordinador del proyecto de Centros de Cooperación para el Fomento, Fortalecimiento y Transferencia de Buenas Prácticas que Apoyan, Cultivan, Adaptan, Comunican, Innovan y Acogen a la comunidad universitaria -ACACIA-. Proyecto ganador del programa Erasmus + de Horizontes 2020 de la Unión Europea. También hace parte del equipo coordinador del programa Arquitectura Pedagógica didáctica y tecnológica para la formación de profesores en y para la diversidad, de la Alianza de Instituciones para el Desarrollo de la Educación y la Tecnología en Colombia- AlDETC- financiado por COLCIENCIAS.

Dora Inés Calderón. Doctora en Educación en el área de Lenguaje de la Universidad del Valle (2005). Profesora de planta de la Universidad Distrital Francisco José de Caldas, adscrita al Doctorado Interinstitucional en Educación en los énfasis de Lenguaje y de Matemáticas y a la Licenciatura en Educación Básica con énfasis en Humanidades y Lengua Castellana. Es miembro fundadora del Grupo de Investigación Interdisciplinaria en Pedagogía del Lenguaje y las Matemáticas -GIIPLyM, adscrito a las Universidades Distrital Francisco José de Caldas y del Valle. Entre sus líneas de investigación están: Argumentación en lenguaje y matemáticas, Didáctica del lenguaje y las matemáticas, Lenguaje y construcción de conocimiento matemático, Formación de educadores (as) matemático (as). Ha sido editora de diferentes publicaciones destacándose los siguientes títulos: Perspectivas en la Didáctica de las Matemáticas; Lenguaje, cultura e investigación: problemas emergentes en educación y, Panorama de los estudios del Discurso en Colombia. Actualmente hace parte del equipo coordinador del proyecto de Centros de Cooperación para el Fomento, Fortalecimiento y Transferencia de Buenas Prácticas que Apoyan, Cultivan, Adaptan, Comunican, Innovan y Acogen a la comunidad universitaria -ACACIA-. Proyecto ganador del programa Erasmus + de Horizontes 2020 de la Unión Europea. También hace parte del equipo coordinador del programa Arquitectura Pedagógica didáctica y tecnológica para la formación de profesores en y para la diversidad, de la Alianza de Instituciones para el Desarrollo de la Educación y la Tecnología en Colombia- AIDETC- financiado por COLCIENCIAS. 

Este libro presenta los resultados de la investigación "El desarrollo de competencia comunicativa en matemáticas en estudiantes sordos", código 1130-405-20203, cofinanciado por Colciencias y la Universidad Distrital Francisco José de Caldas en la vigencia 2007-2010. El proyecto fue realizado por el Grupo de Investigación Interdisciplinaria en Pedagogía del Lenguaje y las MatemáticasGIIPLyM. En términos generales, se pretendió diseñar una propuesta didáctica para la formación matemática inicial de niños sordos, a partir del desarrollo matemático de la lengua de señas colombiana y su relación con sistemas semióticos como el castellano, el figural geométrico y el de numeración decimal.

Para investigar el desarrollo de competencia comunicativa en matemáticas en estudiantes de primeros grados, se optó por la metodología de investigación denominada ingeniería didáctica (Artiguey otros, 1995; Calderón y León, 2012). Desde esta metodología se realizó un diseño para alcanzar el macro objetivo mencionado arriba, a partir del desarrollo de cuatro fases de la ingeniería: la fase de análisis preliminar, en la que se estudió el estado del fenómeno por investigar, es decir el estado de la educación matemática y del lenguaje en aulas de niños sordos de primeros grados y la preparación de los elementos para el diseño didáctico. Para ello se realizaron tres etnografías en colegios exclusivos para niños sordos. La segunda fase de análisis a priori estuvo dedicada a la concepción y el de las situaciones didácticas, que dio como gran resultado EL DISEÑO DIDÁCTICO construido para el desarrollo de competencia comunicativa en matemáticas.

\section{Serie Investigaciones}

